\title{
Políticas Públicas
}

\section{y Sociales: \\ Globalización,}

desigualdad y

nuevas insurgencias

Adrián Serrano-Sanz

Chaime Marcuello Servós

Juan David Gómez Quintero

Pau Marí-Klose

(eds.)

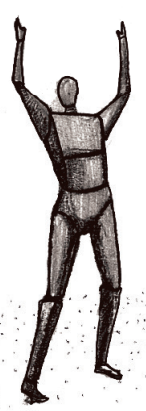





\section{POLÍTICAS PÚBLICAS Y SOCIALES: GLOBALIZACIÓN, DESIGUALDAD Y NUEVAS INSURGENCIAS}





\title{
POLÍTICAS PÚBLICAS Y SOCIALES
}

GLOBALIZACIÓN, DESIGUALDAD Y NUEVAS INSURGENCIAS

\author{
Adrián Serrano-Sanz \\ Chaime Marcuello Servós \\ Juan David Gómez Quintero \\ Pau Marí-Klose \\ (eds.)
}


POLÍTICAS públicas y sociales : globalización, desigualdad y nuevas insurgencias / Adrián Serrano-Sanz... [et al.] (eds.). — Zaragoza : Universidad de Zaragoza, 2017

331 p. : il. ; $23 \mathrm{~cm}$

ISBN 978-84-16723-44-7

1. Políticas públicas. 2. España-Política y gobierno. 3. España-Política social

SERRANO-SANZ, Adrián

$351.84(460)$

Cualquier forma de reproducción, distribución, comunicación pública o transformación de esta obra solo puede ser realizada con la autorización de sus titulares, salvo excepción prevista por la ley. Diríjase a CEDRO (Centro Español de Derechos Reprográficos, www.cedro.org) si necesita fotocopiar o escanear algún fragmento de esta obra.

(C) Adrián Serrano-Sanz, Chaime Marcuello Servós, Juan David Gómez Quintero y Pau MaríKlose (eds.)

1. ${ }^{a}$ edición, Zaragoza, 2017

Edita: Universidad de Zaragoza

ISBN 978-84-16723-44-7

Imprime: Servicio de Publicaciones. Universidad de Zaragoza

Depósito legal: Z 1694-2017 
23.

una mirada desde la alcantarilla puede ser una visión del mundo

la rebelión consiste en mirar una rosa hasta pulverizarse los ojos

Alejandra Pizarnik 



\section{ÍNDICE}

GLOBALIZACIÓN, DESIGUALDAD, NUEVAS INSURGENCIAS. A MODODEPROEMIO.

Pau Mari-Klose, Juan David Gómez Quintero y Chaime Marcuello Servós

\section{GLOBALIZACIÓN}

1. HACIA UNA AGENDA GLOBAL DE GOBERNANZA DE LAS MIGRACIONESFORZOSAS:POSIBILIDADESYESPEJISMO.

Alfredo dos Santos Soares

2. GEOGRAFÍAS LEGALES DESDE LA CIUDAD: REDIBUJANDO EL ESPACIO PÚBLICO EN MADRID Y BARCELONA A TRAVÉS DE PROYECTOS URBANOS GLOBALES.......................................................

Pedro Limón López

3. PLANIFICACIÓN Y DESIGUALDAD EN LA CIUDAD NEOLIBERAL: GEOGRAFÍAS DE LAS CLASES POPULARES.

Chabier Gimeno Monterde y Miguel Montañés Grado

4. NUEVO ENFOQUE DE INTERVENCIÓN PARA CUIDADORES PROFESIONALES EXTRANJEROS A TRAVÉS DE LAS TECNOLOGÍAS.......

María José Gómez Poyato

\section{DESIGUALDAD}

5. RACIAL PASSING: DE ESTIGMATIZADOS A «NORMALES»

Sergio García Álvarez

6. INTERVENCIÓN COMUNITARIA EN GABRIELA MISTRAL, BARRIOOLIVER,ZARAGOZA

Elena Enciso Serrano, Tamara Marín Alquézar y Mari Carmen Martinez Molina 
7. DEL CRECIMIENTO ECONÓMICO A LA SATISFACCIÓN CON LA VIDA: MEDIR LA FELICIDAD EN CIENCIAS SOCIALES.

Gabriela Delsignore

8. LA CALIDAD DE VIDA DE LOS USUARIOS COMO REFERENCIA PARA MEJORAR LAS INTERVENCIONES. UNA EVALUACIÓN DE IMPACTO EN E.M

José Carrón Sánchez, Javier Arza Porras, Sagrario Anaut Bravo y José Antonio Villanueva Oyarzábal

9. LA GESTIÓN COMUNITARIA DE «RECURSOS NATURALES» EN ÁREAS PROTEGIDAS. EL CASO DE LOS ACUEDUCTOS COMUNITARIOS EN LOS PÁRAMOS DE BOGOTÁ, COLOMBIA.

Ángela María Osorio Gómez

10. EFICACIA DE LAS ÁREAS PROTEGIDAS DE ESPAÑA COMO POLÍTICA DE SOSTENIBILIDAD TERRITORIAL: EL PROYECTO SOSTPARK.

David Rodríguez Rodríguez, Javier Martinez Vega e Iván López

11. VIDA INDEPENDIENTE: MARCOS PARA LA ACCIÓN EN LA TERCERA Y CUARTA EDAD

Diana Carolina Mira Tamayo

12. EL SOCIOTIPO Y LA EVALUACIÓN DE LAS INTERVENCIONES DE RESOCIABILIZACIÓN EN LAS POLÍTICAS ASISTENCIALES.......... 225

Raquel del Moral Bergós, J. Navarro y P. C. Marijuán

\section{NUEVAS INSURGENCIAS}

13. CUERPOS CRIP Y ARTE: PRÁCTICAS CREATIVAS TULLIDAS EN ESPACIOS PÚBLICOS

Laura Moya 
14. DINÁMICAS Y POSICIONES SOCIALES TRAS LA

RADICALIZACIÓN ISLAMISTA: UNA APROXIMACIÓN A LOS

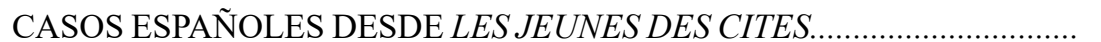

Jesús Carreras Aguerri y Lionel Sebastian Delgado Ontivero

15. VIVIENDO BAJO LA AMENAZA Y EL MIEDO: DOS ESTUDIOS SOBRE EL CASO DE LA VIOLENCIA TERRORISTA EN EUSKADI......... 285

Javier Martín-Peña, Pedro J. Ramos, Alba Albella-Uyarra y Manuel Vilariño

16. SEGURIDAD SUFICIENTE: DISCURSOS DE EXCEPCIONALIDAD.. 301 Adrián Serrano-Sanz

17. EL DERECHO COMO IDEAL REGULATIVO DE LAS POLÍTICAS DE PAZ EN TIEMPOS DE MIEDO AL DESPOTISMO DE LA INCERTIDUMBRE.

Fernando Paz Tabales

18. GOBERNANZA AMBIENTAL EN EL MECANISMO DE DESARROLLO LIMPIO: LIMITACIONES INSTITUCIONALES PARA

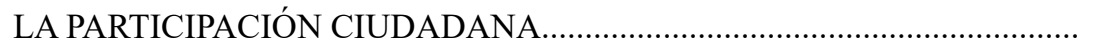

María Lucía Viscuso

19. LAS RONDAS CAMPESINAS GARANTES DE LA JUSTICIA AMBIENTAL FRENTE A LAS POLÍTICAS EXTRACTIVISTAS EN PERÚ...... 353

Raquel Neyra 



\title{
GLOBALIZACIÓN, DESIGUALDAD, NUEVAS INSURGENCIAS. A MODO DE PROEMIO
}

\author{
Pau Mari-Klose \\ Juan David Gómez-Quintero \\ Chaime Marcuello Servós
}

La aceleración de la globalización está produciendo cambios profundos en el tejido social de las sociedades occidentales enfrentándolas a nuevos fantasmas. La crisis iniciada en 2007 ha castigado de manera virulenta a muchos países, especialmente del sur de Europa. Ha expuesto a sus sociedades a niveles de estrés económico y social, que amplias capas de la población han experimentado como ilegítimos, suscitando corrientes de indignación y desafección hacia las instituciones. La vida de muchos españoles y europeos se ha tensionado. Con ello han aparecido oportunidades de capitalizar mediática y políticamente una panoplia de malestares, algunos ligados a la crisis, otros trascienden ese marco temporal, pero que han encontrado en la crisis la mecha para prender el descontento. En los últimos años han proliferado toda clase de empresarios económicos y políticos dispuestos a probar fortuna agitando la bandera de la indignación contra expertos, élites políticas y económicas. ¿Qué ha ocurrido durante estos años que desencadena esta ola de repudio?

Son muchas las transformaciones que sacuden las sociedades, pero una parece cobrar un protagonismo inusitado: la Globalización. Los problemas, riesgos e incertidumbres ligadas a la globalización han pasado al primer plano de conversación política, provocando una relectura de fenómenos sociales que nos acompañan desde hace décadas, como la liberalización, la desindustrialización o la entrada y asentamiento de población inmigrante en los países desarrollados. Muchos ciudadanos de España y Europa sienten la necesidad de recobrar cotas de soberanía para legislar contra amenazas que, con mayor 
o menores visos de realismo, se ciernen sobre ellos: desigualdad social y económica, exclusión social, atentados terroristas, cambio climático y desastres medioambientales, nacionalismos supremacistas o independentistas, etc.

\section{La Globalización y sus descontentos}

Uno de los criterios para evaluar una explicación científica es el principio de parsimonia, también conocido como «la navaja de Ockham». A finales de la Edad Media, Guillermo de Ockham, un filósofo y fraile franciscano de origen inglés, lo enuncia de la siguiente manera: «las cosas esenciales no se deben multiplicar sin necesidad». De varias explicaciones posibles a un fenómeno o problema dado la más sencilla es, a igualdad de condiciones, la más deseable.

El carrusel mediático reclama conocimiento inmediato sobre los temas que imponen los acontecimientos noticiables. Aparecen constantemente explicaciones sencillas para dar cuenta de problemas complejos, como el auge del malestar, la indignación, y su cristalización en forma de nuevos populismos. Una muy en boga en los últimos tiempos es que el surgimiento de estos fenómenos se explica básicamente por el apoyo de los «perdedores de la globalización».

Como tal, la globalización es un fenómeno complejo, presenta muchas dimensiones y un sinnúmero de ramificaciones. La globalización comercial, la deslocalización de las empresas, la globalización financiera, la de las comunicaciones, la proyección cultural del mundo anglosajón en el resto del planeta, la globalización humana que representan las migraciones, el yihadismo internacional, los solicitantes de asilo..., son sólo alguna de las caras de procesos extraordinariamente complejos. Afirmar que cualquier fenómeno social, como el apoyo de algunos segmentos socioeconómicos al populismo, está relacionado con la globalización no es ni cierto ni falso. Es una proposición poco informativa y difícil de falsar. Siempre será posible encontrar alguna hipotética conexión (próxima o lejana) de la «globalización», en sus múltiples dimensiones y ramificaciones, con cualquier fenómeno social que se nos ocurra.

A juicio de muchos de quienes abanderan la tesis, la globalización ha sembrado los países occidentales de personas descontentas. Pero no de cualquier descontento. Ha afectado a su posición económica y su experiencia de clase social. En su versión más épica, la globalización ha creado un nuevo 
grupo de personas que han perdido el tren o han quedado atrás (left behind), que engrosan bolsas de ciudadanos desafectos, proclives a votar partidos antiestablishment.

La tesis de los perdedores de la globalización se nutre de algunos poderosos referentes cognitivos. Uno de los más conocidos es el «gráfico del elefante», producido por el reconocido economista Branko Milanovic en su último libro Global Inequality, y que ha sido descrito como uno de los gráficos más impactantes de las últimas décadas. El gráfico representa en qué medida han cambiado los ingresos per cápita por hogar entre 1988 y 2008 en los distintos tramos de la distribución global de ingresos, desde los hogares más pobres situados en la izquierda del gráfico hasta el $1 \%$ más rico, situado en el extremo de la derecha. El perfil de la curva permite imaginarse fácilmente la silueta de un elefante, con su cola en la parte izquierda, el voluminoso cuerpo del paquidermo en la parte central y su trompa levantada en la derecha.

La lectura del gráfico es que la variación de ingresos en la distribución global las últimas dos décadas dibuja claramente dos grupos de ganadores. Por un lado, tenemos la parte central del elefante, que corresponde a las clases medias de los países asiáticos emergentes. Por otro, las clases más afluentes del mundo, que representan el $1 \%$ más rico (la trompa). Frente a ellos se sitúan los perdedores. Por un lado, los más pobres (el 5-10\% que se sitúa en la cola). Por otro los segmentos que se sitúan inmediatamente antes de la trompa, el $20-25 \%$ de la población mundial que se encuentra justo por debajo del pequeño grupo que si ha conseguido mejorar su posición económica en las dos décadas que van de 1988 a 2008. Estos tramos corresponden aparentemente a las clases medias y bajas de los países occidentales. La conclusión que ha circulado extensamente es que a medida que la economía se globalizaba y la competencia entre países se agudizaba, la mayoría de los ciudadanos del mundo desarrollado no participaban en los beneficios de la globalización.

Aunque el gráfico no acredita realmente la existencia de «perdedores», sino más bien de grandes agregados de la población mundial cuyos ingresos se incrementan menos o quedan estancados, la interpretación generalizada es que las clases medias y bajas de los países occidentales han salido malparados por grandes cambios socioeconómicos acontecidos en los veinte años que analiza Milanovic. 


\section{Gráfico del Eefante de Millanovic}

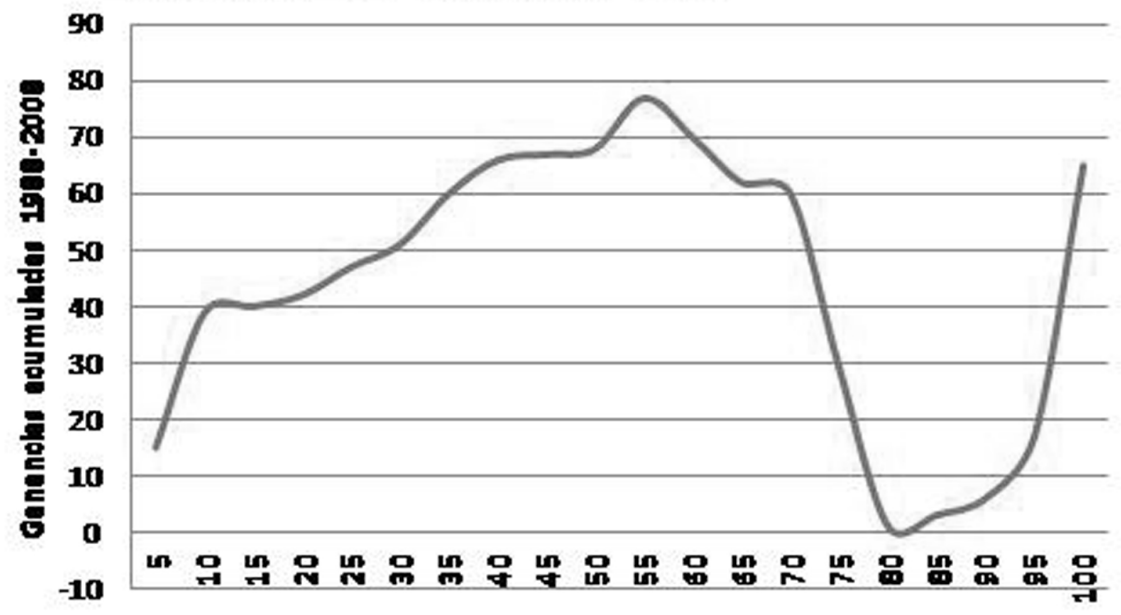

Percentiles

La tesis de Milanovic cae en terreno abonado. Se suma a una catarata de trabajos que en los últimos años han venido constatando el aumento de las desigualdades. Por ejemplo, la OCDE (Growing Unequal o Divided We Stand), de Wilkinkson y Pickett (The Spirit Level), de Tony Atkinson (Inequality. What Can Be Done?), Therborn (The Killing Fields of Inequality), Putnam (Our Kids), y especialmente, de Thomas Piketty (Capital in the XXIst Century) se han convertido en motores de una nueva conversación global sobre la desigualdad y sus consecuencias. En algunos de ellos se identifica la globalización como uno de los posibles factores causantes de la desigualdad, pero ni mucho menos el único ni indubitativamente más relevante. El aumento de la desigualdad es visto, en estos trabajos, como producto de un cúmulo de factores. Desde las transformaciones tecnológicas y los cambios en la estructura ocupacional que provocan, al aumento de la tendencia al emparejamiento selectivo, pasando por toda una serie de reformas de la legislación laboral, el sistema de tributación o los sistemas de protección social, por mencionar solo los factores más discutidos. Es posible vincular (indirectamente) muchos de ellos a la globalización, pero sería injusto no reconocerles entidad propia como factores que influyen en la evolución de la desigualdad con independencia de las presiones estructurales inmediatas que impone la globalización. 
Por otra parte, la globalización no parece tener un efecto unívoco sobre los países occidentales. Como pone de manifiesto un trabajo reciente dirigido por Adam Corlett (2016), que pone en cuestión el planteamiento y conclusiones de Milanovic. En un re-análisis de la explotación de los datos de Milanovic, Corlett evidencia que la curva del elefante depende estrechamente de la lista de países que se incluyen en la muestra y del volumen cambiante de la población de estos países. Ajustados estos factores, la distribución de la variación de ingresos entre 1988 y 2008 es bastante más homogénea. La depresión de ingresos en la base de la trompa (las clases bajas y medias de los países occidentales) es mucho menos aparente.

Una exploración más detallada de lo ocurrido en distintos países muestra que lo que parecen a primera vista ritmos del crecimiento de ingresos muy bajos en los países occidentales es, en realidad, efecto de un análisis defectuoso de los datos Japón y la notable caída de ingresos en la antigua Unión Soviética y los países bálticos. En la mayoría de países de Europa no pueden observarse variaciones sensibles de los ingresos de los tramos medios y bajos de ingresos que justifiquen que podamos hablar de «perdedores de la globalización» de forma generalizada. No cabe duda que la competición internacional puede haber producido «perdedores» a nivel local, devastando sectores e incluso áreas geográficas enteras y condenando al desempleo y la precariedad a muchos trabajadores. Pero no puede hablarse de un efecto comprehensivo e inevitable, derivado de presiones estructurales, que haya empobrecido trasversalmente a clase medias y trabajadoras de Occidente. En buena parte de los países europeos más poblados que analiza Corlett, las rentas de estos grupos aumentan de manera sustancial a lo largo del periodo. En Gran Bretaña el incremento medio anual de los ingresos de la primera decila es superior al 5\%, y el de las siguientes ocho decilas se sitúa entre el 3 y el 4\%. En España, los incrementos anuales experimentados por las 9 primeras decilas oscilan entre el 2 y el $3 \%$ anual, y en Francia e Italia se sitúan en torno al 2\%.

Ciertamente, antes de la crisis, la desigualdad había aumentado en algunos países europeos. Esos incrementos arrancan ya, en algún caso, a finales de los 70. Así ha sucedido en países con bajos niveles iniciales de desigualdad, como Alemania, y en especial los países nórdicos (Finlandia, Suecia, Noruega, y en menor medida Dinamarca). Pero es difícil atribuir ese aumento a la globalización al tratarse de países tradicionalmente muy abiertos al comercio 
internacional. Éstos tienen una larga experiencia gestionando sus efectos colaterales con gran eficacia. Es mucho más fácil vincular esas experiencias a decisiones domésticas sobre impuestos, desregulación del mercado de trabajo o políticas de protección social, o a transformaciones sociodemográficas de sus poblaciones, como puede ser el incremento de la proporción de hogares monoparentales o la acentuación de tendencias al emparejamiento selectivo (OCDE 2011).

Las instituciones y la gestión política de los retos sociales más acuciantes del momento pueden tener una influencia notable sobre la desigualdad, modelando el modo en que la globalización, los cambios tecnológicos o las transformaciones sociodemográficas inciden sobre la desigualdad. Son también claves para entender el modo en que los períodos de crisis han incidido sobre el bienestar de la ciudadanía y, en particular, de los más expuestos a sus efectos más dañinos. Lo que no parecía haber provocado la globalización en varias décadas (en términos de aumento de la desigualdad y la vulnerabilidad económica) lo ha producido en pocos años la Gran Recesión. Así, en países como España, donde la desigualdad se había mantenido (o disminuido, si tomamos una perspectiva más larga) antes de 2008, el índice de Gini se dispara ente 2008 y 2014 (2,3 puntos), acompañado de un aumento notable del riesgo de pobreza (2,5\%). La desigualdad también aumenta considerablemente en otros países afectados por la crisis, como Estonia, Hungría o Chipre, así como la pobreza relativa en Grecia. Sin embargo, no se advierten efectos sustanciales sobre la desigualdad en otros países inmersos en una coyuntura recesiva profunda, como Italia, Irlanda, Portugal o Lituania.

La inexistencia de efectos sociales inequívocos de la globalización o la variabilidad de consecuencias de la Gran Recesión a lo largo de Europa, no ha sido óbice para que se culpara a la globalización, en general, y al proyecto europeo, en particular, por las manifestaciones más cruentas de la crisis. El grave deterioro económico de algunos países en los años de recesión ha sido interpretado como la consecuencia de factores estructurales comunes que tensionan a las sociedades europeas, obviando la enorme diversidad de situaciones económicas de partida, de configuraciones institucionales de sus sistemas de bienestar y de respuestas políticas a la crisis. A ello ha contribuido también una cierta convergencia en la forma en que se ha expresado el malestar. Tanto los líderes de la opinión mediática como los actores políticos (en especial los nuevos actores surgidos al calor de la crisis) han puesto desproporcionada- 
mente el foco en los factores externos como «culpables», a su juicio, de la erosión sufrida en el bienestar. En los últimos tiempos, una nueva hornada de agitadores políticos y mediáticos ha intensificado el discurso que hace a la globalización responsable de los males que acarrea la crisis, ofreciendo una respuesta sencilla a las quejas de los segmentos de población más agraviada, insatisfechas con la falta de reflejos del orden establecido hacia sus problemas, riesgos e incertidumbres.

De este modo, nos encontramos en esta obra que aquí presentamos algunos rostros de los perdedores de la globalización y de la Gran Recesión. Sin ir más lejos, la pobreza y marginalidad urbana aparece en el trasfondo de varios capítulos del libro. En algunos casos para explicar los condicionantes que predisponen a la radicalización yihadista de jóvenes de las periferias, en otros para explicar la difícil convivencia en núcleos urbanos de alta densidad sociodemográfica, y en alguno para reivindicar el trabajo social comunitario y la participación ciudadana.

\section{Los nuevos malestares y su expresión política}

Nuestras sociedades parecen sumidas en una nueva forma de malestar político que alimenta el surgimiento de expresiones de indignación y descontento, junto con el rechazo a las instituciones políticas. Esas expresiones se han multiplicado con la crisis, pero es difícil ligarlas a fenómenos estructurales comunes, pueden expresar cierto miedo al despotismo de la incertidumbre, como se sugiere en uno de los capítulos posteriores. En este sentido, Sonia Alonso (2013) ha puesto de manifiesto que cuando se revisa la evolución de los principales indicadores de confianza en las instituciones representativas de las democracias europeas, en buena parte del centro y el norte de Europa no se han producido variaciones significativas entre 2002 y 2012. Ni en los países del euro (Alemania, Finlandia, Países Bajos o Austria) ni en los que están fuera (Dinamarca, Suecia y Reino Unido) se alteraron significativamente los niveles de confianza en el gobierno o en los partidos, ni cayeron las cotas de satisfacción con la democracia.

Sin embargo, el malestar sí tiene, a partir de 2009, una clara expresión territorial. En comparación con el norte de Europa, en el Sur, la confianza en los gobiernos y los partidos disminuyó consistentemente (con una caída de 27 puntos para los gobiernos y 15 para los partidos en tan solo cuatro años). 
La satisfacción con la democracia también ha caído de forma significativa. El porcentaje de personas muy o bastante satisfechas con la democracia en el Sur de Europa cayó en picado más de 20 puntos porcentuales. El malestar parece, por tanto, un efecto muy evidente del deterioro de la situación económica y social que tiene lugar en estas sociedades durante la Gran Recesión.

En consonancia con esta división, encontramos una fractura en la percepción de la globalización como oportunidad para el crecimiento. En todas las ocasiones en que el Eurobarómetro ha preguntado sobre esta cuestión, ha sido mayor el porcentaje de europeos que están de acuerdo con la idea de que la globalización es una oportunidad que aquellos que están en desacuerdo. En términos europeos, las variaciones desde 2008 han sido menores. La proporción de ciudadanos europeos que declara estar de acuerdo ha caído, pero sólo cuatro puntos desde la primavera de 2008 a otoño de 2013. Estos datos agregados esconden grandes diferencias entre países. Las visiones positivas sobre el impacto de la globalización han disminuido significativamente en los países miembros más castigados por la crisis: 18 puntos en Italia y Chipre, 14 en Grecia y 13 en Portugal. En contraste, las percepciones de la globalización como una oportunidad para el crecimiento aumentaron en países como Luxemburgo (+9), Finlandia (+9) y Alemania (+7). A resultas de ello, en países como Suecia, Dinamarca o Finlandia, más del 70\% de la población muestra una percepción positiva de la globalización, mientras en Italia o Chipre el porcentaje es del 32\% y en Grecia del 27\%. (Eurobarometer 2014: 23).

Ahora bien, obviaríamos una dimensión fundamental si nos quedáramos con la idea de que la posturas anti-globalizadoras expresan el agravio económico de sociedades maltratadas por la crisis. A la fractura económico-territorial se suma a otra fractura interna, que tiene una dimensión educativa (y, asociada a ella, generacional). Las posturas frente a la globalización parten la población europea en dos grupos: los que tienen mayor nivel de formación y los que tienen menos. El 65\% de los europeos que estudiaron hasta los 20 años o más ven con buenos ojos la globalización, por el $44 \%$ de los que acabaron los estudios antes de los 16 años (Eurobarometer 2010).

En los últimos años, dos dimensiones de la globalización han cobrado relevancia inusitada. La inmigración es la segunda cuestión que más preocupa a los ciudadanos europeos dentro de sus países (por detrás del desempleo) y el reto más importante que, a su juicio, afronta la Unión Europea. La evolución 
del indicador es muy marcada. De ser mencionada por sólo el 7\% de la ciudadanía en 2011 entre los dos temas q los ciudadanos consideran más importantes en su país, pasa a serlo por el $36 \%$ en 2015 y el $28 \%$ en 2016. En nueve países es la cuestión que se menciona con más frecuencia, destacando países del centro y norte de Europa afectados por la crisis de los refugiados sirios, como Dinamarca (57\%), Alemania (56\%), Holanda (46\%), Suecia (44\%) y Austria (41\%) (Eurobarometer 2016: 10-11).

En los mismos años aumenta la preocupación por el terrorismo, especialmente en países como Bélgica, donde en 2016 ya es mencionada por el 33\% de la población en Bélgica, 30\% en Francia, y 26\% en Alemania. Se trata de países que han estado en el punto de mira del terrorismo yihadista.

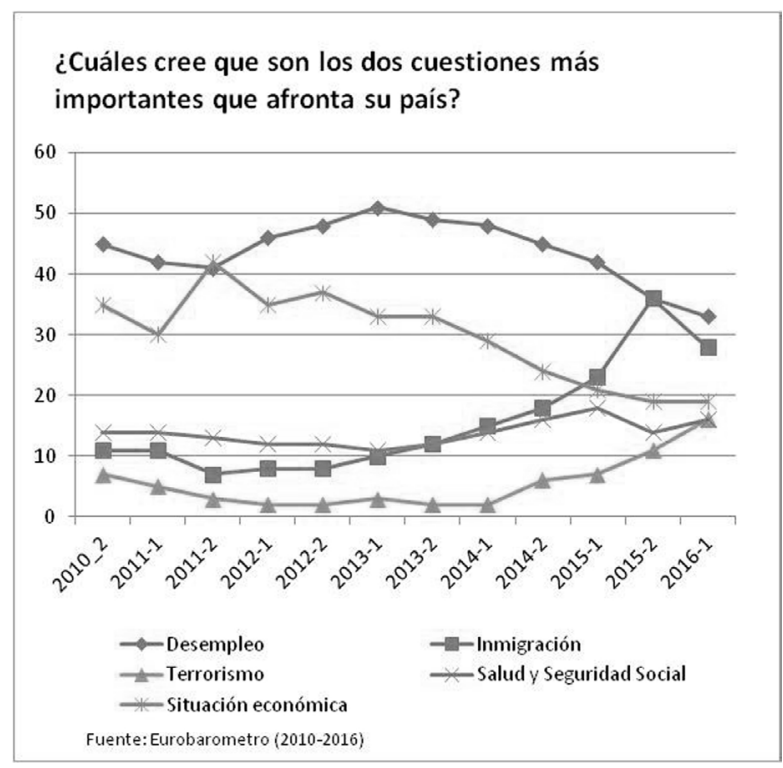

El miedo a terrorismo y a los nuevos vecinos activa ansiedades básicas relativas a la seguridad física y económica. Los discursos de excepcionalidad ante el terrorismo reflejan la frágil línea que separa las libertades ante las sensaciones de seguridad. Ese tipo de ansiedades juega un papel significativo en la conformación de actitudes políticas. No es el único. Esto las convierte en un factor relevante es su puesta en relación con una constelación más amplia de actitudes contrarias a ciertos valores del liberalismo y el cosmopolitismo. El motor fundamental de esta reacción son actitudes primarias de rechazo a 
nuevos estilos de vida, comportamientos sexuales que se aparta de las normas tradicionales, la llegada y asentamiento de inmigrantes o las políticas de reconocimiento y promoción de sus identidades por programas multiculturalistas. De esto modo, uno de los capítulos nos permite apreciar el artivismo crip como una insurgencia que reivindica nuevas expresiones sexuales y corporales que desafían el orden normativo tradicional.

En este sentido, los discursos antiglobalización se inscriben en nuevas lógicas de conflicto cultural. En muchos países del centro y norte de Europa, la hostilidad a la globalización económica y a la mercantilización generalizada bebe de una matriz cultural que se ha ido conformando por oposición al afianzamiento de corrientes culturales postmaterialistas progresistas. Los segmentos menos educados de la población, a menudo de edad más avanzada (y sexo masculino), plantan cara a lo que entienden como una impugnación de los modos de vida tradicionales y su marginación en sus propios países. A medida que se han extendido lo nuevos valores, y nuevas formas de «corrección política», se han ido perfilando también más claramente sectores de la población culturalmente irreductibles. Pero es imposible entender su creciente asertividad y protagonismo sin la labor de agitación que realiza una nueva hornada de políticos dispuestos a «representarlos» (Inglehart y Norris, 2016).

No es casual que varios autores que participan de esta obra alerten de nuevas formas de marginación postmaterialista tales como la soledad, el aislamiento o la expansión silenciosa de una connotación negativa de la dependencia funcional.

Europa ha asistido en los últimos años a la «politización del malestar». En países del Sur de Europa ha sido fundamentalmente una politización del sufrimiento económico, de la precariedad laboral y de la falta de horizontes vitales. La antiglobalización han sido un arma retórica más de un argumentario mucho más amplio, que encuentra en la crisis y las situaciones provocadas por ella el hervidero donde se gesta el malestar. Syriza o Podemos han sido abanderados de este conflicto, aunque sus votantes no hayan sido necesariamente los que más han sufrido la crisis. La indignación de muchos de sus votantes es resultado de la frustración de unas expectativas que se habían desbordado durante la etapa de expansión y se truncan subidamente con la llegada de la crisis, especialmente para algunos colectivos (como son los jóvenes) (Ramiro y Gómez 2016). 
En países del centro y norte de Europa, los partidos anti-establishment, no han renunciado a recabar el apoyo de quienes han experimentado sinsabores económicos de la crisis. Hay evidencia de que sus programas políticos otorgan hoy más relevancia a las cuestiones socioeconómicas y han optado por acentuar el perfil favorable a la protección social en sus propuestas, corrigiendo posiciones más cercanas al neoliberalismo en el origen de estos partidos (Alfonso y Rennwald, sin fecha). Pero fundamentalmente han puesto el dedo en otra llaga, la de los miedos cervales a la descomposición cultural de sus sociedades, así como la supuesta complicidad de los expertos y las élites políticas y económicas en esta deriva. En los últimos años los partidos anti-establishment han encontrado oportunidades insólitas para agitar espantajos y exacerbar con ello las angustias de la ciudadanía. Muchas de esas oportunidades están ligadas directamente a alguna dimensión de la globalización. Para ello han aprovechado que la globalización se ha presentado, en los últimos tiempos, en formas amenazantes (el terrorismo yijadista), desestabilizadoras (la crisis de euro y el temor de los electorados de países ricos a la mutualización de la deuda) y descontroladas (la crisis de refugiados). Convenientemente empaquetadas al efecto, estas amenazas han sido objeto de hábil capitalización política. Ha sido una tormenta perfecta que se ha llevado por delante muchas certidumbres y dejado como legado un cúmulo de desgarros que costará coser.

\section{Bibliografía}

ALFONSO, A. Y L. RENNWALD (sin fecha), «The Changing Welfare State Agenda of Populist Radical Right Parties in Europe», Electoral Realignments and Welfare State Transformations in Europe, ed. Philip Manow and Bruno Palier. Oxford: Oxford University Press.

ALONSO, SONIA (2013), La fractura democratica en la UE ¿encaminados hacia la tormenta perfecta?, Agenda Pública, 21/07/2013. http://www.eldiario.es/ agendapublica/proyecto-europeo/democratica-UE-encaminados-tormenta-perfecta 0 155034792.html.

ATKINSON, A. B. (2015), Inequality. What can Be Done. Cambridge: Harvard University Press.

CORBETT, A. (2016), «Globalization and the lower middle class of the rich world", Resolution Foundation Report.

EUROBAROMETER (2016). Eurobarometer 2016. Public Opinion in the European Union, Mayo 2016, European Comission.

EUROBAROMETER (2014) Eurobarometer 40 years. Effects of the conomic and Financial Crisis on European Public Opinion, European Commission. http:// ec.europa.eu/public_opinion/topics/eb40years_en.pdf. 
EUROBAROMETER (2010), Eurobarometer 73. Public Opinion in the European Union. Report Volum 2, Mayo 2010, European Commission http://ec.europa.eu/ public_opinion/archives/eb/eb73/eb73_vol2_en.pdf

INGLEHART, R. F. Y P. NORRIS (2016), «Trump, Brexit and the Rise of Populism. Economic Have-nots and Cultural Backlash", Harvard Kennedy School Faculty Research Working Papers 16-026.

MILANOVIC, BRANKO (2016). Global Inequality. A New Approach for the Age of Globalization. Cambirdge: Harvard University Press.

OECD (2008), Growing Unequal? Paris: OECD.

OECD (2011), Divided We Stand. Paris: OECD.

PIKETTY, T. (2014), Capital in the Twenty-first Century. Cambridge, Ma: Harvard University Press.

PUTNAM, R. D. (2015), Our Kids. The American Dram in Crisis. Nueva York: Simon \& Schuster.

RAMIRO, L. y R. GÓMEZ (2016), «Radical-Left Populism during the Great Recession: Podemos and Its Competition with the Established Radical Left", Political Studies http://psx.sagepub.com/content/early/2016/06/30/0032321716647400

THERBORN, G. (2013), The Killing Fields of Inequality. Malden: Polity Press.

WILKINSON. R. G. y KATE PICKETT (2009),The Spirit Level. Why More Equal Societies Almost Always do Better. Londres: Allan Lane. 
GLOBALIZACIÓN 



\title{
HACIA UNA AGENDA GLOBAL DE GOBERNANZA DE LAS MIGRACIONES FORZOSAS: POSIBILIDADES Y ESPEJISMO
}

\author{
Alfredo dos Santos Soares \\ fedysantos@hotmail.com
}

\subsection{Introducción}

Abordadas de manera coherente en sus dimensiones tanto objetiva como subjetiva, las migraciones forzosas hodiernas (y venideras) remiten, de modo necesario, a las grandes cuestiones que están alterando, de forma radical, el panorama de la gobernabilidad en la era de la globalización ${ }^{1}$, toda vez que rebasan los límites de la soberanía nacional y demandan la configuración de nuevos ámbitos político y normativo.

Este texto trae a debate la necesidad de considerar dichas migraciones como un problema global que requiere soluciones igualmente globales, ya que ningún Estado por sí sólo es capaz de afrontarlo de forma adecuada. Su propósito es el de, por una parte, examinar el posible alcance normativo, político y humanitario de la emergente agenda global de gobernanza de las migraciones forzosas, apreciable en la Declaración de Nueva York sobre Refugiados y Migrantes $^{2}$. Y, por otra, analizar el papel que las organizaciones regionales, en especial la Unión Europea (UE), pueden desempeñar, tanto en la elaboración como en la implementación de dicha agenda.

1 S. Sassen, Losing Control? Sovereignty in an Age of Globalization, New York, Columbia University Press, 1996.

2 Resolución adoptada por la Asamblea General de Naciones Unidas el 19 de septiembre de 2016 (A/RES/71/1). 
La gravedad, la complejidad así como la índole global de las actuales migraciones forzosas en buena medida han quedado puestas de manifiesto en los recientes flujos de personas migrantes hacia el territorio de la UE, en busca de asilo u otro tipo de protección internacional. A la vista de esta realidad, el alcance analítico del presente texto pretende ser tripartito: conceptual, normativo-político e institucional.

De entrada, se procura cuestionar el lenguaje simplista, reductor y tendencioso a menudo empleado para referirse a la migración y comunicar sobre la misma. Osamos, incluso, argüir que el ginebrino concepto de refugiado resulta corto y desenfocado ante el presente y el porvenir de las migraciones forzosas, un fenómeno nuevo mucho más diverso, transversal y complejo en sus causas y escala, manifestaciones y orientación ${ }^{3}$. Baste con señalar, en tal sentido, que la barbarie reinante por doquier afianza a los conflictos armados como la principal razón de desplazamientos humanos forzosos. Entretanto y de manera simultánea, se asiste a la afirmación real del cambio climático, que tiende a convertirse en la más preponderante fuerza inductora de dichos desplazamientos, toda vez que actúa como factor amplificador sobre las guerras y otros elementos de vulnerabilidad socioeconómica. Debemos, de igual modo, referirnos a desplazamientos forzosos que resultan de los denominados proyectos de desarrollo. Se trata, a fin de cuentas, del alto precio, en forma de exclusión social extrema, incluso de «limpieza étnica disfrazada», que millones de personas están pagando por el actual y dominante modelo económico, que ha demostrado ser profundamente injusto y perverso.

Asimismo, se revisa la (in)adecuación a la actual realidad migratoria de los marcos normativo y político existentes y aplicables en los niveles tanto regional (de la UE) como universal (Naciones Unidas - NU). El texto dirige una mirada crítica a sendas agendas migratorias, poniendo particular énfasis en los desafíos que rodean los denominados Pactos Globales - cuya concertación en el seno de NU se prevé para 2018 -, uno sobre la cuestión de los refugiados y otro para la migración segura, ordenada y regular. ¿Contribuirán dichos pactos

3 Esta afirmación obedece a la necesidad de considerar un enfoque holístico del problema de las migraciones forzosas, tanto en su diagnóstico como en las soluciones. Por lo tanto, no es ajena a la constante advertencia del Alto Comisionado de Naciones Unidas para los Refugiados (ACNUR) en el sentido de no incluir los refugiados en el concepto de migraciones forzosas. 
a facilitar (humanizar) la movilidad y avanzar en el respeto de los derechos humanos de sus actores? ¿Cuánto de esperanza y de espejismo cabe en esta propuesta? ¿En qué medida son los Pactos Globales en fragua la universalización de las nada plausibles normas y políticas migratorias y de asilo de la UE?

La mal llamada «crisis migratoria» referida a la UE ha puesto de relieve las graves limitaciones, la incapacidad y falta de voluntad política de los Estados para hacer frente a las migraciones forzosas de manera razonable y con arreglo a derecho. Es por ello que aquí se intenta romper una lanza por un marco institucional de respuesta adecuado e inclusivo de las encomiables iniciativas de la sociedad civil.

Resultado del análisis crítico, las entrevistas en profundidad y la revisión de la literatura, el texto se estructura en tres secciones. Comienza con un breve acercamiento panorámico a las contemporáneas migraciones forzosas. Examina, acto seguido, la regulación legal y la gestión política de esta realidad desde y por la comunidad internacional. Finalmente, considera la agenda migratoria de la UE y su incidencia en la emergente agenda migratoria global, perceptible en la antedicha Declaración de Nueva York para los Refugiados y los Migrantes.

\subsection{Contexto global de las migraciones forzosas: breve aproximación}

Huelga decir que las migraciones forzosas distan de ser un fenómeno nuevo. Con todo, su creciente magnitud, escala y carácter multicausal confieren novedad y especial complejidad a las actuales, cuyas poliédricas implicaciones todavía no han merecido suficiente atención académica ni política.

A la hora de contextualizar las referidas migraciones, hemos de considerar, entre otros aspectos, el alza exponencial de la desigualdad que caracteriza nuestro mundo globalizado, hasta el punto de convertir la movilidad en «el factor más poderoso y más anhelado de estratificación», toda vez que «las nuevas élites económicas y políticas globales son capaces de cruzar fronteras a voluntad, mientras que los pobres han de permanecer en casa». De allí que «los ricos son globales, la miseria es local» ${ }^{4}$.

4 S. Castles, «La política internacional de la migración forzada», Migración y Desarrollo, n. ${ }^{\circ} 1$ (2003), pp.8-15. 
Es evidente que, excluidos de los beneficios de la globalización económica imperante, las víctimas de desplazamientos forzosos forman parte de la miseria que debe permanecer en casa. Así, pues, no es extraño constatar que la inmensa mayoría de esas víctimas, que se cuentan por decenas de millones, permanece dentro de las fronteras de sus respectivos países de nacionalidad o residencia, desvalidas y a menudo invisibles a los ojos de la llamada comunidad internacional.

En cuanto a su génesis, debemos señalar que la barbarie persistente y proliferante en numerosas zonas del globo terráqueo apuntala a los conflictos armados, las tensiones sociopolíticas y sus corolarios (violencia generaliza$\mathrm{da}$, persecuciones y violaciones de los derechos humanos) como la principal causa de dichos desplazamientos en todo el mundo. Sus víctimas alcanzaron la abrumadora cifra de 65.3 millones a finales de 2015. La mayor parte, 40.8 millones, eran personas desplazadas internamente (PDI), 21.3 millones eran refugiadas, y 3.2 millones solicitantes de asilo ${ }^{5}$.

Entretanto y de manera simultánea, se asiste a la afirmación real del cambio climático, el cual tiende a convertirse en la más preponderante fuerza inductora de desplazamientos forzosos, al actuar como factor amplificador sobre las guerras y otros elementos de vulnerabilidad socioeconómica. A modo de acercamiento a su magnitud, el Centro de Monitoreo de Desplazamiento Interno (IDMC, por sus siglas en inglés) estima que, desde 2008, de media 26.4 millones de personas al año han resultado desplazadas como consecuencia de desastres, muchos de los cuales vinculados al cambio climático ${ }^{6}$. Con anterioridad, la institución Christian Aid había estimado en 250 millones la cifra de personas que, para el año 2050, podrían resultar desplazadas por el cambio climático ${ }^{7}$.

Asimismo, el desplazamiento por la fuerza es el alto precio que millones de personas están pagando por un modelo económico y de desarrollo perver-

5 ACNUR, Tendencias globales 2015, Ginebra, ACNUR, $2016<$ http://www.acnur. org/t3/fileadmin/Documentos/Publicaciones/2016/10627.pdf > (acceso 1.05.2017).

6 IDMC, Global Estimates 2015: People displaced by disasters, Geneva, July 2015, <http://www.internal-displacement.org/assets/library/Media/201507-globalEstimates2015/20150713-global-estimates-2015-en-v1.pdf> (acceso 1.05.2017), p.8.

7 Christian Aid, Human Tide: The Real Migration Crisis. A Christian Aid Report, London, May $2007<$ https://www.christianaid.org.uk/Images/human-tide.pdf $>$ (acceso 1.05.2017), p.6. 
so y profundamente injusto que, además de extremar la concentración de los recursos económicos (incluida la tierra) en manos de unos pocos y la pobreza de la inmensa mayoría, actúa por doquier como una poderosa arma de exclusión y segregación socioeconómica, incluso de «limpieza étnica disfrazada» ${ }^{8}$. Sea bastante recordar, aquí, el llamativo dato arrojado por la ya mencionada Christian Aid, al predecir que de las cerca de 1.000 millones de personas que, para el año 2050, podrían verse desplazadas de forma permanente, en torno a 645 millones lo serían por proyectos de desarrollo, a razón de 15 millones al año'.

El concepto de persona migrante forzosa que resulta de todo lo anterior incluye perfiles todavía insuficientemente estudiados. Además de las legalmente bien conocidas personas refugiadas y solicitantes de asilo, podemos referirnos a las desplazadas medioambientales, a las desplazadas del desarrollo, a las víctimas de la trata, sin obviar a muchas de las irónicamente llamadas inmigrantes económicos, siendo auténticas víctimas de violaciones de derechos humanos.

Es preciso hacer hincapié en el hecho de que la inmensa mayoría de las personas migrantes forzosas permanece dentro de sus propios países. En eso estriba, en efecto, el más importante cambio cualitativo y cuantitativo operado en el seno de las migraciones forzosas globalmente entendido y del problema de los refugiados en particular, al menos desde el final de la guerra fría. De aquí se desprende, fácilmente, que, en la práctica, millones de esas personas necesitadas de protección y asistencia internacional, permanecen desvalidas. Ello plantea ingentes desafíos a la sociedad internacional, a su orden económico, político y legal. Sobre este último aspecto versará la sección que sigue, tratando de examinar en qué grado y medida y con qué eficacia el Derecho internacional regula las migraciones forzosas.

\subsection{El Derecho internacional frente a las migraciones forzosas}

Es sensato suponer que, en cuanto instrumento nacido para poner orden a la vida social internacional, el Derecho internacional también impone límites a los Estados y otros actores (no estatales) que, de forma activa o pasiva, pu-

8 A. Dos Santos Soares, Migrantes forzosos: contextos y desafios de «Responsabilidad de Proteger», Madrid, Universidad Pontificia Comillas, 2015, p. 275.

9 Christian Aid, Human Tide, p.6. 
dieran dañar la dignidad y los derechos de las personas. Y articula un marco normativo e institucional de protección y asistencia a las víctimas de migraciones forzosas.

Es un hecho que estas migraciones vienen configuradas, de forma sistemática, por una multiplicidad de vulneraciones de la dignidad y los derechos de las víctimas. Con todo, en sí mismo considerado, el concepto migraciones forzosas aún no está universalmente aceptado en la legislación internacional. Ello determina la inexistencia de un estatuto legal otorgable a la generalidad de las personas migrantes forzosas $\mathrm{y}$, de resultas, su habitual desamparo.

Conviene, aquí, alabar los avances de derecho blando (soft law) registrados en el seno de la comunidad internacional en materia de protección y asistencia a las PDI, mediante la publicación, en 1998, de los Principios Rectores de los desplazamientos internos ${ }^{10}$. La cristalización de dichos principios en normas jurídicas vinculantes, acaecida en la Convención de la Unión Africana para la protección y la asistencia de los desplazados internos en África (Convención de Kampala ${ }^{11}$, da buena fe de ello.

Entretanto y sin perjuicio del ejemplo africano, es evidente que las migraciones forzosas siguen mereciendo del ordenamiento jurídico internacional un tratamiento ostensiblemente parcial y restrictivo, al reducirlas, cuasi exclusivamente, a los refugiados ex professo. Es decir, las personas refugiadas y solicitantes de asilo conforman, en realidad, el único sector de migrantes forzosos que cuenta con una protección y asistencia efectivas, mediante normativa sustantiva específica y un relevante grado de institucionalización, encarnado en el Alto Comisionado de las Naciones Unidas para los Refugiados (ACNUR).

Eso sí, sin dejar de ser una respuesta parcial y restrictiva a una realidad mucho más diversa, compleja y abrumadora como previamente indicado, cierto es que el Derecho internacional de los refugiados - fundamentalmente nucleado en torno a la Convención sobre el Estatuto de los Refugiados de

10 Informe del Representante del Secretario General sobre los desplazados internos, Sr. Francis Deng, presentado con arreglo a la resolución 1997/39 de la Comisión de Derechos Humanos. Adición. Principios Rectores de los Desplazamientos Internos, UN Doc. E/CN.4/1998/53/Add.2, 11 de febrero de 1998.

11 Adoptada en la capital de Uganda, Kampala, el 23 de octubre de 2009, entró en vigor el 6 de diciembre de 2012. 
$1951^{12}$ y su Protocolo de $1967^{13}$ - constituye, hasta la fecha, la más importante y sistematizada respuesta del ordenamiento jurídico internacional a las migraciones forzosas contemporáneas.

A tenor del artículo $1 \mathrm{~A}(2)$ de esa Convención, es refugiada una persona que se encuentra fuera de su país de nacionalidad o de residencia habitual, tiene un fundado temor de persecución a causa de su raza, religión, nacionalidad, pertenencia a un determinado grupo social u opiniones políticas, y no puede, o no quiere, acogerse a la protección de su país, o regresar a él, por temor a ser perseguido.

Es oportuno recordar que esta definición ha sido ampliada en los contextos regionales africano, mediante la Convención de la Organización de la Unidad Africana (OUA) por la que se regulan los aspectos especificos de los problemas de los refugiados en África ${ }^{14}$, y latinoamericano, a través de la Declaración de Cartagena sobre los Refugiados ${ }^{15}$, dando así cabida a más consideraciones objetivas configuradoras de la condición de refugiado.

En virtud de dichas ampliaciones del ginebrino concepto de refugiado operadas por ambos instrumentos regionales ${ }^{16}$, es posible proporcionar pro-

12 Adoptada en Ginebra, Suiza, el 28 de julio de 1951 por la Conferencia de Plenipotenciarios sobre el Estatuto de los Refugiados y de los Apátridas (Naciones Unidas), convocada por la Asamblea General en su resolución 429 (V), del 14 de diciembre de 1950, entró en vigor el 22 de abril de 1954, de conformidad con el artículo 43, Serie Tratados de Naciones Unidas, No 2545, Vol. 189, p. 137.

13 Firmado en Nueva York el 31 de enero de 1967, entró en vigor el 4 de octubre de 1967, de conformidad con el artículo VIII, Serie Tratados de Naciones Unidas No 8791, Vol. 606 , p. 267.

14 Adoptada por la Asamblea de Jefes de Estado y de Gobierno, en su sexta sesión ordinaria, en Addis-Abeba, el 10 de septiembre de 1969. Entró en vigor con carácter general el 20 de junio de 1974 (UNTS n ${ }^{\circ} 14691$ ). En la actualidad son parte en ella la práctica totalidad de los miembros de la organización (UA - Unión Africana, desde 2002).

15 Adoptada en el ámbito del «Coloquio sobre la Protección Internacional de los Refugiados en América Central, México y Panamá: Problemas Jurídicos y Humanitarios», celebrado en Cartagena de Indias (Colombia) en noviembre de 1984. El texto de la Declaración de Cartagena puede encontrarse en las memorias del coloquio publicadas bajo el título La protección internacional de los refugiados en América Central, México y Panamá: problemas jurídicos y humanitarios, Bogotá, 1986, pp. 332 y ss.

16 En su artículo 1 (2), la Convención de la OUA por la que se regulan los aspectos específicos de los problemas de los refugiados en África aplica el término 'refugiado' también a «toda persona que, a causa de una agresión exterior, una ocupación o una dominación extranjera, o de acontecimientos que perturben gravemente el orden público en una parte o en la totalidad de su país de origen, o del país de su nacionalidad, está obligada a abandonar su residencia 
tección y asistencia no solo a aquellas personas que huyen del país de origen en razón de fundados temores de ser perseguidos por motivos de raza, sexo, religión, nacionalidad, pertenencia a determinado grupo social y opciones políticas, sino también a todas aquellas personas que, viendo amenazada su vida o integridad física o moral por los conflictos armados, la violación masiva de los derechos humanos, la violencia generalizada o cualquier otra circunstancia que perturbe gravemente el orden público, decidan o se vean forzadas a abandonar sus hogares y cruzar la frontera en busca de refugio y protección.

La tendencia ampliatoria del concepto ginebrino de refugiado se ha visto afianzada, en el entorno interamericano, por la sentencia recaída en el Caso Familia Pacheco Tineo v. Estado Plurinacional de Bolivia, el 25 de noviembre de 2013, en cuya parte dispositiva la Corte Interamericana de Derechos Humanos declaró al Estado Plurinacional de Bolivia responsable por la violación del principio de no devolución y de los derechos de: buscar y recibir asilo, a ser oído con las debidas garantías, a la protección judicial, a la integridad psíquica y moral, a la protección de los niños y de la familia, reconocidos en los artículos 22.7 y 22.8, 8, 25, 5.1, 19 y 17 de la Convención Americana sobre Derechos Humanos, en perjuicio de los miembros de la familia Pacheco Tineo. Se trata, sin lugar a dudas, de una sentencia señera, que podría ser clave en el reconocimiento de la condición de refugiado y el otorgamiento del derecho de asilo en todo el sistema americano.

En el contexto regional de la UE, los intentos de ampliación de la definición del concepto ginebrino de refugiado quedan sustanciados, básicamente, en las figuras de protección tempora $1^{17}$ y subsidiaria, creadas en el marco

habitual para buscar refugio en otro lugar fuera de su país de origen o de nacionalidad». A su vez, la Declaración de Cartagena sobre los Refugiados establece, en su Tercera Conclusión, que «la definición o concepto de refugiado recomendada para la región es aquella que, además de contener los elementos de la Convención de 1951 y el Protocolo de 1967, considere también como refugiado a las personas que han huido de sus países porque su vida, seguridad o libertad han sido amenazadas por la violencia generalizada, la agresión extranjera, los conflictos internos, la violación masiva de los derechos humanos u otras circunstancias que hayan perturbado gravemente el orden público».

17 Establecida por la Directiva 2001/55/CE del Consejo, 20 de Julio de 2001, relativa a las normas mínimas para la concesión de protección temporal en casos de afluencia masiva de personas desplazadas y a medidas de fomento de un esfuerzo equitativo entre los Estados miembros para acoger a dichas personas y asumir las consecuencias de su acogida (DO L 212/12 de 7.8.2001). Si bien entró en vigor con carácter general ese mismo año, y no obstante el carácter práctico y eficiente del marco que introduce, este instrumento todavía no ha sido aplicado, ni tampoco se menciona en la Agenda Europea sobre Migración, obviándose, asimismo, su existencia en el contenido del SECA, como se pone de manifiesto en la nota que sigue. 
del todavía inconcluso y controvertido SECA (Sistema Europeo Común de Asilo $)^{18}$.

Aunque resulte obvio, es oportuno constatar que, si bien ampliada, la definición internacional de refugiado y su normativa aplicable excluyen a los demás colectivos de migrantes forzosos supra mencionados. Ello significa que, no obstante los progresos llevados a cabo en materia de indivisibilidad de los derechos humanos, se sigue considerando como factor configurador del estatuto de refugiado únicamente la violación de los derechos civiles y políticos. No así los derechos económicos, sociales y culturales, mucho menos los denominados derechos de tercera generación ${ }^{19}$. Ello por no mencionar a aquellas personas desplazadas por desastres ambientales, muchos de los cuales debidos al cambio climático, tampoco las víctimas del desplazamiento motivado por los proyectos del modelo económico y de desarrollo dominante. Y, como si todo ello fuera poco, sistemáticamente interpretadas desde el punto de vista masculino, las disposiciones del Derecho internacional de los refugiados no contemplan la persecución fundada sobre el género. Además, difícilmente consideran las experiencias de las mujeres perseguidas en la esfera privada por los agentes no estatales. Al revés, despolitiza determinados tipos de violencia tales como el secuestro, la explotación sexual, el matrimonio forzado, la mutilación genital o la esterilización ${ }^{20}$.

Tal y como previamente esbozado, gracias a los esfuerzos de la comunidad humanitaria, desde 1998 las PDI por conflictos armados cuentan, para su protección y asistencia, con normas de derecho blando (soft law), los Princi-

18 Se trata, como bien sintetiza Cristina Gortázar Rotaeche, de un conjunto de normas elaboradas en la UE desde 2001 hasta 2013 y que continúa en progresiva construcción. Su contenido viene integrado por las normas sobre condiciones mínimas comunes en la UE para la acogida a los solicitantes de protección internacional (Directiva sobre condiciones de acogida), las normas comunes sobre los procedimientos a aplicar en el examen (así como las respectivas garantías y recursos; Directiva sobre procedimientos) y las normas de armonización del contenido de los dos estatutos de protección internacional existentes en la UE (el estatuto de refugiado y el estatuto de protección subsidiaria; Directiva sobre requisitos de reconocimiento). Las tres Directivas se aplican junto al denominado Sistema de Dublín (de reparto intra-europeo de la responsabilidad sobre los solicitantes). Vid. C. J. Gortázar Rotaeche, «Como xestionar as solicitudes de asilo en Europa de maneira razoable e acorde a Dereito (unha de cada 113 persoas do mundo é desprazada pola forza)», Encrucillada: Revista galega de pensamento cristián, Vol. 40, N. 200 (2016), pp. 22-37.

19 R. Celis Sánchez Y X. Aierdi Urraza, ¿Migración o desplazamiento forzado? Las causas de los movimientos de población a debate, Bilbao, Universidad de Deusto, 2015.

20 Véase al respecto C. Miguel Juan, Refugiadas: una mirada feminista al derecho internacional, Madrid, Catarata, 2016. 
pios Rectores de los desplazamientos internos, los cuales, sin embargo, resultan poco generosos respecto de las PDI por causas distintas a los conflictos.

Es menester inferir de cuanto precede que el ordenamiento internacional dista de ser una respuesta suficiente a las actuales migraciones forzosas, cuyas causas se revelan cada vez más complejas y solapadas. Urge adaptar el Derecho aplicable existente y adoptar nuevas normas que la realidad social internacional está demandando. Eso sí, suscita gran desasosiego la creciente tendencia generalizada de los Estados a incumplir sus obligaciones hacia las personas refugiadas, incluso vaciando el sacrosanto principio de non-refoulement.

La buena noticia estriba en el hecho de que la comunidad internacional, encarnada en la Organización de las Naciones Unidas (ONU) ha empezado a darse cuenta de la necesidad de comprender y afrontar la realidad migratoria como un desafío que rebasa las fronteras propias de la soberanía estatal y exige una gestión responsable y compartida, coordinada y cooperativa, es decir, una verdadera gobernanza global. Eso mismo ha quedado reflejado en la Cumbre de la ONU sobre refugiados y migrantes, que tuvo lugar en Nueva York, el 19 de septiembre de 2016. La propia ONU la ha calificado como una «oportunidad histórica para elaborar un plan detallado que permita formular una mejor respuesta internacional», $\mathrm{y}$, además, como «un momento decisivo para reforzar la gobernanza de la migración internacional y una oportunidad única para crear un sistema más responsable y predecible de respuesta a los grandes desplazamientos de refugiados y migrantes $\rangle^{21}$.

Aquí llegados, hemos de reconocer que nunca antes la cuestión migratoria había escalado tan alto en la agenda de la política global. Los expertos coinciden en señalar que el documento resultante, la ya mencionada Declaración de Nueva York para los refugiados y migrantes, tiene una gran fuerza moral y podría desembocar en instrumentos jurídicos vinculantes, a semejanza de lo ocurrido con la Declaración Universal de Derechos Humanos, adoptada el 10 de diciembre de $1948^{22}$.

21 ONU, Respuesta a los grandes desplazamientos de refugiados y migrantes $<$ https:// refugeesmigrants.un.org/es/summit-refugees-and-migrants $>$ (acceso 30.03.2017).

22 E. Sagarra Trías, «La Declaración de Nueva York sobre la gestión de migrants y refugiados. ¿Un código de obviedades?». Artículo ANUE (Noviembre 2016), < http://anue.org/ sites/default/files/pdfs/Declaracio\%20de\%20Nueva\%20york\%20-\%20Castellano.pdf> (acceso 2.05 .2017$)$. 
Ciertamente es pronto para saber si estos esfuerzos para lograr el consenso global sobre la gobernanza de las migraciones forzosas llegarán a buen puerto. Con todo, esa Declaración desde un principio parece haber dejado a muchos decepcionados. Su mayor desasosiego nace, además de la ya conocida y habitual falta de voluntad política, del hecho de que los Pactos Globales previstos en dicha Declaración parecen reflejar y dar pie a la legitimación de elementos determinantes de la actual política migratoria de la UE, máxime la primacía del control de las fronteras y la ostensible preferencia por los pactos migratorios $^{23}$, de los que resulta tristemente paradigmático el Acuerdo UETurquía, en vigor desde el 20 de marzo de 2016. Todo ello permite acercarnos, brevemente, a la respuesta política, jurídica y humanitaria que las migraciones forzosas están mereciendo de la UE y sus Estados miembros, y en qué medida y grado dicha respuesta favorece o no el diseño y la puesta en marcha de una agenda global de gobernanza en la materia.

\subsection{La respuesta de la UE a las migraciones forzosas}

Consabido es que el panorama político mundial está cargado de desafíos transnacionales por su naturaleza y transinstitucionales por el tipo de solución que demandan. Ningún gobierno o institución que actúe solo puede afrontarlos eficazmente. Todo lo contrario, requieren de una acción colaborativa entre los gobiernos, las organizaciones internacionales y todas las fuerzas vivas de la sociedad civil ${ }^{24}$.

A su vez, la ONU puso de manifiesto su determinación para hacer frente a tan ingentes desafíos mediante la Agenda 2030 para el Desarrollo Sostenible, consistente en 17 Objetivos del Desarrollo Sostenible (ODS) ${ }^{25}$. De forma individual y cooperativa, los países se disponen a movilizar sus esfuerzos en el

23 Véase G. Almeida \& K. Bamberg, «The UN Summit for Refugees and Migrants: a mirror of the current EU Migration Policy?», 24 November $2016<$ http://eumigrationlawblog. eu/the-un-summit-for-refugees/> (acceso 2.05.2017).

24 The Millenium Project <http://www.millennium-project.org/millennium/challenges. html $>$ (retrieved 30.03.2017). Este Proyecto elabora el siguiente elenco con los 15 principales desafíos a los se enfrenta la humanidad: 1 . Desarrollo sostenible y cambio climático; 2 . Agua limpia; 3. Población y recursos; 4. Democratización; 5. La previsión mundial y la toma de decisiones; 6. Gobernanza global de las tecnologías de información; 7. Brecha entre pobres y ricos; 8 . Problemas de salud; 9. Educación y aprendizaje; 10. Paz y conflictos; 11. Situación de la mujer; 12. Criminalidad transnacional; 13.Energía; 14. Ciencia y tecnología; 15. Ética global.

25 Adoptada el 25 de septiembre de 2015 (A/RES/70/1), entró en vigor el 1 de enero de 2016. 
sentido de poner fin a todas las formas de pobreza, combatir las desigualdades y luchar contra el cambio climático, todo ello sin dejar a nadie atrás.

Entretanto, durante los últimos 2 años, la agenda de la UE en buena medida ha hecho caso omiso de estos desafíos, y ha encumbrado la llamada «crisis migratoria» como el mayor desafío de la Unión. Ahora bien, la respuesta que se ha venido dando, además de contrastar con la envergadura, real o percibida, de este desafío, también pone en tela de juicio la capacidad de la UE para actuar unida, de forma razonable y con arreglo a Derecho y a los valores compartidos.

Es, de igual modo, asaz consabido que las contemporáneas migraciones forzosas configuran un fenómeno per se multifacético y complejo. Empero, las palabras para hablar de ellas usualmente no son inocentes. Todo lo contrario, obedecen a simplificaciones periodísticas, a reduccionismos e incluso a manipulaciones políticas que, infelizmente, con frecuencia calan hondo en la opinión pública.

En efecto, la machacona narrativa establecida en torno a la denominada «crisis migratoria»o, en su versión más generosa, «crisis de refugiados» referida a Europa, se asienta, probablemente, sobre una alarmante tergiversación de la realidad, orientada a allanar el camino a la irresponsabilidad del Estado, la hostilidad, xenofobia e insolidaridad del conjunto de la sociedad hacia los náufragos y parias de nuestro mundo globalizado. El ardid consiste, al parecer, en sembrar el pánico en la sociedad al inducirla a una asfixiante percepción de hallarse en inminencia de padecer una apocalíptica invasión zombi por parte de la totalidad de miserables y hambrientos del globo terráqueo. Nada más lejos de la verdad. Ni todos los migrantes forzosos llaman a la puerta de la Fortaleza Europa, ni es Europa la única responsable de acogerles.

Conviene señalar, en tal sentido, que los Estados Europeos, más precisamente aquellos miembros de la UE no son, ni por asomo, los que más carga de desplazados forzosos por conflictos y persecuciones soportan, cuya cifra global superó con creces los 65 millones, en 2015, como previamente indicado. De hecho, Europa apenas acoge al $6 \%$ de estas personas ${ }^{26}$. La insignificancia de las cifras tanto de solicitantes de asilo que intentan acceder a los Estados miembros de la UE como de refugiados que ya se hallan en ellos, salta a la 
vista desde la simple perspectiva de la mencionada cruda cifra de desplazados forzosos que hay en el mundo y de los más de 500 millones de ciudadanos que la UE alberga.

Entretanto, es terriblemente cierto el que, no obstante su señalada insignificancia numérica, los refugiados se han convertido ya en un poderoso test al proyecto de la UE, haciendo tambalear algunos de sus pilares fundamentales (como la libre circulación Schengen), hasta el punto de convertirse en la mayor amenaza de su ruptura. ¿Acaso otro resultado cabría esperar de una Unión enfrentada a los valores sobre los que se asienta ${ }^{27}$, donde, al igual que la estabilidad presupuestaria, la seguridad y el control de las fronteras priman sobre las vidas humanas?

Es cierto que en el capítulo de la teoría, programático o de buenas intenciones, la UE se muestra consciente tanto de la complejidad del fenómeno migratorio ${ }^{28}$, como también del inmenso y creciente drama del desplazamiento forzoso en el mundo, tal y como refleja la Agenda Europea de Migración ${ }^{29}$ y el subsecuente documento Gestión de la crisis de los refugiados: medidas operativas, presupuestarias y jurídicas inmediatas en el marco de la Agenda Europea de Migración ${ }^{30}$.

27 Baste con recordar, aquí, el artículo 2 del Tratado de la UE que establece lo siguiente: «La Unión se fundamenta en los valores de respeto de la dignidad humana, libertad, democracia, igualdad, Estado de Derecho y respeto de los derechos humanos, incluidos los derechos de las personas pertenecientes a minorías. Estos valores son comunes a los Estados miembros en una sociedad caracterizada por el pluralismo, la no discriminación, la tolerancia, la justicia, la solidaridad y la igualdad entre mujeres y hombres».

28 «Las migraciones son una constante en la historia de la humanidad. Hoy, las personas que intentan alcanzar las costas europeas lo hacen por distintos motivos y por distintos medios. Procuran utilizar vías legales, pero también están dispuestas a arriesgar su vida para escapar de la opresión política, de la guerra y de la pobreza, o para acceder a la reagrupación familiar, a la creación de empresas, a los conocimientos y a la educación. Cada migración cuenta una historia personal. Guiados por los estereotipos y por visiones sesgadas, algunos tienden a centrarse únicamente en determinados tipos de flujos migratorios, dejando de lado la complejidad inherente a este fenómeno, que afecta a la sociedad en muchas formas diferentes y requiere respuestas diversas» (COM[2015] 240 final)

29 Del 13 de mayo de 2015, $\operatorname{COM}(2015) 240$ final.

30 Del 29 de septiembre de 2015 (COM[2015] 490 final/2). En respuesta a la señalada complejidad migratoria, la Unión considera la adopción de diferentes medidas conducentes al desarrollo de un enfoque coherente e integrado que permita aprovechar las ventajas y afrontar los retos del fenómeno migratorio. Ahora bien; es sobre todo en relación con las migraciones forzosas que la UE saca a relucir su «gran sensibilidad y refinada empatía»: «La tragedia vivida por miles de migrantes que ponen sus vidas en peligro para cruzar el Mediterráneo nos ha conmocionado a todos». De ahí que «el imperativo inmediato es proteger a las personas que lo ne- 
En el plano práctico, empero, persiste el disenso entre los Estados miembros, incapaces de aunar medios y voluntades para afrontar, de manera adecuada, el drama de las víctimas de desplazamiento forzoso, motivado por las guerras, la violencia y las persecuciones. Definitivamente, corren malos tiempos para la responsabilidad y la solidaridad. En este sentido, sea bastante señalar que a fecha 29 de marzo de 2017 se había procedido a reubicar a tan solo 10.644 (España, 877 y Portugal, 1154) 31 $^{31}$ de las 160 mil personas necesitadas de protección internacional que, en el marco del plan de emergencia acordado en septiembre de 2015, deberían ser reubicadas desde Grecia e Italia hacia otros Estados miembros de la UE. Tamaña y pasmosa lentitud da paso a inferir que la UE tardará varias décadas en cumplir este su compromiso. Sobra mencionar las 22 mil personas que la Unión se ha comprometido a reasentar, desde fuera de Europa, durante el año 2016. Por lo demás, cunden, al parecer, las soluciones tópicas y crematísticas de muy dudosa legalidad y entidad ética, como las fraguadas en la Cumbre de la Valeta sobre Migración (11-12 de noviembre 2015) ${ }^{32}$, en la Declaración de Bratislava (de 16 de septiembre 2016) y, cómo no, en el polémico y controvertido pacto cerrado entre la UE y Turquía, en Bruselas, el 7 de marzo de 2016. Las organizaciones humanitarias $\mathrm{y}$ de derechos humanos manifiestan su profunda inquietud por un pacto al que tildan de «un despropósito», «subasta de refugiados», un «acuerdo inmoral e ilegal», que vulnera el principio de no devolución, toda vez que permite expulsar a gran escala a todos los extranjeros llegados a las costas griegas,

cesitan», se lee en el número 2 de la susodicha Agenda. De resultas, la Unión apuesta por actuar de forma audaz, decidida y concertada, tratando de articular y mantener el necesario equilibrio entre la solidaridad y la responsabilidad compartida de sus Estados miembros, y articulando un enfoque comprensivo consistente en: «hacer frente a la crisis inmediata, pero también actuar dentro y más allá de la UE para reformar nuestro modo de cumplir las obligaciones que nos incumben con aquellos que necesitan protección, ayudar a los Estados miembros más afectados, honrar las obligaciones de la UE e internacionales en materia de asilo, devolver a aquellos que no necesitan protección a su país de origen, gestionar nuestras fronteras exteriores, tratar las causas fundamentales que motivan a las personas a embarcarse en peligrosos viajes a Europa, y tener en cuenta también la necesidad a largo plazo de Europa de migración legal».

31 Vid. Member States'Support to Emergency Relocation Mechanism (Communicated as of 08 March 2016) <http://ec.europa.eu/dgs/home-affairs/what-we-do/policies/european-agenda-migration/press-material/docs/state_of_play_-_relocation_en.pdf; (acceso 29.03.2017).

32 Destinada a la creación de un «Fondo fiduciario de emergencia para la estabilidad, que permita hacer frente a las causas profundas de la migración irregular y del desplazamiento de personas en África», con una dotación inicial de 1800 millones EUR. Se trata, según la UE, de una iniciativa que «puede formar parte de una asociación de doble sentido para reducir el flujo de migrantes procedentes de África e impulsar el retorno de quienes no reúnen las condiciones para beneficiarse de protección internacional» [ $\operatorname{COM}(2015) 490$ final]. 
incluidos los refugiados sirios. Todo ello transcurre mientras que el mar Mediterráneo, embravecido e insaciable, engulle cada vez más vidas - más de 5 mil tan solo en 2016 - y se convierte en «el naufragio de Europa» ${ }^{33}$.

\subsection{A modo de cierre}

Es alentador constatar que, por fin, la necesidad de una respuesta responsable, coordinada y cooperativa, a escala global, al inaudito sufrimiento de millones de personas víctimas de desplazamientos forzosos aflora y se abre paso en la agenda de la ONU. Con todo, una lectura atenta y detenida de la antedicha Declaración de Nueva York deja poco margen a la esperanza en un futuro marco legal, político e institucional, de índole interestatal, razonablemente protector y garantista para esas personas. Todo lo contrario, parece ir en aumento la tendencia de los Estados a incumplir sus obligaciones internacionales, en materia de asilo y/u otras formas de protección internacional otorgable en contextos de desarraigo motivado por la violencia y las persecuciones. La moderada esperanza en la eficacia de la emergente agenda global de gobernanza de las migraciones forzosas pasa porque, merced a los esfuerzos de importantes sectores de la sociedad civil, tanto en el proceso de edificación como en la implementación de esa agenda no triunfen los intentos que asoman, y mucho, desde la normativa y las políticas migratorias y de asilo de la UE: los de migracionalización del asilo, de securitización, militarización y externalización de la gestión del refugio, así como los de seguir primando el control de las fronteras y la seguridad del Estado sobre la vida y la seguridad de las personas migrantes.

\subsection{Referencias}

ACNUR, Tendencias globales 2015, Ginebra, ACNUR, $2016<\mathrm{http} / /$ www.acnur.org/ t3/fileadmin/Documentos/Publicaciones/2016/10627.pdf>.

ALMEIDA, G. \& K. BAMBERG, «The UN Summit for Refugees and Migrants: a mirror of the current EU Migration Policy?», 24 November $2016<$ http://eumigrationlawblog.eu/the-un-summit-for-refugees/>.

CASTLES, S., «La política internacional de la migración forzada», Migración y Desarrollo, n. ${ }^{\circ} 1$ (2003), pp.1-28.

CELIS SÁNCHEZ, R. y X. AIERDI URRAZA, ¿Migración o desplazamiento forzado? Las causas de los movimientos de población a debate, Bilbao, Universidad de Deusto, 2015.

33 En palabras de J. De Lucas, Mediterráneo: el naufragio de Europa. Valencia: Tirant Humanidades, 2016, $2^{\text {a }}$ edición. 
CHRISTIAN AID, Human Tide: The Real Migration Crisis. A Christian Aid Report, London, May $2007<$ https://www.christianaid.org.uk/Images/human-tide.pdf>.

DE LUCAS, J., Mediterráneo: el naufragio de Europa. Valencia: Tirant Humanidades, 2016.

DOS SANTOS SOARES, A., Migrantes forzosos: contextos y desafíos de «Responsabilidad de Proteger», Madrid, Universidad Pontificia Comillas, 2015.

GORTÁZAR ROTAECHE, C. J., «Como xestionar as solicitudes de asilo en Europa de maneira razoable e acorde a Dereito (unha de cada 113 persoas do mundo é desprazada pola forza)», Encrucillada: Revista galega de pensamento cristián, Vol. 40, Nº 200 (2016), pp. 22-37.

IDMC, Global Estimates 2015: People displaced by disasters, Geneva, July 2015, $<$ http://www.internal-displacement.org/assets/library/Media/201507-globalEstimates-2015/20150713-global-estimates-2015-en-v1.pdf $>$.

MIGUEL JUAN, C., Refugiadas: una mirada feminista al derecho internacional, Madrid, Catarata, 2016.

SAGARRA TRÍAS, E., «La Declaración de Nueva York sobre la gestión de migrants y refugiados. ¿Un código de obviedades?». Artículo ANUE (Noviembre 2016), <http://anue.org/sites/default/files/pdfs/Declaracio $\% 20 \mathrm{de} \% 20 \mathrm{Nueva} \% 20$ york\%20-\%20Castellano.pdf $>$.

SASSEN, S., Losing Control? Sovereignty in an Age of Globalization. New York, Columbia University Press, 1996. 
2

\section{GEOGRAFÍAS LEGALES DESDE LA CIUDAD: REDIBUJANDO EL ESPACIO PÚBLICO EN MADRID Y BARCELONA A TRAVÉS DE PROYECTOS URBANOS GLOBALES}

Pedro Limón López

Grupo de Estudios 'Espacio y Poder', Universidad Complutense de Madrid

\subsection{Introducción: ciudad, gentrificación y Derecho}

Desde la expansión del capitalismo industrial, el estudio de los procesos sociales que tienen lugar a escala urbana ha ido consolidándose en la investigación académica. Tras el impulso pionero y fundamental dado por la Escuela de Sociología de Chicago, enfática en el estudio de los conflictos y relaciones sociales generadas en y entre diversos tipos de comunidades que habitaban la ciudad, la diversificación en investigación urbana fue en paralelo a la división del trabajo científico, máxime tras la irrupción de las ciudades en la esfera global desde finales de los años sesenta y principios de los setenta. Desde entonces, las ciudades no sólo han aumentado la proporción de residentes a nivel mundial, sino que se han ido erigiendo en el centro de los cambios generados en el régimen de acumulación global, consolidándose como puntos centrales en los movimientos migratorios mundiales, en las representaciones sobre a globalización y en los imaginarios urbanos globales (Knox et al, 2003; Harvey, 1982, 1985, 1989, 2001, 2007; Massey, 1990, 1993; Cox et al, 2008; Christophers, 2011).

Por otra parte, en los espacios urbanos se generaron muchos de los nuevos movimientos sociales que pusieron los espacios urbanos en el centro de la agenda política y, a su vez, desplazaron hacia sí mismas la atención de muchos de los estudios científicos. Aunque en el ámbito académico estos lugares han ido acaparando protagonismo desde diferentes perspectivas y a partir de múltiples disciplinas, durante las dos últimas décadas ha habido un objeto de es- 
tudio que ha emergido y se ha convertido en protagonista de muchos de estos estudios y perspectivas de la ciudad: se trata de la gentrificación. ${ }^{l}$

Por supuesto, el estudio de los fenómenos de gentrificación tiene una pertinencia fundamental tanto por la actualidad como por la complejidad que demuestra acerca de los conflictos sociales y políticos que se generan en la ciudad, o por poner de manifiesto la conexión entre los procesos de globalización, los espacios urbanos y el protagonismo del Estado en la articulación de los mismos (Smith, 1979, 1984, 1996; Smith y Williams, 1986; Lees, 2006; Lees, 2011; Lees et al, 2008). Finalmente, implica un profundo desafío teórico y metodológico, no sólo porque critica la naturaleza ideológica del propio término, sino porque supone una oposición teórica entre posturas que priman la estructura, apareciendo la gentrificación como espacialización urbana inherente al capitalismo, y aquellas que dan primacía a las representaciones y la agencia, donde la gentrificación aparece como un proceso complejo en que intervienen múltiples actores en realidades contextuales diversas (Ward, 2010a, 2010b).

Por ello, aquí se propone una perspectiva crítica desde la Geografía urbana del Derecho que permita aproximarse a tales fenómenos desde un análisis histórico y concreto de las prácticas de producción y regulación de estos espacios de gentrificación a través de la normativa institucional que tiene lugar a escala urbana. En el siguiente epígrafe se expondrá el enfoque geográficolegal como perspectiva y metodología a aplicar en el estudio de la gentrificación, desarrollándose las líneas generales, pertinencia y aplicación práctica de la misma.

Posteriormente, se analizan de forma comparativa y a la luz de esta perspectiva heurística dos fenómenos de gentrificación desarrollados en Poblenou

1 Considero la gentrificación urbana como un proceso por el cual un espacio urbano en particular, anteriormente despoblado, socialmente erosionado o sin apenas relevancia en las inversiones o la planificación espacial de la ciudad y ocupados por clases trabajadoras, emerge con un impacto relevante en las prácticas y discursos urbanos, así como en las inversiones desarrolladas de cara a la atracción de consumo, incluyendo la mejora de los entornos físicos o la creación de espacios de ocio (Harvey, 2007: 377). Desde un punto de vista riguroso, hay quien considera el desplazamiento de clases sociales como elemento distintivo (Glass, 1964), si bien hay propuestas que hablan de considerar tanto la nueva creación como la regeneración urbana en sí misma, puesto que en ambos casos tendría un efecto de elitización o gentrificación de lo que antes estaba despoblado o en condiciones ruinosas (Whitehand, 1990; Smith, 2002, 2008). Aunque su traducción más literal recomendaría el uso de la palabra aburguesamiento, en este trabajo se utilizarán los conceptos de gentrificación y elitización urbana como sinónimos. 
(Barcelona) y Hortaleza (Madrid) durante las dos últimas décadas. Finalmente, las conclusiones sistematizan la influencia de las tendencias establecidas alrededor de ambas localidades y en torno a sus dinámicas gentrificadoras, así como el impacto sobre el espacio urbano en su conjunto, mientras se discute la pertinencia y utilidad de ciertos enfoques existentes sobre los procesos urbanos, así como las consecuencias prácticas que tiene su aplicación política.

\subsection{Derecho, espacio y ciudad: geografías legales críticas}

El espacio público se organiza alrededor de formas de exclusión y control, hasta el punto que un rasgo mayoritario de distinción social se significa en función del acceso a un espacio público particular o diferencial (Young y Keil, 2010). Si las dinámicas de gentrificación implican la revitalización, revalorización y aburguesamiento o elitización de una zona concreta a escala urbana, supondrán inevitablemente una reformulación de los espacios públicos, del acceso y del uso al mismo. Siendo esto así, y teniendo en mente que existen otros modos de organizar los ámbitos urbanos gentrificados, la producción política institucional aparece como el foco primario de análisis, especialmente el derecho y la creación normativa.

En las últimas dos décadas y a instancias de las transformaciones globales, ha tenido lugar una expansión de la intervención política a través del derecho, así como una juridificación sin precedentes de las prácticas sociales y políticas desarrolladas en la ciudad. Además, se ha producido una expansión del control social a través de diferentes mecanismos vinculados a la securitización, pasándose de «políticas diseñadas para promover la integración social (...) a otras basadas en la asimilación cultural, la neutralización política o la exclusión social, que se han incrementado al basarse en la creencia de amenazas y riesgos exteriores, así como la prevención de los mismos» (Banakar, 2010: 12-13).

Estas transformaciones han tenido lugar fundamentalmente en los espacios urbanos, y más aún a través de los programas de regeneración y gentrificación urbana, provocando una alteración de las representaciones e imaginarios sobre los valores y las relaciones políticas, pero también sobre los espacios públicos, acrecentando el interés por el impacto de la producción normativa sobre diferentes ámbitos de lo público y de lo político (Lippens, 2004). 
Aunque fue la Sociología jurídica la pionera en este tipo de estudios ${ }^{2}$, eludían cuestiones referentes al espacio público, así como no desarrollaban análisis alguno que vinculase la legislación con el espacio y la imaginación geográfica, pese a haber estrechos vínculos entre la ley y el espacio que no podemos soslayar. Como muestra Blomley (2008: 156), existen nexos espaciolegales interesantes, a saber: que ambos elementos son vistos como productos sociales y como productores de esas mismas relaciones sociales, se producen de forma recíproca; que la espacialidad debe verse como causa y consecuencia de la producción legal; ambos elementos están inscritos en las dinámicas e interacciones de poder que les dan forma y son reformuladas por éstos. Finalmente, el espacio funciona como un imaginario para los derechos, «formando las formas en que éstos se constituyen, contestan y funcionan para producir, y operar desde, espacios delimitados» (Blomley, 2008: 158), mientras que el tipo de categorización legal es un modo concreto de espacialización (Braverman et al, 2013; Bennett y Layard, 2015; Delaney, 2015a, 2015b). La cuestión es qué concepción del mismo produce y es reproducida por qué tipo de proyectos de gentrificación y a través de qué regulaciones.

Formada por distintas perspectivas y corrientes, esta Geografía crítica del Derecho tiene como elemento distintivo el rechazo de la ley y el espacio como entes aislados. ${ }^{3}$ Desde esta visión, ambas esferas son constitutivas entre sí,

2 La Sociología jurídica es «un campo multidisplinar formado por diferentes aproximaciones al estudio del derecho en sociedad (...), y sostiene que todo el derecho y sus manifestaciones deberían estudiarse empírica y contextualmente» (Banakar, 2011: 2). El Derecho es utilizado como un punto de partida desde el cual se analizan una serie de cuestiones teóricas y empíricas que enmarcan, ocultan o incluso proyectan algunos de los conflictos e interrogantes socio-políticos más encarnecidos.

3 La evolución histórica de la Geografía legal se reduce a unos pocos enfoques: el primero de ellos es el que podríamos identificar con la Geografía Regional del Derecho, y que se remonta al análisis seudo-estatal o estatal que, desde la perspectiva del determinismo ambiental, tenían autores como Bodin o Montesquieu, o ya en el siglo XX, en el enfoque pionero de Wigmore, que analiza la influencia de la Geografía sobre el Derecho. En este caso, de lo que se trataba era de hacer tipologías acerca de Estados que, en principio, incluían dentro de clasificaciones conforme a cuestiones vinculadas a la Geografía física. Posteriormente, a instancias de Whittlesey a mediados de los años treinta, se abrió la vía para invertir esta relación, estudiando cómo influye la autoridad efectiva sobre el paisaje, especialmente a partir de leyes concretas reguladoras de aranceles, recursos, propiedad, etc. En estos trabajos se investigan los efectos que tienen las normas sobre la estructura espacial, asumiendo un determinismo normativo absoluto, a partir de una separación analítica entre el Derecho, el espacio y la sociedad (aunque enfaticen en aspectos diferentes). Frente a ellos emerge una Geografía Legal crítica durante los años noventa que tiene como elemento distintivo el rechazo de la ley y del espacio como entes prepolíticos y separados (Johnston et al, 2000: 127-130). Antes al contrario, desde esta perspectiva 
centrándose en tres cuestiones: el análisis de los modos a través de los cuales la acción e interpretación legal produce determinados espacios; la naturaleza situada de la interpretación legal; y en el estudio de las demandas geográficas y representaciones contenidas en el discurso legal (Gregory et al, 2009).

Así, la Geografía política del Derecho se dirige hacia distintos objetos de investigación referidos a la ley en cuanto a sus posibilidades espaciales, como «diferentes espacios y localizaciones; reglas y expectativas que regulan dichos espacios; y las implicaciones de estas distintas espacialidades sobre las cualidades de los actores públicos» (Staeheli, 2010: 71). Tiene como objeto principal de investigación: el análisis de los modos a través de los cuales la acción e interpretación legal produce determinados espacios, partiendo del análisis de impacto de esa interpretación sobre el contexto local (por ejemplo, los controvertidos efectos de las decisiones o sentencias judiciales, así como su ejecución o aplicación legal); la naturaleza situada de la interpretación legal; y en el estudio de las demandas geográficas y representaciones contenidas en el discurso legal (Gregory et al, 2009), especialmente las que cuestionan o reproducen esa congelación de la imaginación política a través de la ley. Además, buena parte de las transformaciones económico-políticas llevadas a cabo en los ámbitos urbanos han sido planificadas o influidas a partir de la aplicación e interpretación legal, especialmente en lo relativo a la exclusión de diferentes colectivos sociales sociales (Mitchell, 1997, 2003; Forest, 2004; Blomley, 2003a, 2004, 2010; Dangschat, 2009; Mitchell y Heynen, 2009; Herbert, 2010; Staeheli, 2010; Baptista, 2013), así como a la compatibilidad de esta metodología con muchos de los estudios procedentes de la Economía Política urbana, especialmente en lo referente al estudio de los procesos de globalización (Blomley, 2003b; Delaney et al, 2010; Barkan, 2011).

Frente a la carencia analítica de las relaciones entre el espacio público, la imaginación geográfica y la elaboración e implementación de ciertas normativas en los ámbitos madrileño y barcelonés, que eluden la importancia de la ley en la Geografía urbana, mediante esta perspectiva se propone investigar qué concepciones de espacios públicos y políticos son articuladas en la ciudad a través de la producción juridica. Además, este punto de vista permite ana-

ambas esferas son no sólo complementarias, sino que se solapan entre sí, «examinando cómo el espacio modifica o reforma los efectos de la ley y, simultáneamente, cómo la ley da forma a las relaciones espaciales» (Martin et al, 2010: 177). 
lizar las relaciones entre el espacio público, la imaginación geográfica y las dinámicas de elaboración e implementación de las normativas analizadas en las regiones barcelonesa y madrileña.

El análisis de dichas normativas es básico en la medida en que producen sus propios modos de entender las formas de espacialización política. Establece narrativas específicas sobre la propiedad, el territorio o el intercambio social (Martin et al, 2010) por lo que su estudio es central en la medida en que la ley articula no sólo un conjunto de controles, sino también significados políticos y culturales mediante los cuales se interactúa y se reformula el espacio público (Blomley, 2008: 156-157). ${ }^{4}$ Así:

[...] en la medida en que lo público se constituye parcialmente en espacios públicos, dónde se localizan tales espacios puede ser algo decisivo [...]. Al cerrar determinados espacios a la expresión política [ampliando y potenciando otros], la exclusión de las voces disidentes son ocultadas por la apariencia de que el espacio público es políticamente inclusivo [...]. Es así como las políticas del espacio público desplazan quiénes son silenciados al dónde se debe practicar la política [...], [y es así como] las políticas del espacio público pueden dar forma a la naturaleza de lo político en el espacio público (Mitchell y Staeheli, 2005: 798).

\subsection{Patios traseros en la ciudad: barrios y nuevas espacialidades urbanas}

Además de los fenómenos particulares desarrollados en Hortaleza y Poblenou, hay que tener en cuenta las tendencias generales mantenidas en los

4 Siguiendo la metodología del análisis crítico del discurso, el estudio se centra en las prácticas de producción política que se producen a partir del discurso legal (Chouliaraki y Fairclough, 1999: 23) sobre el espacio público de la ciudad, estableciéndose por las propias administraciones competentes en materia urbana en las dos últimas décadas. Toda vez que la hermenéutica crítica permite engarzar texto, contexto histórico y actuación de los diferentes sujetos sociales (Denzin y Lincoln, 2005: 311-312), el estudio desarrollado se basa en una visión histórica del discurso legal, así como en el uso de herramientas de categorización retórica. El análisis histórico del discurso observa «cómo determinados asertos vienen a constituir objetos y sujetos (...) explorados en su contexto historic» (Denzin y Lincoln, 2005: 871), mientras que el análisis categorial establece pares categóricos textuales con el fin de codificar lo analizado e identificar las características retóricas del discurso legal a través de las cuales se construyen o reafirman distintos procesos sociales (Denzin y Lincoln, 2005: 830), como sucede en este caso con la higiene y el civismo. Al considerar la imaginación geográfica producida desde el marco institucional, se tienen en cuenta aquellas normativas consideradas urbanas, urbanísticas y relativas al espacio público de la ciudad por las propias Administraciones vinculadas directa e indirectamente a los procesos de gentrificación en Poblenou y Hortaleza, tanto promulgadas por las instituciones locales como por las comunitarias, europeas o estatales. 
casos de Madrid y Barcelona, ya que arrojan luz acerca de la producción normativa emanada de las instituciones vinculadas a las dinámicas de reestructuración urbana y las políticas securitarias durante las últimas décadas.

Dentro de las prácticas normativas institucionales en Madrid destaca el cambio, desde la legislación, de un derecho de uso del espacio público en la calle a su prevención o justificación por su uso, basada en tres elementos de importancia creciente, como son el cerco institucional al espacio público; el civismo como elemento discursivo de legitimación del uso del mismo; y finalmente, la espacialización creciente de potenciales agencias sociales en los ámbitos urbanos a través de políticas territoriales en torno al ocio o el turismo y de las políticas de policía. Estos elementos estatuyen una concepción de espacio público vinculado al espacio geométrico, definido por las instituciones y el control policial del mismo. Pero, simultáneamente, proscriben y someten a control espacios sociales de interacción cotidiana que también son públicos de manera más informal, así como fragmentan y parcelan un lugar como la calle, considerado espacio público de primer orden. Al parcelar dichos espacios, se construyen zonas fronterizas informales en la ciudad que producen un reconocimiento asimétrico de sus imágenes y cartografías urbanas. Pero, en ese afán por dividir y reducir la consideración del espacio público, la regulación ha abarcado una cantidad ingente de ámbitos, sentando las bases para su reversión práctica y representacional. Es interesante notar que, mientras la ley está creando un espacio jerárquico sustentado en las instituciones, territorios especializados y fronteras informales, ha establecido una postura común en cada espacio social y político. Al hacerlo, el objetivo de los municipios y del gobierno regional era especializar y reducir el reconocimiento general del espacio público, pero a través de la regulación sobre espacios, territorios y lugares o, en caso de no existir, de su creación (Limón López, 2014).

En el caso de Barcelona, las tendencias identificadas trazan una imaginación geográfica construida en la ciudad en las dos últimas décadas basada en la orientación exterior, la higiene, la renovación zonal y el civismo como claves explicativas del mapa urbano. El «símbolo de libertad, progreso, convivencia, pluralidad, diversidad, proyección e iniciativa internacionales, tolerancia, solidaridad, paz y crisol cultural ${ }^{5}$ » en que se convertía Barcelona según la legislación contrastaba con una producción normativa de la geografía de la ciudad que suprimía las prácticas informales de manera progresiva del

5 Exposición de motivos de la Ley del Estado 1/2006, de 13 de marzo, por la que se regula el régimen especial del municipio de Barcelona. 
espacio público, así como se somete a excepción el uso colectivo del espacio público ${ }^{6}$, aplastado por la normalización del mismo basada en el uso transitorio, cívico y la renovación e higiene urbana (Limón López, 2012). Por otro lado, las políticas de renovación y territorialización urbanas han parcelado las espacialidades oficiales hasta ser definidas por razones sectoriales que, en última instancia, son dependientes del ámbito institucional y de las imágenes de proyección exterior, habilitando la estructuración y reproducción de diferentes regiones de frontera en la ciudad delimitadas por esos itinerarios de separación (interior) y contacto (exterior) dibujados por los proyectos de renovación, gentrificación y espacialización de actividades en la ciudad.

Pese a las particularidades de ambos núcleos urbanos, comparten algunas tendencias comunes, así como la recurrencia en formas de re-territoralización urbana encarnadas en los proyectos de gentrificación poblenoví y hortaleño.

\subsubsection{Una nueva frontera en Poblenou, punta de lanza global}

Dentro de las dinámicas de renovación urbana en Barcelona, destaca el caso del Distrito de Sant Martí como ejemplo paradigmático de esta re-territorialización de la ciudad. Tras la Modificación del Plan General Metropolitano en el Frente Marítimo del Poblenou (1993) y en el Sector del Front Litoral i Marge del Riu Besòs (2000), se emprendió la renovación de un urbanismo industrial que se consideraba obsoleto. Después de las reivindicaciones vecinales por el reconocimiento del patrimonio industrial como elemento inherente al barrio (Marrero Guillamón, 2003), la Modificación del Plan Especial de protección del patrimonio arquitectónico, histórico y artístico de la ciudad de Barcelona en el Distrito de Sant Martí sentó las bases para el establecimiento de nuevas territorialidades que cuestionaban los espacios históricos, fundamentalmente a través del 1lamado Plan 22@ (Rojas et al, 2007).

La reformulación del Poblenou bajo el proyecto 22@es algo consabido dentro de las transformaciones barcelonesas, pero aquí se pretende mostrar cómo se ha usado la producción legal en torno a dicho proyecto y en relación al barrio poblenoví. En lo sucesivo me referiré a Poblenou como un área que

6 Las primeras por la vía de los artículos 21 y 70 de la Ordenanza sobre los usos de las vías y espacios públicos de Barcelona de 1998. En cuanto al espacio público, se denomina «uso común especial a aquel que somete la vía pública a especial intensidad, ocupación transitoria (art. 27), entre los que destacan los supuestos de celebración de actos públicos, la acampada en los espacios públicos o en vehículos estacionados en éstos (...), la publicidad manual u oral» (art. 28.1.e, fy g). 
alberga la división administrativa de Poblenou, el Parc i la Llacuna de Poblenou, la Vila Olímpica de Poblenou, Diagonal Mar i el Front Marìtim de Poblenou y Provençals de Poblenou (véase figura 5) y que está limitado desde 2006 como «el área que queda enmarcada entre la avenida Prim, la línea del litoral, el parque de la Ciutadella y la avenida Meridiana, y la Gran Vía de las Corts Catalanes, incluido en el distrito de Sant Martí de la ciudad de Barcelona» ${ }^{7}$, todo ello vinculado a los cambios impelidos por el22@.

E1 22@Barcelona es un proyecto de renovación sectorial y territorial de la mayoría de los anteriores espacios fabriles de Poblenou desarrollado en la ciudad condal desde 2000 con vocación de transformar el espacio urbano en clave de ciudad digital y del conocimiento (Oliva, 2003; Guillot, 2004), produciéndose una zonificación basada en el 22@ como distrito tecnológico que resitúe Barcelona globalmente como un modelo a exportar (AAVV, 2011). ${ }^{8}$ En relación con el espacio urbano, el mismo Ayuntamiento de Barcelona define el 22@ como un nuevo modelo de hacer ciudad basado en un proyecto de transformación social, económica y urbana (Ayuntamiento de Barcelona, 2005, 2008, 2009, 2010b, 2012). Así, las intenciones del mismo en relación con la localidad o el espacio local están claras:

El proyecto 22@ Barcelona constituye una oportunidad única de recuperar la vocación productiva del Poblenou y crear una importante polaridad científica, tecnológica y cultural que convertirá a Barcelona en una de las principales plataformas de innovación y economía del conocimiento de ámbito internacional. Con este proyecto, Barcelona está transformando el barrio industrial de Poblenou, que durante más de cien años fue el motor económico principal, en un nuevo modelo de espacio de conocimiento que promueve la colaboración y las sinergias entre la universidad, la tecnología y la empresa con el objetivo de favorecer el desarrollo de la cultura innovadora y del talento [...]. Crea así un entorno diverso y equilibrado donde conviven las empresas más innovadoras con centros de investigación, de formación y transformación de tecnología, con

7 Artículo 1 de las normas urbanísticas del Plan Especial de Protección del Patrimonio Arqueológico, histórico y artístico de la ciutat de Barcelona Districte de Sant Martí, Patrimoni industrial de Poblenou (noviembre de 2006)).

8 Se trata de una nueva centralidad alrededor de Poblenou en relación a Barcelona, que cambia la producción fabril tradicional, por otra basada en industrias limpias renovación urbana y terciarización de las actividades. Según el último informe del estado de ejecución del proyecto, se han renovado el $70 \%$ de las áreas industriales, albergando 7000 empresas y más de 90000 trabajadores, de los cuales un 74.2\% se dedican a lo que se conocen como actividades @ (TIC's, medios de prensa, diseño, tecnologías médicas o energías), por un 58\% en el resto de Cataluña (Ayuntamiento de Barcelona, 2009, 2010a: 3, 2010b: 6, 2012: 54-55). 
comercios, viviendas y zonas verdes que favorecen el dinamismo social y empresarial (Piqué, 2008: 239).

Sólo con echar un vistazo al mapa de la división administrativa de Poblenou dentro del distrito de Sant Martí (figura 1) evidenciamos diferencias importantes con respecto a este reconocimiento local oficial y, lo que es más importante, con relación a los mapas distribuidos oficialmente a escala institucional sobre los límites de Poblenou (figura 2).

A principios del año 2000 ya se preveía una renovación del Poblenou y sus áreas industriales de cara a transformarlo en el distrito de actividades 22@Barcelona (Ayuntamiento de Barcelona, 2000: 6). Así, las propuestas de nueva urbanización finalmente implementadas tenían por objeto una reestructuración de las infraestructuras que permitiese la diferenciación zonal y la aglomeración de clúster22@, modificando la trama previa constituida en torno a grandes fábricas y pequeños talleres. ${ }^{9}$

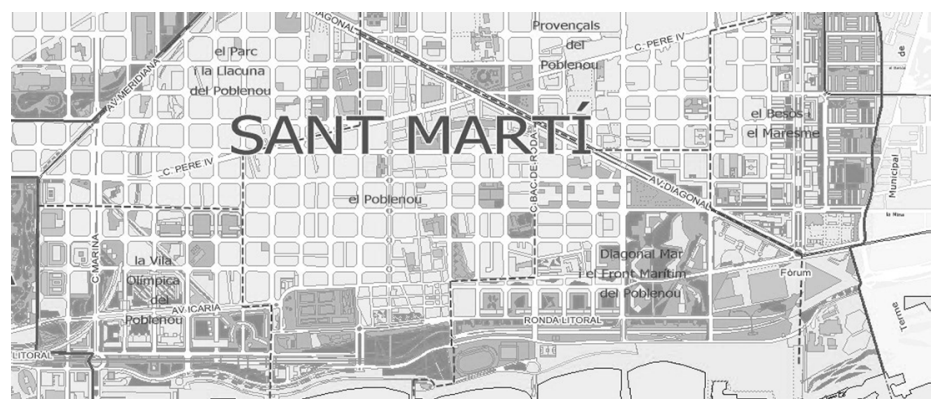

FIGURA 1. Plano de los barrios en el distrito de Sant Martí. FUENTE: Ayuntamiento de Barcelona

9 Artículo 28.3 del Plan Especial de Infraestructuras de Poblenou; Modificación del Plan General Metropolitano en el ámbito del casco antiguo del Poblenou (Ayuntamiento de Barcelona, 2010b: 18-20); 22@ Estado de ejecución (Ayuntamiento de Barcelona, 2009: 15). Los clúster empresariales principales son: Fundación Barcelona Digital, Barcelona Media, Biocat, Barcelona Centre Disseny, InMediaTe y Barcelona Design Innovation Cluster (Ayuntamiento de Barcelona, 2009: 13). 


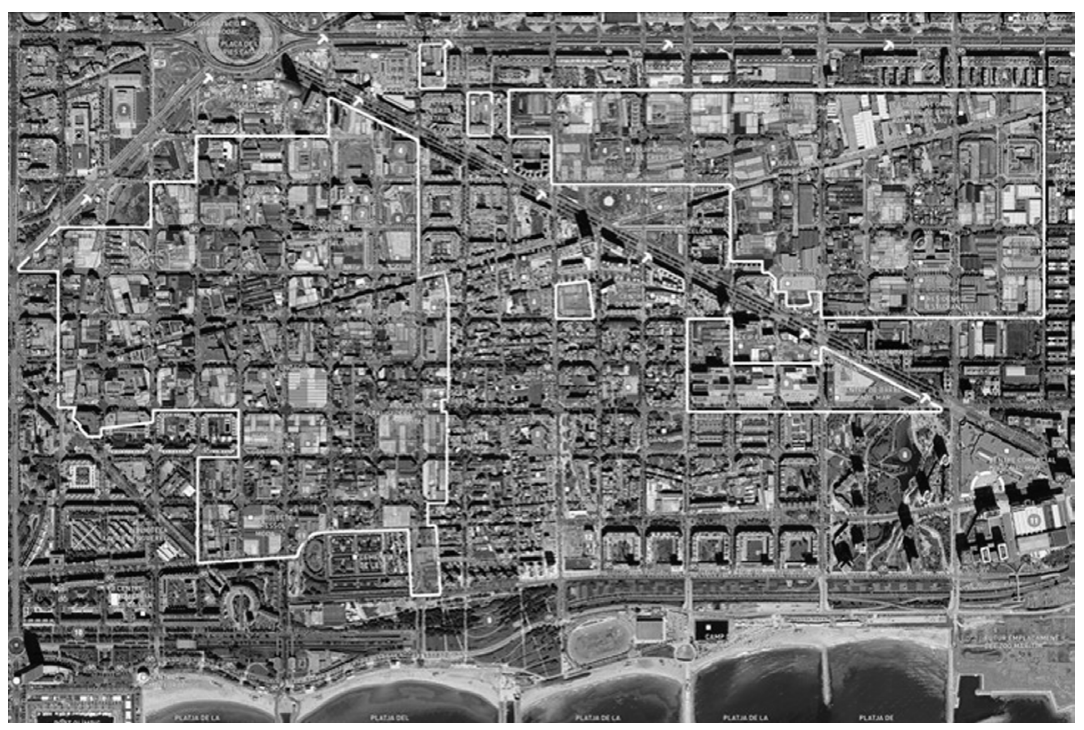

FIGURA 2. Fotografía aérea por satélite de los límites territoriales reconocidos a Poblenou (en blanco el trazado del proyecto 22@). FUENTE: Ayuntamiento de Barcelona

Es más, ese mismo Plan especial de infraestructuras ya contemplaba en el año 2000 que podían producirse o provocarse transformaciones en el entorno local e incluso ir más allá (Ayuntamiento de Barcelona, 2000: 60).

Aunque en un principio se trata de una renovación integral que apela a la memoria histórica industrial en relación con la trama urbana, poco a poco la consideración de la nueva industria (limpia) y el vínculo entre la sostenibilidad, las actividades@y la limpieza en la accesibilidad y la movilidad a dicha zona se irá imponiendo en la estructuración de dicho espacio. ${ }^{10}$ Así, muy pronto empezó a articularse una nueva delimitación poblenoví alrededor de seis áreas nuevas que actuarían como nodos de localización de los clúster implantados en torno a los ejes de: Llull Pujades-Levant, Perú-Pere IV, Parc

10 En la memoria del Plan Especial de Infraestructuras de Poblenou (2000), aparte del énfasis dado a la accesibilidad, la movilidad o la limpieza, se hace hincapié en su coordinación con el tratamiento de residuos, el ciclo del agua, los sistemas de energía y telecomunicaciones en clave @. Por poner un ejemplo claro: se otorgan dos plazas de aparcamiento para bicicletas por cada 80 metros cuadrados construidos de edificios para empresas con actividades@y equipamientos 7@, que son los que tienen que ver con actividades de formación, investigación y divulgación de nuevas tecnologías (artículo 28.3.1.2 ), o sea, las que están vinculadas a nuevas energías, TIC's, bioempresas, I+D+i tecnológica, biomedicina, investigación militar, etc. 
Diagonal, Campus Audiovisuales, Parc Central Eix Llacuna y Llull Pujades Ponent (Ayuntamiento de Barcelona, 2005: 14). Del pasado industrial y la organización histórica del barrio se pasó a hablar de la calidad de vida, la nueva distribución de los espacios de interacción pública, la concentración de actividades intensivas en conocimiento, los centros de formación e innovación sujetos a la renovación urbana o la gestión local, urbana e incluso la rehabilitación del patrimonio histórico industrial en función del 22@. Efectivamente, tanto desde muchas asociaciones vecinales como desde partidos políticos, se ha tenido en cuenta como un proyecto útil y positivo de cara a la transformación de Poblenou. Por una parte, porque, teniendo en cuenta que la reconversión industrial barcelonesa se consideraba como algo necesario e inevitable, suponía conservar un tejido productivo a lo largo del espacio local del barrio que de haberse dado otras dinámicas quizás no habría sido posible, y la reconversión industrial habría tenido consecuencias mucho más negativas en Poblenou, tanto en cuanto a las actividades económicas como de degradación urbana y desplazamientos demográficos masivos. En segundo lugar, la transformación de la industria anterior en actividades tecnológicas es vista también como una renovación de la trama urbana y la introducción de nuevas actividades sociales anteriormente situadas en otras partes de la ciudad, fundamentalmente alrededor del consumo, el ocio y actividades turísticas, transformando las dinámicas sociales del barrio $\mathrm{y}$, por ende, considerándose como una reestructuración urbana hasta cierto punto no sólo necesaria, sino también beneficiosa para Poblenou.

El conflicto viene cuando se redefinen territorios históricos a través del 22@ o se eliminan y modifican zonas de ocio y usos del espacio público, como se reconocen en diversas normas rectoras o de implementación del proyecto o proyecciones cartográficas institucionales, así como también cuando se generan desplazamientos de las centralidades espaciales por la vía del reconocimiento de actividades sociales incluidas dentro de la planificación económica municipal. ${ }^{11}$ Así, conforme reconocía el propio Plan Especial de Establecimiento de Concurrencia Pública, hostelería y otros servicios del distrito

11 En este caso, aunque no es una medida ex profeso el 22@, los artículos 1, 2 y 6 del Plan Especial de Establecimiento de concurrencia pública hostelería y otros servicios del distrito de Sant Martí (aprobado a 21 de julio de 2006) establecía este tipo de imperativos de uso y zonificación del ocio, mientras que los artículos 4.2.5.3 y 4.2.5.4 de la misma norma, y el artículo 5 del Plan especial de ordenación de los establecimientos comerciales destinados a la venta de artículos de recuerdos o souvenirs en la ciudad de Barcelona (acuerdo del Consejo plenario de 27 de abril de 2008) establecen reconocer las actividades populares aunque no de forma auto-organizada ni articuladas libremente. 
de Sant Martí, el desplazamiento de esos núcleos de interacción barrial se produjo hacia sectores de innovación y áreas renovadas que tenían un tratamiento específico, como el sur de la Avenida Diagonal o las áreas de Diagonal Mar, la Plaza de les Glòries o la del Fórum (art. 7.4). Pero además implicaba por parte de la Administración Local la reformulación de las espacialidades oficiales, ya que el 22@no agrupaba ni Poblenou ni Sant Martí, sino que constituía un espacio distinto definido por las nuevas inversiones en innovación y economía del conocimiento (Dot Jutgla et al, 2010; Martí-Costa y Pradel i Miquel, 2012). Donde antes se reconocían bienes locales relevantes o incluso culturales, ahora aparecían desplazados por los de relevancia sectorial (art. 8.2.c) o los entornos que participan de la memoria histórica de la ciudad (art. 10.3.a). La reestructuración espacial del espacio local podría comenzar así a cooptar toda forma de organización autónoma o independiente de esa renovación o nuevo modelo de ciudad según el cual imperan la nueva economía, el paisaje urbano, el patrimonio arquitectónico y monumental, la producción cultural, la innovación, las nuevas tecnologías o la calidad de vida. ${ }^{12}$

Así, se ha desarrollado la zonificación y reterritorialización o espacialización de actividades sociales con efectos diversos. Por un lado, la segregación territorial provocada por la espacialización de determinadas actividades adscritas al barrio a través del 22@, como el ocio, el turismo, el paisaje urbano o los símbolos de la nueva ciudad. En cuanto a los dos primeros aspectos, la Ley 11/2009, de 6 de julio, de regulación administrativa de los espectáculos públicos y las actividades recreativas de Cataluña, tiene un efecto determinante sobre la integración territorial barrial porque, aparte de imponer la zonificación de la congregación del público, excluye en términos prácticos toda actividad política de tales áreas (artículos 4.5b, 5.2a), concordando con el artículo 16.4 de la Ordenanza cívica de Barcelona. ${ }^{13}$ En última instancia, se

12 Artículos 1 del Plan especial de ordenación de establecimientos comerciales destinados a la venta de artículos de recuerdos o souvenirs de la ciudad de Barcelona; artículos 4-5 de la Ordenanza de los usos del paisaje urbano de la ciudad de Barcelona; artículos 30-32 de la modificación del Plan General metropolitano del plan especial de protección del patrimonio arquitectónico histórico-artístico de la ciutat de Barcelona, districte de Sant Martí (noviembre de 2006).

13 En lo que se refiere al estudio de caso poblenoví, este tipo de normativa se plasma con la aprobación en julio de 2014 por parte del Distrito de Sant Martí de un plan de actuación integral en la zona lúdica de Poblenou contra el incivismo. El plan se centra fundamentalmente en el área circundante entre las calles Bolivia, Ciutat de Granada, Pujades, Marina y la Avenida Meridiana, alrededor de locales de concurrencia pública, como discotecas, bares, restaurantes y salas de conciertos. En este caso, se establece la prevención de hechos delictivos en la zona en aras de la seguridad y la convivencia mediante el control del espacio público no sólo por 
han ido aplicando progresivamente políticas territoriales sobre Poblenou en términos de reconocimiento de la espacialización de usos urbanos a la zona de forma subordinada al 22@: uso industrial, oficinas, vivienda, comercial, residencial y recreativo, produciendo una espacialización sectorial de prácticas sociales (Ayuntamiento de Barcelona, 2010b: 30-32) y recreando la zona a partir de Planes Especiales que redefinen el ámbito poblenoví y desbordan el significado anterior del barrio.

\subsubsection{De Hortaleza al mundo}

La reestructuración socio-espacial, económica y morfológica de Hortaleza está directamente vinculada a la Gran Vía de Hortaleza como estructura urbana transformadora no sólo del distrito de Hortaleza, sino del significado de los barrios, especialmente vinculado a los cambios producidos sobre las infraestructuras de transporte, el ocio y consumo locales (y urbanos), el turismo de negocios en relación con la Feria de Madrid y, finalmente, la propia naturaleza del espacio de interacción creado en torno a esta vía. El distrito de Hortaleza está situado al noreste del municipio de Madrid, limitando con el término municipal de Alcobendas al norte, con el distrito de Barajas al este, con el distrito de San Blas al sur y con los distritos de Ciudad Lineal y Fuencarral-El Pardo, al oeste (De Gea Ortigas, 2002).

parte de las autoridades públicas, sino también por parte de los vecinos o de una figura innovadora como los colaboradores cívicos. Esta figura se incluye dentro de un plan de formación, difusión, denuncia y control de las actuaciones incívicas en el espacio mencionado, al tiempo que se incluye la convivencia, la buena vecindad y mayor énfasis en la limpieza de la zona establecida como elementos inseparables de dicho plan, reforzando el eje civismo-higienismo urbano. Este plan es la última piedra de toque de la actuación municipal en términos de civismo e higienismo, pero también ha puesto de manifiesto un tipo de política urbana que ha comenzado a transformar la territorialidad barcelonesa, debido a que la abstracción y ambigüedad de la retórica oficial, aunado con la multiplicación de actividades desarrolladas en la ciudad, dejaba una infinidad de prácticas sociales en un limbo legal, que ha suturado a instancias de la habilitación de políticas territoriales en la ciudad. Esta tendencia ponía de manifiesto una paradoja que se estaba produciendo en la restricción de facto del espacio público: la pacificación forzada del territorio barcelonés contrastaría con la creciente exclusión y parcelación del mismo a partir de las políticas de renovación urbana. El plan lo suscriben la Guardia Urbana, el

distrito de Sant Martí y 30 establecimientos públicos. Véase en http://w110.bcn.cat/portal/site/ SantMarti/menuitem.92b7e9be013e377cf740f740a2ef8a0c/?vgnextoid=216789c2a0e15410V gnVCM1000001947900aRCRD\&vgnextchannel=216789c2a0e15410VgnVCM10000019479 00aRCRD\&id=66952\&lang=es_ES. 
Pese a ser un municipio autónomo hasta 1949 y tener una estructura eminentemente rural, tanto la trama urbana como las formas de actuación y representación social y política cambiarán con la construcción de la Gran Vía de Hortaleza. Esta vía es un doble eje urbano que comunica la vía M-40 con el túnel de Costa Rica y el acceso a la M-30 o, en su bifurcación, con López de Hoyos en dirección Arturo Soria a lo largo de un recorrido de 1.5 kilómetros. Situada en el contexto de distintas reivindicaciones vecinales por la mejora de la carretera de Canillas (FAVB, 2010: 383), la Gran Vía de Hortaleza es uno de los proyectos urbanísticos contemplados en la expansión residencial y de los servicios prevista desde la Administración Local como respuesta al desarrollo de zonas periurbanas en Madrid y el desarrollo urbanístico de diferentes áreas de la ciudad (De Santiago Rodríguez, 2007; Muñoz del Río, 2010)..$^{14}$

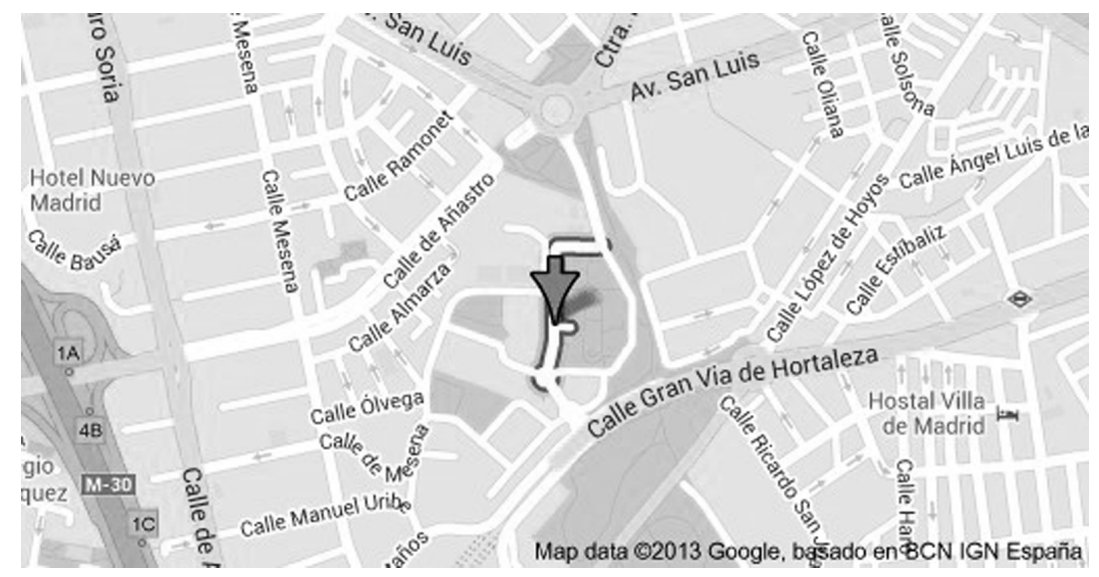

FIGURA 3. Mapa de la conexión de la Gran vía de Hortaleza con Arturo Soria. FUENTE: GoogleMaps

Hasta finales de los años ochenta, en Hortaleza había primado un urbanismo caótico mezclado con áreas residenciales entre amplias zonas rurales (Pastor Muñoz, 1986), así como una insularidad y dependencia completa del centro madrileño por medio de Arturo Soria. Todo esto cambia desde 1986, momento en que se prima la accesibilidad del distrito y sus infraestructuras a través de convenios interadministrativos ${ }^{15}$, «proyectando el cierre por el norte

14 Como establecen el Plan de Ordenación Metropolitana de 1985 o el documento «Madrid, Región Metropolitana», de 1987.

15 Se produjeron acuerdos entre administración central, autonómica y local conforme al Plan general de ordenación territorial de 1985 como dato, posteriormente reconocido en el artículo 6a de la Ley 9/2001, de 17 de julio, del Suelo de la Comunidad de Madrid. 
de la M-40, la construcción de la A-10 (ahora M-11 y M-12), la vía de acceso al aeropuerto (...) o la Gran Vía de Hortaleza junto al metropolitano, favoreciendo la expansión hacia el Este madrileño» (Martín Roda, 1999: 429).

Construida en 1990, la avenida Gran Vía de Hortaleza sustituyó el proyecto de construcción de la autopista Cuzco-Barajas, comunicando el centro de Madrid con los recintos feriales de IFEMA (Gea Ortigas, 2002: 34). Dicha vía cuenta en sus aledaños con importantes empresas, edificios de viviendas de alta calidad, creándose una zona residencial de clase media alta y alta justo en el límite donde los dos núcleos masivos y anteriormente autónomos (los barrios de Canillas y Pinar del Rey) se encontraban (Martín Roda, 1999: 429). ${ }^{16}$ Además, en torno a la calle Gran vía de Hortaleza se abren diferentes bares, locales y oficinas bancarias, así como un centro de atención de discapacidad financiado por Bankia. ${ }^{17}$ Por otra parte, al final de la misma se levanta un centro comercial homónimo con 12.000 metros cuadrados de superficie (López de Lucio, 2006: 14) que hace de nodo o hito entre los dos barrios, de borde entre ambos y de nexo con la apertura de las vías M-30 y M-40 (figura 12) y la carretera del Campo de las Naciones..$^{18}$ Además, supone la consolidación de la clientela y la recreación de un espacio barrial en torno a un «centro comercial que desea atrapar a nuevas clases emergentes, evitando su fuga a otros espacios de consumo» (García Ballesteros, 2001: 283).

En plena prolongación de la calle Arequipa, el Ayuntamiento habilita un terreno y se construye el Comité Olímpico Español. ${ }^{19}$ Además, se abren una comisaría de Policía Municipal y otra de Policía Nacional para Hortaleza y Barajas, habilitándose también un centro de salud. Finalmente, la consolidación de este eje urbano ha supuesto la conexión del distrito en torno a una

16 El tipo de vivienda cambia completamente, pasando a ser zonas de pisos más grandes, con áreas residenciales, zonas verdes o piscinas propias y no directamente accesibles desde la calle.

17 Ver http://www.fundacionbetesda.org/index.php?option=com_content\&view=articl e\&id=69\&Itemid $=189$

18 Siguiendo a Kevin Lynch (1960: 34) y los elementos físicos en torno a los que se establecen geografías de la percepción en los espacios urbanos, los bordes son elementos que el individuo no usa como senda, son o se prestan al observador como líneas que delimitan espacios, líneas que marcan discontinuidades en el paisaje urbano, mientras que los nodos son «los focos estratégicos a los que puede entrar el observador, tratándose típicamente de confluencias de sendas o concentraciones de diversas características, y los hitos (o mojones) son elementos singularizados en el paisaje urbano fácilmente percibidos y que sirven de referencias dentro de una ciudad» (Estébanez Álvarez, 1977: 9).

19 Ver en http://www.coe.es/2012/COEHOME2012.nsf/FHomeDemo?OpenForm. 
trama urbana y al centro metropolitano, abriéndose algunas estaciones de Metro a lo largo del trazado y perdiendo en gran medida el carácter rural que le precedía, conforme a estos cambios sobre la trama urbana y el transporte metropolitano, que son esenciales para la transformación hortaleña.

En primer lugar, el diseño de la Gran vía de Hortaleza además de por razones económico-políticas, obedecía a demandas inacabadas de urbanización de Hortaleza que el Ayuntamiento decidió solucionar en torno a ese trazado (Ayuntamiento de Madrid, 2006), conectando M-30 y M-40 en torno a un nuevo eje urbano. Además, en términos de mercado local, Hortaleza disponía y dispone aún de gran cantidad de suelo edificable en un área con gran demanda de vivienda (Ayuntamiento de Madrid, 2012), produciendo una renovación inmobiliaria y de la trama circundante, así como de las interacciones sociales generadas. Por otra parte, una de las consecuencias generadas ha sido el cambio de la trama no sólo en términos de comunicación, sino conforme a una idea de paisaje urbano determinado. En efecto, el Ayuntamiento de Madrid determinó en su momento la eliminación de espacios urbanos marginables ${ }^{20}$, y la existencia de zonas rururbanas entre dos núcleos autónomos no parecía muy compatible con esas aspiraciones. De hecho, esa misma idea de paisaje y renovación urbana a partir de zonas rurales o rururbanas se ha representado como algo de importancia fundamental para el re-desarrollo y la modernización de servicios o vida urbana en Hortaleza. De este modo, se consolidó la apertura de un eje urbano como política de fronterización higienista por parte de la Administración local. En términos de interacción social, ha supuesto un desplazamiento de las actividades y la centralidad espacial desde los núcleos tradicionales de Pinar del Rey hasta la Gran Vía, así como hacia los Recintos Feriales de IFEMA.

Si analizamos la genealogía de la praxis normativa, observamos que esta re-territorialización tampoco es casual. En primera instancia, la adopción de los proyectos de urbanización se hizo en paralelo a una ubicación económica en la ciudad, aunque fueron tendiendo hacia zonas de nueva creación o la posibilidad de resignificar reivindicaciones anteriores de naturaleza totalmente

20 La prohibición de la mendicidad emana de la Ordenanza Municipal de Policía Urbana y Gobierno de la Villa de Madrid de 1948 (artículo 60), pero su estigmatización bajo el mandato de que los mendigos han de gestionarse sus necesidades en los Albergues de Mendigos se deriva de la modificación establecida por acuerdo plenario de 28 de febrero de 1989 . Finalmente, la Ley 5/2002, de 27 de junio, sobre drogodependencias y otros trastornos adictivos de la CAM, más conocida como Ley antibotellón, supone un endurecimiento de las sanciones por presencia indebida en el espacio público, especialmente en el caso de la mendicidad. 
distinta. Por un lado, la absorción de funciones competenciales y administrativas bajo la figura del concejal-presidente y del gerente se completa con la invasión funcional por parte de la Junta municipal del distrito de toda actividad social, que queda territorializada, despolitizada y formalizada. ${ }^{21}$

En tercer lugar, este desplazamiento de las actividades sociales hacia la Gran Vía de Hortaleza también ha tenido un correlato e impulso en el énfasis dado al distrito como espacio de gestión de la convivencia, entendido de varias formas: por un lado, reaparece el trazado y la proyección del distrito.

Así, se reconoce un papel superior a los distritos en la escala municipal, no sólo por ser mayores en términos territoriales, sino por tener admitidas más competencias e importancia dentro de la política local. Aparecen como la escala fundamental en la «corrección de los desequilibrios y la representación de los intereses de los diversos barrios del municipio»» ${ }^{22}$, así como tienen reconocidas múltiples funciones en torno a la movilidad y los transportes; las obras y las vías públicas, los parques y los jardines, la calidad o la evaluación ambiental, las licencias y autorizaciones o la disciplina urbanística y un gasto presupuestario «en ningún caso inferior al $11 \%$ del presupuesto del Ayuntamiento ${ }^{23}$.

\subsection{Conclusiones}

Comparando los casos, se puede observar que existe una influencia y una confluencia mayor en torno a las representaciones legales del espacio en el caso poblenoví que en el caso hortaleño, en tanto la influencia de la praxis normativa en términos de imaginarios espaciales es reseñable no sólo por las

21 Las figuras del concejal-presidente y el gerente se reconocen en el Acuerdo ANM 2012/15, de 26 de enero, de la Junta de Gobierno de Madrid sobre organización y estructura de los distritos y delegación de competencias en las Juntas Municipales, en los concejales municipales y en los gerentes de los distritos (artículos 1-4). Según el Reglamento orgánico ANM 2005/8, de 23 de diciembre de 2004, de los distritos de la ciudad de Madrid, los gerentes son centrales tanto en el pleno de la junta municipal como en la organización administrativa del distrito (artículos 12, 29 y 30) y sólo es responsable ante el concejal-presidente, que le nombra libremente (artículo 31). En cuanto a la espacialización y regulación de las actividades informales, quedan sancionadas oficialmente en el artículo 1 de la Ordenanza ANM 1998/8, de 30 de julio, de Regulación de la gestión de recintos de Ferias y festejos populares de las Juntas municipales de distrito, así como los artículos 1 y 2 de la Instrucción ANM 2002/6, de 6 de mayo, de organización de las Ferias navideñas o similares en la junta municipal de distrito.

22 Artículo 1.2 del Reglamento Orgánico de los distritos de la ciudad de Madrid, ANM 2005/8, de 23 de diciembre de 2004.

23 Artículos 2 al 6 del citado Reglamento orgánico. 
contestaciones que genera, sino porque ha recreado una forma de pensar el espacio barrial de Poblenou y, posiblemente, desde otros ámbitos de Barcelona. Por el contrario, en el caso madrileño no existe aún un peso tan determinante de esas representaciones del espacio (legal) en la imaginación geográfica cotidiana, resuelta a partir de otras prácticas espaciales y formas de representación clásica.

Sin embargo, en ambos casos se producen actuaciones institucionales en aras de registrar, fomentar o consolidar los cambios producidos sobre ambas localidades que redefinirían espacios cotidianos previamente protagonistas en la arena política de la ciudad, al menos parcialmente. Porque, simultáneamente al reconocimiento de actividades socio-políticas alrededor de la cotidianidad del barrio, en ambos procesos se ha producido un desplazamiento de los núcleos de interacción social y política (centralidades espaciales) hacia nuevas zonas, a saber: el eje de la Gran Vía de Hortaleza en el caso hortaleño y el área delimitada por el proyecto 22@en Poblenou admiten parte de las interacciones anteriores del espacio local, pero crean otras nuevas al desplazar esos ejes de actividad económica, social y política.

En segundo lugar, tanto las formas de redefinir la localidad por parte de las instituciones, como las prácticas que se reapropian de la misma desde la actuación cotidiana de los vecinos, tanto individual como colectivamente, han supuesto un cambio no sólo en cómo se conciben los espacios urbanos en términos de representación, sino cómo se transmite el modo en que éste es practicado y, en el caso del barrio poblenoví y hortaleño, reconstruido.

Incluso aceptando proyectos amplios de reestructuración urbana (como el22@ o la Gran Vía de Hortaleza), el repliegue en las prácticas y proyección del espacio local ha ido hacia otros ámbitos, como la Rambla de Poblenou o la justificación rural frente a la pretensión de urbanización hortaleña. Donde el Ayuntamiento de Barcelona reconstruye los límites de Poblenou alrededor de un proyecto de innovación socio-económica y política, eliminando algunas zonas anteriormente incluidas en el área poblenoví, la práctica diaria y las propuestas colectivas de análisis se realizan en torno a la arteria principal de la vida cotidiana, o sea, la Rambla. En el caso de Hortaleza, donde la propaganda inmobiliaria y las proyecciones institucionales sitúan IFEMA-Valdebebas como una zona límite-renovadora del distrito y del barrio, la organización colectiva obvia su resignificación en términos políticos, para situar el debate alrededor de los espacios excluidos u obviados por dichos proyectos. 
La paradoja es doble: mientras la retórica hace alusión al espacio de la ciudad como un todo, las políticas de renovación y representación territorial se articulan desde espacios e imaginarios singulares, regiones de frontera particulares de la ciudad, estructurando nuevos modos de espacialidad que se encuentran con una proyección constante de la ciudad a modo de imaginario geográfico intermedio entre los proyectos internacionales, renovación, planificación y diseño urbano, por un lado, y otros espacios urbanos cuya atención queda desplazada u oculta por la imaginación geográfica que proyectan las dinámicas anteriores. $\mathrm{O}$ sea, una zona de contacto que es proyectada y planificada como espacio público ex novo o como patio trasero. En este punto, podemos definir patio trasero como «un campo de entrenamiento, un experimento (...), un entorno gigante para aplicar las ideas administrativas y legales más avanzadas» (Neumann, 1999: 78; citado en Kuus, 2004: 474), que proviene de (o bien produce) cierta segregación territorial. En el análisis aquí realizado, el concepto de patio trasero se aplica de un modo similar a la metáfora geopolítica, aunque con respecto a las Administraciones públicas. Del mismo modo que, por ejemplo, durante la Guerra Fría se consideraban diferentes áreas territoriales como patios traseros de los intereses estadounidense o soviético, los lugares aquí analizados han sido objeto de procesos de renovación impelidos normativamente sobre divisiones administrativas preestablecidas (distritos o barrios, generalmente), si bien han instado a una reconfiguración territorial urbana que ha desplazado a sendas zonas, al menos desde el punto de vista institucional, a la categoría de patios traseros en la planificación territorial metropolitana.

\subsection{Bibliografía}

AAVV (2011), «Economía del conocimiento y del territorio», Revista Econòmica de Catalunya, 64, octubre de 2011.

AYUNTAMIENTO DE BARCELONA (2000), Plan Especial de Infraestructuras de Poblenou

AYUNTAMIENTO DE BARCELONA (2005),Estado de ejecución del 22@en torno a la Modificación del plan general metropolitano en el ámbito del casco antiguo de Poblenou, distrito de Sant Martí

AYUNTAMIENTO DE BARCELONA (2008),Estado de ejecución del 22@en torno a la Modificación del plan general metropolitano en el ámbito del casco antiguo de Poblenou, distrito de Sant Martí

AYUNTAMIENTO DE BARCELONA (2009),Estado de ejecución del 22@en torno a la Modificación del plan general metropolitano en el ámbito del casco antiguo de Poblenou, distrito de Sant Martí, diciembre de 2009. 
AYUNTAMIENTO DE BARCELONA (2010a), Estado de ejecución del 22@en torno a la Modificación del plan general metropolitano en el ámbito del casco antiguo de Poblenou, distrito de Sant Martí.

AYUNTAMIENTO DE BARCELONA (2010b), Modificación del Plan General Metropolitano en el ámbito del Casco antiguo del Poblenou (aprobado a $26 \mathrm{de}$ febrero de 2010)

AYUNTAMIENTO DE BARCELONA(2012),Estado de ejecución del 22@en torno a la Modificación del plan general metropolitano en el ámbito del casco antiguo de Poblenou, distrito de Sant Martí.

AYUNTAMIENTO DE MADRID (2006), Finalización de las obras de remodelación del enlace de la calle Costa Rica con la M-30, Madrid: Área de gobierno de urbanismo, vivienda e infraestructuras.

AYUNTAMIENTO DE MADRID (2012), Informe distrital Hortaleza

BANAKAR, REZA (2010), «Studying the rights discourse: a tentative socio-legal framework», Lemann Kristiansen, B. (ed.) (2010) The Nordic Sociology of Law, ( $1^{\text {a }}$ edición) DJOF, Coppenhague.

BANAKAR, Reza (2011), «The sociology of Law: from industrialisation to Globalisation», Working Paper, 11-03, University of Westminster, pp. 1-32.

BAPTISTA, Idalina (2013), «Practices of exception in urban governance: reconfiguring power inside the State», Urban Studies, 50 (1), 39-54, January 2013.

BARKAN, Joshua (2011), «Law and the geographic analysis of economic globalization», Progress in Human Geography, 35 (5), 589-607.

BLOMLEY, Nicholas (2003a), «Law, property and the spaces of violence», Annals of the Association of American Geographers, 93 (1), 121-141.

BLOMLEY, Nicholas (2003b), Unsettling the city: urban land and the politics of property $\left(1^{\mathrm{a}} \mathrm{ed}\right.$.) Routledge, New York.

BLOMLEY, Nicholas (2004). «Un-real estate: proprietary space and public gardening», Antipode, 36 (4), 614-641.

BLOMLEY, Nicholas (2008), «Making space for law», en Cox, K.; Low, M.; y Robinson, J. The Sage Handbook of political geography ( $1^{\mathrm{a}} \mathrm{ed}$.), SAGE, London, pp. 155-168.

BLOMLEY, Nicholas (2010), «The right to pass freely: circulation, begging and the bounded itself», Social and Legal Studies, 19 (3), pp. 331-350.

BENNETT, LUKE y LAYARD, ANTONIA (2015), «Legal Geography: becoming spatial detectives», Geography Compass, 9 (7), pp. 406-422.

BRAVERMAN, Irus; BLOMLEY, Nicholas; DELANEY, David; y KEDAR, Alexandre (Sandy) (2013), «The expanding spaces of law: a timely Legal Geography», Buffalo Legal Studies Research Paper Series, 2013-032, pp. 1-29.

CHRISTOPHERS, BRETT (2011), «Revisiting the urbanization of capital», Annals of the Association of American Geographers, 101 (6), pp. 1347-1364.

COX, Kevin; LOW, Murray; y ROBINSON, Jenny (2008), The Sage Handbook of political geography, SAGE, London. 
DANGSCHAT, JENS S. (2009), «Space matters. Marginalization and its places», International Journal of Urban and Regional Research, 33 (3), September 2009, pp. 835-840.

DELANEY, David (2015a), «Legal Geography I: consitutivities, complexities and contingencies», Progress in Human Geography, 39 (1), 96-102.

DELANEY, David (2015b), «Legal Geography II: discerning injustice», Progress in Human Geography, DOI: 10.1177/0309132515571725, 1-8, 18 de febrero de 2015.

DE SANTIAGO RODRÍGUEZ, E. (2007), «Madrid, 'ciudad única'. Pautas y lógicas espaciales recientes en la región madrileña: las grandes transformaciones estructurales; el despliegue del nuevo 'paradigma único' en la región urbana de Madrid», Urban, 1 (12), pp. 8-33.

DENZIN, N. y LINCOLN, Y. (2005), The Sage Handbook of qualitative research, London-Thousand Oaks-New Delhi: SAGE.

DOT JUTGLA, E.; CASELLAS, A.; PALLARÈS-BARBERÀ, M. (2010), «L'ambigüitat de la producción intensiva en coneixement: el nou espai econòmic del Poblenou», Documentos de Anàlisis Geografica, 56 (3), pp. 389-408, 2010.

ESTÉBANEZ ÁLVAREZ, J. (1977), «Consideraciones sobre la geografía de la percepción», Paralelo, 31 (1), pp. 5-22.

FAVB (2010), «1970-2010. 40 anys d'acció veïnal», Colleció Quaderns de Carrer, 5, maig 2010, Barcelona: FAVB.

FOREST, Benjamin (2004), «The legal (de) construction of geography: race and political community in Supreme Court redistricting decisions», Social and Cultural Geography, 5 (1), 55-73.

GARCÍA BALLESTEROS, A. (2001), «Las motivaciones hacia el uso de los centros comerciales en Madrid», Anales de Geografia de la Universidad Complutense, 21, pp. 257-284.

GEA ORTIGAS, MARÍA ISABEL (2002), Hortaleza y Barajas: historia de los distritos de Madrid, Madrid: La Librería.

Glass, Ruth (1964), «Introduction: aspects of change», in Centre for Urban Studies (ed.) London: aspects of change, MacKibbon, London.

GREGORY, Derek; JOHNSTON, Ron; PRATT, Geraldine; Watts, Michael J. and Whatmore, Sarah (eds.) (2009), Diccionary of Human Geography $5^{\text {th }}$ Edition, Blackwell, Malden.

GUILLOT, SERGI (2004), El proyecto 22@Barcelona. Estado de ejecución y estudio comparativo con experiencias similares en Europa, Barcelona: Aula Barcelona, diciembre 2004.

HARVEY, David (1982), The limits to capital, UCP, Chicago

HARVEY, David (1985), The urbanization of capital, John Hopkins U.P., Baltimore. HARVEY, David (1989), The condition of postmodernity: an enquiry into the origins of cultural change ( $1^{\mathrm{a}}$ ed.), Wiley, New York [traducción castellano (1998), La 
condición de la postmodernidad: investigación sobre los orígenes del cambio cultural, Amorrortu, B.Aires].

HARVEY, David (2001), Spaces of capital: towards a critical geography (1 $\left.{ }^{\mathrm{a}} \mathrm{ed}.\right)$ Routledge-UEP, Edinbourgh [traducción castellano (2007) Espacios del capital, Akal, Madrid]

HERBERT, STEVE (2010), «Contemporary geographies of exclusion III: to assist or punish?», Progress in Human Geography, 35 (2), pp. 256-263.

JOHNSTON, Ronald J.; GREGORY, Derek y SMITH, David M. (2000), Diccionario Akal de Geografía Humana, (1 ${ }^{\mathrm{a}}$ ed.) Akal, Madrid.

KNOX, Paul; AGNEW, John y MCCARTHY, Linda (eds.) (2003), The geography of world-economy ( $1^{\mathrm{a}}$ ed.) Arnold, London.

KUUS, MERJE (2004), «Europe's eastern expansion and the reinscription of otherness in East-Central Europe», Progress in Human Geography, 28 (4), 2004, pp. 472-489.

LEES, Loretta (2006), «Gentrifying down the urban hierarchy: the cascade effect in Portland, Maine», en D. Bell and M. Jayne (eds.) Small cities: urban experience beyond metropolis, Routledge, London, pp. 91-104.

LEES, Loretta (2011) «The geography of gentrification: thinking through comparative urbanism», en Progress in Human Geography, 35 (2), pp. 1-17.

LEES, Loretta; Slater, Tom and Wyly, Elvin (2008), Gentrification, Routledge, New York.

LIMÓN LÓPEZ, PEDRO (2012), «Producción juridica e imaginación global: cartografias urbanas a través de la ley en Barcelona», Geopolitica (s)'. Revista de estudios sobre espacio y poder, 3 (1), Monográfico: políticas urbanas en España: 117-135.

LIMÓN LÓPEZ, PEDRO (2014). «Imaginación geográfica y agencia política: produciendo espacio público a través del Derecho en Madrid (1992-2012)», EURE: revista latinoamericana de estudios urbano regionales, 120: 183-200.

LIPPENS, Ronald (ed.) (2004), Imaginary boundaries of justice: social justice across disciplines, Hart Publishing, Oxford.

LÓPEZ DE LUCIO, R. (2006), «Espacio público e implantación comercial en la Comunidad de Madrid», Cuadernos de investigación urbanística, 1 (23), pp. $1-53$.

MARRERO GUILLAMÓN, I. (2003), «¿Del Manchester catalán al Soho barcelonés? La renovación del Poblenou en Barcelona y la cuestión de la vivienda», Scripta Nova, Revista electrónica de Geografía y Ciencias Sociales, VII, 146 (137), 1 de agosto de 2003.

MARTÍ-COSTA, M. Y PRADEL I MIQUEL, M. (2012), «The knowledge city against urban creativity? Artists' workshops and urban regeneration in Barcelona», European Urban and Regional Studies, 19 (1), pp. 92-108. 
MARTÍN RODA, EVA MARÍA (1999), «Hortaleza: la articulación del espacio en un distrito de la periferia madrileña», Madrid: Revista de Arte, Geografía e Historia, 2, pp. 421-438, 1999.

MARTIN, D.; SCHERR, A. W. y CHRISTOPHER CITY (2010), «Making law, making place: lawyers and the production of space», Progress in Human Geography, 34 (2), pp. 175-192.

MASSEY, DOREEN (1990), Spatial divisions of labour. Social structures and the geography of production ( $1^{\mathrm{a}} \mathrm{ed}$.) McMillan, London.

MASSEY, DOREEN (1993), «Power-geometry and a progressive sense of place», in J. Bird, B. Curtis, T. Putnam, and G. Robertson (eds.) Mapping the future: local cultures, global changes, London: Routledge, pp. 59-69.

MITCHELL, D. (1997), «The annihilation of the space by law: the roots and implications of anti-homeless laws in United States», Anthipode, 29 (3), pp. 303-335.

MITCHELL, D. (2003), «The liberalization of free speech: or, how protest in public space is silenced», Stanford Agora, September 2003. Disponible en http://agorastandford.edu/agora/volume4/articles/mitchell/mitchell.pdf

MITCHELL, DON Y STAEHELI, LYNN (2005), «Permitting protest: parsing the fine geography of dissident in America», International Journal of Urban and Regional Research, 29 (4), 796-813.

MITCHELL, DON Y HEYNEN, NICK (2009), «The geography of survival and the right to the city: speculations on surveillance, legal innovation and the criminalization of intervention», Urban Geography, 30(6), 611-632.

MUÑOZ DEL RÍO, LAURA (2010), «Implicaciones sociales y urbanas de las recientes transformaciones de la estructura comercial en los centros históricos. El caso de la centralidad madrileña», incluido en el Primer bloque La ciudad como ecosistema urbano, del Congreso 'Ciudad, territorio y paisaje: una mirada multidisciplinar', en el Centro de Ciencias Históricas y Sociales del CSIC, en Madrid del 5 al 7 de mayo de 2010.

OLIVA, ANTONI (2003), El districte d'activitats 22@bcn, Barcelona: Aula Barcelona-Publicacions de la Universitat de Barcelona.

PASTOR MUÑOZ, F. J. (1986), Historia del distrito de Hortaleza, Madrid: Ayuntamiento, Concejalía de Relaciones Institucionales y Comunicaciones.

PIQUÉ, J. M. (2008), «El projecte 22@ Barcelona. Present i future», en Informe Annual de la Provincia de Barcelona 2008, Cambra de Comerç de Barcelona: Barcelona, pp. 239-252.

ROJAS, J. PELLICER, I. SANTORO, V. y VIVAS, P. (2007), «@City: lecturas tecnológicas de Barcelona», Athenea Digital, 11 (primavera 2007), pp. 114-131.

SMITH, Neil (1979), «Toward a theory of gentrification: a back to the city movement by capital, not people», Journal of American Planning Association, 45 (4), pp. 538-548.

SMITH, NEIL (1984), Urban Development: nature, capital and the production of space ( $1^{\mathrm{a}}$ ed.) Blackwell, Oxford. 
SMITH, NEIL (1996), The new urban frontier: gentrification and the revanchist city ( $1^{\mathrm{a}}$ ed.) Routledge, London.

SMITH, NEIL (2002), «New globalism, new urbanism: gentrification as global urban strategy», Anthipode, 34 (3), pp. 427-450.

SMITH, NEIL (2008), «Gentrificación generalizada: de la anomalía local a la regeneración urbana», en Ciudades en reconstrucción: necesidades sociales, transformación y mejora de barrios, Territorios, Barcelona, pp. 31-48.

SMITH, NEIL AND WILLIAMS, PETER (eds.) (1986), Gentrification of the city ( $1^{\mathrm{a}}$ ed.) Allen and Unwin, London.

SOJA, EDWARD W. (2000), Postmetropolis. Critical studies of cities and regions ( $1^{\mathrm{a}}$ ed.) Wiley, New York [traducción castellano (2008), Postmetrópolis. Estudios críticos sobre las ciudades y las regiones ( $1^{\mathrm{a}} \mathrm{ed}$.) Traficantes de Sueños, Madrid]

STAEHELI, LYNN A. (2010), «Political geography: democracy and the disorderly public», Progress in human geography, 34 (1), pp. 67-78.

YOUNG, DOUGLAS Y KEIL, ROGER (2010), «Reconnecting the disconnected: the politics of infrastructure in the in-between city», en Cities, 27, pp. 87-95.

WARD, Kevin (2010a), «Towards a relational comparative approach to the study of cities», Progress in Human Geography, 34 (4), 471-487.

WARD, Kevin (2010b), «Entrepenurial urbanism and business improvement districts in the State of Wisconsin: a Cosmopolitan critique», Annals of the Association of American Geographers, 100 (5), 1177-1196.

WHITEHAND, J. W. R. (1990), «Makers of the residential landscape: conflict and change in outer London», Transactions of the Institute of British Geographers, 15 (1), pp. 87-101. 



\title{
PLANIFICACIÓN Y DESIGUALDAD EN LA CIUDAD NEOLIBERAL: GEOGRAFÍAS DE LAS CLASES POPULARES
}

\author{
Chabier Gimeno Monterde y Miguel Montañés Grado \\ Universidad de Zaragoza
}

\subsection{Introducción}

El barrio de Delicias, en la ciudad de Zaragoza, vive las dinámicas propias de los barrios populares europeos, afectados por la actual crisis económica y las políticas de austeridad. Por un lado, los movimientos vecinales, surgidos en el último cuarto del siglo pasado, han pasado de los discursos sobre el «barrio obrero», reivindicando la dotación de infraestructuras, a los de «barrio pobre», contribuyendo a estigmatizar la multiculturalidad durante el nuevo siglo. Y, por otro lado, como otras ciudades medias y metrópolis, Zaragoza ha entrado en un mercado global de competencia por los capitales. Posicionándose en torno a su capacidad de atraer conocimiento y creatividad. Ambos polos, problematización de los barrios populares y metropolización escalar, la configuran como ciudad neoliberal. Esto es, como un escenario clave para las estrategias de desmantelamiento del Estado del Bienestar keynesiano. A la vez que como lugar estratégico de innovación, crecimiento y experimentación institucional local, de la gobernanza delegada. En suma, un nodo crítico en el proceso de neoliberalización, donde se implementan políticas de crecimiento económico orientado al mercado, el consumo de las élites y el control de las poblaciones excluidas (Theodore, Peck y Brenner, 2009: 7).

Para entender cómo afecta esta reestructuración a los barrios populares, analizamos las fases en la co-construcción de la imagen de «barrio pobre», así como las posiciones de los actores del territorio respecto a este proceso. Observando que la implementación de herramientas de planificación urbana, 
como la priorización de algunos barrios, está fuertemente vinculada a la necesidad de las clases medias (y sus científicos sociales) de gestionar un escenario post-empleo para las clases populares.

Para elaborar este análisis, dentro del proyecto $\mathrm{I}+\mathrm{D}+\mathrm{i}$ «Convivencia y barrios multiculturales: conflicto y cohesión social en una España en crisis», hemos realizado entrevistas a técnicos y activistas en el barrio observado, que hemos contrastado con las registradas en la ciudad francesa de Toulouse, en un proceso más avanzado de neoliberalización. La observación participante en encuentros técnicos y comunitarios en ambas ciudades, y nuestro encuentro con los sociólogos urbanos Daniel Sorando y Jean Pierre Garnier nos han permitido construir nuestro propio mapeo de las tensiones y oportunidades que surgen para que la ciudad se transforme, o no, según las necesidades y los deseos de su mayoría social.

\subsection{De «barrio obrero» a «barrio pobre»: actores que construyen el discurso}

Durante las últimas décadas del pasado siglo, el movimiento vecinal, ramificado en varios ámbitos que compartían la misma base social (educación, salud, empleo, etc), ha protagonizado la conformación de los servicios públicos del distrito estudiado. Reivindicando su dotación y colaborando en el diseño de los mismos (García, 1994: 239). La Asociación de Vecinos hegemónica ha realizado varios diagnósticos e intentos de procesos participativos, con los que justificaba la necesidad de un Plan Integral para el distrito por:

a) el empobrecimiento de la zona más antigua del barrio, que es la que acoge al mayor porcentaje de vecinos alóctonos,

b) y la conflictividad potencial de algunos espacios urbanos, bien por ser más concurridos por esos mismos vecinos, bien porque concentran actividades ilegales.

Así, en el tejido social del resto de la ciudad ha calado que, según el discurso de las asociaciones tradicionales del barrio, éste es un espacio en riesgo. Se han dado dos procesos paralelos. Por un lado, los media locales y los autonómicos han tomado como referencia a Delicias como un barrio conflictivo, donde las noticias sobre delincuencia o mala convivencia son habituales. Se trataría de un barrio «en proceso» de degradación, debido, entre otros factores implícitos, a su porcentaje de población de origen migrante. Y, por otro lado, 
en los últimos años han concurrido en el distrito nuevas entidades asistenciales. Entre ambos tipos de entidades han surgido, igualmente, dinámicas de colaboración y de competición, tanto por los recursos, como «por los usuarios».

Partiendo del grupo de entidades y personas movilizadas en torno a los conflictos de convivencia (en el Parque Delicias), se pretendía ahora generalizar el modelo de coordinación a todo el barrio. Y en junio de 2014 se realizó un encuentro comunitario, del que salió el actual Equipo Impulso de representantes asociativos, cuyo fin sería redactar un Plan de Barrio. En esas mismas fechas, el Ayuntamiento de Zaragoza, una fundación filantrópica bancaria y una entidad benéfico-asistencial asentada en el Casco Histórico, acordaron trasladar su experiencia de intervención comunitaria en el centro de la ciudad al barrio de las Delicias. Durante varios meses ambos procesos confluyeron en un equipo comunitario y una misma metodología. En la actualidad, los dos coexisten en Delicias, con mayor o menor hostilidad, según sea la percepción del actor asociativo entrevistado.

En este escenario de colaboración y competición entre entidades, planteamos una reflexión sobre la conflictividad de segundo nivel, aquella que se produce entre actores asociativos y que repercute, bien en la construcción del discurso sobre el barrio («barrio pobre», «barrio multicultural»), bien en la posición simbólica del barrio en la ciudad. Esta nueva conflictividad aparece como consecuencia de la intervención pública y privada sobre un barrio que, como otros, vive al margen de estos actores su propia dinámica de coexistencia (Garnier, 2016: 154), en la que nadie sabe nada de nadie, y todos son impredecibles (Bergua, 2011: 196 y ss.). Dicha conflictividad se manifiesta principalmente en torno a dos ejes: la conflictividad en torno a quién lidera el proceso comunitario invocado y qué modelo ha de seguir este proceso.

Según nuestro análisis, las relaciones asociativas en el barrio se definen por el posicionamiento en torno a dos conglomerados que adquieren varias formas. De un lado, la asociación de vecinos, que se presenta como actor legítimo, por su bagaje histórico en el territorio. De otro lado, el resto de los actores, que oscila entre varias combinaciones que remiten, en su conjunto, a una situación de liderazgo compartido: bien por todos los participantes en el proceso, bien por aquellos más orientados a lo asistencial. Quedando en evidencia que la pugna por mantener la jerarquía es reconocida por todos: como amenaza a la propia posición, al acceso al proceso o a la sostenibilidad del propio proceso. 
Los discursos sobre la «legitimidad» de los actores asociativos, según el lugar en el que se sitúe su sede social (territorio), así como por su vinculación histórica al barrio (ascendencia), están vinculados a la «representación» como «delegación»o «cesión de la soberanía» de los vecinos, en tanto que individuos. Todas las entrevistas coinciden en que el vecindario se ausenta, de forma muy significativa, de las actividades participativas a las que se les invita. El conflicto es entre quienes aspiran al poder hegemónico sobre el barrio, a conformar las expectativas de desarrollo vital del vecindario, y no entre vecinos, pues estos se posicionan claramente al margen de esa tensión.

La ingeniería social en pugna no está teniendo en cuenta el éxodo del vecindario (Virno, 2003: 72), bien porque se aspira a inocular la participación como bálsamo ante la desigualdad (entidad filantrópica), bien porque se aspira a un liderazgo carismático, aun sabiendo de la deserción de los habitantes (asociación vecinal). En este último caso, se orienta su estrategia con el fin de devenir un interlocutor predominante ante una instancia jerárquica superior: el Ayuntamiento. Eludiendo algo que les propone explícitamente la metodología a la que se remiten como técnicos: una reflexión sobre la desafección histórica hacia sus anteriores propuestas «participativas-comunitarias», para partir de lo existente (Gimeno et al., 2016; Marchioni, 2002). Esta reflexión debería incluir la hipótesis de que la población no considera útil, ni necesaria esta estructura asociativa; pero sí otras, que cubren y satisfacen necesidades actuales (de ámbito escolar, deportivas, peñas u ONGs con voluntariado).

\subsection{Imagen pública y claves de priorización}

La construcción de la imagen de «barrio pobre» responde a un proceso en el que cada actor privado y público presente en el territorio juega un rol distinto, pero complementario en cuanto al resultado final: la priorización del barrio, por su posición dentro de la ciudad. Se trata, por tanto, de un proceso de co-construcción de la imagen (Peralva y Macé, 2002). Tanto por parte del activismo vecinal, que se transforma en gestor de la progresiva exclusión sociourbana. Como de quienes concurren en el territorio, una vez ese proceso de estigmatización se ha cronificado: la industria del rescate (Agustín, 2009), la nueva filantropía (Saura, 2016), etc. Y, de la misma forma, también se construye por quienes asumen el relevo del activismo, y se posicionan frente a unos y otros. Quedando los habitantes del barrio al margen de estas dinámicas de pugna por la representación y la gestión de lo sociourbano. Eludiendo este y 
cualquier otro pulso por el poder hegemónico: aquel que pretende uniformar las expectativas (Bergua, 2007: 35). Sobre ellas y ellos, las Ciencias Sociales, al servicio de unos y otros actores, apenas vislumbran nada más allá de la «desafección», «desinterés», «ambivalencia» o «vulnerabilidad» (Equipo Impulso, 2017; Asamblea Delicias, 2017; Giménez et al., 2015).

Dado que el vecindario no comparece, ni en el asociacionismo institucionalizado (Alberich, 2007), ni en el activismo hetárquico (Bergua, 2011: 196), su éxodo o deserción (Virno, 2003: 72) discurre en paralelo a la coconstrucción de la posición de «barrio pobre» dentro de la ciudad. Ésta atraviesa varias fases, en las que los actores despliegan diferentes herramientas, que analizamos a partir de aquí. A la estigmatización del territorio, le siguen la definición del mismo como «rescatable» y la intervención sobre él, hasta alcanzar el «barrio que debe ser» (Sorando y Ardura, 2016). Un proceso que las Ciencias Sociales vienen ensayando con fines diversos, al amparo de una ingeniería social más o menos explícita (Alguacil et al., 2014: 84). Bauman (2006) ya describió esta mecánica de señalar, marcar, separar (o aislar) y dar una «solución final» al conflicto en torno al «deber ser» de la población de un territorio, administrada por una autoridad estatal.

De aquí en adelante, analizaremos cómo los actores territoriales contribuyen a esa co-construcción (tabla 1), que comienza con una fase de creación de la imagen de degradación, de alterización de los habitantes y de la escena urbana de un área de la ciudad. La imagen que, dependiendo de los actores asociativos, se transmite desde el barrio hacia el resto de la ciudad, lo posiciona en esta. Para la entidad vecinal observada, esta imagen forma parte de su retórica discursiva de problematización, cuando no de victimización, del distrito:

a) barrio infradotado de infraestructuras públicas básicas (Equipo Impulso, 2017),

b) con el mayor volumen de población migrante de la ciudad -que no peso porcentual- (Revitasud, 2005: 12)

c) y necesitado de políticas urbanísticas en clave de «re-»: revitalización, regeneración, rehabilitación, etc (Garnier, 2016: 63). 


\begin{tabular}{|c|c|c|c|c|}
\hline & \multicolumn{4}{|c|}{ Posición del barrio en la ciudad } \\
\hline & \multirow{2}{*}{$\begin{array}{c}\text { POPULAR } \\
\text { MULTICULTURAL }\end{array}$} & \multirow{2}{*}{ OBRERO } & ANTES: OBRERO & \multirow{2}{*}{ POBRE } \\
\hline & & & AHORA: POBRE & \\
\hline $\begin{array}{c}\text { FASES DE LA } \\
\text { CONSTRUCCIÓN } \\
\text { DEL } \\
\text { «BARRIO } \\
\text { POBRE» } \\
\end{array}$ & $\begin{array}{c}\text { VECINOS } \\
\text { (ENCUESTA 2015) }\end{array}$ & $\begin{array}{l}\text { ASAMBLEA } \\
\text { DELICIAS }\end{array}$ & $\begin{array}{l}\text { ASOCIACIÓN } \\
\text { VECINAL }\end{array}$ & $\begin{array}{c}\text { ONGs } \\
\text { ASISTEN- } \\
\text { CIALES }\end{array}$ \\
\hline \multirow{3}{*}{ IMAGEN } & Metaestabilidad & Dialéctica & Problematización & $\begin{array}{c}\text { Cambio } \\
\text { demográfico } \\
\end{array}$ \\
\hline & $\begin{array}{l}\text { Uso espacios públi- } \\
\text { cos } \\
\end{array}$ & $\begin{array}{c}\text { Condiciones de } \\
\text { vida }\end{array}$ & Escena urbana & $\begin{array}{l}\text { Vivienda } \\
\text { digna }\end{array}$ \\
\hline & Coexistencia & Ascetismo & $\begin{array}{l}\text { Enfrentamiento / } \\
\text { victimización }\end{array}$ & $\begin{array}{l}\text { Colabora- } \\
\text { ción }\end{array}$ \\
\hline MAPEO & Desconocimiento & Denuncia & Priorización & $\begin{array}{c}\text { Desacuerdo } \\
\text { sin } \\
\text { disensión }\end{array}$ \\
\hline PLAN & No colaboración & Activismo & Plan & Plan \\
\hline $\begin{array}{l}\text { Prioridad de } \\
\text { actores }\end{array}$ & Empleo & Movilización & Urbanismo & Social \\
\hline
\end{tabular}

Tabla 1. Actores del territorio y posición del barrio en la ciudad

Mientras que para las entidades asistenciales lo principal es el cambio demográfico común a otros barrios obreros: la partida de los jóvenes, que buscan barrios de construcción más moderna, y que son sustituidos por migrantes internacionales, que buscan viviendas más económicas. De hecho, aunque la asociación vecinal se centra en la degradación de la escena urbana y comercial (Revitasud, 2005: 8), las organizaciones asistenciales explican el deterioro del parque de viviendas por ese mismo cambio demográfico: jubilados con pocos medios económicos para mejorar sus edificios, que conviven con migrantes que tampoco pueden invertir su escasa renta en ello. Ese vínculo entre baja renta y escasa o nula conservación de la vivienda se retroalimenta longitudinalmente (Alguacil y Renes, 2000); y deja fuera del discurso a algunos propietarios de viviendas degradadas, que rehúsan las inversiones y se lucran aun con bajos alquileres: aspecto sólo señalado desde alguna entidad asistencial, en clave de «abuso detectado».

Ambos conglomerados de opinión coinciden en que el barrio no puede crecer más, pues carece de espacios dentro de la trama urbana consolidada, y que lo que se está produciendo es una sustitución progresiva de población autóctona envejecida por población alóctona empobrecida. Contando todos ellos 
con un fuerte sentimiento de pertenencia al barrio: $87 \%$ manifiesta sentirse muy o bastante a gusto viviendo en el distrito (Giménez et al, 2015: 12). Esto no se traslada, según la asociación vecinal, a una posición de centralidad política en la ciudad: pues el barrio no cuenta con el demandado Plan específico (Pueyo y Zúñiga, 2007: 18), ni con «representantes políticos de primera línea» en su Junta de Distrito. Esta posición de enfrentamiento, común en el activismo vecinal tradicional (Alberich, 2007: 200), contrasta, por el contrario, con la colaboración fluida y consensual de las asociaciones asistenciales con los técnicos y políticos municipales.

El desajuste entre los Ayuntamientos y las estrategias del asociacionismo vecinal, orientadas a impulsar planes específicos para los barrios, está en la base de los diagnósticos que los nutren. En el barrio observado, el foco principal de este Plan se sitúa en la «almendra central» o zona más antigua (Equipo Impulso, 2017). Tomando «la parte por el todo», según algunas entrevistas. Con lo que se permea al resto del distrito la imagen de sus calles más empobrecidas. Para ello, y siguiendo con una relación afianzada en etapas previas a las políticas de austeridad (Alberich, 2007: 202; Revitasud, 2010; Rehabitat, 2013), se recurre a la información y el asesoramiento de expertos y científicos sociales que elaboran el diagnóstico y las propuestas de mejora. De forma que el resultado, la propuesta de Plan, se quiere que actúe como constructor de la agenda municipal sobre el territorio (Theodore, Peck, y Brenner, 2009: 10), al ser el área de Urbanismo del Ayuntamiento la responsable final de la redacción oficial del Plan.

Como analizaremos en breve, este proceso de creación de imagen de «barrio pobre» para una parte de un barrio, definición técnica de la zona prioritaria y sus necesidades, así como de la redacción de un Plan específico de actuación coordinada de todos los actores del territorio, converge con el modelo actual de Politique de la ville francés: los quartiers prioritaires. Y lo hace no sólo por las similitudes en el proceso de delimitación o mapeo de la desigualdad urbana, basada fundamentalmente en la renta media (Darriau et al., 2014: 154), sino también por algunas de las medidas propuestas para evitarla. Este es el caso de las propuestas sobre el «esponjamiento» de algunas calles (Revitasud, 2010: 34), en la línea de las estrategias de demolición francesas. A ambos lados de la frontera se busca, en suma, evitar la concentración urbanística de la vivienda y la población más empobrecidas, apostando por diferirlas en el tiempo y en el espacio. La relación académica y técnica entre ambas realidades urbanas deja al margen, por el contrario, que no hay evaluaciones 
positivas de estas actuaciones en el Estado francés (Epstein, 2013). Y que, según concluiremos, las actuaciones urbanísticas locales apenas inciden en la desigualdad económica entre las clases sociales (Renes, 2015: 98).

También en esta fase de priorización las entidades asistenciales entrevistadas difieren respecto al mainstream del urbanismo técnico-vecinal. Porque señalan en las entrevistas una mayor dispersión de las familias empobrecidas, más allá de los límites establecidos por el mapeo. Y porque manifiestan dudas sobre el proceso liderado por la entidad vecinal hacia un Plan de Barrio: especialmente ante el método seguido para su redacción. Este desacuerdo, sin embargo, no divide al conglomerado vecinal y asistencial, orientado a la necesidad de una intervención integral, en la que se postulan para participar (Equipo Impulso, 2017). Lo que crea un amplio espacio libre para el discurso de oposición al mismo.

Este se ha articulado, dentro de la ruptura que supuso el movimiento $15 \mathrm{M}$ con la fase anterior del vigente régimen político español, en torno a un nuevo activismo con orientación territorial, de barrio (tabla 2). Ocupando ahora el espacio que lo vecinal ha dejado libre, al mutarse en asociacionismo de gestión: el de la dialéctica frente a la imagen que se construye. De forma que, frente a la problematización del barrio, se plantean reivindicaciones welfaristas, en clave bottom-up, sobre las condiciones de vida de las clases populares (Asamblea Delicias, 2017). Apelando para su mejora no a la planificación urbana, si no al ascetismo y la movilización hetárquica propia del movimiento obrero (Campos y del Romero, 2017: 100). Se sirven para ello de otra zona liberada, intersticial, que quienes impulsan la intervención comunitaria no contemplan como herramienta «re-»: la cultura juvenil popular, todavía no institucionalizada, del movimiento hip-hop (Jesu, 2016).

\begin{tabular}{|c|c|c|}
\cline { 2 - 3 } \multicolumn{1}{c|}{} & BARRIO OBRERO & «BARRIO POBRE» \\
\hline $\begin{array}{c}\text { Acción de élites } \\
\text { urbanas }\end{array}$ & $\begin{array}{c}\text { Construcción, industria, } \\
\text { banca, ... }\end{array}$ & Nueva filantropía \\
\hline \multicolumn{2}{|c|}{ Vs } \\
\hline $\begin{array}{c}\text { Acción de } \\
\text { habitantes de } \\
\text { barrios }\end{array}$ & AVV transformadora & AVV asistencial (gestión) \\
\cline { 2 - 4 } & Tradición activista & $\begin{array}{c}\text { Restos de asociacionismo } \\
\text { transformador }\end{array}$ \\
\hline
\end{tabular}

Tabla 2: Mutación de los actores en los barrios obreros 


\section{4. El ciudadanismo ante las clases populares}

\subsubsection{La ciudad neoliberal y su clase media: ciudadanista, creativa y participativa}

De la experiencia del barrio observado queremos extraer una pauta que sirva para entender, en tanto que habitantes de los barrios populares e investigadores sociales, cómo se vincula la construcción del «barrio pobre» con la ciudad neoliberal. Una ciudad que no es una consecuencia, sino un objetivo más de quienes auspician la actual fase del capitalismo (Caldeira, 2010). En tanto que espacio donde se reproduce la subordinación, conocer cómo funciona la ciudad también nos permite evitar o modelar su impacto sobre nuestras vidas (Garnier, 2016: 126).

Con este objetivo, establecemos una relación entre la ciudad neoliberal como fenómeno global, las ciudades del actual Estado español y el barrio observado. La primera característica común es que las ciudades globales compiten entre sí por atraer las inversiones financieras, una vez los agentes económicos postindustriales han dejado de necesitarlas como lugares de producción de bienes para el consumo (Theodore, Peck, y Brenner, 2009: 2). La especialización en el turismo, las nuevas tecnologías o las finanzas, entre otros mercados, permite a las ciudades situarse en un escaparate mundial, en el que deben ser las más atractivas para los fondos de inversión, grandes empresas, etc. Esta dinámica de urbanización de la actividad económica ha protagonizado en España el ciclo político anterior a la crisis de legitimidad institucional, que vehiculó el movimiento 15M (Delgado, 2016). De forma que, al llegar posteriormente al poder las candidaturas municipalistas que gobiernan algunas grandes ciudades, han heredado las consecuencias de estos proyectos, a menudo meramente especulativos (Mansilla, 2017). Con todo, la vinculación de estos gobiernos municipales de la llamada «Segunda Transición» a las clases medias (Delgado, 2016; Garnier, 2016: 198), tanto como a la burguesía intelectual, ha marcado su posicionamiento frente a esas dinámicas económicas y urbanas. Pues una parte significativa de su base social se identifica con esa cultura globalizada y postindustrial, en la que el conocimiento (cognitariado, clases creativas, emprendeduría, etc) y el «buen vivir» (slow life) sustituyen a los relatos welfaristas del periodo anterior. En el caso de Zaragoza, este sustrato municipalista proviene, entre otros, de quienes alentaron y auspiciaron desde diversos think tanks socialdemócratas y postmarxistas una ciudad de grandes proyectos internacionales, con referentes ahistóricos y cosmopolitas, 
que dejaban atrás la identidad rural-localista. Este es el caso de la Exposición Internacional de 2008 y sus foros medioambientales. O el proyecto de barrio tecnológico en la llamada Milla Digital (A Zofra, 2013). Ambos colindantes al barrio multicultural observado.

Esa referencia global al capital cognitivo está en la base de las llamadas «ciudades creativas» (Florida, 2009). En el entorno geográfico de Zaragoza, las ciudades de referencia internacional, con las que compite como objetivo de inversiones, han plasmado su inmersión en lo creativo en la construcción de contenedores culturales o tecnológicos, en la organización de estructuras público-privadas y en eventos internacionales: el Bilbao Bizkaia Design and Creativity Council, etc. Estos han estado en el centro de las actividades socioculturales y de economía del conocimiento entre las que han surgido los movimientos municipalistas. Contando Zaragoza para ello con espacios como La Azucarera, La Harinera o, en el caso estudiado, el edificio Etopía. En ellos se han desarrollado actividades que comenzaban a acercarse al estudio de las clases populares desde el paradigma de esta nueva clase media cosmopolita: Open Urban Lab, Jornadas Zaragoza Smart City, etc.

Esta clase media globalizada, como antes la clase media intelectual, se ha alejado definitivamente del análisis de la ciudad como escenario de un conflicto más amplio entre clase dominante y subordinada (Garnier, 2016: 143). Abanderando el multiculturalismo -como «deber ser» y no «de facto»- y reclamándose como «multitudes», confluyen en la desaparición de la clase obrera como tradicional sujeto de la acción emancipadora (Delgado, 2016). Quedando las clases populares en una posición de alejamiento progresivo de esos nuevos consensos y, para algunos, en los límites de la secesión social (Epstein y Kirszbaum, 2016; Garnier, 2016: 154). Para evitar esta progresiva fractura, el nuevo municipalismo y, en general, el ciudadanismo, proponen incidir en: la democracia local (presupuestos participativos, procesos comunitarios, etc) y la «regeneración urbana participativa» (Open Urban Lab, etc).

La primera implica, en el territorio estudiado, la opción por planes territoriales que partan del tejido social que interviene o que nace en los barrios, como forma de combatir la desafección. Y la segunda, cuestiona la pertinencia de las propuestas urbanísticas previas, en clave «re-», todavía presentes en el asociacionismo vecinal y con resultados que hoy se evalúan negativamente (Kirszbaum, 2015): pues apenas han abordado con eficiencia lo social, mucho más metaestable (Bergua, 2007: 55). Al contrario, a través de la participación 
y la cultura se apuesta por un nuevo exorcismo urbano, que diluya los fantasmas de la desigualdad inherente al capitalismo (Sorando, 2014: 366).

\subsubsection{Gestionar un escenario post-empleo para las clases populares}

Por tanto, las clases medias -creativas, participativas y cosmopolitasorientan sus políticas sociales y urbanas hacia los barrios populares desde un nuevo enfoque, a partir de la irrupción del movimiento $15 \mathrm{M}$. No pudiendo eludir, al implementarse en estos territorios, la imagen del «barrio pobre» que entidades asistenciales y vecinales han venido construyendo con el nuevo siglo. El objetivo común de ambos conglomerados, de representación y de gestión, converge en la necesidad de gobernar un escenario post-empleo para las clases populares. Pues el anterior abandono de las mismas, tal y como señalan los diagnósticos comunitarios (Giménez et al., 2015; Revitasud, 2005), pone en riesgo a la «ciudad segura» (Garnier, 2010: 239).

¿Qué o quiénes son sujeto de esta gobernanza neoliberal, que prioriza territorios? Más allá de las clasificaciones de renta que los mapeos de la geografía urbana nos proponen, nuestro análisis señala a una población residual (Bauman, 2005: 24), que ha perdido su partida en el juego del libre mercado: descualificada, envejecida, «desadaptada» cívica y culturalmente, etc. Para este creciente porcentaje de quienes habitan los barrios de la antigua corona obrera, en lugar de la justicia social o redistributiva que el Estado del Bienestar impulsaba, según el relato socialdemócrata, la ciudad neoliberal plantea un colonialismo interior, en el que las clases populares son perimetradas (geolocalizadas), infantilizadas (dependientes) y «etnificadas» (problematización de la migración internacional). Para ello se recurre a mecanismos de securitización altamente tecnológicos (Rigouste, 2007), entre los que podemos situar a las propias Ciencias Sociales. A los que acompañará, según el modelo del Estado del Bienestar mediterráneo, el conglomerado benéfico-asistencial.

En el caso aragonés, huyendo tanto del obrerismo propio del asociacionismo vecinal tradicional como del vecindario ajeno a la «inclusión a través del empleo», el municipalismo recurre al término «gente» como pantalla para mantener en una higiénica indefinición a las clases populares (Delgado, 2016: 16). Clases a las que durante la observación anotamos que se condena por su «conservadurismo», por su escaso «dinamismo» (especialmente comercial) o por lo inapropiado de una escena urbana que nunca ha diseñado: «tu barrio es muy feo». Aquí, la multiculturalidad, al contrario que el centro histórico, en 
proceso de gentrificación (Sorando y Ardura, 2016), es sujeto de alterización y problematización: «esto afecta a vecinos e inmigrantes».

Por otra parte, ¿dónde se encuentran estos territorios prioritarios? Por definición, los barrios «no creativos", «no emprendedores», «no cosmopolitas» y poco «participativos» (Epstein, 2009: 81) son aquellos no habitados (todavía) por las clases medias correspondientes. Especialmente, cuando no son capaces de atraerlas ni a ellas ni a sus inversiones, locales o supralocales. Los barrios abandonados por el capitalismo financiero, primero, y desbordados por la pobreza que han generado las políticas públicas de la austeridad, después (Renes, 2015: 101). Excepcionalmente, estos barrios pueden cambiar su posición en la ciudad neoliberal, si mantienen relación con infraestructuras de transporte, que los pueden situar en el contexto de la metropolización (Garnier, 2014). En ese caso, pueden ser «re-» generados mediante las políticas urbanísticas que introducen la mixité o mezcla social, bajo riesgo de que sus habitantes sean sustituidos por las clases medias globalizadas (Epstein, 2016).

Dada crisis de legitimidad del relato socialdemócrata en la ciudad observada, por el papel clave de éste en el periodo de la especulación inmobiliaria (A Zofra, 2013), el municipalismo ha dirigido su discurso y su gestión, explícitamente, a los barrios perdedores de la ciudad globalizada. Confluyendo así en las políticas participacionistas las clases medias cosmopolitas y los gestores del conglomerado benéfico-vecinal asentados en los barrios de la ciudad consolidada. Entre ambos se están delimitando, como hemos visto, las zonas prioritarias de estos barrios. En el estudiado, se recurre para ello a la categorización de «periferia interior» de su centro histórico (Revitasud, 2010: 34). Señalando así al conjunto de espacios degradados que se ubican en el centro del barrio, correspondientes a zonas de una antigua periferia que quedó congelada en el tiempo; pues el crecimiento de la trama urbana la atravesó en su recorrido, dejándola olvidada en su desarrollo (Kápstein, 2010: 31). La ausencia total o parcial de regulación urbana durante el periodo especulativo del desarrollismo franquista, ha causado la aparición de estas áreas «vulnerables» en el interior de los barrios. Áreas más o menos vivibles, hasta que, tras otro periodo de acumulación capitalista a través de la especulación urbanística, se traspasa el «umbral desencadenante» o momento crítico, determinado por la combinación de factores económicos (Gran Recesión), de planeamiento urbano (vínculo entre asociacionismo vecinal y urbanismo socialdemócrata), de 
contexto social (barrio multicultural), etc. Ese es el escenario actual (Renes, 2015).

Y, finalmente, ¿cómo se interviene para atenuar el conflicto social al que, en tanto que riesgo previsible, pretende anticiparse este nuevo modelo de mediación (Delgado, 2016)? La ciudad neoliberal despliega tres estrategias principales para el encauzamiento de las clases populares. La ya citada mezcla social o mixité, orientada a diluir demográficamente la concentración espacial de las clases diagnosticadas como «peligrosas» (Kirszbaum, 2014). La implementación de políticas culturales que, mediante su expansión por el territorio, invisibilicen la desigualdad socioeconómica que la escena urbana podría transmitir (Garnier, 2016: 71). Y, con efecto corrector, a la vez que como bisturí de la distinción (Bourdieu, 1988), se renueva la exigencia de un civismo que remite a la cultura de las clases dominantes, como modelo universalizable (Delgado, 2016: 91). La convergencia de ciudadanismo y actores del territorio ha adaptado estas estrategias al contexto de los barrios populares de Zaragoza (y otras ciudades), en un proceso todavía en marcha.

En suma, esta problematización de la cultura endógena y de la vida cotidiana de un barrio multicultural es síntoma de que la clase media global y su cultura dominante necesitan ser reconocidas como tales (Grignon y Passeron, 1992: 72). Como reacción anudada, los antiguos barrios periféricos, del cinturón obrero de las ciudades del siglo XX, reclamaron al Estado las infraestructuras que su condición de ciudadanía incluida a través del empleo (y los impuestos) les permitía exigir. Mientras que ahora, una vez dotados de los servicios públicos welfaristas, en un escenario post-empleo y desde su cultura multiétnica ${ }^{1}$, no pocas voces de los barrios afirman que nunca serán como la ciudad que «debe ser» (Caldeira, 2010). Durante la observación, un rapero local rimaba «aquí no viene el guiri, a visitar los monumentos,... organizan la city, de sus planes estamos fuera». Distanciándose así de una intervención público-privada que identifican con los grupos sociales exclusógenos ${ }^{2}$ y de la que querrían mantenerse cultural ¿y espacialmente? separados. Esta es la otra co-construcción de la posición del barrio en la ciudad.

1 Que hemos observado, entre otros escenarios, en algunas actividades culturales juveniles, como el hip-hop.

2 Los grupos sociales que tienen acceso a los recursos ciudadanos, a los medios de consumo y a la información, y que generalmente viven al margen de los problemas sociales de los grupos subordinados (Alguacil y Renes, 2000). 


\section{5. Conclusiones}

El trabajo de campo desarrollado en un barrio de la antigua corona obrera nos permite establecer dos conclusiones principales. En primer lugar, el abordaje de estos barrios desde el ciudadanismo municipalista se encuentra con una limitación que es común a todas las políticas de la ciudad: las palancas que pueden revertir la actual desigualdad social y económica no pueden activarse desde las instituciones locales (Garnier, 2016). La inclusión social a través del empleo, propia del periodo previo a la Gran Recesión, no puede ser facilitada por quienes no pueden legislar sobre las relaciones laborales, la contratación pública de servicios o la regulación de los mercados internacionales. De ahí que la respuesta participacionista, pueda estar obviando cuál es la pregunta fundamental (Subirats, 2010: 18), también por parte de las clases populares.

Y, en segundo lugar, la apelación a que los excluidos participen de la vida política local (Talpin, 2016) o a que imiten la cultura de la clase media global, remite a las clases populares a un escenario de responsabilización de su alejamiento progresivo de la «normalidad», tanto como de su propio «rescate». En línea con la culpabilización de los «vecinos residuales» que la ideología neoliberal esgrime para justificar la creciente brecha de oportunidades entre unos y otros barrios de la ciudad (Renes, 2015: 102). Esto es así, no tanto por lo que declaran las intervenciones en clave comunitaria: la aspiración a una mejor convivencia. Si no por lo que no declaran: que, contra lo que propone la intervención social preventiva y promotora, renuncia a promover un cambio en la relación de fuerzas, en términos hetárquicos, $y$, por tanto, a un reparto diferente de la riqueza.

Ambas conclusiones, la impotencia del relato ciudadanista local y la renuncia a promover un cambio de raíz, explicarían la escasísima concurrencia vecinal en los eventos participacionistas (constatada por todos los actores) y el consenso en torno a la emergencia de un vecindario revanchista. Como las encuestas advierten, una cuarta parte del barrio estudiado desconfía de la administración local para la resolución de sus necesidades prioritarias. No acepta la multiculturalidad. Y asume un discurso de competencia por abajo, ante las políticas de austeridad (Giménez et al., 2015).

El mismo relato que hoy se yergue en barrios antes obreros y ahora «pobres», donde nuevos caudillismos han encontrado su principal granero de votos, apenas unos kilómetros al norte. El hueco dejado por el asociacionismo 
vecinal obrerista queda así cubierto por nuevas expectativas de cambio social. Y no por propuestas de «re-»generación del izquierdismo, aunque se postulen al margen del ciudadanismo, y que tan sólo han tenido impacto en otros actores en competencia por la hegemonía simbólica del barrio.

Para quienes aspiramos a unos barrios y pueblos donde no se limiten las expectativas de vida, en beneficio de los intereses de los grupos exclusógenos (Garnier, 2016: 208), urge provocar nuevos encuentros entre vecinos de diferentes culturas, pero con un mismo interés: una vida digna. Es en lo que tenemos en común donde está el relato autónomo que aún no hemos articulado.

\subsection{Bibliografía}

AGUSTÍN, L. (2009), Sexo y marginalidad. Emigración, mercado de trabajo e industria del rescate, Madrid, Editorial Popular.

ALBERICH, T. (2007), Contradicciones y evolución de movimientos sociales en España, Documentación social, 145, 183-210.

ALGUACIL, J. et al. (2014), La vulnerabilidad urbana en España. Identificación y evolución de los barrios vulnerables, Empiria, 27, 73-94.

ALGUACIL, J. y RENES, V. (2000), Pobreza urbana y procesos sociales. En EDIS et al., Las condiciones de vida de la población pobre desde la perspectiva territorial, Madrid, FOESSA - Cáritas, pp. 209-272.

ASAMBLEA DELICIAS (2017), Contra la especulación y el negocio de la pobreza en el barrio de Delicias, disponible en http://asambleadelicias.blogspot.com.es/

A ZOFRA - Grupo de Estudios Metropolitanos (2013), De la euforia del ladrillo a la crisis. Zaragoza, puesta a producir en el último ciclo capitalista, Zaragoza, A Zofra.

BAUMAN, Z. (2005), Vidas desperdiciadas, Barcelona, Paidós.

BAUMAN, Z. (2006), Modernidad y Holocausto, Madrid, Sequitur.

BERGUA, J.A. (2007), Lo social instituyente. Materiales para una sociología no clásica, Zaragoza, Prensas Universitarias

BERGUA, J.A. (2011), Estilos de investigación social, Zaragoza, Prensas Universitarias de Zaragoza.

BOURDIEU, P. (1988), La distinción. Criterio y bases sociales del gusto, Madrid, Taurus.

CALDEIRA, T. (2010). Espacio, segregación y arte urbano en el Brasil, Madrid, Katz.

CAMPOS, A. y DEL ROMERO, L. (2017), Reapropiació o consum de la ciutat? Conflictes $i$ resistències urbanes davant l'urbanisme neoliberal a València, Quaderns-e, 22 (1), 88-104.

DARRIAU, V. et al. (2014), Politique de la ville en France métropolitaine: une nouvelle géographie recentrée sur 1300 quartiers prioritaires, Paris, INSEE. 
DELGADO, M. (2016), Ciudadanismo, Madrid, Catarata.

EPSTEIN, R. (2009), «Démocratie et participation: l'exemple de la rénovation urbaine», en J. Donzelot, La ville à trois vitesses, París, Éditions de la Villette.

EPSTEIN, R. (2013), La rénovation urbaine. Démolition-reconstruction de l'Etat, Paris, Presses de Sciences Po.

EPSTEIN, R. (2016), Le «problème des banlieues» après la désillusion de la rénovation, Métropolitiques, enero.

EPSTEIN, R. y KIRSZBAUM, T. (2016), Territoires perdus versus territoires oubliés: les deux discours de la fracture, Urbanisme, 399, 57-59.

EQUIPO IMPULSO (2017), Diagnóstico de Delicias. Equipo Impulso del proceso comunitario de Delicias, documento inédito.

FLORIDA, R. (2009), Las ciudades creativas, Barcelona, Paidós.

GARCÍA, S. (1994), «Ciudadanía en España», En Alabart, A. et al. (comps): Clase, poder u ciudadanía, Madrid, Siglo XXI.

GARNIER, J.P. (2010), Une violence éminemment contemporaine, Marsella, Agone.

GARNIER, J.P. (2014), «¿Hacia una nueva ciudad celeste?» GeocritiQ, 88.

GARNIER, J.P. (2016), Un sociólogo urbano a contracorriente, Barcelona, Icaria.

GIMÉNEZ, C. et al. (2015a), Encuesta 2015 sobre convivencia intercultural en el ámbito local. Delicias (Zaragoza). Síntesis de resultados del informe territorial, Barcelona, Obra Social La Caixa.

GIMENO, Ch. et al. (2016), «La intervención comunitaria: retos y propuestas», En Raya, E. y Pastor, E. (coord.), Trabajo social, derechos humanos e innovación social, Cizur Menor, Navarra, Aranzadi.

GRIGNON, C. y PASSERON, J.C. (1992), Lo culto y lo popular, Madrid, Endymion. JESU, L. (2016), L'élite artistique des cités. Métamorphoses de l'ancrage du hip-hop dans les quartiers populaires en France (1981-2015), Université de Lorraine, Tesis doctoral.

KÁPSTEIN, P. (2010), Vulnerabilidad y periferia interior, Cuadernos de investigación urbanística, 71, 7-114.

KIRSZBAUM, T. (2014), Mixité, En A. BIHR et R. PFEFFERKORN, Dictionnaire des inégalités, Paris, Armand Colin.

KIRSZBAUM, T. (dir.), En finir avec les banlieue? Le désenchantement de la politique de la ville, Bibliothèque des territoires, Éditions de l'Aube, 2015

MANSILLA, J.A. (2017), Los nuevos municipalismos y el fin de la Historia, Quaderns-e, 22 (1), 1-4.

MARCHIONI, M. (2002), «Organización y desarrollo de la comunidad: la intervención comunitaria en las nuevas condiciones sociales», En M.L. SARRATE (coord.) Programas de animación sociocultural, Madrid, UNED.

PERALVA, A. y MACÉ, E. (2002), Médias et violences urbaines: débats politiques et construction journalistique, París, IHESI.

PUEYO, A. y ZÚÑIGA, J.L. (2007), Delicias: un barrio de hoy para el futuro. Propuestas de rehabilitación urbana del barrio de delicias en Zaragoza, Zaragoza, Sociedad Municipal de Rehabilitación Urbana de Zaragoza. 
RENES, V. (2015), La trascripción espacial del empobrecimiento general. Los barrios como el sumidero de los desechos de la crisis, Papeles de relaciones ecosociales y cambio global, 130, 89-102.

REHABITAT (2013), Proyecto Rehabitat. Estrategia de cohesión transfronteriza, Zaragoza, Sociedad Municipal de Rehabilitación Urbana de Zaragoza.

REVITASUD (2005), Estudio sociourbanistico del Barrio de Delicias en Zaragoza, Zaragoza, Sociedad Municipal de Rehabilitación Urbana de Zaragoza.

REVITASUD (2010), Estudios y elaboración de propuestas piloto de revitalización urbana en barrios residenciales transfronterizos (1945-1960), Zaragoza, Sociedad Municipal de Rehabilitación Urbana de Zaragoza.

RIGOUSTE, M. (2007), L'ennemi intérieur, de la guerre coloniale au contrôle sécuritaire, Cultures \& Conflits, 67.

RODRÍGUEZ, A. y VICARIO, L. (2005), « Innovación, competitividad y regeneración urbana: los espacios retóricos de la "ciudad creativa" en el nuevo Bilbao », Ekonomiaz 58.1 , 262-295.

SAURA, G. (2016), Neoliberalismo como discurso: la evaluación en educación entre tecnologías políticas neoliberales y la nueva filantropía, Revista Educação, Sociedade \& Culturas, 47, 11-30.

SORANDO, D. (2014), Espacios en conflicto. Un analisis relacional del cambio social en los centros estigmatizados, Madrid, UCM. (Tesis doctoral).

SORANDO, D. y ARDURA, Á. (2016), First we take Manhattan: la destrucción creativa de las ciudades, Madrid, La Catarata.

SUBIRATS, J. (2010), Si la respuesta es gobernanza, ¿cuál es la pregunta? Factores de cambio en la política y en las políticas, Ekonimiaz, 75, 16-35.

TALPIN, T. (2016), Une répression à bas bruit. Comment les élus étouffent les mobilisations dans les quartiers populaires, Métropolitiques, febrero.

THEODORE, N., PECK, J. y BRENNER, N. (2009), Urbanismo neoliberal: la ciudad y el imperio de los mercados, Temas sociales, 66, 1-11.

VIRNO, P. (2003), Gramática de la multitud, Madrid, Traficantes de Sueños 



\title{
4 \\ NUEVO ENFOQUE DE INTERVENCIÓN PARA CUIDADORES PROFESIONALES EXTRANJEROS A TRAVÉS DE LAS TECNOLOGÍAS
}

\author{
$M^{a}$ Jose Gomez Poyato \\ Universidad de Zaragoza / Cruz Roja Zaragoza \\ mjgomez@unizar.es
}

\subsection{Introducción}

El concepto de cuidado ha sido una expresión constante en todas las sociedades. Este cuidado se ha asumido como algo normal y cercano, desarrollado por cuidadores informales (la familia) como pieza clave. Sin embargo, este continuo cuidado lleva consigo unas consecuencias psicológicas, físicas, biológicas y emocionales que con el tiempo repercuten en su salud y por consiguiente en la calidad de vida de los familiares.

Con estas circunstancias en 2006, el Gobierno con el apoyo de todos los partidos políticos y organizaciones sociales decidió poner en marcha el proceso de debate y aprobación de lo que hoy se conoce como la Ley de Promoción de la Autonomía Personal y Atención a la Dependencia. Esta Ley de 39/2006 de 14 de diciembre, se propone ofrecer servicios y prestaciones económicas de atención a la dependencia y recoge, aunque de manera excepcional que al final se ha convertido en mayoritaria, la atención a la Dependencia en el domicilio a cargo de familiares.

El cuidado realizado por familiares o amigos a los individuos que no pueden cuidar de sí mismos es una práctica social extendida. En España es una práctica muy común, que actualmente, aun existiendo la Ley de la Dependencia, supera ampliamente a la acción que tendría que venir del Estado en el sistema de Bienestar en el que nos encontramos. Autores como Gomá y Subirats (2003) y Rodríguez Cabrero (2004) exponen que el modelo de bien- 
estar característico de España es el modelo mediterráneo. Se pretende dar una visión general del Estado de Bienestar en España, pero existe una extensa bibliografía al respecto, (para consultar autores como: Gomà y Subirats, 2001; Arriba González, 2008; Antón Morón, 2009; Esping Andersen, 2010; del Pino y Rubio 2013, etc). Este modelo está sustentado sobre la familia, siendo éste uno de sus rasgos más característicos y destacables. La familia es la principal proveedora de cuidados.

Estos cambios se han realizado a partir de cuatro procesos que han sido, la universalización, la moderación del gasto social, la descentralización del poder público y la privatización (Navarro, 2006). Todos los procesos que se ha desarrollado en distintas facetas políticas han confluido en la creación de un Estado de Bienestar dando lugar a que se tengan extensas coberturas y desarrollo de prestaciones de carácter asistencial, aunque desigual en su reparto dentro del territorio español como consecuencia de la descoordinación de las diferentes políticas estatales, autonómicas y municipales.

Aun así, es cierto que aunque los modelos institucionales han variado con el tiempo y ha habido importantes transformaciones en las últimas décadas, cuando no llega el Estado interviene el mercado con un elevado coste para las familias. El término familiarísimo hace referencia según Esping Andersen, (2004) a la forma conjunta en que el bienestar se distribuye por parte del Estado, el mercado y la familia. El problema es discernir si estos cuidados son dados porque es algo inherente en nuestra cultura o es el resultado de la carencia de los servicios que tenían que ser prestados por el Estado y el mercado. Esto evidencia una carencia en las políticas sociales planteadas.

Como afirma Beck (2006), aún en la entrada en el siglo XXI, la familia sigue siendo el punto central donde se va a producir el cuidado de las personas dependientes aunque las estructuras familiares hayan variado del concepto tradicional de pareja estable y ahora son más inestables e individuales. Esto no implica que aunque la familia no responda al modelo anteriormente conocido, la sociedad no asimile el concepto de cuidar, porque se siguen manteniendo los vínculos de apoyo entre familiares de carácter económico, solidario y de cuidado de forma distinta a la tradicional, con una apertura no sólo familista sino extensible a la contratación de personal dedicado al cuidado.

Este tipo de atención dentro del domicilio, cuando es realizada por los propios familiares, se denomina cuidado informal y es el que se ejerce sobre aquellas personas más próximas a nuestro entorno sin recibir ninguna pres- 
tación económica a cambio. Sin embargo, el desgaste de los familiares en el tiempo hace que opten por la contratación de cuidadores formales. Muchos de estos cuidadores formales son extranjeros. Algunos de ellos ya han vivido experiencias de cuidado de familiares en sus países de origen, pero esto no hace que sean eficientes a la hora de cuidar a personas de forma remunerada.

\subsection{La tarea de cuidar}

El ser humano a lo largo de la historia ha desarrollado su capacidad en relación al cuidado de los de su mismo género como una forma de garantizar la supervivencia de la especie. Según Montorio (1999) las razones que llevan al cuidado de otros pueden ser de naturaleza altruista, por sentimientos de culpa, por obligación, por motivos económicos, etc.

Pero cuidar no es una tarea fácil, los cuidados pueden suponer en algunos casos una cantidad de trabajo que va a repercutir en la salud de las personas que ejerzan como cuidadores. Según definición dada por Rivera (2001), un cuidador informal se podría decir que es toda persona no remunerada que asume el rol de cuidar, mientras un cuidador formal se diría que es toda persona remunerada que asume el rol de cuidar, en ambos casos se responsabilizan de ayudarlo en aquellas actividades de la vida diaria que lo requiera.

Existe ya un perfil predeterminado que identifica quién debe tener la responsabilidad de cuidar, sean tanto cuidadores informales como formales. Aunque el perfil de los cuidadores es muy variado, en porcentaje más alto, un $85 \%$, suelen ser de género femenino de edad entre 35 y 60 años. Cuando no existe la posibilidad de que este papel lo asuma una mujer, entonces son los varones los que se ocupan del cuidado. Según Bazo, (1998) se designa como una tarea cuya identidad es femenina, ya que las mujeres parecen estar más preparadas para el cuidado de otros por su cualidad maternal. Además los cuidadores formales extranjeros se encargan no solo del cuidado sino también de la limpieza y mantenimiento del hogar. Esta saturación de tareas hace que con el tiempo repercutan en su salud, en su estado emocional y en su relación social.

Desde numerosas organizaciones privadas se han desarrollado distintas intervenciones con el ánimo de mejorar esta situación a través de programas socioeducativos para formar y capacitar a estos cuidadores formales extranjeros, que en su mayoría no cuentan con titulaciones homologadas en España. 


\subsection{El proyecto educativo de Cruz Roja Zaragoza}

Desde hace unos años y debido a los recortes presupuestarios en todas las áreas se ha visto afectado el planteamiento, no tanto de información, pero sí de formación para los cuidadores profesionales y es por eso que una de la misiones de las organizaciones no gubernamentales es trabajar para lograr una sociedad más cohesionada, en la cual no haya espacio ni para la discriminación ni la marginación o por cualquier tipo de razón. Simplemente la observación de la realidad junto a la investigación en el tema que nos ocupa, nos demuestra que nos encontramos frente a situaciones de vulnerabilidad que se generan y que afectan a la formación de los cuidadores formales.

A lo largo de la historia, Cruz Roja se ha ido centrando en diferentes ámbitos según la época en la que se encontraban. Los objetivos de la entidad tal y como fueron expuestos en los Convenios de Ginebra de 1949 y en los Protocolos de 1977, (Bruel i Carreras, 1999) y por lo tanto su evolución, se puede dividir en tres etapas distintas que han marcado las actuaciones de la organización. En la actualidad, estas acciones están encaminadas a acciones preventivas a favor del Bienestar Social y la calidad de vida y que se divide en distintas áreas; Acción Social, Cooperación al Desarrollo, Acciones en pro de la Paz, Defensa de los Derechos Humanos y Medio Ambiente. Dentro de la acción preventiva de Acción Social se encuentra el proyecto elegido para la presente investigación «Préstamo de productos de apoyo y Cuidados al cuidador» (a partir de ahora, PPCC).

La idea con que nace este proyecto es el de desarrollar acciones encaminadas a apoyar al cuidador ofreciéndole material ortoprotésico con un alquiler bajo, además de ofrecerle un aprendizaje gratuito del uso del material. Pero con el tiempo se vio que este objetivo no cubría todas las necesidades de todos los tipos de cuidadores, tanto formales como informales, y que se necesitaba completar el proyecto.

Es aquí cuando surge el programa educativo en relación a los cuidados de las personas dependientes. El objetivo de este programa educativo era la preparación de una batería de charlas-taller que se repitieran trimestralmente, en las que se informaría de temas relacionados con los cuidados y que permitieran a los cuidadores desempeñar su rol en las mejores condiciones. Otro objetivo de estos talleres es el influir en la forma de cuidar y eliminar los efectos negativos que viene derivados del cuidado. 
Siguiendo las directrices de Cruz Roja, el fin de estos programas educativos es que los cuidadores tengan herramientas que puedan servirles para afrontar las dificultades que les vayan surgiendo tratando de hacer más independiente al enfermo y de mejorar la calidad de vida del cuidador (Dooley, 2004) y (Goodman, 1990).

Zarit (1990) propone que estos programas educativos no deben ser muy extensos en el tiempo y que deben realizarse en grupos, ya que las personas que suelen participar suelen ser los cuidadores principales tanto formales como informales tienen el tiempo muy limitado. El proyecto PPCC sigue estas líneas proponiendo una batería de charlas-taller que no suelen durar más de seis semanas con grupos de diez personas.

En el futuro se quería potenciar la realización de estos programas educativos a través de formas más novedosas basados en comunicaciones on-line que facilitarían al cuidador no tener que desplazarse de su casa para recibirlas (Fernández, 2003).

En febrero de 2014, esto se convirtió en una realidad con el teléfono gratuito para los cuidadores, el 900365 100, de atención de 09:00 a 21:00h de lunes a viernes, en el cual se atienden sus demandas y se aclaran dudas sobre los cuidados. Dicha línea se incluye dentro de un sistema multicanal de información y atención, a través del teléfono y de internet en la página web www. sercuidador.es.

Aunque las tecnologías nos ayudan a avanzar y a llegar a más personas, también se debe tener en cuenta que una parte de la población no puede o no sabe acceder a las mismas. Es por esto que siguen en marcha los cursos presenciales, que están pensados con el mismo objetivo, mejorar los conocimientos de los cuidadores sobre el tema del cuidado y que les ayude a afrontar mejor el momento en el que se encuentran, además de conocer a otras personas en su misma situación.

Zarit (1990) comenta que los cambios que se pueden conseguir con estos programas educativos suelen ser de escasos resultados, porque, aunque los cuidadores aumentan sus conocimientos también aumentan sus cotas de estrés al tener que enfrentarse a la situación, aunque también reconoce que no se ha comprobado su eficacia en su totalidad. Otros autores como Fernández (2003) comentan que aunque las mejoras emocionales no son muy visibles ni muy inmediatas, ya que los cuidadores tienen que asimilar la información recibida, 
los cambios suelen venir con el tiempo mejorando la calidad de vida de los mismos a largo plazo.

En Cruz Roja el programa educativo que se realiza para los cuidadores comenzó su andadura en 2008 solo con una charla-taller, Técnicas de Movilización, siendo una de las más demandadas por los usuarios, y es a partir de finales de 2011 cuando se derivan medios humanos al proyecto que se dedicarán a ampliar este ciclo formativo creando seis charlas que se imparten a lo largo de un trimestre, volviéndose a repetir el ciclo en cada trimestre. De esta forma en el año se imparten tres ciclos trimestrales completos exceptuando los meses de julio, agosto y diciembre en los que no están programados.

Las seis charlas-taller inciden en los siguientes aspectos; Adaptación del Entorno en el domicilio, Productos de Apoyo Complementarios, Taller de Espalda Sana, taller de Relajación, Dieta y Nutrición y aseo y vestido del paciente.

\subsection{Nueva realidad}

En el siglo XXI se ha convertido en todo un reto el proporcionar cuidados a las personas dependientes. La situación de crisis que vivimos desde el 2008 ha creado una nueva realidad, (Marcuello- Servos, Ch y Marcuello, C 2015). Se ha cronificado el ámbito de los cuidadores con las reducciones producidas en la ley de la dependencia y no solo eso, sino que ha creado un fuerte impacto en las organizaciones sociales del Tercer Sector, en especial en las de Acción Social. Además, cada vez es más difícil acceder a cursos o talleres que capaciten a estas personas frente a este tipo de empleo debido a los recortes para los planes de formación.

Teniendo presente que nos encontramos en la era del conocimiento y de la información, con un gran avance en el área de las tecnologías que están transformando la realidad muy rápidamente, influyendo en nuestra vida cotidiana y condicionándola con dispositivos de hardware y aplicaciones de software que están modificando las formas de interacción social. De ahí, que podemos aprovechar esta revolución tecnológica para realizar formaciones on-line con estos cuidadores formales extranjeros.

Partiendo de la idea de que cualquier persona en un momento dado puede convertirse en cuidador de otra y que proyectos como el que se desarrolla en Cruz Roja Zaragoza (Cruz Roja Española, 2013) sirven para prevenir, contro- 
lar, mitigar o neutralizar deficiencias y limitaciones en la actividad que estas personas tienen que realizar con las personas que cuidan sean familiares o personal contratado, se debe enfocar todos los esfuerzos hacia la identificación de esas necesidades, para introducir de ese modo el trabajo desde las claves de las tecnologías.

El objetivo general de esta investigación seria analizar el programa de acción de Cruz Roja Española en Zaragoza para mejorar desde el ámbito de la salud la calidad de vida de los cuidadores formales dentro del proyecto de «Cuidados al cuidador» con la introducción de la tecnología, (memoria interna CRE, 2014). Como objetivo específico se basaría en el tratamiento y cuidado de las personas enfermas o discapacitadas de forma temporal o crónica a través de la prestación de acciones formativas, lúdicas o espacios de encuentro para dar respuesta a las necesidades básicas, promover la autonomía y la autogestión, con ayuda de profesionales y voluntarios, contando con las herramientas tecnológicas.

Teniendo en cuenta que tanto las personas destinatarias, el personal técnico y el voluntario vertebran los ejes del trabajo en Cruz Roja Zaragoza donde se desplegaría las claves del e-Social Work y de la formación a través de las tecnologías como sistema de intervención. Un sistema que se desarrollaría en el ámbito local logrando una mayor visibilidad de lo realizado y llegando a más personas.

Es importante recordar que estas herramientas tecnológicas tienen un bajo coste económico y una agilidad en los servicios. Requiere de personal técnico como motor de la gestión y supervisión del proyecto y, además, hace partícipe al voluntariado tan importante para esta organización del tercer sector.

Partiendo de la idea de que cualquier persona en un momento dado puede convertirse en cuidador de otra y que proyectos como el que se desarrolla en Cruz Roja Zaragoza sirven para prevenir, controlar, mitigar o neutralizar deficiencias y limitaciones en la actividad que estas personas tienen que realizar con las personas que cuidan, se debe enfocar todos los esfuerzos hacia la identificación de esas necesidades, teniendo en cuenta estos cambios y los nuevos escenarios que originan para introducir de ese modo el trabajo desde las claves del e-Social Work, como manera complementaria a la habitual del Trabajo Social. 


\subsubsection{Cambios en Cruz Roja Zaragoza con los procesos digitales}

Desde Cruz Roja en Zaragoza se trabaja de manera altruista por la sociedad aragonesa y se responde a las necesidades que se van detectando, con el objetivo de fomentar el intercambio de experiencias desarrollando herramientas que lo faciliten. Esto se hace apostando por la exploración de procesos innovadores, como es el caso de las tecnologias.

Como ya hemos dicho anteriormente en 2008 se notaron los efectos de la crisis produciéndose recortes dentro de la propia entidad y teniendo que plantear nuevas vías de actuación. Fue en 2013, cuando en Zaragoza se adoptó un proceso de convergencia digital favorecido por la entrada de nuevas tecnologías que se podían adaptar para mejorar los procesos de intervención con los usuarios.

Esto supuso un cambio en nuestra concepción del mundo, modificando formas de pensar, hábitos culturales, mercados de trabajo...y también introduciendo cambios en la forma de actuar. El papel de las profesionales sigue siendo insustituible y necesario, incluso en un plano tecnológico. Pensar en una actuación profesional ajena o alejada de las TICs es pensar de forma restrictiva (Memoria interna CRE, 2014).

Por eso desde Cruz Roja Zaragoza se quiso investigar en proyectos relacionados con los avances tecnológicos para aplicarlos en la provisión de servicios a los colectivos más desfavorecidos siendo uno de ellos el proyecto de Cuidando al Cuidador. La aplicación de las tecnologías no se debería describir en este caso como un proyecto aparte sino más bien como una herramienta de trabajo transversal dentro del proyecto. Con esta herramienta se pretendía incrementar la calidad de las atenciones y dar una respuesta personalizada y rápida ya sea a los cuidadores formales como a los informales.

El método de intervención que se ofrecería quedaría marcado por estas claves. La intervención en cada caso iría dirigida a mejorar su autogestión y ayudarle a alcanzar el mayor grado posible de integración y calidad de vida, así como las posibilidades que se intuyen con esta herramienta de trabajo y los retos a los que podríamos responder son evidentes, dando respuesta especializada a las necesidades básicas del cuidado y del cuidador.

Las TIC permitirían la gestión de la información y de los recursos por parte de los técnicos de una forma más eficiente y efectiva con aplicaciones 
directas de intervención a través de las tecnologías creadas específicamente para su perfil. Se recogerían y registrarían todos los datos de cada usuario del servicio, teniendo una información actualizada y pudiendo seguir los avances de los cuidadores en su formación para mejorar su calidad de cuidado así como su calidad de vida.

Los beneficios son muchos permitiendo una comunicación más personal y directa con los beneficiarios para conocer su estado, centrándose en una atención individual o colectiva a través de la implementación de tecnologías adecuadas para ello. Presenta un seguimiento y evaluación continuada del usuario desde el primer momento que es intervenido hasta que termina su recorrido. Puede dar paso a crear un modelo de intervención unitario para todos al centrarse en las tecnologías. Además se podrían co-dinamizar actuaciones con distintos profesionales que formaran parte de los equipos interdisciplinares siendo capaces de implementar su formación en estas nuevas tecnologías, integrando los métodos y las herramientas tradicionales con las posibilidades que despliegan las TICs u otras tecnologías, en definitiva, abriendo nuevas puertas de actuación.

Además, como se ha comentado anteriormente, tienen un bajo coste, las acciones no requieren de presupuestos grandiosos y da pie a una agilidad en los servicios, con la aplicación de las TIC ya existentes a nivel de información, comunicación. Las TIC están transformando nuestra forma de vivir y sobre todo de trabajar. Esto es solo un ejemplo de ello, un reto para la reformulación de los proyectos y de los beneficiarios utilizando como herramienta efectiva de trabajo las tecnologías disponibles. Se abre pues una línea de trabajo que deberá buscar respuestas preventivas para mejorar y hacer frente a estos cambios. Así como adelantar problemas y ámbitos de intervención para buscar soluciones tecnológicas y herramientas que permitan cada vez mejores soluciones.

\subsubsection{El servicio de Video atención}

Desde hace dos décadas Cruz Roja Española lleva trabajando por la mejora de la calidad de vida de las personas mayores y de las personas que las cuidan desde un enfoque integral tanto bio-psico-social como relacional, para conseguir una intervención enmarcada en el paradigma de Envejecimiento Activo definido por la Organización Mundial de la Salud en 2002,como la manera de mejorar la calidad de vida a medida que la persona envejece. 
Bajo este paradigma se ha tenido que estructurar una nueva forma de actuar centrándose en la persona a la que va dirigida la acción, en este caso seria los cuidadores, utilizando para ello las estrategias de «Proximidad Local» incluidas dentro del Centro de Contacto, que es la herramienta informática con la que se trabaja con la estructura anteriormente citada y que asume la importancia de incluir las nuevas tecnologías aplicadas dentro del trabajo que se realiza con los cuidadores tanto informales como formales.

De esta forma aparece el «servicio de Video-atención», para unir esfuerzos desde el campo de la tecnología y la innovación con una nueva forma de intervención en este colectivo, y que su objetivo general está orientado a proporcionar un servicio formativo de forma directa sin tener que acudir a la sede físicamente donde se realizan los talleres, capacitando a los cuidadores en las habilidades y capacidades necesarias para el cuidado. Se plantea desde la visión de un servicio activo, flexible y cercano a la realidad y a sus necesidades, teniendo en cuenta el uso de las tecnologías.

Aunque la figura del técnico es importante en este servicio, también lo va a ser el voluntario quien junto al técnico realizaran las sesiones de atención con los cuidadores que así lo hayan solicitado, pudiendo ser éstas, una o dos veces por semana, a través de una aplicación informática diseñada para ello y manteniendo una secuencia de actividades definidas y estructuradas por el técnico en función del nivel de capacitación que necesite el cuidador.

El perfil del cuidador al que se le ofrezca este servicio será el de cuidador principal, que no tenga una red de apoyo familiar o social que pueda quedarse con la persona enferma para poder acudir a los talleres que se ofrecen de forma presencial.

El equipamiento que se requiere es muy sencillo, una tablet, un videoteléfono y una conexión a internet (bien con conexión fija mediante ADSL o móvil). Cruz Roja se encarga de la provisión, configuración, instalación y mantenimiento del equipo. El objetivo es utilizar las nuevas tecnologías como herramienta facilitadora de intercomunicación entre los cuidadores, su entorno cercano y el Centro de Contacto. Además se le posibilita el poder acceder a una serie de servicios específicos dependiendo de la persona, a través de la cartera de servicios de la institución.

Las sesiones de formación serán pautadas por el técnico dependiendo de la disponibilidad del profesorado de los talleres, lo normal una vez a la se- 
mana o cada quince días, y los voluntarios, parte primordial en el servicio, además son los encargados de realizar las llamadas de seguimiento y mantener el contacto con los cuidadores a través del programa tecnológico, realizando una atención individualizada dependiendo de la situación y las capacidades de cada participante después de realizar una serie de pruebas estandarizadas, y un seguimiento pautado.

Las sesiones se realizan de manera interactiva, el cuidador desde su domicilio visualizara al formador / técnico / voluntario a través del equipo y el formador / técnico / voluntario visualizara al cuidador en la pantalla del ordenador donde se encuentre la campaña específica del servicio. Al finalizar cada sesión se realiza una valoración de seguimiento y en función de dicha valoración se configurara las siguientes sesiones por el técnico.

Otra de las aplicaciones de este sistema es que el cuidador puede ponerse en contacto con el Centro de Contacto cuando quiera y será atendido por un operador ya sea de su localidad o de ámbito provincial, autonómico o nacional. Las llamadas se atienden a través de un sistema informático que permitirá al operador disponer de la información del usuario de forma inmediata. La petición que pueda realizar el cuidador queda registrada en un sistema de mensajería interna que está conectado a cada responsable del Centro de Contacto de la localidad del usuario, de esta forma no se pierde información que será gestionada en la mayor brevedad posible.

Dependiendo de la evolución del cuidador se pueden programar agendas de seguimiento puntual o de forma periódica, que consistirán en video llamadas con un motivo concreto o bien para asesoramiento de talleres, programación de actividades o información de otros servicios. Desde un principio se establece un modus operandi para el correcto desarrollo del servicio. Los agentes participantes son; dos técnicos de Cruz Roja en Zaragoza, uno del servicio tecnológico y otro del proyecto de cuidadores, un voluntario (operador de Centro de Contacto) y el usuario/ cuidador.

El procedimiento es el siguiente, valorado el cuidador por el técnico del servicio, se procederá a la asignación del mismo al técnico de Centro de Contacto que ejecutara las órdenes de trabajo con la herramienta tecnológica para establecer el adecuado seguimiento de la actividad. Se adjudicara el servicio a un voluntario con la formación específica en el servicio y en el software. Habrá un seguimiento periódico de la actividad con introducción de los datos por el propio voluntario en el momento de realizar la sesión, planificando los 
informes mensuales, las revisiones de control y las oportunas visitas domiciliarias que hayan sido solicitadas y programadas. Si en cualquiera de las sesiones se vieran cambios significativos en el desarrollo se mandaría correo urgente al técnico del servicio para que este se pusiera en contacto con el usuario y concretar una visita domiciliaria personalizada donde se evaluaría in situ la situación activándose los protocolos pertinentes.

Otra pieza importante para que el servicio funcione sin ningún imprevisto es la creación de argumentarios que sirvan de guía a los voluntarios en el desarrollo de la sesión. De esta forma el referente de Centro de Contacto tiene la seguridad de que se sigue el mismo desarrollo en todos los procesos sin variaciones, con lo cual la forma de actuación es estándar para todos los equipo.

\subsection{Retos}

Las posibilidades que se intuyen en este servicio y los retos a los que podríamos responder son evidentes. En primer lugar, se buscaría dar respuesta especializada a las necesidades básicas del cuidado y del cuidador.

Las TIC permitirían la gestión de la información y de los recursos por parte de los profesionales de una forma más eficiente y efectiva con aplicaciones directas de intervención a través de las tecnologías creadas específicamente para su perfil.

Por otro lado los equipos interdisciplinares y en ellos los trabajadores sociales serían capaces de implementar su formación en estas nuevas tecnologías, integrando los métodos y las herramientas tradicionales con las posibilidades que despliegan las TICs u otras tecnologías, abriendo nuevas puertas de actuación.

Los beneficios son muchos permitiendo una comunicación más personal y directa con los beneficiarios para conocer su estado, centrándose en una atención individual o colectiva a través de la implementación de tecnologías adecuadas para ello. Presenta un seguimiento y evaluación continuada del usuario desde el primer momento que es intervenido hasta que termina su recorrido. Puede dar paso a crear un modelo de intervención unitario para todos al centrarse en las tecnologías.

Además, como se ha comentado anteriormente, tienen un bajo coste, las acciones no requieren de presupuestos grandiosos y da pie a una agilidad en los servicios, con la aplicación de las TIC ya existentes a nivel de información, 
comunicación. Las TIC están transformando nuestra forma de vivir y sobre todo de trabajar. Esto es un solo ejemplo de ello, un reto para la reformulación del Acción Social basado en las tecnologías disponibles.

\subsection{Bibliografía}

ANTON MORON, A. (2009). Reestructuración del estado de bienestar. Madrid, Talasa.

ARRIBA GONZÁLEZ, A. (2008). Políticas y bienes sociales: procesos de vulnerabilidad y exclusión social. Madrid, Fundación FOESSA.

BAZO, M. (1998). El cuidado familiar en las personas ancianas con enfermedades crónicas: el caso de los pacientes con enfermedad de Alzheimer. Revista Española de Geriatría y Gerontología, 33, pp.49-56.

BECK, U. (2006). La sociedad del riesgo. Barcelona, Paidós.

BRUEL I CARRERAS, A. (1999). Ciento cuarenta años de Utopía. Reflexiones acerca de los principios fundamentales de la Cruz Roja y de la Media Luna Roja. Madrid, Cruz Roja Española.

CRUZ ROJA ESPAÑOLA (2014). Memoria 2014. Mimeo.

CRUZ ROJA ZARAGOZA (2013) El Centro de Contacto en Zaragoza. Documento interno, Zaragoza, mimeo.

CRUZ ROJA ESPAÑOLA (2013) Programa Altitude Agents y su desarrollo. Documento interno, Madrid, mimeo.

CRUZ ROJA ESPAÑOLA (2013) El Servicio de Video atención y su desarrollo. Documento interno, Madrid, mimeo.

DEL PINO, E Y RUBIO, J. (2013). El Estado de Bienestar en la Encrucijada. Políticas Sociales en Perspectiva Comparada. Madrid, Tecnos.

DOOLEY, N. (2004). Improving quality of life for persons with Alzheimer's disease and their family caregivers: brief occupational therapy intervention. American Journal of Occupational Therapy, 58, pp. 561-569.

ESPING ANDERSEN, G. (2004). La politica familiar y la nueva demografía. En ICE. Consecuencias de la evolución demográfica y de la economía. Barcelona, ICE.

ESPING ANDERSEN, G. (2010). Los tres grandes retos del Estado de Bienestar. Barcelona, Ariel.

FERNANDEZ, J (2003) «Ayudando al cuidador del anciano: un programa televisivo para llegar a cada casa» en revista Intervención Psicosocial, n 12, pp. 345352.

GÓMA, R Y SUBIRATS, J. (2001). Estado de Bienestar: Nueva agenda para la innovación social. En Garde, J.A: Informe 2000: Política Social y Estado de Bienestar en España. Madrid, Fundación Hogar Empleado.

GÓMA, R Y SUBIRATS, J. (2003). Estado de Bienestar y Comunidades Autónomas. La descentralización de las políticas sociales en España. Madrid, Tecnos. 
GOODMAN, C. (1990). A model telephone information and support program for caregivers of Alzheimer's patients. Gerontologist, 30, pp.339-404.

LEY 39/2006, de 14 de Diciembre, de Promoción de la Autonomía Personal y Atención a las Personas en situación de Dependencia. BOE299 de 15 de diciembre de 2006.

MARCUELLO-SERVÓS, CH. MARCUELLO, C (2015) Cuando vuelva a salir el sol: poscrisis, participación y sociedad civil, En Fundación Encuentro (2015) Informe España, 2015. Homenaje a JMa Martín Patino, Madrid, Fundación Encuentro, pp.465-486

MEMORIA INTERNA DE CRE. (2014). Préstamo de productos técnicos y apoyo al cuidador en Zaragoza,mimeo.

MONTORIO, I. (1999). Una visión psicosocial de la dependencia. Desafiando la perspectiva tradicional. En F. J. Leturia, J. J. Yanguas y M. Leturia (Coord.), Las personas mayores y el reto de la dependencia en el siglo XXI (115-136). San Sebastián, Departamento de Servicios Sociales de la Diputación Social de Guipúzcoa.

NAVARRO, V. (2006). ¿Qué es una Politica Nacional de Salud? Intervención en la Asociación internacional de Políticas de Salud, Barcelona.

RIVERA, J. (2001). Redes familiares en el cuidado del anciano con demencia. Análisis evolutivo de un estudio poblacional. Madrid, Consejo Económico y Social de la Comunidad de Madrid.

RODRÍGUEZ CABRERO, G. (2004). El estado de bienestar e España: debates, desarrollo y retos. Madrid, Fundamentos.

ZARIT S. H. (1990). Interventions with frail elders and their families: are they effective and why? In M.A. P. Stephens, J. H. Crowther, S. E. Hobfoll y D. L. Tennenbaum (Eds.), Stress and coping in life families. Nueva York: Hemisphere. 
DESIGUALDAD 

5

RACIAL PASSING: DE ESTIGMATIZADOS A «NORMALES»

\author{
Sergio García Álvarez \\ sergiogarcia1975@gmail.com \\ Doctorando en Sociología de la Políticas Públicas y Sociales por la Universidad de \\ Zaragoza
}

\title{
5.1.Introducción
}

A las consabidas estrategias de aculturación o enculturación, o cualquier forma de estrategia de asimilación o separación por parte de un grupo minoritario respecto a la cultura dominante, donde el denominador común se explica mediante estrategias colectivas ,que en su mayoría tienden a aspirar a una igualdad de trato, encontramos una estrategia individual que, tras detectar la distancia entre sus aspiraciones y el trato recibido, tiende a organizar las acciones del sujeto para que no sea identificado como miembro de su grupo de origen.

Mi objetivo en estas páginas radica en proponer una reflexión sobre una aproximación teórica que explica y posibilita el éxito de esta estrategia individual, destinada a eludir la discriminación racial, denominada como Racial Passing, por lo que se ha realizado una revisión de la bibliografía sobre este proceso, al que se le ha sumado una posible explicación teórica goffmaniana con el objeto de, no sólo llegar a entenderlo en su contexto geográfico temporal (ya que se describe principalmente en USA entre el siglo XIX y hasta mediados del siglo XX), sino de entender procesos similares actuales en nuestro entorno.

La posibilidad de eludir la discriminación racial, gracias a estrategias individuales como el racial passing, nos permitirá asumir a su vez la existencia de una normativa social punitiva no escrita, entendida como un marco norma- 
tivo que discrimina (estigmatiza) a sujetos pertenecientes a diversos colectivos, impidiendo su acceso a los recursos en igualdad de condiciones, y cuya aplicación es comprobada día a día por profesionales como los trabajadores sociales, quienes trabajamos con dichos colectivos.

Los derechos de todas las personas se verán enteramente satisfechos si reparamos en la existencia de dicha normativa no escrita, y aceptamos la necesidad de que sea tenida en cuenta en el diseño de las políticas públicas a implementar en un mundo globalizado, que tiende a repetir procesos de estigmatización sobre los mismos colectivos, independientemente del contexto geográfico.

\subsection{Racial Passing}

\subsubsection{Definición}

Podemos proponer diferentes definiciones sobre este concepto distanciadas en el tiempo, ya que encontramos la realizada en 2001 por Randall Kennedy ${ }^{1}$, la publicada por Alida Bakker en 2003 citando a Brooke Krooger, y la de Walter White² de 1947.

Comenzando por el autor más mencionado en la bibliografía consultada, «Passing es un engaño que permite a una persona adoptar ciertos roles o identidades mediante las cuales sería excluido por las normas sociales imperantes en ausencia de su conducta engañosa $»^{3}$ (Kennedy, R. 2001), por lo que se define como una estrategia engañosa llevada a cabo por el sujeto, quien interpreta roles o identidades a los que no podría acceder según las normas sociales que prevalecen.

Alidda Bakker realizó su tesis bajo el título «Racial Passing as a Social Statement: Exposing Rules, Boundaries, and Prejudices in U.S. Society that Contribute to a Power Imbalance between Social Groups $»^{4}$, y dirigida por el

1 http://moritzlaw.osu.edu/students/groups/oslj/files/2012/03/62.3.kennedy.pdf. Visualizado en noviembre de 2016

2 http://www.unz.org/Pub/SaturdayRev-1947oct11-00013. Visualizado en noviembre de 2016.

3 Traducción propia del original «Passing is a deception that enables a person to adopt certain roles or identities from which he would be barred by prevailing social standards in the absence of his misleading conduct» (R. Kennedy,2001)

4 http://arts.studenttheses.ub.rug.nl/16496/1/MA1563793ABakker.pdf. Visualizado en noviembre de 2016. 
Dr. M.Messner ${ }^{5}$. Cita a Brooke Kroeger ${ }^{6}$, quien la define como «cuando la gente se presenta eficazmente como diferente de quien se entiende que es» (Kroeger, B, 2003:7) ${ }^{7}$, definición global sobre cualquier tipo de passing como gender passing o social passing, y que nos sitúa en una representación social aceptada como tal, asumiendo el sujeto que no representa lo que él piensa que es.

Walter White, además, numeró en el año 1947, siendo presidente de la $\mathrm{NAACP}^{8}$, en 12.000 las personas negras de piel clara que transitaban las fronteras cada año:

Muchos negros son juzgados como blancos. Cada año desaparecen aproximadamente 12.000 negros de piel blanca, personas cuya ausencia no puede explicarse por la muerte o la emigración. Casi cada uno de los 14 millones de negros discernibles en los Estados Unidos conoce al menos a un miembro de su raza que está "Passing" -la palabra mágica que significa que algunos negros pueden pasar como blancos, hombres y mujeres que han decidido que les hará ser más felices y tener más éxito si huyen de la proscripción y la humillación que la línea de color americana les impone (White, W. 1947)9 .

En esta definición, White responde al objeto de la estrategia, nombrando razones como la felicidad y el éxito de aquellos que la practican, con el objeto de transitar la línea que les separa de las personas blancas.

Las tres definiciones describen una estrategia llevada a cabo por personas que aceptan la necesidad de alterar su identidad racial, que es posible gracias a su descripción física, con el objeto de obtener beneficios relacionados con

5 Profesor titular en sociología en la Berkeley University. Más información en https:// dornsife.usc.edu/cf/faculty-and-staff/faculty.cfm?pid=1003528

$6 \mathrm{http} / /$ www.mixedracestudies.org/wordpress/?tag=brooke-kroeger. Visualizado en noviembre de 2016.

7 Traducción propia del original «It is passing when people effectively present themselves as other than who they understand themselves to be» (Kroeger, B, 2003:7)

8 http://www.naacp.org/ Visualizado en noviembre de 2016.

9 En Walter White, Why I Remain a Negro, Saturday Evening Post, Oct. 11, 1947, traducción propia del original «Many Negroes are judged as whites. Every year approximately 12,000 white-skinned Negroes disappear - people whose absence cannot be explained by death or emigration. Nearly every one of the 14 million discernible Negroes in the United States knows at least one member of his race who is "passing"- the magic word which means that some Negroes can get by as whites, men and women who have decided that they will be happier and more successful if they flee from the proscription and humiliation which the American color line imposes on them». 
sus necesidades, pues asumen una autopercepción contraria a la que muestran en sociedad, y que es aceptada por ésta.

Igualmente debemos detenernos en el trabajo de Emily $\mathrm{Nix}^{10}$ y Nancy Qian ${ }^{11}$ titulado "The Fluidity of Race: "Passing" in the United States, 1880$1940 »^{12}$. En el resumen podemos leer:

Agrupando la población completa de censos históricos entre 18801940 , documentamos que más del $19 \%$ de hombres negros «pasaron» por (hombre) blanco en algún momento de su vida, alrededor del 10\% de los cuales «volvieron» a ser negros; El «paso» fue (gracias a) la reubicación geográfica en comunidades con un porcentaje más alto de blancos, y ocurrió en la mayoría, en los estados norteños. La evidencia sugiere que el «paso» se asoció positivamente con mejores oportunidades político-económicas y sociales para los blancos con respecto a los negros. (Nix, E. Qian. N. 2015) ${ }^{13}$

En resumen, y atendiendo a los trabajos mencionados, podríamos definir racial passing como tránsito racial, y como una conducta o estrategia realizada por personas que, gracias a sus rasgos físicos, pueden simular ser de otro grupo étnico, blanco en este caso, con el objeto de llevar a cabo sus expectativas de mejora, participación o acceso a recursos, asumiendo que, no son, en realidad, lo que aparentan ser, pues «La indeterminación racial ${ }^{14}$ está en el corazón del Passing; Es la condición previa que lo hizo posible» (Hobbs. A,

$10 \mathrm{http} / /$ economics.yale.edu/sites/default/files/files/Graduate/place1516/Nix.pdf. Visualizado en noviembre de 2016.

$11 \mathrm{http} / / /$ aida.wss.yale.edu/ nq3/NANCYS_Yale_Website/styled/index.html, Visualizado en noviembre de 2016.

$12 \mathrm{http}: / /$ aida.wss.yale.edu/ nq3/NANCYS_Yale_Website/resources/papers/NixQian_20150101.pdf. Visualizado en noviembre de 2016.

13 Traducción propia del original «Using the full population of historical Censuses for 1880-1940, we document that over $19 \%$ of black males "passed" for white at some point during their lifetime, around $10 \%$ of whom later "reverse-passed" to being black; passing was accompanied by geographic relocation to communities with a higher percentage of whites and occurred the most in Northern states. The evidence suggests that passing was positively associated with better political-economic and social opportunities for whites relative to blacks».(Nix, E. Qian. N. (2015).

14 Según el Pew Reseach (http://www.pewresearch.org/) (visualizado en marzo de 2017), ya que desde el año 2000 existe la opción de elegir más de una raza en los cuestionarios de Estados Unidos, se registran hasta 63 posibilidades para identificar a los ciudadanos gracias a la combinación de alternativas. La última encuesta, realizada en 2010, reveló que nueve millones de estadounidenses utilizan más de una categoría racial para definirse. El número de personas que se identifican como birraciales o multirraciales se ha duplicado desde 1980. 
2014:8) ${ }^{15}$. Esta indeterminación se ha llamado color line, o línea de color, en cuanto a aquellos que han sido capaces de traspasarla.

\subsubsection{Enumeración de casos}

El estudio de Nix y Qian de 2015 muestra que, entre finales del SXIX, y mediados del SXX, un 19\% de los hombres negros hicieron uso de esta estrategia, pero que únicamente un $9 \%$ de éstos lo hicieron de manera irreversible, y que el cambio social, político y económico siendo «blancos» era positivo. Prosiguiendo con las estimaciones de R. Kennedy, ya que éste autor igualmente refiere la estimación de Walter White en 1947 mencionando a su vez a otros autores, encontramos:

Walter White afirmó que anualmente «aproximadamente 12,000 negros de piel blanca desaparecen» en la sociedad blanca. Roi Ottley afirmó que había cinco millones de «negros blancos» en los Estados Unidos y que entre cuarenta y cincuenta mil «pasaban» anualmente. Las estimaciones del profesor John H. Birmania fueron considerablemente más bajas. Él postuló que unos 110.000 negros vivían en el lado blanco de la línea de color, y que entre 2.500 y 2.750 «pasaban» anualmente. Dada su naturaleza reservada, nadie sabe con certeza la incidencia del «Passing».( Kennedy, R. 2001:1) ${ }^{16}$

Las estimaciones, a mediados del siglo pasado, eran sobre 12.000 las personas negras que transitaban su identidad al año a personas blancas, aunque la proliferación de parejas mixtas en cuanto a su color de piel habría facilitado el registro de muchos más casos de Racial Passing. Sin embargo, si entendemos esta estrategia dentro de la definición de R. Kennedy como un engaño, y por lo tanto sancionable, entendemos que esta práctica puede ser de no retorno, ya que la obtención de beneficios gracias a ella se verían amenazados. En todo caso, las cifras estiman entre 2.500 y 40.000 las personas negras que practicaron esta estrategia cada año. Si estimamos la población negra de USA

15 Traducción propia del original «Racial indeterminacy lies at the core of passing; it is the precondition that made passing posible»(Hobbs. A, 2014:8)

16 Traducción propia del original «Walter White claimed that annually "approximately12,000 white-skinned Negroes disappear" into white society.Roi Ottley asserted that there were five million "whiteNegroes" in the United States and that forty to fifty thousand passed annually. Professor John H. Burma's estimates wereconsiderably lower. He posited that some 110,000 blacks lived on the white side of the color line and that between 2,500 and 2,750 passed annually.Given its secretive nature, no one knows for sure the incidence of passing.»(Kennedy, R. 2001:1 
en $1950^{17}$ en unos $10 \mathrm{M}$, equivaldrían a entre un $0,025 \%$ y un $0,4 \%$ de la población de personas negras que cada año practicaban esta estrategia. Un 9\% correspondería a 900.000 estrategas de no retorno. Si este periodo de tiempo lo calculamos como 50 años, serían 18.000 personas los que lo realizarían anualmente.

\subsubsection{Temporalidad de la estrategia. Historias personales}

Las estrategias comunes a aquellos que lo han practicado evidencian que el tránsito no tiene por qué ser permanente. Durante el periodo en el que estuvieron vigentes las leyes Jim Crow, « Muchos "Passers” afroamericanos sólo «pasaron» como blancos durante el día para tener mejores perspectivas de empleo. Otros sólo pasarían de vez en cuando, digamos por una noche, para acceder a un restaurante o un hotel «blanco», que se puede llamar "Passers casuales"». (Bakker, A. 2015, 7)

Encontramos lo que Bakker denomina «Casual Passing», entendido como una estrategia de oportunidad ante distintas situaciones cotidianas, que pueden ser mantenidas en el ámbito laboral o académico y de manera reversible. Este es el caso de «Harry S. Murphy, quien tenía la tez blanca y el pelo castaño ondulado, que dijo que "realmente no veía por qué todo el alboroto" cuando pasó como blanco durante su primer año en la Universidad de Mississippi entre 1945 y 1946» (Hobbs, A.2014:11) ${ }^{19}$

«Las fuentes sobre el passing son abundantes, pero a menudo se encuentran en lugares improbables»(Hobbs.A, 2014: 7) ${ }^{20}$. La más repetida en la literatura consultada menciona a Ellen Craft $^{21}$, quien también se hizo pasar por hombre, y su esposo William. Igualmente se menciona a Walter White ${ }^{22}$,

17 https://www.census.gov/newsroom/cspan/1940census/CSPAN_1940slides.pdf

18 Traducción propia del original «(...) many African American passers only passed as White during day in order to have better job prospects". Others would only pass occasionally, say for an evening, to access to a white restaurant or hotel, which may be called casual passing». (Bakker, A. 2015, 7).

19 Traducción propia del original «Harry S. Murphy, who had white complexion and wavy brown hair, said that he "really did not see what all the fuss about" when he passed as white during his freshman year at the University of Mississippi in 1945 and 1946» (Hobbs, A. 2014:11)

20 Traducción propia del original «Sources on passing are abundant, but often found in unlikely places» (Hobbs.A, 2014:7)

$21 \mathrm{http} / / /$ biography.yourdictionary.com/ellen-craft. Visualizado en noviembre de 2016,

$22 \mathrm{http} / /$ www.biography.com/people/walter-white-9529708. Visualizado en noviembre de 2016. 
activista de derechos sociales y presidente de la NAACP entre 1931 y 1954 , cuyo físico permitió a su familia sentarse en la zona para blancos de los autobuses $^{23}$. A estos casos igualmente se le ha sumado los de descendientes de parejas formadas por esclava y «señor», siempre y cuando la piel de sus hijos e hijas fuera lo suficientemente clara como para pasar por blancos. También está constatado un caso que llegó a los tribunales:

El caso más sensacional surgido de un supuesto intento de passing fue la demanda que enfrentó a Alice Jones contra Leonard Kip Rhinelander. Jones era la hija de una madre blanca y un padre negro, una pareja modesta de clase media. Los Rhinelanders, por el contrario, se codeaban en los círculos más altos de la sociedad rica de Nueva York. Kip era el heredero de los millones de sus padres. Cuando supieron que su hijo se había casado con una camarera «de color», insistieron en que pusiera fin a la relación. (...) el 27 de noviembre de 1924, alegando que Alice le había engañado acerca de su raza. Al principio (él) alegó que le había engañado diciendo falsamente que ella era blanca. Más tarde, él alegó que ella lo había engañado no por falsedad absoluta pero, más sutilmente, callando pero sabiendo y aprovechando su creencia errónea que ella era blanca. (Kennedy, R. 2001:4) ${ }^{24}$.

Las consecuencias de esta práctica también se han visto refleja das en la literatura. Kennedy cita a Joel Williamson ${ }^{25}$, profesor emérito de la North Carolina University, quien relata en «New People: Miscegenation and Mulattoes in the United States» ${ }^{26}$ que «los blancos del sur a principios del siglo XX se volvieron paranoicos ante los negros "invisibles"»(Kennedy.R, 2001: 6) ${ }^{27}$.

23 Junto al acceso a restaurantes, o a aseos públicos, las zonas de asiento de las personas negras fueron reguladas por las Leyes Jim Crow.

24 Traducción propia del texto original «The most sensational case arising from an alleged effort to pass was the lawsuit that pitted Alice Jones against Leonard Kip Rhinelander. Jones was the daughter of a white mother and a black father, a couple of modest means. The Rhinelanders, by contrast, traveled in the highest circles of white, wealthy New York Society; Kip stood to inherit millions from his parents' estate. When they learned that their son had married a colored waitress, they insisted that he put an end to the relationship (...) sought an annulment on November 27, 1924, claiming that Alice had deceived him about her race. Initially he alleged that she had tricked him by stating falsely that she was white .Later he alleged that she had tricked him not by outright falsehood but, more subtly, by silently but knowingly taking advantage of his mistaken belief that she was white».( Kennedy, R. 2001:4).

$25 \mathrm{http} / /$ history.unc.edu/people/emeriti-faculty/joel-williamson/. Visualizado en diciembre 2016.

26 Williamson, J. «New People: Miscegenation and Mulattoes in the United States (The Free Press, 1980)

27 Traducción propia del original «Southern whites in early twentieth century became paranoid about invisible blackness» (Kennedy.R , 2001:6). 
Igualmente se relatan acciones de grupos de presión de personas blancas, que ya actuaban en el primer cuarto del siglo pasado, incidiendo en las legislaciones, como podemos leer en el resumen de la Tesis de Jhon Cofer Landon:

El 20 de marzo de 1924, la Asamblea General de Virginia promulgó la legislación más completa de la nación para asegurar la integridad racial. Detrás de la intención política de la ley, estaba el trabajo de una organización de supremacía blanca llamada el «Club de los Anglo-Sajones de América». Los líderes de este club se veían como portavoces de una generación consciente de que, acerca la raza, se percibía la inferioridad del negro estadounidense en términos biológicos más que sociales. Obsesionados con la idea de mantener la pureza racial blanca, creían que la mayor amenaza a la que se enfrentaba América era la degeneración moral, intelectual y física de sus ciudadanos a través del cruce de razas blancas y no blancas. La Ley de Integridad Racial, que prohíbe el matrimonio entre blancos y no blancos en Virginia, fue el primer paso en su plan para prevenir la mongrelización de la sociedad americana. (Landon, J. 1978) ${ }^{28}$.

La prohibición, dentro del estado de Virginia, del matrimonio entre parejas de blancos y negros, o la «Mongrelization» o mezcla entre personas negras con blancas, era defendida por grupos de presión como los «Anglo-Saxon Clubs of America» en los años 20 del siglo pasado, tal y como podemos leer en el texto de Landon.

Tenemos que resaltar que, en 1875 , el caso Dred Scott vs. Sandford ${ }^{29}$ dictaminó que los descendientes de personas africanas libres o esclavos no eran ciudadanos y no ostentaban los privilegios recogidos en la constitución, como poder presentar una demanda ante un juez. Los mulatos producto del «señor

28 Traducción propia del original «On March 20, 1924 the Virginia General Assembly enacted the nation's most comprehensive legislation to insure racial integrity. Behind the bill's political passage lay the work of a white-supremacist organization called the Anglo-Saxon Clubs of America. The leaders of these clubs saw themselves as spokesmen for a raceconscious generation that perceived the American Negro's inferiority in biological rather than social terms. Obsessed with the idea of maintaining white racial purity, they believed that the greatest threat facing America was the moral, intellectual, and physical degeneration of its citizens through the interbreeding of white and non-white races. The Racial Integrity Law, which forbade the intermarriage of whites and non-whites in Virginia, was the first step in their plan to prevent the mongrelization of American society». (Landon, J. 1978). Visualizado en https:// libra2.lib.virginia.edu/public_view/m326m183 en diciembre de 2016

$29 \mathrm{https} / /$ supreme.justia.com/cases/federal/us/60/393/. Visualizado en noviembre de 2016. 
blanco» y la mujer negra (esclava) permitió emplear la llamada hypodescent ${ }^{30}$, mediante la que se asignaba el estatus racial reconocido como inferior al descendiente.

Ahondando en la clasificación que se generó acerca de la «línea de color», Charles Chesnut, en 1889, en un artículo titulado «What Is a White Man?» ${ }^{31}$, desgrana la diversidad de situaciones que estipulaban la «raza» de las personas del sur de USA, situando en un octavo la ascendencia negra para que el sujeto se calificara como mulato o con otra acepción:

Las personas de color se dividieron, en la mayoría de los Estados del Sur, en dos clases, designadas por la ley como negros y mulatos, respectivamente. El término negro se usaba en su sentido etnológico, y no necesitaba definición; Pero el término «mulato» fue sostenido por la promulgación legislativa para agrupar a todas las personas de color no negras. Las palabras cuarterón y mestizo se emplean en algunos de los libros de leyes, aunque no se definen; Pero el término octoroon, como indicando una persona que tiene un octavo de sangre negra, no se usa en absoluto, hasta donde el escritor ha podido observar. (Chesnutt, Charles W. (1889) ${ }^{32}$.

\subsubsection{En la actualidad}

Aunque «A principios de los 1940 y en los 1960, los testimonios personales comenzaron a declarar que las pérdidas eran simplemente demasiadas para soportarlas; Había llegado el momento de renunciar y "volver a casa"»

30 https://www.ncbi.nlm.nih.gov/pubmed/21090902. Visualizada en noviembre de 2016.

31 Chesnutt, Charles W. (1889) «What Is a White Man?» The Independent, 41, 30 May: 5-6. Visualizado en http://www.chesnuttarchive.org/works/Essays/whiteman.html en noviembre de 2016.

32 Traducción propia del original «The colored people were divided, in most of the Southern States, into two classes, designated by law as Negroes and mulattoes respectively. The term Negro was used in its ethnological sense, and needed no definition; but the term "mulatto" was held by legislative enactment to embrace all persons of color not Negroes. The words "quadroon" and "mestizo" are employed in some of the law books, tho not defined; but the term "octoroon," as indicating a person having one-eighth of Negro blood, is not used at all, so far as the writer has been able to observe» (Chesnutt, Charles W. (1889) «What Is a White Man?» The Independent, 41. 30 May: 5-6). 
(Hobbs, A. 2014: 6) 33 , en la actualidad, y tal y como relata R.Kennedy, en referencia a un artículo de Jay Mathews en el Washington Post, se ha constatado un caso de Racial Passing inverso al habitual, como el de Mark L. Stebbings ${ }^{34}$, candidato en 1985 al distrito de Stockton (California), mayoritariamente de personas negras e hispanas, que se presentaba como negro teniendo padres blancos. A su primera mujer blanca le siguieron dos mujeres negras, y la última le introdujo en la NAACP. Gracias a su nariz ancha, su pelo rizado y su activismo social, tomó conciencia de que era negro ${ }^{35}$, ya que «Preguntado en el fin campaña cómo podía identificarse como negro cuando sus padres fueron oficialmente clasificados como blancos, Stebbins respondió que era negro porque se sentía negro. Preguntado acerca de la identidad racial de Stebbins, un amigo negro comentó que Stebbins es "lo que dice que es" ». (Kennedy, R, $2001)^{36}$

Igualmente R. Kennedy menciona el caso, en 1989, de los hermanos Malone, quienes optaron a una plaza de bomberos en Boston. Tras lograr la plaza, y optar uno de ellos a un ascenso posterior, se llegó a juicio al comprobarse que en la primera auto descripción se denominaron como personas blancas. Al cambiar a personas negras en su intención a ascender, la sentencia dictaminó que una persona era negra: «1) mediante la observación visual de sus características; (2) por pruebas documentales apropiadas, tales como certificados de nacimiento, estableciendo de ascendencia negra; o (3) por pruebas de que ellos o sus familias se consideran negros y se consideran negros en la comunidad $»^{37}$

33 Traducción propia del original «As early in the 1940's and through the 1960's, personal testimonies began to declare that the losses were simply too much to bear; it was time to give up and "come home"» (Hobbs. A. 2014:6)

$34 \mathrm{http} / /$ www.smartvoter.org/2010/06/08/ca/state/vote/stebbins_m/. Visualizado en diciembre de 2016.

$35 \mathrm{https}$ //www.washingtonpost.com/archive/politics/1984/05/06/hue-andcry/47807b05-892c-416e-82ad-acbaa7cb6016/. Visualizado en noviembre de 2016.

36 Traducción propia del original «"Asked in the midst of the recall campaign how he could identify himself as black when his parents were officially classified as white, Stebbins replied that he must be black because he felt black. Questioned about Stebbins's racial identity, a black friend remarked that Stebbins is "whatever he says his is." »(Kennedy. R, 2001)

37 Malone v. Haley, No. 88-339 (Mass. Sup. Jud. Ct. July 25, 1989). Traducción propia del original« "(1) by visual observation of their features; (2) by appropriate documentary evidence, such as birth certificates, establishing black ancestry; or (3) by evidence that they or their families hold themselves out to be Black and are considered to be Black in the community.» Visible en https:/georgetownlawjournal.org/articles/107/racial-commodification-promise-of/ pdf . (visualizado en noviembre de 2016) 
La sentencia dictaminó sobre la observación en cuanto a las características de la persona, que demostraba que una persona era negra, lo cual justificaría igualmente que no lo fuera, ante ausencia, y tal y como se aprecia en la segunda cuestión, de documentación que lo acreditara en cuanto a ascendencia genealógica basada en la partida de nacimiento.

La tercera cuestión que plantea la sentencia argumenta tanto la consideración de la comunidad (término propio del mundo anglosajón), como la traducción del hold themselves out, que nos sitúa en «sostener a ellos mismos hacia fuera», como idea propia del racial passing.

Esta sentencia resulta de especial relevancia si tenemos en cuenta que, en nuestro entorno, no sería posible que preguntaran por la etnia en un cuestionario para optar a un trabajo ${ }^{38}$. En USA aún prosigue siendo una pregunta que genera recelos, pero que no es ilegal, ya que «Los requisitos que un solicitante proporciona en la solicitud se han sostenido para ayudar a apoyar una demanda de discriminación racial cuando se demostró que un empleador nunca contrató a un solicitante de la minoría, (dado que) la teoría es que la imagen era necesaria para que un empleador recordara que los solicitantes fueran miembros de grupos minoritarios» ${ }^{39}$

La literatura al respecto no puede acreditar sentencias que declaren ilegal preguntar en USA por la pertenecía étnica, ya que, tal y como dice la «teoría», de este modo, el empleador puede recordar qué candidatos pertenecen a grupos minoritarios. Ahondado en esta cuestión, encontramos en las conclusiones de un artículo de Camille Gear Rich ${ }^{40}$ de 2013 sobre este caso, y el impacto de la necesidad de declarar la raza en los empleos.

Este ensayo demuestra que, argumentando (...) sobre la «raza electiva», los empleadores, los políticos y los jueces pueden acercarse a los programas de acción afirmativa, (...) pero también a los objetivos funcionalistas de los

38 La L.O. 15/1999, de 13 de diciembre, de Protección de Datos de Carácter Personal no lo permite.

39 http://employment-law.freeadvice.com/employment-law/hiring/job_interview_questions.htm. Visualizado en noviembre de 2016. Traducción propia del original «"The requirements that an applicant furnish a picture has been held to help support a claim for race discrimination when it was demonstrated that an employer never hired a minority applicant, the theory being that the picture was required so that an employer would remember which applicants were members of minority groups"»

40 Associate Professor of Law, University of Southern California, Gould School of Law. 
Programas de diversidad. El enfoque funcionalista esbozado aquí permite a los empleadores un rango de discreción para hacer preguntas sobre (...) descripción racial, pero sigue siendo lo suficientemente dinámica como para explicar las múltiples formas en que se vive y experimenta la raza. El análisis promete permitir a los empleadores discutir la raza en formas que tienden a desestabilizar construcciones raciales e, igualmente importante, administrar responsablemente programas de acción afirmativa en la era de la raza electiva. ${ }^{41}$.(Gear.C. 2014)

La era de la raza electiva supondría el comienzo, en realidad, de la aceptación del Racial Passing. Camille Gear $\mathrm{Rich}^{42}$, menciona el caso de Eric Longmire $^{43}$ para contextualizar la posibilidad de la elección de raza, que se encuentra en la actualidad dentro de la posibilidad de elección de género u otras posibles elecciones:

El modelo de la raza electiva trata la identificación racial como más parecido a las elecciones que los individuos hacen con respecto a la orientación sexual, que es más ampliamente reconocida como un patrón de identificación que varía para un individuo dependiendo del contexto, período de vida e incluso oportunidades de vida. Alternativamente, puede compararse con las elecciones que los individuos hacen con respecto a la identificación religiosa, lo que también puede variar en función de las circunstancias de la vida, la forma en que se hace una pregunta, las prácticas sociales actuales o la posición de clase (Gear.C. $2014)^{44}$

Quizá en un futuro. Actualmente, la era de la raza electiva, y otras cuestiones como indica esta autora, parecen no propias del presente.

41 Gear. C(2013). Affirmative Action in the Era of Elective Race: Racial Commodification and the Promise of the New Functionalism. Visualizado en http://georgetownlawjournal. org/files/2013/11/Rich.pdf en noviembre de 2016.

$42 \mathrm{http} / /$ georgetownlawjournal.org/files/2014/06/Rich-Elective.pdf. Visualizado en noviembre de 2016.

43 Más información en https://www.law.duke.edu/clrp/conference/pw/papers/Elective_Race.pdf. Visualizado en diciembre de 2016.

44 Traducción propia del original «the model of elective race treats racial identification as being more akin to the choices individuals make with regard to sexual orientation, which is more widely recognized to be an identification pattern that varies for an individual depending on context, life period, and even life chances. Alternatively, it might be compared to the choices individuals make with regard to religious identification, which similarly may vary based on life circumstances, the manner in which a question is asked, one's current social practices, or class position»( Gear.C. 2014) 


\subsection{Aproximación teórica}

Hoy pueden leerse, en la totalidad de los medios escritos de comunicación, noticias referidas a movilizaciones sociales en USA de personas negras o latinas como reacción a la victoria de D. Trump. La bipolarización política, acrecentada por la proliferación de líneas ideológicas nacidas el amparo de la desigualdad socioeconómica, parece propiciar un peor escenario para las personas con la piel más negra. El Rope Center ${ }^{45}$ hace posible observar la intención de voto y las encuestas realizadas tras las elecciones celebradas en aquel país, que describe el voto tanto en hombres blancos, como en mujeres, o entre personas negras o latinas. Según esta empresa impulsada por la Universidad de Cornell, estos dos últimos colectivos han votado en los últimos ocho lustros al partido demócrata. Igualmente, las mujeres en general votaron al partido demócrata en las elecciones desde 1996, pero con un máximo del $56 \%$ a Obama en 2008. Los hombres blancos, por el contrario, desde 1976 siempre han votado en su mayoría al partido republicano. Estas cifras hacen intuir la tendencia de voto y los posibles resultados electorales, teniendo en cuenta que, aproximadamente, el $80 \%$ de la población estadounidense es de piel blanca. .

No fue hasta mediados del SXX cuando fueron derogadas las Jim Crow Laws $^{46}$ : el tránsito racial o racial passing ha supuesto una necesidad destinada a presentarse en sociedad en contra de lo que el sujeto asumía como autopercepción, y como respuesta a la discriminación sufrida. En esta línea, «La jurista Cheryl Harris ha argumentado que la "blancura" es una forma de propiedad, un privilegio que asignó injustamente recursos económicos, políticos, sociales e institucionales a lo largo de la línea del color $\gg($ Hobbs, A. 2014: $12)^{47}$ lo que plantea diferentes campos de estudio, que van desde el acceso a los recursos, los derechos y el marco normativo de los sujetos, o las relaciones sociales e institucionales.

Esta asignación injusta se explica partiendo de la idea de que «Alguien serio (que quiera) comprender la sociedad estadounidense debe abordar los

$45 \mathrm{http} / / /$ ropercenter.cornell.edu/ (visualizado en noviembre de 2016)

46 http://www.crf-usa.org/black-history-month/a-brief-history-of-jim-crow. Visualizado en noviembre de 2016.

47 Traducción propia del original «Legal scholar Cheryl Harris has argued that whiteness is a form of property, a privilege that unfairly allocated economic, political, social, and institutional resources along the color line» (Hobbs, A. 2014:12), 
problemas de la raza y la división racial» (Bobo, L.D. et al., 2012: 38) 48 $^{4}$ Los prejuicios suponen el punto de partida de esta división, y la desigualdad de oportunidades el marco para comprender una estrategia que posibilita al actor disipar la discriminación sufrida, y promover sus opciones de mejora.

Para Gordon Allport prejuicio es una «Actitud aversiva u hostil hacia una persona que pertenece a un grupo, simplemente porque pertenece a ese grupo $\mathrm{y}$, por lo tanto, se presume que tiene las cualidades atribuidas al grupo ${ }^{49}$ (Allport, 1958 (1954):11). Siendo esta definición de las primeras, e igualmente aceptada en la actualidad, se advierte que no se puede comprender el Racial Passing sin poner el juego una actitud resultante de la existencia de personas identificadas como pertenecientes a un grupo, y a las que se les otorga una cualidad negativa, o estigma, únicamente por pertenecer a dicho grupo.

Erwing Goffman definió estigma ${ }^{50}$, asignado a un «individuo inhabilitado para una plena aceptación social» (Goffman. E, 1963:7). Para este autor «La sociedad establece los medios para categorizar a las personas y el complemento de atributos que se perciben como corrientes y naturales en los miembros de cada una de esas categorías» (Goffman. E, 1963:11), por lo que los estigmas, -comunes a un colectivo-, se describen dentro de su identidad social como «un atributo que lo vuelve diferente de los demás (...) y lo convierte en alguien menos apetecible» (Goffman. E, 1963: 12).

Cabe destacar, sin embargo, que la metodología empleada por Goffman en sus investigaciones ha creado controversia en tanto en cuanto ha otorgado al paciente o sujeto de estudio un lugar preponderante. Igualmente, cabe de-

48 Traducción propia del original «Anyone serious about understanding American society must some early point engage the problem of the race and racial division» (Bobo, L.D. el al. 2012:38) en Bobo, Lawrence D. 2012. «The Real Record on Racial Attitudes». Pp. 38-83 in Social Trends in American Life Findings from the General Social Survey since 1972. Princeton, NJ: Princeton University Press.

49 Traducción propia del original «aversive or hostile attitude toward a person who belongs to a group, simply because he belongs to that group, and is therefore presumed to have the objectionable qualities ascribed to the group» (Allport, 1958 (1954):11) Disponible en http://faculty.washington.edu/caporaso/courses/203/readings/allport_Nature_of_prejudice.pdf. Visualizado en febrero de 2017.

50 En la inmensa mayoría de la bibliografía consultada se establecen unos antecedentes históricos que mencionan el estigma como propio del mundo de la antigua Grecia. De hecho, «Los griegos, que aparentemente sabían mucho de medios visuales, crearon el término estigma para referirse a signos corporales con los cuales se intentaba exhibir algo malo y poco habitual en el status de quien los presentaba» (Goffman. E, 1963:11) 
stacar que sus estudios se han centrado en sujetos pertenecientes a instituciones de salud mental en los años 50 y 60 del siglo pasado, lugares que nada tienen en común con los de hoy en día.

La publicaciónes en 1961 de «Asylums», y en 1963 de «Stigma; notes on the management of spoiled identity», se encuentran demasiado cercanas en el tiempo como para no comprender que la estigmatización que Goffman propone sobre determinados sujetos ha sido estudiada, en su gran mayoría, sobre pacientes de salud mental, quienes sufren las consecuencias psicológicas de la estigmatización social y, en consecuencia, la desviación propia de la no normalización. Esta posible «victimización» del sujeto, objeto de estudio, ha supuesto, sin duda alguna, el centro de las críticas a Goffman, ya que ha eludido focalizar en cuestiones sociales estructurales al centrarse en la denominada micro-sociología.

Esta idea nos hace preguntar sobre los estrategas, ya que para comprenderla, el «problema fundamental relativo a estos grupos es su lugar en la estructura social: las eventualidades que enfrentan estas personas en la interacción cara a cara son solo una parte del problema, y no pueden comprenderse sin una referencia a la historia, el desarrollo político y a las estrategias habituales del grupo» (Goffman, E. 1963:148), cuestión que menciona la necesidad de tener en cuenta cuestiones socio-estructurales, pero en las que no ahonda Goffman. Sin embargo, sí que propone una división entre estigmatizados y lo que denomina «normales», lo que supone una evidente división estructural:

un individuo que podía haber sido fácilmente aceptado en un intercambio social corriente posee un rasgo que puede imponerse por la fuerza a nuestra acción, y que nos lleva a alejarnos de él cuando lo encontramos, anulando el llamado que nos hacen sus restantes atributos. Posee un estigma, una indeseable diferencia que no habíamos previsto. Daré el nombre de normales a todos aquellos que no se apartan negativamente de las expectativas particulares que están en discusión (Goffman. E, 1963: 15)

En este contexto teórico, este trabajo aborda una estrategia individual conocida como Racial Passing en USA desde el SXIX, en personas cuyo fenotipo les permitía «hacerse pasar por blancos», con el objeto de superar la discriminación resultante de su identidad racial, y acceder a diferentes necesidades y recursos. Puede ser descrita, en la actualidad, en personas pertenecientes a 
colectivos que sufren el prejuicio y la discriminación, pero que son capaces de encubrir su procedencia identitaria. La desigualdad de oportunidades resulta ser el marco para comprender una estrategia que posibilita al actor disipar la discriminación sufrida, y promover sus opciones de mejora. La discriminación se muestra como un comportamiento, el prejuicio como una actitud, y la ignorancia como a un problema de conocimiento: discriminación, prejuicio e ignorancia conforman la conceptualización de los tres problemas principales

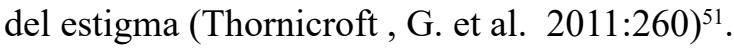

El Racial Passing será efectivo siempre y cuando el estigma pueda ser ocultado, impidiendo mecanismos relacionados con la discriminación sufrida por el grupo, por lo que dicho término «será utilizado, pues, para hacer referencia a un atributo profundamente desacreditador; pero lo que en realidad se necesita es un lenguaje de relaciones, no de atributos» (Goffman, E. 1963:13). El lenguaje de relaciones, ante la ignorancia, el prejuicio y la discriminación, responde a cómo afrontar el estigma cuando no puede ser ocultado, teniendo en cuenta que Goffman describe tres tipos de estigmas, clasificados en las deformaciones físicas, los defectos del carácter del individuo, y «los estigmas tribales de la raza, la nación y la religión, susceptibles de ser transmitidos por herencia o contaminar por igual a todos los miembros de una familia» (Goffman. E, 1963:14). Racial Passing es una estrategia de encubrimiento realizada por quien, si no la llevara a cabo, no sería capaz de acceder a diversos recursos, y ante la posibilidad de desprenderse de una atribución que le resulta negativa, o que le impide responder a una necesidad, organiza sus acciones provocando una divergencia entre su origen racial y su proyección social. Estrategia que conlleva sus riesgos, ya que «Dado que el mundo espacial del individuo se divide en regiones diferentes, de acuerdo con las contingencias contenidas en ellas, para el manejo de la identidad social y la personal consideramos algunos de los problemas y consecuencias del encubrimiento. (...). Aquel que se encubre tiene necesidades no previstas que le obligan a suministrar una información que lo desacredita (Goffman. E, 1963:102)».

51 Thornicroft, G., Szmukler, G., and K. T. Mueser (Eds.), 2011. Oxford textbook of community mental health. Oxford University Press, USA. Igualmente se puede observar en https://www.researchgate.net/profile/Diana_Rose2/publication/6476355_Stigma_Ignorance_prejudice_or_discrimination/ links/00b7d53738fc3d60d8000000/Stigma-Ignorance-prejudice-or-discrimination.pdf (visualizado en febrero de 2017) en una publicación de 2007 en el British Journal of Psyquiaty, publicado por Grahan Thornicroft el al. 
Desarrollando esta idea central, para Link \& Phelan $(2001)^{52}$, quienes realizan un trabajo que recoge las referencias bibliográficas comunes a las secuelas del trabajo de Goffman ${ }^{53}$, el etiquetaje distingue a las personas, las cuales son asociadas a características indeseadas -estereotipos-, y agrupadas como «ellos» frente al grupo dominante, otorgando a las personas etiquetadas una pérdida de estado y discriminación que les conducen a resultados desiguales. Estos resultados dependen del acceso al poder social, económico y político que permita identificar la desigualdad, la construcción de estereotipos, la separación de las personas etiquetadas en categorías distintas y la plena ejecución de la desaprobación, rechazo, exclusión y discriminación. El individuo que pasivamente sufre un atributo negativo a causa de su pertenencia a un grupo, puede, de manera activa, y si sus rasgos físicos se lo permiten, pasar de estigmatizado a «normal»:

existe el estigma cuando convergen los siguientes componentes interrelacionados.1) Las personas distinguen y etiquetan las diferencias humanas. 2) Las creencias culturales dominantes vinculan a las personas etiquetadas a características indeseables, a estereotipos negativos. 3) Las personas etiquetadas se colocan en categorías distintas para lograr cierto grado de separación entre «nosotros»y «ellos». 4) Las personas marcadas experimentan pérdida de estado y discriminación que conducen a resultados desiguales. 5) La estigmatización depende enteramente del acceso al poder social, económico y político que permita identificar la diferencia, la construcción de estereotipos, la separación de las personas etiquetadas en categorías distintas y la plena ejecución de la desaprobación, rechazo, exclusión y discriminación. (Link \& Phelan.2001: 367)

52 Visualizado en febrero de 2013 en https://campus.fsu.edu/bbcswebdav/institution/academic/ social_sciences/sociology/Reading\%20Lists/Mental\%20Health\%20Readings/Link-AnnualReview-2001. pdf.

53 En Crocker et al. (1998), Stafford \& Scott. (1986), y Jones et al (1984) se pueden leer diversos argumentos en la misma línea. Link y Phelan resumen todos ellos en su trabajo de 2001.

54 Traducción propia del original «(...) "stigma exists when the following interrelated components converge. In the first component, people distinguish and label human differences. In the second, dominant cultural beliefs link labeled persons to undesirable characteristics - to negative stereotypes. In the third, labeled persons are placed in distinct categories so as to accomplish some degree of separation of "us" from "them." In the fourth, labeled persons experience status loss and discrimination that lead to unequal outcomes. Finally, stigmatization is entirely contingent on access to social, economic, and political power that allows the identification of differentness, the construction of stereotypes, the separation of labeled persons into distinct categories, and the full execution of disapproval, rejection, exclusion, and discrimination» (Link \& Phelan (2001:367). 


\subsection{Conclusiones}

Son consabidas las diversas estrategias colectivas de aculturación o enculturación, o asimilación o separación por parte del grupo minoritario respecto al grupo dominante, donde aquel tiende a aspirar a una igualdad de trato. Pero también podemos describir una estrategia individual, destinada a organizar las acciones del sujeto, para que no sea identificado como perteneciente a un grupo que constata que no se cumple esta aspiración.

Racial Passing es una estrategia individual llevada a cabo por personas que aceptan la necesidad de ocultar su identidad racial, pues asumen una autopercepción contraria a la que muestran en sociedad, y que es aceptada por ésta, ya que la identidad social de los que «pasan» se describe mediante atribuciones comunes a su grupo de pertenencia, entrando en juego la discriminación, el prejuicio y la ignorancia hacia éstos por parte de un grupo mayoritario. Se describen en consecuencia sujetos estigmatizados frente a «normales», por lo que el objeto de la estrategia se basa en la posibilidad de cambio de un lado a otro, lo que supone obtener beneficios relacionados con su necesidad de participación y acceso a los recursos.

Dicha estrategia ha sido llevada a cabo por biracials o personas cuya descripción física les ha permitido hacerse pasar por «blancos», en un contexto donde éstos han tenido un contexto legislativo, social, o económico favorable en comparación con aquellos que no lo eran. Estos tres campos de las ciencias sociales vienen a ser determinantes en posteriores análisis, pues sus pretensiones, centradas en la obtención y acceso a recursos, han otorgado beneficios en función de los impedimentos legales y sociales que tenía no ser persona blanca.

Los impedimentos sociales actuales pueden ser descritos como un conjunto de normas sociales punitivas no escritas, que suponen el cuerpo normativo del estigma, que impide la participación en igualdad de condiciones de todas las personas.

Las personas que han llevado esta estrategia a cabo han podido hacerlo tanto temporal como definitivamente, si bien su temporalidad ha dependido del ámbito de la estrategia, pues la obtención de recursos ha supuesto en su mayoría un incremento de ingresos gracias al ámbito laboral. En consecuencia, su reversibilidad ha dependido de la sanción social esperada. 
En el contexto actual, y en nuestro entorno, merecería focalizar en futuros trabajos hacia las personas que pueden sufrir prejuicios y discriminación, puesto que igualmente son candidatos a llevar a cabo el Racial Passing, entendida como una estrategia aplicable a la definición dada, y con idéntico objeto.

\subsection{Bibliografía}

ALLPORT, Gordon W. 1954. The Nature of Prejudice. Garden City, NJ: Double-day. BOBO, Lawrence D. 2012.«The Real Record on Racial Attitudes». Pp. 38-83 in Social Trends in American Life: Findings from the General Social Survey since 1972. Princeton, NJ: Princeton University Press.

BOBO, Lawrence. 2000. «Reclaiming a Du Boisian Perspective on Racial Attitudes.» Annals of the American Academy of Political and Social Science 568: $186-202$

BOBO, Lawrence. 1997. The Color Line, the Dilemma and the Dream: Racial Attitudes and Relations at the Close of the Twentieth Century. In Civil Rights and Social Wrongs: Black- White Relations Since World War II, ed. J. Higham. University Park: Penn-sylvania State University Press.

CROCKER J, MAJOR B, STEELE C. 1998. Social stigma. In The Handbook of Social Psychology, ed. DT Gilbert, ST Fiske, 2:504-53. Boston, MA: McGraw-Hill

CHESNUTT, Ch. W. (1889)«What Is a White Man?» The Independent, 41. 30 May: 5-6.

DU BOIS, W.E.B. [1899] 1996. The Philadelphia Negro: A Social Study. Philadelphia: University of Pennsylvania Press

GAVIRIA, E., GARCÍA-AEL, C., \& MOLERO ALONSO, F. (2012). Investigación-acción :Aportaciones de la investigación a la reducción del estigma. Madrid: Sanz y Torres.

GEAR. C (2013). «Affirmative Action in the Era of Elective Race: Racial Commodification and the Promise of the New Functionalism» Georgetown Law Journal.

GEAR. C. (2014). «Elective Race: Recognizing Race Discrimination in the Era of Racial Self-Identification» The Georgetown Law Journal. Vol 102.

GOFFMAN, E. 1963. «Estigma. La identidad deteriorada». Buenos Aires: Amorrortu Ediciones.

GOFFMAN, E. (2009; 1981). La presentación de la persona en la vida cotidiana (2a ed.). Buenos Aires: Amorrortu.

GOFFMAN, E., \& Centro de Investigaciones Sociológicas. (2006). Frame analysis : Los marcos de la experiencia. Madrid: Centro de Investigaciones Sociológicas.

HOBBS.A (2016). «A Chosen Exile: a history of racial passing in american life". Harvard University Press.

JONES E, FARINA A, HASTORF A, MARKUS H, MILLERDT, SCOTT R. 1984. Social Stigma: The Psychology of Marked Relationships. New York: Freeman 
KENNEDY. R. (2001). «Racial Passing». Ohio State Law Journal. Vol. 62: 1145

KROEGER, B.(2003) «When People Can’t be Who They Are».New York: Public Affairs.

LANDON, J.(1978). «The plea for racial integrity: a history of the Anglo-Saxon Clubs of America.»

LANGSTON HUGHES (1950)«Fooling Our White Folks,» Negro Digest

LINK BG, PHELAN JC. 2001. Conceptualizing stigma. Annual Review of Sociology, 27:363-385

NIX.E, QUIAN. N.(2015).«The fluidity of race». Yale University.

ROTH, W. D. (2005). 'The End of the One-Drop Rule? Labeling of Multiracial Children in Black Intermarriages. 'Sociological Forum 20(1): 35-67

STAFFORD MC, SCOTT RR. 1986. «Stigma deviance and social control: some conceptual issues». In The Dilemma of Difference, ed. SC Ainlay, G Becker, LM Coleman. New York: Plenum

THORNICROFT, G., SZMUKLER, G., and K. T. MUESER (Eds.), 2011. Oxford textbook of community mental health. Oxford University Press, USA.

WHITE. W. (1947) «Why I Remain a Negro», Saturday Evening Post, Oct. 11.

WILLIAMSON, J. (1980). «New People: Miscegenation and Mulattoes in the United States». The Free Press. 
6

\title{
INTERVENCIÓN COMUNITARIA EN GABRIELA MISTRAL, BARRIO OLIVER, ZARAGOZA
}

\author{
Elena Enciso Serrano, Tamara Marín Alquézar y \\ Mari Carmen Martínez Molina \\ La Bezindalla S. Coop
}

De 2009 a 2016 se llevó a cabo una Intervención Comunitaria en la zona de Gabriela Mistral, un conjunto de 288 viviendas edificadas en1955 por la Obra Sindical del Hogar y Arquitectura, con espacios comunes entre los edificios, (asumidos por el Ayuntamiento de Zaragoza en el año 1999). En este conjunto se ha concentrado un alto porcentaje de personas con multitud de necesidades. Se encuentra en el Barrio Oliver, situado al oeste de la ciudad de Zaragoza, el cual cuenta en la actualidad con más de 16.000 habitantes. Gabriela Mistral es una de las zonas más deterioradas física y socialmente del barrio, y también de la ciudad de Zaragoza, en la que viven personas autóctonas (payas) cada vez más mayores, población gitana y población inmigrante (africana mayoritariamente).

a) Durante estos siete años se llevaron a cabo dos proyectos de intervención: Proyecto Rehabitat: 2009 - 2012; financiación europea y gestión de Zaragoza Vivienda.

b) Proyecto ConVida: 2013-2016; financiación Ayuntamiento de Zaragoza y Obra Social de La Caixa (en el inicio); gestión de diferentes entidades sociales: Asociación Amediar, Asociación de Vecinos y Vecinas Oliver Aragón (AVV Oliver), Cooperativa de Iniciativa Social La Bezindalla (en adelante La Bezindalla).

Los dos proyectos compartieron su objetivo general: contribuir a la mejora de la convivencia en Gabriela Mistral. Cada uno sirviéndose de unas líneas 
de intervención y actividades específicas (con coherencia y continuidad entre los diferentes periodos) para lograrlo.

Durante estos años se establecieron muchas y buenas relaciones con la población, se abordaron muchos de los temas y necesidades de la comunidad, se compartieron buenos y no tan buenos momentos. Se realizaron muchas actividades con población infantil y adulta hablando de cuidado y respeto de las zonas comunes, de relaciones vecinales, de habilidades personales... Se acompañó a las comunidades que lo demandaron en la mejora de su organización y gestión de sus conflictos de convivencia, se contribuyó a formación de vecinas y vecinos en temas de comunidad y barrio, se crearon grupos estables de actividad, se trabajó junto a otros proyectos del barrio con el objetivo común de mejorar el día a día de la población, se trasladaron las necesidades de Gabriela Mistral a las diferentes administraciones...

Sin embargo, en diciembre de 2016, desde el equipo técnico de La Bezindalla, planteamos finalizar la intervención en Gabriela Mistral y así lo trasladamos al Ayuntamiento. Tras una profunda reflexión técnica, consideramos que, en esos momentos, el proyecto no estaba dando respuesta a lo que una parte importante de la población del barrio consideraba que necesitaba Gabriela Mistral y esto, hacía que no se implicaran en las propuestas.

El aumento de las necesidades ha ido generando un entorno cada vez más deteriorado, en el que los problemas de convivencia preocupan, pero la población ha empezado a demandar soluciones rápidas, inmediatas, punitivas y ejercidas por terceros. Sin embargo, nuestra intervención era más pedagógica, transformadora a medio-largo plazo y, además, requería de la implicación directa de la población.

Exponemos a continuación un resumen de la experiencia con el objeto de generar reflexión y aprendizaje en relación a los aspectos clave de la Intervención Social Comunitaria.

\subsection{El territorio, la población y los/as agentes}

Oliver es un barrio de fuertes contrastes sociales debido a la llegada de nuevos vecinos y vecinas, provenientes de otras zonas de la ciudad y de origen extranjero y a la permanencia en el barrio de su población tradicional, en la que destaca un importante número de población gitana. La población de Oliver siempre ha sido inmigrante, en su origen porque procedía de otras ciuda- 
des y pueblos de España. A esta mezcla social, se unen los contrastes urbanísticos destacando la progresiva sustitución del tradicional parque de vivienda (parcelas de escasa altura), por nuevas viviendas de varios pisos y adosados.

Algunos aspectos que caracterizan y dan identidad al barrio Oliver, extraídos del Diagnóstico estratégico del Barrio Oliver, (AVV Oliver y Zaragoza Vivienda, 2010), son los siguientes:

- Población con escasos recursos económicos.

- Nivel educativo bajo.

- El $65 \%$ de los escolares estudian fuera del barrio.

- Importante número de personas mayores que viven solas.

- Pervivencia de valores rurales: solidaridad, vecindad, ayuda mutua,....

- Barrio con una imagen negativa: interna y externa.

- Retraso de las actuaciones institucionales.

- Movimiento vecinal organizado desde 1970.

En el mismo documento se concluye que el barrio «arrastra hoy en día las secuelas de su origen, un barrio urbanizado por sus propios vecinos, sin ninguna planificación. Esto, unido al abandono institucional, ha ido generando problemas que se intentan paliar». Además, el hecho de ser considerado un barrio periférico lo deja ajeno al ente de la ciudad, «como si hubiese algo que separase ambas realidades urbanas ». También existe un fuerte sentimiento de pertenencia y orgullo de vivir en él.

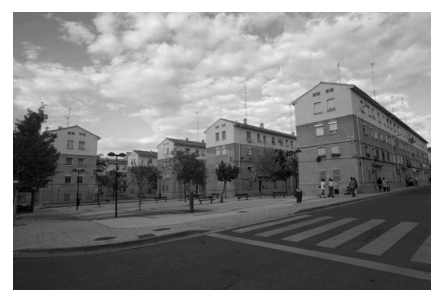

FIGURA 1. Gabriela Mistral. Fuente: Proyecto Rehabitat

Las características principales de la población de Gabriela Mistral, basado en el Estudio Sociológico de los residentes en Gabriela Mistral (Rehabitat, 2010a), son las siguientes:

-Diversidad cultural significativa entre el vecindario con distintos momentos de llegada: primeros pobladores años 50 (provenientes de dife- 
rentes puntos de la ciudad y pueblos tanto de Aragón como de otros puntos de España), población gitana en los 90 y población inmigrante en la última década. Esto configura la siguiente composición:

a) El 35\% de la población es de etnia gitana

b) Un $22 \%$ son inmigrantes

c) El $43 \%$, payos

-Relaciones sociales marcadas por la hostilidad (en la mitad de las comunidades de vecinos existen conflictos manifiestos), motivada por la desconfianza mutua, la falta de respeto a normas de algunos grupos más conflictivos y el uso privativo de los espacios comunes con prácticas que molestan al resto de vecinos. El factor edad también está presente, produciendo una brecha entre el uso de los espacios que hacen los niños, en detrimento del que hacen las personas más mayores.

a) Más de un $30 \%$ de las personas que viven en Gabriela Mistral viven solas.

b) El $40 \%$ tiene ingresos declarados inferiores a $600 €$, casi la mitad de las familias tienen algún grado de endeudamiento.

c) La tasa de desempleo ronda el 55\% (a fecha actual este dato es sensiblemente superior) y en el $34 \%$ de los hogares todos sus miembros son inactivos.

d) Hay alto nivel de analfabetismo.

Desde 2012, el empeoramiento del nivel socioeconómico general de la zona, visibilizó más situaciones de exclusión que afectan fundamentalmente a la infancia. Esto repercutió negativamente en la convivencia comunitaria, las relaciones vecinales y el estado del entorno, produciendo un aumento de conflictos. Sin embargo, también generó situaciones de solidaridad y ayuda, que, en algunos casos, terminaron contribuyendo a incrementar el malestar de los que dan la ayuda, al ver que no consiguen las transformaciones que pretendían. (Amediar, AVV Oliver, Zaragoza Vivienda, 2013)

Se comenzó a generar, como consecuencia, una opinión generalizada de que las ayudas sociales se dan a quien no se debe, que son injustas, que las reciben siempre los mismos, etc. llevando a actitudes discriminatorias. 
Siguiendo el análisis realizado en el citado proyecto europeo, (Rehabitat, 2010), destacamos otra clasificación de la población desde la perspectiva de la integración social (es decir, tomando en consideración las habilidades y los comportamientos, tanto personales como sociales). De esta manera, la configuración humana de la zona responde a las siguientes características:

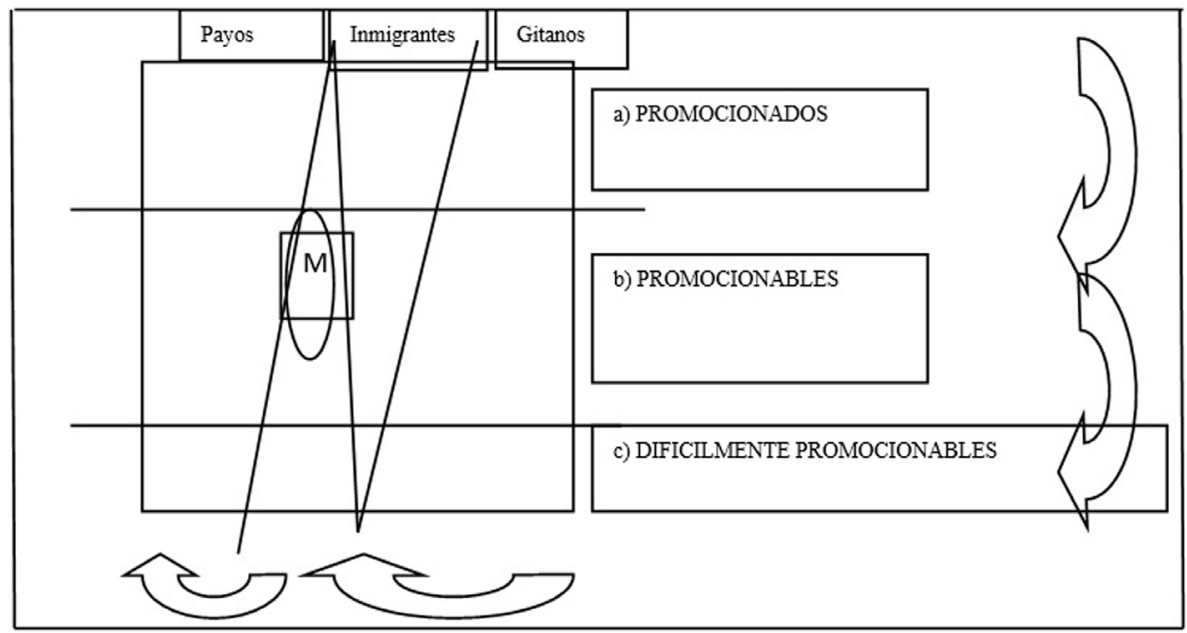

FIGURA 1. Clasificación de la población desde la perspectiva de la integración social. Fuente: Proyecto Rehabitat (2010)

Fijándonos en las posibilidades de promoción que posee cada grupo familiar (y las personas que lo componen), se considera adecuado hacer referencia a: «familias en situación de promoción », «familias en situación de ser promocionables » y, finalmente, «familias difícilmente promocionables ».

Partiendo de este análisis, personas y familias pertenecientes a los tres colectivos (payos, gitanos e inmigrantes) se encuentran en cada una de las tres categorías, aunque es cierto que la presencia relativa de cada uno de ellos puede variar.

Básicamente, se puede concluir que el primer grupo (difícilmente promocionables) viene definido (en su relación con los demás grupos) por su no aceptación de las normas de convivencia. Este grupo es el principal foco de conflicto existente. El segundo grupo (promocionables) adopta estrategias de evitación del conflicto, ausencia de una respuesta organizada y ubica el problema y la solución en los miembros de la categoría anterior. Un caso especial 
es el protagonizado por los mayores, que tienden a la «reclusión», así como a manifestaciones sintomáticas de su situación vital (estrés, ansiedad). Por último, el grupo de los promocionados ponen en práctica una estrategia clara de huida, es decir, de abandono de la zona en el momento en que su situación económica se lo permite.

En lo relacionado con las comunidades de vecinos y vecinas se observó, desde 2012, que la situación de crisis y desestructuración social, les afectó e hizo que cada vez fuera más complicado para ellas mantener una organización y convivencia. El empeoramiento de las situaciones familiares produjo que algunas personas se fueran y que las que iban llegando, generalmente con un nivel de promoción inferior, no consideraban prioritario, «lo comunitario». Por lo general, se mantienen con un funcionamiento satisfactorio aquellas comunidades en las que los vecinos no han ido cambiando y conviven los de siempre, los primeros vecinos y vecinas.

En el barrio Oliver existen dos foros de relación y coordinación entre agentes del barrio (entidades públicas y privadas gestoras de proyectos sociales y asociaciones vecinales, medioambientales, de participación ciudadana) que en su mayoría se articulan en torno a dos mesas de trabajo:

- Mesa de infancia: aglutina los proyectos que trabajan con infancia, adolescencia y juventud en el ámbito de la educación tanto formal como informal.

- Mesa de agentes: aglutina a las entidades y proyectos que intervienen con la población en general.

\subsection{Los Proyectos de Intervención Social Comunitaria realizada}

Como hemos comentado, durante 7 años se intervino profesionalmente desde la perspectiva del Trabajo Social Comunitario, desarrollando dos proyectos que pasamos a exponer:

\subsubsection{El proyecto Rehabitat}

Antes de explicar en qué consistió la intervención, es importante decir que este proyecto respondió al entendimiento y esfuerzo conjunto del movimiento vecinal, por una parte, y de la Administración (o, al menos, una 
representación de la misma) por otra. Es decir, hace años la Asociación de Vecinos Aragón del barrio Oliver convocó a las Administraciones Públicas para solicitar una intervención integral en Gabriela Mistral, ante la necesidad de mejorar su estado físico y, de forma especial, la convivencia social y comunitaria existente en la zona. La Sociedad Municipal Zaragoza Vivienda, coincidiendo con el diagnóstico realizado por la Asociación, se comprometió a intervenir diseñando y llevando a cabo el proyecto Rehabitat, cofinanciado por el Fondo Europeo de Desarrollo Regional de la Unión Europea. Éste fue el punto de partida; posteriormente se fueron sumando otras entidades sociales, así como órganos de la Administración.

El proyecto, cuya temporalidad (tres años) estaba establecida desde el inicio, consistió en «implicar a la población de Gabriela Mistral en la rehabilitación de los espacios comunes y en su mantenimiento posterior, con el objetivo de mejorar la convivencia y conseguir un entorno más saludable a todos niveles, a través de un proceso de participación vecinal y de dinamización social, que incluía formación y empleo a un grupo de residentes, para que ellos mismos llevaran a cabo la rehabilitación de los espacios comunes».

Se trabajó en base a los siguientes objetivos:

- Rehabilitar los espacios comunes de Gabriela Mistral, de manera que respondan a las necesidades de las personas que los usan y disfrutan.

- Favorecer la participación vecinal en la mejora del entorno en el que viven.

- Mejorar el uso y disfrute de los espacios comunes.

- Conseguir una mayor cohesión social de la población residente, así como una mayor integración en el entorno del barrio.

- Fomentar el empleo entre las personas residentes.

El proceso se inició con una fase de conocimiento, establecimiento de relaciones de confianza y elaboración del diagnóstico de la situación. En la siguiente fase se llevó a cabo un amplio proceso participativo para la recogida de propuestas de mejora de los espacios comunes, así como la realización de actividades que permitieran la relación positiva entre la población. Se concluyó con un proceso de formación y empleo a través del cual un grupo de 
vecinos y vecinas llevaron a cabo las obras de adecuación de los espacios. Es decir, el proyecto tenía un principio y un final definidos desde el comienzo del mismo, así como un objetivo claro y palpable para la población que justificaba la intervención.

\subsubsection{El proyecto Gabriela Mistral «ConVida»}

El Proyecto Gabriela Mistral ConVida nació como continuidad del Proyecto europeo Rehabitat. Al finalizar éste y ante la constatación de que esta zona de Oliver requería de un periodo de tiempo mucho más largo para profundizar sobre los procesos iniciados y lograr una transformación de su situación de partida, la Asociación de Vecinos y Vecinas de Oliver, Zaragoza Vivienda y la Asociación Amediar, ya implicadas en el proyecto anterior, apostaron por continuar con un trabajo conjunto, aportando cada una desde su visión específica para abordar este reto de manera complementaria. Éste fue el punto de partida del Proyecto Gabriela Mistral ConVida.

En la Figura 2 se resume la historia de la gestión de la intervención en la zona de Gabriela Mistral.

Dado que existían en el territorio recursos que abordaban muchas de las necesidades detectadas, las estrategias del proyecto se basaron en las claves de éxito del Proyecto Rehabitat y se diseñaron para intentar dar respuesta a las relacionadas con los conflictos de convivencia (vecinal y en espacios públicos comunes), de implicación del territorio en su propio desarrollo y mejora, de

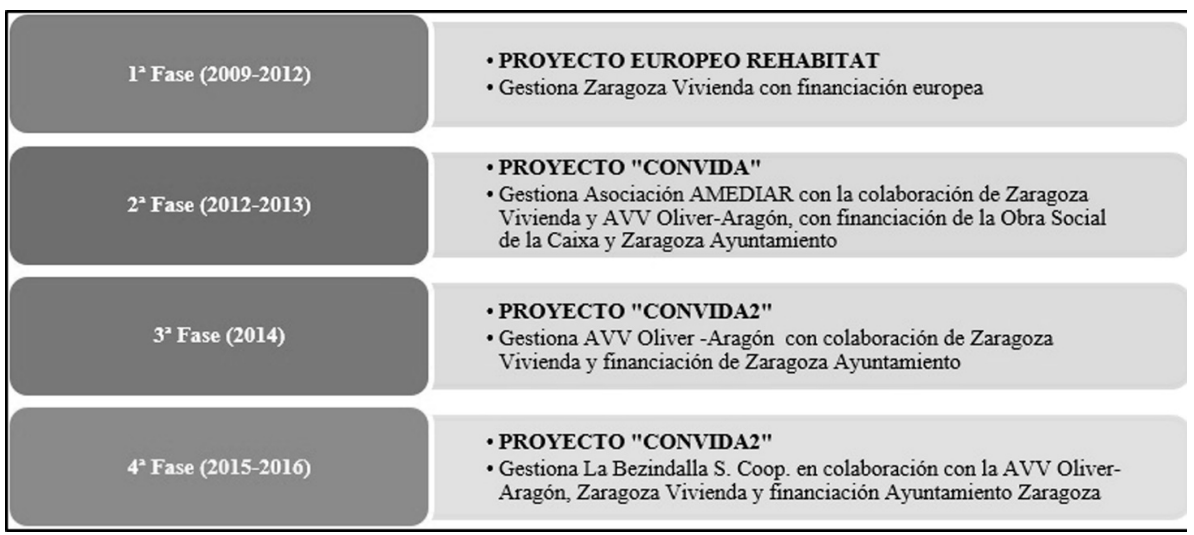

FIGURA 2. Historia de la gestión de la intervención en la zona de Gabriela Mistral. Fuente:

Elaboración propia 
rescatar y dar visibilidad a los aspectos positivos que tiene la comunidad y de hacer todo esto de manera coordinada y en común con los agentes que ya intervenían en la zona. De esta manera se pretendía conseguir una intervención complementaria que diera respuesta a varias necesidades de manera simultánea y coordinada. Además, se daba continuidad a procesos ya iniciados y que necesitaban de un impulso para poder ser asumidos de manera autónoma por el propio barrio y por los propios vecinos.

El objetivo del Proyecto ConVida fue el de contribuir a la mejora de la calidad de vida de los vecinos/as de la zona favoreciendo la convivencia vecinal, mediante un dispositivo profesional que trabajaba en interacción directa con el vecindario y las entidades públicas y privadas, aplicando estrategias de mediación interpersonal y comunitaria, teniendo en cuenta factores de distintividad cultural significativa y aprovechando las redes de coordinación existentes.

Esto se trabajó a través de las siguientes líneas de intervención:

1. Comunidades vecinales: Con el objetivo de mejorar la convivencia y el funcionamiento de las comunidades de vecinas y vecinos de Gabriela Mistral, generando aprendizajes que faciliten su autonomía en el futuro. Podemos destacar el trabajo realizado con 15 comunidades vecinales con las que se abordaron sus dificultades de organización, reparto de tareas, asunción de responsabilidades, hábitos de convivencia, conflictos..., realizando procesos de mediación, asesoramiento, acompañamiento o información, dependiendo de sus necesidades. Por otra parte, se realizó formación sobre comunidad y convivencia con diferentes grupos de personas adultas y se abordaron conflictos en el espacio público fomentando las relaciones vecinales para la búsqueda de alternativas.

2. Espacios positivos de relación: Generar espacios positivos de relación entre la población que faciliten la convivencia y la relación intercultural e intergeneracional, fomentando así la cohesión social.

Destacamos dos de los grupos estables más representativos generados por el proyecto, El Puchero de Gabriela: mujeres (mayoritariamente gitanas) que partiendo del interés común por la cocina, trabajan aún hoy en día, sus habilidades personales y sociales, se relacionan con el barrio y la ciudad; y La PACo: Pandilla de Apoyo a la Comunidad, grupo de niños y niñas que, partiendo de un análisis de las necesidades y capacidades de su entorno (en lo 
físico y relacional), trabajaron en el cuidado y respeto hacia la zona incidiendo en cómo mejorar las relaciones inter-generacionales.

Dentro de esta línea, se planteó contar con un grupo impulso, grupo motor, facilitador... formado por vecinos y vecinas de la zona implicadas y comprometidas, como otro grupo estable, como un nuevo espacio positivo de relación para facilitar la apertura de la zona al barrio.

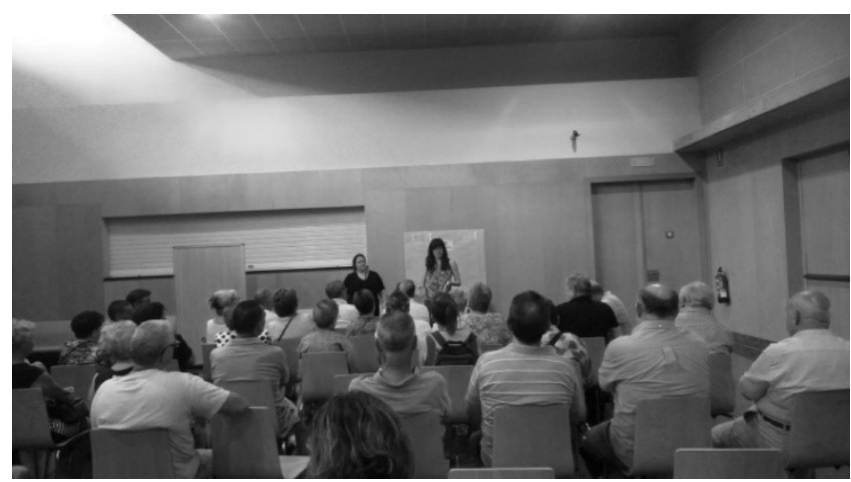

IMAGEN 2. Reunión vecinal. Fuente: La Bezindalla (2016)

3. Espacio Técnico de Relación: El objetivo era aprovechar las sinergias y espacios de coordinación que había en el barrio para contribuir a dar una respuesta integral a las necesidades de vecinas y vecinos que viven en Gabriela Mistral. Esto se materializó en la participación del equipo de intervención en todas las reuniones de las Mesas, de agentes e infancia, además de la coordinación específica mantenida con proyectos, entidades y profesionales concretos para desarrollar actividades, talleres, procesos conjuntos.

$\mathrm{Y}$ un eje transversal, el cuidado y respeto hacia el entorno, en lo físico y en lo relacional: convivencia. Como se puede observar, las líneas de intervención y cada una de las actividades que desarrolladas tenían como objetivo incidir en la mejora de la convivencia, a través del cuidado y respeto hacia el entorno físico y de las relaciones personales. En concreto, en el último periodo del proyecto se trabajó desde esta transversalidad en el tema de la imagen (generada y percibida) que tenían las personas respecto a Gabriela Mistral, centrando el trabajo en identificar, para después visibilizar, lo positivo que hay en la zona. 


\subsection{Claves metodológicas}

En sendos proyectos se ha definido la intervención y se ha trabajado tomando como referencia las siguientes claves metodológicas, las cuales emanan directamente del trabajo social comunitario:

1. El trabajo se desarrolla en una comunidad claramente delimitada, con una población y unas relaciones determinadas. Se realiza para la comunidad, es decir, está dirigido a conseguir un cambio social, a mejorar su calidad de vida. Y, por último, se realiza con la comunidad, es decir, con la implicación y participación activa de la población.

2. La presencia continua del equipo de profesionales en el territorio. Esta presencia se concreta en la utilización de los espacios comunes de Gabriela Mistral como escenario principal para la realización de las actividades programadas, lo que permite el contacto continuo con la población, el conocimiento mutuo y el establecimiento de relaciones de confianza.

3. Las actividades son meros instrumentos para facilitar momentos de encuentro y relación entre la población, fomentando así el conocimiento mutuo y generando sentimiento de identidad y de pertenencia a un mismo entorno. Por tanto, el contenido de cada actividad es secundario frente al objetivo, es decir, es un medio para conseguir un fin. Si bien es verdad que nos esforzamos por responder a sus intereses y necesidades a la hora de programar actividades para conseguir una mayor motivación y, por tanto, una mayor participación.

4. Lo importante son los procesos que se generan a través de las actividades. Éstos deben capacitar a la población para ser protagonistas de sus propias decisiones, para ser capaces de identificar y actuar sobre sus problemas, para encontrar estrategias que respondan al bienestar de toda la comunidad.

5. Cuidado y transmisión de los mismos mensajes de fondo (coherencia) a través de toda la intervención, los cuales se basan siempre en el respeto hacia las personas y hacia el entorno y en todo lo que tiene que ver con la vida en comunidad. 
6. No dar nunca por cerrada una programación. Todo es susceptible de cambio en función de cómo sea recibido por los vecinos y vecinas implicados/as, de lo que ellos y ellas nos propongan, de lo que los foros de coordinación del barrio se planteen, es decir, como toda intervención comunitaria la intervención está viva, en continuo cambio y adaptándose a la realidad con la que se trabaja: reflexión y redeinición constante.

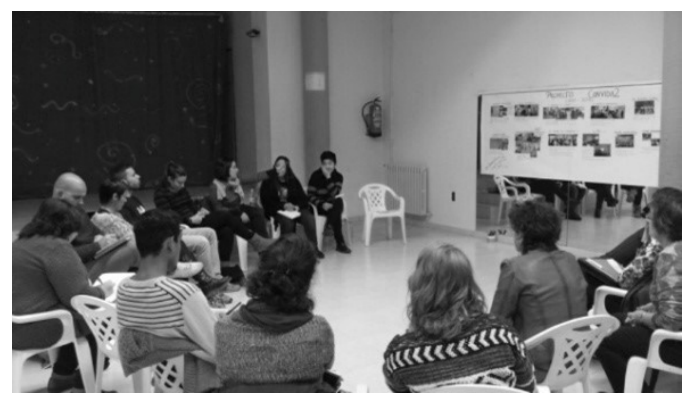

IMAGEN 3. Reunión agentes. Fuente: La Bezindalla (2016)

7. La coordinación no sólo es un elemento metodológico básico, sino que es un objetivo en sí misma. La intervención del Propyecto «ConVida» complementa la intervención que se realiza en el territorio desde otros servicios y proyectos. Se trabaja con la misma población $\mathrm{y}$ hay que ser capaces de generar estrategias que aprovechen los diferentes esfuerzos en la consecución de objetivos comunes. El objetivo es que la población de Gabriela Mistral se incorpore y participe de los servicios del barrio Oliver, no crear opciones alternativas de exclusividad para esta zona del barrio y, en ningún caso, crear competencia entre recursos.

8. La intervención mediadora profesional en la gestión de la diversidad y de los conflictos existentes. Entendiendo la mediación como un proceso para analizar, gestionar, transformar y solucionar conflictos que se basa en reconocer la autonomía y autodeterminación de las personas que se hacen responsables de su parte en el mismo. El proceso requiere establecer relaciones de igualdad para, de manera cooperativa y colaborativa analizar la situación que genera conflicto por medio de la comunicación. Este proceso puede establecer nuevas relaciones 
entre los participantes, genera aprendizaje y aporta la visión de que el conflicto puede ser constructivo.

9. Una clara apuesta por la Intervención Comunitaria desde la Cultura de Paz, que se trabaja generando y fomentando relaciones positivas que potencien las capacidades para construir Paz: incorporar la creatividad, el diálogo y el trabajo cooperativo a la hora de afrontar conflictos y establecer relaciones, partiendo de la aceptaciónde la diferencia y el compromiso con los valores humanos.

\section{4. ¿Qué circunstancias hacen que planteemos el fin de esta intervención?}

Como hemos introducido anteriormente, en diciembre de 2016 el equipo técnico de intervención, formado por dos Trabajadoras Sociales, una Educadora y una Mediadora planteamos finalizar la intervención en Gabriela Mistral por considerar que, en esos momentos, el proyecto no daba respuesta a lo que una parte importante de la población del barrio consideraba necesario en Gabriela Mistral y hacía que no se implicara en lo que proponíamos.

El proyecto siempre ha sido cuestionado por una parte de la comunidad (y por algunos/as agentes profesionales), pero las personas valoraban que si el proyecto desaparecía, ellas estarían peor. En el último periodo de intervención la comunidad no hacía esa valoración, sino que cada vez más personas manifestaban que el proyecto no daba respuesta a sus necesidades y demandaban soluciones más rápidas, inmediatas, punitivas y ejercidas por terceros.

Con el paso del tiempo, las necesidades de las personas que viven en Gabriela Mistral han aumentado (las personas mayores siguen envejeciendo y cada vez necesitan más apoyos, la mayoría de la población sigue sin poder acceder a un empleo, hay mucha población infantil en entornos familiares deteriorados y sin control de personas adultas, personas que no consideran la comunidad como un valor a cuidar, usos delictivos relacionados con sustancias ilegales, la población nueva que llega a la zona tiene las mismas necesidades anteriormente descritas y por lo tanto no se equilibra la población...) esto ha generado un entorno cada vez más deteriorado para el que los problemas de convivencia preocupan y son prioritarios pero no se comparte la forma de afrontarlos propuesta desde el proyecto . 
El territorio se ha convertido en reclamo de población con necesidades, por lo comentado anteriormente y porque las viviendas, comunidades y entorno están cada vez más deteriorados y hacen que los precios de alquiler y venta sean cada vez más bajos. También se da un aumento de las ocupaciones de viviendas asociadas a malos usos de las mismas y de los espacios comunes.

Desde finales de 2013 no contamos en el proyecto de intervención con un objetivo tangible, visible y reconocible para todas las personas (a diferencia de la intervención de mejora física que se realizó en la primera fase de la intervención con el Proyecto Rehabitat). No tener algo concreto, físico sobre lo que intervenir, dificultó a las personas la comprensión del objetivo del proyecto y por lo tanto su implicación en el mismo.

Desde el conflicto vecinal vivido en 2015 en el barrio, se extendió y caló el discurso de desprestigio del proyecto. No toda la comunidad pasó a opinar que el proyecto no servía para nada, pero muchas personas optaron por mantenerse al margen para no tener que «dar eplicaciones» a sus vecinos y vecinas sobre los motivos de su participación en el proyecto.

Desde enero de 2016, fue bajando la participación vecinal en los procesos y actividades (a excepción de los grupos estables) con relación a otros años.

A nivel profesional, entre los agentes participantes en el barrio, consideramos que hay diferencias importantes en la concepción de la intervención comunitaria. Esto dificultó la coordinación, que a pesar de ello, fue rica, potente y enriquecedora.

\subsection{Aprendizajes}

De este proceso, hemos extraído aprendizajes, personales y profesionales. Exponemos a continuación los que consideramos más relevantes:

1. Es necesario que las personas que forman parte de una comunidad se impliquen activamente en su transformación, pasando de la queja a la acción. Por ello, es recomendable contar con un grupo motor, un grupo facilitador que pueda reflexionar y llegar a acuerdos sobre cuáles son las principales necesidades a abordar y de quién depende su solución (comunidad, administración, ...), estableciendo estrategias y participando en el seguimiento de los procesos llevados a cabo desde el proyecto. 
2. Las actividades propuestas deben responder a necesidades de la comunidad y, aunque no vayan a participar en ellas todos los grupos de población, no puede ocurrir que sean percibidas como actividades dirigidas solo a un colectivo. En concreto, es contraproducente para la intervención que las actividades se vean para una de las principales partes del conflicto (actividades para los/as gitanos/as, actividades para los/as payos...).

3. Si algún grupo de población no siente que él también debe cambiar algo para mejorar la situación, aprender o ceder ante el conflicto, no se implicará en los procesos del entorno, por lo tanto, no llegaremos a abordar la situación correctamente.

4. Las situaciones puntuales de crisis (vandalismo, agresiones, ocupaciones organizadas de viviendas, etc) impactan en la comunidad generando nuevos movimientos inesperados: cambios de posicionamiento ante el conflicto, nuevas partes implicadas, cambios en las relaciones (positivas o negativas) ya establecidas... Es importante incorporar a las nuevas personas, las nuevas posiciones, los cambios de relación en los procesos... cualquier cambio. Esto requiere de tiempo. Tiempo para, a la vez que continua un proceso, sin pararlo, encontrar los momentos y lugares oportunos para que «lo nuevo» entre a formar parte, introduciendo los cambios necesarios para que todas las partes estén de acuerdo en cómo continuar. Para ello, realizamos entrevistas individuales y grupales, participamos en reuniones políticas y de colectivos, convocamos a los grupos para informar y recoger, estamos en la calle, en contacto con las personas...

5. La comunidad necesita ver resultados. Por dos motivos: primero, porque necesita vivir mejor e ir solucionando las situaciones que le preocupan y afectan. Segundo, porque está dedicando tiempo, esfuerzo, interés y trabajo y tiene la necesidad de que se conozca lo que se hace, quién participa, lo que se acuerda, lo que se consigue y lo que no.

6. Cuando el escenario de intervención es complicado y empieza a haber desconfianza entre vecinos/as y hacia las profesionales, hay que plan- 
tearse la continuidad de la intervención. Finalizar antes de llegar al «punto de no retorno» para evitar el trauma.

7. Es necesario generar procesos largos en el tiempo que contribuyan a crear hábitos y arraigar las transformaciones que se van consiguiendo entre la población. Sin embargo, esto que es básico para los resultados de la intervención, es incompatible con la gestión de proyectos a través de convenios y negociaciones anuales con la Administración.

8. Es clave que haya una apuesta política clara (sobre todo en el caso en el que la financiación es pública) no solo proveedora de dinero, sino también de respaldo ideológico y metodológico y por lo tanto, de liderazgo. La Administración es una de las partes implicadas en la Intervención Comunitaria en un territorio con alto nivel de necesidades. La Administración es quien puede aportar la integralidad necesaria en este tipo de territorios.

9. Finalizar una intervención requiere de un proceso con la comunidad, en el que es deseable que participen todas las partes y necesita tiempo. Solo así es posible realizar el «cierre» de los procesos abiertos.

10. Trabajar en Intervención Social Comunitaria es apasionante y complicado. Por eso, tener/ser/formar parte de un equipo sólido, en el que hay confianza mutua y complicidad, es esencial. Esto requiere de cuidar al equipo y por tanto a las personas que lo forman.

\subsection{Bibliografía}

AMEDIAR, AVV OLIVER-ARAGÓN Y ZARAGOZA VIVIENDA (2013). Exposición y reflexión sobre el proceso. Zaragoza. Documento inédito.

AVV OLIVER-ARAGÓN y ZARAGOZA VIVIENDA (2010). Diagnóstico estratégico del Barrio Oliver. Disponible en http://www.ebropolis.es/files/File/Documentos/diagnostico-Oliver.pdf.

LA BEZINDALLA (2016). Memoria Proyecto ConVida. Zaragoza. Documento inédito.

REHABITAT (2010a). Estudio sociológico de los residentes en las zonas de Gabriela Mistral (Oliver) y Peñetas (Miralbueno). Zaragoza. Documento inédito.

REHABITAT (2010b). Proyecto de acción colectiva para la zona de Gabriela Mistral, Barrio Oliver. Zaragoza. Documento inédito. 


\section{7 \\ DEL CRECIMIENTO ECONÓMICO A LA SATISFACCIÓN CON LA VIDA: MEDIR LA FELICIDAD EN CIENCIAS SOCIALES}

Gabriela Delsignore Máspoli

gabriela@unizar.es

7.1. El crecimiento económico como indicador de prosperidad y la medición del bienestar socioemocional

El Producto Interior Bruto (PIB) fue propuesto por primera vez como indicador del crecimiento económico en un informe presentado al Congreso de Estados Unidos por el economista Simon Kuznets ${ }^{1}$ en el año 1934 (Kuznets, 1937). En la actualidad, sigue siendo la base para el estudio del crecimiento, el desarrollo ${ }^{2}$ y la desigualdad en la distribución del ingreso (índice de Gini y curva de Lorenz), si bien hay que tener en cuenta que un PIB alto no necesariamente indica un nivel alto de bienestar o de calidad del sistema social sino, solamente, una mayor actividad económica, tal como indicó el propio Kuznets en su informe al Congreso.

Según el análisis realizado por Tatyana Soubbotina en un estudio sobre crecimiento económico y desarrollo sostenible del Banco Mundial (Soubbotina, 2000), el Producto Interior Bruto (PIB) per cápita -que se calcula a partir del valor de la producción total anual de bienes y servicios dentro de las fronteras de un país, dividido entre el número de habitantes- y el Producto Nacional Bruto (PNB) per cápita -que es el PIB más la renta de los factores productivos nacionales en el exterior menos la renta de los factores extranjeros en el

1 Premio nobel de economía en 1971.

2 Banco Mundial: http://wdi.worldbank.org/table/4.2 
país, dividido entre el número de habitantes- son indicadores estadísticos que permiten medir el bienestar material relativo de los diferentes países.

Soubbotina también analiza las principales limitaciones que éstos presentan en cuanto medidas de desarrollo, ya que resultan insuficientes para explicar cómo dos países con el mismo nivel de Producto Nacional Bruto (PNB) per cápita presentan resultados diferentes en materia de desarrollo humano.

Por otra parte, afirma que dichos indicadores no permiten observar cuán equitativa es la distribución del ingreso en un país, debido a que se centran exclusivamente en la producción de las economías domésticas, empresas y sector público, y no toman en cuenta factores como el acceso a la educación y a la sanidad, la economía sumergida y la informal, la calidad del medioambiente, la esperanza de vida o la libertad de las personas, factores determinantes a la hora de calcular el desarrollo de un país (ib., 2000).

\subsubsection{El Índice de Desarrollo Humano}

En 1990, el Programa de Naciones Unidas para el Desarrollo (PNUD) incorporó una nueva herramienta para medir el desarrollo de los países: el Índice de Desarrollo Humano (IDH).

Es un índice compuesto que combina la riqueza de las economías y la de las vidas humanas, y cuestiona el paradigma de la conexión automática en el que el mero incremento del ingreso crea vidas prósperas.

Se basa en el paradigma de desarrollo humano (ul Haq, 2003) que sostiene que la vinculación entre crecimiento económico y prosperidad debe ser creada a partir del diseño de políticas públicas específicas que permitan traducir la cantidad de crecimiento económico - que tiene como eje el mercado y los sectores productivos- en calidad de dicho crecimiento; es decir, que coloque en el centro de la mirada a la calidad de vida de las personas.

El Índice de Desarrollo Humano (IDH) del Programa de Naciones Unidas para el Desarrollo (PNUD, 2015) incorpora 3 dimensiones: a) salud -vinculada a la esperanza de vida-, b) educación -en relación al nivel educativo alcanzado- y c) nivel de vida digna -a partir del PNB per cápita-, en más de 180 países. Fue propuesto por Mahbub ul Haq (2003/1995) en 1990 y se basó en el análisis realizado por Amartya Sen (2003) ${ }^{3}$.

3 Premio nobel de economía en 1998. 
En palabras de Mahbub ul Haq (ib., 2003/1995), la diferencia determinante entre las escuelas del crecimiento económico y las escuelas del desarrollo humano es que las primeras se enfocan exclusivamente en el incremento del ingreso, mientras las segundas incorporan otras opciones humanas: económicas, sociales, culturales y políticas. En definitiva, «el objetivo del desarrollo es crear un ambiente apto para que las personas disfruten de una vida larga, saludable y creativa» (ib., 2003/1995: 17).

\subsubsection{El bienestar en el estado de bienestar}

Ruut Veenhoven ${ }^{4}$ afirma que existe una tendencia en la investigación sociológica (Veenhoven, 2008) a igualar el bienestar público o del estado ( $\mathrm{Wel}$ fare State) con el bienestar de las personas (Well-being). Además, el castellano cuenta con una dificultad añadida ya que utiliza un único término (bienestar) para expresar ambos conceptos: Welfare y Well-being. Para aumentar el grado de confusión en castellano, podríamos añadir el concepto Wellness, otra acepción de bienestar que lo vincula al «buen funcionamiento de la actividad somática y psíquica de las personas», según el Diccionario de la RAE (Real Academia Española, 2014).

Saber en qué medida el estado de bienestar (Welfare State) contribuye al bienestar de las personas (Well-being); si el incremento del presupuesto del Estado garantiza una distribución equitativa del bienestar, o si, en cambio, su incidencia es mínima y solo influye en la distribución del ingreso; si elimina la privación de las clases bajas o solo reduce la resistencia de éstas a aquélla, incluso si opera como paliativo de la social democracia al capitalismo (Wright, 2013), son algunas de las reflexiones que surgen a partir del análisis de la investigación desarrollada por Ruut Veenhoven ${ }^{5}$ entre los años 1980 y 1990.

Dicho estudio midió el tamaño del estado de bienestar (Welfare State) a través del gasto en seguridad social en 41 países, y el bienestar de las personas (Well-being) en términos de cómo éstas gestionan su vida de manera saludable y feliz (Veenhoven, 2000).

4 Profesor emérito de «Condiciones sociales para la felicidad humana» de la Universidad Erasmus de Rotterdam (Países Bajos), director del Banco de datos mundial sobre Felicidad (World Database of Happiness) y fundador-editor de la publicación Journal of Happiness Studies.

5 Profesor emérito de la Universidad de Illinois. Asesor e investigador Senior de Gallup desde 1999, en «bienestar y calidad de vida». 
Los resultados pusieron en evidencia que no había ninguna relación entre el tamaño del estado de bienestar (Welfare State) y el nivel de bienestar de las personas (Well-being) y que éste tampoco era mayor en los estados de bienestar, ni su distribución más equitativa.

El estudio concluyó que en países con nivel alto presupuesto social las personas no son más sanas ni más felices que en países donde éste es menor. La población en estos países no vive más tiempo, ni tiene mejor estado de salud o mayor felicidad (ib.). En definitiva, el aumento o reducción del gasto en seguridad social no está directamente relacionado con el aumento o disminución en el nivel de salud y la felicidad de la ciudadanía.

Con relación a la distribución y la equidad, el estudio mostró que tampoco había conexión entre el tamaño del estado de bienestar y la equidad en la distribución del bienestar entre la población de un estado. En los países donde el gasto social era alto, la dispersión de la salud y la felicidad no era menor que en los países prósperos con menor gasto social. Por lo que, aumento y reducción del gasto social no estaban relacionados con la equidad en la distribución en salud o felicidad (ib.).

\subsubsection{Bienestar, calidad de vida y felicidad: El ámbito de la sociología}

Como he mencionado anteriormente, son muchos los autores que hacen referencia a cómo las mediciones del PIB y el PNB per cápita resultan insuficientes para evaluar el bienestar general de los individuos, y la relevancia que tiene el modo en el que éstos gestionan su vida en busca de mayor longevidad, prosperidad y felicidad (ib. Kuznets, 1937) (Veenhoven, 2000) (Soubbotina, 2000) (ul Haq 2003/1995) (Sen, 2003) (Decancq \& Schokkaert, 2014) (Bericat, 2015:37).

También el Informe de la Comisión para la Medición del desempeño económico y el progreso social (Comission on the Measurement of Economic Performance and Social Progress) realizado por Stiglitz, Sen y Fitoussi (2009) sostiene que es necesario centrarse más en la medición del bienestar de la población que en la de sus ingresos.

Se suman a estas posiciones -y además las complementan- los estudios de Ed Diener ${ }^{6}$ sobre 30 años de evolución del concepto de bienestar y la cons-

6 «En otras palabras, el concepto equivale a cuánto nos gusta la vida que vivimos» (Veenhoven, 2001a, 3.1). 
trucción del Índice de Calidad de Vida de las naciones, que desarrolla en dos niveles -básico y avanzado-, con la medición de siete variables en cada caso (QOL - Quality of Live Index), que integra en el Combined Quality of Live Index (Diener, 1995).

QOL Index Básico discrimina entre países desarrollados e incluye las variables: a) poder adquisitivo, b) tasa de homicidios, c) satisfacción de necesidades básicas, d) tasa de suicidios, e) tasa de alfabetización, f) violaciones de los derechos humanos y g) deforestación. El Avanzado, evalúa naciones altamente industrializadas a través de las variables: a) médicos por habitante, b) tasa de ahorro, c) ingreso per cápita, d) bienestar subjetivo, e) porcentaje de estudiantes universitarios, f) igualdad de ingresos y g) tratados medioambientales firmados.

Los trabajos de Diener ponen de manifiesto que la medición del bienestar incluye elementos que trascienden la mera prosperidad económica o material. También destacan la importancia que tienen las perspectivas subjetivas (de los individuos) a la hora de evaluar la propia vida (Diener et al., 1999).

Sobre esta base, Veenhoven (1984) propone una definición sociológica de «felicidad general» que combina la satisfacción de la vida con el bienestar subjetivo. En palabras de Veenhoven: «La felicidad es el grado en el que una persona evalúa positivamente la calidad de su vida actual en todos sus aspectos. En otras palabras, el concepto equivale a cuánto nos gusta la vida que vivimos $\left.^{6}\right\rangle$ (Veenhoven, 2001a, 3.1).

Asimismo, hace una distinción entre la evaluación cognitiva y la afectiva que realizan los individuos acerca de su propia vida. El juicio general de la satisfacción que se nutre de dos fuentes de información: Por un lado, la comparación cognitiva con estándares de calidad de vida y, por otro, la comparación afectiva acerca de cómo se siente uno la mayor parte del tiempo (ib., 2008).

Y sobre la discusión de si el bienestar subjetivo debería ser objeto de estudio de la psicología o de la sociología dado que es, de algún modo, un «estado mental», Veenhoven lo incluye en el ámbito de la sociología por dos razones:

a) Porque el bienestar de los individuos brinda información sobre la calidad del sistema social en el cual éstos viven. Si la sociología estudia el malestar de las personas podrá detectar condiciones sociales que permitan, por ejemplo, ajustar -o aplicar nuevas- políticas públicas (ib., 2008). 
b) Porque el bienestar subjetivo es uno de los factores que determinan el comportamiento y la participación, tanto en el ámbito político como organizacional, laboral o social, a la vez que permite comprender la funcionalidad del sistema. Las personas felices son mejores ciudadanas, están mejor informadas acerca de cuestiones políticas, son más propensas a ejercer su voto, participan y se implican más activamente en procesos sociales, a la vez que son menos radicales en sus posturas políticas (Lyubomirsky, King \& Diener, 2005).

De este modo, este sociólogo que ya en 1970 había propuesto la felicidad como objeto de investigación científica (Veenhoven, 1970), concluye que el bienestar subjetivo es, a la vez, resultado y factor dinamizador del sistema social, lo que lo hace objeto central de la sociología (ib., 2008).

\subsection{Medir el bienestar, la satisfacción y la felicidad: Una selección de índices}

Los trabajos preparatorios de la Comisión para la medición del desempeño económico y el progreso social (Afsa et al., 2008) ofrecen un pormenorizado estudio de la evolución de los índices de progreso social, económico y de bienestar subjetivo. Concretamente, recuperan la dimensión que reviste mayor interés para evaluar el bienestar subjetivo en ciencias sociales, que es el nivel de satisfacción con la propia vida (o con el trabajo actual, o la salud).

Como he mencionado anteriormente, las principales conclusiones del Informe de la Comisión para la medición del desempeño económico y el progreso social (Comission on the Measurement of Economic Performance and Social Progress) realizado por Stiglitz, Sen y Fitoussi (ib. 2009) señalan que los indicadores de crecimiento económico resultan insuficientes para medir el bienestar, la satisfacción y la felicidad de las personas, en concordancia con Kuznets (1937), Veenhoven (2000), Soubbotina (2000), ul Haq (2003/1995) y Sen (2003). Por otra parte, sostienen que en la actualidad resulta imprescindible poder estudiar la evolución de lo que los bienes de consumo aportan a la vida de las personas en un marco de sostenibilidad.

El PIB es el indicador económico validado por analistas para estudiar el crecimiento y es medido sistemáticamente por entidades estadísticas oficiales. Permite sacar conclusiones acerca de la riqueza y el desarrollo, y facilita la realización de estudios comparados. Cada vez se extiende más la opinión de que dicho indicador resulta insuficiente para conocer la calidad de vida de la población. Como veremos a continuación, son muchas las iniciativas acadé- 
micas, de agencias de investigación y otras entidades dedicadas a «estudiar la felicidad»-sea que la midan directamente, sea que elaboren modelos e indicadores o que generen informes periódicos-que, en los últimos años incluyen la medición de estados emocionales, del grado de satisfacción con la vida personal o de felicidad en los análisis que realizan.

Los Índices de felicidad y bienestar seleccionados y propuestos en los párrafos que siguen, se basan en variables que miden dichos aspectos $\mathrm{y}$, si bien en muchos ámbitos confluyen y coinciden, no terminan de ser comparables en cuanto a dimensiones y temporalidad se refiere.

En este sentido, estoy de acuerdo con Decancq \& Schokkaert (2014) en la idea relativa a que los/las profesionales de las ciencias sociales tenemos pendiente construir un único indicador que permita medir, analizar y poder comparar la evolución del bienestar socioemocional y la felicidad entre personas y países.

- Las principales encuestas a partir de las cuales se han construido Índices de satisfacción con la vida, bienestar socioemocional y felicidad son: Encuesta de Bután (Centre for Bhutan Studies) ${ }^{7}$.

- Encuesta Mundial Gallup (Gallup World Poll - GWP)

- Encuesta Mundial de Valores (World Values Survey - WVS) ${ }^{9}$.

- Encuesta Europea de Calidad de vida (EuroFound, European Quality of Life Surveys - EQLS $)^{10}$.

- Encuesta Social Europea (European Social Survey - ESS) ${ }^{11}$.

Después de haber revisado y analizado los principales índices de desarrollo, bienestar, calidad de vida, armonía, satisfacción y felicidad -sin pretender haberlo hecho de manera exhaustiva-, presento a continuación una selección de los que considero más relevantes para ser tomados en cuenta en el momento de reflexionar acerca de la construcción de un único índice de satisfacción con la vida y felicidad, que pueda ser consensuado por los profesionales de las ciencias sociales ${ }^{12}$.

7 http://www.grossnationalhappiness.com/

8 http://www.gallup.com/topic/category_wellbeing.aspx

9 http://www.worldvaluessurvey.org/wvs.jsp

$10 \mathrm{http} / / / \mathrm{www}$.eurofound.europa.eu/surveys/european-quality-of-life-surveys

$11 \mathrm{http}: / /$ www.europeansocialsurvey.org/

12 A este respecto, existe un inventario que recopila someramente índices de Progreso Humano (Yang, 2014). 


\subsubsection{Felicidad Nacional Bruta (FNB) - Gross National Happiness (GNH)}

El Índice de Felicidad Nacional Bruta (FNB) que fue desarrollado por el Centro de Estudios de Bután y se basa en una encuesta que se aplica desde el año 1972, de manera intermitente,se evalúa 4 factores: 1) desarrollo socioeconómico sostenible e igualitario, 2) preservación y promoción del patrimonio cultural, 3) conservación del medioambiente y 4) gobierno responsable y transparente. El diseño del cuestionario incluye 9 dimensiones: a) bienestar psicológico, b) uso del tiempo, c) vitalidad de la comunidad, d) diversidad cultural, e) salud, f) educación, g) diversidad medioambiental, h) nivel de vida y i) gobierno.

Bután ha sido el país miembro de las Naciones Unidas que en el año 2011 llevó la propuesta de introducir en la agenda política internacional la Felicidad Interior Bruta como indicador entre las naciones ${ }^{13}$ (Naciones Unidas, 2011). Sin embargo, algunas características de su población -mayoritariamente rural $(61 \% \text { en } 2015)^{14}$ - hacen que la experiencia butanesa no sea trasladable a otros países en cuanto a la aplicación de instrumentos de medición se refiere.

A este respecto, cabe destacar que: a) una gran parte de la población es analfabeta, por lo que las encuestas solo pueden ser administradas a través de entrevistas personales, b) muchas de las preguntas con escalas en la respuesta no pueden traducirse adecuadamente a la totalidad de lenguas que se hablan en el país, por lo que es necesario reducir las escalas de cinco ítems a tres, c) no está extendido el uso de relojes entre la población de las zonas rurales, lo que dificulta que se pueda medir el uso del tiempo; además, las personas no organizan su día a partir de horas específicas, y d) la economía se desarrolla mayoritariamente en el sector informal, por lo que resulta difícil medir factores económicos y de ingresos de la población (Pennock \& Ura, 2011).

\subsubsection{Quality-of-Life Index (QLI) - Índice de Calidad de Vida}

Divulgado por única vez en el año 2005, el Índice de Calidad de Vida (Quality-of-Life Index, QLI) fue elaborado por The Economist Intelligence Institute y analizó 9 dimensiones en 111 países, que son: a) bienestar material,

$13109^{a}$ Asamblea General de las Naciones Unidas. Resolución 65/309: Felicidad, hacia un enfoque holístico del desarrollo. Resolución aprobada el 19 de julio de 2011.

14 Datos del Banco Mundial: http://datos.bancomundial.org/indicador/SP.RUR.TOTL. ZS 
b) salud, c) estabilidad política y seguridad, d) familia, e) comunidad, f) clima y geografía, g) seguridad en el empleo, h) libertad política, i) igualdad de género (The Economist, 2005) ${ }^{15}$.

\subsubsection{Happy Planet Index (HPI) - Índice del Planeta Feliz}

El Índice global de bienestar sostenible -Happy Planet Index (HPI)de la New Economics Foundation (NEF), entidad fundada en 1986 (Jeffrey, Wheatley \& Abdallah, 2016), se basa en los conceptos propuestos por Ruut Veenhoven: Happy Live Years / Happy Life Expectancy (Veenhoven, 1996) y se calcula sobre la base de: a) el bienestar experimentado (con datos de la Encuesta Mundial Gallup), b) la esperanza de vida (que toma del PNUD) y c) la distribución desigual de ambos factores en cada país (en porcentaje), en relación con el d) impacto (o huella) ambiental (Global Footprint Network). Se estudia desde el año 2006, cada 3 años, en 150 países. (NEF, 2016) ${ }^{16}$.

Happy Planet Index $\approx$ (Bienestar experimentado x Esperanza de vida) x Distribución desigual

\section{Huella ambiental}

Por otra parte, en el año 2009, esta institución analizó el bienestar personal y social en 22 países europeos y publicó el informe: Cuentas Nacionales de Bienestar: Traer riqueza real en el balance de situación (National Accounts of Well-being: Bringing real wealth onto the balance sheet).

El Informe analiza las siguientes dimensiones: Bienestar individual: a) bienestar emocional (sentimientos positivos y ausencia de sentimientos negativos), b) satisfacción con la vida, c) vitalidad, d) autoestima, optimismo y resiliencia y e) funcionamiento positivo (autonomía, competencia, compromiso, sentido y propósito). Bienestar social: a) relaciones de apoyo, b) confianza y pertenencia. También midió el bienestar en el trabajo (Michaelson et al., 2009).

En la actualidad, tiene disponible un cuestionario online (en inglés) basado en la $\mathrm{ESS}^{17}$ que permite crear un perfil personal y comparar los resultados con países europeos.

15 En este estudio del año 2005, España ocupa el lugar 10 del ranking, por encima de Finlandia, Estados Unidos y Canadá.

$16 \mathrm{http} / / /$ happyplanetindex.org

17 Disponible en: http://www.nationalaccountsofwellbeing.org/engage/survey.html 


\subsubsection{Better Life Index (BLI) - Índice para una Vida Mejor}

Better Life Index (BLI) -Índice para una Vida Mejor-, de la OCDE (Organisation for Economic Cooperation and Development) (OECD, 2013) es un índice compuesto e interactivo que, a través de una herramienta online, permite observar cómo se colocan los países en niveles diferentes de progreso, según la valoración que haga el usuario acerca de los factores relativos a la vida y el bienestar ${ }^{18}$.

Se aplica desde el año 2011 y analiza las siguientes 11 dimensiones del bienestar en 36 países $^{19}$ : a) vivienda, b) ingresos, c) empleo, d) comunidad, e) educación, f) medioambiente, g) compromiso cívico, h) salud, i) satisfacción, j) seguridad y k) balance vida-trabajo. La herramienta se encuentra disponible en varios idiomas -también en castellano-, y se nutre de estadísticas de la OCDE, las Naciones Unidas, instituciones oficiales de cada país y de la Encuesta Mundial Gallup.

\subsubsection{Legatum Prosperity Index (LPI) - Índice Legatum de} Prosperidad

El Índice de Prosperidad del Instituto Legatum (Legatum Prosperity Index, 2015), desde el año 2007 combina 89 indicadores de crecimiento económico y bienestar personal. Se construye en base a 8 dimensiones: a) economía, b) emprendimiento y oportunidades, c) gobernanza, d) educación, e) salud, f) seguridad, g) libertad personal y h) capital social (Legatum, 2013). Establece un ranking anual de 142 países prósperos en base a datos que toma, principalmente, de la Encuesta Mundial Gallup, el Banco Mundial, Amnistía Internacional, WHO y la Encuesta Mundial de Valores (World Values Survey).

\subsubsection{Index Social Development (ISD) - Índice de Desarrollo Social}

El Índice de Desarrollo Social -Index Social Development (ISD)- del Instituto Internacional de Estudios Sociales -institución con apoyo técnico y financiero del Banco Mundial-, en el año 2011 propone un índice que analiza datos recogidos entre los años 1990 y 2010, en 193 países (de Haan et al., 2011) (Veenhoven, 2012). Mide 6 dimensiones: a) activismo social, b) aso-

18 Disponible en: http:// www.oecdbetterlifeindex.org

19 http://stats.oecd.org/Index.aspx?DataSetCode=BLI 
ciacionismo, c) cohesión intergrupal, d) seguridad y confianza interpersonal, e) igualdad de género y f) minorías en riesgo de exclusión. Trabaja con datos de UNESCO, OCDE, Encuesta Mundial de Valores (WVS) y Encuesta Social Europea (ESS), de un total de 25 fuentes $^{20}$.

\subsubsection{Social Progress Index (SPI) - Índice de Progreso Social}

El Índice de Progreso Social -Social Progress Index (SPI)- del Social Progress Imperative, impulsado por Michael Porter (2013), se construye en torno a 3 dimensiones: a) necesidades básicas humanas, b) bases del bienestar y c) oportunidad - con 4 componentes cada una-, y analiza la situación de 128 países a través de 50 indicadores. Utiliza datos de la Encuesta Mundial Gallup y UNESCO, entre otras.

Este modelo parte de la premisa que sostiene que el desarrollo, si se basa exclusivamente en el progreso económico, resulta insuficiente. Propone incluir aspectos como calidad de vida, medioambiente y oportunidades para que las sociedades alcancen el progreso tanto económico como social ${ }^{21}$.

Actualmente se está trabajando en la construcción metodológica de un marco de aplicación europea de dicho Índice (European Commission, 2016).

\subsubsection{Happy Income (HI) Index - Índice de Renta Feliz}

Aloys Prinz y Björn Bünger (2011), investigadores de la Universidad de Münster, construyeron el Happy Income (HI) Index, un índice de bienestar general de países que combina la medición del bienestar económico (nivel de ingresos) con el psicosocial (evaluación subjetiva de la vida) en países europeos. Los autores sostienen que el estudio del bienestar socio-económico de una sociedad está determinado, tanto por elementos objetivos y materiales (económicos), como subjetivos y psicosociales (satisfacción subjetiva con la vida o felicidad).

Asimismo, afirman que este índice constituye un instrumento de gran utilidad que complementa la medición de la calidad de vida en las naciones, más allá de otros indicadores alternativos como el Happy Life Years (HLY), propuesto por Ruut Veenhoven en 1996 (Veenhoven, 2004). Y añaden que puede ser utilizado para elaborar y diseñar políticas y tomar decisiones.

20 Acceso a datos online: http://www.indsocdev.org/data-access.html

21 Acceso web: www.socialprogressindex.com 


\subsubsection{Ingresos equivalentes - Equivalent Incomes}

Ingresos equivalentes (Equivalent Incomes) es una medida de progreso social en Europa que construyen Decancq y Schokkaert (2014), investigadores de la Universidad Católica de Lovaina. Lo hacen a partir del análisis de 5 dimensiones, con datos de la Encuesta Social Europea (ESS) de 2008 y 2010. Dichas dimensiones son: a) condiciones materiales de vida, b) salud, c) actividades productivas, d) ocio e interacción social, e) economía y seguridad física (Decancq \& Lugo, 2013). Conscientes de las limitaciones del método explican, por ejemplo, que el índice capta las diferencias de preferencias entre grupos y no entre individuos.

\subsubsection{Harmony Index (HI) - Índice de Armonía}

El Índice de armonía -Harmony Index (HI) - construido por Daniel A. Bell y Yingchuan Mo (Bell \& Mo, 2015), analiza 4 dimensiones: a) armonía en la familia, b) en el país, c) en el mundo y d) en la naturaleza, en 27 y 43 países, basándose en el concepto confucionista de armonía. Aunque de modo preliminar, afirman que es posible que un país ocupe posiciones altas en el ranking de armonía sin que tenga niveles altos de riqueza, ni una democracia consolidada. Sin embargo, plantean que la armonía depende más de cuán extendida esté la democracia que del PIB.

\subsubsection{1. Índice de Bienestar socioemocional (IBSE) - Socioemotional Well-being Index (SEWBI)}

El Índice de Bienestar socioemocional, IBSE -Socioemotional Well-being Index, SEWBI- ha sido desarrollado por Eduardo Bericat (2013) ${ }^{22}$. Parte de la noción de «bienestar subjetivo», que incluye estados emocionales con un fundamento eminentemente social, y la reconceptualiza como «bienestar socioemocional». Para esto, recurre al cuerpo teórico de la sociología de las emociones (Bericat, 2013); concretamente, a la obra Theodore D. Kemper y Randall Collins (Bericat, 2015:37).

El modelo empírico de medición del bienestar socioemocional de Bericat (ib. 2013) está compuesto por 4 factores que incluyen la evaluación que las

22 Catedrático de Sociología de la Universidad de Sevilla (España). 
personas hacen de los mismos, a través de la valoración de 10 estados emocionales que han experimentado recientemente.

Éstos son: a) nivel de estatus (Factor 1), es decir, la cantidad de recompensas que una persona recibe voluntariamente de las otras -que relaciona con estados emocionales de tristeza, depresión y soledad-, b) situación objetiva general en la que vive (Factor 2) -a la que asocia los estados de disfrute, alegría y satisfacción-, c) el sí mismo, el propio yo o persona (Factor 3) -que vincula a los estados emocionales de autoestima, optimismo y orgullo-, y d) nivel de recursos de poder con los que afronta sus interacciones sociales (Factor 4) -que relaciona con descanso, calma y energía-.

Desde esta perspectiva, la felicidad es una realidad multidimensional, condicionada fundamentalmente, por estas cuatro dimensiones: el estatus, la situación, la persona (sí mismo) y el poder.

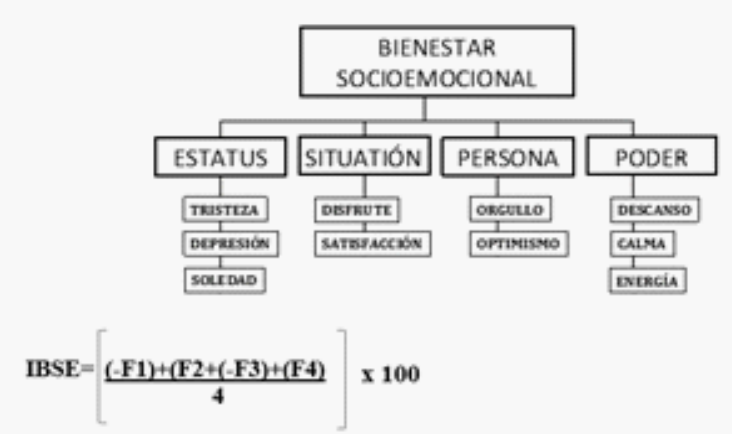

Índice de Bienestar Socioemocional: Factores y estados emocionales. Fuente: Eduardo Bericat, 2013

El IBSE fue validado a partir de datos de la Encuesta Social Europea (ESS, 2006) -55 preguntas que miden variables de bienestar personal y social, y estados emocionales- y del Barómetro del Centro de Investigaciones Sociológicas de diciembre de 2011, que incorporó una pregunta sobre estados emocionales (CIS, 2011:13, pregunta 23) ${ }^{23}$.

23 «A continuación le voy a hacer unas preguntas sobre cómo se siente en la actualidad. ¿Podría decirme en qué medida se siente últimamente muy, bastante, poco o nada...? a) orgulloso/a de sí mismo/a, b) preocupado/a por las cosas que le están sucediendo, c) rebosante de energía y vitalidad, d) que está solo/a, e) que está disfrutando mucho de la vida, f) deprimido/a, sin ganas de hacer nada, g) estresado/a por la cantidad de cosas que tiene que hacer, h) satisfecho/a con la vida que lleva» (Barómetro del CIS n. ${ }^{\circ} 2.923$ ). 
A partir de la construcción de este Índice, Bericat ha realizado sucesivos análisis de la realidad socioemocional de la población de España, estudiando la desigualdad social y el bienestar socioemocional de las personas. Ha elaborado una tipología del malestar y bienestar emocional, ha analizado el IBSE en situaciones de enfermedad y discapacidad, empleo y desempleo, pobreza y riqueza, en población joven y adulta, en mujeres y hombres en su libro Excluidos de la felicidad (Bericat, 2015).

\subsubsection{World Happiness Report - Informe Mundial de Felicidad}

El Informe mundial de felicidad -World Happiness Report ${ }^{24}-$ de la Red de Soluciones de Desarrollo Sostenible de las Naciones Unidas (UN Sustainable Development Solutions Network), es un Informe anual que presenta el ranking de países según la Escala de Vida de Cantril (Cantril, 1965). Analiza datos del Banco Mundial y de la Encuesta Mundial Gallup en más de 155 países, a través de 6 dimensiones: a) PIB per cápita, b) redes de apoyo social y relaciones personales, c) esperanza de vida relacionada con «vivir más años de manera saludable», d) libertad para tomar decisiones, e) buen gobierno -vinculado a la percepción del grado de corrupción- y f) generosidad (Helliwell et al., 2016) ${ }^{25}$. Helliwell incorpora otros cinco aspectos interconectados: a) la dimensión social, b) la humana (incluida especialmente la salud), c) la económica, d) la ambiental y e) la política (SHEEP Principle) (Helliwell, 2014).

Desde el año 2012 los sucesivos Informes Mundiales de Felicidad insisten en la relevancia e interés que dichas mediciones presentan para los gobiernos a la hora de orientar el diseño de políticas públicas y evaluar el bienestar general de la población.

El Informe 2017 destaca la importancia que tienen la salud (mental y física) y las relaciones personales en la percepción de felicidad en países ricos, a diferencia de los más pobres, en los que cobran mayor relevancia el trabajo y la calidad del trabajo (Helliwell, 2017).

Además, coloca a España como uno de los 15 países en los que más ha caído (junto con Italia y Grecia) la percepción de felicidad (con un valor negativo: -0,669). Esto podría explicarse por factores económicos, políticos y sociales de la experiencia post crisis.

$24 \mathrm{http}: / /$ worldhappiness.report/

25 Metodología utilizada: http://www.gallup.com/178667/gallup-world-pollwork.aspx; http://worldhappiness.report/faq/ 


\subsection{Una mirada sobre la España feliz}

Los gráficos que se presentan a continuación han sido elaborados a partir de datos obtenidos de la búsqueda realizada sobre estudios del Centro de Investigaciones Sociológicas (CIS), que incluyeran el término «felicidad» en alguna de sus preguntas.

Identificar que han sido 68 en el periodo comprendido entre los años 1967-2016 (1,68 de media en 50 años), permite observar cómo se pasó de la casi inexistencia ( 0 o 1 estudio por año) a la realización de tres estudios por año, en 2012 y 2013.

A partir del año 2014 se realizan entre 12 y 14 estudios al año, cuando se incorpora al cuestionario del Barómetro, de manera definitiva, una pregunta vinculada a la autopercepción de felicidad ${ }^{26}$.

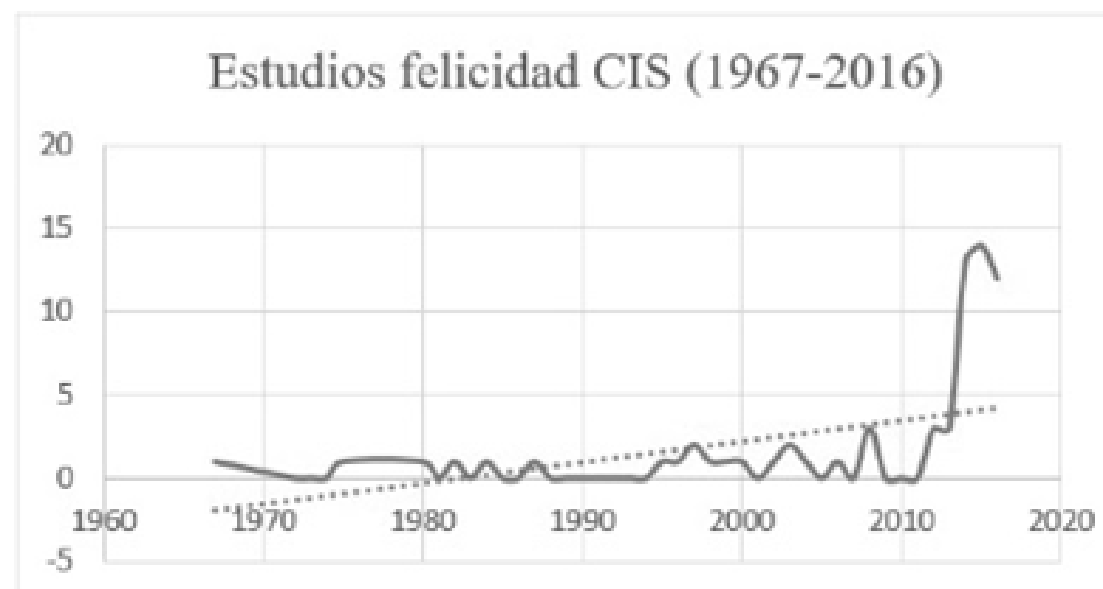

Fuente: Centro de Investigaciones sociológicas. Elaboración propia.

26 En términos generales, ¿en qué medida se considera usted una persona feliz o infeliz? Por favor, use una escala de 0 a 10 en la que 0 significa que se considera «completamente infeliz» y 10 que se considera «completamente feliz» (Tabla J25). 


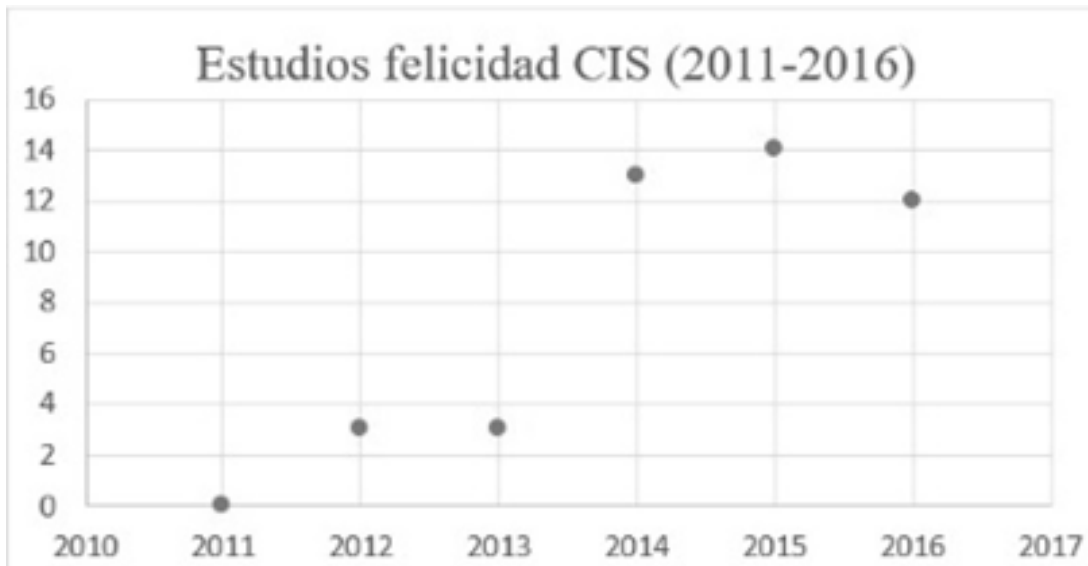

Fuente: Centro de Investigaciones sociológicas. Elaboración propia.

En el año 2008, el Centro de Investigaciones Sociológicas publicó un estudio sobre Redes sociales y bienestar que analizó datos del CIS, de Metroscopia (2007) y del International Social Survey Programme (2003). El informe planteaba que la calidad de vida de las personas está condicionada por la calidad de las relaciones personales y familiares, la cual corresponde a la calidad afectiva de las relaciones (Meil, 2008).

Además de la medición sobre bienestar socioemocional que contiene la pregunta 23 del Barómetro de diciembre de 2011 mencionada anteriormente (Estudio 2.923), utilizada por Eduardo Bericat en la validación de su modelo (ib., 2013), el Barómetro de enero de 2012 analiza la valoración de la población acerca de aspectos tales como el trabajo, la familia, la política, el bienestar económico, el tiempo libre, la salud, la religión y las relaciones personales (amistad y pareja), y posiciona a la salud y la familia por encima del trabajo y el bienestar económico (CIS, 2012).

El análisis más completo de los revisados hasta el momento, es el publicado en el Anuario de 2013 (CIS, 2014) en el capítulo referido a Hábitos sociales, que analiza las siguientes dimensiones relativas a felicidad y satisfacción con la vida personal: a) escala de egoísmo de los ciudadanos, b) tolerancia de diversos comportamientos socialmente no legítimos, c) factores para ser feliz, d) escala de felicidad personal, e) escala de satisfacción con la vida 
personal, f) escala de satisfacción con distintos aspectos de la vida personal, g) escala de control sobre la manera en que se desarrolla su vida ${ }^{27}$ (CIS, 2013).

Como he mencionado anteriormente, es a partir del año 2014 que se incluye en el cuestionario del Barómetro del CIS una pregunta que solo mide la percepción de felicidad a través de la Escala de felicidad personal.

\subsection{El futuro de la felicidad}

Hasta aquí el desarrollo de una primera síntesis en el campo de los estudios sobre bienestar y felicidad. Acabo de presentar los que, desde mi punto de vista, son los principales autores, desarrollos e índices (con sus dimensiones y variables) que deberían ser tenidos en cuenta en el momento de reflexionar acerca de la medición de la felicidad y el bienestar socioemocional.

Lo expuesto hasta el momento, aunque de modo provisional, muestra cómo muchos de estos índices se basan en variables que miden aspectos relativos al campo de estudio y, si bien en muchos aspectos confluyen y coinciden, no terminan de ser comparables en cuanto a dimensiones, alcance y temporalidad se refiere.

A continuación presento un cuadro-resumen de referencia con los índices mencionados en este trabajo, por año en el que se construyó o utilizó por primera vez y autor (o institución):

\begin{tabular}{|l|l|l|}
\hline Año & Autor/Institución & Denominación Índice \\
\hline 1934 & Simon Kuznets & $\begin{array}{l}\text { Producto Interior Bruto } \\
\text { (PIB) }\end{array}$ \\
\hline 1972 & $\begin{array}{l}\text { Centro de Estudios de } \\
\text { Bután }\end{array}$ & $\begin{array}{l}\text { Gross National Happiness } \\
\text { (GNH) - Felicidad Nacio- } \\
\text { nal Brutal (FNB) }\end{array}$ \\
\hline 1990 & PNUD & $\begin{array}{l}\text { Índice de Desarrollo } \\
\text { Humano (IDH) }\end{array}$ \\
\hline 1995 & Ed Diener & $\begin{array}{l}\text { (Combined) Quality of } \\
\text { Live Index - Indice de } \\
\text { Calidad de Vida Combi- } \\
\text { nado }\end{array}$ \\
\hline 1996 & Ruut Veenhoven & $\begin{array}{l}\text { Happy-Life Years (HLY) } \\
\text { - Años de Vida Feliz }\end{array}$ \\
\hline
\end{tabular}

27 Estudio n. ${ }^{\circ} 2.990$ de junio de 2013. 


\begin{tabular}{|c|c|c|}
\hline Año & Autor/Institución & Denominación Índice \\
\hline 2005 & The Economist & $\begin{array}{l}\text { Quality-of-Life Index } \\
\text { (QLI) - Índice de Calidad } \\
\text { de Vida }\end{array}$ \\
\hline 2006 & $\begin{array}{l}\text { New Economics Foun- } \\
\text { dation }\end{array}$ & $\begin{array}{l}\text { Happy Planet Index (HPI) } \\
\text { - Índice del Planeta Feliz } \\
\end{array}$ \\
\hline 2007 & Legatum Institute & $\begin{array}{l}\text { Legatum Prosperity Index } \\
\text { (LPI) - Índice Legatum de } \\
\text { Prosperidad }\end{array}$ \\
\hline 2011 & Prinz y Bünger & $\begin{array}{l}\text { Happy Income (HI) Index } \\
\text { - Índice de Renta Feliz } \\
\end{array}$ \\
\hline 2011 & Banco Mundial & $\begin{array}{l}\text { Index Social Develop- } \\
\text { ment (ISD) - Índice de } \\
\text { Desarrollo Social }\end{array}$ \\
\hline 2012 & UN, John Helliwell & $\begin{array}{l}\text { World Happiness Report } \\
\text { - Informe Mundial de } \\
\text { Felicidad }\end{array}$ \\
\hline 2013 & OCDE & $\begin{array}{l}\text { Better Life Index (BLI) } \\
\text { - Índice para una Vida } \\
\text { Mejor }\end{array}$ \\
\hline 2013 & Eduardo Bericat & $\begin{array}{l}\text { Socioemotional Well- } \\
\text { being Index (SEWBI) } \\
\text { - Índice de Bienestar } \\
\text { Socioemocional }\end{array}$ \\
\hline 2013 & Michael Porter & $\begin{array}{l}\text { Social Progress Index } \\
\text { (SPI) - Índice de Progreso } \\
\text { Social }\end{array}$ \\
\hline 2014 & Decancq y Schokkaert & $\begin{array}{l}\text { Equivalent Incomes - In- } \\
\text { gresos Equivalentes }\end{array}$ \\
\hline 2015 & Daniel Bell & $\begin{array}{l}\text { Harmony Index (HI) - } \\
\text { Índice de Armonía }\end{array}$ \\
\hline
\end{tabular}

CUADRO-RESUMEN: Medición de felicidad y bienestar. Índices, por autor y año. Elaboración propia

Como he mencionado anteriormente, considero que las ciencias sociales poseen, en la actualidad, desarrollo conceptual e instrumentos suficientes como para incorporar un índice a través del cual sea posible medir, analizar y comparar la evolución de la «felicidad» (bienestar socioemocional, satisfacción con la propia vida y calidad de la misma) entre personas y países. 
En este sentido, unificar criterios de medición, permitirá realizar análisis profundos y seguimientos comparados de la evolución de la calidad de vida de las personas, la calidad afectiva de las relaciones sociales y la satisfacción con la propia vida, complementarios a los estudios de la distribución del ingreso per cápita.

Por otra parte, al contar con información sobre la calidad del sistema social será posible diseñar y elaborar políticas públicas más ajustadas a la experiencia y necesidades de la ciudadanía.

Entiendo que el desafío de la sociología en este sentido es generar un índice consensuado, que pueda ser trasladado y utilizado por centros de investigación, organismos públicos y agencias estadísticas oficiales de los estados de manera estandarizada y sistemática. Tenemos trabajo.

\subsection{Bibliografía}

AFSA, C., BLANCHET, D., MARCUS, V., PIONNIER, P., RIOUX, L., MIRA D'ERCOLE, M., RANUZZI, G. \& SCHREYER, P. (2008). Survey of existing Approaches to measuring Socio-economic Progress. Commission on the Measurement of Economic Performance and Social Progress.

BELL, D. A. \& MO, Y. (2014). «Harmony in the World, 2013: The Ideal and the Reality». Social Indicators Research 118, n. $^{\circ} 2$, pp. $797-818$.

BELL, D. A. \& MO, Y. (2015). «The China Model: Political Meritocracy and the Limits of Democracy». Princeton University Press.

BERICAT, E. (2013). «The Socioemotional Well-Being Index. Theoretical Framework and Empirical Operationalisation». Springer Science+Business Media Dordrecht.

BERICAT, E. (2015). Excluidos de la felicidad. Las desigualdades de bienestar emocional en España y Europa. En: https://www.researchgate.net/publication/287814426

CANTRIL, H. (1965). The pattern of human concerns. New Brunswick, NJ. Rutgers University Press.

CENTRO DE INVESTIGACIONES SOCIOLÓGICAS - CIS. (2011). Barómetro de diciembre. Estudio $n^{\circ}{ }^{\circ}$ 2.923. Diciembre 2011.

CENTRO DE INVESTIGACIONES SOCIOLÓGICAS - CIS. (2012). Barómetro de enero. Estudio n. ${ }^{\circ} 2.927$. Enero, 2012.

CENTRO DE INVESTIGACIONES SOCIOLÓGICAS - CIS. (2013). Barómetro de junio. Estudio n. ${ }^{\circ}$ 2.990. Diciembre 2013.

CENTRO DE INVESTIGACIONES SOCIOLÓGICAS - CIS. (2014). Anuario 2013. Mayo, 2014. 
DE HAAN, A., VAN STAVEREN, I., WEBBINK, E. \& FOA, R. (2011). «The last mile in analysing well-being and poverty: Indices of Social Development». ISD (Indices of Social Development). Working Paper Series n. ${ }^{\circ}$ 2011-03. The Hague. Institute of Social Studies.

DECANCQ, K. \& SCHOKKAERT, E. (2014). Beyond GDP. Measuring Social Progress in Europe. Euroforum. Ku Leuven.

DIENER, E. (1995). «A value based index for measuring national quality of life». Social Indicators Research. Vol. 36, n. ${ }^{\circ}$ 2, pp. 107-127.

DIENER, E., SUH, E., LUCAS, R. \& SMITH, H. (1999). «Subjective Well-being: Three Decades of Progress». Psycological Bulletin, Vol. 125, n. ${ }^{\circ}$ 2. American Psycological Association, pp. 276-302.

ESS ROUND 3: EUROPEAN SOCIAL SURVEY (2016). ESS-3 2006 Documentation Report. Edition 3.6. Bergen, European Social Survey Data Archive, NSD - Norwegian Centre for Research Data for ESS ERIC.

ESS ROUND 6: EUROPEAN SOCIAL SURVEY (2012). Data file edition 2.3. NSD

- Norwegian Centre for Research Data, Norway - Data Archive and distributor of ESS data for ESS ERIC.

EUROFOUND (2014). Social cohesion and well-being in the EU. EuroFound- Bertelsmann Stiftung.

EUROPEAN COMMISION (2016). The EU Regional Social Progress Index: Methodogical Note (EU-SPI). Directorate-General. Regional and Urban Policy. Economic Analysis Unit.

FUKUDA-PARR, S. (2003). «The Human Development Paradigm: Operationalizing Sen's Ideas on capabilities». Feminist Economics, Vol. 9, n. ${ }^{\circ}$ 2-3, pp. 301-317.

GALLUP, G. (1976). «Human Needs and Satisfactions: A Global Survey». Oxford Journals. Social Sciences. Public Opinion Quarterly. Volume 40 Issue 4. The American Association for Public Opinion Research (AAPOR), pp. 459-467.

HELLIWELL, J. (2014). "Social norms, happiness and the environment: closing the circle». Sostainability: Science, Practice \& Policy. Winter 2014, Vol. 10, Issue 1.

HELLIWELL, J., LAYARD, R., \& SACHS, J. (2016). World Happiness Report 2016, Update (Vol. I). New York. Sustainable Development Solutions Network.

HELLIWELL, J., LAYARD, R., \& SACHS, J. (2017). World Happiness Report 2017, New York. Sustainable Development Solutions Network.

JEFFREY, K., WHEATLEY, H. \& ABDALLAH, S. (2016). The Happy Planet Index: 2016. A global index of sustainable well-being. London. New Economics Foundation.

KUZNETS, S. (1937). «National Income and Capital Formation, 1919-1935. A preliminary Report». Publications of the National Bureau of Economic Research, Vol. 32. New York. NBER.

LEGATUM INSTITUTE (2013). Legatum Prosperity Index. Methodology and Technical Appendix.

LEGATUM INSTITUTE (2015). Legatum Prosperity Index. Legatum Institute. 
LYUBOMIRSKY, S., KING, L. \& DIENER, E. (2005). «The benefits of frequent positive affect: Does happiness lead to success?» Psychological Bulletin, Vol. 131, n. ${ }^{\circ}$ 6. American Psychological Association, pp. 803-855.

MICHAELSON, J. ABDALLAH, S., STEUER, N., THOMPSON, S. \& MARKS, N. (2009). National Accounts of Well-being: bringing real wealth onto the balance sheet. New Economics Foundation, Mary Murphy. London. UK.

NACIONES UNIDAS (2011). 109 Asamblea. Resolución 65/309: Felicidad, hacia un enfoque holístico del desarrollo. Resolución aprobada por la Asamblea General el 19 de julio de 2011. A/RES/65/309.

NEF (2016). Happy Planet Index 2016. Methods Paper. New Economics Foundation.

OECD (2013). OECD Guidelines on Measuring Subjective Well-being. OECD Publishing.

PENNOCK, M. \& URA, K. (2011). «Gross National Happiness as a Framework for Health impact assessment». Environmental Impact Assesment Review, n. ${ }^{\circ} 31$, pp. $61-65$. Crown Copiright 2010. Elsevier.

PNUD (2015). Informe sobre Desarrollo Humano 2015. Trabajo al servicio del desarrollo humano. Communications Development Incorporated, Washington DC, EE.UU.

PORTER, M., STERN, S., \& LORIA, R. A. (2013). Social progress index 2013. Washington, DC: Social Progress Imperative.

PORTER, M., STERN, S., \& GREEN, M. (2015). Social Progress Index 2015. Washington, DC: Social Progress Imperative.

PRINZ, A. \& BÜNGER, B. (2011). «The usefulness of a Happy Income Index». EconPapers n. ${ }^{\circ}$ 15, Discussion Papers from Center of Applied Economic Research Münster (CAWM), University of Münster.

REAL ACADEMIA ESPAÑOLA (2014). Diccionario de la lengua española. $23^{\mathrm{a}}$ Edición. Madrid.

SEN, A. (2003). «Development as Capability Expansion». Readings in Human Development: Concepts, Measures, and Policies for a Development Paradigm. Edited by Fukuda-Parr \& Shiva Kumar. New Delhi and New York. Oxford University Press.

SOUBBOTINA, T. P. (2000). Beyond Economic Growth: An Introduction to Sustainable Development. World Bank Publications.

STIGLITZ, J., SEN, A. \& FITOUSSI, J. P. (2009). Report by the Commission on the Measurement of Economic Performance and Social Progress. Paris.

THE ECONOMIST (2005). The Economist Intelligence Unit's Quality-of-life Index. The World in 2005.

UL HAQ, M. (2003/1995). «The Human Development Paradigm». Readings in Human Development. Edited by Fukuda-Parr \& Shiva Kumar. Oxford, UK. Oxford University Press, pp. 17-34.

VEENHOVEN, R. (1970). «Geluk als onderwerp van wetenschappelijk onderzoek». Sociologische gids, 17(2), 115-122. 
VEENHOVEN, R. (1984). «Conditions of Happiness». D. Reidel Publishing Company, Member of Kluwer Academic Publishers Group. Dordrecht/Boston/Lancaster.

VEENHOVEN, R. (1996). «Happy Life expectancy. A comprehensive measure of quality-of-life in nations». Social Indicators Research, vol. 39, pp. 1-58.

VEENHOVEN, R. (2000). «Well-being in the Welfare State. Level not Higher, Distribution not More Equitable». Journal of Comparative Policy Analysis, vol. 2, pp. 91-125.

VEENHOVEN, R. (2001a). «Qualità della vita e felicità. Non è proprio la stessa cosa». Salute e Qualità della Vita. A cura di: G. de Girolamo, A. Becchi, F.S. Coppa, D. De Leo, G. Neri, P. Rucci \& P. Scocco, Centro Scientifico Editore. Torino, Italia. Capitolo 6, pp. 67-95.

VEENHOVEN, R. (2001b). What we know about Happiness. Paper presented at the dialogue on "Gross National Happiness". Woudschoten, Zeist, Netherlands.

VEENHOVEN, R. (2004). «Happy Life Years: A measure of Gross National Happiness». K. Ura, and K. Galay (eds.), Gross national happiness and development - Proceedings of the First International Seminar on Operationalization of Gross National Happiness. Centre for Bhutan Studies, Thimphu, pp. 287-319.

VEENHOVEN, R. (2008). «Sociological Theories of Subjective Well-being». The Science of Subjective Well-being: A tribute to Ed Diener. Edited by Michael Eid \& Randy Larsen. Guilford Publications. New York, pp. 44-61.

VEENHOVEN, R. (2012). Social Development and Happiness in Nations. Working paper n. ${ }^{\circ}$ 2012-3. The Hague. Institute of Social Studies.

WILKINSON, R. \& PICKETT, K. (2009). Desigualdad. Un análisis de la (in)felicidad colectiva. Turner Noema.

WRIGHT, E. O. (2013). «Transforming Capitalism through Real Utopias». American Sociological Review, 78, pp. 1-25.

YANG, L. (2014). «An Inventory of Composite Measures of Human Progress». Occasional Paper. Human Development Reports. UNDP. 
8

\section{LA CALIDAD DE VIDA DE LOS USUARIOS COMO REFERENCIA PARA MEJORAR LAS INTERVENCIONES. UNA EVALUACIÓN DE IMPACTO EN E.M.}

\author{
José Carrón Sánchez \\ Universidad de Zaragoza \\ jcarron@unizar.es \\ Javier Arza Porras \\ Universidad Pública de Navarra
}

\author{
Sagrario Anaut Bravo \\ Universidad Pública de Navarra \\ José Antonio Villanueva Oyarzábal \\ ADEMNA
}

\subsection{Introducción}

\subsubsection{Avances conceptuales en la calidad de vida como eje de la intervención}

La investigación en torno a la calidad de vida y la discapacidad, ha conseguido avances importantes en la fundamentación científica de sus principales dimensiones y en el diseño de indicadores que permiten medirlas. Desde nuestra perspectiva, la propuesta más consolidada es la desarrollada por Schalock y Verdugo (Schalock y Verdugo, 2010). A partir de él, se han diseñado algunos de los instrumentos de evaluación de la calidad de vida con mayores evidencias de validez en el ámbito nacional e internacional (Aznar y Castañón, 2005; Chou et al., 2007; Verdugo, Schalock, Gómez, y Arias, 2007; Flores, Jenaro, González-Gil, y García-Calvo, 2010; Gómez, Verdugo, y Arias, 2010; Verdugo, Gómez, Arias, y Schalock, 2011; Verdugo et al., 2013).

Los nuevos enfoques en torno a la calidad de vida como elemento central en el abordaje de la discapacidad tienen para el caso de la esclerosis múltiple un reflejo preciso en los Principios Internacionales para promover la calidad de vida de las personas con esclerosis múltiple (MSIF, 2002). En ellos los parámetros médicos y asistenciales pasan a constituir, en sintonía con el concepto de calidad de vida de la OMS (WHOQOL Group, 1995), un elemento más dentro de un planteamiento estratégico dirigido a lograr una mejora significativa en la calidad de vida de los afectados. Se estructura en torno a 
10 principios, cuya sola enumeración nos pone en la pista de este cambio de enfoque: independencia y empoderamiento; asistencia médica; asistencia continua (cuidados de larga duración); promoción de la salud y prevención de la enfermedad; apoyo a miembros de la familia; transporte; empleo y actividades de voluntariado; pensiones y ayudas económicas por discapacidad; educación; vivienda y accesibilidad a edificios públicos.

En el marco de nuestro programa de investigación, y desde esta perspectiva, durante el año 2011 desarrollamos con la asociación ADEMNA un estudio cuyo objeto era el conocimiento de la situación y necesidades de las personas afectadas por esta enfermedad en Navarra, concluyendo con una propuesta de acciones enfocadas a la mejora de su calidad de vida (Carrón y Arza, 2013).

La investigación nos mostraba mejoras significativas principalmente en aspectos médico-sanitarios, pero también revelaba debilidades en otras áreas relacionadas con la autonomía y movilidad de las personas afectadas, con su inserción en el ámbito laboral, con sus relaciones sociales, con la necesidad de mejorar el apoyo a su entorno familiar o con la imagen social.

En los análisis relacionados con los servicios e intervenciones que tienen a las personas como destinatario último del proceso desarrollado por cualquier organización, la complejidad creciente de las estructuras y la fragmentación de la atención al usuario constituye uno de los puntos críticos más relevantes. Esta reorientación hacia la persona no es exclusiva del ámbito sanitario ni del social, sino que está presente en la orientación de cualquier organización moderna. De hecho, la gestión de la calidad la incluye como uno de sus ejes fundamentales. Tanto la norma ISO como el modelo EFQM (Aenor, 2016), que constituyen los sistemas con mayor implantación en el ámbito de la calidad, sostienen que las organizaciones deben orientarse hacia el logro de la satisfacción en sus clientes como elemento que guíe la gestión de la organización.

Pero ya a principios del siglo XX, en la definición del modelo de trabajo social de caso, Mary E. Richmond, ponía el acento en la importancia que los enfoques centrados en la persona tenían para el logro de una eficaz y eficiente coordinación y cooperación entre distintas agencias (Richmond, 1995). Posteriormente, a finales de los años 50, Helen Harris revisaría críticamente este modelo, y especialmente la manera en la que había sido puesto en práctica, aportando fundamentalmente dos matizaciones: a) el proceso de trabajo de 
caso no debe ser conducido únicamente por el o la «especialista», sino que se debe lograr la participación activa de la persona; b) el trabajo de caso debe centrarse en la persona y en el proceso de atención, y no en el problema (Harris, 1970).

Estas aportaciones de Helen Harris estaban muy influenciadas por las enseñanzas de Carl Rogers y su enfoque humanista. Rogers abunda en la necesidad de lograr la participación de la persona en el análisis y la resolución de sus propios problemas. Plantea que el peso de la terapia debe estar en la persona y no en el terapeuta. Asimismo, insiste en aportar una gran importancia a las actitudes del terapeuta. Si el peso de la terapia debe llevarlo la persona, el terapeuta debe encargarse de construir una relación facilitadora. Para ello, debe tener integradas tres tipos de actitudes básicas: la empatía, la aceptación positiva incondicional y la autenticidad o congruencia (Rogers, 1997).

Sin embargo hay autores que ponen de manifiesto que, en ocasiones el excesivo énfasis que podemos encontrar relativo a la centralidad de los procesos participativos de las personas no son sino una postura «estética» sin mayor impacto en la intervención. Es el caso de Martín-García et al. (2006) que, refiriéndose a las políticas participativas en el ámbito de la salud, afirman que «el paciente en el centro del sistema es una máxima repetida hasta la saciedad, aunque realmente responda a pura retórica». En el mismo sentido, Martínez y Sanjuán (2009) plantean «cómo sistemas sanitarios que dicen estar -centrados en el paciente/usuario- tienen tan poco en cuenta su toma de decisiones en el diseño de políticas sanitarias públicas, lo que se ha venido a denominar, siguiendo las corrientes de la Ilustración de los siglos XVII y XVIII, como -despotismo sanitario-, reflejado en el hecho de que se trata de un sistema que hace todo por el paciente sin tener en cuenta al paciente».

Una estrategia que cobra progresivamente fuerza para hacer realidad esa centralidad de la población usuaria en los procesos organizacionales en el ámbito de la discapacidad, es potenciar que la calidad de vida se convierta en el eje articulador de la organización en su conjunto. En esa línea, el enfoque de derechos promulgado en la Convención sobre los Derechos de las Personas con Discapacidad (ONU, 2006) propone que el modelo de calidad de vida se convierta en el vehículo para implementar y monitorizar los derechos. 


\subsubsection{Una estrategia de investigación para situar la calidad de vida como motor del cambio organizacional}

Desde esta perspectiva, una vez dado el primer paso con la investigación sobre la situación y necesidades de las personas afectadas, necesitábamos un nuevo reto dentro del programa global de investigación. Se revelaba esencial analizar el impacto de los recursos y servicios sociosanitarios en la calidad de vida, evaluar la evolución de la calidad de vida de las personas usuarias y evidenciar la relación entre las dimensiones de calidad de vida y la especificidad de las intervenciones que se estaban llevando a cabo.

En la primera fase de la nueva línea de investigación, financiada por Fundación Caja Navarra (2014-15), se procedió a la aplicación de la escala GENCAT (Verdugo et al. 2007) una vez realizada su adaptación para las personas con Esclerosis Múltiple en la nueva versión GENCAT+EM. Se recogieron un total de 191 cuestionarios relativos a la calidad de vida de las personas usuarias de ADEMNA, 63 cumplimentados por profesionales y 128 por personas usuarias de los servicios. En 56 casos disponemos de una información-espejo, tanto de la valoración ofrecida por el profesional como por la propia persona afectada.

Los resultados obtenidos han permitido estructurar conclusiones en tres niveles diferentes: valorar los datos de cada una de las ochos dimensiones de las personas usuarias; contrastar la información obtenida desde una perspectiva de los profesionales y de las personas usuarias, analizando el contraste en cada una de las dimensiones; valorar las diferencias entre los dos tipos de intervención, el Centro de Día y la prestación de otros servicios.

Las personas con esclerosis múltiple que utilizan los servicios ofrecidos por ADEMNA destacan el bienestar emocional como la dimensión más afectada en relación con su calidad de vida. De las ocho dimensiones, el bienestar emocional recibe en una escala porcentual la puntuación más baja, un 77,0\%, seguida de bienestar físico y desarrollo personal, un $80,2 \%$ y un $80,4 \%$ respectivamente. A continuación figuran, y por este orden, relaciones interpersonales, inclusión social y autodeterminación. Por el contrario, dimensiones como el bienestar material, con un $88,5 \%$, y sobre todo lo relativo a sus derechos, calificada con un $93,9 \%$, son las que tienen una mejor valoración desde la perspectiva de las personas afectadas. 


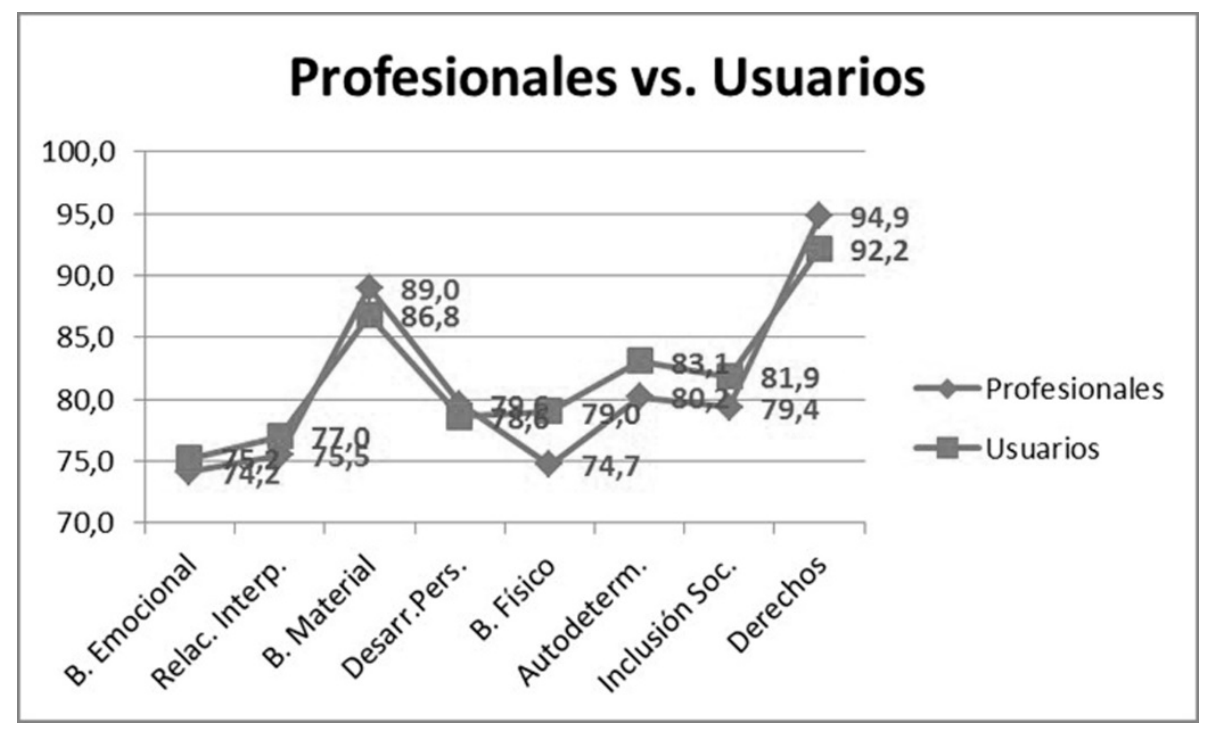

GRÁFICO 1. Valoración de las dimensiones de Calidad de Vida. Fase I: Profesionales vs. Población Usuaria

Si contrastamos las valoraciones otorgadas por los profesionales y las personas usuarias, utilizando para ello aquellos casos de los que disponemos de «cuestionarios-espejo» los usuarios otorgan un 75,2 sobre 100 al nivel de su bienestar emocional y los profesionales que desarrollan dichos servicios un 74,2 sobre 100. En ambos casos son las puntuaciones más bajas de cada una de las ocho dimensiones a las que hemos hecho referencia. Las dos perspectivas presentan una estructura muy similar en cuanto a la relevancia de las diferentes dimensiones. Coinciden en la valoración del bienestar emocional como la dimensión más afectada, pero también presentan una coincidencia significativa en identificar las áreas con puntuaciones más altas. Los aspectos relacionados con los derechos, con el bienestar material o con la autodeterminación son las dimensiones con valoraciones más elevadas tanto por los usuarios del centro como por los profesionales. Destaca, por la ruptura de ciertos estereotipos, que en relación con el bienestar físico las personas afectadas (se autoasignan un 79,0) se perciben significativamente mejor que la valoración de su situación física que realizan los profesionales (un 74,7\%).

Finalmente, en relación con la asistencia al Centro de Día o, por el contrario, a otro tipo de servicios que presta la asociación se produce un diferencial 
revelador para futuros retos del proyecto. Respecto a las personas que acuden a otro tipo de servicios, habitualmente con una frecuencia menor, las valoraciones de profesionales y usuarios son prácticamente parejas. En cambio, los cuestionarios-espejo de aquellos que acuden con regularidad al Centro de Día muestran unas valoraciones notablemente dispares. Los profesionales, en todas las dimensiones valoradas, asignan puntuaciones más bajas que las asignadas por las personas usuarias. Este diferencial es especialmente significativo en lo relativo a la autodeterminación o a la inclusión social, pero en el caso del bienestar físico los usuarios llegan a superar en casi ocho puntos porcentuales la valoración realizada por los profesionales.

Con estos resultados disponíamos de una información estratégica para encarar los siguientes pasos del programa global de investigación. Pretendemos diseñar una adaptación de la intervención orientada por los datos de las diferentes dimensiones de calidad de vida y evaluar el impacto que esta nueva estrategia puede tener en la mejora de la calidad de vida de la población usuaria.

\subsection{Estrategia metodológica}

En la segunda fase, cuyo objetivo general es el diseño y la implementación de medidas de mejora a partir de los resultados anteriores, el principal cambio organizacional que se pretende es consolidar un proceso de trabajo para la redefinición y adaptación de los PIAs en función de la valoración particular de las dimensiones de calidad de vida. Esa adaptación se aplicará a un subgrupo de la población usuaria que conformen el grupo experimental en tanto que se definirá otro subgrupo en el que se continuará trabajando con los protocolos habituales. Los resultados de ambos subgrupos podrán contrastarse en los diferentes planos en que se analizaron los resultados de la fase anterior.

Como medida general estratégica para el funcionamiento de la entidad se establece la necesidad de identificar un elemento a través del cual se articulen los cambios en la atención que se presta a la población usuaria. Se selecciona el PIA (Programa Individualizado de Atención) como estructura en la que aplicar esas modificaciones adaptadas a cada persona usuaria y que permitirá hacer un seguimiento y control de su aplicación y resultados.

En una jornada de trabajo del equipo investigador con los profesionales de la entidad se discute y acuerda la oportunidad de esta estrategia, se esta- 
blece la creación de un grupo de trabajo y se consensúa una dinámica para la aplicación en los procesos de atención. Ello deberá verse traducido en el diseño de modificaciones específicas en los correspondientes PIAs de una muestra de población usuaria así como su comparación con otra muestra de control.

Para la selección de sendas muestras experimental y control, se identificó a las 18 personas atendidas en el Centro de Día y se les administró a todas ellas la escala GENCAT+EM perfeccionada en la fase anterior de la investigación. Sobre cada persona usuaria se realizaron dos evaluaciones previas una de ellas autoadministrada directamente por las personas usuarias y otra realizada por los profesionales del Centro de Día.

Sobre el total de población usuaria se realizó una división en dos muestras de 9 personas cada uno en función de variables de género, nivel de discapacidad y dependencia, afectación de la enfermedad y situaciones personales para que ambas muestras fueran lo más equilibradas posibles.

Por sorteo se escogió una de las muestras, que se identificó como grupo experimental, y que fue la seleccionada para llevar a cabo las modificaciones en sus respectivos PIAs. Dichas modificaciones se establecen de acuerdo con las prioridades establecidas en el grupo de trabajo a partir de los resultados de la aplicación inicial de la escala

Las puntuaciones son dispares entre unos y otros sujetos, pero la pauta constante que seguimos es partir de aquellas áreas con menor puntuación y es en base a ellas que se definen los objetivos. Sin embargo, nos encontramos con la dificultad de que las áreas con puntuaciones más bajas no siempre coincidían en ambas evaluaciones (población usuaria/profesionales). Se decidió valorar cada caso y priorizar el criterio del terapeuta, teniendo en cuenta que la experiencia clínica nos indica una cierta frecuencia de anosognosia de las personas usuarias, es decir, la falta de conciencia en ocasiones de sus propias situaciones o limitaciones.

De entre las personas seleccionadas para el grupo experimental, una de ellas se traslada a otro recurso por lo que nos vemos obligados a eliminar de dicha muestra. Otra de los miembros del grupo experimental no puede acudir al recurso durante un periodo de tiempo significativo por lo que resulta imposible aplicar las modificaciones diseñadas en su PIA y también causa baja 
en el grupo experimental. Para equilibrar ambos grupos una de las personas usuarias que inicialmente estaba previsto que formara parte de la muestra de control pasa a integrar la muestra experimental una vez introducidos las modificaciones correspondientes en su PIA.

Finalmente nos encontramos con dos muestras, experimental y control, de 8 personas usuarias cada una que corresponden al 100\% de personas que podían ser consideradas válidas para formar parte del estudio.

Los cambios individualizados propuestos para cada uno de los miembros del grupo experimental han dispuesto de 3 meses para su aplicación, si bien las incidencias cotidianas en la evolución de la enfermedad pero también las relacionadas con la vida cotidiana, el entorno familiar, etc. de la población usuaria ha hecho, como ya hipotetizaba el equipo de profesionales, que el desarrollo de su aplicación haya sido desigual.

\subsection{Resultados obtenidos}

En la valoración previa a la intervención, los dos grupos muestrales (experimental y control) ofrecen un perfil razonablemente similar de las diferentes dimensiones de calidad de vida para ambos. En la valoración hecha por los profesionales las dimensiones más destacadas eran Derechos $(93,1$ experimental y 91,1 control) y Bienestar Material (89,5 experimental y 89,7 control). Las menos valoradas eran RR. Interpersonales (en torno a 70 en ambos) y Bienestar Emocional (si bien en este caso con una diferencia muy acusada: 77,0 en experimental y 61,6 en control). En la valoración hecha por la población usuaria la situación era similar. Destacaban Derechos y Bienestar Material, siendo las valoraciones más bajas la dimensión de RR. Interpersonales y la de Bienestar Emocional (también con una elevada diferencia entre experimental, 80,1, y control, 68,8)

\subsubsection{Evolución del Grupo Experimental}

En la valoración realizada por los profesionales partíamos de una distribución por dimensiones en la que los elementos más valorados eran los Derechos y el Bienestar Material y los déficits eran más acusados en RR. Interpersonales, Bienestar Físico y Autodeterminación. 


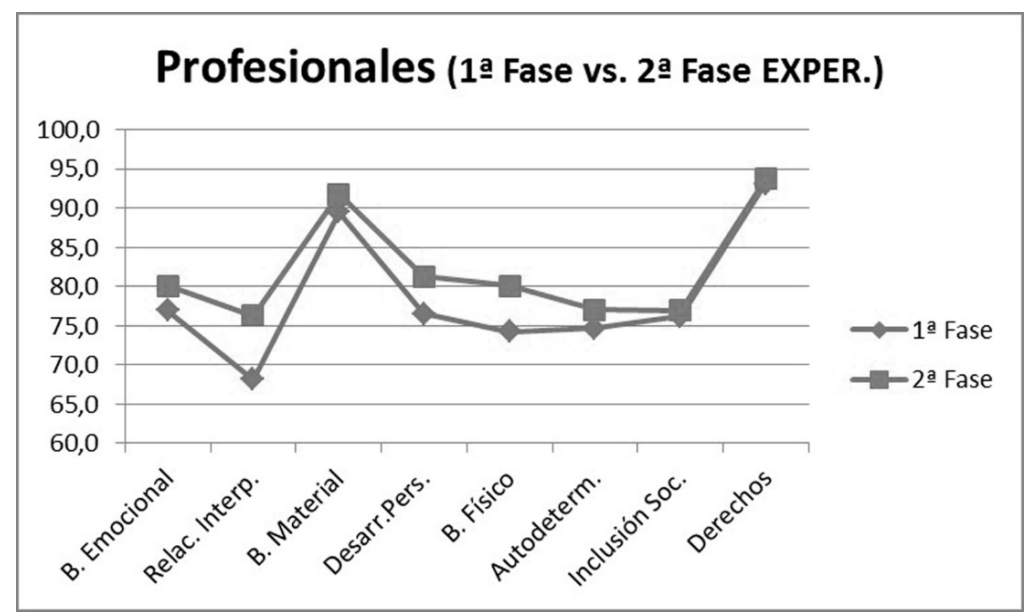

GRÁFICO 2. Valoración de las dimensiones de Calidad de Vida por los Profesionales. G. Experimental Fase I vs. Fase II

Todas las dimensiones han aumentado en la $2^{\mathrm{a}}$ Fase respecto a la $1^{\mathrm{a}}$. Las diferencias son especialmente significativas en la dimensión de RR. Interpersonales con un aumento de 8,1 puntos de crecimiento, la de Bienestar Físico con 5,9 puntos, y el Desarrollo Personal con 4,7 puntos. Precisamente las dos primeras eran las más bajas en la valoración inicial.

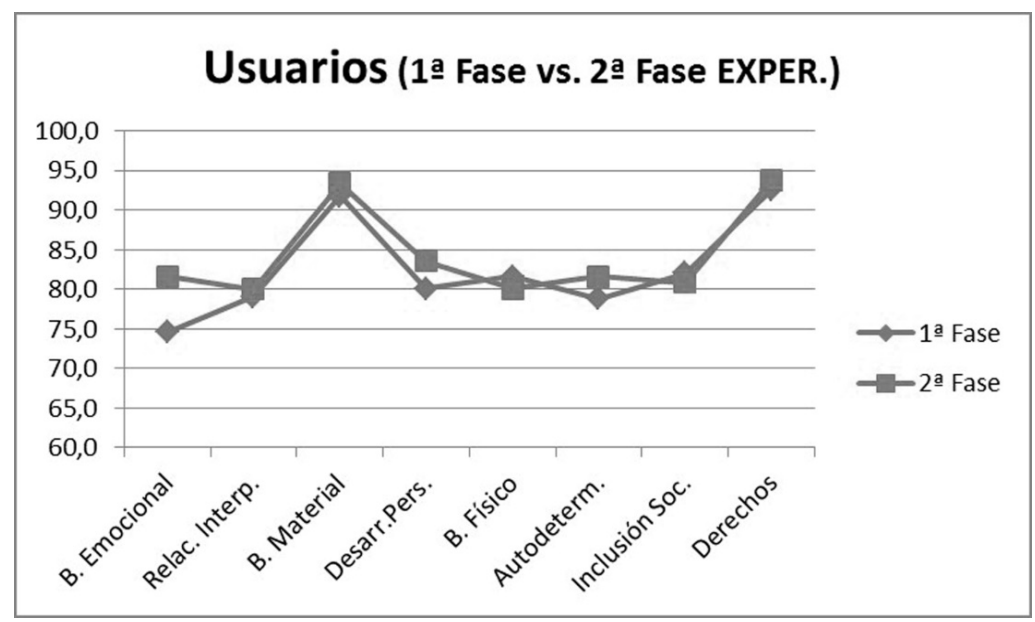

GRÁFICO 3. Valoración de las dimensiones de Calidad de Vida por la Población Usuaria. G. Experimental Fase I vs. Fase II 
Desde la perspectiva de la población usuaria partíamos de una distribución similar a la de los profesionales, en la que destacaban los Derechos $(92,5)$ y el Bienestar Material $(91,8)$, con las puntuaciones más bajas en Bienestar Emocional $(74,6)$ seguido de Autodeterminación y RR. Interpersonales. La diferencia más significativa entre ambas valoraciones se situaba en las RR. Interpersonales, con una diferencia de más de 10 puntos (el 79,1 de los usuarios frente al 68,1 de los profesionales).

La evolución en esta $2^{\mathrm{a}}$ Fase, según la población usuaria, ha sido bastante menos significativa en su conjunto que la que recogen los profesionales. Destaca de manera especial la mejoría que han percibido en su Bienestar Emocional (un incremento de 7,0 puntos) y el Desarrollo Personal (3,5 puntos). En el resto de dimensiones, los cambios han sido poco perceptibles, incluso con alguna ligera disminución en la valoración del Bienestar Físico o la Inclusión Social.

En las medidas realizadas previas a la intervención, si bien mantenían un perfil similar en cuanto a las dimensiones más afectadas, todas las dimensiones de la calidad de vida se situaban en valores superiores desde la perspectiva de la población usuaria que desde la mirada de los profesionales. Las diferencias de valoración eran especialmente notables en la afectación de las RR. Interpersonales (con 11,6 de sobrevaloración por parte de la población usuaria) o del Bienestar Físico (con 10,7 puntos por encima). En cambio, la mayor coincidencia la encontramos en la valoración del Bienestar Emocional (con solamente una décima de diferencia entre ambas puntuaciones) o el Bienestar Material (valorado en 2,5 puntos más por la población usuaria que por los profesionales).

En las medidas posteriores a la intervención, también todas las puntuaciones recibidas son superiores en la valoración hecha por la población usuaria. Pero en este momento las puntuaciones se ajustan mucho más, disminuyendo de manera notable las diferencias entre ambos colectivos. Es de destacar que es precisamente en RR. Interpersonales y Bienestar Físico, dimensiones que presentaban los mayores diferenciales en las medidas pre-intervención, donde se produce la mayor disminución de la distancia de valoración, pasando de 11,6 a 2,9 en la primera de esas dimensiones y de 10,7 a 0,6 en la segunda de ellas. 


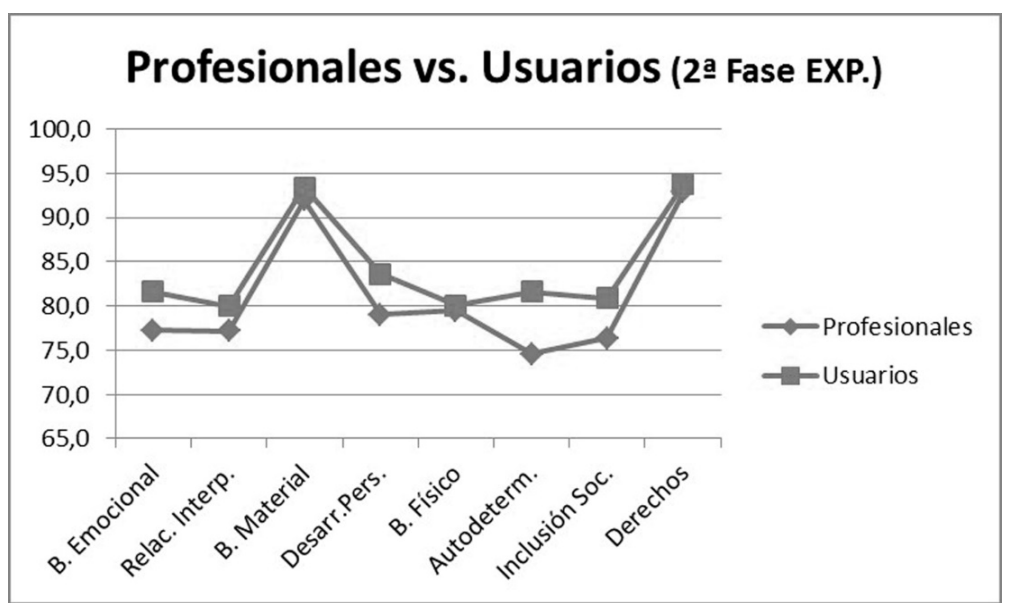

GRÁFICO 4. Valoración de las dimensiones de Calidad de Vida por Profesionales vs. Población Usuaria. G. Experimental Fase II

\subsubsection{Evolución del Grupo Control}

En el caso del grupo de control, desde la valoración hecha por los profesionales la distribución inicial de las dimensiones tenía como valoraciones más destacadas los Derechos y el Bienestar Material, a notable distancia del resto. Entre las dimensiones más afectadas destacaba sobremanera la puntuación relativa al Bienestar Emocional (con un 61,6\%), seguida de la Autodeterminación y las Relaciones Interpersonales.

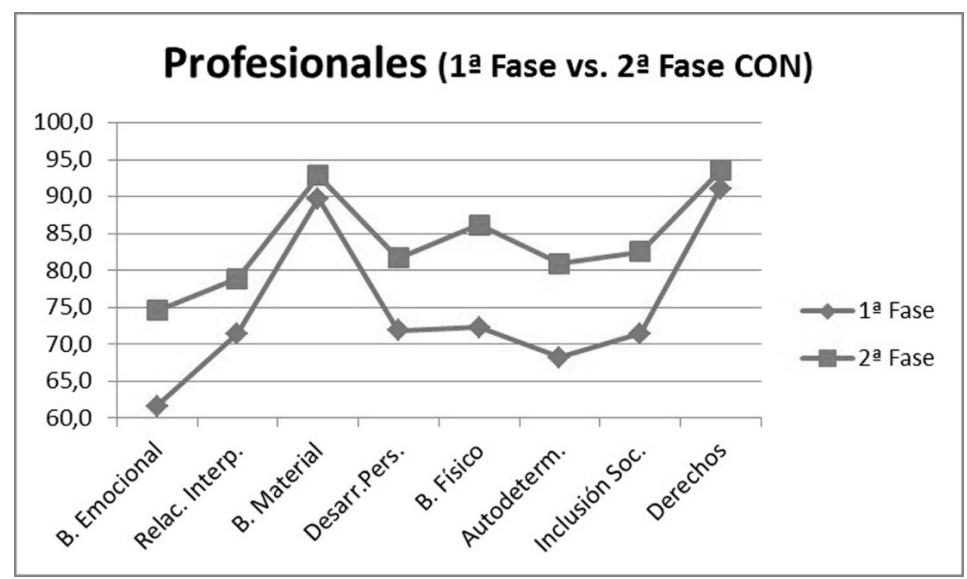

GRÁFICO 5. Valoración de las dimensiones de Calidad de Vida por los Profesionales. G. Control Fase I vs. Fase II 
Los datos reflejados en las mediciones post-intervención nos ponen de manifiesto un aumento de todas las dimensiones de la calidad de vida en comparación con los obtenidos en el momento previo a la intervención. El mayor diferencial se produce en el Bienestar Físico que se ve mejorado en 13,8 puntos entre ambas fases. Pero es muy importante también poner de manifiesto el importante aumento que se observa precisamente en las dos dimensiones más afectadas en la valoración previa: el Bienestar Emocional incrementa su valoración en 12,9 puntos y la Autodeterminación en 12,7 puntos.

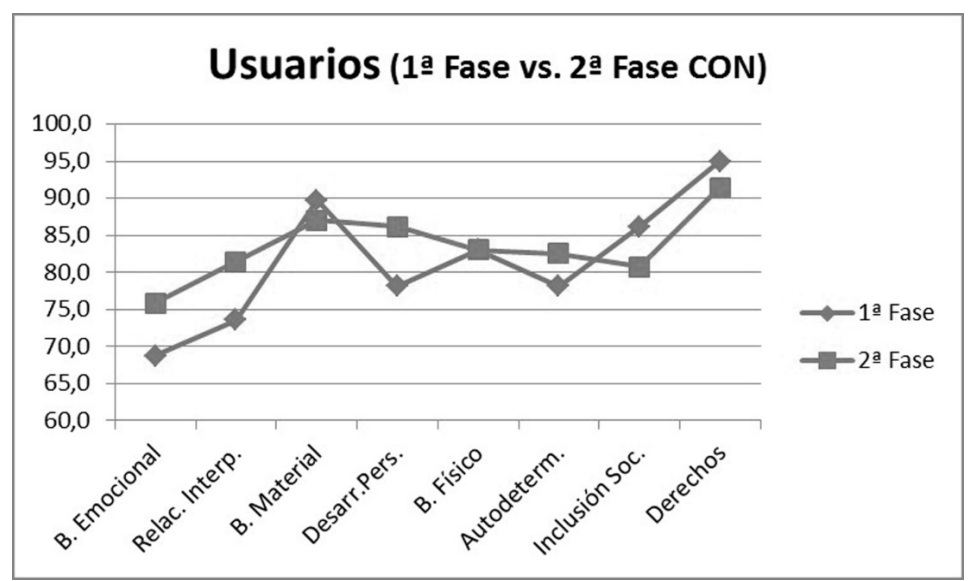

GRÁFICO 6. Valoración de las dimensiones de Calidad de Vida por la Población Usuaria. G. Control Fase I vs. Fase II

Las valoraciones realizadas por la población usuaria en el momento previo a la intervención tenían como dimensiones más valoradas los Derechos y el Bienestar Material (95,0 y 89,7 respectivamente), mientras que las valoraciones más bajas correspondían al Bienestar Emocional y las RR. Interpersonales, con un 68,8 para la primera y un 73,6 en el caso de la segunda.

En las puntuaciones posteriores a la intervención se aprecia una mayor homogeneización de las diferentes dimensiones reduciendo las importantes distancias que se observaban entre ellas, aunque no cambian la posición ordinal de cada una (las más valoradas siguen siendo Derecho y Bienestar Material y Bienestar Emocional la que tiene menor puntuación). Esta homogeneización tiene lugar en la medida en que las dimensiones con mayor valoración bajan su puntuación (como es el caso de Inclusión Social, que lo hace en 5,4 
puntos, Derechos o Bienestar Material) al tiempo que las más afectadas ven aumentar la suya (RR. Interpersonales incrementa su valoración en 7,9 puntos y Bienestar Emocional lo hace en 7,1).

Al igual que ocurre en las valoraciones previas a la intervención relacionadas con el grupo experimental, en el grupo control todas las dimensiones son valoradas más positivamente por la población usuaria que por los profesionales, si bien el perfil de la interrelación entre las diferentes es similar, con una mayor puntuación de Derechos y Bienestar Material y las más bajas en el Bienestar Emocional, RR. Interpersonales y Autodeterminación. En todo caso, las diferencias entre ambas miradas eran especialmente notables en lo que respecta Inclusión Social (en la que los profesionales otorgan una puntuación 14,7 puntos inferior a la de la población usuaria), Bienestar Físico (con una diferencia de 10,7 puntos) y Autodeterminación (9,9 puntos inferior en el caso de la valoración profesional). No existen, en cambio, apenas diferencias en cuanto a la valoración de dimensiones como el Bienestar Material o las RR. Interpersonales.

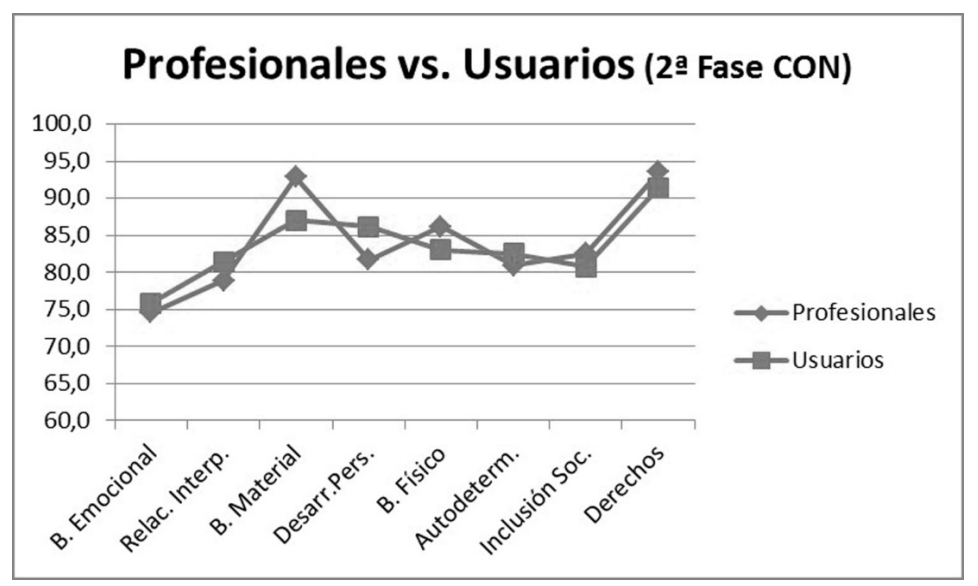

GRÁFICO 7. Valoración de las dimensiones de Calidad de Vida por Profesionales vs. Población Usuaria. G. Control Fase II

Las valoraciones realizadas tras la intervención se aproximan de manera muy notable en ambas perspectivas. Este efecto tiene lugar por un doble movimiento: Como hemos visto más arriba, en el caso de los profesionales se produce un incremento de la valoración en todas las dimensiones, mientras 
que no ocurre así en el caso de la población usuaria en la que, en la valoración post-intervención, algunas de las dimensiones ven reducidas sus puntuaciones. Y, por otra parte, es precisamente en algunas de las dimensiones en las que se observaban mayores diferencias entre ambas perspectivas previamente a la intervención (como es el caso de Inclusión Social o Bienestar Físico) en las que confluyen una notable subida de la valoración profesional y una disminución de la otorgada por la población usuaria. El resultado final es que en el contraste entre ambas miradas, posterior a la intervención, la línea que une las diferentes dimensiones se ha aproximado notablemente hasta dejar los máximos diferenciales en un rango que en ningún caso supera los 6 puntos $\mathrm{y}$, además, eliminando exclusividad en la sobrevaloración por parte de la población usuaria respecto a los profesionales.

\subsection{Conclusiones}

Se ha podido hacer un análisis en el que se compara la evolución de las medidas introducidas, tanto desde el punto de vista de los profesionales como de la población usuaria, así como la evolución de los diferenciales de ambas miradas tanto en el grupo experimental como en el grupo control.

Los resultados nos muestran, en conjunto, sensibles mejoras en el grupo experimental en las diferentes dimensiones de calidad de vida analizadas. Esta mejoría se constata tanto desde la perspectiva de los profesionales como desde la valoración realizada por la población usuaria.

Asimismo, las notables diferencias que se apreciaban entre ambas perspectivas se han visto reducidas de manera significativa en relación con las puntuaciones obtenidas antes de las mejoras implementadas en la Fase II del proyecto de investigación.

Si bien no tan relevantes, se han constatado igualmente cambios positivos en las valoraciones correspondientes al grupo de control en el que no se habían modificado los parámetros de la intervención.

En definitiva, unos resultados que nos aportan algunas evidencias acerca de que la selección de áreas de mejora, su implementación de manera selectiva e individualizada, y el seguimiento de su aplicación son estrategias positivas para mejorar la atención a la población usuaria. Pero que, por otro lado, evidencian las especiales dificultades de este tipo de población y la necesidad de 
analizar de manera muy precisa las dinámicas organizativas para solventar determinadas dificultades metodológicas y de implementación.

Ha quedado de manifiesto que hubiera sido necesario un periodo de tiempo mayor para poder desarrollar en toda su extensión los cambios introducidos. La reflexión conjunta entre el equipo de investigación y los profesionales de la entidad evidencia también la necesidad de un mayor consenso con la población usuaria en la identificación de esos objetivos de mejora. Un seguimiento más continuo de la evolución de los cambios introducidos tal vez hubiera permitido detectar algunas de las dificultades en el transcurso del proceso. Y, finalmente, algunas de las incidencias acontecidas con la muestra nos ha hecho ser más conscientes aún de la incertidumbre que los procesos vitales de la población usuaria introduce en los procesos metodológicos, como variables siempre presentes, y la necesidad de su permanente adaptación cuando se trabaja sobre el terreno. La especificidad de la esclerosis múltiple (con su carácter recidivante e imprevisible) debe estar muy presente en relación con la estabilidad de las muestras para los siguientes pasos de este programa de investigación. Aun así, estamos convencidos de que estos resultados constituyen un elemento de avance para la mejora de las estrategias de intervención y en el ajuste de la percepción social en torno a la esclerosis múltiple.

\subsection{Bibliografía}

AENOR (2016) Sistemas de gestión de la calidad. Disponible en http://www.aenor. es/aenor/certificacion/calidad/calidad.asp\#.WI-XiFPhDcs. Con acceso el 21-122016.

AZNAR, A.S. Y CASTAÑÓN, D.G.(2005) «Quality of life from the point of view of Latin American families: a participative research study» en Journal of Intellectual Disability Research, vol. 49, $\mathrm{n}^{\circ} .10$, pp. 784-788.

CARRÓN, J. Y ARZA, J. (2013) «Esclerosis múltiple, calidad de vida y atención sociosanitaria» en International Journal of Organizations / Revista Internacional de Organizaciones, $\mathrm{n}^{\circ}$. 11, pp. 37-54.

CHOU, Y. C., SCHALOCK, R. L., TZOU, P. Y., LIN, L. C., CHANG, A. L., LEE, W. P., Y CHANG, S. C. (2007) «Quality of life of adults with intellectual disabilities who live with families in Taiwan» en Journal of Intellectual Disability Research, vol. 11 n 51 , pp. 875-883.

FLORES, N., JENARO, C., GONZÁLEZ-GIL, F., y GARCÍA-CALVO, P. (2010). «Análisis de la calidad de vida laboral en trabajadores con discapacidad» en Zerbitzuan, $\mathrm{n}^{\circ} .47$, pp. 95-107. 
GÓMEZ, L., VERDUGO, M.A. y ARIAS, B. (2010) «Calidad de vida individual: avances en su conceptualización y retos emergentes en el ámbito de la discapacidad» en Psicología Conductual, vol. 18, n. 3, pp. 453-472.

HARRIS, H. (1970) El trabajo social individualizado. Madrid, Ed. Rialp, MARTÍN-GARCÍA, M., PONTE-MITTELBRUN, C. Y SÁNCHEZ-BAYLE, M. (2006) «Parte IV. Ecosalud y participación social: Participación social y orientación comunitaria en los servicios de salud» en Gaceta Sanitaria, vol. 20, nº. Supplement 1, pp. 192.

MARTÍNEZ, J.R. Y SANJUÁN, A. (2009) «¿Por qué hablamos de continuidad de cuidados cuando realmente queremos decir satisfacción profesional? » en $R e$ vista de Administracion Sanitaria, vol. 7, nº. 4, pp. 661.

MSIF (2002) Principles to promote quality of life with people of Multiple Sclerosis. Disponible en: http://www.msif.org/about-us/advocacy/principles-to-promotequality-of-life/ Con acceso el 15-01-2015.

ONU (2006). Convención Internacional sobre los Derechos de las Personas con Discapacidad. Disponible en http://www.un.org/esa/socdev/enable/documents/ tcconvs.pdf. Con acceso 19-12-2016

RICHMOND, M.E. (1995) El caso social individual; El diagnóstico social: Textos seleccionados. Madrid, Ed, Talasa.

ROGERS, C.R. (1977) Psicoterapia centrada en el cliente :práctica, implicaciones y teoría, Barcelona, Ed. Paidós.

SCHALOCK, R.L. y Verdugo, M.Á. (2010) Calidad de vida: manual para profesionales de la educación, salud y servicios sociales. Madrid. Ed. Alianza.

VERDUGO, M.A., SCHALOCK, R. L., GÓMEZ, I., y ARIAS, B. (2007) «Construcción de escalas de calidad de vida multidimensionales centradas en el contexto: La escala GENCAT» en Siglo Cero, vol. 38, n 224, pp. 57-72.

VERDUGO, M.A. y SCHALOCK, R.L. (2009) «Quality of Life: From Concept to Future Applications in the Field of Intellectual Disabilities» en Journal of Policy and Practice in Intellectual Disabilities, vol. 6, $\mathrm{n}^{\circ} .1$, pp. 62-64.

VERDUGO, M.A., GÓMEZ, L. E., ARIAS, B., y SCHALOCK, R. L. (2011). «The integral quality of life scale: Development, validation, and use» en Kober, R.(ed) Enhancing the quality of life of people with intellectual disabilities. Springer. pp. 47-60.

VERDUGO, M.A., GÓMEZ, L. E., ARIAS, B., SANTAMARÍA, M., CLAVERO, D., y TAMARIT, J. (2013). Evaluación de la calidad de vida en personas con discapacidades intelectuales o del desarrollo: La escala INICO-FEAPS. Madrid. FEAPS

WHOQOL Group (1995) «The World Health Organization quality of life assessment (WHOQOL): position paper from the World Health Organization» en Social science \& medicine, vol. 41, $\mathrm{n}^{\circ}$. 10, pp. 1403-1409. 
9

\title{
LA GESTIÓN COMUNITARIA DE «RECURSOS NATURALES» EN ÁREAS PROTEGIDAS. EL CASO DE LOS ACUEDUCTOS COMUNITARIOS EN LOS PÁRAMOS DE BOGOTÁ, COLOMBIA
}

\author{
Ángela María Osorio Gómez \\ Universidad Jean Moulin-Lyon 3
}

\subsection{Introducción}

«Aunque no existamos ni en los libros ni en los mapas, existimos» Pronunciamiento de Gachinoco citado por Zambrano (1993)

El contexto actual de cosmo-capitalismo ${ }^{1}$ nos obliga a pensar en la forma de proteger la «naturaleza» del desequilibrio ecológico que amenaza la continuidad de la vida, incluso aquella de la especie humana. En medio de este escenario nos preguntamos si es posible desarrollar nuevos modelos que nos permitan proteger el medio ambiente de ciertas actividades antrópicas que causan daños irreversibles a los ecosistemas. Es así como emerge la categoría de área protegida, la cual representa una construcción humana que busca limitar el impacto de esta misma especie sobre ciertos ecosistemas. Por lo tanto, un área protegida se refiere al «perímetro dentro del cual la protección es el objetivo (o uno de los objetivos) político asignado por los gestores y las sociedades de una manera general» (Depraz, Guyot y heredero, 2012, p.92; Traducción Ángela Osorio).

1 Categoria tomada de Dardot, Laval (2014; p. 12): « Nous sommes à l'époque du cosmo-capitalisme, dans lequel, delà de la sphère du travail, les institutions, les activités, les temps de vie sont soumis à une logique normative général qui les refaçonne et les réoriente selon les buts et les rythmes de l'accumulation du capital» 
Con respecto a las áreas protegidas, hacemos hincapié en que su límite es un proceso que involucra de manera directa e indirecta a todo el mundo y que está en desarrollo y transformación constante. Además, el establecimiento del límite de estas áreas y de su gestión, responde a ciertas corrientes de pensamiento que determinan la relación «permitida» entre los seres humanos y la «naturaleza». De esta manera, este trabajo tiene como objetivo presentar una reflexión sobre el paradigma integrador de la «naturaleza», el cual propone combinar ciertas actividades antrópicas con la protección del medio ambiente. Esto, permite reconocer la importancia del carácter social y cultural de la «naturaleza» a la hora de intentar protegerla.

Este trabajo establece un vínculo entre las áreas protegidas y la gestión comunitaria de «recursos naturales» para determinar si esta gestión representa una amenaza a los ecosistemas o si por el contrario, debe ser reconocida como un sistema informal de protección. Para dar respuesta a este planteamiento, hemos tomado como caso particular los acueductos comunitarios de la ciudad de Bogotá. Cabe resaltar que esta ciudad se encuentra hoy en día en medio de un proceso de delimitación de áreas protegidas que tiene lugar, debido a la importante presencia de ecosistemas de vital importancia ecológica y social como el ecosistema de Páramo.

\subsection{Metodología}

Teniendo en cuenta la complejidad del estudio de las áreas protegidas en relación a la gestión comunitaria del agua, se requiere de un amplio uso de enfoques y técnicas metodológicas para abordar este tema de una manera holística. Así, para la realización de la investigación cuyos resultados se presentan en este documento, se utilizó la triangulación metodológica y la triangulación de fuentes de información.

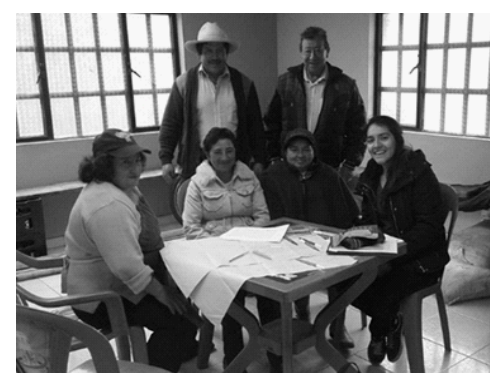

Fotografía 1. Taller de cartografía social con usuarios del acueducto Piedra Parada 
De esta manera, a partir de un enfoque participativo de la metodología cualitativa y cartográfica, se hicieron entrevistas semi-estructuradas y la geo referenciación de los acueductos no estatales de la ciudad de Bogotá. Todo esto, permitió establecer cuáles de estos acueductos son comunitarios y cuales se encuentran en áreas protegidas. Luego se seleccionó un acueducto comunitario y se realizaron dos talleres de cartografía social, uno con las usuarias de los acueductos comunitarios y otro con las y los gestores (ver Foto 1). La metodología de esta investigación se presenta de una forma detallada en el anexo 1 .

\subsection{Resultados}

\subsubsection{Páramo: Un sistema socio-ecológico}

El Páramo es un biotopo neo tropical de alta montaña. En Colombia, los Páramos tienen una superficie de 1,925,410 hectáreas, 746.644 de los cuales están ubicados dentro de parques nacionales. Estos ecosistemas representan el $2 \%$ del territorio del país, lo que representa la mayor área existente de este ecosistema en el mundo. El 90\% de la flora de los páramos es endémica y está en peligro de extinción como el Espeletia ou Fraijón (ver foto 2) (Rivera y Rodríguez, 2011). Por otra parte, además de su gran diversidad, los páramos proporcionan importantes servicios ecosistémicos, dentro de los cuales cabe destacar la regulación del agua y captura de carbono.

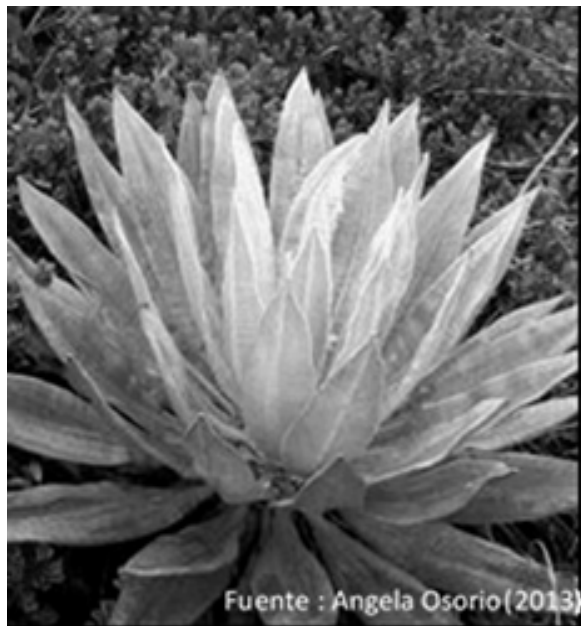

Fotografía 2. Espeletia ou Fraijón 
Esta última tiene relación con las bajas temperaturas que favorecen las tasas bajas de mineralización y la utilización de nutrientes. Estas características producen que el suelo tenga una alta capacidad de absorción de carbono, la cual es más importante que en la selva tropical como podemos ver en el Cuadro 2.

\begin{tabular}{|l|c|c|}
\hline & PÁRAMO & SELVA TROPICAL \\
\hline Vegatación & 20 & 250 \\
\hline Suelo & 1.700 & 50 \\
\hline Total & 1.720 & 300 \\
\hline
\end{tabular}

Cuadro 2. Captura de carbono de los Páramos y la Selva Tropical. Fuente: García, 2003 et Hofstede, 1999, citado por PGN, 2008, p.20

En cuanto a los ecosistemas de las altas montañas de Colombia (por encima de 3.000 metros y hasta 5.775 metros que corresponde al El Pico Cristóbal Cólon que es el punto más alto del país) se pueden clasificar en cuatro pisos térmicos de acuerdo con la clasificación de José Cuatrecasas: Sub-Páramo, Páramo, superpáramo y nieves perpetuas como se muestra en la Figura 1. Esta distribución espacial de los pisos térmicos no corresponde a la totalidad de las montañas de Colombia pero sirve para entender de una manera general los ecosistemas de Páramo de este país. En general, los Páramos están formados por tres zonas, la primera y más baja es el Subpáramo que se encuentra entre los 3000 y 3500 metros sobre el nivel del mar (m.s.n.m.), la temperatura de esta zona varía entre 6 y 10 grados centígrados y se caracteriza por la presencia de arbustos. La segunda zona es el Páramo que está entre los 3,500 y 4,000 m.s.n.m. y que cuenta con temperaturas entre los 3 y 6 grados centígrados, en esta zona las especies más e importantes son los frailejones (Espeletia), los pajonales (Calamagrostis) y los Chuscales (Chasqueatessellata). Finalmente, la tercera la zona es el Superpáramo que se encuentra a partir de los 4.000 m.s.n.m y que tiene temperaturas entre 0 y 3 grados centigrados (PGN, 2008, 21).

El cambio de zonas puede ser observado a través de la flora ya que puede haber una disminución del tamaño de esta que oscila entre los 2 y 15 metros de altura tal como se ilustra en la Figura 2. Esta variación de altura representa un criterio fundamental para la delimitación de este ecosistema. 


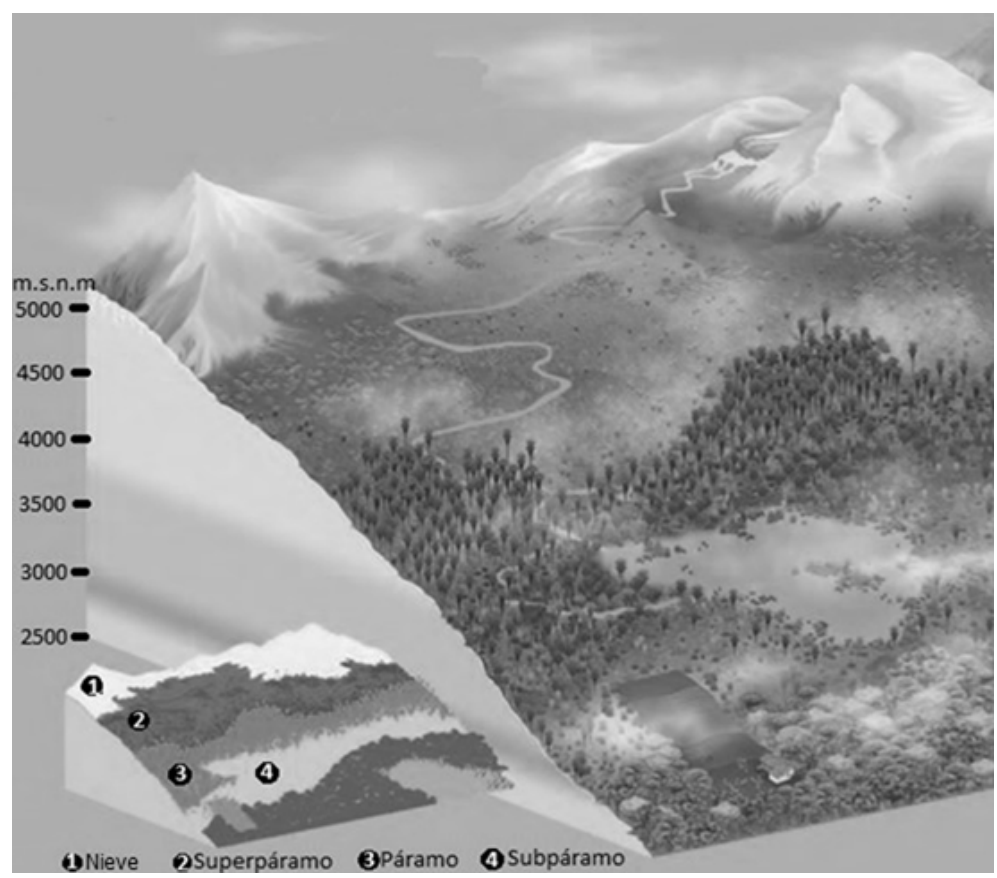

Fuente: Adaptado de Rangel Ch. 2000, citado por Rivera, Rodríguez, 2011

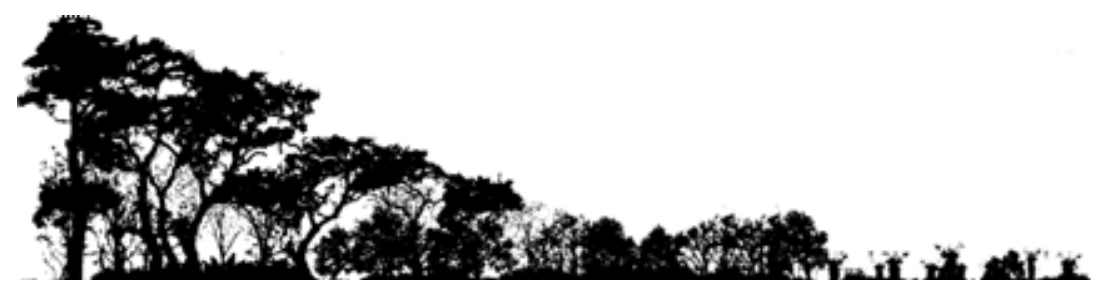

Figura 1. Distribución espacial de las zonas de Páramo

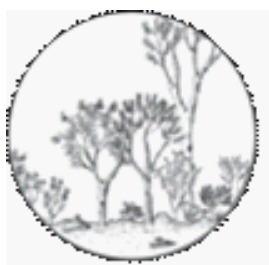

SGBPREARA9

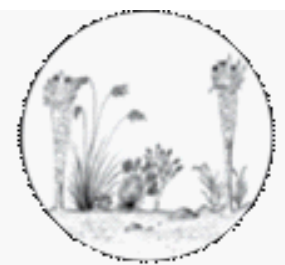

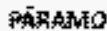

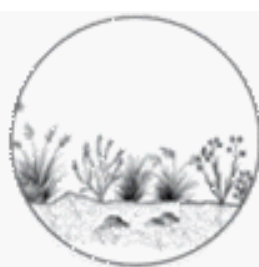

SEPEFARAATSO

Figura 2. Cambio de flora en las tres zonas de Páramo. Fuente: Instituto Alexander Von Humboldt, 2015 
Hasta este momento hemos definido lo que es un páramo desde una perspectiva ambiental y hemos destacado sus principales servicios ecosistémicos. Sin embargo, el análisis ecológico de los páramos pasa también por la relación con las sociedades. Efectivamente, estos ecosistemas son también el resultado de acciones antrópicas, es decir, deben ser considerados como sistemas socioecológicos. Cabe afirmar que hoy en día no existen espacios «naturales» o sin ninguna intervención humana en toda la superficie del globo (Depraz, 2008, p.4). Así, podemos decir que el suelo de los páramos es de alguna manera una creación humana (PGN, 2008, p.29) porque su productividad bruta y neta han sido modificados por la agricultura. De hecho, los pueblos precolombinos como los Muiscas (comunidad que vivía alrededor de Bacatá, actual Bogotá) y actualmente los pueblos Yanakunas y Nasa (Cauca, Colombia) han cohabitado con Páramos desde hace más de 30.000 años y han transformado estos ecosistemas para satisfacer necesidades como el refugio y alimento.

De esta manera, cabe afirmar que desde tiempos precolombinos existe una relación vital entre las comunidades y los Páramos en Colombia, especialmente en lo que concierne el suministro de agua. Esta relación es evidente en las comunidades indígenas como los Muiscas cuya diosa madre, Bachué, emergió del agua. Esta relación existe todavía hoy en el seno de algunas comunidades indígenas y campesinas, las cuyas actividades cotidianas se siguen estableciendo en torno al agua.

\subsubsection{La situación legal de los Páramos}

A pesar de la importancia ecológica y social de los Páramos, la legislación colombiana no protege estos ecosistemas y las propias instituciones estatales lo reconocen: «los Páramos están en un déficit de protección ya que no son parte del sistema de áreas protegidas o sin otro instrumento que les da una protección especial» (Sentencia C-035/2016, pg.9). Cabe recordar que estos ecosistemas son esenciales para la regulación del ciclo del agua en Colombia y proporcionan el $70 \%$ de agua que la población de este país consume, por lo tanto actualmente se promueve una delimitación de ellos sobre una base técnica, ambiental, social y económica. Es así como la Sentencia C-035/2016 indica que el Ministerio de Medio Ambiente y Desarrollo Sostenible será la institución responsable de esta delimitación a partir de los datos proporcionados por el Instituto Alexander von Humboldt. También es de destacar que en el Plan Nacional de Desarrollo 2014-2018 del gobierno de Juan Manuel Santos, ya había expresado la importancia de la mencionada delimitación así como la 
responsabilidad del Ministerio de Medio Ambiente y Desarrollo Sostenible en este proceso. Sin embargo, esta delimitación no se ha avanzado y la legislación colombiana sigue sin establecer normas especiales para la protección de estos ecosistemas. Por esta razón, sólo el 39\% de los Páramos del país están protegidos a través de la figura de los parques nacionales, clasificación que corresponde a la categoría II de las áreas protegidas de la Unión Internacional para la Conservación de la Naturaleza (UICN).

En cuanto a los instrumentos legislativos, es importante destacar que estos son esenciales para proteger el medio ambiente, sin embargo, no sustituyen al establecimiento de áreas protegidas, es decir, de un «perímetro dentro del cual la protección es la meta (o metas) asignado por los gestores de políticas y empresas de manera general» (Depraz heredera Guyot y Laslaz, 2012, p.92). A pesar de esto, en Colombia la protección de los ecosistemas no comenzó con la delimitación de las fronteras para luego implementar acciones de protección, por el contrario, se ha dado prioridad a los planes de protección y proyectos sin fijar áreas con límites claros. Esta situación ha producido una deficiencia en la protección de los ecosistemas debido a la constante transformación de los cambios de políticas de las autoridades locales.

Por otro lado, en Colombia los Parques Nacionales Naturales se definen como:

Área de extensión que permita su autorregulación ecológica y cuyos ecosistemas en general no han sido alterados substancialmente por la explotación u ocupación humana, y donde las especies vegetales de animales, complejos geomorfológicos y manifestaciones históricas o culturales tienen valor científico, educativo, estético y recreativo Nacional y para su perpetuación se somete a un régimen adecuado de manejo (Parques Nacionales Naturales, 2017).

Esta definición es muy similar a la sugerida por la Categoría II de la UICN, no obstante la definición de Colombia carece de la última parte de la definición propuesta por la UICN (2015): «el respeto por el medio ambiente y la cultura de las comunidades locales».

Por lo tanto, podemos decir que la política de protección del medio ambiente de Colombia, desde su definición, no reconoce la importancia del respeto a la cultura y rol de las comunidades locales que habitan en zonas prioritarias de protección. 
De la misma manera, la política medioambiental colombiana se basa en la idea de que las comunidades son depredadoras de la naturaleza y en ese sentido, para la protección de los espacios «naturales» se debe impedir cualquier tipo de acción antrópica. Así, autoridades de este país como como el Instituto Geográfico Agustín Codazzi, afirman que «solo el 16 por ciento de los suelos de Colombia está blindado contra la depredación ambiental del hombre» (IGAC, 2015). Con esto es posible afirmar que el paradigma hegemónico de protección de la «naturaleza» en Colombia es el paradigma radical, el cual establece una separación entre los seres humanos y la «naturaleza» ya que considera la sociedad es depredadora, con lo cual niega la posibilidad de que exista una protección efectiva si hay un vínculo con las actividades humanas (Depraz, 2008, p.116). Sin embargo, teniendo en cuenta que los Páramos, son sistemas socio-ecológicos, es esencial establecer instrumentos legislativos que reconozcan a protección de los derechos de las comunidades locales, al mismo tiempo que se busca proteger la naturaleza.

El paradigma integrador podría ser tomado como la base para un reconocimiento de los aspectos sociales y culturales en la protección del medioambiente. Este paradigma considera que la acción de las sociedades puede ser necesaria para la buena gestión de los ecosistemas, por lo cual propone una protección con las mujeres y los hombres y no contra ellas y ellos como en el caso del paradigma radical (Depraz, Guyot et Héritier, 2012). Sin embargo, sigue estando latente la idea sobre la amenaza que representan las actividades antrópicas sobre los ecosistemas, y de la misma manera, surge la cuestión por cuales son las actividades que deben «permitirse» dentro de ecosistemas de gran importancia medioambiental como los Páramos para garantizar el derecho de las comunidades a realizar ciertas actividades sobre los territorios pero al mismo tiempo, evitando causar daños irreversibles a los ecosistemas. Para resolver estos cuestionamientos, a continuación se propone un análisis de la gestión comunitaria del agua en un Páramo de Bogotá, lo cual nos permite desarrollar una reflexión que tenga en cuenta si efectivamente dicha gestión representa una amenaza para estos ecosistemas o si por el contrario debe ser reconocida como un sistema informal de protección del medio ambiente.

\subsection{3. ¿La gestión comunitaria de agua en Bogotá, una amenaza o un sistema de protección informal de los Páramos?}

Todo lo anteriormente descrito sobre el páramo y la importancia ambiental y ecológica que tiene para Colombia no ha significado el ejercicio del De- 
recho Humano al Agua de toda la población colombiana. Esta situación tiene una relación directa con los niveles de desigualdad de este país, el cual se ubica, de acuerdo con su coeficiente de Gini $(0,0052$ en 2016) dentro de uno de los más desiguales de América Latina. Así, el panorama de desigualdad en Colombia se agrava si se hace un análisis comparativo entre el campo y la ciudad, lo cual es evidente si se tiene en cuenta que más de la mitad de las y los habitantes de zonas rurales de Colombia no tienen acceso a agua potable ni al servicio de saneamiento (UNICEF, 2015).

En el caso de Bogotá, ciudad capital de Colombia, la desigualdad entre el campo y la ciudad se refleja principalmente en lo que concierne el servicio público de agua potable. Con una población total 7,878,783 personas (Secretaría Distrital de Planeación de Bogotá, 2016), la empresa pública de esta ciudad (Acueducto de Bogotá) presta este servicio a tan solo las 1.992 .927 personas (Observatorio ambiental de Bogotá, 2017) que se encuentran en la zona urbana y que corresponde al $25 \%$ del territorio de la ciudad. A esto se puede añadir que el marco legislativo del servicio público de agua y saneamiento ${ }^{2}$ ha impuesto una serie de condiciones que ha favorecido la privatización de la gestión de este servicio, restringido la gestión que puede ser desarrollada por comunidades locales. Esta legislación privatizadora desconoce que desde hace décadas y frente a la insuficiente cobertura del servicio público de agua, el alto precio del servicio, la falta de control del Estado sobre los recursos hídricos y la contaminación de estos, entre otros aspectos, las y los habitantes de los sectores más aislados y menos favorecidos de la ciudad han ejercido sus derechos ciudadanos a la asociación y a la participación para tener acceso al agua potable. Esto último daría cuenta de una gestión no estatal de agua en Bogotá que permite que las personas que viven en el $75 \%$ de la ciudad que corresponde a la zona rural ejerzan el Derecho Humano al Agua.

Como hallazgo de esta investigación se puede resaltar la identificación de 75 acueductos no estatales en Bogotá que están distribuidos en ocho de las veinte localidades de la ciudad. Como puede verse en el Mapa 1, la gestión no estatal del servicio público del agua no representa un fenómeno aislado en esta ciudad sino que tiene lugar en casi la totalidad de su territorio y principalmente en la zona rural.

El hecho de existan acueductos no estatales en localidades rurales de Bogotá es una variable principal de esta investigación, ya que casi la totalidad

2 Construido a partir de la Constitución Política de 1991 y la Ley 142 de 1992 
la zona rural de Bogotá se encuentra por encima de los 3.000 m.s.n.m y esto implica la presencia del ecosistema de Páramo. Así, para determinar las implicaciones de la gestión del agua realizada por comunidades locales sobre los ecosistemas de Páramo, se tomó el acueducto de Piedra Parada-Cerrito Blanco como caso de estudio. Este acueducto se encuentra al suroeste de la ciudad de Bogotá en la vereda Pasquilla de la localidad 19 (Ciudad Bolívar) el cual suministra agua potable a 165 usuarios, es decir, aproximadamente 660 beneficiarios de los sectores de Paso Alto Colorado Lagunitas y Cerrito Blanco.

Cabe mencionar que esta localidad se caracteriza por su carácter rural, zona que corresponde al $73.9 \%$ del total del territorio y su altitud varía entre 2.400 y 3.700 m.s.n.m. Asimismo, Ciudad Bolívar se caracteriza por el fenómeno de construcción espontánea de viviendas por parte de familias con un bajo poder adquisitivo, situación que se viene evidenciando desde la segunda mitad el siglo XX, y que se relación con la forma en la que es llevada adelante la gestión comunitaria del agua en esta localidad.

El Estado colombiano considera este tipo de construcción como ilegal, lo cual ha sido tomado por las instituciones como un argumento para no proporcionar servicios públicos como el servicio de agua potable. Así, frente a la necesidad de contar con agua, electricidad y saneamiento, las comunidades se han ido organizado para proveerse a ellas mismas estos servicios básicos.

Por lo tanto, se puede decir que la gestión comunitaria del agua aparece en este territorio como una acción de la comunidad local frente a la falta de garantías del Estado que considera que viven en la ilegal y del mercado no ha ofrecido ningún tipo de servicio debido a su bajo poder adquisitivo.

En cuanto al proceso de consolidación del Acueducto Piedra Parada y Cerrito Blanco, es posible mencionar que se ha transformado a través del tiempo, teniendo en cuenta la inclusión efectiva de nuevas técnicas y tecnologías para su funcionamiento. Así, a partir de los talleres de cartografía social y de la entrevista realizada al señor Polidoro Castiblanco, Presidente del acueducto Parada Piedra-Cerrito Blanco, podemos decir que este acueducto ha pasado por tres etapas en su proceso de consolidación:

En un primer momento, cuando la comunidad no tenía la infraestructura para llevar agua de los ríos a las viviendas de los habitantes, las mujeres acompañadas de sus hijos eran las responsables de ir cada día a los diferentes arroyos para recoger el agua destinada al consumo familiar. 


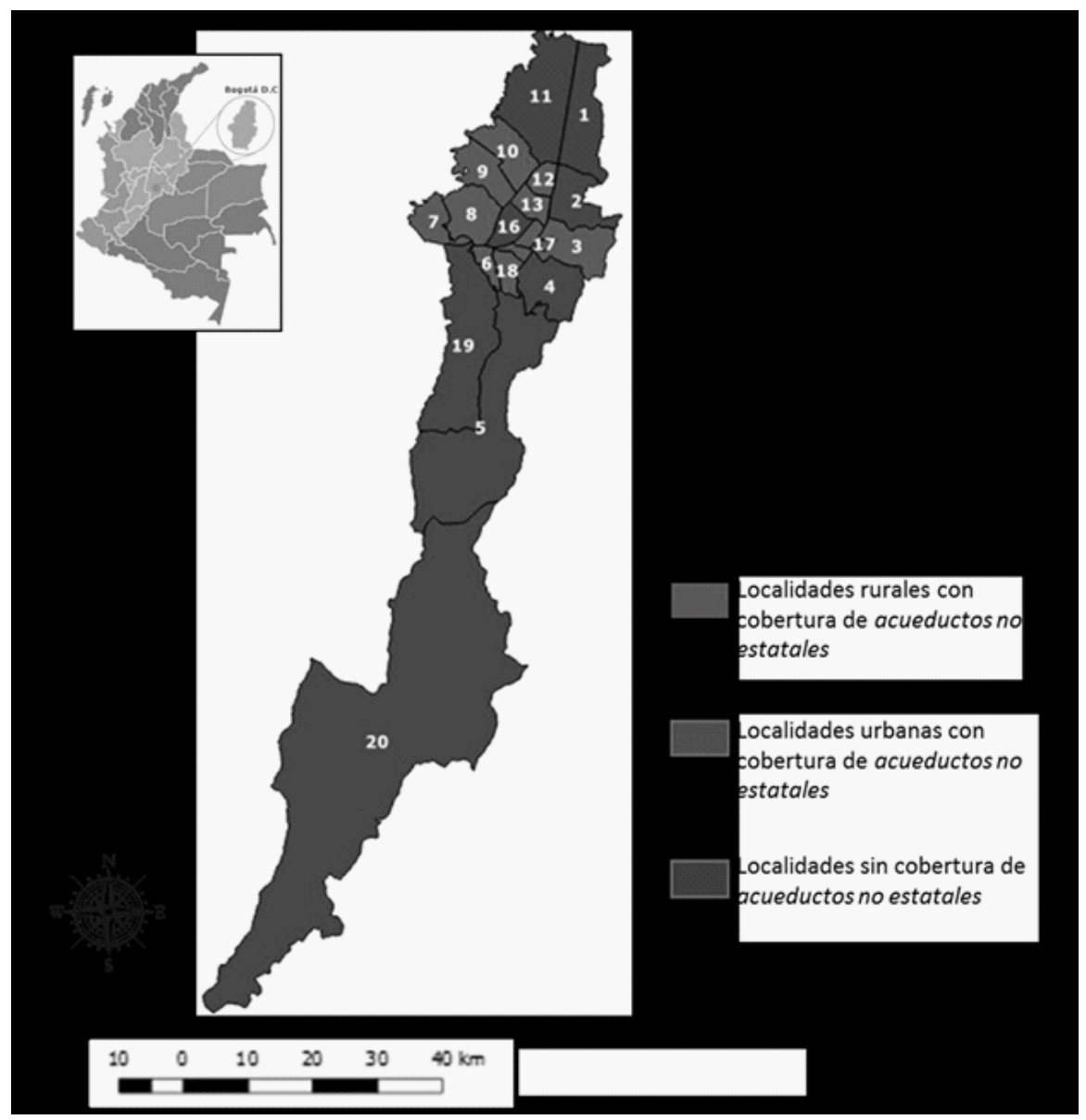

Mapa 1. Cobertura de acueductos no estatales en Bogotá. Fuente: Osorio (2016)

Luego, un segundo paso fue la organización de la Minga para construir zanjas como puede verse en la Foto 3. Estas zanjas permitieron a la comunidad llevar agua desde la montaña hasta caminos próximos de las viviendas, lo cual redujo el tiempo dedicado por las mujeres a la recolección de agua. Sin embargo, esto no pudo garantizar el acceso continuo y en cantidades suficientes al recurso hídrico para esta comunidad. Además, el tema de la calidad del agua que se consumía empezó a ser un factor importante dado el uso de pesticidas y la presencia de ganado en la zona. 


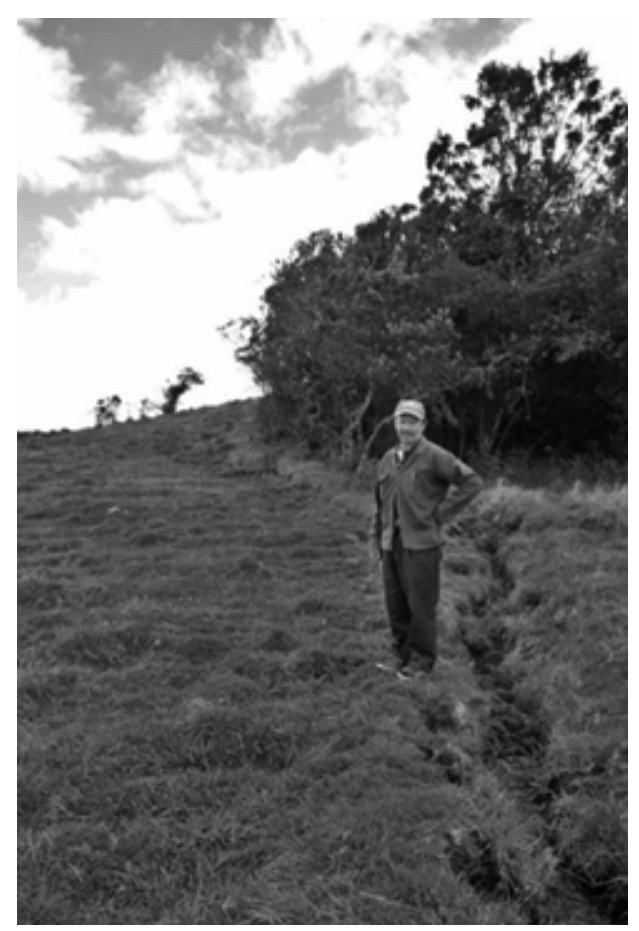

Fotografía 4. Zanjas construidas a partir de la Minga

Por último, se llevó a cabo la construcción de un sistema de potabilización y distribución del agua que permitió asegurar la continuidad del servicio, la calidad agua y el acceso a 17 metros cúbicos por familia (cantidad establecida para el año 2016). Esto ha sido posible gracias a la introducción de técnicas, tecnologías y a la formación de los gestores del agua. Hoy en día el acueducto cuenta con 2 plantas de tratamiento que se encuentran sobre el Páramo de las Mercedes, cerca de 5 arroyos como se puede ver en la figura 3.

A través de los principios de gestión comunitaria propuestos por Elinor Ostrom (2011, p.165) se analizaron las entrevistas y los talleres de cartografía social y se pudo determinar que: la gestión comunitaria del agua realizada por este acueducto comunitario es eficaz, sostenible y duradera. Efectivamente, este acueducto reúne 7 de los 8 principios propuestos por Ostrom (2011), a saber: 1) límites claramente definidos; 2) Coherencia entre las reglas establecidas y el contexto local; 3) Acuerdos colectivos; 4) Existencia de control y supervisión de la gestión; 5) Existencia de sanciones de diferentes grados; 6) 
Existencia de mecanismos de resolución de conflictos y 8) Relación con otras instituciones en varios niveles. Sin embargo, el principio 7 (Reconocimiento mínimo de los derechos de la organización) no se cumple, dado que la legislación de servicios públicos de Colombia promueve la privatización del recurso hídrico por parte de grandes empresas en detrimento del derecho de participación y asociación de las comunidades locales.

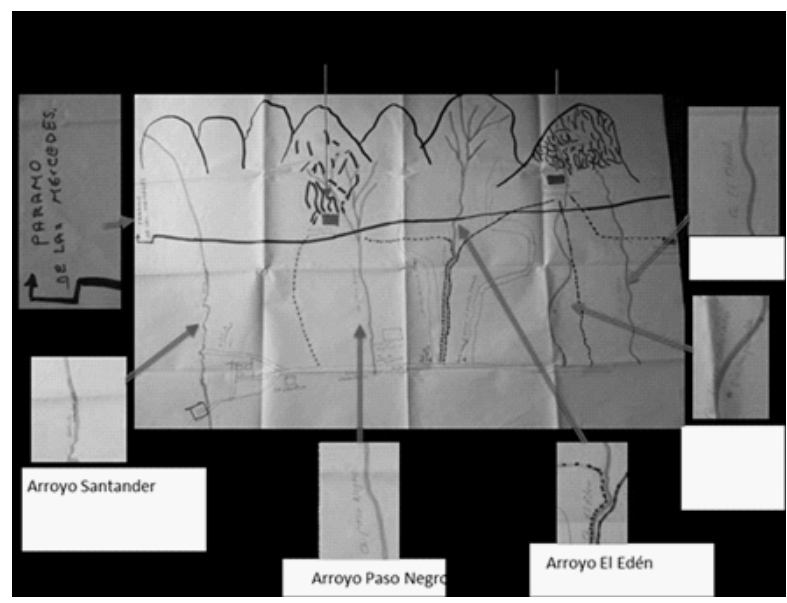

Figura 3. Estructura ecológica principal que rodea el acueducto de Piedra Parada-Cerrito Blanco. Vereda Pasquilla, Ciudad Bolívar. Realización colectiva a través del taller de cartografía social con las y los gestores del acueducto de Piedra Parada-Cerrito Blanco.

Por otro lado existen actualmente otras amenazas exógenas tales como la minería, la ganadería y el cultivo extensivo y el proyecto de expansión del Relleno Sanitario de doña Juana que ponen en riesgo al ecosistema de Páramo y por ende la durabilidad de la gestión comunitaria del agua.

El análisis anterior nos permite afirmar que este acueducto representa, en términos de Ostrom (2011), una institución que realiza una gestión comunitaria de recursos naturales de largo plazo. Sin embargo, es necesario determinar cuál es el impacto de esta gestión sobre el ecosistema. Así, los mapas-resultado de los talleres de cartografía social nos permiten afirmar que el acueducto Piedra Parada-Cerrito Blanco ejecuta acciones de protección del ecosistema de Páramo que no solo evitan la degradación de este ecosistema sino que también contribuyen a su restauración. Efectivamente, este acueducto comunitario ha instalado cercas vivas alrededor de dos arroyos como se puede ver en la Figura 4 y también ha realizado jornadas de reforestación del Páramo 
acompañado por la comunidad de la vereda y el Jardín Botánico de Bogotá desde el año 2004. Las zonas reforestadas se ilustran en la Figura 5.

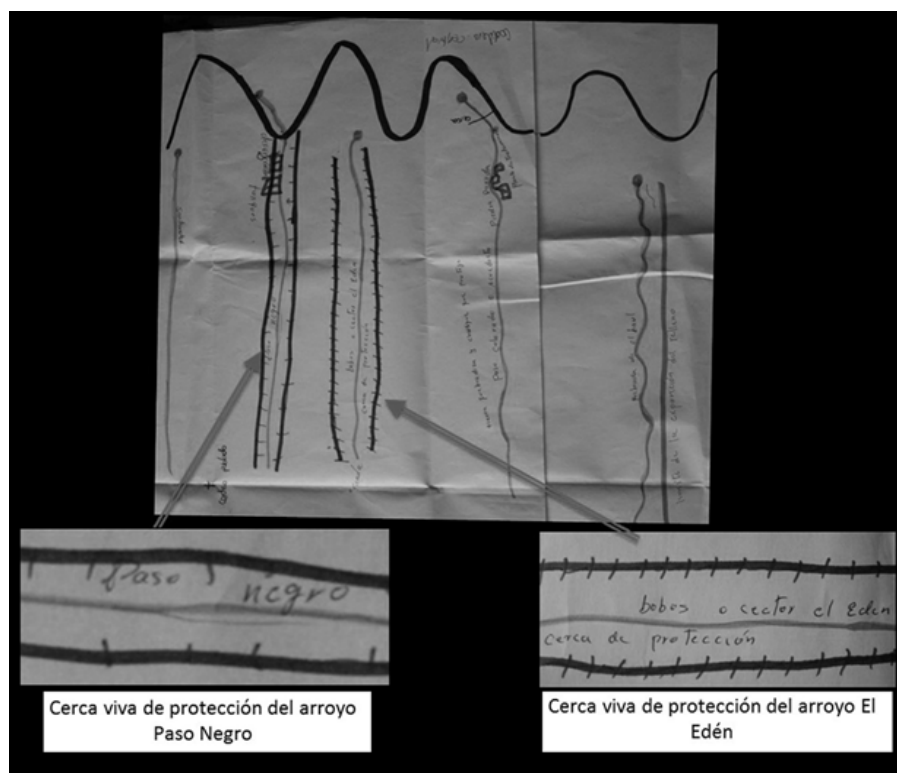

Figura 4. Localización de las cercas vivas establecidas por el acueducto Piedra Parada-Cerrito Blanco. Vereda Pasquilla, Ciudad BolívarRealización colectiva a través del taller de cartografía social con las usuarias del acueducto de Piedra Parada-Cerrito Blanco.

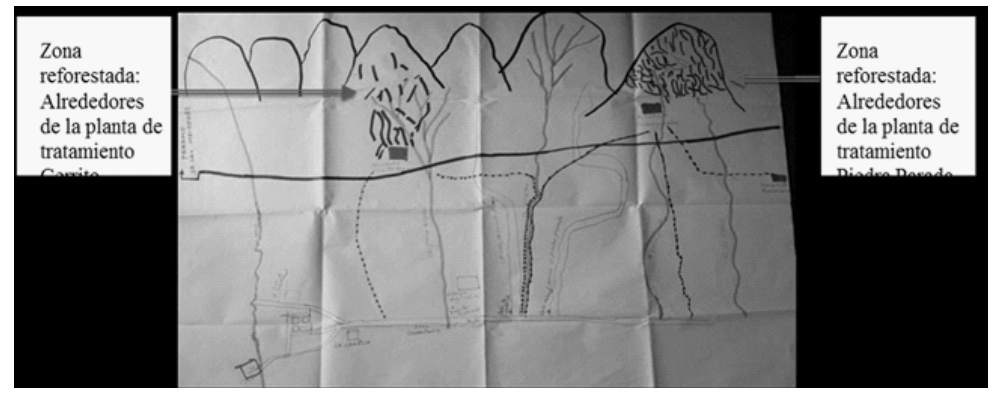

Figura 5. Localización de las zonas reforestadas gracias a la gestión del acueducto Piedra Parada-Cerrito Blanco. Vereda Pasquilla, Ciudad Bolívar. Realización colectiva a través del taller de cartografía social con las y los gestores del acueducto de Piedra Parada-Cerrito Blanco.

Así, es posible afirmar que el Acueducto Piedra Parada y Cerrito Blanco ha implementado medidas de protección al Páramo que permiten la durabilidad de los servicios ecológicos de este ecosistema tales como la regulación del ciclo hidrológico. Los resultados de esta protección pueden evidenciarse 
a través del análisis paisajístico que se hizo en el Páramo de Las Mercedes, y particularmente de la flora existente alrededor de la infraestructura del acueducto. En efecto, la bocatoma del acueducto está ubicada a 3348 m.s.n.m. lo que implica la presencia de la fauna característica del ecotono SubpáramoPáramo y como se puede observar en la Foto 3, los Espeletia o Frailejones que son la planta característica de este econoto está presente, demostrando unas condiciones ecológicas adecuadas.

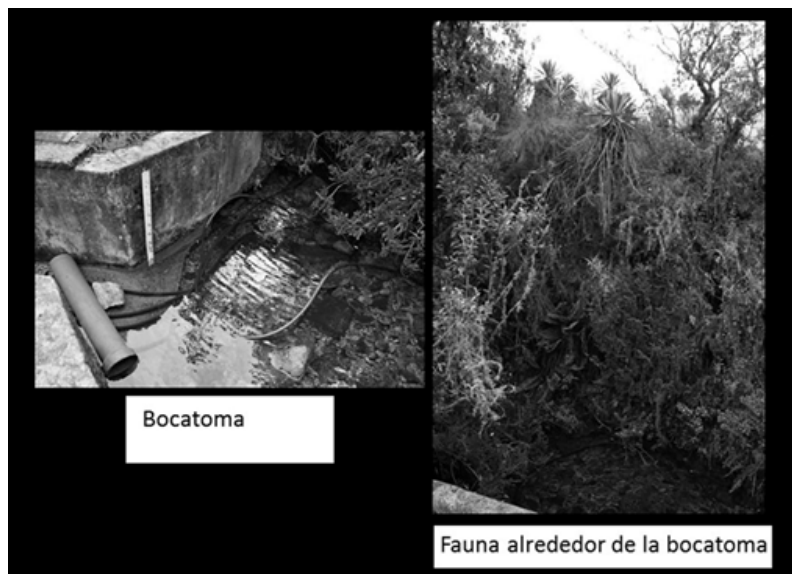

Fotografía 3. Fauna alrededor de la bocatoma del Acueducto Piedra Parada-Cerrito Blanco. Fuente: Ángela Osorio (2016)

Finalmente ${ }^{3}$, se propone la siguiente definición de acueducto comunitario: sistema que permite a una comunidad organizada llevar agua potable a la misma comunidad que lo gestiona. Así, un acueducto comunitario realiza una gestión informal ${ }^{4}$ del recurso hídrico como resultado de la relación vital de las comunidades con el territorio y de un proceso histórico de empoderamiento

3 Una comunidad organizada es un grupo de personas que durante años ha desarrollado la capacidad de considerar acciones a largo plazo en su territorio en varios aspectos, en lo político, lo económico o lo cultural. Por lo que su acción se caracteriza por la capacidad de asociación, la autogestión, la igualdad de derechos y obligaciones entre sus miembros, la participación comunitaria y la solidaridad. (Salazar, 2010, pp. 2-4).

4 Utilizamos la noción de informalidad para hacer hincapié en que la gestión comunitaria del agua en Bogotá representa una serie de actividades y de prácticas realizadas fuera de las reglas institucionales oficiales y que escapan de las medidas, los archivos y las estadísticas oficiales. Es necesario recalcar que con esta noción no se establece una relación entre este tipo de gestión y la ilegalidad o la criminalidad (Benafla, 2015). De hecho, la gestión comunitaria no se limita a las actividades que violan la norma, sino que garantiza el derecho humano al agua de las comunidades desfavorecidas de la ciudad. 
político. Los acueductos comunitarios entonces desdibujan la dimensión meramente técnica de un sistema de abastecimiento de agua potable, para pasar a representar una construcción social y política instaurada sobre la base de una economía solidaria y los saberes locales. Además, los acueductos comunitarios son esenciales para garantizar el Derecho Humano al Agua de las comunidades menos favorecidas de la ciudad. En definitiva, el reconocimiento de la gestión llevada a cabo a través de estos acueductos, así como de su rol en la protección de los Páramos es esencial en el establecimiento de los límites y de la gestión de las áreas protegidas del Bogotá desde la perspectiva del paradigma integrador de protección de la «naturaleza».

\subsection{Conclusiones}

Esta investigación pretende hacer un aporte a la lucha cotidiana de las comunidades campesinas de Bogotá por el reconocimiento de: su existencia, su relación vital con el agua y el Páramo y su eficiente gestión del recurso hídrico. Esta comunidad históricamente invisibilizada nos demuestra a través de los acueductos comunitarios la importancia de proteger los Páramos, de desmercantilizar el agua y de continuar a trabajar para que toda persona en cada lugar del mundo pueda ejercer el Derecho Humano al Agua.

Los resultados de esta investigación son un primer paso en el análisis del paradigma integrador de protección de la «naturaleza» a través de la gestión comunitaria del agua en Bogotá. Este análisis permite concluir que los Páramos son sistemas socio-ecológicos que han sido habitados históricamente por comunidades indígenas y campesinas. Así que es indispensable que estos ecosistemas sean protegidos a través de una categoría de protección que garantice una co-gestión entre diferentes actores y principalmente las comunidades locales. Actualmente solo el 39\% de los Páramos son protegidos oficialmente a través de la figura de Parque Nacional Natural, pero su importancia en la relación del ciclo hídrico hace necesaria la protección de la totalidad de las áreas de este ecosistema el cual está amenazados por actividades antrópicas como la minería, la ganadería y la agricultura extensiva a lo largo del país y en el caso de Bogotá también por el proyecto de ampliación del relleno sanitario Doña Juana, lo cual pone en un alto riesgo el sistema hídrico de Colombia y por ende la vida de las comunidades de este país.

Por otro lado, las comunidades campesinas de Bogotá realizan una gestión del agua que garantiza el ejercicio del Derecho Humano al Agua en los sectores que han sido invisibilizados por las políticas de servicios públicos 
del nivel nacional y descentralizado. El reconocimiento y el apoyo técnico y financiero a esta gestión representa un paso esencial en la garantía de los derechos humanos, lo cual es obligación del Estado Colombiano.

Finalmente, se debe tener en cuenta que los Páramos han sido el escenario de muchos de los conflictos sufridos por las comunidades en este país y trabajaremos para que estos territorios no sigan siendo lugares de conflicto sino de encuentros y reconciliación. El agua, como elemento vital, es el punto de partida del escenario de resolución de conflictos que esperamos en Colombia, así que hacemos una invitación a continuar construyendo reflexiones que aborden la defensa de los derechos de las comunidades de Bogotá y de todo el país, especialmente en lo que concierne el Derecho Humano al Agua. A partir de la información obtenida a través de esta investigación, podemos proponer cuatro puntos clave para un análisis más detallado de la gestión comunitaria del agua en áreas protegidas:

a) La variable temporal de la gestión comunitaria del agua en Bogotá analizando la relación entre el régimen de lluvias, las actividades agrícolas y los acueductos comunitarios en un contexto de cambio climático.

b) El tema del saneamiento, el cual es indispensable para la protección de ecosistema de Páramo y la perdurabilidad de un acceso a agua de calidad.

c) El sistema alternativo de riesgos en zonas de Páramo, así como la agricultura ecológica.

d) Ampliación de los estudios a lo largo del territorio colombiano en donde existen más de 10.000 acueductos comunitarios que en su mayoría requieren la implementación de técnicas y tecnológicas para mejorar la calidad y cobertura del sistema de aprovisionamiento y saneamiento.

\subsection{Anexo I}

Metodología

\begin{tabular}{|l|l|}
\hline Metodología cualitativa & Metodología cartográfica \\
\hline \multicolumn{2}{|c|}{ Recolección de información } \\
\hline Revisión bibliográfica & $\begin{array}{l}2 \text { talleres de cartografía social (con } \\
\text { los gestores comunitarios del agua y } \\
\text { con los usuarios del acueducto comu- } \\
\text { nitario Piedra parada-Cerrito blanco, } \\
\text { localidad de Ciudad Bolívar) }\end{array}$ \\
\hline
\end{tabular}




\begin{tabular}{|l|l|}
\hline Metodología cualitativa & Metodología cartográfica \\
\hline \multicolumn{2}{|c|}{ Recolección de información } \\
\hline $\begin{array}{l}\text { Observación directa: } \\
\text { Paricipación en 3 mesas men- } \\
\text { suales del agua en la localidad } \\
\text { de Usme y Ciudad Bolivar }\end{array}$ & \multirow{2}{*}{ Goerreferenciación de 75 acueductos } \\
\cline { 1 - 2 } $\begin{array}{l}11 \text { entrevistas semi-estructura- } \\
\text { das a diferentes actores (funcio- } \\
\text { narias y funcionarios públicos, } \\
\text { gestores y gestoras, miembros } \\
\text { de ONG's, usuarias, profesores } \\
\text { universitarios) }\end{array}$ \\
\hline
\end{tabular}

\begin{tabular}{|l|l|}
\hline \multicolumn{2}{|c|}{ Procesamiento y análisis de datos } \\
\hline $\begin{array}{l}\text { Grabación en formato mp3, } \\
\text { transcripción y análisis de las } \\
\text { entrevistas y de las mesas men- } \\
\text { suales del agua de la localidad } \\
\text { de Usme y Ciudad Bolívar. }\end{array}$ & $\begin{array}{l}\text { Análisis de los mapas-resultado de } \\
\text { los talleres de cartografía social y } \\
\text { procesamiento de coordenadas con el } \\
\text { programa Qgis 2.14.2 }\end{array}$ \\
\hline
\end{tabular}

Realización Ángela Osorio (2017)

\subsection{Bibliografia}

BENNAFLA, K. (2015). " Notion à la une : informalité. Geoconfluences ». Ressources de géographie pour les enseignants. Recuperado de http://geoconfluences.ens-lyon.fr/informations-scientifiques/a-la-une/notion-a-la-une/notion-ala-une-informalite

DARDOT, P. et LAVAL, C. (2014) Commun : essai sur la révolution au XXIe siècle. Editions La Découverte. Paris, France.

DEPARTAMENTO NACIONAL DE PLANEACIÓN (2015) Diagnóstico de la pobreza rural. Colombia 2010-2014. Dirección de Desarrollo Rural Sostenible - DDRS Subdirección de Producción y Desarrollo Rural —SPDR. Bogotá D.C. DEPRAZ, S. (2008) Géographie des espaces naturels protégés. Armand Colin. 2008 DEPRAZ, S., GUYOT, S. et HÉRITIER, S. (2012) Atlas mondial des espaces protégés.

INSTITUTO DE INVESTIGACIÓN DE RECURSOS BIOLÓGICOS ALEXANDER VON HUMBOLDT, Fondo Adaptación (2015). Transición bosque-

5 La geo referenciación se realizó a partir del trabajo de campo de Angela Osorio (2016) y los Mapas de riesgo del Hospital de Bosa (2013-2016) 
páramo. Bases conceptuales y métodos para su identificación en los Andes colombianos. Editores Sarmiento, C; León, O. Bogotá.

OBSERVATORIO AMBIENTAL DE BOGOTÁ (2017). Usuarios con Servicio de Acueducto de EAB ESP- NUCAA. Recuperado de http://oab2.ambientebogota. gov.co/es/indicadores? $\mathrm{id}=136 \& \mathrm{v}=\mathrm{l} \#$

OSTROM, E. (2011) El gobierno de los bienes comunes. Fondo de cultura económica. Mexico.

PARQUES NACIONALES DE COLOMBIA (2017). Categorías de áreas protegidas. Recuperado de http:/www.parquesnacionales.gov.co/portal/es/sistema-deparques-nacionales-naturales/categorias-de-areas-protegidas/

PROCURADURÍA GENERAL DE LA NACIÓN (2008) Situación de los páramos en Colombia frente a la actividad antrópica y el cambio climático. Procuraduría delegada para asuntos ambientales y agrarios. Colección de asuntos ambientales $\mathrm{N}^{\circ} 4$

RIVERA, D. y RODRÍGUEZ, C. (2011). Guía divulgativa de criterios para la delimitación de páramos de Colombia. Ministerio de Ambiente, Vivienda y Desarrollo Territorial e Instituto de Investigación de Recursos Biológicos Alexander von Humboldt. 68 págs. Bogotá.

SECRETARÍA DE PLANEACIÓN (2016). Información para la toma de decisiones. Estadísticas. http://www.sdp.gov.co/PortalSDP/InformacionTomaDecisiones/ Estadisticas/ProyeccionPoblacion

SECRETARÍA DISTRITAL DE PLANEACIÓN (2009). Conociendo la localidad de Ciudad Bolívar: Diagnóstico de los aspectos físicos, demográficos y socioeconómicos. Recuperado de http://oab2.ambientebogota.gov.co/es/documentacion-e-investigaciones/resultado-busqueda/conociendo-la-localidad-de-ciudadbolivar

TORRES, G (2015). «Solo el 16 por ciento de los suelos de Colombia está blindado contra la "depredación ambiental" del hombre». Servicio de noticias del Instituto Geográfico del Agustín Codazzi. Recuperado de http:/noticias.igac.gov.co/ solo-el-16-por-ciento-de-los-suelos-de-colombia-esta-blindado-contra-la-depredacion-ambiental-del-hombre/

UNICEF (2015) El agua potable y el saneamiento básico en los planes de desarrollo. Recuperado de http://www.unicef.org/colombia/pdf/Agua3.pdf

UICN (2015). Informe anual. Recuperado de

https://portals.iucn.org/library/sites/library/files/documents/2016-016-Es.pdf

ZAMBRANO, C. (1993). «Aunque no estamos ni en libros, ni en mapas, existimos». In: Zambrano, C. Hombres de páramo y montaña, los yanaconas del macizo colombiano. Instituto colombiano de antropología. Bogotá, Colombia. 



\title{
EFICACIA DE LAS ÁREAS PROTEGIDAS DE ESPAÑA COMO POLÍTICA DE SOSTENIBILIDAD TERRITORIAL: EL PROYECTO SOSTPARK
}

\author{
David Rodríguez Rodríguez \\ Instituto de Economía, Geografía y Demografia. Consejo Superior de Investigacio- \\ nes Cientificas. Madrid, España. \\ Javier Martínez Vega \\ European Topic Centre. Universidad de Málaga. España.
}

Iván López

Universidad de Zaragoza. Facultad de Ciencias Sociales y del Trabajo. Área de Sociología. Zaragoza, España.

\subsection{Antecedentes}

La riqueza geográfica, ambiental y cultural de España determina unos niveles de biodiversidad específica de hábitats y de paisajes especialmente altos en el contexto europeo (CBD, 2014) y así también una mayor responsabilidad hacia la conservación la biodiversidad, los servicios ecosistémicos y los recursos naturales ligados a su conservación como el suelo. Las 1.557 APs existentes en España en 2011 abarcan una superficie terrestre cercana a las 6.283.000 ha (alrededor del 12,4\% del territorio nacional) (Jiménez, 2012). Respecto de la Red Natura, los 1.446 Lugares de Importancia Comunitaria (LICs) y 595 Zonas de Especial Protección para las Aves (ZEPAs) existentes en 2011 cubrían una superficie aproximada de 13.740 .000 (lo que equivale a más de un 27\% del territorio español) (Múgica et al, 2012). Tal extensión sitúa a España a la cabeza de la UE, con un promedio del 18,36\%, en cantidad de territorio terrestre dedicado prioritariamente a la conservación de la biodiversidad (European Commission, 2016) y muy por encima de la media mundial (en torno al 15\%) (UNEP-WCMC, 2014).

En España, al igual que en muchas otras partes del Mundo, se ha asumido generalizadamente que los recursos teóricamente protegidos en las APs estaban adecuadamente conservados por el mero hecho de estar amparados por la normativa y/o medidas de gestión aplicadas a estos espacios (Mora \& Sale, 2011; Rodríguez-Rodríguez y Martínez-Vega, 2013), aunque las evidencias 
empíricas que avalan tal asunción resulten aún bastante limitadas globalmente (Juffe-Bignoli et al., 2014) y, en ocasiones, contradictorias (Gray et al., 2016).

Pese a los avances destacables en materia de protección legislativa del territorio y los recursos en él contenidos, distintos indicadores muestran importantes presiones latentes, como la artificialización del suelo, especialmente patentes en las zonas costeras y periurbanas de las grandes ciudades españolas entre los años 2000 y 2006 (Jiménez, 2012). Asimismo, indicadores de respuesta ante estas y otras presiones, como los planes de recuperación de especies amenazadas o los planes de gestión de APs, muestran un estado desfavorable, insuficiente para garantizar la conservación eficaz de dichos recursos (Jiménez, 2012; Múgica et al., 2012). Todo ello hace necesario un riguroso análisis territorial que evalúe la eficacia ambiental de lo que, en la práctica, quizás haya sido la principal herramienta de sostenibilidad territorial en España: las APs. De hecho, los análisis de cambios de usos del suelo, fragmentación y aislamiento de APs y sus terrenos circundantes se consideran una línea de actuación prioritaria en materia de sostenibilidad y uno de los mayores retos para la conservación de la biodiversidad en España (Jiménez, 2012).

Distintas normas nacionales e internacionales en materia de conservación de la biodiversidad requieren la evaluación de la eficacia de las APs en España: el Convenio para la Diversidad Biológica (art. 7), la Directiva 92/43/ CEE, relativa a la conservación de los hábitats y las especies de flora y fauna silvestres; (arts. 11 y 17), la Ley del Patrimonio Natural y de la Biodiversidad (arts. 10, 17.b, 47 y 67.b), o la Ley de Parques Nacionales a través del Plan Director de la Red de Parques Nacionales (art. 7). Sin embargo, la evaluación sistemática de la eficacia de las APs es un tema aún pendiente en España (Rodríguez-Rodríguez et al., 2015).

La evaluación de la eficacia de las APs ha evolucionado con rapidez desde el IV Congreso Mundial de Parques celebrado en el año 1992, donde se identificó la gestión eficaz como uno de los cuatro temas más importantes sobre conservación de APs a escala global. Poco después, la Unión Internacional para la Conservación de la Naturaleza (UICN) publicó el marco metodológico de evaluación de la eficacia de la gestión de las APs (Hockings et al., 2000). Actualmente, existen más de 50 metodologías de evaluación de APs en el mundo (Leverington et al., 2010), 40 de ellas en Europa (Nolte et al., 2010). La décima Conferencia de las Partes del Convenio sobre Diversidad Biológica (CBD) acordó invitar a las partes signatarias al desarrollo de indicadores específicos de evaluación de la eficacia de la gestión de las APs con los siguientes 
objetivos: 1) expandir e institucionalizar este tipo de evaluaciones para lograr la evaluación del $60 \%$ de la superficie protegida global en 2015 y transferir los resultados de dichas evaluaciones a la base de datos global sobre evaluación de la eficacia de la gestión; 2) e incluir información acerca de la gobernanza y los impactos y beneficios sociales de las APs (CBD, 2010).

Sin embargo, hasta fechas recientes tan solo el $29 \%$ de las APs mundiales habían realizado algún tipo de evaluación de su eficacia conservacionista (Coad et al., 2013) y muchas de estas evaluaciones se basan en metodologías rápidas y subjetivas, como RAPPAM (Ervin, 2003) o METT (Stolton et al., 2007), no consideradas exactas (Carranza et al., 2014) o suficientemente precisas (Cook et al., 2014) para evaluar los resultados de conservación. Otras metodologías más rigurosas, como la evaluación del PEIN de Cataluña (Mallarach, 2008) o el Sistema de Evaluación de la Eficacia de las Áreas Protegidas (Rodríguez-Rodríguez \& Martínez-Vega, 2012), han supuesto notables avances respecto al rigor metodológico de las evaluaciones, pero siguen sin poder demostrar los vínculos entre protección/gestión de APs y resultados de conservación (Rodríguez-Rodríguez \& Martínez-Vega, 2016 a). Los estudios que emplean diseños semi-experimentales tipo BACI, que permiten atribuir con mayor exactitud los efectos conservacionistas de las APs, son escasos $\mathrm{y}$, mientras la evidencia empírica sugiere la eficacia de las APs para evitar la transformación de los hábitats protegidos, sus efectos sobre la conservación de especies protegidas son menos concluyentes (Geldmann et al., 2013).

Adicionalmente a sus efectos prioritarios sobre la conservación de la biodiversidad, la declaración de APs puede tener efectos beneficiosos o perniciosos sobre las poblaciones y economías locales como consecuencia de los cambios en la asignación y acceso a los recursos naturales (Naughton-Treves et al., 2005; Scherekenberg et al., 2010), lo cual hace necesario complementar el análisis de la sostenibilidad ambiental de la APs con el análisis de los otros dos pilares de la sostenibilidad: la sociedad y la economía (NNUU, 2014). El enfoque ecosistémico actualmente vigente aconseja incluir al ser humano y sus actividades como parte integrante del ecosistema (CBD, 2000). Igualmente, el escenario de profunda crisis social y económica que ha atravesado España aconseja analizar el efecto socioeconómico de las políticas de protección territorial de espacios para minimizar sus costes y maximizar sus beneficios, identificando: ¿a qué grupos sociales y económicos afecta?; ¿de qué manera?; ¿afectan por igual distintas redes de APs?; ¿cómo pueden minimizarse los costes y maximizarse los beneficios socioeconómicos de las APs? 
Diversos autores han sugerido la necesidad de emplear controles adecuados para evaluar exactamente los efectos de la protección de espacios (Addison, 2011; Geldmann et al., 2013), aunque advierten de la dificultad de emplear controles de características similares a las APs a partir de una muestra existente, así como de recabar series temporales de datos de seguimiento de datos ambientales fuera de APs.

\subsection{Evaluación de la sostenibilidad global de las APs en España basada en evidencia: el proyecto SOSTPARK}

El proyecto SOSTPARK surge de la constatación del incumplimiento de la necesidad de evaluar sistemáticamente la eficacia conservacionista de las APs detectada hace casi dos décadas (Múgica y Gómez-Limón, 2002; Rodríguez-Rodríguez et al., 2015). También trata de evaluar empíricamente el papel de las APs españolas como motores de desarrollo socioeconómico sostenible.

SOSTPARK forma parte del Plan Nacional de I+D+i 2013-2016 Orientada a los Retos de la Sociedad, dentro del Sub-Área Temática de Geografía, enmarcado en el Reto sobre «Seguridad, calidad alimentaria; actividad agraria productiva y sostenible; sostenibilidad de los recursos naturales; investigación marina y marítima». En él participan nueve investigadores de cuatro instituciones distintas: el Instituto de Economía, Geografía y Demografía del Consejo Superior de Investigaciones Científicas (coordinador), la Universidad Rey Juan Carlos, la Universidad de Zaragoza, el Centro Temático Europeo de la Universidad de Málaga y el Departamento de Ecología de la Universidad de Málaga. Tiene un presupuesto de 193.000€ y una duración de 3 años, habiendo comenzado en octubre de 2015. Está financiado por el Ministerio de Economía, Industria y Competitividad.

El objetivo principal del proyecto SOSTPARK (CSO2014-54611-JIN) es evaluar los efectos ambientales, sociales, económicos e institucionales de distintas redes de áreas protegidas en España como principal política pública para la conservación de la biodiversidad y de los valores culturales y servicios ecosistémicos asociados.

SOSTPAK se divide en dos fases. La primera fase constituye un análisis cuantitativo del grado de protección territorial (sostenibilidad ambiental) conferida por APs españolas pertenecientes a cinco redes de APs terrestres (reservas naturales, parques nacionales, parques naturales, LICs/ZEcs y ZEPAs) mediante indicadores espacialmente explícitos de conservación del suelo, un 
recurso natural y económico de primer orden en España, así como de la biodiversidad. Dichas redes se han escogido por representar un gradiente de rigor normativo y por ser nominal, normativa y gestionariamente similares en el conjunto del estado.

Se ha evaluado el efecto de un censo de dichas redes de APs sobre tres indicadores espaciales de sostenibilidad ambiental del recurso suelo: artificialización del suelo, fragmentación y aislamiento. Dicho análisis ya ha finalizado, dando como resultado la producción de cuatro artículos (ver Estudios concluídos). Tres de ellos, a escala nacional, han empleado los datos espaciales de usos del suelo del proyecto CORINE-Land Cover (CLC) para los años: 1990 (año inicial) y 2006 (año final). En otro artículo a escala autonómica (Navarra), en el que se han usado datos de CLC 2006 y 2012, se ha analizado específicamente el efecto de la legislación y gestión de las APs sobre la artificialización del suelo. En el análisis de la biodiversidad actualmente en curso se están analizando la representación de la biodiversidad amenazada en redes autonómicas de APs (como la RENPA, en Andalucía) y los efectos de estas redes de APs sobre los taxones protegidos y los ecosistemas, a escalas nacional o autonómica.

La segunda fase de SOSTPARK, actualmente en desarrollo, prevé un análisis cualitativo y cuantitativo de la sostenibilidad social, económica e institucional de las APs españolas a tres escalas: nacional, autonómica (Andalucía) y municipal. A escalas nacional y autonómica se identificarán gremios afectados por o interesados en la declaración de APs y se recabará su percepción institucional acerca de los efectos de estas áreas sobre el territorio. A escala local, la percepción organizacional acerca de los efectos socioeconómicos de una muestra andaluza de APs se comparará con el análisis estadístico del efecto de la declaración de dicha muestra a partir de estadísticas oficiales (series temporales de variables socioeconómicas), usando municipios dentro y fuera de APs como controles (MPBACI). Se analizará el caso de Andalucía por ser una Comunidad costera, multiprovincial (incluyendo provincias costeras e interiores), abarcar grandes ciudades y zonas rurales, y disponer de series temporales largas y amplias de datos socioeconómicos estandarizados a escala municipal.

En ambas fases del proyecto, se prevé usar como controles zonas adyacentes alrededor de dichos espacios aplicando un diseño de investigación geo-estadístico tipo Multiple-Paired-Before-After-Control-Impact (MPBACI; Smith, 2002), de forma que se pueda discriminar el efecto combinado del 
tiempo (fecha de declaración: antes-después) y de la localización de los datos (dentro-fuera de las APs). Metodológicamente se emplea prioritariamente el enfoque de "polígono protegido» (Rodriguez-Rodríguez et al., 2016 ${ }_{\mathrm{b}}$ ) resultado de los análisis espaciales de superposición de capas digitales para evitar problemas derivados del solapamiento de figuras de protección de APs sobre el mismo espacio físico y poder mejorar la atribución de los efectos, en lugar del análisis clásico de las fronteras administrativas de cada AP.

Adicionalmente a los efectos ambientales, socioeconómicos e institucionales de las cinco redes de APs terrestres, se aprovechó el interés y colaboraciones existentes al inicio del proyecto entre el IP y la Universidad de Málaga para ampliar los objetivos del proyecto al medio marino adaptando el análisis de la parte terrestre del mismo a la Red de Reservas Marinas de España gestionada por el MAPAMA. Se escogió analizar la red de Reservas Marinas por ser una red ya consolidada, reducida en número y extensión, y con normativa y gestión homogéneas. En este caso, los indicadores de eficacia ambiental se refieren a la calidad de las aguas, la abundacia de especies protegidas y de interés comercial, la presencia de especies exóticas invasoras y la calidad de los hábitats bénticos. El análisis socioeconómico es análogo al de la parte terrestre, aunque con algunos indicadores de eficacia específicos del medio marino (pe. pesca).

Por último, se determinará qué variables (legislación, gestión, tamaño, antigüedad, entre otras) influyen más decisivamente en la sostenibilidad de este tipo de herramientas de gestión territorial terrestre y marina con objeto de extraer recomendaciones que favorezcan una gestión territorial ambientalmente sostenible, socialmente equitativa y económicamente rentable dentro y fuera de las APs.

\subsection{Objetivos transversales del proyecto}

Además de los objetivos científicos antes indicados, esta investigación comprende los siguientes objetivos trasversales.

1. Incrementar la cohesión de los grupos de investigación sobre sostenibilidad territorial. 
Este objetivo busca, en consonancia con la Estrategia Española de Ciencia y Tecnología y de Innovación 2013-2020, optimizar las capacidades de distintos grupos de investigación que llevan años trabajando sobre la sostenibilidad territorial en España, entre otros, el «Grupo de Análisis Geográfico Multiescalar del Cambio Global» del Instituto de Economía, Geografía y Demografía del CSIC, el Grupo de «Planificación Ambiental para el Desarro1lo», de la Universidad Rey Juan Carlos, el Centro Temático Europeo de la Universidad de Málaga, o el Grupo de «Sociología del Cambio Climático y Desarrollo Sostenible» de la Universidad Carlos III.

Además de estos socios del proyecto, las diferentes temáticas de estudio han conllevado contactos y colaboraciones concretas con otras organizaciones territoriales relevantes, como el Organismo Autónomo Parques Nacionales, el Ministerio de Agricultura, Pesca, Alimentación y Medio Ambiente, la Consejería de Medio Ambiente y Ordenación del Territorio de Andalucía, el Departamento de Desarrollo Rural, Medio Ambiente y Administración Local de Navarra, el Instituto Español de Oceanografía, la Sociedad Española de Ornitología, el Instituto de Historia Natural de Granollers o el Instituto de Ecología Litoral.

2. Hacer más eficiente la transferencia de resultados de investigación a la sociedad.

Este objetivo, también establecido como eje prioritario en la Estrategia Española de Ciencia y Tecnología y de Innovación 2013-2020, se plasma en la creciente preocupación del grupo por la repercusión social de la ciencia y por la participación de distintos colectivos sociales tanto en la fase de investigación, como en la de divulgación de resultados, sobre la que se ha hecho un especial hincapié. En este sentido, está previsto divulgar los resultados del proyecto entre los actores territoriales relevantes de distintas maneras y en distintos formatos, como publicaciones de distintos tipos (artículos científicos, monografía divulgativa, hojas-resumen, notas de prensa), comunicaciones o pósteres en congresos, talleres, o reuniones bi- o multi-laterales con decisores públicos y otros actores.

3. Promocionar territorios innovadores y sostenibles.

El objetivo global de SOSTPARK se alinea notablemente con otro de los ejes prioritarios de la Estrategia Española de Ciencia y Tecnología y de 
Innovación y con el objetivo de desarrollo socioeconómico sostenible de la Estrategia Europea Horizon 2020. Busca generar modelos alternativos y sostenibles de desarrollo que maximicen la potencialidad socioeconómica de los territorios usando para ello las APs y que ayuden asimismo a prevenir y mitigar los efectos de crisis originadas por modelos de desarrollo insostenibles mediante recomendaciones concretas.

4. Incrementar la difusión y el liderazgo internacionales de la ciencia española.

SOSPARK pretende ampliar la repercusión nacional e internacional de la investigación territorial española, aumentando la experiencia de los participantes en publicaciones y colaboraciones con otros grupos de primer nivel, lo cual constituye otro de los ejes prioritarios de la Estrategia Española de Ciencia y Tecnología y de Innovación. Para ello, se intentará publicar todos los estudios del proyecto en revistas internacionales indexadas en el SCI o en el SSCI de factor de impacto superior a 2.

\subsection{Estudios concluídos}

Entre octubre de 2015 y abril de 2017, se han concluido los siguientes estudios en el marco del proyecto:

- Rodríguez-Rodríguez, D. \& Martínez-Vega, J. En revisión. Effect of legal protection and management on the environmental performance of protected areas: A Spanish case study. Land Use Policy.

- Rodríguez-Rodríguez, D. \& Martínez-Vega, J. En revisión. Representation and protection of threatened biodiversity by the largest Spanish regional network of protected areas. Journal for Nature Conservation.

- Rodríguez-Rodríguez, D. \& Martínez-Vega, J. Enviado. Analysing subtle threats to conservation: a nineteen year assessment of fragmentation and isolation of Spanish protected areas. Landscape and Urban Planning.

- Rodríguez-Rodríguez, D. \& Martínez-Vega, J. En revisión. Protected area effectiveness against land artificialisation in Spain. Science of the Total Environment.

- Rodríguez-Rodríguez, D. \& Martínez-Vega, J. Enviado. Assessing recent environmental sustainability in the Spanish network of National Parks and their statutory peripheral areas. Applied Geography. 


\subsection{Agradecimientos}

Es justo reconocer y agradecer las aportaciones de todas las personas que han colaborado con el proyecto aportando datos, opiniones, sugerencias, revisando materiales, y ayudando al desarrollo del mismo en sus múltiples facetas y estudios. La lista sería muy larga, por lo que hacemos este agradecimiento extensible a todas ellas.

El proyecto SOSTPARK ha sido financiado por el Ministerio de Economía, Industria y Competitividad (CSO2014-54611-JIN).

\subsection{Referencias}

ADDISON, P. 2011. A global review of long-term Marine Protected Area monitoring programmes: The application of a good framework to marine biological monitoring. A report prepared for the Joint Nature Conservation Committee. JNCC. Peterborough, UK. Disponible desde: http://jncc.defra.gov.uk/ pdf/jncc455_Vol1_Vol2\%20combined_web.pdf (Accedido el 27/04/2017).

CARRANZA, T.; MANICA, A.; KAPOS, V. \& BALMFORD, A. 2014. Mismatches between conservation outcomes and management evaluation in protected areas: A case study in the Brazilian Cerrado. Biological Conservation, 173: $10-16$.

CBD. Convention on Biological Diversity. 2000. COP 5 Decision V/6. Ecosystem Approach. United Nations Environment Programme, Nairobi. Disponible desde: https://www.cbd.int/decision/cop/default.shtml?id=7148 (Accedido el 27/04/2017).

CBD. Convention on Biological Diversity. 2010. COP 10 Decision X/31. Protected Areas. United Nations Environment Programme, Nairobi. http://www.cbd. int/decision/cop/?id=12297 (Accedido el 27/04/2017).

CBD. Convention on Biological Diversity. 2014. Information. Country profiles. Spain. United Nations Environment Programme, Nairobi. http://www. cbd.int/countries/?country=es (Accedido el 27/04/2017).

COAD, L.; LEVERINGTON, F.; BURGESS, N.D.; CUADROS, I.C.; GELDMANN, J.; MARTHEWS, T.R.; MEE, J.; NOLTE, C.; STOLL-KLEEMANN, S.; VANSTEELANT, N.; ZAMORA, C.; ZIMSKY, M. \& HOCKINGS, M. 2013. Progress towards the CBD protected area management effectiveness targets. PARKS, 19.1.

COOK, C.N., CARTER, R.W., HOCKINGS, M. 2014. Measuring the accuracy of management effectiveness evaluations of protected areas. Journal of Environmental Management, 139: 164-171

ERVIN, J. 2003. Rapid Assessment and Prioritization of Protected Areas Management (RAPPAM) Methodology. WWF. Gland, Switzerland. 
EUROPEAN COMMISSION. EUROPEAN COMMISSION. 2016. Environment. Nature \& Biodiversity. Natura 2000 Barometer. Disponible desde: http:// ec.europa.eu/environment/nature/natura2000/barometer/index_en.htm (Accedido el 27/04/2017)

GELDMANN, J.; BARNES, M.; COAD, L.; CRAIGIE, I.D.; HOCKINGS, M. \& BURGESS, N.D. 2013. Effectiveness of terrestrial protected areas in reducing habitat loss and population declines. Biological Conservation, 161: 230-238.

GRAY, C.L.; HILL, S.L.L.; NEWBOLD, T.; HUDSON, L.N.; BÖRGER, L.; CONTU, S.; HOSKINS, A.J.; FERRIER, S.; PURVIS, A. \& SCHALERMANN, J.P.W. 2016. Local biodiversity is higher inside than outside terrestrial protected areas worldwide. Nature Communications, 7: 12306; doi:10.1038/ ncomms 12306 .

HOCKINGS, M.; STOLTON, S. \& DUDLEY, N. 2000. Evaluating effectiveness: a framework for assessing the management of protected areas. IUCN, Gland, Switzerland, and Cambridge, UK.

JIMÉNEZ, L.M. (Dir.). 2012. Sostenibilidad en España 2012. Capitulo Especial Energía Sostenible para todos [2012 Año Internacional de la Energía]. Ministerio de Agricultura, Alimentación y Medio Ambiente, Madrid.

JUFFE-BIGNOLI, D.; BURGESS, N.D.; BINGHAM, H.; BELLE, E.M.S.; DE LIMA, M.G.; DEGUIGNET, M.; BERTZKY, B.; MILAM, A.N.; MARTINEZ-LOPEZ, J.; LEWIS, E.; EASSOM, A.; WICANDER, S.; GELDMANN, J.; VAN SOESBERGEN, A.; ARNELL, A.P.; O'CONNOR, B.; PARK, S.; SHI, Y.N.; DANKS, F.S.; MACSHARRY, B. \& KINGSTON, N. 2014. Protected Planet Report 2014. UNEP-WCMC. Cambridge, UK.

LEVERINGTON, F.; LEMOS, K.; COURRAU, J.; PAVESE, H.; NOLTE, C.; MARR, M.; COAD, L.; BURGUESS, N.; BOMHARD, B. \& HOCKINGS, M. 2010. Management effectiveness evaluation in protected areas $-a$ global study. $2^{\text {nd }}$ ed. University of Queensland, Brisbane.

MALLARACH, J.M. (Coord.). 2008. Protegits, de fet o de dret? Primera avaluació del sistema d'espais naturals protegits de Catalunya. Institució Catalana d'Història Natural. Disponible desde: http://ichn.iec.cat/Avaluacio_Espais. htm (Accedido el 27/04/2017).

MORA, C. \& SALE, P.F. 2011. Ongoing global biodiversity loss and the need to move beyond protected areas: a review of the technical and practical shortcomings of protected areas on land and sea. Marine Ecology Progress Series, 434: 251-266.

MÚGICA, M. y GÓMEZ-LIMÓN, J. (Coords.) 2002. Plan de Acción para los espacios naturales protegidos del Estado Español. Fundación Fernando González Bernáldez, Madrid.

MÚGICA, M., MARTÍNEZ, C., GÓMEZ-LIMÓN, J., PUERTAS, J. Y ATAURI, J.A. 2012. Anuario 2011 del estado de las áreas protegidas en España. Fundación Fernando González Bernáldez, Madrid. 
NAUGHTON-TREVES, L.; BUCK, M. \& BRANDON, K. 2005. The role of protected areas in conserving biodiversity and sustaining local livelihoods. Annual Review of Environmental Resources, 30: 219-252.

NNUU. Naciones Unidas. 2014. Temas principales. Desarrollo sostenible. Disponible desde: $\quad$ http://www.un.org/es/ga/president/65/issues/sustdev.shtml (Accedido el 27/04/2017).

NOLTE, C.; LEVERIGNTON, F.; KETTNER, A.; MARR, M.; NIELSEN, G.; BOMHARD, B.; STOLTON, S.; STOLL-KLEEMANN, S. \& HOCKINGS, M. 2010. Protected Area Management Effectiveness Assessments in Europe. A review of application, methods and results. University of Greifswald, Greifswald, Germany.

RODRÍGUEZ-RODRÍGUEZ, D. \& MARTÍNEZ-VEGA, J. 2012. Proposal of a system for the integrated and comparative assessment of protected areas. Ecological Indicators, 23: 566-572.

RODRÍGUEZ-RODRÍGUEZ, D. y MARTÍNEZ-VEGA, J. 2013. Evaluación de la eficacia de las áreas protegidas. El Sistema de Evaluación Integrada de Áreas Protegidas (SEIAP). Resultados de la primera evaluación integrada de los espacios naturales protegidos de la Comunidad de Madrid. Fundación BBVA, Madrid.

RODRÍGUEZ-RODRÍGUEZ, D.; MARTÍNEZ-VEGA, J.; TEMPESTA, M. \& OTERO-VILLANUEVA, M.M. 2015. Limited uptake of protected area evaluation systems among managers and decision-makers in Spain and the Mediterranean Sea. Environmental Conservation, 42(3): 237-245.

RODRÍGUEZ-RODRÍGUEZ, D. \& MARTÍNEZ-VEGA, J. 2016. What should be evaluated from a manager's perspective? Developing a salient protected area effectiveness evaluation system for managers and scientists in Spain. Ecological Indicators, 64: 289-296.

RODRÍGUEZ-RODRÍGUEZ, D.; RODRÍGUEZ, J.; BLANCO, J.M. \& ABDUL MALAK, D. 2016. Marine protected area design patterns in the Mediterranean Sea: Implications for conservation. Marine Pollution Bulletin, 110(1): 335-342.

SCHRECKENBERG, K.; CAMARGO, I.; WITHNALL, K.; CORRIGAN, C.; FRANKS, P.; ROE, D.; SCHERL, L.M. \& RICHARDSON, V. 2010. Social assessment of conservation initiatives. A review of rapid methodologies. Natural Resource Issues No. 22, IIED, London.

SMITH, E.P. 2002. BACI design. In El-Shaarawi, A.H. \& Piegorsch, W.W. (Eds.) Encyclopedia of Environmetrics, Vol. 1; pp: 141-148. John Wiley \& Sons. Chichester.

STOLTON, S., HOCKINGS, M., DUDLEY, N., MACKINNON, K., WHITTEN, T., LEVERINGTON, F. 2007. Reporting progress in protected areas. A site level management effectiveness

Tracking Tool, 2nd edn. World Bank/ 
WWF Forest Alliance and WWF, Gland http://d2ouvy59p0dg6k.cloudfront.net/ downloads/mett2_final_version_july_2007.pdf (Accedido el 27/04/2017).

UNEP-WCMC. United Nations Environment Programme-World Conservation Monitoring Centre. 2014. Mapping the World's special places. Opening access on global protected areas. Disponible desde: http://www.unep-wc$\mathrm{mc}$.org/featured- projects/mapping-the-worlds-special-places (Accedido el 27/04/2017). 
11

\title{
VIDA INDEPENDIENTE: MARCOS PARA LA ACCIÓN EN LA TERCERA Y CUARTA EDAD
}

\author{
Diana Carolina Mira Tamayo \\ 566550@unizar.es \\ Universidad de Zaragoza
}

\subsection{Vida independiente y el modelo de envejecimiento exitoso en la tercera y cuarta edad}

La declaración Política y el Plan de Acción Internacional de Madrid sobre el Envejecimiento (2002:47), instó a los responsables políticos a potenciar la independencia de las personas de edad y crear condiciones que promuevan su calidad de vida y les permitan vivir, de forma independiente en su propia comunidad tanto tiempo como sea posible o como ellos deseen. La promoción de la vida independiente hace referencia a la prevención de la dependencia, y a la capacidad de las personas mayores para desempeñar las funciones relacionadas con la vida diaria (capacidad de vivir en comunidad, recibiendo poca o ninguna ayuda); no obstante, no se debe confundir la vida independiente con la autonomía, ya que esta última hace referencia a la facultad humana para gobernar sus propias acciones, la propia vida. (Libro Blanco del Envejecimiento Activo, 2011:288).

La vida independiente es inherente a la capacidad funcional; es por ello, que Rowe y Kahn (1997:434) consideraron que para que se pueda experimentar un envejecimiento exitoso es necesario que exista: bajo riesgo de enfermedad y discapacidad, una alta función física y cognitiva y un compromiso con la vida (participación social). Posteriormente, Rowland (2012), analiza el envejecimiento con éxito de Rowe y Kahn (1987) y clasifica a la población de la tercera edad en tres grupos principales: las personas que experimentan envejecimiento con éxito, envejecimiento normal y patológico. Por otra parte, 
incluye un grupo de transición entre la tercera y la cuarta edad; esta última es clasificada como un grupo con problemas de funcionamiento y dependencia. Los miembros de este grupo tienen discapacidades graves y necesitan un poco de ayuda o supervisión personal, aunque la gran mayoría de ellos todavía viven en la comunidad. Por último, se encuentran, las personas pertenecientes a la cuarta edad, consideradas como dependientes, y con una carga importante de envejecimiento secundario; no obstante, existen investigaciones que evidencian que la satisfacción y el bienestar de la vida son posibles a pesar de la mala salud. (Sax, 1993). A continuación se describe cada uno de los estadios de la tercera edad, la edad de transición y la cuarta edad, con sus correspondientes características.

\begin{tabular}{|c|c|c|}
\hline Grupo & Categorías de estadios de la vida & Características principales \\
\hline \multicolumn{3}{|c|}{ Tercera edad } \\
\hline $1^{\circ}$ & $\begin{array}{l}\text { Éxito / envejecimiento- óptimo } \\
\text { alto }\end{array}$ & $\begin{array}{l}\text { Independencia: no requiere } \\
\text { asistencia para realizar las acti- } \\
\text { vidades básicas de la vida diaria }\end{array}$ \\
\hline $2^{\circ}$ & $\begin{array}{l}\text { Medio habitual de envejeci- } \\
\text { miento }\end{array}$ & Envejecimiento normal \\
\hline $3^{\circ}$ & Envejecimiento enfermo- Medio & $\begin{array}{l}\text { Envejecimiento patológico (a } \\
\text { veces necesita ayuda con las } \\
\text { actividades de la vida diaria) }\end{array}$ \\
\hline $4^{\circ}$ & $\begin{array}{l}\text { Transicional o de independencia } \\
\text { limitada }\end{array}$ & Fragilidad \\
\hline \multirow[t]{3}{*}{$5^{\circ}$} & $\begin{array}{l}\text { nfermedad y deterioro con la } \\
\text { edad }\end{array}$ & Discapacidad \\
\hline & Cuarta edad & $\begin{array}{l}\text { Dependencia: siempre necesita } \\
\text { asistencia con las actividades } \\
\text { básicas de la vida diaria }\end{array}$ \\
\hline & $\begin{array}{l}\text { Enfermedad y deterioro con la } \\
\text { edad }\end{array}$ & \\
\hline
\end{tabular}

TABLA 1.Envejecimiento exitoso en la tercera y cuarta edad. Elaboración propia, inspirada en la clasificación de Rowland (2012:170)

Como se observa en la tabla 1, los miembros del grupo de envejecimiento óptimo o con éxito, no presentan discapacidades o enfermedades y viven independientemente. Experimentan un retraso prolongado en el inicio de las enfermedades o discapacidades relacionadas con la edad (compresión de la morbilidad). El perfil de las personas que tienden a permanecer en este grupo son: casadas, con un buen nivel educativo y que adoptan estilos de vida sanos como: no fumar, realizar ejercicio regularmente, tener un peso y 
una dieta saludable (Rowland, 2012). Estos factores protectores determinantes de un envejecimiento saludable y exitoso son expuestos por Kirkwood (2005), que aduce que la longevidad y sus formas parecen estar explicadas en un $25 \%$ por factores genéticos mientras que el $75 \%$ lo están por las condiciones socio-comportamentales. De forma tal que aunque las limitaciones del envejecimiento y la vejez proceden de la biología, existe un amplio margen para el cambio y la actuación ambiental y, éstas explican una importante parte de las formas de envejecer desde un envejecimiento activo, positivo y con éxito a un envejecimiento con enfermedad, dependencia y sufrimiento. Por lo tanto, el objetivo de los sistemas sanitarios y la investigación gerontológica, es maximizar la proporción de personas que experimenten un envejecimiento saludable y exitoso en la tercera y cuarta edad.

El segundo grupo integra a las personas mayores que experimentan el envejecimiento normal o primario, el cual está impregnado por cambios debidos a la edad. Entre los cambios normales más evidentes nos encontramos con: pérdida de fuerza y de resistencia, vista cansada, crecimiento de pelos nuevos en orejas y orificios nasales, pérdida de memoria a corto plazo, calvicie, pérdida de masa ósea, disminución de la estatura, pérdida de audición y menopausia etc. (Hayflick, 1999:88). El perfil de este grupo son personas de la tercera edad que debido a los cambios del envejecimiento normal y a la vulnerabilidad ante enfermedades y condiciones discapacitantes que éstos experimentan, tienen cierta probabilidad de que éstas aparezcan de forma relativamente temprana. Un mecanismo clave para retrasar la enfermedad y las condiciones discapacitantes es la adopción de estilos de vida saludables desde edades tempranas; pero estas decisiones no son suficientes sino que se deben mejorar los determinantes de la salud, ya que la desigualdad social a lo largo de toda la vida es un obstáculo importante para llegar a un envejecimiento saludable y exitoso.

El tercer grupo está instituido por personas que presentan un envejecimiento secundario debido a que la probabilidad de enfermar aumenta con la edad, los cambios normales de la edad hacen a la persona mayor más vulnerable a enfermedades crónicas o accidentes. Más de las tres cuartas partes de personas mayores muy provectas padecen de tres a nueve condiciones patológicas importantes. (Hayflick, 1999:88).En este grupo se incluye a personas activas e independientes que tienen discapacidades leves y moderadas, por ejemplo, debido a artritis o problemas de audición o visión. Mientras que este subgrupo pertenece a la categoría de «envejecimiento enfermo» de Rowe y 
Kahn, se considera que la etiqueta adscrita tiene una carga engañosa, debido a que las consecuencias de las enfermedades en este subgrupo de edad son mínimas y muchas personas son capaces de llevar vidas tan activas y satisfactorias como las de otros en la tercera edad.

Coexiste un grupo de transición entre la tercera y la cuarta edad, que presenta deterioro en el funcionamiento. Los miembros de este grupo tienen discapacidades severas y necesitan ayuda personal o supervisión, aunque la gran mayoría de ellos todavía viven en la comunidad. Las consecuencias de las discapacidades graves para mantener un grado razonable de independencia -como seguir viviendo en el propio hogar- varían según la disponibilidad de apoyo, especialmente de un cónyuge, otros miembros de la familia y servicios comunitarios. El Plan de Acción Internacional de Madrid sobre el Envejecimiento (2002:47), señaló que: «la independencia incluye la posibilidad de residir en el hogar durante el mayor tiempo posible». En este grupo se incluyen las personas mayores denominadas frágiles que presentan situaciones de alto riesgo de deterioro, que se acompaña de alguna discapacidad y en algunos casos dependencia ante un agente o proceso externo sobre ellos. La menor reserva o resistencia ante diferentes agresiones puede llevar con mayor o menor rapidez a la pérdida de autonomía o de independencia. Se consideran personas frágiles a las que se encuentran en proceso de transición a la cuarta edad y presentan más de tres de las siguientes características: padecen pluripatología, dificultad para realizar las actividades básicas de la vida diaria, precisando ayuda para la realización de estas actividades, personas que está en transición entre la tercera y la cuarta edad ( $>$ de 80 años), polifarmacia, viudedad reciente, haber sido hospitalizado recientemente, precaria situación económica, presencia de deterioro cognitivo, persona que ha padecido un accidente recientemente (caída). (Martínez y Molina, 2009).

En términos de la categorización de Rowe y Kahn, el grupo de transición también se caracteriza por un «envejecimiento enfermo», caracterizado por la vulnerabilidad, fragilidad y la entrada en la cuarta edad. Una vez más, las connotaciones totalmente negativas del envejecimiento enfermo están en desacuerdo con los hallazgos de la investigación de que la satisfacción y el bienestar de la vida son posibles a pesar de la mala salud. Como señaló Sax (1993: 133): «las personas mayores que tienen dificultades de salud, particularmente aquellas debidas a enfermedades crónicas, generalmente se adaptan, siguen llevando una vida independiente y reportan que su salud es satisfactoria». La resiliencia y los factores protectores positivos en las personas que transitan de 
la tercera a la cuarta edad, permiten que pese a las pérdidas, también se puedan encontrar ganancias y factores positivos que incrementan el bienestar.

La transición a la cuarta edad también presenta vulnerabilidad a la enfermedad y deterioro debido a la edad, estas condiciones permiten que la persona mayor pueda experimentar discapacidad, la cual se define como: «una o más limitaciones en las actividades básicas de la vida diaria (como comer, lavarse / bañarse, vestirse y entrar y salir de la cama), dado que tales limitaciones severas tienden a estar estrechamente relacionadas con demandas de atención a largo plazo» (Lafortune et al., 2007: 4). Los datos sobre las limitaciones graves de actividades básicas de la vida diaria proporcionan un enfoque más estricto para definir las poblaciones de transición a la cuarta edad. La discapacidad suele ser un concomitante de las afecciones crónicas, éstas comprenden el $5 \%$ de todos los casos de enfermedad, y causan alrededor del 60\% de los costes médicos, son de interés primordial para los ciudadanos, así como para los profesionales de la salud, puesto que se estima que afectan al $20 \%$ de la población total. A su vez, a partir de los 75 años un porcentaje superior al $50 \%$ padece cuatro o más enfermedades crónicas. Las personas mayores que presentan pluripatología, del mismo modo, también son polimedicadas. La discapacidad aumenta en función de la edad a más de cinco de cada diez entre los mayores de 74 años y a tres de cada 4 personas en el grupo de 85 y más años (Informe de las Personas Mayores en España: 2014). El verdadero reto para las políticas públicas es que estas personas que padecen alguna discapacidad puedan tener una vida independiente.

Para conocer la realidad de la dialéctica de la tercera edad en buenas condiciones de salud y una cuarta edad dependiente y con una carga importante de envejecimiento secundario, se presentan los datos de diversas fuentes estadísticas para realizar un análisis contextual de los colectivos de la cuarta edad dependiente, tercera edad independiente y del estado de transición entre ambos. Cabe destacar, que no toda la población de la cuarta edad es dependiente, por lo tanto, no es una realidad generalizable, debido a que el envejecimiento es heterogéneo, y hay factores, intrínsecos y extrínsecos que influyen de forma diferente en cada individuo. En la tabla posterior se pueden observar diferentes indicadores de funcionalidad en la tercera edad, edad de transición y en la cuarta edad en España. 


\begin{tabular}{|c|c|c|c|c|c|c|c|}
\hline \multirow[t]{2}{*}{ Indicadores } & \multicolumn{2}{|c|}{ Tercera edad } & \multicolumn{2}{|c|}{ Edad de transición } & \multicolumn{2}{|c|}{ Cuarta edad } & \multirow[t]{2}{*}{$\begin{array}{l}\text { Fuente de } \\
\text { los datos }\end{array}$} \\
\hline & 65-74 años & Ind & 75-84 años & Ind & $>85$ años & Ind & \\
\hline Discapacidad & $30 \%$ & $70 \%$ & $44 \%$ & $56 \%$ & $65 \%$ & $35 \%$ & $\begin{array}{l}\text { INE (2011- } \\
12) \text { ENS }\end{array}$ \\
\hline $\begin{array}{l}\text { Actividades } \\
\text { funcionales }\end{array}$ & $19,9 \%$ & $80,1 \%$ & $43,2 \%$ & $56,8 \%$ & $66,8 \%$ & $33,2 \%$ & $\begin{array}{l}\text { INE (2011- } \\
12) \text { ENS }\end{array}$ \\
\hline Autocuidado & $5,1 \%$ & $94,9 \%$ & $16,2 \%$ & $78,7 \%$ & $43,4 \%$ & $56,6 \%$ & $\begin{array}{l}\text { INE (2011- } \\
\text { 12) ENS }\end{array}$ \\
\hline $\begin{array}{c}\text { Actividades del } \\
\text { hogar }\end{array}$ & $10,6 \%$ & $89,4 \%$ & $29,3 \%$ & $70,7 \%$ & $63,9 \%$ & $36,1 \%$ & $\begin{array}{l}\text { INE (2011- } \\
\text { 12) ENS }\end{array}$ \\
\hline $\begin{array}{c}\text { Actividades básicas } \\
\text { de la vida diaria } \\
(A B V D)\end{array}$ & $22 \%$ & $78 \%$ & $40 \%$ & $60 \%$ & $60 \%$ & $40 \%$ & EISS(2012) \\
\hline $\begin{array}{c}\text { Actividades instru- } \\
\text { mentales de la vida } \\
\text { diaria }(A I V D)\end{array}$ & $28 \%$ & $72 \%$ & $52 \%$ & $48 \%$ & $77 \%$ & $23 \%$ & EISS (2012) \\
\hline $\begin{array}{c}\text { Dependencia-Bene- } \\
\text { ficiarios }\end{array}$ & $\begin{array}{r}65-79 \\
17,68 \% \\
\end{array}$ & $82,32 \%$ & & & $\begin{array}{c}>80 \\
54,44 \%\end{array}$ & $45,56 \%$ & $\begin{array}{l}\text { IMSERSO } \\
(2017)\end{array}$ \\
\hline Cronicidad & $84,36 \%$ & $15,64 \%$ & $91,33 \%$ & $8,67 \%$ & $93,03 \%$ & $6,97 \%$ & EUS (2014) \\
\hline $\begin{array}{c}\text { Hospitalización } \\
\text { (últimos } 12 \text { meses) }\end{array}$ & 17,778 (si) & $\begin{array}{l}10,55 \\
\text { (no) }\end{array}$ & $\begin{array}{c}13,47 \% \\
\text { (si) }\end{array}$ & $\begin{array}{c}6,74 \% \\
\text { (no) }\end{array}$ & $\begin{array}{l}6,12 \% \\
\text { (si) }\end{array}$ & $\begin{array}{l}2,54 \% \\
\text { (no) }\end{array}$ & EUS (2014) \\
\hline $\begin{array}{c}\text { Utilización servicios } \\
\text { de urgencias (últi- } \\
\text { mos } 12 \text { meses) }\end{array}$ & $9,45 \%(\mathrm{si})$ & $\begin{array}{c}11,48 \% \\
\text { (no) }\end{array}$ & $\begin{array}{c}9,09 \% \\
\text { (si) }\end{array}$ & $\begin{array}{c}6,66 \% \\
\text { (no) }\end{array}$ & $\begin{array}{c}3,69 \% \\
\text { (si) }\end{array}$ & $\begin{array}{c}2,53 \% \\
\text { (no) }\end{array}$ & EUS (2014) \\
\hline Accidente en casa & $4,5 \% 8 \mathrm{si})$ & $\begin{array}{c}95,5 \% \\
\text { (no) }\end{array}$ & $\begin{array}{c}7,35 \% \\
\text { (si) }\end{array}$ & $\begin{array}{c}92.65 \% \\
\text { (no) }\end{array}$ & $\begin{array}{c}12,98 \% \\
\text { (si) }\end{array}$ & $\begin{array}{c}87,02 \% \\
\text { (no) }\end{array}$ & EUS (2014) \\
\hline
\end{tabular}

TABLA 2. Indicadores funcionales en la tercera y cuarta edad ${ }^{12}$

De la tabla 2, se puede inferir que en todas las variables de la cuarta edad se observa una minoración significativa en la funcionalidad, así mismo que los cambios en la funcionalidad son inversamente proporcionales, a mayor edad, menor independencia; pero esta situación no es generalizable a toda la categoría social de la cuarta edad, ya que existen personas independientes.

1 Ind se corresponde con «independientes»

2 (ENS) Encuesta Nacional de Salud: 2011-2012; (EISS) Encuesta de Integración Social y Salud: 2012; IMSERSO: perfil de la persona beneficiaria con prestación según sexo y edad. Abril de 2017; (EUS) Encuesta europea de Salud: 2014 
En la tabla 2 se evidencian algunas variables a tomar en consideración, por ejemplo en cuanto a la discapacidad son independientes en la tercera edad un $70 \%$, frente a un $35 \%$ en la cuarta edad; de forma análoga, en la población de la tercera edad en cuanto a la independencia existe un $82,32 \%$ en la tercera edad frente a un $45,56 \%$ en la cuarta edad. En las actividades básicas de la vida diaria, la población de la tercera edad independiente, duplica a la cuarta edad, y en las actividades instrumentales de la vida diaria, la población de la tercera edad prácticamente triplica a la cuarta edad independiente. No obstante, la cuarta edad es una etapa bastante rara entre los menores de 80 años, e incluso en edades más avanzadas la mayoría de la población sigue siendo independiente. La mayoría de las personas nunca llegan a la cuarta edad, excepto quizás brevemente antes de la muerte. La transición a una cuarta edad prolongada suele requerir una supervivencia prolongada, que es más frecuente entre las mujeres debido a su mayor longevidad (Crimmins, 2002). Hay visiones conciliadoras sobre tendencias que afectan a la cuarta edad; pese a que un $54,44 \%$ de las personas pertenecientes a este subgrupo son beneficiarias de prestaciones de la Ley de la dependencia en España, esta cifra no incluye a las personas de este subgrupo etario que viven de forma independiente y que experimentan un envejecimiento exitoso; paralelamente a lo anterior, cabe destacar que también hay personas con discapacidad, que pueden participar en la sociedad, ser útil y productivo, y alcanzar la satisfacción con la vida. La vida independiente es una de las características positivas más importantes y prevalecientes en la tercera y cuarta edad.

\subsection{Debates subyacentes al envejecimiento con éxito en la cuarta edad}

Siguen vigentes los debates conciliadores sobre las tendencias que afectan a la cuarta edad. Algunos autores sostienen que las estrategias para lograr el envejecimiento exitoso están retrasando la entrada en la cuarta edad, en lugar de reducir la proporción de hacerlo. Baltes y Smith (2003), por ejemplo, son escépticos acerca de los beneficios a largo plazo de la extensión de la vida, argumentando que: «cada vez más, las noticias científicas sobre las perspectivas de supervivencia en la vejez están cambiando de un enfoque de ganancia a aspectos de la pérdida» (ibid: 123). Del mismo modo, Masoro (2001: 417) concluyó, a partir de una revisión de la investigación, que «es muy improbable que una persona mayor pueda vivir sin tener un deterioro significativo». Por otra parte, también argumentó que las modificaciones ambientales y los estilos de vida tienen más potencial para retrasar la entrada a la cuarta edad, en lugar 
de eliminar, el daño molecular asociado con el envejecimiento. Por lo tanto, interpretó las modificaciones del estilo de vida como «una ralentización del proceso de envejecimiento». También consideró que una creciente prevalencia del envejecimiento exitoso podría aumentar la extensión y duración de la discapacidad, aunque en edades más avanzadas; no obstante, determinó que el concepto de envejecimiento exitoso era engañoso en el sentido de que creaba expectativas infundadas de vejez sin discapacidad. Por último, sus propios experimentos evidenciaron que las ratas con una ingesta baja en calorías tenían vidas más largas que aquellas en una dieta más calórica, sin embargo, sufrieron deterioro senescente en el mismo intervalo temporal (ibid.: 418).

En cambio, Vaillant y Mukamal (2001: 840) sostienen que una mayor longevidad se traduce en menos, no más, años de discapacidad y que «la mayor parte del deterioro mental antes de los 80 años refleja la enfermedad y no el proceso normal de envejecimiento». Con retraso en el envejecimiento y sin compresión de la morbilidad, la gente se volvería «vieja», en el sentido de tener una capacidad funcional severamente alterada, en edades posteriores. Por lo tanto, las preguntas para futuras investigaciones sobre la Cuarta Edad incluyen: ¿Está aumentando la edad promedio de entrada a la Cuarta Edad y el número promedio de años vividos en la Cuarta Edad está disminuyendo?.

En definitiva, el denominado «envejecimiento exitoso» se ha desplegado como un término en la literatura gerontológica más largo y más amplio que el de la tercera edad. Como marco discursivo, aunque el envejecimiento exitoso tiene una larga historia en la escritura académica, ha sido «anclado» como un paradigma dominante en la gerontología por Rowe y Kahn en su artículo, envejecimiento con éxito (1987). Dillaway y Byrnes señalan que el envejecimiento exitoso es uno de los muchos términos (envejecimiento: productivo, ingenioso, independiente, saludable, activo, positivo y óptimo) que desde los años setenta se ha utilizado para expresar una opinión positiva del envejecimiento. Como concepto, ha demostrado ser más exitoso que otras terminologías centradas en las pérdidas, teniendo más efecto tanto en la gerontología académica como en la política (como se cita en Gilleard y Higgs, 2015: 117).

\subsection{Esperanza de vida con compresión de la morbilidad}

El tiempo entre la jubilación y la buena salud es cada vez mayor; «La persona promedio que se jubila hoy puede anticiparse a vivir y estar en buena salud por lo menos 15 años después de la jubilación» (James y Wink, 2007). 
Esto representa una nueva etapa de vida, caracterizada por la buena salud y la ausencia de obligaciones laborales o familiares. Esta falta de obligaciones y roles definidos se combina con la buena salud e independencia para hacer de este tiempo de la vida «la edad de oportunidad para el cumplimiento personal» (James y Wink, 2007: 69).

Las aseveraciones de que las sociedades envejecidas experimentan una «compresión» de la morbilidad en las edades avanzadas -o si no su compresión, entonces su aplazamiento-, han sido demostradas en diferentes fuentes estadísticas (véase el gráfico 1). Parece razonable creer que a pesar de la disminución del bienestar colectivo observado desde los años ochenta, la sociedad «moderna tardía» ha experimentado una expansión constante, aunque desigual, en términos absolutos y relativos de una vida activa más sana. En el siguiente gráfico se puede observar tres grupos de datos cruciales sobre la esperanza de vida; el primero evalúa la media de años con limitación de la actividad, con limitación moderada de actividad y con limitación severa de actividad. El segundo grupo la media de años vividos con y sin morbilidad crónica y por último el tercer grupo valora la media de años que se esperan con buena, regular y mala salud percibida.
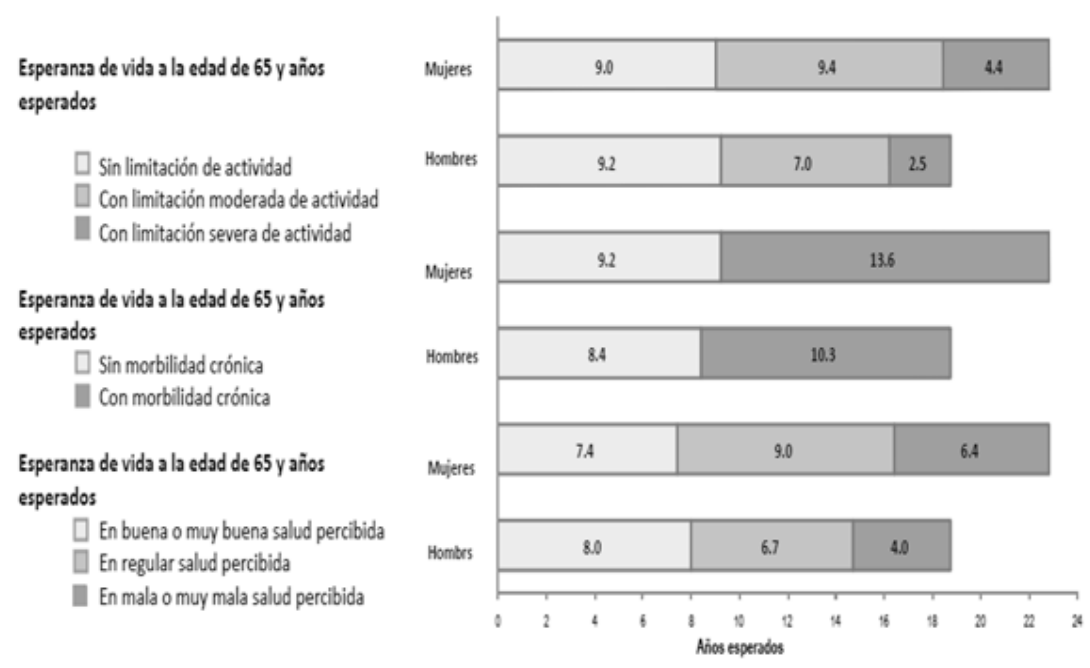

GRÁFICO1. Esperanza de vida y esperanzas de vida saludable en España a los 65 años basadas en limitación de actividad (AVS), morbilidad crónica y salud percibida en España (Datos de SILC 2013) .Informe de 2013 de Europhen Health and Life Expectancy 
El anterior gráfico enfatiza como la esperanza de vida sin limitación de actividad a partir de los 65 años en España, es superior en los hombres (9,2 años) que en las mujeres ( 9 años). En efecto, cada vez existen más años de vida independiente por la compresión de la morbilidad, de manera que la aparición de la limitación se retrasa y los años vividos en condiciones saludables aumentan a partir de los 65 años. Las mujeres viven más años pero en peores condiciones; como se puede ver, padecen mayor número de años con limitación moderada y severa de la actividad con respecto a los hombres; siendo esta última prácticamente el doble, con respecto a los hombres de la misma edad. El aumento de la prevalencia de enfermedad degenerativa crónica con la edad y el aumento de la frecuencia de la morbilidad múltiple parecen características omnipresentes de las sociedades de envejecimiento contemporáneo (Marengoni et al., 2011). El gráfico 1 corrobora esta afirmación debido a que las mujeres viven de media 13,6 años con morbilidad crónica frente a los hombres que viven 10,3 años en la misma situación. La mayoría de las personas de la cuarta edad (de 80 años o más) tienen un cierto grado de morbilidad múltiple, típicamente asociada con múltiples enfermedades crónicas (Formiga et al., Marengoni et al., 2008); esta última puede ser la razón por la cual las mujeres, por su longevidad, valoran peor su salud (de media esperan vivir con mala salud autopercibida 6,4 años, frente a los 4 años de los hombres).

Los debates subyacentes a la compresión de la morbilidad no están del todo claros, debido a que la enfermedad y el resultado la misma cambian con el tiempo y no siempre - quizás no por lo general - debido a la mejora de la atención médica y la tecnología. La morbilidad, y la enfermedad son fenómenos potencialmente separables y cada uno tiene asociaciones diferentes y discutiblemente contingentes con la edad y el envejecimiento. La enfermedad, en términos de una mayor prevalencia de las llamadas «enfermedades degenerativas» y el aumento de los niveles de incapacidad, es difícil de predecir porque los diversos elementos -la enfermedad, los costos y la discapacidad- no son derivados fijos de la demografía. La característica intrínseca y universal de vivir más tiempo o incluso si es una tendencia que aumenta continuamente a través de cada década de la vida adulta, es menos clara (Gilleard y Higgs, 2015: 49).

\subsection{Vida independiente y marcos para la acción en la tercera y cuarta edad}

La sociedad moderna tardía demuestra que la vida puede mejorarse de muchas maneras importantes, la vida humana en general y el envejecimien- 
to humano en particular plantean más preguntas de las que la ciencia puede responder. Es aquí donde se necesitan desarrollar maneras significativas de manejar situaciones en la vida que en muchos aspectos no pueden ser controladas. A continuación se esbozarán una serie de ideas o debates acerca de cómo mejorar la concepción de la tercera y cuarta edad independiente en la sociedad moderna tardía.

En primer lugar, es necesario conocer donde surge la dialéctica creada para la distinción entre la tercera y cuarta edad, o la distinción entre grupos de personas mayores «más saludables», y aquellos más propensos al deterioro y el declive. Uno de los principales problemas del envejecimiento poblacional es la construcción social del mismo y los imaginarios colectivos que subyacen, creando narrativas y discursos que abogan o apoyan la visión de la tercera y cuarta edad. La tercera edad es alimentada de virtudes de autonomía, salud y actividad y la cuarta edad esta marcada por la discapacidad, la dependencia y finalmente la muerte (Holstein y Minkler, 2003: 793). En definitiva, se atribuye el envejecimiento exitoso e independiente a la tercera edad y el envejecimiento sin éxito y dependiente a la cuarta edad; por lo tanto, la idea de mantener un ethos, de envejecimiento exitoso e independiente en la cuarta edad requiere una respuesta diferente, como puede ser una mayor resiliencia para resistir las atribuciones de fragilidad e incapacidad evocadas por la presencia de una edad más avanzada.

En los últimos años, los investigadores en gerontología han revaluado la fragilidad y la cuarta edad en una variedad de maneras (Grenier 2007, Gilleard y Higgs 2010, 2011). En los estudios biomédicos y geriátricos, las construcciones de la fragilidad y la cuarta edad se utilizan para referirse a un diagnóstico o condición médica y como un medio de dirigir los recursos para la salud y el cuidado social. En las ciencias sociales, la fragilidad y la cuarta edad han sido consideradas como construcciones socioculturales, ejemplos de prácticas utilizadas para clasificar y determinar la elegibilidad para los servicios de salud pública y de atención social, y lugares simbólicos y significativos en la vida tardía (Gilleard y Higgs 2010).

En segundo lugar se puede corroborar que cada vez existen más años de vida independiente por la compresión de la morbilidad, de manera que la aparición de la limitación se retrasa y los años vividos en condiciones saludables aumentan a partir de los 65 años. La salud es probablemente el aspecto más deseado y habilitador del capital humano o «el determinante más importante del empoderamiento frente a la vulnerabilidad», (Goujon y Lutz 2004: 141). 
La vida independiente es una realidad, nunca antes en la historia de la humanidad el hombre había llegado democráticamente a la cuarta edad, cada vez, la esperanza de vida aumenta y mantener una esperanza de vida libre de discapacidad es crucial. Por lo tanto, si la población mayor, tiene una esperanza de vida en constante crecimiento, el curso de la vida sufrirá cambios drásticos; a continuación se enumeran los cambios previsibles en el curso de la vida:

a) Para Riley y Riley (1994a, 1994b) el surgimiento de un postretirement con su correspondiente período de vida libre de problemas de salud, puede no ser coherente con esta estructuración del curso de la vida. Riley y Riley (1994b) sugieren que una reformulación del curso de la vida podría ocurrir de tal manera que en lugar de ocurrir consecutivamente como lo hacen actualmente, se prevé la posibilidad de que un individuo pudiera ingresar y abandonar la fuerza de trabajo a intervalos / edades variables para reforzar la formación educativa para mejorar la carrera o el cambio ocupacional o participar de períodos prolongados (aunque breves en comparación con la jubilación). Por otra parte la Tercera Edad podría ser eliminada por políticas que aumenten la edad de jubilación.

b) Por otra parte, es vital pensar que si las personas mayores cada vez son poseedoras de una férrea salud y no sólo eso, sino que progresivamente la edad de jubilación irá en aumento, como corolario del aumento de la esperanza de vida; debido a lo anterior, es necesario indagar en qué tipo de actividades pueden participar las personas que viven una vida independiente. La respuesta a este desafío vital, deviene del estadista y filósofo romano Marcus Tullius Cícero, que en 1942, escribió un ensayo titulado De Senectute, en el que pone en labios de Catón el viejo estas palabras: «¿de qué negocios? ¿De los que la juventud ejecuta con sus fuerzas? ¿No hay pues, otras cosas, aún sin fuerzas corporales, puedan ejecutar los viejos con su espíritu?». Los clásicos tenían claro que había dos modos de actividad, clasificaban las artes en liberales y serviles; por lo tanto las personas mayores pueden dedicarse a lo que denominaron los antiguos, artes liberales, que no tienen que ver con la fuerza sino con el saber.

En tercer lugar, como queda plasmado en la tabla 2, son axiomáticas, las diferencias en las fuentes estadísticas, nacionales e internacionales; las cuales 
presentan serias dispersiones en cuanto a los datos en la tercera y cuarta edad. Los informes dividen a las personas mayores en grupos etarios, muy dispares; por lo tanto se crea el problema de generalización, ya que si se comparan los datos se puede perder parte de la población de la tercera o cuarta edad. Es interesante también, tener en cuenta que existe dispersión conceptual entre autores sobre la operacionalización de la cuarta edad; incluso el punto de corte entre países difiere (80 en españa-85 años en Estados Unidos).

En definitiva, la sociedad se enfrenta ahora a un tipo diferente de envejecimiento sustentado por fuerzas y respuestas culturales y económicas cambiantes, después de realizar el análisis de la vida independiente se puede concluir que se está transformando el paisaje en torno al cual tradicionalmente se construyó el envejecimiento. A nivel conceptual, el período de la cuarta edad representa uno de los principales retos contemporáneos donde la continuidad y el cambio se refieren a una tensión que establece la cuarta edad como una transición digna de reconsideración.

\subsection{Bibliografía}

BALTES, P.B \& SMITH, J. (2003), «New frontiers in the future of aging: from successful aging of the young old to the dilemmas of the fourth age». Gerontology, 49(2), pp.123-135.

CARR, D. \& KOMP, K. (2011). Gerontology in the era of the third age: implications and next steps, New York, Springer Publishing Company.

CHISTENSEN, K. DOBLHAMMER, G. RAU, R., \& VAUPEL, J.W (2009), «Ageing populations: The challenges ahead». The lancet, 374, pp. 1196-1208.

CICERON, M.T. (2001), Cato maior de senectute.Madrid, Ed. Triacastela.

CRIMMINS, E.M. (2002), Health expectancies: What can we expect from summary indicators of population health: Geneva: World Health Organization. pp. 213219.

DILLAWAY, H.E. \& BYRBES, M. (2009), «Reconsidering successful aging a call for renewed and expanded academic critiques and conceptualizations». Journal of applied Gerontology, 28(6), pp. 702-722.

ENCUESTA EUROPEA DE SALUD, 2014. Estado de salud: Cifras relativas. Instituto Nacional de Estadística. Disponible en: http://www.ine.es/dyngs/INEbase/ es/operacion.htm?c=Estadistica_C\&cid $=1254736176784 \&$ menu $=$ resultados\&i $\mathrm{dp}=1254735573175$

ENCUESTA DE INTEGRACIÓN SOCIAL Y SALUD (2012). Instituto Nacional de Estadística. Disponible en: http://www.ine.es/dyngs/INEbase/es/operacion.htm? $\mathrm{c}=$ Estadistica_C\&cid $=1254736176987 \&$ menu $=$ resultados $\& \mathrm{i}$ $\mathrm{dp}=1254735573175$ 
ENCUESTA NACIONAL DE SALUD (2011-2012). Ministerio de Sanidad, Servicios Sociales e Igualdad. Disponible en: https://www.msssi.gob.es/estadEstudios/estadisticas/encuestaNacional/encuesta2011.htm

EUROPEAN HEALTH \& LIFE EXPECTANCY. (2015). EHLEIS: Informe de países Volumen 9.

FORMIGA, F., FERRER, A. Y OTROS. (2013), «Patterns of comorbidity and multimorbidity in the oldest old: the octabaix stydy». European journal of internal medicine, 24(1), pp. 40-44.

FRIES, J.F (1980), «Aging, Natural Death and the Compression of Morbidity». New England Journal of Medicine, 303 (3), pp. 130-135.

GOUJON, A., \& LUTZ, W. (2004), Future human capital: Population projections by level of education. The end of world population growth in the 21st century: New challenges for human capital formation and sustainable development, London, Earthscan, pp. 121-157.

GRENIER, A. (2007), «Constructions of frailty in the English language, Care Practice and the lived experience». Aging and society, 27(3) pp. 425-446.

HAYFLICK L. (1999). Cómo y por qué envejecemos. Barcelona, Herder, pp. 87-107.

HIGGS, P. \& GILLEARD, C. (2010), «Theorizing the fourth age: Aging without agency». Aging and Mental Health, 14(1), pp. 121-128.

HIGGS, P. \& GILLEARD, C. (2011), The third age as cultural field. In D.C. Carr \& k. komp (eds.), Gerontology in the era of the third age: implications and next steps. New York, Springer, pp. 33-49.

HIGGS, P. \& GILLEARD, C. (2015), Rethinking Old Age: Theorising the Fourth Age. London, Palgrave Macmillan.

HOLSTEIN, M.B., \& MINKLER, M. (2003), «Self, society, and the new gerontology». The Gerontologist, 43(6), pp. 787-796.

JAMES J.B, WINK, P. (Eds.). (2007). The crown of life: Dynamics of the early postretirement period. New York, Springer.

KIRKWOOD, T.B.L. (2005), «The biological science of human ageing», en Johnson, M.L., Bengston, V.L., Coleman, P.G. Y Kirwood, R.B.L. (eds.), Age and Ageing: Cambridge University Press.

LAFORTUNE, G; BALESTAT (2007), The disability study expert group members. Trends in severe disability among elderly people: Assessing the evidence in 12 OECD countries and future implications (OECD Health Working Papers, no. 26). Paris.

LAS PERSONAS MAYORES EN ESPAÑA (2014). Datos Estadísticos Estatales y por Comunidades Autónomas. Instituto de Mayores y Servicios Sociales. Disponible en: http://www.imserso.es/InterPresent1/groups/imserso/documents/binario/22029_info2014pm.pdf

LIBRO BLANCO DEL ENVEJECIMIENTO ACTIVO. (2011). Instituto de Mayores y Servicios Sociales. Disponible en: http://www.imserso.es/InterPresent1/ groups/imserso/documents/binario/8088_8089libroblancoenv.pdf 
MARENGONI, A., ANGLEMAN S., Y OTROS (2011), «Aging with multi-morbidity: A systematic review of the literature». Aging Research Reviews, 10(4), pp. 430-439.

MARTÍNEZ C. Y MOLINA J. (2009), Desarrollo de criterios, indicadores de complejidad y estrategias de manejo en fragilidad. Agencia de Evaluación de Tecnologías Sanitarias de Andalucía. Sevilla.

MASORO, E.J. (2001), «Successful aging. Useful or misleading concept? ».The Gerontologist, 41(3), pp. 415-418.

NEUGARTEN, B. (1974), "Age groups in American society and the rise of the young-old». Annals of the American Academy of Political and Social Science, pp. 187-198.

PLAN DE ACCIÓN INTERNACIONAL DE MADRID SOBRE EL ENVEJECIMIENTO (2002). Naciones Unidas. Disponible en: https://social.un.org/ageingworking-group/documents/mipaa-sp.pdf

RILEY, M. W, \& RILEY (1994a), «Age integration and the lives of older people». The Gerontologist, 34, pp. 110-115.

RILEY, J., \& RILEY, M. W. (1994b), «Beyond productive aging: Changing lives and changing structures». Ageing International, 21(2), pp. 15-19.

ROWE, J. W., \& KAHN, R. L. (1987), «Human aging: Usual and successful». Science, 237, pp. 143-149.

ROWE, J. W., \& KAHN, R. L. (1997), «Successful aging». The Gerontologist, 37(4), pp. 433--440.

ROWE, J. W., \& KAHN, R. L. (1998), Successful aging (large print edition). New York, Random House.

ROWLAND, D. (2012), Population Aging: The Transformation of Societies. London, Springer, pp. 167-182

SAX, S. (1993), Ageing and public policy in Australia. Sydney: Allen and Unwin

SIGEL, J.S. (1990). Review of «A fresh map of life: The emergence of the third age». Population and Development Review, 16(2), pp. 363-367

VAILLANT, G.E; \& MUKAMAL, K. (2001), «Successful aging». The American Journal of Psychiatry, 158(6), pp. 839-847. 



\title{
EL SOCIOTIPO Y LA EVALUACIÓN DE LAS INTERVENCIONES DE RESOCIABILIZACIÓN EN LAS POLÍTICAS ASISTENCIALES
}

\author{
del Moral, R., Navarro, J. y Marijuán, P.C. \\ Grupo de Bioinformación, Instituto Aragonés de Ciencias de la Salud (IACS) \\ \& Instituto de Investigación Sanitaria de Aragón (IIS Aragón) \\ rdelmoral.iacs@aragon.es
}

\subsection{Introducción: el sociotipo y la sociedad contemporánea}

El nuevo concepto del Sociotipo se propone como un término que comprende el conjunto de relaciones sociales en las que se desenvuelve la persona de modo regular en cada etapa de su vida: desde la adolescencia y la juventud, a la madurez y la senectud. El sociotipo representa tanto los lazos sociales del individuo como el tiempo de comunicación que les dedica y la satisfacción que obtiene. Es decir, la estructura global de relaciones y sus procesos de actualización, básicamente mediante la conversación cara a cara.

El sociotipo forma parte de la naturaleza social de nuestra especie, estableciendo una tríada definitoria junto con el genotipo y el fenotipo (del Moral y Navarro, 2012; del Moral et al., 2017; Marijuán et al., en publicación). Basándonos en dicha triada conceptual, y alineado con la «Hipótesis del Cerebro Social» (Allman, 1999; Dunbar, 2004), el constructo del sociotipo aboga por la existencia de una preferencia evolutiva en nuestra especie acerca de unos promedios determinados de interacción social, básicamente realizados en conversación cara a cara (del Moral y Navarro, 2012; del Moral et al., 2017). De la misma manera que hay consenso científico sobre la validez de los constructos genotipo y fenotipo para la especie humana, a pesar de sus respectivos grados de variabilidad, podrían también desarrollarse métricas específicas respecto a la constancia relativa del entorno social a la que los individuos de nuestra especie están adaptados evolutivamente: el sociotipo. La estimulación cerebral media que se genera a través de las interacciones relacionales en ese entor- 
no social, junto con otros sustitutos y sucedáneos elaborados culturalmente, constituiría una autentica necesidad mental para el bienestar de la persona.

Una cierta medida de la «eficacia» del sociotipo se calcularía como el sumatorio del $n .^{\circ}$ de relaciones $\times$ tiempo medio dedicado $\times$ satisfacción media obtenida.

$$
\text { Sociotipo eficiente }=\Sigma \mathrm{Ri} \times \mathrm{Ti} \times \mathrm{Si} .
$$

De hecho cada persona establece su propio «mix» de relaciones diarias entre sus distintos círculos de relación. Según la personalidad y según las distintas culturas (y también es fundamental el género) se establece una notable convergencia de valores entre el número medio de relaciones sociales de las personas en sus distintos círculos (básicamente: familia, amigos, conocidos, relaciones de trabajo o estudios) y también en el tiempo que se dedica a hablar (preferiblemente cara a cara). Es el famoso «número de Dunbar» de 150-200 conocidos con los que una persona se relaciona de manera estable (Dunbar, 2004).

El sociotipo se desarrolla a la par del desarrollo físico de la persona, a lo largo de su ciclo de vida, existiendo sociotipos característicos para la adolescencia, la juventud, la edad adulta y para las personas mayores. Constituye un arco que se va desarrollando en paralelo al ciclo de vida (Berry y De Geest, 2012). En la adolescencia se empieza a construir un sociotipo propio diferenciado de los padres y la familia (con cambios dramáticos y una explosión de amistades e interacciones), que luego durante la juventud y la madurez se consolida alrededor de los promedios antes mencionados, hasta la vejez en la que prácticamente el sociotipo colapsa. En cada etapa el sociotipo manifiesta rasgos críticos y problemas específicos para llegar hasta un desarrollo acorde con las preferencias de cada individuo. En cada caso concreto, el sociotipo depende también, aparte del género y la edad, del tipo de personalidad, la profesión, la clase social, el lugar de residencia (urbano/rural), el medio cultural, el estado de salud... En los estudios de campo realizados se pueden apreciar ya algunas de estas diferencias (del Moral y Navarro, 2012; del Moral et al., 2017; Marijuán et al., en publicación).

\subsubsection{El aislamiento social, un problema creciente}

La necesidad de comunicarnos es perentoria: la soledad es una de las situaciones más difíciles de sobrellevar para el ser humano. Sentirse excluido 
no sólo se refleja en el cerebro con la misma activación en áreas similares que el dolor físico, sino que además va acompañado de un sentimiento semejante. La soledad es un problema creciente. En esta era de la información, donde los individuos están hiperconectados mediante las nuevas tecnologías, paradójicamente ha disminuido el número de relaciones sociales satisfactorias, y el tiempo que dedican a hablar cara a cara las personas.

En las sociedades actuales hay un cambio significativo en el modo en que se mantienen las relaciones sociales. La intrusión de las nuevas tecnologías de la información y la comunicación (TIC), a pesar de muchos otros efectos positivos, habría contribuido a la importante desintegración social que también está ocurriendo por otras razones: inestabilidad laboral, crisis económica, marginación de las minorías, expansión urbana, migración etc. En nuestro tiempo, las redes relacionales son aparentemente más grandes y más rápidas, pero más transitorias y desprovistas de contacto personal, de modo que los individuos corren mayor riesgo de aislamiento social, en particular los ancianos. Las relaciones disminuidas y las estructuras debilitadas del «capital social» penalizan el desarrollo de la vida cotidiana y disminuyen el bienestar de las personas (Putnam, 2000). La evidencia en los países en rápido desarrollo es que el crecimiento económico y el desarrollo tecnológico impulsados por la «revolución de la información» han ido de la mano con un aumento de trastornos mentales y del comportamiento, de mayor desintegración familiar y exclusión social, y de menor confianza social (Bok 2010; Huppert, 2010). Se supone que vivimos en una sociedad «tecnológicamente civilizada», donde la presencia omnipresente de los medios de comunicación y las TICs ha alterado dramáticamente los estilos de vida. Pero no está claro el efecto que tal inclusión y el uso excesivo de las TICs están teniendo en nuestras relaciones sociales y calidad de vida. ¿En qué medida podrían las computadoras, los teléfonos celulares y los televisores reemplazar nuestra necesidad de relaciones cara a cara? ¿Son facilitadores, sustitutos, o falsos sucedáneos? ¿Tal vez ambos? (Easterbrook, 2003; Roberts, 2014).

En 1950, 4 millones de estadounidenses vivían solos, constituyendo el 9\% de los hogares; sin embargo los datos del censo de 2011 muestran que casi 33 millones de estadounidenses viven solos, lo que representa el $28 \%$ de los hogares estadounidenses - un aumento de trescientos por ciento. El mismo proceso se está llevando a cabo en diferentes países, por ejemplo en Suecia el porcentaje de hogares «individuales» alcanza el 47\%, Gran Bretaña 34\%, $31 \%$ en Japón, $29 \%$ en Italia y $25 \%$ en Rusia. Vivir solo, paradójicamente, podría simbolizar nuestra necesidad social de volver a conectar (Klinenberg, 
2012). Igualmente, en el Censo de los Estados Unidos de 1985, el número promedio de confidentes era de tres; mientras que en el censo de 2004 el promedio fue de 2, pero la cifra más común fue cero de confidentes para casi el 25\% (Cacciopo y Patrick, 2008). Alarmantemente, el fenómeno es similar en la mayoría de los países occidentales.

En España, según la Encuesta de Uso del Tiempo (INE, 2010), las personas pasan cada vez menos tiempo para interactuar físicamente y cara a cara. Entre 2003 y 2010 la participación en la vida social y actividades lúdicas disminuyó, mientras que el tiempo dedicado a computadoras (redes sociales, recuperación de información, juegos de computadora) aumentó sustancialmente, desde el 17,3\% de la población en 2003 hasta el 30\% en 2011. En los últimos años ha habido una transferencia significativa de la vida social y actividades de diversión colectiva a actividades individualizadas tales como juegos de computadora, Internet, ver televisión. En este sentido, es significativo que en España y en otros países, las tasas de suicidios hayan aumentado dramáticamente en las últimas tres décadas.

Se puede afirmar que a escala internacional encontramos diversos indicadores relacionados con la infelicidad en alza (depresión, ansiedad, suicidios, familias desestructuradas), mientras que indicadores de la felicidad como pueden ser la satisfacción con la vida, el bienestar o la satisfacción personal, están situados hoy día por debajo de los valores de décadas anteriores - este fenómeno lo ha ilustrado dramáticamente el autor Robert D. Putnam en su obra magistral Bowling Alone (Putnam, 2000): «Por numerosas razones, la vida es más fácil en una comunidad dotada de un stock sustancial de capital social» (Putnam, 1995: 67).

\subsubsection{Consecuencias psicobiológicas de la soledad}

En la actualidad, la ausencia de vínculos sociales se ha convertido en una experiencia común: más del $80 \%$ de los niños y el $40 \%$ de los mayores de 65 años se sienten solos periódicamente. Los niveles de soledad disminuyen gradualmente en los años medianos de la edad adulta y aumentan con la edad, alcanzando el máximo alrededor de los 70 años (Weeks, 1994; Oldenburg, 1999; Pinquart y Sorensen, 2001; Berguno et al., 2004; Cacioppo y Cacioppo, 2014). Como numerosos estudios han demostrado, existe una asociación entre el aislamiento social, principalmente el aislamiento percibido, y la mala salud física y mental que no pueden explicarse con los diferentes comportamientos 
de salud. El aislamiento social disminuye los años de vida de las especies sociales, de Drosophila (Ruan y Wu, 2008) a Homo sapiens (House et al., 1988). La falta de vínculos sociales tiene efectos deletéreos sobre la salud a través de su efecto sobre el cerebro, los procesos hipotalámico-hipofisario-suprarrenal (HPA), los procesos vasculares, la presión arterial, la transcripción de genes, la inflamación, el sistema inmunológico y la calidad del sueño (Cacioppo y Hawkley, 2009).

Las investigaciones indican que el aislamiento social percibido (es decir, la soledad) es un factor de riesgo y puede contribuir a un desempeño cognitivo más pobre, mayor deterioro cognitivo y una función ejecutiva más pobre, así como a un aumento de la negatividad y cognición depresiva que acentúan la sensibilidad a las amenazas sociales (Berkman, 2009). De hecho, la soledad se asocia no sólo con una mala salud física; también incluye trastornos psiquiátricos como la esquizofrenia y los trastornos de la personalidad, pensamientos suicidas, depresión y Alzheimer (Berkman, 2009; Cacioppo y Hawkley 2009).

Así, no es de extrañar que trastornos mentales como la esquizofrenia, la depresión, la epilepsia, la demencia, el alcoholismo y otras sustancias constituyen el $13 \%$ de la carga global de morbilidad, un porcentaje que supera las enfermedades cardiovasculares y el cáncer (Collins et al., 2011). Estudios europeos estiman que en el período de un año, 165 millones de personas (38\% de la población) desarrollarán una enfermedad mental (Wittchen et al., 2011), en la mayor parte de los casos exacerbada por el creciente aislamiento de segmentos enteros de la población.

\subsection{Necesidad de un nuevo enfoque en las políticas asistenciales}

Dadas las tendencias demográficas y el aumento de esperanza de vida, el segmento de población de mayor edad está aumentado de forma considerable, y aún lo va a hacer más, con el consiguiente incremento de costes en el sistema sanitario estatal. Por lo que claramente se hace precisa una reorientación de las políticas asistenciales para que promuevan el envejecimiento activo y saludable con el objetivo, primero, de que las personas mayores vivan una vida más feliz y autosuficiente y, segundo, que se reduzca la carga para el sistema de salud. Para ello, se hace preciso tener una visión más ajustada de las relaciones sociales del mayor, esto es, del «sociotipo geriátrico.» 


\subsubsection{El sociotipo geriátrico}

Conforme vamos envejeciendo el número de familiares, amigos y conocidos tiende a disminuir, en parte por el paso del tiempo, y también a consecuencia de los nuevos modos de vida y las nuevas tecnologías. La investigación en el sociotipo geriátrico propone obtener una nueva visión y los instrumentos necesarios para aquilatar cuantitativa y cualitativamente las relaciones de la persona mayor. Es importante conocer el estado general de las relaciones así como la cantidad de tiempo que habla esa persona mayor, reduciendo los riesgos para la salud física y mental que causa el aislamiento. Por ello, en esta investigación, además de desarrollar un cuestionario general del sociotipo adaptado a la población geriátrica (de más de 65 años), se pretende diseñar un cuestionario reducido para su uso en consulta geriátrica, que ayude en la detención rápida de situaciones de riesgo que deban ser trasladadas a los servicios sociales o asistenciales disponibles.

En general, para el estudio del sociotipo geriátrico, se consideran los siguientes rangos de edad:

- De 65 a 75: Persona independiente y activa. El objetivo con estas personas debería ser fomentar su cooperación en actividades sociales que impliquen tanto una utilidad para la sociedad como una mejora de las relaciones sociales de estas personas. Que se sientan más útiles y más integradas, que su retiro laboral no se convierta en un rápido declive psíquico y físico.

- De 75 a 85: Persona semi-dependiente para la que hay que encontrar una vida más saludable e independiente de lo que es habitual en la actualidad. Evitar la medicalización y promover las medidas más sencillas de salud, de modo que un estilo de vida más proclive al ejercicio, la alimentación sana, la estimulación cognitiva, y la mejora de las relaciones sociales prolonguen su vida útil e independiente.

- A partir de 85: En general, personas dependientes para las que hay que retrasar el paso a residencias. Numerosas experiencias atestiguan que un proceso sostenido de «envejecimiento activo y saludable» puede prolongar la auto-suficiencia y salud general del mayor hasta una edad mucho más avanzada de lo que se cree. El apoyo psicológico por parte de organizaciones de voluntariado y de las instituciones para proporcionar relaciones sociales y un sentido de compañía a estas personas es fundamental. 


\subsubsection{El sociotipo en las intervenciones de resociabilización}

Desde la conceptualización del sociotipo se pueden contemplar nuevos métodos para la activación de la interacción social y la promoción de hábitos de vida saludables: organización de reuniones sociales y actividades conjuntas, promoción de las relaciones sociales en torno a actividades lúdicas, dieta saludable, ejercicio físico, terapias de rehabilitación cognitiva y emocional, etc. De hecho, buena parte de la intervención a nivel municipal, autonómico y estatal se centra en la promoción indirecta de la sociabilización a través de actividades guiadas.

Un aspecto importante en la evaluación de intervenciones es la falta de indicadores adecuados acerca de cambios en la sociabilización y la adquisición de nuevas pautas de relaciones. En esta faceta de evaluación el cuestionario del sociotipo puede contribuir significativamente a la correcta evaluación de las intervenciones. Ello es esencial puesto que las barreras a la participación social de los ancianos en las intervenciones colectivas son múltiples.

Un factor fundamental a la hora de superar las barreras a la participación social es contrarrestar la influencia de los miedos sociales y la pérdida de identidad. Existen barreras inevitables a la participación social, que incluyen la enfermedad/discapacidad, la pérdida de amigos y familiares, la pérdida de una comunidad local, y la percepción de falta de oportunidades sociales. La evidencia actual sugiere que los mayores también evitan las oportunidades de participación social por temor a ser rechazados y/o explotados por sus compañeros, lo que conduce a patrones cognitivos y de comportamiento que mantienen la soledad, como la atención selectiva a estímulos sociales negativos (Goll et al., 2015). Asimismo, el miedo a perder identidades preferidas conduce a que frecuentemente se eviten las oportunidades sociales por temor a perder aquellos aspectos más preferidos o más valorados de las identidades propias. En particular, se temen perder las identidades ligadas a los sujetos colectivos (prejuicios nacionalistas, raciales, de género, de clase social...), así como de estilo de vida (auto-concepciones «independientes» y «juveniles»), y el rechazo a incurrir finalmente en la dependencia de los servicios asistenciales.

Evidentemente, la problemática actual, tanto por su extensión como por su intensidad, reclama un cambio profundo en las políticas asistenciales. No se trata tan solo de garantizar la sostenibilidad sanitaria y asistencial, que está en entredicho, pues está claro que el sistema actual es insostenible; sino también la búsqueda de una mayor calidad de vida en un aspecto fundamental de 
nuestra naturaleza social. Son muchos y muy profundos los cambios que han experimentado nuestras sociedades (sociodemográficos, culturales, tecnológicos, económicos, etc.). Y frente a ello deben diseñarse nuevas modalidades asistenciales y de intervención social con criterios más apegados a los problemas de fondo, a las nuevas posibilidades tecnológicas, y que a la vez resulten más susceptibles de evaluación. Contribuir a esta nueva orientación es el objetivo esencial del Cuestionario del Sociotipo (SOCQ), cuya metodología se describe a continuación.

\subsection{Metodología}

\subsubsection{Hipótesis y objetivos}

La cuestión fundamental que se encauza en este estudio es un tema que no está suficientemente investigado todavía. De hecho, ninguno de los cuestionarios que evalúan la soledad y la ausencia de relaciones sociales (UCLA, MSPSS, SIN, Duke, SELSA, MOSS, ZIMET, SSB, De Jong...) contemplan suficientemente el fenómeno social de la comunicación.

Partiendo de la «Hipótesis del Cerebro Social», se pretende estudiar empíricamente la estructura y dinámica de relaciones sociales del individuo, y específicamente cómo esas relaciones conforman un factor fundamental del riesgo de aislamiento y deterioro de salud física y mental. Esto es, en el abordaje empírico del presente estudio se va a desarrollar un nuevo indicador, basado en un cuestionario tipo — mediante métodos psico-sociométricoscomo instrumento capaz de medir las interacciones que demanda «de forma adaptativa» el cerebro social de cada individuo. Como objetivos específicos se pretende:

- Desarrollar un cuestionario capaz de medir de forma fiable y que pueda medir el concepto de sociotipo y validarlo en población española comprendida entre 18-80 años de edad.

- Generalizar el concepto de sociotipo y su indicador como medio general de estudio psicológico. Para ello se correlacionará con otros indicadores utilizados en el ámbito de la salud mental.

- Demostrar su uso como herramienta de evaluación de las intervenciones de resocialización. 


\subsubsection{Procedimiento metodológico}

Diseño del estudio. La estructura del estudio está basada en el método correlacional con un diseño transversal analítico. La totalidad de los datos se ha obtenido mediante autoevaluación, utilizando un conjunto de cuestionarios a través de Internet, complementado con entrevistas cara a cara. El trabajo se ha iniciado con un estudio cualitativo buscando las principales características de las redes sociales y los hábitos de conversación en diferentes edades, a través de entrevistas semi-estructuradas y grupos focales (narrativas de experiencias personales, estados de ánimo, interacciones dinámicas, etc.). Este estudio cualitativo ha incluido 45 entrevistas (convenientemente diversificadas por edad, género y clase) (Cohen et al., 2003). Esa experiencia cualitativa inicial ha proporcionado una serie de datos sobre cómo se contempla la noción teórica del sociotipo en diferentes circunstancias personales y dominios sociales. Posteriormente, se ha aplicado un muestreo de conveniencia a 165 sujetos, todos ellos estudiantes de dos centros educativos, que fueron interrogados utilizando un modelo preliminar (del Moral y Navarro, 2012). Como resultado de estos trabajos, y en consonancia con la literatura citada anteriormente, se han propuesto las dimensiones emergentes de «familia», «amigos», «conocidos» $\mathrm{y}$, en su caso, «compañeros de estudio o de trabajo» como los principales factores que una definición básica de sociotipo debe incluir. Una plataforma en línea ha dado apoyo a la finalización de la encuesta y la recopilación de datos (www.surveymonkey.com).

Tamaño muestral y reclutamiento de pacientes. El número de participantes ha excedido los criterios de evaluación de la validez del constructo, habitualmente estructurado en 10 individuos por ítem (del cuestionario definitivo) (Comrey, 1985). Por tanto, el cuestionario debería ser administrado a unos $\mathrm{N}=400$ individuos como mínimo. Considerando unas pérdidas del $20-25 \%$ resultarían unos $n=500$ sujetos. Los participantes se seleccionaron del censo de la ciudad de Zaragoza mediante muestreo estratificado para obtener sujetos del rango de edad estudiado (18-80 años), ambos géneros, y representativos de los diferentes niveles socioculturales y económicos, así como con diferente nivel de interés por las nuevas tecnologías y las redes sociales. La mayoría de los participantes accedieron a la encuesta a través de Internet, pero alrededor del 15\% fueron entrevistas cara a cara (para los ancianos), tratando intencionalmente de cubrir las diferentes características de género, edad y estado. En todos los casos, los criterios de inclusión fueron edad $>18$ años, ser capaz de leer y escribir en español, y no sufrir trastornos físicos o mentales graves. El 
número final de participantes $(\mathrm{n}=1.075)$ ha excedido por tanto el criterio de evaluación de validez, resultando en una muestra que ha sido psicométricamente adecuada para el estudio.

Confidencialidad de los datos y aspectos éticos. Los resultados de los distintos cuestionarios han sido utilizados únicamente con fines de investigación; los datos obtenidos son confidenciales y en ningún caso se cederán a terceros, remitiéndonos a la Ley Orgánica 15/99 de Protección de Datos de Carácter Personal. El presente estudio ha cumplido con todos los requisitos éticos y ha contado con el certificado favorable de la Comisión Ética de Aragón (CEICA) para su realización.

Análisis estadístico. De los 32 ítems iniciales se han seleccionado aquellos con mayor coeficiente discriminativo en sus respectivos dominios (Comrey, 1985; Múñiz et al., 2005). La estructura factorial del cuestionario ha sido evaluada mediante Análisis Factorial Exploratorio (EFA), siguiendo el método de componentes principales con rotación Varimax ortogonal. Para confirmar la legitimidad del análisis se ha confirmado que el índice KMO (Kaiser-MeyerOlsen) tiene un valor $>0,70$ y que el test de esfericidad de Bartlett produce un resultado significativo. El número de componentes se ha decidido usando los criterios de Kaiser (Kaiser, 1960), que requiere eigenvalues superiores a 1, además de valorar el gráfico de sedimentación del test scree de Cattel (Cattell, 1966). Se ha empleado el criterio de peso factorial $>0,5$ para determinar los ítems que se han de adscribir a un determinado factor. El porcentaje de varianza explicada en cada ítem por su factor de pertinencia ha sido calculado con los valores de las comunalidades c2, la fiabilidad de escalas y subescalas mediante el $\alpha$ de Cronbach y la relación con el criterio mediante $r$ de Pearson. Los tests de contraste se han calculado con el test t-Student para medidas independientes o mediante los valores $\mathrm{z}$ asociados al test $\mathrm{U}$ de Mann-Whitney dependiendo de la hipótesis de normalidad. Los análisis han sido realizados mediante el paquete estadístico SPSS versión 16.

Mediciones. Se han contemplado las siguientes variables y cuestiones:

- Variables de base: La encuesta ha registrado un conjunto de variables sociodemográficas que proporcionan una visión general de las circunstancias sociales de los participantes, tales como: sexo, edad, relaciones (con pareja/ casado, soltero, separado/divorciado, viudo), convivencia (solo, pareja, pare- 
ja e hijos, otra familia, amigos, residencia), lugar (rural, urbano), educación (sin estudios, primaria, escuela secundaria, universidad), empleo (estudiante, desempleado, empleado, jubilado), salario (salario mínimo interprofesional (SMI), 2 SMI, 2-4 SMI, >4 SMI), satisfacción social (utilizando una escala visual analógica -VAS, de 0 a 100).

- Cuestionario de Sociotipo (SOCQ): A los sujetos se les ha preguntado un conjunto de 32 ítems, evaluando así la calidad de sus relaciones con familiares, amigos, conocidos y compañeros de estudio / trabajo (8 preguntas para cada uno). Los tres primeros dominios se han propuesto como subescalas de un factor general de sociotipo, y el cuarto se ha propuesto como escala independiente, para ser utilizado cuando corresponda (en este caso, el 49,5\% de los empleados y el 11,3\% de los estudiantes). Los ítems han sido desarrollados por un panel de expertos multidisciplinares. La redacción de ítems ha sido guiada por una tabla de especificaciones de contenido, lo que ha permitido su ajuste, validez conceptual y representatividad. El número de ítems se ha sobredimensionado para seleccionar aquellos con las mejores propiedades psicométricas. Con el fin de contrarrestar los efectos de los estilos de respuesta y sesgos, la encuesta ha utilizado un formato de respuesta de elección forzada, calificando el grado de acuerdo con cada una de las afirmaciones, algunas de ellas en puntaje inverso, usando una escala tipo Likert con 6 opciones de respuesta, de 0 (nunca) a 5 (siempre).

\subsection{Resultados}

Muy resumidamente se presentan los principales resultados del estudio (Marijuán et al., en publicación).

\begin{tabular}{|ll}
\hline Sexo, mujeres (\%) & $718(66.8)$ \\
Edad, Me (DE) & $49.7(21.47)$ \\
Estado civil (\%) & \\
$\quad$ casado/a o emparejado/a & $562(52.3)$ \\
soltero/a & $275(25.6)$ \\
separado/a o divorciado/a & $63(5.8)$ \\
viudo/a & $175(16.3)$ \\
Convivencia $(\%)$ & \\
$\quad$ solo/a & $264(24.6)$ \\
\hline
\end{tabular}




\begin{tabular}{|ll|}
\hline con pareja & $290(27.0)$ \\
con pareja e hijos & $255(23.8)$ \\
con familiares & $170(15.8)$ \\
con amigos & $60(5.5)$ \\
residencia & $36(3.3)$ \\
Lugar de residencia (\%) & \\
rural & $131(12.2)$ \\
urbano & $944(87.8)$ \\
Nivel de estudios (\%) & \\
sin estudios & $157(14.6)$ \\
estudios primarios & $151(14.0)$ \\
estudios secundarios & $142(13.2)$ \\
universitarios & $625(58.2)$ \\
Situación laboral (\%) & \\
estudiante & $122(11.3)$ \\
desempleado & $117(10.9)$ \\
empleado & $534(49.7)$ \\
jubilado & $302(28.1)$ \\
Nivel de ingresos (\%) & \\
<Salario Mín. Interprofesional (SMI) & $256(23.8)$ \\
1-2 SMI & $389(36.2)$ \\
2-4 SMI & $332(30.9)$ \\
S S SMI & $98(9.1)$ \\
\hline
\end{tabular}

TABLA 1. Principales características sociodemográficas de los participantes

Los modelos de confiabilidad probados para el SOCQ han mostrado una alta robustez. Todas las escalas y subescalas encajaban mejor con el modelo congenérico, siendo las estimaciones obtenidas de $\mathrm{R}=0.81$ para la 'SOCQ' general, $\mathrm{R}=0.81$ para familia, $\mathrm{R}=0.90$ para amigos, $\mathrm{R}=0.71$ para Conocidos, $\mathrm{R}=0.87$ para trabajo/estudios. Es decir, el $\alpha$ de Cronbach obtenido es de 0.81 para el SOCQ general, y de 0.87 cuando se contempla la dimensión extra de trabajo/estudio. Por otra parte, la media de los valores de los restos de los ítems para el SOCQ general fue de 0.52, siendo de 0.64 para la subescala familia, de 0,77 para la subescala amigos, de 0,45 para la subescala conocidos, Y de 0.72 para la subescala trabajo/estudio. 


\begin{tabular}{|c|c|c|c|c|c|c|c|c|}
\hline Variable (rango) & $\begin{array}{l}\text { hombre } \\
(\mathrm{n}=357)\end{array}$ & $\begin{array}{c}\text { GÉNERO } \\
\text { mujer } \\
(\mathrm{n}=718)\end{array}$ & $\mathrm{p}^{\mathrm{a}}$ & $\begin{array}{c}18-30 \\
\text { años } \\
(\mathrm{n}=241)\end{array}$ & $\begin{array}{c}31-45 \\
\text { años } \\
(n=290)\end{array}$ & $\begin{array}{c}E D A D \\
46-65 \\
\text { años } \\
(\mathrm{n}=256)\end{array}$ & $\begin{array}{c}>65 \\
\text { años } \\
(\mathrm{n}=288)\end{array}$ & $\mathrm{p}^{\mathrm{b}}$ \\
\hline $\begin{array}{l}\text { SOCQ-general }(0-60) \\
\mathrm{Me}(\mathrm{DE})\end{array}$ & $\begin{array}{l}44.48 \\
(8.27)\end{array}$ & $\begin{array}{l}44.97 \\
(8.27)\end{array}$ & 0.825 & $\begin{array}{l}46.33 \\
(6.96)\end{array}$ & $\begin{array}{l}45.54 \\
(6.75)\end{array}$ & $\begin{array}{l}44.70 \\
(8.61)\end{array}$ & $\begin{array}{l}43.04 \\
(9.78)\end{array}$ & $<0.001$ \\
\hline $\begin{array}{l}\text { Familia }(0-20) \\
\mathrm{Me}(\mathrm{DE})\end{array}$ & $\begin{array}{l}17.01 \\
(3.18)\end{array}$ & $\begin{array}{l}17.46 \\
(3.10)\end{array}$ & 0.027 & $\begin{array}{l}17.33 \\
(3.04)\end{array}$ & $\begin{array}{l}17.31 \\
(2.79)\end{array}$ & $\begin{array}{l}16.92 \\
(3.80)\end{array}$ & $\begin{array}{l}17.38 \\
(2.94)\end{array}$ & 0.333 \\
\hline $\begin{array}{l}\text { Amigos }(0-20) \\
\mathrm{Me}(\mathrm{DE})\end{array}$ & $\begin{array}{l}14.90 \\
(4.79)\end{array}$ & $\begin{array}{l}15.14 \\
(4.94)\end{array}$ & 0.454 & $\begin{array}{l}17.16 \\
(3.04)\end{array}$ & $\begin{array}{l}15.99 \\
(3.53)\end{array}$ & $\begin{array}{l}15.09 \\
(4.06)\end{array}$ & $\begin{array}{l}12.50 \\
(6.50)\end{array}$ & $<0.001$ \\
\hline $\begin{array}{l}\text { Conocidos }(0-20) \\
\mathrm{Me}(\mathrm{DE})\end{array}$ & $\begin{array}{l}12.60 \\
(3.31)\end{array}$ & $\begin{array}{l}12.53 \\
(3.42)\end{array}$ & 0.778 & $\begin{array}{l}11.77 \\
(3.40)\end{array}$ & $\begin{array}{l}12.16 \\
(3.15)\end{array}$ & $\begin{array}{l}12.78 \\
(2.91)\end{array}$ & $\begin{array}{l}13.29 \\
(3.75)\end{array}$ & $<0.001$ \\
\hline $\begin{array}{l}\text { Estudio/trabajo } \\
(0-20) \\
\mathrm{Me}(\mathrm{DE})\end{array}$ & $\begin{array}{l}10.28 \\
(6.90)\end{array}$ & $\begin{array}{c}8.99 \\
(7.35)\end{array}$ & 0.005 & $\begin{array}{l}13.39 \\
(5.07)\end{array}$ & $\begin{array}{l}12.09 \\
(5.78)\end{array}$ & $\begin{array}{l}11.31 \\
(6.12)\end{array}$ & $\begin{array}{c}1.72 \\
(4.87)\end{array}$ & $<0.001$ \\
\hline $\begin{array}{l}\text { Satisfaction Social } \\
\text { (VAS 0-100) } \\
\text { Me (DE) }\end{array}$ & $\begin{array}{c}73.75 \\
(20.01)\end{array}$ & $\begin{array}{c}71.95 \\
(21.93)\end{array}$ & 0.217 & $\begin{array}{c}73.40 \\
(19.16)\end{array}$ & $\begin{array}{c}74.14 \\
(19.63)\end{array}$ & $\begin{array}{c}70.38 \\
(21.69) \\
\end{array}$ & $\begin{array}{r}71.98 \\
(24.23) \\
\end{array}$ & 0.262 \\
\hline
\end{tabular}

TABLA 2. Diferencias en el SOCQ general y en las diversas subescalas en base a género y edad

\begin{tabular}{|c|c|c|c|c|c|c|}
\hline & Nunca & $\begin{array}{r}\text { Casi } \\
\text { nunca }\end{array}$ & A veces & A menudo & $\begin{array}{c}\text { Casi } \\
\text { siempre }\end{array}$ & Siempre \\
\hline $\begin{array}{l}\text { 1. Habla y se relaciona } \\
\text { con su familia }\end{array}$ & o & o & o & o & o & o \\
\hline $\begin{array}{l}\text { 2. Su familia es } \\
\text { importante para Vd. }\end{array}$ & $\mathrm{o}$ & o & $\mathrm{o}$ & $\mathrm{o}$ & o & $\mathrm{o}$ \\
\hline $\begin{array}{l}\text { 3. Los miembros de su } \\
\text { familia } \\
\text { se preocupan por } \mathrm{Vd} \text {. }\end{array}$ & o & o & $\mathrm{o}$ & o & $\mathrm{o}$ & o \\
\hline $\begin{array}{l}\text { 4. Se divierte y se ríe } \\
\text { con su familia }\end{array}$ & o & o & o & o & $\mathrm{O}$ & o \\
\hline $\begin{array}{l}\text { 5. Habla y se relaciona } \\
\text { con los amigos }\end{array}$ & $\mathrm{o}$ & $\mathrm{o}$ & $\mathrm{O}$ & $\mathrm{O}$ & $\mathrm{O}$ & $\mathrm{O}$ \\
\hline $\begin{array}{l}\text { 6. Tiene amigos con los que } \\
\text { contar } \\
\text { y compartir problemas }\end{array}$ & $\mathrm{O}$ & $\mathrm{O}$ & $\mathrm{O}$ & $\mathrm{O}$ & $\mathrm{O}$ & $\mathrm{O}$ \\
\hline $\begin{array}{l}\text { 7. Considera importante } \\
\text { mantener } \\
\text { las relaciones con sus } \\
\text { amistades }\end{array}$ & $\mathrm{O}$ & $\mathrm{O}$ & $\mathrm{O}$ & $\mathrm{O}$ & $\mathrm{O}$ & $\mathrm{O}$ \\
\hline $\begin{array}{l}\text { 8. Se divierte y se ríe con } \\
\text { los amigos }\end{array}$ & $\mathrm{O}$ & $\mathrm{O}$ & $\mathrm{O}$ & $\mathrm{O}$ & $\mathrm{O}$ & $\mathrm{O}$ \\
\hline $\begin{array}{l}\text { 9. Habla y se relaciona } \\
\text { cómodamente con sus } \\
\text { conocidos }\end{array}$ & $\mathrm{O}$ & $\mathrm{O}$ & $\mathrm{O}$ & $\mathrm{O}$ & $\mathrm{O}$ & $\mathrm{O}$ \\
\hline
\end{tabular}




\begin{tabular}{|l|cccccc|}
\hline $\begin{array}{l}\text { 10. Le cuesta entablar } \\
\text { conversación con gente } \\
\text { que no conoce }\end{array}$ & O & O & O & O & O & O \\
\hline $\begin{array}{l}\text { 11. Le es fácil conseguir el } \\
\text { apoyo de sus conocidos }\end{array}$ & O & O & O & O & O & O \\
\hline $\begin{array}{l}\text { 12. Las relaciones con los } \\
\text { conocidos le resultan } \\
\text { forzadas }\end{array}$ & O & O & O & O & O & O \\
\hline $\begin{array}{l}\text { 13. Habla y se relaciona } \\
\text { satisfactoriamente con los } \\
\text { compañeros }\end{array}$ & O & O & O & O & O & O \\
\hline $\begin{array}{l}\text { 14. Tiene confianza } \\
\text { personal en sus compañeros }\end{array}$ & O & O & O & O & O & O \\
\hline $\begin{array}{l}15 . \text { Cuando habla con sus } \\
\text { compañeros siente que le } \\
\text { hacen caso }\end{array}$ & O & O & O & O & O & O \\
\hline $\begin{array}{l}16 . \text { Se siente valorado } \\
\text { profesionalmente por sus } \\
\text { compañeros }\end{array}$ & O & O & O & O & O & O \\
\hline
\end{tabular}

TABLA 3. Cuestionario SOCQ en español, donde se incluyen los ítems seleccionados para las subescalas familiares, amigos, conocidos, y compaceros de trabajo/colegas de estudio

\subsection{Discusión}

Este es el primer estudio empírico, hasta donde conocemos, que trata de alcanzar una definición tanto teórica como operativa del constructo de sociotipo, delimitando la estructura esencial de relaciones sociales de la persona (Marijuán, 2009; del Moral y Navarro, 2012). La constancia relativa de las distintas capas relacionales y su dinámica de actualización constituiría una de las características esenciales que acompañan a cada individuo a lo largo de su ciclo de vida. Dada la orientación empírica aquí seguida para el uso de este nuevo indicador en áreas de salud mental y bienestar general, otros constructos relacionados con la soledad, el sufrimiento psicológico y las dimensiones de la personalidad han contribuido a delimitar y establecer el horizonte en esta primera exploración.

Se puede afirmar que el cuestionario de sociotipo propuesto es válido en términos de estructura, y suficientemente fiable en términos de consistencia interna. Se ha establecido una escala general consistente en las subescalas familiares, amigos, conocidos, y otra subescala separada formada por compañeros de trabajo/colegas de estudio (esta última a ser aplicada cuando sea pertinente), explicando todas ellas un alto porcentaje de varianza. Todas las escalas y subescalas han encajado con el modelo congenérico de fiabilidad 
probado, lo que sugiere que la definición del SOCQ, en términos de elementos y componentes, parece bastante extensa para referirse a varias facetas interrelacionadas (como la pertenencia, el habla, el cuidado, el apoyo, la risa, la confianza, los valores, las relaciones) que podrían estudiarse en trabajos futuros.

Es interesante destacar que en el análisis de género, los hombres han mostrado una red social más fuerte en términos de compañeros de trabajo o compañeros de estudio, mientras que en las mujeres la red más importante se muestra en términos de familia. Este resultado no es inesperado dados los factores culturales y sociales implicados, así como los distintos intereses relacionales y reproductivos (Pinker 2008, 2014). En cuanto a la edad, encontramos diferencias significativas entre la juventud, la etapa adulta, la madurez y la senectud en relación con el sociotipo en general, así como las subescalas de amigos, conocidos y compañeros de trabajo. Al respecto, la subescala de conocidos alcanza las puntuaciones más altas en la última etapa (ancianos) y las más bajas en la primera etapa (los jóvenes); mientras que para el sociotipo general y las otras subescalas las puntuaciones más altas aparecen en la primera etapa, y las puntuaciones más bajas afloran en la última etapa. Evidentemente, para los ancianos, los amigos y la familia desaparecen gradualmente de la escena relacional, y su interrelación social se ve reducida progresivamente a lo casual y a lo débil (Yang y Victor, 2011; Berkman, 2009; Steptoe et al., 2013, Cacioppo y Cacioppo, 2014). Sin embargo, las puntuaciones en familia no mostraron cambios significativos a lo largo de las diferentes etapas de la vida, posiblemente debido al reemplazo generacional que ocurre dentro del conjunto de la red familiar. Estudios futuros sobre sus respectivas estructuras y los tiempos de conversación delimitarán la extensión y las interrelaciones de estos fenómenos relacionados con la edad.

El mensaje central de este estudio tiene que ser entendido dentro de la triada genotipo-fenotipo-sociotipo discutida en la Introducción (Berry, 2011; Marijuán, 2009; del Moral y Navarro, 2012). La conexión social ya reside potencialmente en nuestros genes, y es en el desarrollo de esta conexión donde se asienta nuestra salud, tanto mental como física. Situar adecuadamente el constructo en el centro de nuestra naturaleza social conlleva el problema de que se entrecruzan demasiados factores, pero aunque esos factores de confusión representan dificultades conceptuales, al mismo tiempo establecen las direcciones más importantes que se deben seguir para avanzar en el sociotipo. 
Hecho que concuerda con la pluralidad de factores que contiene el enfoque del «capital social» (Putnam 2000; Putnam et al. 2004), con lo que se proporciona una base psicosocial más clara a esa noción.

Entre las direcciones de trabajo futuras, en primer lugar, está la naturaleza de los lazos interpersonales y los diferentes tipos de lazos sociales (Granovetter 1973, 2005), incluyendo la dinámica cognitiva de los lazos, la inversión específica de la memoria y las equivalencias asimétricas entre los lazos sociales (Lazer, 2009; Pentland, 2014); la centralidad de la conversación en la creación y ruptura de los lazos humanos (Dunbar, 2004; Turkley, 2015); las inevitables diferencias de género tanto en los vínculos sociales como en los intereses relacionales/reproductivos; la estrecha interrelación entre fenotiposociotipo durante el curso de vida de cada individuo, así como las posibles consecuencias epigenéticas de los desastrosos/exitosos entornos sociales (Berry y De Gest, 2012); el papel de las nuevas tecnologías de la comunicación que revolucionan el mix de sociotipos individuales (Roberts, 2014; Keen, 2015); los esquemas sociales y culturales para la distribución del trabajo y del ocio y su actual desorganización (Putnam 2000; Putnam et al. 2004); el papel de las redes sociales en la salud y la enfermedad (Fowler y Christakis, 2008); las epidemias contemporáneas de soledad y depresión (Cacioppo y Cacioppo, 2014); etc. De alguna manera, todos esos problemas intratables, derivados de las complejas circunstancias de la vida social, rodean al sociotipo y lo conforman. A medida que el constructo aquí propuesto vaya siendo debidamente delimitado y diversificado (a lo largo de estudios futuros, dado que el presente estudio es sólo un primer paso), un número creciente de temas podrían beneficiarse de esta nueva forma de pensar.

\subsection{Conclusión}

El presente estudio tiene un doble aspecto, por un lado establecer aspectos cualitativos y cuantitativos acerca de la naturaleza social de la persona, y por el otro establecer un nuevo indicador que sea útil ante un problema creciente de las sociedades contemporáneas, el aislamiento social, que está emergiendo como una auténtica plaga, y que afecta en particular a las personas mayores. El constructo de sociotipo fruto del presente trabajo ha resultado válido y fiable, así como estrechamente asociado con métricas ya validadas de soledad y angustia psicológica. El constructo varía notablemente a lo largo del curso de 
la vida y las circunstancias de los individuos, basándose en su género y edad, e incluyendo las diferentes situaciones personales, culturales y socioeconómicas de las redes sociales.

La importancia potencial de esta clase de estudios en las políticas asistenciales se evidencia en la propia evolución de los programas sociales y las intervenciones que actualmente se implementan, tanto a nivel municipal como regional, nacional y europeo. En ese sentido, el cuestionario que aquí se desarrolla (SOCQ) supone una nueva herramienta para colaborar en la evaluación de las actividades e intervenciones de resociabilización. Consideramos que la información proporcionada por la definición operativa del constructo de sociotipo, a pesar de su carácter preliminar, podría ser útil para guiar el desarrollo y la evaluación de estos programas destinados a mejorar y/o fortalecer las redes sociales de las personas en riesgo, dadas sus características demográficas (sin familia, ni trabajo, violencia doméstica, huérfanos, inmigrantes, etc.) o debido a la edad (vulnerabilidad de niños o jóvenes, y especialmente los ancianos).

\subsection{Agradecimientos}

Este estudio ha sido financiado por el Proyecto FIS PI12/01480 (Instituto de Salud Carlos III) y fondos FEDER («Una manera de hacer Europa»).

\subsection{Bibliografía}

ALlMAN, J. M., Evolving Brains, Scientific American Library, New York, 1999.

BERGUNO, G., P. LEROUX, K. MCAINSH y S. SHAIKH, «Children's experience of loneliness at school and its relation to bullying and the quality of teacher interventions», Qualitative Report, vol. 9 (2004), pp. 483-499.

BERKMAN, L., «Social Epidemiology: Social Determinants of Health in the United States: Are We Losing Ground?», Annu Rev Public Health, vol. 30 (2009), pp. 27-41.

BERRY, E., y S. DE GEEST, «Tell Me What You Eat and I Will Tell You Your Sociotype: Coping with Diabesity», RMMJ, vol. 3 (2012), e0010.

BERRY, E., «The role of the sociotype in managing chronic disease: Integrating biopsycho-sociology with systems biology». Medical Hypotheses, vol. 77 (2011), pp. 610-613.

BOK, D., The politics of happiness, Princeton, Princeton University Press, 2010.

CACIOPPO, J., y S. CACIOPPO, «Social Relationships and Health: The Toxic Effects of Perceived Social Isolation», Social and Personality Psychology Compass, vol. 8 (2014), pp. 58-72. 
CACIOPPO, J., y L. HAWKLEY, «Perceived social isolation and cognition», Trends in Cognitive Sciences, vol. 13 (2009), pp. 447-454.

CACIOPPO J., y W. PATRICK, Loneliness: Human Nature and the Need for Social Connection, New York, W.W. Norton \& Company, 2008.

CATTELL, R. B., «The scree test for the number of factors», Multivariate Behavioral Research, vol. 1 (1966), pp. 245-76.

COHEN, L., L. MANION, y K. MORRISON, Research methods in education, London, Routledge Falmer, 2003.

COLLINS, P. Y., V. PATEL, S. S. JOESTL, D. MARCH, T. R. INSEL, A. S. DAAR, et al., «Grand challenges in global mental health», Nature, vol. 475 (2011), pp. 27-30.

COMREY, A. L., y H. LEE, A first course in factor analysis, Hillsdale N.J. [u.a.], Erlbaum, 1992.

COMREY, A. L., Manual de análisis factorial, Madrid, Catedra, 1985.

DEL MORAL, R., J. NAVARRO, y P. C. MARIJUÁN. The «Sociotype» Approach to Social Structures and Individual Communication: An Informational Exploration of Human Sociality. Information Studies and the Quest for Transdisciplinarity. Unity in Diversity. World Scientific Series in Information Studies, Mark Burgin y Wolfgang Hofkirchner (eds.). 2017, Vol. 9., pp. 387-412.

DEL MORAL, R., y J. NAVARRO, «The "Sociotype": a new conceptual construct on the structure and dynamics of human social networks». Poster presentado en: AAAS Annual Meeting «Flattering the World: Building a Global Knowledge Society», Vancouver, 16-20 Febrero 2012.

DUNBAR, R., y S. SHULTZ, «Evolution in the Social Brain», Science, vol. 317(2007), pp. 1344-1347.

DUNBAR, R., The human story. London, Faber and Faber; 2004.

EASTERBROOK, G., The progress paradox, New York, Random House, 2003.

FOWLER, J., y N. CHRISTAKIS, «Dynamic spread of happiness in a large social network: longitudinal analysis over 20 years in the Framingham Heart Study», $B M J$, vol. 337(2008), a2338-a2338.

GOLL, J. C., G. CHARLESWORTH, K. SCIOR, y J. STOTT, «Barriers to Social Participation among Lonely Older Adults: The Influence of Social Fears and Identity», Plos one, vol. 23 (2015), https://doi.org/10.1371/journal.pone.0116664

GRANOVETTER, M., «The Strength of Weak Ties: A Network Theory Revisited», Sociological Theory, vol. 1 (1983), pp.201.

GRANOVETTER, M., «The Impact of Social Structure on Economic Outcomes», Journal of Economic Perspectives, vol. 19 (2005), pp. 33-50.

HAWKLEY, L., y J. CACIOPPO, «Loneliness Matters: A Theoretical and Empirical Review of Consequences and Mechanisms», Annals of Behavioral Medicine, vol. 40 (2010), pp. 218-227.

HOUSE, J. S., K. R. LANDIS, y D. UMBERSON, «Social relationships and health», Science, vol. 241 (1988), pp. 540-5. 
HUPPERT, F., «Happiness breeds prosperity», Nature, vol. 464 (2010), pp. 12751276.

KAISER, H. F., «The application of electronic computers to factor analysis», Educational and Psychological Measurement, vol. 20 (1960), pp. 141-151.

KEEN, A., The Internet is not the answer, Atlantic Books Ltd, 2015

KLINENBERG, E., Going Solo: Extraordinary Rise and Surprising Appeal of Living Alone, New York, Penguin Press, 2012.

LAZER, D., A. PENTLAND, L. ADAMIC, S. ARAL, A. BARABASI, D. BREWER, et al. «Social Science: Computational Social Science», Science, vol. 323 (2009), pp. 721-723.

MARIJUÁN, P. C., J. MONTERO-MARÍN, J. NAVARRO, J. GARCÍA-CAMPAYO, y R. DEL MORAL, «The "Sociotype" Construct: Gauging the Structure and Dynamics of Human Sociality» (en publicación, PLoS ONE)

MARIJUÁN, P. C., «The role of information networks in the evolution of social complexity», en Banquete-nodes and networks, Madrid, Seacex/Turner, 2009.

MORALES, P., B. UROSA, y A. BLANCO, Construcción de escalas de actitudes tipo likert, Madrid, La Muralla, 2003.

MUÑIZ, J., A. M. FIDALGO, E. GARCIA-CUETO, R. MARTINEZ, y R. MORENO, Análisis de los Items, Madrid, La Muralla, 2005.

MUÑIZ, J. Teoría Clásica de los Test, Madrid, Piramide Psicologia, 2001.

OLDENBURG, R., The great good place, New York, Marlowe, 1999.

PENTLAND, A., Social physics, New York, The Penguin Press, 2014.

PINKER, S., The sexual paradox, New York, Scribner, 2008.

PINKER, S., The village effect, Atlantic Book ltd., 2014.

PINQUART, M., y S. SORENSEN, «Influences on loneliness in older adults: A metaanalysis», Basic \& Applied Soc. Psychology, vol. 23 (2001), pp. 245-266.

PUTNAM, R., L. FELDSTEIN, y D. COHEN, Better together, New York, Simon \& Schuster, 2004.

PUTNAM, R. «Bowling alone: America’s declining social capital», Journal of Democracy, vol. 6 (1995), pp. 65-78.

PUTNAM, R. Bowling alone, New York, Simon \& Schuster, 2000.

ROBERTS, P., The impulse society, New York, Bloomsbury, 2014.

RUAN, H., y C. F. WU, «Social interaction-mediated lifespan extension of Drosophila $\mathrm{Cu} / \mathrm{Zn}$ superoxide dismutase mutants», Proceedings of the National Academy of Sciences, vol. 105 (2008), pp. 7506-7510.

STEPTOE, A., A. SHANKAR, P. DEMAKAKOS,y J. WARDLE, «Social isolation, loneliness, and all-cause mortality in older men and women», Proceedings of the National Academy of Sciences, vol. 110 (2013), pp. 5797-5801.

TURKLEY, S., Reclaiming conversation, New York, Penguin Press, 2015.

WEEKS, D. J., «A review of loneliness concepts with particular reference to old age», Int.J. Ger. Psyc., vol. 9 (1994), pp. 345-355. 
WITTCHEN, H. U., F. JACOBI, J. REHM, A. GUSTAVSSON, M. SVENSSON, B., JÖNSSON, J. OLESEN, et al., «The size and burden of mental disorders and other disorders of the brain in Europe 2010», Eur Neuropsychopharmacol., vol. 21 (2001), pp. 655-679.

YANG, K., y C. VICTOR, «Age and loneliness in 25 European nations», Ageing and Society, vol. 31(2011), pp. 1368-1388. 
NUEVAS INSURGENCIAS 



\title{
CUERPOS CRIP Y ARTE: PRÁCTICAS CREATIVAS TULLIDAS EN ESPACIOS PÚBLICOS
}

\author{
Laura Moya Santander \\ Universidad de Zaragoza \\ lmoya@unizar.es
}

\subsection{Arte contemporáneo y representación}

\begin{abstract}
The dream of a suitable political work of art is in fact the dream of disrupting the relationship between the visible, the sayable, and the thinkable without having to use the terms of a message as a vehicle. It is the dream of an art that would transmit meanings in the form of a rupture with the very logic of meaningful situations.(Ranciere, 2004: 63)
\end{abstract}

Según expresa García Canclini (2010), la sociología, desde principios del siglo $\mathrm{XX}$, ha tenido la necesidad de entender los movimientos artísticos en conexión con los procesos sociales. Los movimientos sociales que han recurrido al arte como herramienta de protesta y transformación, el arte político de los movimientos artísticos de los años sesenta o el arte activista (artivismo) de los años ochenta hasta la actualidad, han contribuido a hacer más fluidas las relaciones entre arte y sociedad. $\mathrm{Y}$ es que las prácticas artísticas basadas en objetos se han desplazado hacia prácticas insertadas en contextos que finalmente participan de medios de comunicación que van desde los espacios urbanos a las redes digitales pasando por las distintas formas de participación social.

Más adelante, en la década de los 90 y a principios del siglo XXI, cuando se asentaron las artes como un lugar de exploración de las insuficiencias y potencialidades de la vida común, un número creciente de artistas dejó de inte- 
resarse en construir obras y comenzó a participar en la formación de ecologías culturales (Laddaga, 2010). Estas ecologías se refieren a prácticas que no suponen tanto la realización de objetos concluidos, sino más bien, la exploración de modos experimentales de coexistencia de personas y de espacios, de imágenes y de tiempos. En estas ecologías, los artistas son originadores de procesos en los que intervienen como sujetos cualesquiera aunque situados en lugares singulares de una red de relaciones. Con efectos locales aunque con flujos no territorializados, estas ecologías tienen consecuencias artísticas y sociales, pues estos proyectos se inician por la voluntad de explorar las formas de la vida social y su modificación.

Pero además, en el arte contemporáneo, la cuestión del espectador se situó en el centro de las discusiones entre arte y política, ya que se consideraba que este era a la vez separado de la capacidad de conocer (permanece ante una apariencia) y del poder de actuar (observar, pasivo e inmóvil) (Ranciere, 2010). Sin embargo, como expresa Ranciere (2010), con el arte contemporáneo no se trató de un cambio de posiciones, sino del cuestionamiento de las distribuciones de las capacidades e incapacidades ligadas a estas posiciones, tales como mirar y actuar, pasividad-actividad, escucha-acción. Es en este arte de finales de los sesenta, pero también en el más actual, en el que se atraviesan las fronteras entre los que actúan y los que miran, en el que se alteran las distribuciones de roles, donde todas las competencias artísticas tienden a salir de su propio ámbito y a intercambiar sus lugares y sus poderes. Por eso, dice Ranciere que lo que hay en el arte contemporáneo son escenas de disenso, es decir, reconfiguraciones de lo sensible. $\mathrm{Y}$ esta reconfiguración consiste en un proceso de subjetivación política, en la acción de capacidades no contadas que deshacen la unidad de lo dado y cuestionan la evidencia de lo visible, para dibujar una nueva topografía de lo posible (Ranciere, 2010).

Si algo define al arte contemporáneo, es que en esta cultura de las artes emerge el lenguaje en el campo estético. Entendiendo la textualidad en el sentido de que un signo no encierra en si mismo un único significado y significante, las prácticas artísticas de este arte se definen en relación a las operaciones sobre un conjunto de términos culturales, haciendo colisionar los distintos niveles de lectura y representación que deconstruyen el paradigma simbólico de la modernidad ya que favorecen la transitoriedad, la hibridación, la deslocalización, etc.. (Foster, 2001). Por tanto, el arte contemporáneo tiene un rasgo que lo distingue de todo el arte hecho desde 1400, y es que sus principales 
ambiciones no son estéticas (Danto, 2012). De hecho, es la transformación del campo cultural lo que da posibilidad a este arte y da sentido a la obra.

Estas transformaciones en el arte tuvieron lugar por la crítica a la representación que se gestó en trabajos europeos de teoría crítica durante esos años. Barthes, Foucault, Derrida, etc. fueron algunos de los autores que favorecieron un enfoque interdisciplinar de las dinámicas de la representación, estudiando la construcción de la representación en los sistemas sociales y la perpetuación y el funcionamiento de estos sistemas a través de la representación (Wallis, 2001; Danto, 2012). El espíritu deconstructivo entendió las teorías en términos de poder-opresión, las cuales se hicieron extensivas al modernismo. Así, se hicieron críticas a las suposiciones de que la pintura y la escultura habían sido los vehículos del desarrollo del arte, considerando que esto no era más que el reforzamiento de privilegios de las instituciones que las acogían. Si bien los templos fueron siempre emblemas de poder, lo eran de una forma enmascarada por la espiritualidad de sus prácticas. En tanto que los museos fueron presentados como templos de la verdad a través de la belleza, las realidades del poder fueron invisibles hasta entonces., el museo, la galería, las colecciones, etc. fueron vistos como factores conservadores del statu quo y el artista fue coaccionado a producir obras que reforzasen estas instituciones. Por eso, los artistas que trabajaban fuera del sistema, se consideraban como factores del cambio social al hacer un arte que subvertía el status por esquivar las instituciones que la deconstrucción reveló opresivas (Danto, 2012).

Pero, la crítica a la representación en la sociedad, no sólo está en la base de la transformación contemporánea del arte. Las clasificaciones, las representaciones, son construcciones ficticias y contradictorias, son maneras de circunscribir mediante el aislamiento de ciertos elementos de similitud y su conversión en criterios para la diferenciación. Representaciones conceptuales tales como imágenes, lenguajes o definiciones que a su vez construyen representaciones sociales tales como la raza, el género o la capacidad, no son hechos naturales aunque dependan de un elemento material del mundo real. Más bien, son selecciones arbitrarias (definir, nombrar, clasificar, catalogar, etc.).

Si se considera en términos sociales, la representación atiende a los intereses del poder, pues estas designaciones son inevitablemente jerárquicas en el sentido de que privilegian un elemento en vez de otro, cumpliendo una función ideológica al determinar la producción de sentido y valor. Pero en todo sistema aparecen márgenes para la resistencia y espacios o comunidades que pueden ser habitados. Así, la crítica de la representación atiende a la construc- 
ción cultural (imágenes, ideologías, símbolos, etc.) y el arte, precisamente, ha manejado estas construcciones. Por lo que, el arte aparece como potencia cultural para desafiar las convenciones establecidas de la representación (Wallis, 2001).

Es precisamente el arte, quien con su capacidad de ficcionar genera interferencias en la gramática cultural, cuestionando la normalidad y naturalidad de las relaciones de poder y de dominio. La gramática cultural es el sistema de reglas que estructura las relaciones e interacciones sociales y comprende también las divisiones sociales del espacio y del tiempo que determinan las formas de movimiento y las posibilidades de comunicación (Grupo autónomo a.f.r.i.k.a., Luther Blisset y Sonja Brünzels, 2000). Dentro de las formas culturales, es donde tiene lugar la acción política, dado que es en estas en donde se negocia la reproducción y la estabilidad de las relaciones de poder. La gramática cultural resulta efectiva porque permanece invisible tras una supuesta naturalidad. Pero, el sistema de reglas de la gramática cultural no es en absoluto neutral, pues es expresión de relaciones sociales de poder y de dominio y sus reglas juegan un papel fundamental en su producción y reproducción (Grupo autónomo a.f.r.i.k.a., Luther Blisset y Sonja Brünzels, 2000). Estas representaciones, no sólo se producen y reproducen en el nivel verbal-discursivo, sino también, a través de las normas sociales que determinan la vida cotidiana de la gente, mediante reglas y formas de interrelación. Estas reglas se transmiten en innumerables situaciones diarias y normas de comportamiento usuales de la vida cotidiana. Así, se dan formas cotidianas de ejercer el poder en lo pequeño, mediante ofertas de identificación (Grupo autónomo a.f.r.i.k.a., Luther Blisset y Sonja Brünzels, 2000). Dentro de estas, las jerarquizaciones de capacidad también funcionan por los principios de la opresión y del autoposicionamiento dentro del estrecho marco social. De hecho, aunque la autoidentificación puede suponer un potencial de transgresión al ser endógena (es decir, escogida por el propio grupo), si esta se basa en el modelo de identificación propuesto por el poder, puede tener un efecto social estabilizador al perpetuar las atribuciones que fundamentan la opresión. Por ello, en cuanto a las jerarquizaciones sociales, la autodenominación transgresora se da, no sólo cuando se produce una apropiación de un término para convertirlo en identidad por un propio grupo, es decir, una autodenominación endógena, sino también en tanto que esta no produce un posicionamiento basado en categorías creadas por el poder, las cuales quedan perpetuadas con dicho posicionamiento. Por ello, para conocer como funciona la gramática cultural en cuanto a las jerarquías de capacidad y como el arte puede desconfigurarlas, cabe desnaturalizar 
categorías como salud o capacidad y mostrar como estas categorías operan en el mantenimiento de dichas representaciones. Así, posteriormente, se podrán mostrar posicionamientos subversivos a tal orden dentro del arte y las posibilidades que estos generan.

\subsection{Las jerarquizaciones de salud y capacidad}

El cuerpo, expresión de la imperfección humana y portador de la diferencia, se convirtió en los siglos XVIII y XIX, en aquello que debía ser regulado, en objeto de saber y objetivo de control (Rodríguez y Ferreira, 2010). La tara, esa diferencia que a partir de esa época fue entendida como desviación de la norma, fue regulada, y el cuerpo que la porta, clasificado como discapacitado, fue disciplinado. Atendiendo a las nuevas relaciones de producción/ reproducción y refiriéndose a la salud hecha norma, se generó la dicotomía salud-deficiencia, que categoriza a los cuerpos a partir de un ideal orgánico, nombrándolos o clasificándolos según un estado de salud regulado y disciplinado por el dictamen experto (médico) que erige la norma o normalidad orgánica (ilimitada, no restringida y eficiente) (Rodríguez y Ferreira, 2010). Así mismo, refiriéndose a la capacidad, se generó la dicotomía entre funcionamiento eficiente o capacidad y funcionamiento ineficiente o discapacidad, sin considerar formas de funcionamiento menos habituales que desarrollan dichas capacidades y que por procedimiento normativo confunden capacidad con funcionalidad. A su vez, estas categorías generaron la dicotomía organismo (salud-enfermedad) - funcionamiento (eficiente-ineficiente) (Toboso y Guzmán, 2009; 2010).

Ambos, tanto el ideal orgánico como el ideal funcional, construidos a partir de la norma, se inscriben y tienen su interconexión en el cuerpo, que se toma como lugar y práctica del discurso médico-capacitista, el cual se inserta en las representaciones y prácticas que a nivel orgánico y a nivel funcional, respectivamente, participan en la producción del cuerpo normativo (Toboso y Guzmán, 2009; 2010). Bajo la «mirada médica» se clasifica a los cuerpos según el estándar de salud, disciplinando a los que se desvían del mismo para que se acerquen lo más posible al ideal orgánico. Sin considerar que la norma de salud responde a un habitus, una característica arbitraria pero dominante que se hizo norma y que depende del contexto social. Bajo la «mirada capacitista», la capacidad antecede en importancia a la funcionalidad, por lo que no se considera que las distintas funcionalidades como expresiones diferentes de funcionamiento posible sean verdaderamente funcionales (Toboso y Guzmán, 
2010). Es decir, se iguala capacidad a funcionalidad mayoritaria y así cada funcionalidad mayoritaria (socialmente legitimada) se identifica con la capacidad correspondiente. De esta manera, y dado que el conjunto de capacidades configura el cuerpo normativo, se configura el mismo a partir de las funcionalidades legítima(da)s. Por tanto, las miradas «médica» y « capacitista» producen un cuerpo normativo, ideal y único posible, pese a la presencia de otros cuerpos diferentes que no se consideran relevantes, pues el cuerpo normativo anula otras alternativas y las invisibiliza.

Tanto «mirada médica» (proyectada sobre el organismo), como la mirada «capacitista» (sobre el funcionamiento), son performativas; es decir, actúan en la producción del cuerpo normativo. Por ejemplo, cada conflicto con una barrera del entorno supone un acto performativo, en el que se reproduce la categoría de discapacidad y se opera sobre el cuerpo considerado deficiente, al recordarle su anormalidad por no poder habitar ese espacio y materializando sobre este los contenidos normativos del discurso médico-capacitista (Abbott, 2010). Estos actos performativos producen y reproducen la distancia social entre el cuerpo normativo y otros cuerpos, la posición central del primero y la posición periférica de los otros (los «anormales», los cuerpos dis-capacitados).

Pese al avance que supone en la década de los años setenta del siglo XX la consideración de la discapacidad como resultado de restricciones sociales, provocadas por un entorno hostil pleno de barreras sociales y ambientales (Oliver, 1998), la deficiencia a nivel orgánico sigue naturalizada, concibiéndose y representándose como una carencia o falta de normalidad. Dicha deficiencia es ligada al cuerpo, un cuerpo sin cultura, presocial y sin capacidad de acción, objeto todavía del discurso médico-capacitista. Es precisamente esta «anormalidad», la que continúa anclando este cuerpo en el espacio de lo otro, perpetuando en la cultura una línea divisoria entre el cuerpo orgánica y funcionalmente normativo (el cuerpo «capacitado», que se contempla como universal y positivo) y el cuerpo discapacitado ( designado con criterios restrictivos), dando lugar a que esos otros cuerpos sean señalados, sus experiencias invisibilizadas y su existencia marcada como «otra» (desviada e inferior), al ser construida su diferencialidad en términos de carencia y negación (Young, 2000). Dicho de otro modo, la «normalidad de los cuerpos capacitados es insertada en cualquier pensamiento y comportamiento como un privilegio o estado deseable del ser (y) la noción de cuerpo capacitado asume estándares 
normativos o universales a través de los cuales los otros cuerpos son juzgados» (Palacios, 2008: 173).

Sin embargo, pese al avance en considerar la discapacidad como una categoría construida y determinada por el entorno social, esta conclusión no deja de situarse dentro de las categorías propuestas por el poder para denominar lo diferente y perpetuar la norma y su representación.

Así, aunque el «modelo social» de la discapacidad supuso un hito en cuanto a la comprensión de la discapacidad a partir de los años 70 , y se la liberó de la atribución individual y médica en el que la había encerrado el «modelo médico-rehabilitador». La consideración de la discapacidad como socialmente construida trajo consigo dos sujeciones a lo normativo. Por una parte, la suposición de que todos los cuerpos no normativos vivían una misma opresión generada por las barreras del entorno. Dando lugar así, a una homogenización de condiciones y experiencias de sujetos que, bajo estas suposiciones, se veían aunados en un mismo colectivo oprimido. Y, por otra parte, dicha suposición perpetuó la reproducción de la categoría discapacidad, haciendo uso, por tanto, de las categorías del poder y de la diferenciación entre estas.

Sin embargo, en los últimos años estas categorizaciones del poder, entre la salud y la deficiencia, entre la capacidad y la discapacidad, también han recibido críticas más allá del «modelo social». Si bien se desmontó la naturalización de la dicotomía entre capacidad-discapacidad, cabe deshacer el binomio salud-deficiencia para comprender como opera la diferencialidad a nivel orgánico.

Dado que el cuerpo se abandonó al dictamen médico y, con este, la deficiencia o el impedimento, pues se los consideraba en términos biológicos, consecuencia de una afección. El desmontaje de la salud-deficiencia requiere la puesta en escena del cuerpo. Un cuerpo que se entendió como mero producto biológico pero que, sin embargo, tiene mucho que decir. Porque si entendemos que la salud es una construcción social basada en características arbitrarias y mayoritarias que se hacen norma, el cuerpo es el que porta dichas atribuciones. Y, si estas atribuciones no son naturales, el cuerpo tampoco lo es.

Sacar al cuerpo del discurso médico-capacitista y mostrarlo como potencia desestabilizadora de este discurso, prepara el terreno para desmontar la representación del poder. Y, precisamente, desmontar la construcción de la deficiencia, es posible mostrando la multiplicidad de experiencias. Porque 
las experiencias subjetivas son tan diversas que no pueden encerrarse en una categoría homogénea, en un grupo de personas que pasa a ser un colectivo. Porque las experiencias expresan el punto de vista de los cuerpos, es decir, son experiencias corporales y en ello radica su posibilidad y su manera de habitar el espacio.

Por todo ello, cabe mostrar las experiencias de esos cuerpos que han sido clasificados como «otros», «deficientes», «discapacitados». Y, no hacerlo desde una categorización del poder, sino, desde la ruptura con estas categorías. Porque, como se expresó anteriormente, la autodenominación puede perpetuar las categorías establecidas si nos basamos en estas para la delimitación de sujetos. Pero, si escogemos una apropiación y no la limitamos a un colectivo, jugamos con las categorías y las jerarquías del poder. Así ocurre con el término crip, que es el diminutivo de la palabra cripple (tullido o tarado) y que, pese a ser una reapropiación endógena de un término que anteriormente fue despectivo, se convierte en una suerte de respuestas a la norma. Y que, más allá de suponer reutilizaciones de las categorías del poder, no restringe a nadie la entrada en el mismo: «deficientes, Un mundo crip es posible» (McRuer, 2006; 73).

Por ello, a continuación se exponen algunas acciones artísticas del movimiento crip con la intención de mostrar como desde los márgenes se genera posibilidad para deshacer las representaciones con respecto a la norma orgánica y funcional y creer en que un mundo crip es posible.

\subsection{Arte crip en espacios públicos}

El cuerpo es el que habita los espacios y, como tal, el que genera posibilidades de experiencias. No estamos hablando de un cuerpo en relación a las experiencias de posibilidad física, sin atender a las condiciones mentales (intelectuales o psicológicas). Atendemos al cuerpo en todas sus condiciones, pero si hablamos de cuerpo y, con este, englobamos a las condiciones mentales, es porque consideramos al cuerpo en su relación con el espacio, es decir, siendo el que habita el espacio y por el que se establecen relaciones con y dentro de los espacios. Por eso, atendemos a las experiencias corporales, como esas experiencias que desmontan las jerarquías y las configuraciones de poder. Porque los espacios no han sido configurados para cuerpos con experiencias fuera de las categorizaciones de lo sano y lo capaz. Pero, estos cuerpos también habitan estos espacios y generan posibilidad. 
En las artes, las experiencias de estos cuerpos no han sido tenidas en cuenta de manera generativa, sino que han sido descritas en términos de carencia y falta de normalidad (Sandahl, 2002). Los artistas a menudo han recurrido a la discapacidad como metáfora de la alteridad, habitualmente estigmatizada. «Protesis narrativa» lo denominan Mitchell y Snyder (Shandahl, 2002). Pero, como expresa Sandahl (2002), estas consideraciones pueden cambiar y, una vez desestigmatizadas, son estados generadores que permiten una enorme gama de diversidades en términos corporales, espaciales y sociales. Así, desde el lenguaje de la injuria y jugando con el humor, los cuerpos crip desmontan categorías jerárquicas de la salud y la capacidad para presentar nuevas posibilidades de subjetivación.

Las performances autobiográficas de Mary Duffy, Mike Lamitola, Cheryl Marie Wade o Greg Walloch explotan los estereotipos de la discapacidad y, con el humor, ponen en valor la diferencia de los cuerpos que son clasificados como diferentes por la norma orgánica y funcional. Victoria Ann Lewis's, Joan Lipkin, Terry Galloway, John Belusso, Susan Nussbaum o Carrie Sandahl, con sus obras, expresan experiencias del día a día de estos cuerpos y critican su representación mainstream. Ni estas ni otras actuaciones caen en el esencialismo de desafiar narrativas tradicionales con narrativas alternativas pero bajo la autodefinición que oculta la experiencia subjetiva y fenomenológica, porque dicho ocultamiento no deja de ser expresión de opresión hacia la diferencia propia de cada condición y, por tanto, esencialismo, básico para componer las categorías del poder.

\subsubsection{Cuerpos y espacio}

Aunque la cultura dominante ha descrito la experiencia de estos cuerpos como falta o pérdida, los artistas que cuentan con estos cuerpos, entienden su experiencia como una respuesta creativa de maniobras adaptativas hacia unos espacios no creados para estos cuerpos (Sandahl, 2002).¿Cómo pueden afectar estas respuestas creativas al campo estético y al espacio que este ocupa y genera? Los espacios físicos nos dicen quién está allí, quién puede participar y de que manera puede hacerlo. Por ello, los cuerpos sirven como metáfora para la organización de los espacios. Así, a medida que ampliamos la idea de lo que constituye un cuerpo representable, expandimos la idea de cómo organizar el espacio en si. En efecto, también los espacios de las artes están configurados en función de la norma del sujeto ideal orgánico y funcional, privilegiando la presencia de los cuerpos capacitados. Por eso, la creación de espacios abiertos a la diversidad de cuerpos, alteraría inmediatamente la ideología del espacio, 
produciéndose un cambio de orden más amplio. Pero si además los espacios simbolizan por ellos mismos la norma orgánica y funcional y su configuración puede ser desconfigurada por estos cuerpos, por su presencia y por sus intervenciones artísticas, se producen situaciones de generación del valor positivo de la diferencia. Un ejemplo de desconfiguración simbólica y de desorden del espacio mediante una intervención artística, es la acción que tuvo lugar en la calle «Invalidenstrasse» de Viena. El grupo Dance Ability realizó en este espacio una danza crip, en la que invitaban a los viandantes a moverse con sus sillas, muletas, bastones, agolpando sus cuerpos, arrastrándose y apoyándose los unos en los otros para danzar al ritmo de la música. De tal manera, que desconfiguraban la estilización de la danza, desordenaban el espacio y se valían de sus materiales para bailar, desorganizando las configuraciones del espacio. Pero además, la elección de este lugar «Invalidenstrasse» la calle de los inválidos, tiene un componente subversivo crip. Ocupar un espacio que lleva por nombre una clasificación negativa de unos cuerpos que son diversos orgánica y funcionalmente y que estos cuerpos y otros cuerpos dancen con libertad de movimientos por este lugar, desordenando estas representaciones y haciendo de estas, una fiesta de la diversidad, presenta una ruptura total con la jerarquía del poder sano y capaz, valiéndose de la celebración de ser diferente ${ }^{1}$.

\subsubsection{Lenguajes}

Tan importante es habitar y participar en el espacio como hacer llegar el mensaje. A medida que estos cuerpos entran en el espacio social, los medios de comunicación que se dan dentro de ese espacio cambian y, al mismo tiempo, cambia la configuración del uso del espacio social. Es decir, se reordena el espacio público.

Generalmente, en el espacio, también en los espacios artísticos, la comunicación es bilateral, compuesta por un orador y una audiencia. Pero, la disposición de estos cuerpos, genera una dimensión más fluida, ya que el lenguaje se convierte en multidireccional, al encontrarse apoyos a la comunicación en ambos lados de la división normativa, es decir, múltiples canales de comunicación que interactúan entre el/los oradores y el/los que reciben el mensaje. Esta comunicación se logra de manera cooperativa, aunque no está exenta de negociaciones y de maneras de acomodación confrontadas.

1 Más información en: https://www.facebook.com/Invalidenstrasse-Invalidstreet-272831192764692/ 


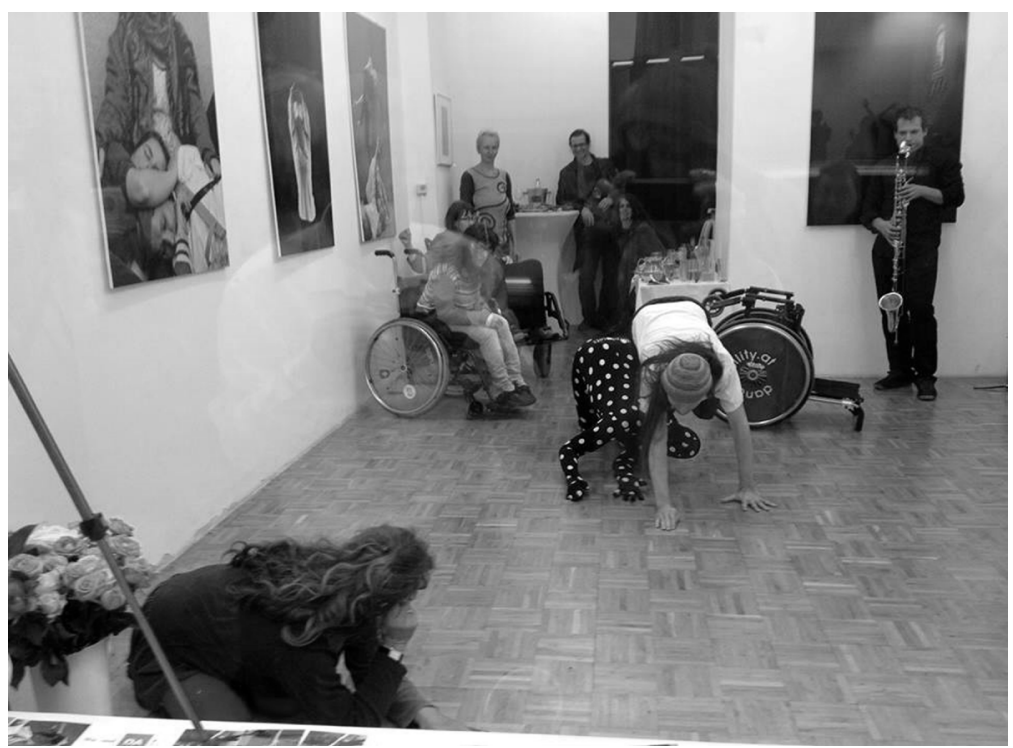

FOTO: Dance Ability, acción artística Invalidenstrasse, https://www.facebook.com/Invalidenstrasse-Invalidstreet-272831192764692/

Por ejemplo, un mismo espacio artístico, puede estar habitado por el cuerpo de una persona con diversidad visual que requiere más luz para poder moverse por el espacio e identificar los movimientos de los otros, mientras que un cuerpo con diversidad auditiva que también habita ese espacio requiere de una luz tenue para leer los subtítulos de una pantalla. Así mismo, la multitud de canales de comunicación que se despliegan en un espacio habitado por multiplicidad de cuerpos, puede abrumar a una persona con una neurodiversidad como el autismo. Sin embargo, si se negocian estos canales de comunicación y de manera cooperativa se produce la transmisión de mensajes, se reorganizan los espacios en los que todos los cuerpos participan. Así es como el lenguaje verbal, se vuelve espacial, físico y colectivo, no sólo individual y oral, haciendo que el espacio ya no esté dispuesto en función de una división, sino que el espacio esté dispuesto para cuerpos continuos enlazados en una red (Sandahl, 2002). El uso innovador del espacio, por tanto, se convierte en parte de la estética de la comunicación de un acto artístico, mostrando como el lenguaje es espacial, además de oral y textual (Sandahl, 2002).

Un ejemplo de ello son la puesta en escena de poemas en lengua de signos. La poesía en lengua de signos añade una dimensión más al lenguaje, 
la lateralidad. Es decir, se muestra una imagen del lenguaje que modifica la imagen fonocéntrica del lenguaje (Sampedro, 2012). La poesía signada se caracteriza por la iconicidad, es decir, la visualidad de los significados y la continuidad entre representación lingüística y mimética, por la visualidad de las metáforas utilizadas y por el ritmo poético que, al signar, varía en función de la velocidad y nitidez de movimientos síngnicos y la intensificación y sintetización de la expresión (Sampedro, 2012). Dentro de estas variaciones rítmicas, la poesía signada se caracteriza por el ritmo de la alternancia espacial, es decir, de lugares laterales espaciales, lo que en las lenguas orales es desconocido (Sampedro, 2012). De tal manera que, la poesía signada, se basa en el uso de los signos pero también en el uso del lenguaje espacial, para narrar desde el detalle más pequeño hasta la trama de un poema, mediante el cuerpo del artista.

Un ejemplo de esta poesía, son los hermanos Rosaria e Giuseppe Giuranna, que mediante la Lengua de Signos Italiana y la disposición de su cuerpo en el espacio, desarrollan poemas gestionando el espacio y sus cuerpos ${ }^{2}$. Así, es que la poesía sorda, pone al cuerpo en el centro de la obra, apoyándose en este para narrar la poesía y describir historias complejas al mismo tiempo. Como explica Brueggeman (Sandahl, 2002), la poesía sorda tiene un énfasis en la presencia, participación, energía encarnada y creación, opuestas a la objetivación habitual hacia estos cuerpos. Como dijo Herrero (2015), la clave de la poesía signada está en la belleza de la signación, que es como una danza, y en la expresión del signante, que es un actor.

Otro ejemplo en el que el lenguaje se convierte en desconfiguración de lo normativo, es la performance Touch and diagnoze de la artista Cheng Yong. En esta performance, la artista llena su cuerpo de mensajes en braille no táctil que sólo es perceptible a la vista. Ella, se tumba en una mesa, repleta también de estos puntos, para que seis personas le toquen. Así, en esta performance, hace una crítica a las dicotomías que se generan por la comunicación reglada desde lo normativo, sirviéndose de su cuerpo como propio expositor de estas divisiones.

2 Un ejemplo de ello, Rosaria Giuranna, poema L'inno Della https://www.youtube. com/watch?v=y9FYv8JE1ig 


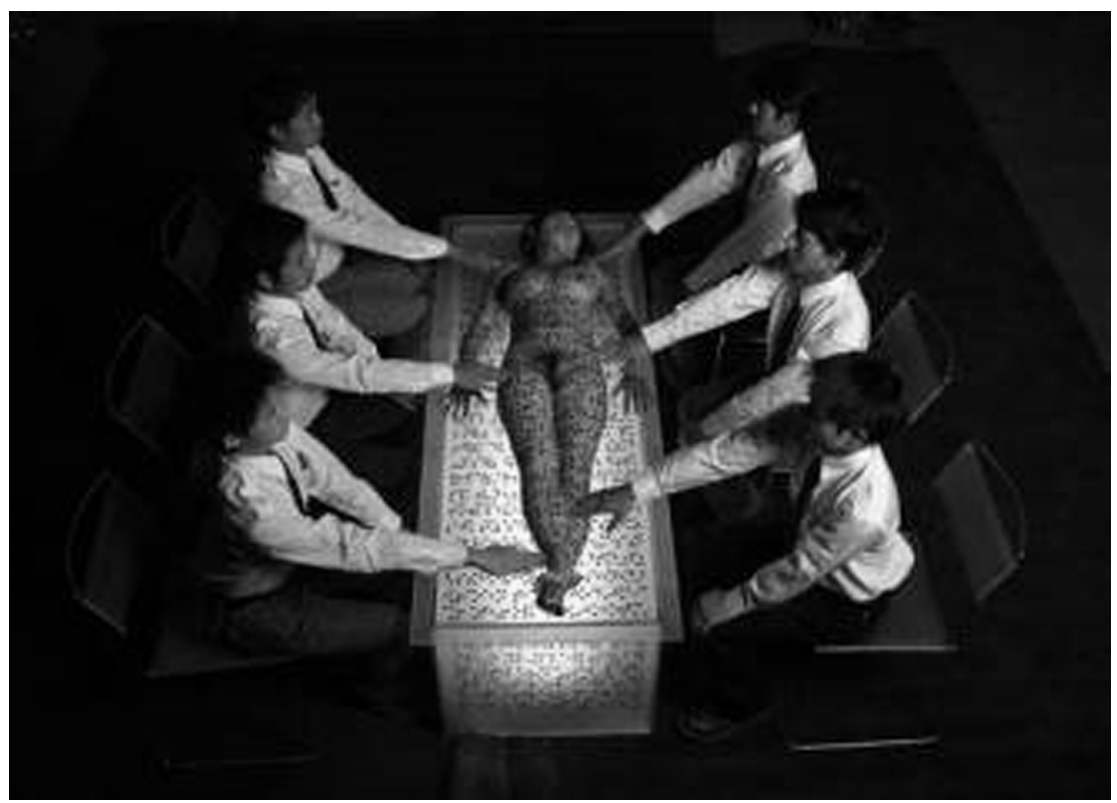

Foto: Artista Chen Yong, performance «Touch and Diagnoze», www.unojoparaelarte.wordpress. com

\subsubsection{Dispositivos}

Las condiciones de estos cuerpos también alteran la relación que se tiene con el espacio en referencia a la perspectiva que se tiene sobre dicho espacio y los que lo habitan. En efecto, cada experiencia corporal concreta, da lugar a una perspectiva del cuerpo en el espacio, que afecta a la información sensorial sobre el espacio y el cuerpo. Por eso, la exploración de estas experiencias en relación al cuerpo y el espacio, puede sugerir nuevos movimientos de relación en los cuerpos dentro del espacio. Mientras que la representación dominante describe los dispositivos de movilidad como símbolos de derrota, limitación o debilidad, estos cuerpos describen estos dispositivos como extensiones de sus cuerpos que amplían el movimiento y la perspectiva de estos cuerpos con el espacio. Por tanto, si se amplía esta experiencia a más cuerpos, se generan nuevas formas de movimiento y perspectiva dentro de los espacios, reconfigurando el sentido de los mismos (Sandahl, 2002).

Un ejemplo de ello, es la bailarina Charlene Curtis. Ella, retrata en sus danzas la sensación de liberación cuando el cuerpo se funde con el desliza- 
miento de la silla. A través del espacio. La silla es más que una herramienta para mover el cuerpo de un lugar a otro. La silla tiene cualidades expresivas y artísticas. Ella no la entiende como una entidad separada. Explora el significado de la silla como una extensión en si misma y como expresión de esa relación a través del movimiento (Sandahl, 2002).

Pero no sólo los cuerpos se pueden valer de dispositivos conocidos como la silla, sino que también los cuerpos pueden indagar en otras formas de movimiento en el espacio, mediante trapecios, cuerdas, etc. Así, estos y otros cuerpos que exploran nuevas perspectivas del espacio, dan significados mistos a diferentes dimensiones del espacio (Sandahl, 2002).

En nuestro entorno más cercano, la compañía de danza «Ruedapies», explora movimientos de danza a partir de la relación de los cuerpos con el espacio en sus diversas condiciones corporales y mediante los variados dispositivos de movilidad.

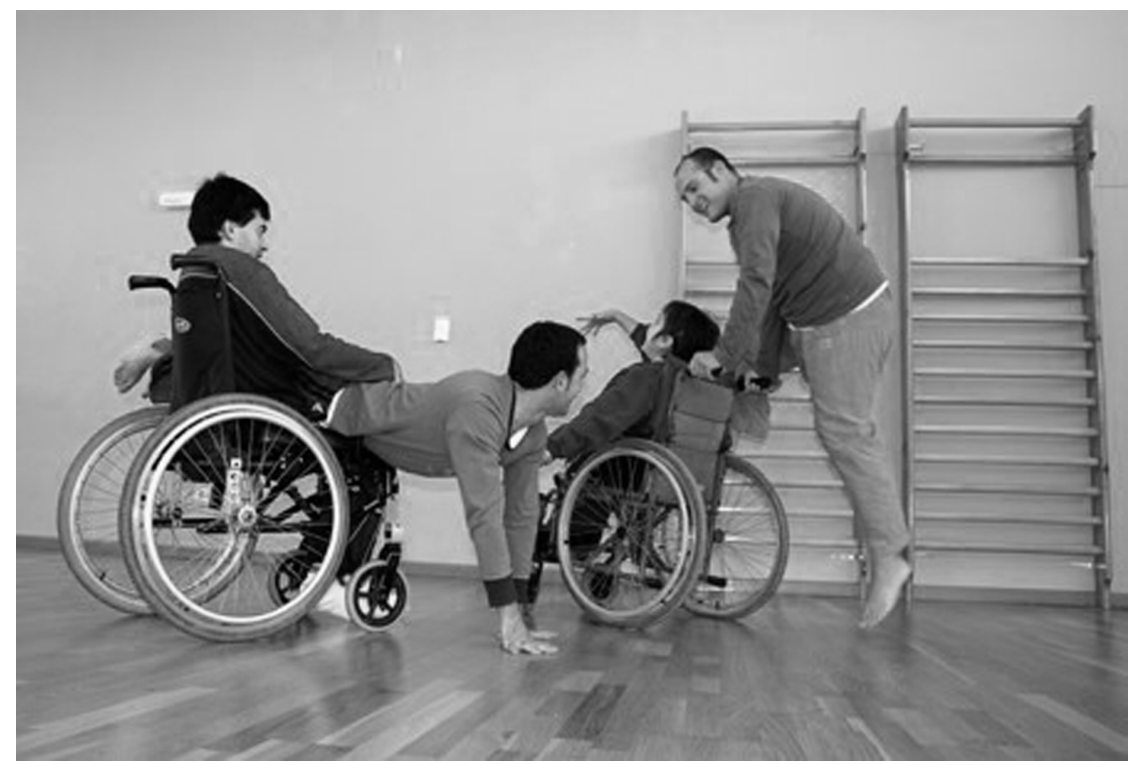




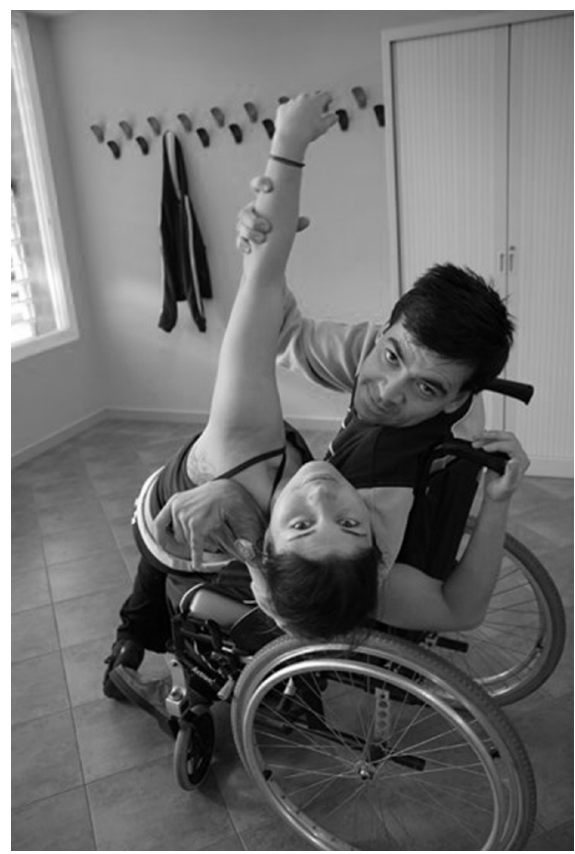

FOTO: Compañía Ruedapies, espectáculo «Hibridaciones» www.ruedapies.es

\subsubsection{Asimetría}

Estos cuerpos también cuestionan los valores estéticos del espacio. Con sus movimientos, proporcionan una puesta en valor de la asimetría como un componente positivo y crítico de la cultura dominante que entiende como positivo sólo lo perfecto y simétrico. Por tanto, la presentación y participación de estos cuerpos, además de reconfigurar el uso del espacio, lo desconfigura de su componente estético basado en la perfección. Los cuerpos de estos artistas se muestran y, con ellos, se deshacen representaciones de lo simétrico en las obras y los espacios artísticos.

Un ejemplo de ello, es la artista Mary Duffy con su performance sobre «La Venus de Milo». En esta performance, la artista atiende a su cuerpo asimétrico para desafiar los intentos de normalización. De fondo, un espacio negro aterciopelado y simétrico, en el centro ella, acostada en la misma postura que La Venus y con su cuerpo asimétrico, sin brazos y con una mano justo después del hombro. Moviendo la cabeza para enfatizar una narración que cuenta cómo el hacer uso de los pies en vez de las manos fue catalogado por la profesión médica como patológico e inaceptable. Dicha narración trató de 
acomodarla con brazos de prótesis torpes, tratando de hacerla más completa, menos visible. Pero ella, siempre se ha sentido completa y funcional. Su actuación, basada en el método «mira y cuenta» (Stare and tell), hace una fusión del ver y el decir, poniendo en primer plano el cuerpo para ser visto y ser explicado (Garlan-Tomshon, 2000). Así, con su cuerpo considerado asimétrico, subraya la arbitrariedad de la simetría, al considerarse dicha simetría como la única forma completa-funcional y ocultando las formas de otros cuerpos cuya apariencia se aleja más que la de otros de este ideal.

No obstante, esta asimetría en el arte, no sólo se pone en valor con la participación de cuerpos asimétricos. Como expone Siebers (2006), esta estética de la asimetría también puede enfocarse en el espacio. Un espacio quebrado, dañado o destruido. Unas obras artísticas quebradas que no son actuales, como las esculturas de cuerpos humanos quebrados de griegos y romanos, pero también el actual arte vandálico, ejemplifican metáforas de la convivencia con la asimetría que no necesariamente debe ser tildada de no estética. Imágenes, por tanto, que dejan de ser contempladas como un símbolo de la imperfección para comprenderse como experiencias de la variación corporal y espacial.

Las imágenes bandalizadas no representan lo que representaban antes de su lesión, pues el acto de vandalismo modifica la función referencial de la obra de arte, creando una nueva imagen. Esto da lugar a dos consecuencias: por una parte, el acto de vandalismo es un acto de creación porque una nueva imagen cobra vida y, por otra parte, al crear una nueva imagen, esta se convierte en potencia de un nuevo referente que emerge (Siebers, 2002). La originalidad de la obra de arte no está ligada a su perfección, sino a su simbolización única de la subjetividad humana. Este simbolismo es tan contundente, que un acto vandálico no puede perjudicarlo, pero si, dirigirlo hacia nuevos significados y emociones (Siebers, 2002).

Las obras quebradas o deterioradas son capaces de inspirar nuevas visiones de subjetividad, visiones más sintonizadas que las imaginadas por las formas de arte tradicionales acerca de la vulnerabilidad y la diversidad de los seres humanos (Siebers, 2002). En este tipo de arte, surge la visión de un tipo diferente de estética, que afecta a las emociones y sensibilidades de las personas que experimentan esa obra. 


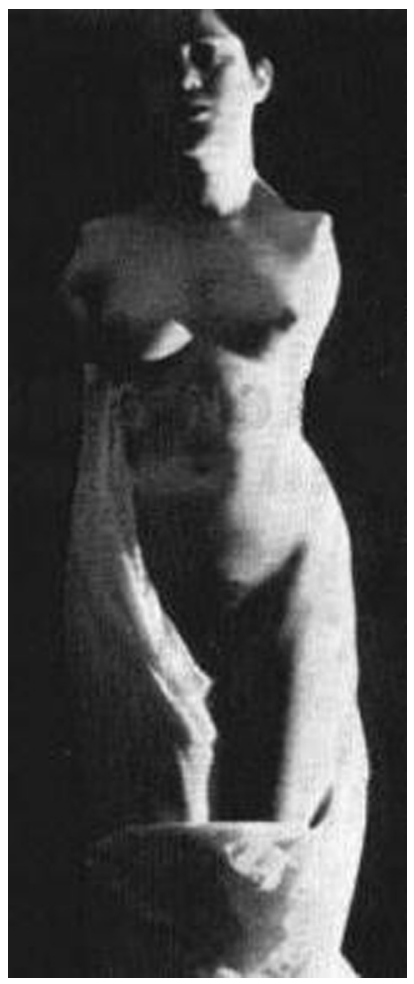

FOTO: Artista Mary Duffy, performance «Venus of Milo», http://quod.lib.umich.edu/m/mqrimage/ x-02206-UND-04/02206_04

Las obras mismas, están sujetas a un deterioro más parecido al ciclo de vida humano que a la existencia glaciar de piezas de museo y, evocan, como resultado, las formas de verdad y de belleza (Siebers, 2002). No se trata, por tanto, de hacer ver como estético, como bello, el cuerpo clasificado como discapacitado, sino de hacer ver ese cuerpo como posibilidad, cambiando la forma en la que se perciben sus formas, cambiando no sólo la forma en la que se perciben las obras de arte, sino también la forma de producción estética del arte (Siebers, 2002).

\subsubsection{Tiempo}

La relación de estos cuerpos con el tiempo, también altera el espacio y el sentido de este. La relación del cuerpo con su estado, el espacio y las maniobras adaptativas para posibilitar su habitar, dan lugar a ritmos diferentes de estos cuerpos por el espacio. El uso del tiempo para conservar la energía y 
minimizar el dolor y el desgaste corporal, da lugar a disposiciones diferentes del tiempo y el espacio. Un ejemplo de las negociaciones entre el tiempo y el dolor, es la pieza de baile «Still/Here» del artista Bili T. Jones. En esta pieza, el artista muestra la experiencia de enfrentar la propia mortalidad y el uso del tiempo y el espacio por personas con enfermedad terminal. Actualmente, la compañía Back to Back, con su performance «Lady eats Apple», indaga la relación entre el tiempo y la fragilidad, el espacio de tiempo entre vivir y morir. Esta compañía profundiza en lo simbólico y colapsa el espacio entre lo épico y lo cotidiano.

Pero además, los ritmos de estos cuerpos son diferentes a los marcados normativamente y, dado que estos cuerpos son disciplinados en el tiempo y en el espacio para alcanzar las normas sociales, resulta que las vivencias con el tiempo también expresan una relación diferente con el cuerpo y el espacio. Un ejemplo de ello, es la relación que Eli Clare expresa en su poema «Pesadilla»: «I practiced the sounds TH' 'SH' and 'SL' for years, a pianist playing endless hours of scales, I had to learn the muscle of my tongue». Este es un ejemplo, de como estos cuerpos son sometidos a la norma médico-capacitista, modificando la relación del tiempo y el espacio desde lo normativo. Pero también, dicha experiencia puede tener un componente subversivo al experimentarse y romper con los ritmos normativos impuestos por tal representación.

\subsubsection{Desrepresentaciones actuales}

Como dice Riva Lehrer, son estos cuerpos los que deben gestionar su propia representación, mediante su experiencia corporal subjetiva, pues estos artistas deben tener control sobre su propia representación, ya que estas personas han sido objetivizadas por muchos medios de representación: espectáculos, libros de medicina, publicidad, etc. Su objetivo como artista es crear un contexto para que las visiones de estos otros cuerpos se sitúen en medio de un despliegue sin fin de la posibilidad (Sandahl, 2005). En nuestro entorno más cercano, otro ejemplo de ello es el colectivo La rara trope, que, mediante la creación audiovisual, busca la autorepresentación y la narración en primera persona de los cuerpos que han sido clasificados como «locos». En la muestra «Apuntes para una psiquiatría destructiva», junto con otros grupos de trabajo, exponen narraciones del día a día de estos cuerpos, haciendo una crítica a la representación mediante las imágenes mainstream de la locura. 
No obstante, es interesante finalizar con dos amplios proyectos que esperan ser el comienzo de la desrepresentación de la norma orgánico-funcional en estos cuerpos y desde el entorno más cercano, el europeo, encontramos Kroppsfunktion y Una Mirada Diferente.

Kroppsfunktion, es un proyecto noruego que lleva en marcha desde 2015, dando lugar a dos festivales y un libro en el que se han recogido las experiencias de este proyecto ${ }^{3}$. Mediante la coreografía, generan lenguajes entre los cuerpos para hablar de diferentes maneras. Especializados en la danza, pero también escribiendo textos, con música y cine, indagan en las relaciones entre lenguaje, movimientos, espacio y cuerpos fuera de la norma orgánica y funcional.

Una Mirada Diferente, es un proyecto que lleva realizándose desde el año 2013 en Madrid (España). Este proyecto, mediante las artes escénicas, pone en valor los cuerpos con diversidad funcional, realizando talleres y obras que desmontan las categorizaciones sobre lo sano y lo capaz. Desde sus inicios, realizan un festival al año entre los meses de mayo y junio, que presenta obras de teatro, performance, danza, etc., con diversidad de cuerpos que habitan los espacios artísticos y desmontan estas categorizaciones, a partir de la multidimensionalidad de lenguajes, el apoyo de dispositivos, la modificación de los ritmos y el humor para reírse de la norma simétrica ${ }^{4}$.

\subsection{Conclusiones}

Las ecologías culturales de las últimas tres décadas, impulsadas por un giro posthistórico de las artes, han desplazado la dimensión estética, provocando una apertura de medios y desdibujando la línea divisoria entre autor/ obra y autor/espectador. Pero si bien algo define al arte contemporáneo, es la emergencia de la textualidad y la crítica a la representación. Las prácticas artísticas han hecho colisionar los significados simbólicos de términos culturales, mostrando el carácter construido y no natural de los mismos. Imágenes, lenguajes o definiciones que a su vez construyen representaciones, se han visto cuestionados por un arte que ha manejado dichas construcciones, pero que en esta época, se convierte en potencia cultural para desestabilizar las convenciones establecidas de la representación.

3 Proyecto Kroppsfunktion www.croppsfunktion.org

4 Un ejemplo de ello, es un vídeo promocional del festival del año 2016 :

http://cdn.mcu.es/espectaculo/una-mirada-diferente-2015-2016/ 
Es precisamente el arte el que, con su capacidad de ficcionar, genera interferencias a la representación de la norma orgánica y funcional. Categorías como la salud o la capacidad, que se enlazan a un componente material para considerarse naturales, han sido desveladas en su arbitrariedad social y cultural. Así, el arte también ha mostrado dicho desmontaje y, los cuerpos, presencia encarnada de la propia experiencia, han aparecido en escena para transgredir dicha normalidad.

Los cuerpos, con sus condiciones diversas, son los que habitan los espacios y cuyas experiencias suponen desmantelamientos de las categorizaciones de salud/deficiencia y capacidad/discapacidad. Estos cuerpos, en los espacios artísticos, dan lugar a una apertura que desordena las configuraciones normativas y plantea nuevas posibilidades de generación. Los lenguajes que provocan una multidireccionalidad de canales y de comunicación, los dispositivos con los que se amplían las perspectivas y se producen variedad de movimientos, la asimetría de cuerpos y espacios que ponen en valor lo quebrado o fracturado como componentes de lo estético y funcional o la diferencialidad de ritmos que muestran la variedad de relaciones espacio-tiempo y la rigidez de la adscripción a la norma social son elementos que provocan una descodificación de la norma orgánico-funcional en los espacios y la posibilidad de reconfiguración de los mismos.

En este texto, siguiendo las aportaciones de Sandahl (2002), se han querido mostrar algunas acciones artísticas crip que, mediante la crítica a la norma orgánica y funcional y valiéndose de la experiencia encarnada, generan nuevas configuraciones del espacio. Se ha tratado, por tanto, de mostrar algunos proyectos artísticos que tienen lugar en distintas partes del mundo, y que se generan por las experiencias de cuerpos que no se ajustan a la norma orgánicofuncional o que, pese a ajustarse corporalmente a la misma, se aventuran en experienciar relaciones diferentes de su cuerpo con el espacio. Por tanto, se ha tratado de mostrar la mayor diversidad en cuanto a condiciones corporales y zonas geográficas en las que estas prácticas artísticas tienen lugar.

No obstante, y tratando de localizar y perfilar los siguientes pasos de este arte deconstructivo, se ha prestado finalmente atención a la desrepresentación de la norma que promueven los proyectos Kroppsfunktion y Una Mirada Diferente. Desde el contexto europeo, estos proyectos presentan similitudes en cuanto a la subversión de la norma de la salud y la capacidad y plantean nuevos terrenos en los que seguir trabajando desde las artes escénicas y, en los que esperamos nuevos proyectos que incluyan más áreas artísticas con 
este mismo fin. Por ello, y dado que esta senda es escasamente transitada en Europa, queremos continuar profundizando en las posibilidades que generan estos proyectos y otros nuevos que puedan aparecer en el panorama artístico.

\subsection{Bibliografía}

ABBOTT, S. (2010). Resistant Bodies: Claims to Liberation and Desire at the Intersections of Crip and Queer. (Tesis inédita), Wesleyan University.

CRIMP, D. (2001). Imágenes. En: Wallis, B. (Ed.) (2001): Arte después de la modernidad. Nuevos planteamientos en torno a la representación. Madrid: Akal. 175188.

DANTO, A. C. (2012). Después del fin del arte. El arte contemporáneo y el linde de la historia. Barcelona: Paidós

FOSTER, H. (2001). Asunto Post. En: Wallis, B. (Ed.) (2001): Arte después de la modernidad. Nuevos planteamientos en torno a la representación. Madrid: Akal. 189-202.

GARCÍA CANCLINI, N. (2010). La sociedad sin relato. Antropología y estética de la inminencia. Buenos Aires: Katz.

GARLAN-TOMSHON, R. (2000): «Staring back: Self-representations of disabled performance artists.» American Quarterly, 52(2), 334-338.

Grupo autónomo a.f.r.i.k.a., Luther Blisset y Sonja Brünzels, (2000). Manual de Guerrilla de la Comunicación. Barcelona: Virus.

HERRERO, A. (2015). Ver la poesía. Alicante: Agua Clara.

LADDAGA, R. (2010). Estética de la emergencia. Buenos Aires: Adriana Hidalgo Editora

LIPPARD, L. R. (2001). Caballos de troya. Arte activista y poder. En: Wallis, B. (Ed.) (2001): Arte después de la modernidad. Nuevos planteamientos en torno a la representación. Madrid: Akal. 343-362.

MCRUER, R. (2006). Crip Theory: Cultural signs of Queerness and Disability. New York: New York University Press.

OLIVER, M. (1998). Una sociología de la discapacidad o una sociología discapacitada. En: Barton, L. (Coord.), (1998). Discapacidad y sociedad. Madrid: Ediciones Morata, 34-58.

PALACIOS, A. (2008). El modelo social de discapacidad: orígenes, caracterización y plasmación en la Convención Internacional sobre los Derechos de las Personas con Discapacidad. Madrid: CERMI.

RANCIÈRE, J. 2004. The Politics of Aesthetics: The Distribution of the Sensible. Nueva York: Continuum.

RANCIÈRE, J. (2010). El espectador emancipado. Castellón: Ellago.

RODRIGUEZ, S. Y FERREIRA, M. A. (2010). «Diversidad funcional: Sobre lo normal y lo patológico en torno a la condición social de la discapacidad» Cuadernos de Relaciones Laborales, núm. 1, vol. 28, 151-172. 
SAMPEDRO, M. A. (2012, enero). La poesía en lengua de signos. Una introducción. En: III Congreso Estatal de Lengua de Signos Española.

SANDAHL, C. (2002). «Considering Disability: Disability Phenomenology's Role in Revolutionizing Theatrical Space» Journal of Dramatic Theory and Criticism. 16.2: $17-32$.

SANDAHL, C. (2005). «From the Streets to the Stage: Disability and the Performing Arts» PMLA: 620-624.

SIEBERS, T. (2002). «Broken Beauty: Disability and Art Vandalism.» Michigan Quarterly Review, Vol. XLI, 2. URL: http://hdl.handle.net/2027/spo.act2080.0041.206

SIEBERS, T. 2006. «Disability Aesthetics» Journal for Cultural and Religious Theory $7,2.63-72$.

TOBOSO, M. Y GUZMÁN, F. (2009, noviembre). Diversidad funcional: Hacia la deconstrucción del cuerpo socialmente normativo. En: simposio: «Cultura, cuerpo género. Incorporar la desigualdad», Congreso SIEG 2009.

TOBOSO, M. Y GUZMÁN, F. (2010). «Cuerpos, capacidades, exigencias funcionales... y otros lechos de Procusto.» Política y Sociedad, 47(1), 67-83.

WALLIS, B. (2001). ¿Qué falla en esta imagen? Una introducción. En: Wallis, B. (Ed.) (2001): Arte después de la modernidad. Nuevos planteamientos en torno a la representación. Madrid: Akal. 9-15.

YOUNG, I. M. (2000). La justicia y la política de la diferencia. Madrid: Cátedra. 


\title{
DINÁMICAS Y POSICIONES SOCIALES TRAS LA RADICALIZACIÓN ISLAMISTA: UNA APROXIMACIÓN A LOS CASOS ESPAÑOLES DESDE LES JEUNES DES CITES
}

\author{
Aguerri, Jesús C. \\ Universidad de Zaragoza \\ Doctorando en Sociología de las Políticas Públicas y Sociales \\ jcarrerasaguerri@gmail.com \\ Delgado, Lionel $S$. \\ Universidad de Zaragoza \\ Master en Sociología de las Políticas Públicas y Sociales \\ lio.delgado.ontivero@hotmail.com
}

Como afirma el sociólogo francés Gerard Mauger (2016), en los último años, la prensa francesa ha focalizado sobre un colectivo al que ha denominado les jeunes des cites, todos los problemas que preocupan a los políticos y a la opinión pública francés. Estos jóvenes de clase baja, generalmente de ascendencia inmigrante, y residentes en la periferia de las metrópolis francesas se han convertido en los sospechosos habituales cuando se habla de delincuencia y de radicalización islamista.

Los recientes atentados ocurridos en suelo europeo han reavivado el interés político y mediático por este colectivo. Las sospechas que han recaído sobre ellos han contribuido a estigmatizarlos y a separarlos todavía más de la sociedad francesa. Sin embargo, este fenómeno no es ni mucho menos reciente, como nos recuerdan casos de la década de los 90, como el de Khaled Kelkal. Khaled fue joven argelino cuyos atentados cometidos en el verano del 1995 horrorizaron a Francia, pero cuya trayectoria vital y palabras, recogidas por el sociólogo Dielmar Loch tres años antes de los atentados, avergonzaron a parte de la sociedad francesa (Cano, 2015).

Aunque se circunscriben a la realidad francesa, el trabajo de Mauger y el análisis realizado por Cano del caso Khaled Kelkal permiten ligar teóricamente la radicalización islamista con una serie de dinámicas sociales y de posiciones sociales influidas especialmente por dichas dinámicas. Si bien en España no existe una figura homologa a los jeunes des cites, al igual que tampoco ha habido atentados de carácter yihadista en los últimos años, sí que hemos visto 
un gran número de operaciones policiales destinadas a detener a ciudadanos residentes en España por realizar actividades relacionadas con el terrorismo yihadista. Entre junio de 2013 y mayo de 2016, más de 120 personas fueron detenidas en España por actividades relacionadas con el Estado Islámico. En torno al $50 \%$ de los detenidos habían vivido durante toda su vida en nuestro país, y nueve de cada diez se han radicalizado durante su residencia en España (Reinares \& García-Calvo, 2016).

En consecuencia, no podemos afirmar que España se encuentre al margen de lo que se ha denominado «radicalización islamista». El caso del Estado Español es significativamente distinto al francés, pero el esquema analítico desarrollado por Mauger y las conclusiones de Cano sobre el caso de Khaled Kelkal, nos dotan de una referencia a la hora de interpretar los datos estadísticos de los que disponemos sobre radicalización islamista en España. Por lo que buscamos extraer de los análisis de la sociedad francesa realizados por los sociólogos mencionados un esquema teórico que nos permita contextualizar los datos de los que disponemos sobre el caso español

Gérard Mauger (2016) señala cómo sobre una pequeña fracción de lo que los medios de comunicación franceses denominan «les jeunnes de cités» recaen la mayoría de los problemas sociales que preocupan a los políticos, medios y científicos franceses. Las sospechas de radicalización islamista, de conductas delictivas y de la participación en disturbios ha convertido a una fracción minoritaria de los jóvenes franceses de clase popular, a menudo de origen o ascendencia inmigrante y relegados en las «Zones Urbaines Sensibles» (2016, p. 39), en la encarnación contemporánea de aquellas clases peligrosas que ya preocupaban a los padres del Estado Inglés en el siglo XIX (Corrigan \& Sayer, 1985).

Este grupo social heterogéneo que ha venido a denominarse en la sociedad francesa «jeunes de cités» es, como afirma Mauger, el producto de una crisis de reproducción de las clases populares que se inició en la segunda mitad de la década de los setenta. Este grupo sobre el que recae la sospecha de ser el nicho de la «radicalización islamista» es, por tanto, la consecuencia de fenómenos sociales más amplios como: «la desindustrialización, el paro, la precarización del empleo obrero, la terciarización de los empleos sin cualificación, la transformación del espacio residencial, la masificación del sistema escolar y los cambios en los marcos de referencia de los jóvenes de clase popular» (Mauger, 2016, p. 40). 
Diferentes dinámicas sociales han transformado de forma notable nuestras sociedades durante las últimas décadas. Ya desde los 90 se habla de crisis de las identidades y de crisis de las ideologías (Dubar, 2002). Profundos cambios en la economía han traído una nueva forma de organizar la producción y han provocado la dualizaciónn, precarización y terciarización de los mercados de trabajo (Wacquant, 2001). Además, los Estados se han ido sumando progresivamente a unas políticas de retroceso en lo social, pero de expansión en lo penal, un proyecto político que se ha denominado neoliberalismo (2012). El resultado de estas dinámicas ha sido que las regiones dominadas del espacio social han quedado fragmentadas, tanto de forma objetiva como subjetiva, y simbólicamente estigmatizadas (Pereira, Slater, \& Wacquant, 2014). Alejadas, por tanto, de los discursos emancipa torios del siglo XX, lo que nos permite hablar de una «crisis de identidad en las regiones dominadas el espacio social» (Aguerri, La artículación de la cuestión social en el espacio social contemporaneo: heterogeniedad, crisis y dominación, 2017).

A pesar de que España ha seguido un desarrollo particular, no ha sido impermeable a los efectos de estos fenómenos. Además, la crisis económica de 2008 ha permitiendo que se intensifique la influencia de estas grandes dinámicas en nuestro país, de modo que el espacio social se ha configurado de forma similar a otros países europeos (Aguerri, 2016). Sin embargo, no podemos extrapolar directamente las investigaciones de Mauger o el caso de Khalel Khal al contexto español. Pero sí que debemos tener en cuenta estos trabajos para ser conscientes de que los procesos de «radicalización islamista», deben inscribirse en ciertas disposiciones y dinámicas del espacio social en el que tienen lugar.

Si bien, el peso que se le da a las estructuras objetivas es variable, bastantes estudios coinciden en señalar que las estructuras sociales en las que se ven inmersos los agentes tienen un peso importante a la hora de abordar la radicalización islamista. Autoras como Brenan-Galvin (2002) señalan como los entornos urbanos del mundo globalizado en el que vivimos crean unas condiciones de frustración, humillación y desligazón con el sistema político que fomentan la radicalización y la violencia. En la misma línea, encontramos a Horgan, que habla de vulnerabilidades (vulnerabilities) como factores que hacen a ciertos individuos más proclives a la radicalización y que pueden estar estructuralmente condicionados (2005, p. 101). En España también encontramos autores que, reconocen la relación entre estructuras sociales y radicalización, como Jordan (2009) o de la Corte $(2005 ; 2007)$. 
Por tanto, la presente comunicación propone relacionar las conclusiones obtenidas por estos sociólogos con los datos sociodemográficos recabados por el Instituto Elcano sobre los detenidos en España por actividades relacionadas con el Estado Islámico en los últimos años. El resultado de esta tarea nos permite observar que en España, al igual que en Francia, la radicalización islamista es un fenómeno que envuelve mayoritariamente a jóvenes nacionales, residentes en áreas urbanas, con trayectorias vitales marcadas por la precariedad económica y los encontronazos con el sistema penal.

\subsection{Les jeunes des cites y la radicalización islamista}

Basándose principalmente en sus propias encuestas, el sociólogo francés Gerard Mauger (2016) analiza la génesis de la actual «culture de rue», cuyos orígenes sitúa en la crisis de reproducción de las clases populares que se inició en Francia en la segunda mitad de la década de los setenta.

Mauger describe cómo el fracaso escolar, condicionado principalmente por proceder de hogares con bajo capital cultural, lleva a «les jeunes des cites» a abrazar la «culture de rue» como vehículo para alcanzar un reconocimiento que compense la estigmatización y frustración producidos por el fracaso contante en el sistema escolar. El abandono del sistema escolar, al término del ciclo obligatorio o antes, y la inmersión en el grupo de pares deja a estos jóvenes en una difícil situación. Ya que solo disponen de una fuerza física obsoleta y de un título escolar desvalorizado para lograr un empleo. A esta cuestión se le une que sus prácticas culturales idealizan valores como la fuerza física o la insubordinación, ligados a una virilidad heredada del proletariado industrial que desentona con los requerimientos de los empleos subalternos del sector servicios.

Esta falta de horizontes en la economía legal, unida a una cultura que se erige como oposición y rechazo de aquello por los que sus miembros se sienten rechazados, propician la aparición de conductas delictivas. A través de ciertas prácticas y conductas, estos jóvenes se invisten de un «capital agnostique», una suerte de capital basado en la tendencia a la revuelta y a la combatividad, que se valora dentro de la «culture de rue». (2016, p. 50). 
En sus investigaciones posteriores a los disturbios de noviembre de $2005^{1}$, Mauger (2011) registra cómo se va tornando dominante entre estos jóvenes una visión "ethnicisée» ${ }^{2}$ del mundo social, que hace de la dimensión étnica la causa única de su condición dominada. Sin negar la existencia de cierta discriminación étnica en la sociedad francesa, Mauger (2016, p. 50), apoyándose en Brinbaum y en Kieffer (2005), afirma que no se pueden achacar exclusivamente a ella los fracasos escolares y profesionales. Estos fracasos están, sobre todo, determinados por las dinámicas de reproducción y herencia del capital cultural, que afectan tanto a los hijos de inmigrantes como a los que no lo son.

En este contexto, los imanes pueden encontrar en estas «cités» abandonadas por todos una tierra de misión en la que la religión aparece como el último recurso simbólico disponible para unos jóvenes escolar y profesionalmente descalificados $^{3}$ (Mauger, 2016, p. 50) La crisis de identidad a la que hacíamos referencia en apartados anteriores, unida al retroceso del discurso obrero y de sus organizaciones, facilitan una creciente «vuelta a los orígenes» por parte de los migrantes y de sus descendientes, una resignifiación propia a partir de su condición de inmigrantes. Esto abre una demanda de prácticas, actividades y discursos que se complementa con una oferta plural de discursos y prácticas religiosas. Esta diversidad en la oferta es posible gracias a la naturaleza no institucionalizada del Islam, que permite autonomía en la prácticas y competencias religiosas.

De este modo, se configura un campo religioso en el que se pugna por la definición legítima del Islam, pero en el que también están en juego opor-

1 Tras la muerte de un joven a manos de la policía se produjeron en varias ciudades francesas numerosos disturbios que se caracterizaron por la quema de automóviles y por los enfrentamientos entre policías y jóvenes locales. Si bien, no fue el primer hecho de este tipo, sí que fue el que más relevancia mediática obtuvo, dada su intensidad.

2 Ethnicisée es el participio pasado del verbo francés etthniciser, definido por el diccionario Larousse como «definir cualquier cosa desde un punto de vista étnico» (traducción propia a partir de la definición original en francés, disponible aquí: http://www.larousse.fr/ dictionnaires/francais/ethniciser/186361). Al carecer de este verbo en castellano hemos optado por mantener la forma verbal en el idioma original.

3 Traducción propia a partir de disqualifié, participio del verbo francés disqualifier. Este verbo se puede traducir al castellano como descalificar, pero es sinónimo de los verbos franceses déshonorer y discréditer (http://www.larousse.fr/dictionnaires/francais/disqualifier/25978), que se traducen como deshonrar y desacreditar, respectivamente. En castellano el verbo descalificar también tiene el doble sentido de «desacreditar, desautorizar o incapacitar a alguien o algo» y de «eliminar a alguien de una competición [...]» (http://dle.rae.es/?id=Cb0Fp9S). Debe notarse, por tanto, el juego que se realiza con ambas acepciones del verbo, entendiéndolo fundamentalmente según su acepción de desacreditar, desautorizar o incapacitar. 
tunidades simbólicas, sociales y económicas. Mauger señala que podemos encontrar dos polos en esta oferta del Islam. Por una parte, tenemos a los sectores más establecidos, que gozan de una legitimidad tradicional y de cierta erudición religiosa; $y$, por otra parte, tenemos a nuevos entrantes, que se caracterizan por la «ortopraxis». A su vez, estos discursos son objeto de apropiación $\mathrm{y}$ reinterpretación por parte de «les jeunes des cites». Esto da lugar a una gran diversidad de vivencias del Islam entre las que se encuentran las interpretaciones radical-yihadistas. A su vez, éstas también se diferencian entre sí a nivel individual, pero Mauger distingue dos «cas de figure» ${ }^{4}$.

En primer lugar, tendríamos a los intelectuales de nueva generación para los cuales el Islam ofrece una redención moral, se articula para ellos como una buena conducta que les otorga una recualificación que palía la relegación académica. Es una estrategia de revalorización simbólica que les lleva a abrazar la ortopraxis, ya que ésta es más visible y más accesible que la ortodoxia religiosa (que requiere cierta erudición). En segundo lugar, Mauger describe a los jóvenes que saltan del universo de las bandas -y de la delincuencia más o menos profesional- al yihadismo radical. Este discurso basado en cierta interpretación de la yihad, apela a la movilización de propiedades guerreras asociadas a los creyentes y ofrece una interpretación simplista del mundo social, que descansa sobre la oposición entre infieles y creyentes. Es fácil apreciar cómo este discurso encaja dentro de los valores de «la culture da rue» y con las exigencias del «capital agnostique», permitiendo, además, convertir los elementos estigmatizadores en rasgos valorizados y en signos de la elección divina.

A unas conclusiones similares a las de Mauger, llega Miguel Ángel Cano (2015) apoyándose en la entrevista que el sociólogo alemán Dielmar Loch le realizó en 1992 a Khaled Kelkal, un joven francés de ascendencia argelina que el 29 de septiembre de 1995 fue abatido por la policía tras atribuírsele diferentes atentados cometidos por el GIA ese mismo año ${ }^{5}$ Kelkal fue entrevistado cuando tenía 21 años en el marco de una investigación sobre los jóvenes de las Banlieues francesas que Loch estaba llevando a cabo. Durante la entrevista Kelkal habla, entre otras cosas, de sus vivencias en Vaulx en Velin -un suburbio de la ciudad de Lyon-, de su etapa escolar, de su redescubrimiento del Islam en prisión, y de la falta de oportunidades y futuro en Francia. Toda su

4 Expresión francesa que se traduciría como "casos posibles" o "casos tipo"

5 El 7 de octubre de 1995 el diario francés Le Monde publicó la entrevista que Loch le había realizado a Kelkal. A ésta le acompañaba un titular cuya traducción reza: «Khaled Kelkal, víctima del racismo cotidiano». (Cano, 2015, p. 8) 
narrativa está marcada por un sentimiento de no encajar en la sociedad francesa, por la experimentación constante de la exclusión y el rechazo por parte de los franceses blancos ajenos a su barrio. El impacto de estas vivencias se ve claramente cuando Kelkal narra su trayectoria escolar.

Como alumno con buenas notas en su etapa en el collège, Kelkal pudo ir a instituto en Lyon, lo cual supuso salir de su barrio y comenzar a estudiar en clases en las que «solo estaban los ricos» $(2015$, p. 13) y en las que «los otros alumnos nunca habían visto en su clase a un chico árabe» (2015, p. 11). Los sentimientos de falta de pertenencia y la percepción de la discriminación y el rechazo le llevarán a perder la motivación. Por lo que comenzó a dejar de lado los estudios. Durante esta fase de su vida comenzó a acercarse a la pequeña delincuencia, lo que lo acabó llevando a cumplir una pequeña condena en prisión. Allí, gracias a un compañero de celda, aprendió árabe y profundizó en su interés por el Islam.

La entrevista realizada por Loch se celebra cuando Kelkal ya ha salido de prisión y está buscando un empleo. El testimonio del joven da cuenta de la naturaleza precaria del trabajo al que puede acceder y de la falta de perspectivas de futuro a las que se enfrenta. Sus palabras hacen referencia a cómo su condición de expresidiario (2015, p. 22) y de residente de una Banlieue (2015, p. 21) le dificultan la obtención de un buen empleo. Estos percepciones, lejos de tener un carácter meramente subjetivo, corroboran la existencia de estigmas que recaen sobre aquellos que han pasado por prisión y sobre los residentes de determinadas zonas urbanas ${ }^{6}$

También es reseñable cómo Kelkal rechaza a la Mission Locale ${ }^{7}$, por considerar que no les importaba lo que él quisiera hacer con su vida, ni en qué ámbito profesional deseara trabajar, ofreciéndole solo la realización de prácticas en campos ajenos a sus estudios (Cano, 2015, p. 17). De esto modo, la Mission Locale se convierte en la tercera institución pública -sumándose al sistema escolar y al de justicia- mencionada por Kelkal que no cumplió su función y que, de hecho, contribuyo a alejarlo más de la sociedad francesa.

6 Estas realidades han sido ampliamente documentadas por Loïc Wacquant y por los demás miembros de la Leverhulme Urban Advanced Marginality Network

7 La Mission Locale es el servicio estatal de oficinas públicas encargadas de la integración social y laboral de los jóvenes. 
Ya hemos mencionado cómo el sistema escolar le hizo sentirse excluido, lo que lo acabo llevando a apartarse de él, pero solo hemos mencionado de pasada el sistema de justicia francés. Debemos retomar este punto porque la administración de justicia francesa es la tercera institución pública que marcó la vida de Khaled Kelkal. Como ya hemos mencionado, su paso por la cárcel hizo recaer sobre él un estigma que dificultó su reincorporación al mundo del trabajo. Pero la cárcel no solo contribuyo a privarle de un trabajo de cara a futuro, sino que además le hizo perder el que tenía entes de entrar en ella. Kelkal narra cómo, dado que pasó cierto tiempo -no se menciona exactamente cuánto- entre su detención y su entrada definitiva en prisión ${ }^{8}$, aprovechó este impasse para buscar y encontrar un trabajo:

Yo tenía un puesto muy bueno. Lo único que yo quería era: trabajar, dar una parte a mis padres, guardar algo de dinero para después, ahorrar dinero, casarme, tener niños, tener una vida como los demás. La vida, ¿qué es entonces? La vida es tener retoños, criar niños. Eso es la vida. (Cano, 2015, p. 17)

Paradójicamente, la descripción de su estancia en prisión es bastante positiva, en tanto que afirma que aprovechó para aprender árabe y que también aprendió mucho sobre la vida en grupo y sobre el Islam. Pero, estas consideraciones sobre su encarcelamiento como periodo vital no impiden que tenga una imagen negativa del sistema de justicia francés. Dado que consideraba que éste aplica criterios racistas en su funcionamiento, lo cual viene a reforzar su sentimiento de exclusión y de no pertenencia a la sociedad francesa. Como afirma durante la entrevista:

Yo no tengo ningún tipo de derechos. Si estando yo en la calle alguien me ataca y yo me defiendo, en ese caso el otro está en su derecho y yo no. Eso está claro. Y ello simplemente porque yo ya he estado en la cárcel. Incluso en el caso de una banda de skins, si ellos me atacan y yo actúo en legítima defensa -en ese caso soy yo el que va a la cárcel (Cano, 2015, p. 23).

Con respecto a la relación de Kelkal con el Islam, debemos señalar que la entrevista se realiza antes de que el joven se integre en el GIA y que relación con el islam no permite apreciar ningún tipo de tendencia a la violencia, como ilustran muy bien estas palabras del propio Kelkal:

8 A este lapso de tiempo contribuyó tanto que la primera sentencia tardo en dictarse, como que fue recurrida, por lo que se debió dictar una segunda 
[...] he vivido un gran enriquecimiento del espiritu al haber conocido el Islam. Todo se ha abierto. Y yo ahora no veo la vida ... más fácil, pero sí más coherente. Cuando ahora veo en la televisión algunas cosas ya no reacciono más como lo hacía antes. Antes, cuando veía algo así, entonces quería devolver el golpe. Pero la violencia, eso ya no entra en consideración. Ahora tengo compasión de esa gente (Cano, 2015, p. 12).

El caso de Kelkal ilustra como la «re-islamización» se manifiesta para los jóvenes de la Banlieues francesas como una oportunidad de redención -generalmente tras pasados delictivos-y de recomposición identitaria y contestataria (2015, p. 26). Su interpretación del Islam los vincula a una comunidad, la umma, que transciende las nacionalidades -Kelkal, por ejemplo, afirma sentirse musulmán, y no francés ni árabe- les dota de un proyecto personal y político; y, como señalaba Mauger (2016), les permite llevar a cabo una estrategia de revalorización simbólica. Esta estrategia hace que puedan racionalizar los rasgos estigmatizadores que los relegan socialmente y resignificarlos en un sentido positivo.

\subsection{El yihadismo vinculado al Estado Islámico en España: Rasgos sociodemográficos}

Los contextos español y francés son notablemente distintos, no solo debido a las diferencias temporales de las transformaciones económicas descritas previamente, sino que debemos recordar que los procesos de descolonización de los territorios africanos de ambos estados presentan diferencias sustanciales. Así mismo, el fenómeno migratorio se ha vivido en momentos distintos $\mathrm{y}$ ha sido enfocado de formas dispares. Pero, siendo conscientes de estas diferencias, el análisis realizado por Mauger nos ofrece un marco de referencia con el que comprar los datos de los que disponemos sobre yihadismo salafista en España.

Los datos con los que trabajaremos a continuación han sido recogidos por Reinares y Garcia-Calvo (2016) en el Informe Estado Islámico en España, auspiciado por el Real Instituto Elcano. En el citado informe sus autores realizan un análisis exhaustivo de los casos referidos a individuos detenidos en España por actividades relacionadas con el Estado Islámico (EI), entre junio de 2013 y mayo de 2016. La explotación de estos datos les permite extraer información relevante sobre los procesos de radicalización islamista en nuestro país, y sobre las características sociodemográficas de los detenidos. 
Como veremos a continuación, los contextos y perfiles descritos por Mauger, muestran ciertas similitudes con las conclusiones a las que apuntan los datos analizados por Reinares y García-Calvo. Esta convergencia debe llevarnos a, al menos parcialmente, tener en cuenta la investigación y análisis realizados por Mauger.

En primer lugar, debemos apreciar que nos encontramos ante un fenómeno que envuelve a una población fundamentalmente joven. De los 124 casos registrados por los autores del Real instituto el Cano (2016), el 83,1\% de los detenidos eran hombres con una edad media de 31 años en el momento de la detención, el 63'1 \% de ellos tenía entre 20 y 34 años $(2016$, p. 21). Reinares y Garcia-Calvo solo disponen de información sobre la edad de inicio del proceso de radicalización de poca más de un cuarto de los individuos estudiados. Sin embargo, basándose en los casos en los que sí disponen información, sitúan entre los 15 y los 19 años el tramo de edad en el que se inician con mayor frecuencia los procesos de radicalización. Ambos datos, la preponderancia de hombres jóvenes entre los detenidos y la estimación del inicio de la radicalización en edades tempranas, nos permiten hablar de un proceso mayoritariamente vinculado a la juventud, lo que se presenta como el primer punto común entre el análisis realizado en Francia por Mauger (2016) y la realidad española.

El segundo punto en común con el análisis realizado con Mauger lo encontramos en el luegar de nacimiento y la nacionalidad de los sujetos. Entre 1996 y 2012, tan solo el 16,7\% de los detenidos en España por terrorismo yihadista, o muertos en un acto suicida, contaban con nacionalidad española, y solo el 4'8\% había nacido en España (Reinares \& García-Calvo, 2016, p. 24). Sin embargo, «prácticamente la mitad de los detenidos en España por actividades relacionadas con el EI desde 2013 [hasta mayo de 2016]- el 45,3\%tienen nacionalidad española» (2016, p. 24).

Además, 9 de cada 10 detenidos en España por vinculación con el EI residían en nuestro país. Desglosar a estos individuos según su procedencia arroja que: el $42,2 \%$ son hijos de inmigrantes (en torno al $80 \%$ de ellos nacidos en España y el resto llegados a Espala siendo niños), el 51,7\% son inmigrantes de «primera generación» y el 6'1\% son ciudadanos españoles sin antepasados inmigrantes. Si unimos a aquellos que -siendo hijos de inmigrantes- nacieron o han vivido casi toda su vida en España, con aquellos que no tienen ascendencia inmigrante, nos encontramos con que el $48,3 \%$ por cierto de los detenidos son personas que han vivido prácticamente toda su vida en 
el territorio del estado español, conformando el exponente de lo que se ha venido a denominar «yihadismo homegrown». Pero esta definición del yihadismo «de cosecha propia» no debe llevarnos a pensar que todo lo que queda fuera de este término se corresponde a procesos de radicalización que se dan fuera de nuestro país. Como documentan Reinares y García-Calvo, el 73,8\% de los detenidos se radicalizó dentro de territorio español. En consecuencia, podemos apreciar cómo, a pesar de las profundas diferencias en cuanto a los flujos migratorios, tanto en Francia como en España debemos hablar de un fenómeno con una importante dimensión interna.

En tercer lugar, resulta reseñable que «el $64,8 \%$ de los detenidos desde 2013 por actividades relacionadas con esa organización yihadista [EI] lo fueron en ciudades de entre 50.001 y 500.000 habitantes, lo que cuadruplica la distribución del total de la población residente en España para las localidades de entre 50.001 y 100.000 habitantes y la duplica en el caso de las ciudades de entre 100.001 y 500.000 habitantes» (2016, p. 26). Como vemos, este yihadismo vinculado al EI tiende a concentrarse en áreas urbanas de tamaño medio. Entre éstas destacan la ciudad de Ceuta, donde residían y fueron detenidos una quinta parte de los individuos que componen la muestra; y hasta once ciudades de la provincia de Barcelona, donde fue detenida y residía una cuarta parte de la muestra. Tras la provincia de Barcelona y la ciudad de Ceuta, se encuentra, aunque con un número de casos significativamente menor, la ciudad de Melilla y 6 localidades de la Comunidad de Madrid. Cabe destacar que «la distribución de los detenidos por la geografía española no se corresponde con la de la población musulmana» $(2016$, p. 27). En el caso de la provincia de Barcelona, los detenidos están 11 puntos porcentuales sobrerrepresentados respecto al porcentaje de población musulmana -o de ascendencia musulmanade la provincia, y en el caso de la ciudad de Ceuta la sobrerrepresentación es de 19 puntos (2016, p. 27).

En vista de los datos, podemos afirmar que el yihadismo radical en España, tiene un importante cariz urbano. Como observábamos al repasar el análisis de Mauger, «les jeunes de cites» es un grupo social propiamente francés vinculado a unos ambientes urbanos característicos, por lo que no sería posible hacer una extrapolación directa de estas categorías al contexto español. Sin embargo, que en ambos países la radicalización islamista sea un fenómeno urbano representa una nueva convergencia entre el trabajo de Mauger y la realidad española. 
En cuarto lugar, cabe destacar que la relación de estos sujetos con los campos jurídicos y religiosos también tiene lugar siguiendo unas coordenadas similares a las descritas por Mauger. Uno de los datos más significativos de los detenidos por actividades relacionadas con el EI en España es la importante cantidad de ellos que poseían antecedentes penales, la gran mayoría de ellos por delitos de delincuencia común, especialmente por tráfico de drogas. Reinares y Garcia-Calvo (2016) han podido confirmar que una quinta parte de los detenidos tenía antecedentes penales previos, pero se carece de información a este respecto en más de la mitad de los casos. Aun así, los autores estiman que hasta 4 de cada 10 detenidos tendrían antecedentes penales (2016, p. 33). A estos datos, que deban ser tomados con cautela por ser estimaciones, se les une que las instituciones penitenciarias aparecen como el lugar de radicalización del $6,7 \%$ de los casos documentados (2016, p. 40).

También resulta relevante mencionar que, según las estimaciones de los investigadores del Instituto Elcano, solo el 11\% de los miembros de su muestra tenían, en el momento de ser detenidos, conocimientos relevantes del Islam y de la sharía, frente al $89 \%$ restante que tenían una formación más bien elemental.

Mauger (2011) establecía un cierto continuum entre el universo de la delincuencia, más o menos profesional, y la radicalización islamista. Los datos de los que disponemos para España, parecen apuntar a que en nuestro contexto ambos campos no son mutuamente ajenos. Esto no implica necesariamente que haya una interrelación estructural entre ambos -aunque la radicalización en prisión sería un punto de unión, pero el porcentaje de estos casos es bajo- sino que cierta cantidad de individuos transitan ambos campos.

Con respecto a la inscripción en el campo religioso, Mauger señala cómo prima la ortopraxis frente a una ortodoxia que requerirá un mayor grado de erudición. La falta de conocimientos significativos sobre el credo religioso y su ley viene a corroborar que, pese a que la configuración del campo en España pueda ser diferente, estos individuos se inscriben en posiciones similares a las de sus homólogos franceses. Optando por una praxis religiosa rigorista, pero dejando de lado la adquisición de conocimientos teóricos significativos.

Por último, debemos aproximarnos a la posición social de los sujetos estudiados, para ello debemos recurrir a los datos relativos a la última ocupación conocida de 90 de los 124 casos con los que trabajan Reinares y García-Calvo. En primer lugar, cabe destacar que el 26,7\% de los individuos que componen 
la muestra estarían vinculados a la categoría profesional «personal de servicios». Los siguientes grupos más numerosos los componen aquellos que se encontraban en paro $(25.5 \%$ ) y aquellos que carecían de actividad económica $(16,6 \%)$. Presentan porcentajes menos significativos los autónomos $(7,8 \%)$, los estudiantes $(7,8 \%)$, los obreros especializados $(6,7 \%)$, los obreros no especializados $(5,6 \%)$, los empresarios con asalariados $(2,2 \%)$, y los profesionales y administrativos $(1,1 \%)$.

La reseñable mayoría compuesta por personal de servicios, parados y personas sin una ocupación económica conocida nos debe llevar a observar que estamos ante individuos que ocupan principalmente posiciones dominadas en el espacio social. A la posición económica le debemos sumar su condición de inmigrantes (de primera o segunda generación) y la juventud -generalmentede estos individuos. Podemos afirmar que estamos ante las regiones del espacio social más castigadas por fenómenos como: advenimiento de la economía post-fordista -en la que el trabajo se dualiza, precariza y terciariza- y la puesta en marcha del proyecto político neoliberal -en el que el Estado tiende a retirarse de sus funciones tradicionales en materia de asistencia social-.

\subsection{Conclusiones}

En vista de los datos que hemos aportado, debemos conlcuir que el terrorismo de corte yihadista ya no puede ser abordado como un fenómeno exclusivamente internacional, en el que individuos de unos países cometen atentados contra Estados con los que no tienen apenas vinculaciones directas. Estamos ante individuos que, tanto en el caso francés como en el español, se radicalizan en suelo legalmente europeo ${ }^{9}$ y que, al menos, residen en estados europeos. Estos hechos vienen a reforzar la tesis de que los procesos de radicalización deben ser estudiados atendiendo a la idiosincrasia económica y social del país $\mathrm{y}$, especialmente, a la actuación del estado.

Los datos aportados también nos permiten concluir que en España, al igual que en Francia, a radicalización islamista es un fenómeno que envuelve mayoritariamente a jóvenes que han vivido casi la totalidad de su vida en Europa, residentes en áreas urbanas, sin grandes conocimientos del Islam, y con

9 Se debe hacer la precisión «legalmente europeo», dado que decir suelo Europeo podría llevar a entender la frase en sentido geográfico, lo que excluiría a las ciudades autónomas de Ceuta y Melilla, dado que no forman parte, geográficamente, del continente Europa 
trayectorias vitales marcadas por la precariedad económica y los encontronazos con el sistema penal.

Como señala el esquema analítico de Mauger (2016), y como corrobora el caso de Khaled Kelkal expuesto por Cano (2015), en un contexto de precariedad y estigmatización, abrazar la interpretación del islam del yihadismo salafista se manifiesta para ciertos jóvenes de ascendencia inmigrante como una estrategia de revalorización simbólica. Esta interpretación del Islam aparece como la solución a la situación de anomia en la que se ven sumidos por la sociedad francesa. De este modo, la radicalización aparece como una toma de posición dentro de una región del espacio social ocupado por una población concreta.

Si bien, como ya hemos dicho, los contextos francés y español son notablemente distintos, es posible observar cómo, la precariedad laboral, el desempleo, y la intervención del Estado desde lo penal son factores que inciden sobre ciertos jóvenes. Estos elementos estaban presentes en la Francia de los noventa, como ilustra el caso de Khaled Kelkal (Cano, 2015), siguen presentes en la Francia contemporánea, como muestra el trabajo de Mauger (2016) y parecen no ser realidades ajenas a las personas juzgadas en los últimos años en España por actividades relacionadas con el Estado Islámico.

\subsection{Referencias}

AGUERRI, J. C. (2016). Marginaidad Urbana Avanzada en la España contemporánea. En J. Carreras, J.-D. Gómez-Quintero, \& C. Marcuello, Políticas Públicas y Sociales: Tiempos de ruptura y oportunidad (págs. 60-71). Zaragoza: Prensas Universitarias de la Universidad de Zaragoza.

AGUERRI, J. C. (2017). La artículación de la cuestión social en el espacio social contemporaneo: heterogeniedad, crisis y dominación. En C. Gimeno, III Jornadas Aragonesas de Sociología. Zaragoza: Prensas Universitarias.

BRENNAN-GALVIN, E. (2002). Crime and Violence in an Urbanizing World. Journal of International Affairs, 56(1), 123-145.

BRINBAUM, Y., \& KIEFFER, A. (2005). D'une génération à l'autre, les aspirations éducatives des familles immigrées: ambition et persévérance. Éducation et Formations(72), 53-75.

CANO, M. Á. (2015). El caso «Khaled Kelkal»: Una clave para entender la radicalización islamista en la Europa del año 2015. Revista Electrónica de Ciencia Penal y Criminología(17), 1-28.

CORRIGAN, P., \& SAYER, D. (1985). The Great Arch: English state formation as cultural revolution. Oxford: Basil Blackwell. 
DE LA CORTE, L. (2005). La lógica del terrorismo. Madrid: Alianza.

DE LA CORTE, L., \& JORDÁN, J. (2007). La yihad terrorista. Madrid: Síntesis.

DUBAR, C. (2002). La crisis de las identidades: la interpretación de una mutación. Barcelona: Bellaterrra.

HORGAN, J. (2005). The psychology of terrorism. London: Routledge.

JORDÁN, J. (2009). Procesos de radicalización yihadista en España. Análisis sociopolítico en tres niveles. Revista de Psicología Social, 2(24), 197-216.

MAUGER, G. (2011). Les raisons de la colère: sur l'émeute de novembre 2005. In S. Béroud, B. Gobille, A. Hajjat, \& M. Zancarini-Fournel, Engagements, rebellions et genre (1968-2005). Paris: Archives Contemporaines.

MAUGER, G. (2016). «Jeunes de cités». Délinquance, émeutes et radicalisation islamiste. Tempo Social, revista de sociología da USP, $28(2), 39-56$.

PEREIRA, V. B., SLATER, T., \& WACQUANT, L. (2014). Territorial Stigmatization in action. Environment and Planing A, 46.

PINTO, J. M. (1991). Considerações sobre a produção social da identidade. Revista Crítica de Ciencias Sociales(32), 217-231.

REINARES, F., \& GARCÍA-CALVO, C. (2016). Estado Islámico en España. Madrid: Real Instituto Elcano.

WACQUANT, L. (2001). Parias Urbanos. Buenos Aires: Manantial.

WACQUANT, L. (2012). Three Steps to a Historical Anthropology of Actually

Existing Neoliberalism. Social Anthropology(20), 69-90. 



\section{VIVIENDO BAJO LAAMENAZA Y EL MIEDO: DOS ESTUDIOS SOBRE EL CASO DE LA VIOLENCIA TERRORISTA EN EUSKADI}

\author{
Javier Martín-Peña \\ Universidad de Zaragoza \\ jmape@unizar.es \\ Pedro J. Ramos \\ Universidad de Zaragoza \\ pjramos@unizar.es
}

\author{
Alba Abella-Uyarra \\ Universidad Complutense de Madrid \\ alba.abella.uyarra@gmail.com \\ Manuel Vilariño \\ Universidad de Zaragoza \\ mvilarino@unizar.es
}

\subsection{Introducción}

Generalmente, cuando se piensa en el terrorismo o violencia terrorista es fácil tender a imaginar las formas de agresión física más explícitas (e.g., un atentado con bomba, un asesinato) y los efectos y daños en el corto plazo. Sin embargo, la violencia terrorista abarca también la amenaza futura de violencia, lo cual permite crear un clima de temor y miedo a la repetición de esas acciones (Schmid, 2011). Consecuentemente, cuando uno está amenazado por un individuo o por un grupo, (por ejemplo a través del anuncio explícito de amenaza del grupo terrorista, o a través de comportamientos tales como amenazas de muerte, intimidaciones, entre otras conductas) la situación amenazante tiende a inundar la vida de los individuos, además de impactar sobre el presente, el pasado y el futuro de la persona y su entorno.

Colectivos como los periodistas amenazados por el crimen organizado, el caso del caricaturista danés que fue amenazado desde que dibujó una caricatura de Mahoma, las amenazas y asesinatos contra la revista Charlie Hebdó en París, son ejemplos de cómo la violencia o una serie de actos de violencia están dirigidos a crear un efecto psicológico (es decir, miedo o terror sobre una audiencia más amplia que la víctima directa) además de unos potenciales daños físicos. Los efectos de estas situaciones a menudo implican un alto nivel de incertidumbre en la vida cotidiana de la persona amenazada, teniendo 
un impacto en el funcionamiento psicosocial de la misma y de su entorno, y favoreciendo también una extensión del miedo hacia la sociedad.

El caso que aborda este trabajo es el de la violencia terrorista en Euskadi, que estuvo activa hasta finales de 2011, cuando el grupo terrorista ETA (Euskadi ta Askatasuna) anunció el fin de sus acciones armadas. Este estudio analiza la experiencia de personas amenazadas en un contexto de violencia terrorista. Concretamente, se pretende comprender mejor el impacto sobre su funcionamiento psicosocial a partir de la situación experimentada como personas amenazadas. Para ello, se parte de participantes que fueron acosados y amenazados por el grupo terrorista ETA en el País Vasco o Euskadi (España). En segundo lugar, se pretende explorar el impacto psicosocial que ha supuesto durante los primeros ciclos vitales de la vida de una víctima indirecta el hecho de convivir diariamente con una persona amenazada por la banda terrorista ETA. Para ello, se parte de una entrevista en profundidad a una persona joven que vivió la amenaza como hija de un amenazado.

Desde un enfoque centrado en las víctimas, se pretende contribuir a visualizar cómo las acciones perpetradas por los victimarios resultaron en situaciones de amenaza y procesos psicosociales a través de los cuales se promovió el hostigamiento, el asesinato, y por ende, la exclusión. Considerando el contexto de post-violencia en Euskadi, el estudio puede contribuir con actuaciones que puedan enmarcarse en políticas de intervención sobre la memoria de lo sucedido, como el actual Memorial en proceso, o Museos de Memoria, recogidos en la Ley de Reconocimiento y Protección Integral a las Víctimas del Terrorismo.

Este trabajo describirá, en primer lugar, algunos aspectos básicos de la violencia terrorista. En segundo lugar, sobre el contexto de violencia y sus componentes. En tercer lugar, se presentará la metodología efectuada, y en cuarto lugar, los resultados. En quinto y último lugar, se presentarán las reflexiones finales y un esbozo de contribución inicial relacionado con políticas públicas para la memoria de las víctimas.

\subsection{La violencia terrorista: un fenómeno heterogéneo}

A pesar de la heterogeneidad que caracteriza a la violencia terrorista (y de ahí la dificultad para su delimitación precisa), uno de los aspectos que la caracterizan y la diferencian de otras formas de violencia es que implica el uso premeditado de la agresión sobre ciertos objetos o personas tratando de con- 
seguir un objetivo ejemplificador. Se busca que la agresión tenga efectos que excedan los daños sufridos por las víctimas directas, multiplicando su eficacia a través de la sensación de inseguridad, ansiedad, miedo o pánico, es decir, a través del terror que provoca (De la Corte, Sabucedo y Moreno, 2004). De este modo, Walter (1969) señala que el proceso de terror estaría compuesto por tres elementos básicos: 1) la acción o la amenaza de violencia; 2) la reacción emocional; 3) los efectos sociales. Las víctimas, receptoras de esas acciones de amenaza y violencia no suelen ser el último objetivo de la violencia, sino que junto con la victimización derivada son un instrumento que sirve como un amplificador para enviar un mensaje a una audiencia más amplia. De este modo, la amenaza de violencia, o el hecho de estar amenazado, es un elemento relevante como daño condicional para infundir miedo. Según Schmid (2011), las amenazas ganan credibilidad a partir de eventos violentos anteriores, y muchas personas pueden vivir con miedo a lesiones o incluso la muerte. La violencia perpetrada es una especie de «acto ejemplar», y es un instrumento para intimidar, impresionar o coaccionar a otras partes que están vinculadas, directa o indirectamente, a las víctimas o grupo objetivo. Los perpetradores dañan a sus víctimas para influir indirectamente en un objetivo final (e.g., el gobierno, los responsables políticos). En consecuencia, los grupos terroristas a menudo aterrorizan a un grupo objetivo como símbolo e instrumento para expandir inseguridad y miedo ante el público.

\subsection{La violencia terrorista de ETA en Euskadi}

En este sentido, el caso de la violencia de ETA en Euskadi en España ha sido relevante debido al número de personas que estaban bajo amenaza, al proceso de amedrentamiento en esta Comunidad contra quienes fueron considerados objetivos por parte de la banda terrorista, así como los heridos y personas asesinadas. De las 857 víctimas mortales, 576 corresponden a víctimas en Euskadi (Alonso, Domínguez y García, 2010). Así pues, este estudio no se centra en las víctimas del resto de España, sino en las víctimas de ETA en Euskadi, puesto que el fenómeno de la amenaza y el acoso aplicado por el entramado de ETA ha sido fundamentalmente perpetrado en Euskadi y también en Navarra.

Respecto a la organización terrorista, ETA surgió en 1959 como un grupo armado que aplicó la violencia terrorista con propósitos de motivación sepa- 
ratista (para conseguir la independencia de Euskadi, pero incluyendo cuatro provincias de España - País Vasco y Navarra - y tres territorios en el suroeste de Francia). Es importante señalar que en 2011 el grupo terrorista anunció su cese de actividad armada, aunque la organización no se ha disuelto oficialmente. Una reciente revisión de la historia y evolución de ETA puede encontrarse en López-Romo (2015).

La selección de víctimas de ETA se basó principalmente en la profesión, la pertenencia a determinados partidos políticos, ideología, posición pública o crítica hacia la organización terrorista (Varona, 2009). Las personas amenazadas incluyeron civiles, concejales, jueces, fiscales, funcionarios penitenciarios, periodistas y profesores universitarios, empresarios, entre otros, así como también militares y policías. Aunque no existe un acuerdo total, algunos estudios han estimado que alrededor de 40.000 personas estuvieron bajo amenaza de ETA (Gesto por la Paz, 2000). López-Romo (2015) muestra datos de más 15.000 personas de amplios sectores sociales que estuvieron bajo amenaza.

En cuanto a las acciones de violencia, se fomentó un contexto de hostigamiento, que algunas asociaciones por la paz denominaron «violencia de persecución» (Gesto por la Paz, 2000). El hecho de estar bajo amenaza incluía también en ocasiones un amplio espectro de acciones de acoso, a través de amenazas, intimidación, extorsión, agresión, entre otros, incluido el asesinato. Varona (2009) ejemplifica la amplitud y multiplicidad de contextos de victimización (ver Tabla 1). Más allá de la selección de objetivos, las acciones de violencia y sus efectos, algunos autores han apuntado a que la violencia y el acoso terrorista perpetrado en Euskadi por ETA, es indicativo de un propósito de exclusión sobre los sectores señalados como objetivos (Martin-Peña, Opotow y Rodríguez-Carballeira, 2011).

\begin{tabular}{|c|c|}
\hline- & Personas que han sobrevivido a varios atentados. \\
\hline- & Personas que sobreviven a un atentado y tienen que llevar escolta. \\
\hline- & $\begin{array}{l}\text { Personas a quienes ETA asesinó a su padre, marido u otro familiar hace años y después de ello } \\
\text { llevan escolta. }\end{array}$ \\
\hline- & $\begin{array}{l}\text { Personas amenazadas que han llevado escolta, porque son o han sido concejales, o miembros de } \\
\text { organizaciones que defienden los derechos de las víctimas, o simplemente críticas con ETA. }\end{array}$ \\
\hline- & $\begin{array}{l}\text { Personas que unas horas o días después de asesinarles a un familiar han recibido pintadas y/o } \\
\text { llamadas de amenazas e insultos. }\end{array}$ \\
\hline- & $\begin{array}{l}\text { Personas que simultánea y consecutivamente han sido insultadas, agredidas, amenazadas y, en } \\
\text { ocasiones, asesinadas o a las que se ha intentado asesinar. }\end{array}$ \\
\hline
\end{tabular}

TABLA 1: Tipos de victimización. Fuente: Varona (2009: 411-412) 


\subsection{Objetivos del estudio}

Partiendo de lo anteriormente expuesto, el objetivo de este trabajo consiste en analizar las vivencias de personas amenazadas por ETA para comprender mejor cómo estas situaciones impactaron sobre su funcionamiento psicosocial. Se parte de una muestra de individuos que estuvieron bajo amenaza por el grupo terrorista ETA en Euskadi. Para ello, se encuestó a participantes que fueron acosados y amenazados por el grupo terrorista ETA en el País Vasco o Euskadi (España). En segundo lugar, se pretende explorar el impacto psicosocial que ha supuesto durante los primeros ciclos vitales de la vida de una víctima indirecta el hecho de convivir diariamente con una persona amenazada por la banda terrorista ETA. Para ello, se administró una entrevista en profundidad a una persona joven que vivió la amenaza como hija de un amenazado. Ante la memoria de lo irreparable, el estudio puede ser útil en aras a promover actuaciones para la memoria de las víctimas.

\subsection{Metodología}

\subsubsection{Participantes y procedimiento}

Este trabajo forma parte de un estudio más amplio que aborda la violencia de ETA en Euskadi. En un primer estudio, a través de una investigación transversal y de un análisis de componentes principales (ACP), se encuestó a personas amenazadas por ETA en Euskadi $(\mathrm{N}=87)$, durante el año 2009. El ACP es una técnica estadística de síntesis de la información, o reducción de la dimensión (número de variables). Así, se extrajeron los factores potenciales a través de esta técnica.

En primer lugar, los participantes fueron contactados a través de 18 informantes clave, que fueron seleccionados por su experiencia directa o indirecta con víctimas y personas amenazadas de ETA. Entre esos informante clave, hubo personas amenazadas principalmente del ámbito académico, judicial, político, expolitico, y familiar de persona bajo amenaza. En segundo lugar, se procedió a enviar una carta de invitación a participar en una encuesta on-line. Se utilizó el muestreo bola de nieve, recomendado para contactar con población oculta en situaciones de conflicto y violencia (Cohen y Arieli, 2011). 
Es importante destacar que durante esta época, la violencia y la amenaza aún estaban activas en Euskadi, por lo cual fue necesario mantener la discreción y el mantenimiento de la confidencialidad de la información proporcionada sobre las identidades, rutinas...etc., recabada sobre algunos de los participantes. A los participantes se les pidió colaboración para obtener información sobre sus experiencias y vivencias sobre la situación de amenaza (e.g., formas de violencia, consecuencias psicosociales...) siempre garantizando la confidencialidad y seguridad.

En relación a los datos sociodemográficos, la muestra estuvo formada por un total de 87 individuos con las siguientes características: 72,4\% eran hombres, de edades entre 40 y 49 años, y la mayoría de ellos nacieron en el País Vasco $(78,2 \%)$. El lugar de residencia fue principalmente la ciudad (46,0\%) y pueblos $(44,8 \%)$ en el País Vasco, mientras que el 9,2\% vivía en otras zonas fuera del País Vasco. Las clases medias $(70,1 \%)$ y las clases media-bajas $(16,1 \%)$ fueron los niveles socioeconómicos más comunes. La ocupación más frecuente: política $(41,1 \%)$, sector privado $(21,1 \%)$, educación $(11,1 \%)$, autónomo $(6,7 \%)$, jubilado $(5,6 \%)$. La duración de los años bajo amenaza: $M$ $=10.3$, DT $=6.3$. Un $35,6 \%$ señaló que sufrió algún tipo de ataque del tipo agresión física (e.g., incendiario, pintura-bomba).

\subsubsection{Medidas}

«Efectos psicosociales». De forma concreta y de cara a analizar los efectos psicosociales de estar amenazado, se diseñó un cuestionario «ad hoc», con ítems basados en estudios previos sobre la temática (e.g., Martin-Peña y Varela-Rey, 2014) para averiguar el impacto psicosocial de las personas amenazadas. Un total de 30 ítems resultantes fueron filtrados a partir de 43 iniciales, tras efectuar los análisis estadísticos. Los participantes respondieron sobre la intensidad o grado en el cual experimentaron cada una de las situaciones, en una escala de cinco puntos tipo Likert, puntuando entre 0 (nada) y 4 (extremo). La consistencia interna $(\alpha)$ para los mencionados 30 ítems fue .95.

«Vivencias sobre los efectos de estar amenazado». El cuestionario tuvo una pregunta de respuesta abierta a partir de la cual los participantes pudieron contribuir con ejemplos adicionales sobre su experiencia. 
En un segundo estudio se propuso conocer el impacto que supone haber vivenciado la amenaza de ETA en el seno familiar en víctimas indirectas. Se efectuó para ello una entrevista en profundidad en 2015 con una mujer joven de 26 años, hija de una persona que durante décadas permaneció bajo amenaza por la organización terrorista en Euskadi. El muestreo como tal ha sido de conveniencia, habiendo pedido autorización expresa a la persona para colaborar en el proyecto. La finalidad de la entrevista fue la de analizar la percepción e influencia de la situación de amenaza vivida durante las primeras etapas de su ciclo vital. La entrevista está basada en aspectos y categorías de estudios previos aquí revisados (e.g., Martin-Peña, Andrés, Ramos-Villagrasa y Escartín, 2016).

\subsection{Resultados}

Los resultados obtenidos del primer estudio, a partir del análisis estadístico, y que a continuación se resumen, señalan a seis factores que parecen predominar en el impacto sobre el funcionamiento psicosocial en personas amenazadas: 1) Procesos de pensamiento y percepción de riesgo; 2) Reacciones emocionales; 3) Círculos de vulnerabilidad; 4) Sospechas/desconfianza; 5) Interacciones sociales; 6) Seguridad y libertad de movimiento.

Factor 1: Procesos de pensamiento y percepción de riesgo. Muestra la interpretación cognitiva de la situación amenazante, centrada en la percepción de vulnerabilidad al riesgo y a la incertidumbre. Puede comprender miedos y cogniciones anticipatorias: experimentar un ataque contra uno mismo y/o contra alguien del entorno cercano; pensar en ser el próximo objetivo; pensar en ser públicamente reconocido; pensamientos de abatimiento, y pensamientos sobre el hecho de abandonar la actual situación y el lugar de residencia. Un participante lo describe de este modo: «Es imposible transmitir lo que significa vivir todos los días en el corredor de la muerte, donde es posible que te despidas por la mañana de tus seres queridos, mujer, padres, hijos y que ya no les vuelvas a ver nunca más».

Factor 2: Reacciones emocionales. Muestra las respuestas negativas a la situación amenazantes y de estrés, abarcando un amplio espectro de respuestas al hecho de estar amenazado, tales como como sentimientos de tristeza, ansiedad, sentirse desbordado, sentimientos de desasosiego e irritabilidad, o tomar medicación como medio paliativo de afrontar la 
situación. Un participante señala su caso: «Mi padre, de profesión militar, estaba amenazado por ETA y padecía una gran ansiedad y estrés que obviamente proyectaba en el resto de la familia, y yo, evitando agravar esta situación, nunca comenté nada, lo cual era una gran carga psicológica».

Factor 3: Círculos de vulnerabilidad. Este factor se refiere al impacto y sufrimiento causado por la situación de amenaza al entorno inmediato de la persona, como la pareja, hijos, u otros familiares. El siguiente es un ejemplo de testimonio a este respecto: «Una vida perdida porque nadie puede imaginar lo que puede significar un noviazgo o un matrimonio, no de dos personas, sino de cuatro todo el tiempo. Esa vida robada jamás nadie la devolverá, solamente lo mitiga la esperanza de que todo ese sacrificio no haya sido en vano y todo esto no sea, en el futuro, nada más que un mal recuerdo de los libros de historia».

Acerca de los hijos, otro participante señala: «Tus hijos están marcados para toda la vida y ellos todavía son pequeños (11 y 8 años), y han aprendido a valorar lo que hace su madre y su padre. Ellos maduran antes que un niño de su edad. Valoran otras cosas diferentes».

Factor 4: Sospechas/desconfianza. Se refiere a las sospechas y al hecho de desconfiar de otras personas, debido a la incertidumbre de la potencial amenaza. A menudo está relacionada con la incertidumbre de quien es la otra personas, pensando por ejemplo, que la otra persona puedan planificar algún tipo de ataque o aportar información para ese objetivo».

Por ejemplo: «Es un sentimiento sordo, poco intenso pero continuo que hace que me cueste entablar conversación con personas desconocidas o que ya conozco desgraciadamente como piensan y por otro lado me permite hablar con confianza con las personas que ya sé que opinan como yo».

Factor 5: Interacción social. Aborda la disrupción e incluso la pérdida en las relaciones sociales en general (distinta a la del entorno cercano) como por ejemplo, los vecinos. Un ejemplo: «[...] decidimos participar en una candidatura no nacionalista. Mi pareja salió elegida pasando a ser cargo electo en el municipio. A partir de ese momento, empezamos a sufrir el rechazo de los que anteriormente eran nuestros convecinos. Determinadas 'amistades' se alejaron de nosotros; a nuestros hijos se les dejó de invitar a ciertos eventos de otros niños». 
Factor 6: Seguridad y libertad de movimiento. Se refiere a las restricciones en el estilo de vida, hábitos, y conductas de precaución, ligado a la necesidad de medidas de protección y seguridad. Puede ser necesaria la protección personal o escolta, medidas autoprotección (e.g., mirar debajo del vehículo propio para verificar la existencia de un artefacto explosivo), cambios en las rutinas de la vida cotidiana, evitación de ciertos lugares de riesgo en el espacio público, y evitación de algunos grupos o colectivos de personas, todo ello como forma de disminuir el riesgo.

Un participante describe su vida diaria bajo medidas de seguridad y protección personal: «Soy una mujer [...] y ejerzo de concejala socialista en el País Vasco. Simplemente mis ideas políticas y ser cargo público me convierten en una víctima más en la lista etarra. Pero no solamente a mí, también a mi familia. Estoy casada y tengo 3 hijos, al pequeño de los cuales aún acompaño al colegio; ésto supone tener que ir diariamente al centro escolar con mis 2 escoltas y variar continuamente de itinerarios igual que cuando tengo que ir a las compras, al médico, a visitar a mi familia... He tenido que renunciar a pasear, a ir a la playa o a la piscina, y sobre todo a la improvisación. Todos mis actos tienen que estar controlados, desde el simple hecho de abrir el buzón o utilizar el coche familiar hasta la manera de situarme en un local público (siempre de cara a la puerta de entrada)».

En cuanto a los resultados del segundo estudio, se presentan en la Tabla 2 algunos extractos del caso analizado, clasificados en los seis mencionados factores, que representan las áreas psicosociales sobre las cuales impacta el hecho de vivir bajo amenaza.

\begin{tabular}{|l|l|}
\hline \multicolumn{1}{|c|}{ Factores } & \multicolumn{1}{c|}{ Fragmentos de testimonio } \\
\hline $\begin{array}{l}\text { 1.Procesos de pensamiento y per- } \\
\text { cepción de riesgo }\end{array}$ & $\begin{array}{l}\text { «Tenía la sensación de que me iban a identificar, de -Ésta mira } \\
\text { quién es y de que iban a por mí. También cuando algún com- } \\
\text { pañero de mi padre decía que había llevado debajo una bomba } \\
\text { y había ido con su hija durante no sé cuántos kilómetros, luego } \\
\text { si me enteraba yo de estas cosas, que todo era de oídas, pues } \\
\text { pensaba a lo mejor me puede pasar a mi pasado mañana.» }\end{array}$ \\
\hline 2. Reacciones emocionales & $\begin{array}{l}\text { «Obviamente me alteraba; en aquella época había cada dos } \\
\text { meses alguna noticia y el mensaje iba a llegar a casa y él [su } \\
\text { padre] lo iba a saber y yo tenía sueños de que iba a aparecer } \\
\text { en mi casa una bomba y de que se moría todo el mundo menos } \\
\text { yo.» }\end{array}$ \\
\hline
\end{tabular}




\begin{tabular}{|l|l|}
\hline 3. Círculos de vulnerabilidad & $\begin{array}{l}\text { «En mi casa todo era secreto y eso nos ha afectado en el com- } \\
\text { portamiento a todos y en la forma de vida y de comunicarnos } \\
\text { dentro de la familia totalmente.» }\end{array}$ \\
\hline 4. Sospechas/desconfianza & $\begin{array}{l}\text { «Cuando veníamos de viaje y había alguna persona enfrente } \\
\text { del garaje o algo, pues no se metía [mi padre] directamente } \\
\text { al garaje, estaba dando siempre vueltas, luego se quedaba vi- } \\
\text { gilando, iba a casa, se quedaba cuatro horas mirando por la } \\
\text { ventana a ver qué hacía esa persona.» }\end{array}$ \\
\hline 5. Interacción social & $\begin{array}{l}\text { «Bueno pues entre otras cosas, yo jamás les he dicho a mis } \\
\text { amigas en que trabajaba mi padre, muchas de mis amigas no } \\
\text { son conscientes de todo esto.» }\end{array}$ \\
\hline 6. Seguridad y libertad movimiento & $\begin{array}{l}\text { «Evitaba todos los sitios en los que pudiese haber personas que } \\
\text { defendiesen la independencia, que defendiesen un poco lo que } \\
\text { hiciese ETA. Desde Herriko Tabernas, hasta pueblos en los que } \\
\text { se sabía que se movía cierto ambiente.» }\end{array}$ \\
\hline
\end{tabular}

TABLA 2. Extractos del caso clasificados según los factores de impacto psicosocial

\subsection{Reflexiones finales e implicaciones para políticas públicas de memoria}

Las personas amenazadas por ETA en Euskadi representaron uno de los primeros eslabones dentro del proceso del terror impuesto por el entramado terrorista en esa Comunidad, el cual podía evolucionar hacia múltiples formas de victimización, incluso el asesinato. En conjunto, los resultados muestran un mapa del impacto selectivo de la violencia terrorista, que promueve una situación de hostigamiento continuo para influenciar sobre las conductas de los considerados como enemigos. Cuando una persona está bajo amenaza, las respuestas iniciales (e.g., miedo, ansiedad, desconfianza, o conductas de precaución) pueden salvar la vida del individuo, siendo adaptativas en ese contexto. Sin embargo, cuando esas mismas respuestas son crónicas, entonces empiezan a jugar en contra de la persona, favoreciendo un funcionamiento psicosocial disfuncional. Es algo paradójico, puesto que las mismas respuestas que por un lado permiten salvar la vida, por otro lado, acaban dificultándola en extremo.

Así, las personas amenazadas viven con escasez de seguridad y libertad de movimiento, como resultado de la amenaza continua. En este sentido, $\mathrm{Mu}-$ llainathan y Shafir (2013) señalan cómo diferentes tipos de escasez tienden a capturar nuestra atención, centrándola más en el corto plazo, y constriñendo nuestra mente, debido a que tenemos menos cognición para el resto de la vida, afectando a la habilidad para prestar atención o toma de decisiones. Güss, Foust y Dörner (2013), señalan que la alta activación debido a amenazas y miedo, convierte al pensamiento en cortoplacista y de una resolución cogniti- 
va más baja. En cualquier caso, los efectos psicosociales derivados tienen un impacto que va más allá de aspectos intra-individuales, y que se extienden al entorno cercano. La extensión del terror a través de esos efectos psicosociales puede traducirse en una violencia como instrumento para la exclusión de quienes fueron objetivos o víctimas, entendida esa exclusión en un sentido amplio como se verá a continuación (Martin-Peña, Opotow y Rodríguez-Carballeira, 2011). El miedo a esa exclusión de una parte de la sociedad en su conjunto, puede ser suficiente para desincentivar respuestas críticas contra quienes promueven la violencia.

En relación a contribuciones dirigidas a la memoria de las víctimas, López-Romo (2016b) señala la necesidad de fomentar políticas públicas de memoria, las cuales informen de lo sucedido, enfatizando el Estado de derecho y el rechazo a la violencia política y las ideologías que la justifican. En relación a ello, Memoriales como el Centro para la Memoria de las Víctimas del Terrorismo pueden ser herramientas de interés (Mate, 2006). López-Romo (2016a) en relación a la memoria de las víctimas, señala el «principio de análisis de las causas», que al menos en parte, debería realizarse a través de estudios basados en evidencias que puedan contribuir a mostrar y analizar el «cómo fue posible» que ocurriera la violencia y el contexto que ayudó a mantenerla, relacionado con otro principio, denominado como «de no repetición». De acuerdo con Opotow (2011) la contribución que puede hacer la psicología y psicología social a Memoriales y Museos que se focalicen en injusticias, violencia y violaciones de derechos humanos es relevante. Estas actuaciones pueden ir dirigidas a visibilizar los procesos psicosociales a través de los cuales se promovió la exclusión, la amenaza e incluso el asesinato de quienes fueron colectivos amenazados.

Analizar las bases y procesos psicosociales subyacentes a la mencionada exclusión, puede ser un objetivo para la intervención sobre la memoria de las víctimas, desde la perspectiva de la psicología social. Un enfoque a partir del cual se analice el rol, desde un nivel de análisis Meso, de agresores o victimarios, víctimas y también el rol jugado por la sociedad en su conjunto, hacia las víctimas. Partiendo de un enfoque en que la violencia terrorista en Euskadi ha sido un instrumento para la exclusión de las categoría/s social/es (e.g., partido político, profesión, creencias políticas, crítico con ETA) que eran consideradas por ETA como enemigas, y que esas categorías estuvieron formadas por grupos de personas heterogéneas, conviene destacar que dicha exclusión puede producirse en tres niveles, tomando la perspectiva de Opotow (2011): 
- Exclusión dentro de la sociedad, referida a que restringe o anula la libertad de distintos aspectos de la persona y su entorno, como la libertad de movimiento, las rutinas de la vida cotidiana, o el derecho a la seguridad, y que además, promueve el estigma social dentro de la comunidad.

- Exclusión de la sociedad, referido a quienes tuvieron que marcharse de Euskadi por motivos de seguridad o ante la extorsión económica. En este sentido, no hay cifras concluyentes de personas amenazadas que abandonaron Euskadi por esta situación (López-Romo, 2015).

- Exclusión como aniquilación, referido a la exclusión más extrema, como es la destrucción de la persona, mediante el asesinato.

Las acciones de violencia suelen disponer de una serie de factores psicosociales subyacentes, que pueden darse con anterioridad a la conducta violenta pero también con posterioridad. Por ejemplo, para el desarrollo de la violencia suele necesitarse de un contexto que promueva determinados aspectos. La categorización social, por ejemplo, tiende a fomentar juicios dicotómicos y pensamientos maniqueos hacia quienes son delimitados como objetivos, del tipo nosotros-ellos. Grupos heterogéneos de personas pasan a ser categorizados por los victimarios como enemigos de acuerdo a los criterios que ellos convengan. Así, se favorece una percepción de homogeneidad exogrupal, por parte de los victimarios (endogrupo) hacia las víctimas que formaron grupos heterogéneos. Ese es un elemento que ayuda a su deshumanización, clave para perpetrar conductas de violencia.

El señalamiento y la estigmatización de las víctimas potenciales, indica que lo que convierte a los crímenes en terrorismo es la transformación de la condena genérica de un colectivo al señalamiento de individuos específicos, como concreción del concepto de enemigo (Ibarra, 2002). La amenaza mediante el señalamiento de personas concretas debido a su pertenencia a una categoría social es el inicio de un proceso que promueve la mencionada exclusión en sus diversas dimensiones. Este señalamiento, puede hacerse a través del espacio público mediante carteles, pintadas, (muchas de tipo intimidatorio, difamatorio) o mediante la construcción de discursos de legitimación de la violencia en los «mass media». El mencionado señalamiento, por el hecho de estar amenazado y llevar protección personal, puede estimular el estigma $\mathrm{y}$ rechazo social. El miedo al estigma del individuo amenazado se relaciona a 
veces con la ocultación de su situación a personas del entorno, aún no habiendo sucedido un acto de violencia explícita. En este sentido, un participante señaló: «sales con personas que no conocen tu situación, y no se lo comentas, estas con mentiras viviendo prácticamente una vida $\mathrm{B}$, y todo por tu seguridad, así que ves pasar el tiempo y las relaciones que podrían ser, están basadas en mentiras por tu parte.»

La construcción de un contexto posterior a las conductas de violencia es necesario para facilitar su justificación por parte de los victimarios. Se necesita articular discursos de legitimación de la violencia que atribuyan la responsabilidad al adversario y promuevan su deshumanización, útiles para el endogrupo victimario. Desde la percepción de la sociedad sobre la violencia, la teoría de la «creencia en un mundo justo» (Lerner, 1980) es un fenómeno importante. Se refiere a que la persona piensa que cada uno tiene lo que se merece, por ejemplo, en relación a una víctima de injusticias. A veces, en contextos de violencia, se traduce en el «algo habrá hecho», que simboliza que alguna razón habrá para que una persona haya sido destinataria del acto violento. Lo cual tiende a culpabilizar a la víctima y servir a su vez de justificación. Es un aspecto psicosocial relevante, puesto que incluye a la parte de la sociedad que no es víctima ni victimaria, a menudo denominada como «bystanders» o espectadores. Un ejemplo de esto puede ser el siguiente extracto de un familiar de una víctima de ETA (Arjona, 2011): «La viuda de un hombre asesinado por ETA cuenta su experiencia de percepción después del asesinato. Su hija comentó sobre el asesinato con una profesora en la escuela. (Profesora: $\mathrm{P})$ : ¿Por qué mataron a tu padre? - (Niña: N) Por nada. - (P) Pues por algo será. Por nada no matan a nadie.»

Estos espectadores de injusticias pueden mantener la mencionada creencia para conseguir percibir su mundo como más predecible, controlable. Y a través de distorsiones cognitivas se puede racionalizar la desgracia de la víctima, convirtiéndola en merecedora, y por tanto no tan injusta (Hafer y Ruber, 2015). De igual modo, las personas pueden justificar el sufrimiento de un inocente, argumentando que ese sufrimiento tiene beneficios para las víctimas. Un participante amenazado comentó a este respecto: «Oír que encima tenemos chofer y coche y no tenemos problemas de aparcamiento, por ir escoltados.»

Para finalizar, destacar lo que De la Cuesta, Varona, Mayordomo y San Juan $(2012$, p. 117) señalan, en línea con una propuesta en pro de la memoria respecto a las personas amenazadas: «resulta fundamental la importancia del 
concepto de relato, como conocimiento detallado de un hecho, por las personas amenazadas dentro de la construcción de la memoria. En este ámbito debe actuarse, de forma innovadora, con nuevos soportes, dentro de un lenguaje audiovisual, especialmente atractivo para los jóvenes, simultáneamente riguroso y didáctico.»

Nota: Una versión previa del Estudio 1 fue publicada en 2016 en la revista «Behavioral SciencesofTerrorismandPoliticalAggression», doi: 10.1080/19434472.2016.1198412. Una versión previa del Estudio 2 fue publicada en 2016 «e-Eguzkilore: Revista Electrónica de Ciencias Criminológicas», vol. 1. Este trabajo se ha realizado enmarcado en una línea de investigación de un proyecto del MINECO (PSI2016-75915-P) y del Grupo de Estudios sobre la Sociedad del Riesgo (Universidad de Zaragoza, Gobierno de Aragón y FSE).

\subsection{Bibliografía}

ABELLA-UYARRA, A. (2016), «Dos investigaciones sobre la victimización terrorista: sistematización de testimonios y estudio de caso único», e-Eguzkilore: Revista Electrónica de Ciencias Criminológicas, vol. 1, pp. 1-48.

ALONSO, R., DOMÍNGUEZ, F. y GARCÍA, M. (2010), Vidas rotas. Historia de los hombres, mujeres y niños víctimas de ETA, Madrid, Espasa.

ARJONA, P. (Director) (2011), Las voces de Antigona [StoryBoard.-Motionpicture]. Spain.

COHEN, N., y ARIELI, T. (2011), «Field research in conflict environments: Methodological challenges and snowball sampling.», Journal of Peace Research, vol. 48, pp. 423-435. doi: $10.1177 / 0022343311405698$

DE LA CORTE, L., SABUCEDO, J. M. y MORENO, F. (2004), «Dimensiones psicosociales del terrorismo», En L. de la Corte y A. Blanco (Eds.), Psicología y derechos humanos, Barcelona, Icaria, pp. 189-220.

DE LA CUESTA, J. L., VARONA, G., MAYORDOMO, V. y SAN JUAN, C. (2012), Informe retorno. Donosti, Instituto Vasco de Criminología.

GESTO POR LA PAZ (2000), Ante la violencia de persecución. Recuperable de http://www.gesto.org/violenciapersecucion.htm.

GÜSS, C. D., FOUST, A., y DÖRNER, D. (2013), «Fear of suicide terrorism: Consequences for individuals and politics», En S. J. Sinclair and D. Antonius (Eds.), The political psychology of terrorism fear (pp. 107-124), New York, Oxford University Press.

HAFER, C. L., y RUBEL, A. N. (2015), The why and how of defending belief in a just world, Advances in Experimental Social Psychology, vol. 51, pp. 41-96.

IBARRA, J. L., (2002), «Tópicos políticos y deslegitimación del poder judicial», Teoría y Realidad Constitucional, vol. 8, pp. 217-234.

LOPEZ-ROMO, R. (2015). Informe Foronda. Los contextos históricos del terrorismo en el País Vasco y la consideración social de sus víctimas 1968-2010, Vitoria, Instituto de Historia Social Valentín de Foronda. 
LÓPEZ-ROMO, R. (2016a), La memoria de las víctimas del terrorismo, Recuperado de: https://gaizkafernandez.com/2016/10/15/raul-lopez-romo-la-memoria-delas-victimas-del-terrorismo-el-correo-15-x-2016/.

(2016b), ¿Por qué un memorial?, Recuperado de: https://gaizkafernandez. com/2017/05/03/raul-lopez-romo-por-que-un-memorial/.

MARTÍN-PEÑA, J., ANDRÉS, A., RAMOS-VILLAGRASA, P. J., y ESCARTÍN, J. (2016), «Living under threat: psychosocial effects on victims of terrorism», Behavioral Sciences of Terrorism and Political Aggression, doi: 10.1080/19434472.2016.1198412.

MARTIN-PEÑA, J., OPOTOW, S., y RODRÍGUEZ-CARBALLEIRA, A. (2011), «Amenazados y víctimas del entramado de ETA en Euskadi: Un estudio desde la teoría de la exclusión moral», Revista de Psicología Social, vol. 26, pp. 177-190.

MARTIN-PEÑA, J., y VARELA-REY, A. (2014), «Terrorist threats in the Basque Country: Its impact on the psychosocial sphere of victims.», Oñati Socio-Legal Series, vol. 4, pp. 507-524.

MATE, R. (2006), Justicia de las víctimas y reconciliación en el País Vasco, Madrid, Fundación Alternativas.

MULLAINATHAN, S., y SHAFIR, E. (2013), Scarcity. Why having too little means so much, New York, Henri Colt.

OPOTOW, S. (2011), «How this was posible: interpreting the Holocaust», Journal of Social Issues, vol. 67, pp. 205-224.

SCHMID, A.P. (2011), «The definition of terrorism», En A. P. Schmid, ed., The Routledge Handbook of terrorism research, Oxon, UK, Routledge, pp. 39-98.

VARONA, G. (2009), Atención institucional a las víctimas del terrorismo en Euskadi, Recuperable de: https://euskadi.net/x83-eduki/es/contenidos/libro/bkg_publicaciones_ararteko2/es_bakegune/adjuntos/ararteko_informe_victimas.pdf.

WALTER, E.V. (1969), Terror and resistance, New York, Oxford University Press. 



\title{
16 \\ SEGURIDAD SUFICIENTE: DISCURSOS DE EXCEPCIONALIDAD
}

\author{
Adrián Serrano-Sanz \\ Universidad de Zaragoza \\ 631284@unizar.es
}

\subsection{Introducción}

Los atentados del 7 de enero (7E, en adelante) y 13 de noviembre $(13 \mathrm{~N}$, en adelante) de 2015 en Paris y del 14 de julio (14J, en adelante) de 2016 en Niza han supuesto un viraje en el enfoque antiterrorista europeo.

Tras el 7E el gobierno francés propuso a la Asamblea Nacional un proyecto de ley antiterrorista llamado Loi relative au renseignement (Loi $\mathrm{N}^{\circ}$ 2015-912, 2015) que sería aprobado en mayo con una amplia mayoría (Assamblé Nationale, 2015), entrando en vigor en julio. El 13N se produjeron nuevos sucesos terroristas a los que el gobierno francés respondió decretando el estado de excepción, vigente en la actualidad, y cerrando las fronteras.

Una de esas ampliaciones se debió a los sucesos del 14J, Día Nacional de Francia, cuando un camión irrumpió en las celebraciones en Niza atropellando a la multitud congregada en el paseo marítimo.

La respuesta legislativa del gobierno francés, criticada por diferentes colectivos e individuos (Le Monde, 2015), se mantiene en vigor debido al cambio cualitativo del contexto francés en lo referente al terrorismo.

Pese a que la citada situación de inseguridad favorece una línea política dura y de excepción contra el terrorismo, no es el úncio elemento que con- 
tribuye a su mantenimiento. La justificación de la excepcionalidad requiere de una interpretación en una serie de términos que evidencien la necesidad de su existencia. Esto es, requiere de un discurso interpretativo. ¿Bajo qué lógica funciona el discurso de la excepcionalidad? Esta será la pregunta que se abordará en este artículo.

\subsection{El discurso de la seguridad suficiente y el discurso de la excepcionalidad}

El discurso de la excepcionalidad no funciona como discurso-final, sino como discurso-medio subordinado para facilitar otro superior en orden, el de la seguridad suficiente, que sí funciona como discurso-fin.

Leudar, Marsland y Nekvapil (2004) demuestran que las presentaciones de eventos en el discurso político y las acciones posteriores están relacionadas, añadiendo que dicha presentación prepara el terreno para una violencia futura. Por esto, al final de la sucesión excepcionalidad-seguridad suficiente, donde el discurso de la excepcionalidad funciona como discurso-medio y el de la seguridad suficiente como discurso-fin, este último actúa, a su vez, como discurso-medio que da paso a la acción.

\subsubsection{El discurso de la seguridad suficiente}

El discurso de la seguridad suficiente es el puente entre discurso y acción. Este enfoque discursivo es anómalo en cuanto a sus características de aparición y existencia, ya que depende del contexto de anomalía política en el que el modo de operar habitual resulta inoperante para responder a las exigencias de la realidad sociopolítica.

Si bien en una situación política no-anómala la seguridad se configura como un medio para garantizar las libertades de los ciudadanos como un $m i$ nimo-para-ejercer (las libertades) «manteniendo un estado de convivencia que permita el ejercicio de derechos y libertades» (Rescasens i Brunet, 2007, p.133), en las situaciones anómalas la conceptualización de la seguridad se realiza de forma distinta.

La clave se sitúa en la reconceptualización de la relación libertad-seguridad, entrando a operar una lógica cuantitativa que la modula la siguiente forma: cuánta seguridad es suficiente para ejercer las libertades. 
Por tanto, se pasa de la conceptualización de la seguridad como mínimopara-ejercer (las libertades) a cuánto-mínimo-para-ejercer (las libertades). Así, en los casos de anomalía política la pregunta sería: ¿cuál es el nivel mínimo de seguridad para ejercer las libertades? Una vez esbozado el concepto de la seguridad suficiente cabe preguntarse, ¿cuáles son los elementos de inicio y justificación de su discurso? Estos elementos son una amenaza que implique inseguridad e incertidumbre y un hecho desencadenante.

En primer lugar, la amenaza existente necesita tener un carácter invisible e inespecífico, así como de una duración prolongada en el tiempo. Por otro lado, es necesaria la existencia de una fuente emisora que sea identificable. El carácter invisible e inespecífico de una amenaza supone que su materialización no es previsible en el tiempo ni ubicable en el espacio y, por tanto, genera incertidumbre, creando una atmósfera de «presencia continua» y, por tanto, «riesgo continuo».

En segundo lugar, que se genere este discurso depende de la aparición de un desencadenante en el que se materialice la amenaza y, por tanto, pase de ser inespecífica a específica. Este paso tiene una importancia clave para el inicio del discurso de la seguridad suficiente ya que actúa como «ruptura temporal» (Holland, 2011, p.88) en la normalidad posibilitando la introducción del discurso, y sus consecuencias posteriores, en la sociedad.

\subsubsection{El discurso de la excepcionalidad}

En el apartado anterior se ha definido el discurso de la seguridad suficiente como el paso de una dinámica de mínimo-para-ejercer (las libertades) a otra de cuánto-mínimo-para-ejercer (las libertades).

Sin embargo, el paso de una dinámica de discurso a otra no se realiza de forma espontánea, si no requiere de un intervalo de tiempo que justifique la introducción de la segunda en base a la diferenciación respecto de la primera de ellas debido a la aparición de un hecho desencadenante que suponga que las realidades a las que se refiere el discurso son cualitativamente distintas.

En ese periodo de tiempo nace el discurso de transición que se ha dado en llamar discurso de la excepcionalidad.

Las características de este sentarán las bases del siguiente, por tanto, es necesario definir los elementos de esta transición para conocer el desarrollo 
posterior y, también, los puntos fundamentales de las acciones a las que precede.

El discurso de la excepcionalidad apoya su argumentación en un hecho desencadenante y una amenaza percibida a lo largo del tiempo, de forma coincidente con el discurso de la seguridad suficiente, y, así mismo, otro que aparece aquí y que se repite y refuerza más tarde. Este elemento es la creación de identidades en los instantes posteriores a la aparición de una brecha en la normalidad social y política mediante la Membership Categorization (Sacks, 1995).

El Membership Categorization Analysis (MCA, en adelante) fue formulado por Sacks (1995) como un análisis del proceso para dotar de sentido a otros individuos y sus actividades (Leudar et al., 2004). El modelo recibe el nombre de MIR (Sacks, 1995) como acrónimo de las siglas Membership, Inference-rich y Representative. Sacks (1995) afirma la existencia de grupos de categorías agrupadas en clases con propiedades comunes entre sí.

En primer lugar, sobre las clases de categorías, Sacks (1995) afirma que son clases «qué»-tipo, en referencia a las «características de los miembros de un grupo que definen y que tienen la potencia de clasificar a cualquier miembro de la población» (p.40). A continuación, afirma que estas pueden denominarse de igual forma como «inference-rich» (Sacks, 1995, p.40).

Aquí, Sacks (1995) se refiere a que:

una gran parte del conocimiento que los miembros de una sociedad tienen sobre esta se ordena en términos de las categorías «qué»-tipo y por el propio carácter de esas categorías son susceptibles de ser recuperadas en situaciones en las que no existe suficiente experiencia previa y que, por tanto, se puede crear conocimiento sobre una categoría concreta que se desconoce. (p.41).

Por último, cualquier miembro de cualquier categoría es presumiblemente representativo de dicha categoría, por lo que «el conocimiento de un miembro es almacenado en la categoría a la que pertenece dicho miembro» (Sacks, 1995, p.41). En Leudar et al. (2004), el análisis se basa en las categorías de nosotros/ellos, utilizados como standarized relational pair (SRP, en adelante) en el sentido dado por Sacks (1972): 
Si cualquier miembro de $\mathrm{X}$ conoce su posición respecto de un miembro de $\mathrm{Y}$, entonces $\mathrm{X}$ conoce la posición $\mathrm{Y}$ respecto de sí mismo. X también sabe que si $\mathrm{Y}$ sabe que posición tiene $\mathrm{Y}$ respecto de $\mathrm{X}$, entonces $\mathrm{Y}$ conoce qué posición tiene $\mathrm{Y}$ respecto de $\mathrm{X}$. (p.37)

Así, la referencia a uno de ellos (X o Y, indistintamente), los sitúa a ambos en un plano relacional donde uno evoca la existencia del otro (Leudar et al., 2004) incluso en términos de «derechos y obligaciones» (Sacks, 1972, p.37). Los SRP están construidos como «clases de dos-categorías con relación entre sí porque existen en base a la misma categoría pero al mismo tiempo resultan excluyentes» (Sacks, 1995, p.48).

Para «establecer una clase de dos-categorías es necesario definir un grupo y categorizarlo en base a una característica representativa y, entonces, asimilar al otro grupo mediante una característica predominante en él» (Sacks, 1995, p.48), lo que supone un proceso de creación de identidades donde «nosotros es superior» (Holland, 2012, p.82) a ellos. Solomon (2009) da un ejemplo de SRP al analizar las lógicas de construcción de identidades durante la war on terror norteamericana:

La identidad norteamericana fue (re)producida dentro del discurso de la guerra contra el terror a través de equivalencias enlazando «bueno», «civilizado», «pacífico», «valores», «dignidad» y «justicia». Estos significantes agrupados recibieron su significado por oposición a cadenas de significantes como «diabólico», «asesino», «terror» y «tiranía». (p.10)

No existe un método sistemático para el análisis MCA (véase Stokoe, 2012) pero, sin embargo, uno de los ejemplos más relevantes es el de Leudar et al. (2004) donde se analiza el discurso de George W. Bush del 11 de septiembre de 2001 (Bush, 2001) (11S, en adelante) y del que puede inferirse una estructura analítica de ocho etapas:

1. Existencia de un ataque y creación del par relacionado nosotros/ellos

2. Descripción del atacante mediante sus actos. Descripción de las consecuencias físicas y psicológicas del ataque

3. Fallo en el objetivo psicológico del ataque

4. Asociación en términos de SRP: nosotros-víctimas/ellos-asesinos

5. Nosotros, y nuestro país, representamos la libertad

6. Enfrentamiento ideológico 
7. Anticipación de acciones

8. De víctima a justiciero

\subsection{Análisis}

\subsubsection{Muestra}

Se han tomado tres discursos de François Hollande correspondientes a los sucesos del 7E (Hollande, 2015a), 13N (Hollande, 2015b) y 14J (Hollande, 2016) en el idioma original para evitar la pérdida de matices en el discurso, como se indica en Fairclough (1995). Los tres discursos tienen entre sí dos características comunes que facilitan el análisis comparativo: emisor y momento de emisión.

En todos ellos el emisor es el Presidente de la República y su aparición en el tiempo coincide con los días de los ataques. Asumiendo que el Estado tiene la competencia en seguridad y defensa, la elección del representante del Estado como fuente facilita establecer la línea de orientación gubernamental en ese contexto. El momento del tiempo resulta, a su vez, clave para entender la dimensión contextual del mensaje (Polonska-Kimungyi y Gillespie, 2016). Un plazo de tiempo corto favorece la aparición de la «primera reacción» del Estado, en la cual se puede entrever el enfoque de la respuesta.

\subsubsection{Método y categorías de análisis}

Para Fairclough (1995, p.188) «el análisis del texto es un análisis de forma-contenido» ya que «el significate (forma) y el significado (contenido) contituyen una unidad dialéctica de signficado inseparable» (Fairclough, 1995, p.212) y señala que «cada evento discursivo tiene tres dimensiones: es un texto (oral o escrito), es una instancia de una práctica discursiva que implica la producción y la interpretación del texto y es parte de una práctica social» (Fairclough, 2008, p.174).

Por tanto, el análisis del discurso puede dividirse de esa forma en un modelo tridimensional acorde con los elementos del discurso: textual, intertextual y contextual (Fairclough, 1995; Polonska-Kimungyi y Gillespie, 2016).

El nivel textual se corresponde con aspectos lingüísticos y «analiza los textos en función de su léxico y elementos» (Fairclough, 1995, p.196), a continuación, el análisis intertextual se centra en los «órdenes de discurso como 
configuraciones particulares de prácticas convencionales que están disponibles para los productores de textos en situaciones sociales concretas» (Fairclough, 1995, p.188) y, por último, el nivel de análisis contextual explora la conexión entre el uso del lenguaje y la práctica social (Polonska-Kimungyi y Gillespie, 2016, p.6).

El análisis de los discursos se centrará en el plano contextual mediante el análisis textual. Sin embargo, se hará referencia a la intertextualidad ya que «media la conexión entre lenguaje y contexto social» (Fairclough, 1995, p.189) focalizando la atención de la práctica del discurso entre productores e intérpretes, «cuyas propiedades dependen de la naturaleza de la práctica sociocultural» (Fairclough, 1995, p.211).

El análisis contempla tres factores: membership categorization, la información sobre los sucesos en tanto que descripción de los acontecimientos e información relacionada y la capacidad integradora como búsqueda de concentrar a la población en torno a la unidad.

\subsubsection{Resultados}

16.3.3.1. Discurso de François Hollande el 7 de enero de 2015

Membership categorization

El discurso comienza con la primera etapa, que se extiende durante el primer párrafo:

Mes chers compatriotes,

Aujourd'hui, la France a été attaquée en son cour, à Paris, dans les locaux-mêmes d'un journal. Cette fusillade d'une violence extrême a tué douze personnes et en a blessé plusieurs. [...]. Je veux ici leur dire que ce message de la liberté, nous continuerons à le défendre en leur nom.

Aquí se introduce la existencia de un ataque y se dibuja el par relacionado sin identificar a ellos como una entidad concreta. Sin embargo, durante todo el párrafo se va definiendo por los actos que se les atribuye (cette fusillade d'une violence extrême a tué douze personnes et en a blessé plusieurs), lo que también hace referencia a la segunda etapa, donde se describe al ellos por sus acciones sin nombrarlos. 
Una de las definiciones implícitas del ellos durante este párrafo se hace en base a la representación de las víctimas del ataque como símbolo de libertad (ce message de la liberté), lo que implica que los atacantes son, por tanto, enemigos de la libertad. Al final de este primer párrafo se afirma nous continuerons à le défendre en leur nom, lo que se relaciona con la etapa tercera, ya que implica que el objetivo de atacar la libertad de expresión y provocar miedo a expresarse libremente (objetivo psicológico) ha fallado a pesar de haber logrado eliminar a los dibujantes (objetivo físico), que se convierten en un sinónimo de libertad. El texto continúa reforzando la asociación Charlie Hebdo ${ }^{1}$-libertad-Francia y definiendo a los atacantes por sus actos (lâche attentat; obscurantisme; lâche assassinat).

Sin embargo, no es hasta la mitad del texto cuando se hace una referencia explícita a los agresores, pero no como entidad, sino con un general le terrorisme et le fondamentalisme, que si bien no define a los agresores, da pie a interpretaciones sobre su afiliación. Esta «especificación» de los agresores se hace después de un extracto especialmente relevante y de interés para ahondar en la creación del binomio nosotros/ellos:

\section{C'est la République toute entière qui a été agressée}

Si ha sido evidente la definición del ellos como enemigos de la libertad, es en este momento donde esa distancia entre pares se amplía al describir el nosotros mediante una cadena donde se enlazan de forma explícita las características que lo conforman.En c'est la République toute entière qui a été agressée se equipara $\mathrm{CH}$, que ha sido el objeto físico de la agresión con la República, es decir, contra Francia, luego $\mathrm{CH}$ es sinónimo de Francia/República y los autores del ataque no son Francia.

$\mathrm{Y}$, a continuación, se agrega más información para ahondar en esa definición:

La République, c'est la liberté d'expression, la République, c'est la culture, c'est la création, c'est le pluralisme, c'est la démocratie.

Por tanto, al equipararse $\mathrm{CH}$ con Francia/República, y añadirse, además, que la República es cultura, creación y pluralismo, se deja al ellos definido como contrario a la cultura, a la creación y al pluralismo, lo que concuerda

$1 \mathrm{CH}$, en adelante 
con la definición de obscurantisme que se daba al principio del discurso, para finalizar añadiendo que la República es «la democracia», por lo que ellos son no-democracia.

Para agrandar esa diferencia, después de toda la cadena Hollande añade: c'est cela qui était visé par les assassins, lo que dibuja un panorama perfectamente definido de confrontación.

Las últimas etapas, séptima y octava, se presentan a continuación:

Nous devons répondre à la hauteur du crime qui nous frappe, d'abord en recherchant les auteurs de cette infamie et faire en sorte qu'ils puissent être arrêtés, puis ensuite jugés et punis très sévèrement. Tout sera fait pour les appréhender.

Se prepara el terreno para las acciones posteriores (nous devons répondre à la hauteur du crime; d'abord en recherchant les auteurs de cette infamie) y, al mismo tiempo, pasa de ser la víctima del ataque a un buscador de justicia en la misma oración (tout sera fait pour les appréhender). Estas etapas se refuerzan al final del discurso cuando se afirma la liberté será toujours plus forte que la barbarie o la France a toujours vaincu ses ennemis, preparando las acciones posteriores que serán adoptadas e indicando que Francia no va a ser solamente una víctima.

El discurso finaliza con una oración perteneciente a la tercera etapa (rien ne pourra nous faire fléchir de la détermination qui est la nôtre), ya que indica que, pese a los daños ocurridos durante el ataque, el objetivo psicológico ha fallado porque la determinación de Francia no va a romperse.

\section{Información}

La información aportada, entendida como descripción de los acontecimientos no es muy numerosa en este discurso, casi toda la carga discursiva se dirige a la creación de un binomio nosotros/ellos.

\section{Integración}

En el discurso se hacen varias referencias a la unión de todos los franceses. Algunos ejemplos de esto son notre meilleure arme, c'est notre unité, l'unité de tous nos concitoyens face à cette épreuve. Rien ne peut nous diviser, rien ne doit nous opposer, rien ne doit nous séparer ; j'invite toute la popula- 
tion à s'y associer [refiriéndose al día de duelo nacional] o le rassemblement de tous, sous toutes ses formes, voilà ce qui doit être notre réponse.

Aunque no se haga referencia explícita a quién tiene que unirse, el uso de tous y las invitaciones a toda la población, suponen un intento de generar un nosotros adscrito a la cadena descrita más arriba. Este llamamiento a la unidad reviste de importancia al haber definido a los agresores como fundamentalistas, ya que la asociación es sencilla.

Chérif y Said Kouachi eran franceses nacidos en París, de rasgos árabes y musulmanes, por lo que las posibles asociaciones posteriores Islam-terrorismo eran un riesgo evidente teniendo en cuenta, además, el tratamiento de algunos medios de comunicación, como France 24, de los acontecimientos de CH (Polonska-Kimungyi y Gillespie, 2016), como así se confirmó en el informe del Collectif contre l'islamophobie en France (2016), donde se mostró una correlación evidente entre los atentados de enero y el número de actos relacionados con la islamofobia, registrandose un total de 162 ese mes frente a un 67,5 de media el resto de meses del año.

\subsubsection{Discurso de François Hollande el 13 de noviembre de 2015}

\section{Membership categorization}

El discurso se inicia con un párrafo que recoge lo descrito en las dos primeras etapas:

Mes chers compatriotes,

Au moment où je m'exprime, des attaques terroristes d'une ampleur sans précédent, sont en cours dans l'agglomération parisienne. Il y a plusieurs dizaines de tués; il y a beaucoup de blessés, c'est une horreur.

No es necesario que se defina a los autores, basta con la descripción de los actos y sus consecuencias para reavivar el binomio nosotros/ellos, que ya se creó durante los ataques en $\mathrm{CH}$, por lo que con una cantidad menor de palabras se consigue repetir la estructura de introducción del discurso del 7E, repitiendo incluso la entrada al cuerpo del texto (mes chers compatriotes).

Posteriormente, aparece una referencia clara a la etapa cuarta, al afirmar c'est une terrible épreuve qui une nouvelle fois nous assaille. Nous savons d'où elle vient, qui sont ces criminels, qui sont ces terroristes, donde se aso- 
cian los pares nosotros/ellos a ellos-terroristes/criminels y nosotros, por tanto, víctimas

A partir de este pequeño fragmento, el resto del discurso gira en torno a las etapas siete y ocho.

Face à la terreur, la France doit être forte; elle doit être grande et les autorités de l'Etat, fermes son algunos ejemplos de la etapa séptima, finalizando con nous le serons, donde se aprecia el paso de una a otra.

Uno de los párrafos es especialmente interesante por el enlace entre la etapa tercera, la séptima y la octava:

Ce que les terroristes veulent, c'est nous faire peur, nous saisir d'effroi. Il y a effectivement de quoi avoir peur, il y a l'effroi. Mais il y a, face à

l'effroi, une Nation qui sait se défendre, qui sait mobiliser ses forces et qui une fois encore saura vaincre les terroristes.

El párrafo comienza anunciando el objetivo psicológico (ce que les terroristes veulent, c'est nous faire peur, nous saisir d'effroi. Il y a effectivement de quoi avoir peur, il y a l'effroi) para anunciar el fallo de este objetivo (Mais il y a, face à l'effroi, une Nation qui sait se défendre) y finalizar con una preparación de acciones mostrando la determinación de enfrentar ese miedo (qui sait mobiliser ses forces et qui une fois encore saura vaincre les terroristes).

Por último, para reforzar la confianza en los aparatos del Estado, Hollande hace una petición que será fundamental para anular la posible resistencia al establecimiento del estado de excepción y que facilitará el refuerzo del par nosotros en contra del ellos: Je vous demande de garder ici toute votre confiance dans ce que nous pouvons faire avec les forces de sécurité pour préserver notre Nation des actes terroristes.

\section{Información}

A diferencia del discurso de $\mathrm{CH}$, este tiene una mayor carga informativa.

Se describen los acontecimientos ocurridos, pero, sobre todo, se anuncian las medidas adoptadas para revertir la situación.

En primer lugar, se anuncia una movilización del mayor número de efectivos posibles para neutralizar a los terroristas y, a continuación, el decreto del estado de excepción y el cierre de fronteras. 


\section{Integración}

Comparando con el discurso anterior, en este no apenas hay referencias explícitas a la unidad.La única identificable es nous devons également faire preuve d'unité et de sang-froid, en el resto del texto no hay ninguna referencia.

16.3.3.3. Discurso de François Hollande el 14 de julio de 2016 Membership categorization

La primera etapa se condensa en una sola oración:

L'horreur... L'horreur de nouveau vient de s'abattre sur la France.

Como ya se ha indicado, no es necesario ahondar en la definición de los pares y simplemente es necesario reforzar la diferencia previa.

Cuando se indica l'horreur no es necesario definir a los agresores, sus identidades están claras para los receptores pese a no ser explícitas puesto que se genera una relación entre este ataque y los anteriores (de nouveau) y, por tanto, la validez de las conexiones de las otras situaciones son aplicables ahora.

La segunda y la cuarta etapa se desarrollan a continuación, donde se describe, de nuevo, a los agresores mediante la narración de sus actos sin revelar su identidad indicando las consecuencias físicas del ataque y reforzando la relación nosotros-víctimas/ellos-asesinos:

Nous déplorons à l'instant où je parle 77 victimes dont plusieurs enfants et une vingtaine de blessés en urgence absolue. Cette attaque, dont le caractère terroriste ne peut être nié, est encore une fois d'une violence absolue.et une vingtaine de blessés en urgence absolue.

Aquí se indica la naturaleza de ataque terrorista, sin indicar de qué tipo, para posteriormente definirlo como islamiste y a sus ejecutores como fanatiques.

En el párrafo donde se define a los agresores como fanatiques, se encuentra la etapa quinta:

La France a été frappée le jour de sa fête nationale, le 14 juillet, symbole de la liberté, parce que les droits de l'Homme sont niés par les fanatiques, et que la France est forcément leur cible. 
Se establece de nuevo una conexión de cadena Francia-14 julio-libertad, que implícitamente sugiere que Francia representa la libertad, a lo que se añade la alusión a los derechos del Hombre como resultado del 14 de julio para reforzar esa relación y referirse a los atacantes como enemigos de la libertad al indicar que sont niés par les fanatiques [los derechos del Hombre], et que la France est forcément leur cible.

Las etapas tercera y cuarta se encuentran enlazadas al final del texto:

La France est affligée par cette nouvelle tragédie. Elle est horrifiée par ce qui vient de se produire, cette monstruosité qui consiste à utiliser un camion pour tuer, délibérement tuer, des dizaines de personnes qui venaient simplement pour fêter le 14 juillet.

Aquí se observa la asociación nosotros-víctimas/ellos-asesinos, que resulta más clara incluso que en los otros discursos ya que la descripción dada facilita la relación víctima-asesino si se piensa en el desarrollo del ataque, donde un camión embiste a personas en la calle, lo que niega toda posibilidad de escapar o poder defenderse para personas pacíficas qui venaient simplement pour fêter le 14 juillet.

Justo después de esta etapa se encuentra la tercera que se condensa, al igual que la entrada al discurso, en una sola oración:

La France, elle est éplorée, elle est affligée mais elle est forte, et elle sera toujours plus forte

Aquí se indica de forma implícita el fallo en el objetivo psicológico indicando que pese a la violencia del ataque esto no solo no va a afectar a la determinación de Francia, sino que la va a convertir en más fuerte.

Las etapas séptima y octava están dispersas por el texto:

Notre arsenal législatif a été considérablement renforcé. Mais nous devons, puisque nous sommes dans une période estivale, rehausser encore notre niveau de protection.

En este extracto se aprecia la preparación del terreno para posteriores acciones, al indicar que pese a haberse reforzado el arsenal legislativo, se 
debe mejorar el nivel de protección, lo que introduce la posibilidad de nuevas acciones en el futuro próximo para combatir la amenaza.

Entre otras, una de las medidas puede categorizarse dentro de la octava categoría, donde la víctima pasa a ser buscador de justicia:

Rien ne nous fera céder dans notre volonté de lutter contre le terrorisme et nous allons encore renforcer nos actions en Syrie comme en Irak.

Aquí se observa un cambio sustancial en el enfoque que recuerda a la intervención de George W. Bush (Bush, 2001) tras el 11S al colocar el foco contra el terrorismo tanto en el interior como en el exterior. Este es un enfoque usual en la política norteamericana (véase Gamarra, 2007), no así en la europea, donde generalmente el terrorismo se ha considerado como un problema de ámbito policial y no militar.

\section{Información}

Al igual que en el caso del $13 \mathrm{~N}$, y a diferencia del de $\mathrm{CH}$, este discurso tiene una carga informativa alta.

Tras la descripción de los hechos, se anuncian diferentes medidas para contrarrestar la situación en el territorio. Entre otras, se decide mantener la Operación Centinela ${ }^{2}$ a su nivel máximo, desplegar 10.000 efectivos militares y aumentar la vigencia del estado de excepción que se decretó el 13 de noviembre de 2015 tres meses más, así como el refuerzo en los controles de las fronteras.

\section{Integración}

A diferencia de los discursos anteriores, en este no hay ninguna referencia explícita a la unidad de todos los franceses o que pueda interpretarse como un llamamiento a toda la población.

\subsection{Conclusiones}

En este texto se han analizado tres discursos de François Hollande correspondientes al $7 \mathrm{E}, 13 \mathrm{~N}$ y $14 \mathrm{~J}$.

2 La Operación Centinela contempla el despliegue de efectivos militares en territorio francés para labores de vigilancia antiterrorista y protección de puntos sensibles. Fuente: Ministère de la Défense. 
La elección de estos discursos, y no otros relacionados, se justifica por la lógica expresada sobre la existencia de dos tipos de discursos dependientes de las situaciones de excepcionalidad política que se han dado en llamar el discurso de la seguridad suficiente y el discurso de la excepcionalidad, abordado aquí.

Se ha planteado el discurso de la excepcionalidad como una transición entre un periodo de no-anomalía a otro de anomalía política en el que el elemento fundamental del discurso es la creación de identidades y su definición respecto de las características del propio grupo en el que «el "nosotros", que precisa de "ellos"» (Connor, 2008, p.51) es «superior y más moderno» (Holland, 2012, p.82).

En los tres discursos analizados aparecen siete de las ocho etapas inferidas de Leudar et al. (2004). Solamente hay una que no es identificable en ninguno de ellos, la sexta, definida como enfrentamiento ideológico.

Como se indica en Holland (2012, p.82) «en contraste con las llamadas de Bush a la comprensión teológica del diablo entre los religiosos americanos ${ }^{3}$, Blair se dirigió al Dios de la Inglaterra Media: el sentido común (Asch, 2005, pp.28-29)», pues bien, en este caso, Hollande no se dirige al Dios francés, el laicismo, simplemente no configura los pares del conflicto como enfrentados en base a criterios ideológicos o de carácter religioso, sino que lo hace en una aproximación en la que se contraponen libertad contra amenaza.

En cuanto al orden de aparición de las etapas, no necesariamente coinciden con el inferido de Leudar et al. (2004), lo cual no es realmente relevante, ya que lo importante es la presentación de las etapas y no su orden.

Así mismo, si se comparan los tres discursos aparecen tendencias significativas que dibujan un patrón de continuidad en el tiempo y de conexión entre ellos.

En primer lugar, aumenta de forma significativa el volumen de información ofrecida en el discurso. Si en el discurso referente al 7E el porcentaje de información ofrecido es del $20,5 \%$, en el del $13 \mathrm{~N}$ y el $14 \mathrm{~J}$ son el $36,91 \%$ y el $51,98 \%$, respectivamente.

3 «Aunque pase por el valle de sombra de muerte, no temeré mal alguno, porque tú estás conmigo» (Bush, 2001) (Correspondiente a Salmos 23). 
Relacionado de forma inversa, a medida que se dan rupturas de la normalidad en los contextos social y político, la capacidad integradora de los discursos va disminuyendo hasta desaparecer, desde el 9,4\% el 7E hasta el $0 \%$ el $14 \mathrm{~J}$, pasando por un $1,4 \%$ el $13 \mathrm{~N}$.

Esta relación entre información e integración señala directamente las prioridades del gobierno respecto de la realidad y es una muestra clara de la intención de mostrar a los ciudadanos la capacidad de enfrentar y atajar la amenaza, algo a lo que Hollande se refirió de forma explícita el $13 \mathrm{~N}$, y que por otro lado muestra que lo urgente, a medida que aumentan los ataques, no es la integración sino el combate.

Otra tendencia relacionada con esto, y que viene a reforzar el párrafo anterior, es que a medida que se encadenan los discursos, se observa la preeminencia de las etapas séptima y octava del MCA respecto de todas las demás.

Esto reforzaría la idea de que la prioridad del gobierno es preparar el terreno social para la introducción de acciones destinadas a revertir la situación y a mostrar determinación pasando de ser víctima a guardián de la seguridad de las masas, «a veces incluso por encima de sus propios derechos» (Myhen y Walklate, 2008, p.234, citado en Ahmed, 2015, p.7; Holland, 2011).

Al margen de la discusión de resultados es necesaria una reflexión profunda sobre el después del discurso de la excepcionalidad y del de la seguridad suficiente, es decir, sobre las acciones que se introducen mediante ellos.

Dichas acciones, que se presentan como inevitables por la interpretación del contexto, llevan a una expansión del control social que «normaliza la amenaza terrorista» (Jackson, 2013, p.271, citado en Ahmed, 2015, p.4) legitimando al gobierno y, por implicación, a las medidas de excepcionalidad como necesarias para mantener la seguridad nacional y evitar la repetición de nuevas escenas de terror (Hollis-Touré, 2016), lo que cierra el círculo en torno a la expansión del control social, que se convierte en «legítimo» $\mathrm{y}$ «necesario».

En el momento en que esto se produce se genera una nueva narrativa del sentido de la nación que lleva aparejada consecuencias que amenazan la supervivencia de los sistemas democráticos como tal ya que, entre otras, requieren una adhesión a la nueva interpretación social y política.

En Holland (2011), Hollis-Touré (2016) y Kiwan (2016) se evidencian los intentos de creación de una narrativa y una interpretación «patriótica» de 
los sucesos terroristas en los que la función de los ciudadanos consiste en apoyar al gobierno en la guerra antiterrorista (Holland, 2011), lo que implica que una visión alternativa sitúa a los individuos fuera de la nueva idea de «nación» (Hollis-Touré, 2016).

Kiwan (2016) afirma:

El estado de excepción post-Charlie Hebdo requirió de «buenos ciudadanos franceses» que apoyaran la línea editorial de Charlie Hebdo y de «buenos intelectuales franceses» que pusieran el foco en las consecuencias observando las normas y valores republicanos: libertad [de expresión] y laicismo (por delante de igualdad y fraternidad) y la amenaza para su supervivencia. (p.242)

Los estados de excepción y las medidas excepcionales parecen haber conducido en el pasado reciente a lo que Friedrich (1941, p.812, en Agamben, 2010, p.18) denominó como «dictadura constitucional», que, mediante medios excepcionales, «se propone salvaguardar el orden constitucional».

Al margen de estas consideraciones, lo cierto es que el estado de excepción sí parece haberse «emancipado de una situación bélica [...] para ser utilizado como medida de policía extraordinaria frente a desordenes y sediciones internas, convirtiéndose así en ficticio o político, en lugar de efectivo o militar» (Agamben, 2010, p.15).

\subsection{Referencias}

AGAMBEN, G. (2010). Estado de excepción: Homo Sacer II, 1. Valencia: Pre-Textos.

AHMED, S. (2015). The «emotionalization of the "war on terror"»: counter-terrorism, fear, risk, insecurity and helplessness. Criminology \& Criminal Justice, 15(5), 1-16.

ASSAMBLÉ NATIONALE. (05 de 05 de 2015). Analyse du scrutin $n^{\circ} 1109$. Obtenido de http://www2.assemblee-nationale.fr/scrutins/detail/\%28legislature $\% 2$ 9/14/\%28num\%29/1109

BUSH., G. W. (11 de 09 de 2001). The White House. Obtenido de https://georgewbushwhitehouse.archives.gov/news/releases/2001/09/20010911-16.html

COLLECTIF CONTRE L'ISLAMOPHOBIE EN FRANCE. (2016). Rapport 2016. Obtenido de www.islamophobie.net: http://www.islamophobie.net/sites/ default/files/Rapport-CCIF-2016.pdf

CONNOR, W. (1998). Etnonacionalismo. Madrid: Trama Editorial.

FAIRCLOUGH, N. (1995). Critical Discourse Analysis: papers in the critical study of language. Singapore: Longman Publishing. 
FAIRCLOUGH, N. (2008). El análisis crítico del discurso y la mercantilización del discurso público: las universidades. Discurso \& Sociedad, 2(1), 170-185.

GAMARRA, Y. (2007). La defensa preventiva contra el terrorismo internacional y las armas de destrucción masiva: una crítica razonada. Revista CIDOB d'Afers Internacionals(27), 227-251.

HOLLAND, J. (2011). «When you think of the Taliban, think of the Nazis»: Teaching Americans '9/11' in NBC's The West Wing. Millenium: Journal of International Studies, 40(1), 85-106.

HOLLAND, J. (2012). Blair's War on Terror: Selling Intervention to Middle England. The British Journal of Politics and International Relations, 14, 74-95.

HOLlande, F. (07 de 01 de 2015a). Présidence de la République. Obtenido de http://www.elysee.fr/declarations/article/allocution-a-la-suite-de-l-attentat-ausiege-de-charlie-hebdo/

HOLlande, F. (13 de 11 de 2015b). Présidence de la République. Obtenido de http://www.elysee.fr/declarations/article/declaration-du-president-de-la-republique-a-la-suite-des-attaques-terroristes-a-paris/

HOLlande, F. (14 de 07 de 2016). Présidence de la République. Obtenido de $\mathrm{http} / / / \mathrm{www}$. elysee.fr/declarations/article/declaration-a-la-suite-des-evenementsde-nice-2/

HOLLIS-TOURÉ, I. (2016). The multidirectional memory of Charlie Hebdo. French Cultural Studies, 27(3), 293-302.

KIWAN, N. (2016). Freedom of thought in the aftermath of the Charlie Hebdo attacks. French Cultural Studies, 27(3), 233-244.

LE MONDE. (1 de 04 de 2015). La galaxie des opposants au projet de loi sur le renseignement. Obtenido de http://www.lemonde.fr/pixels/visuel/2015/04/01/la-galaxie-des-opposants-au-projet-de-loi-sur-le-renseignement_4607266_4408996. html

LEUDAR, I., MARSLAND, V., \& NEKVAPIL, J. (2004). On membership categorization: «us», «them» and «doing violence» in political discourse. Discourse \& Society, 15(2-3), 243-266.

LOI ${ }^{\circ}$ 2015-912 du 24 juillet 2015 relative au renseignement. (26 de 07 de 2015). Journal Officiel de la République Française. France.

POLONSKA-KIMUNGYI, E., \& GILLESPIE, M. (2016). Terrorism discourse on French international broadcasting: France 24 and the case of Charlie Hebdo attacks in Paris. European Journal of Communication, 31(5), 1-16.

RESCASENS I BRUNET, A. (2007). La seguridad y sus políticas. Barcelona: Atelier Libros.

SACKS, H. (1972). An initial investigation of the usability of conversational data for doing sociology. En D. Sudnow, Studies in Social Interaction (págs. 31-74). The Free Press.

SACKS, H. (1995). Harvey Sacks: Lectures on conversation: Volumes I \& II. (G. Jefferson, Ed.) Cornwall: Blackwell Publishing. 
SOLOMON, T. (2009). Social logics and normalisation in the War on Terror. Millenium: Journal of International Studies, 38(2), 1-26.

STOKOE, E. (2012). Moving forward with membership categorization analysis: Methods for systematic analysis. Discourse Studies, 14(3), 277-203. 



\title{
EL DERECHO COMO IDEAL REGULATIVO DE LAS POLÍTICAS DE PAZ EN TIEMPOS DE MIEDO AL DESPOTISMO DE LA INCERTIDUMBRE
}

\author{
Paz Tabales, Fernando \\ Universidad de Zaragoza \\ Graduado en Filosofia \\ Master en Sociología de las Políticas Públicas y Sociales \\ fernandopaztabales@hotmail.com
}

\subsection{Introducción: Filosofía del Derecho y globalización}

Nos encontramos aquí con la intervención de alguien que intenta filosofar en un Congreso de Sociología. Concretamente, de alguien que intenta pensar filosóficamente el Derecho en un espacio como éste, dedicado a introducirnos sociológicamente en la cuestión de la globalización, en al menos dos dimensiones: la facticidad de la desigualdad que ha generado y genera y la posibilidad de nuevas insurgencias. Necesariamente, por tanto, es ésta una intervención intempestiva, que irrumpe reclamando un espacio propio, inasequible a ninguna ciencia. Si este espacio del pensamiento puede ser reducido al sentido de una ciencia, no sabemos cuál, entonces el cientificismo tiene razón y la filosofía no tiene sentido. Pero no nos pongamos dramáticos, Filosofía y Sociología se pueden llevar bien, incluso acceder a algo así como una iluminación recíproca. Yo mismo, si bien me he dedicado y me dedico a la Filosofía, he realizado un Máster de Sociología en esta casa, que nos acoge. Si se me concede en este espacio la posibilidad de una intervención filosófica, espero convencer de su conveniencia.

El asunto que he decidido tratar es la conexión entre derecho y política, esta vez para hablar de una paz posible destinada a minimizar la fáctica incertidumbre vivida, ciertamente generalizada. Cualquier lectura cotidiana de cualquier periódico, sobre todo en esta última década, nos hace temer fenómenos tales como la prima de riesgo, las barreras psicológicas de puntos en las bolsas, los movimientos de los fondos de capital riesgo popularmente co- 
nocidos como «fondos buitre» y en general lo que pase globalmente y pueda llegar a ser relevante para los todopoderosos «mercados», sea en un viñedo del Campo de Borja o en un rinconcito de China. Esta intervención no está destinada a constatar sociológicamente esta percepción, ni a constatar económicamente su correlato real o tratarla como meramente imaginaria Tampoco pretendo dilucidar históricamente su trayectoria. Modestamente deseo introducir un elemento, el elemento jurídico en sentido estricto, como ideal regulativo a la hora de gestionar esta percepción que considero generalizada. A esta percepción la he dado en llamar miedo, concretamente: miedo al despotismo de la incertidumbre. Veremos el motivo.

Sin duda hay muchas preguntas que contestar, y poco tiempo. No olvidemos que la filosofía no trata de una verdad óntica al estilo de las ciencias, ni pretende decirnos lo que hay que hacer al estilo de la política, sino que kantianamente trata de desvelar los juicios secretos de la razón común, esto es, merleaupontianamente, todo su fondo de irracionalidad. Así, la razón común es un campo de batalla para ideales regulativos, y el derecho en sentido estricto es una posibilidad, con suerte un porcentaje. Algo haremos, con todo. ¿Qué es el derecho, en primer lugar? Aquí daremos una definición provisional, aparentemente ingenua -nada más lejos, si uno dedica el tiempo suficiente al estudio de esta pregunta-. ¿Qué significa que lo entendamos como ideal regulativo? Sin duda, tiene efectos en su concepción misma. ¿Qué puede ser eso de la política?

¿Cuál es el criterio para hablar de paz? Y todo junto: ¿qué puede ser una política de paz? Ya hemos pasado poco más de la mitad de nuestro título, pero quedan: miedo, despotismo, incertidumbre. Para tratar conceptualmente, fenomenológicamente, estas cuestiones, me valdré de clásicos como Montesquieu o Kant. Cerrado esto, emplearé por un lado a Boaventura de Sousa Santos, por el otro a Luigi Ferrajoli. Sin duda seré injusto con todos aquellos que me sirvan de herramientas, pero dado que no intervengo con ánimo de sentar cátedra sobre lo que quisieron decir o dejar de decir, solicito me excusen de antemano. Comencemos.

\subsection{Breves apuestas conceptuales}

Entiendo por derecho lo siguiente: «el conjunto de condiciones bajo las cuales el arbitrio de uno puede conciliarse con el arbitrio del otro según una ley universal de la libertad» (Kant, 2012: 39). Esto no es ni la medida del derecho privado generalizado, ni es lo que se ha solido entender -en mi opinión 
malentender- por iusnaturalismo. Tampoco es algo así como un epifenómeno, una fantasmagoría superestructural que funciona ideológicamente al servicio de la estructura económica capitalista. Si tuviera que denominar de alguna manera mi manera de pensar el Derecho, la catalogaría de iuspublicismo racional. Pero dejaré esto a un lado, por inoportuno. Defiendo que, en toda su generalidad e inconcreción, es la formulación más pura de la Idea de Derecho, del Derecho Posible o Derecho Virtual. O también: la presento como mi candidata a la formulación más pura de los presupuestos ontológicos de todo derecho, más acá de todos aquellos prejuicios que nos toca poner entre paréntesis. Esta definición provisional es resultado de una reducción fenomenológica, el derecho en sentido estricto una vez llevada a cabo la epojé.

Que todo arbitrio sea, en general, conjugable según «una ley universal de la libertad» significa algo más fácil de decir que de comprender, y mucho más fácil que de hacer en nuestra contingencia infinita: que cualquiera pueda hacer realidad su voluntad siempre y cuando esta satisfacción del deseo sea conjugable con en principio cualquier otra satisfacción del deseo que a su vez satisfaga la susodicha condición de satisfacción. Dicho de otra manera: al no sólo haber vivencia del deseo sino también y siempre el problema de la convivencia, nuestra definición de derecho es una definición de posible gestión de dicha convivencia. ¿Por qué esta gestión, y no otra? Porque pretende, además, ser racional, en el sentido hobbesiano o humenao de que está al servicio de las pasiones en general, en dos de sus sentidos: pasiones como inclinaciones y como padecimientos. La Idea de Derecho se caracteriza así por pretender la justa convivencia de inclinaciones y padecimientos o también, dicho en términos utilitaristas, por la maximización del placer general -en tanto que minimización del dolor general-.

El ideal regulativo jurídico significa aquí, weberianamente, que hablamos de normas y no de hechos. Nuestra posición filosófica es en este sentido ideológicamente neutral, pero axiológicamente normativa (con respecto a principios y no a valores, pues hablamos de derecho en sentido estricto, y no de ética). Tratamos así, idealmente, de conseguir una convivencia more geometrico. Podemos citar a otro clásico como Leibniz a este respecto:

La doctrina del derecho es de la índole de aquellas ciencias que no dependen de experimentos, sino de definiciones, no de las demostraciones de los sentidos, sino de las de la razón, y son, por así decirlo, propias del derecho y no del hecho (...) sus principios son todos ellos condicionales, y ni siquiera necesitan que algo exista, sino que se siga algo a su supuesta existencia (...) No se 
derivan de los sentidos sino de una imaginatio clara y distinta, que Platón denominaba Idea, y que cuando se expresa con palabras es lo mismo que la definición (...) Así pues (...) puede entenderse que algo es justo, aunque no haya quien ejerza la justicia (...) de manera semejante a como los cálculos matemáticos son verdaderos, aunque no haya ni quién numera ni qué numerar... (Leibniz, 1991: 70-71)

Bien, ¿y qué entender, al fin, por lo político? Aquí apostamos conceptualmente por entender el ser político en relación con el deber ser jurídico o, dicho de otra manera: entender que política es lo que no habría si el asunto del Estado de Derecho fuera un asunto meramente constatativo, de blancos y negros, y no tan grisáceo como de hecho es. El asunto es que la Forma Derecho no parece ofrecer un ordenamiento jurídico en positivo, y en este ser frío e indiferente de la forma emerge lo político, la parte luchando por encarnar el todo. Observamos esta idea en textos de Hegel o Lacan y, más recientemente y en relación con lo político mismo, en La razón populista de Ernesto Laclau. Ésta es también la lectura que hace Carl Schmitt sobre el movimiento histórico- espiritual burgués. Oswald Spengler decía que el pueblo alemán no podía «vivir sin una forma que nos sirva de algo más que de un simple consuelo en las situaciones difíciles» (Watson, 2017: 52). Lo político nace desde ese ánimo totalitario, desde la necesidad de algo más que el «simple consuelo» de tener razón jurídica en sentido estricto, pues esta razón es aparentemente, como le gusta decir a Sousa Santos, Razón indolente.

Creo que la política es nuestro medio insuperable de convivencia, y la entiendo schmittianamente como la situación que es siempre ya decisiva, en el sentido de ser una decisión pre-racional en «la distinción política específica (...) de amigo y enemigo» (Schmitt, 2014: 59) y, consiguientemente, en el asunto de la paz. O, con Debray: la política es el «plano de realidad específica delimitado por la formación y la disgregación de los grupos humanos» (Debray, 1983: 41), es decir, una dimensión de la existencia que implica la posibilidad de la guerra.

El derecho puede idealmente regular lo político, más allá del mero «es gibt», como único deber ser posible post-muerte de Dios, esto es, atendiendo a una - pretendida- utilidad universal y no a este o aquel valor en el juego de La tiranía de los valores. La irreductibilidad de lo político planteada aquí implica a su vez la imposibilidad de que el ideal jurídico estricto sea real, pero esta 
imposibilidad es aquí entendida freudianamente: esto es, como aquello que hay que dilucidar para iluminar la facticidad con ideas que desahoguen y den respiro, que sean útiles. En esta intervención, una idea pacifista, recogiendo el guante de Norberto Bobbio. Pero, ¿qué puede significar esto tan intrínsecamente difuminado de la paz? Sabemos cuando leemos a los grandes como Hobbes que es en este principio en el que se basan las teorías del contrato social. Conviene citar al respecto a un pensador más reciente, de la talla de Ferrajoli:

Éste es un principio -iuris et in iure- del estado de derecho tan obvio como desatendido (...) significa (...) que el derecho es la negación de la fuerza desregulada y que la fuerza desregulada es la negación del derecho. Bien podemos llamar a este principio «principio de la paz» (...) puede definirse como la expectativa del no uso desregulado de la fuerza, o bien de su único uso que es el regulado por normas hipotético-deónticas como reacción, taxativamente prevista y limitada, a un acto ilícito. En este sentido la paz es la negación del bellum omnium (Ferrajoli, 2011a: 445)

El principio de paz funciona aquí al modo kantiano de los «principios metafísicos de la doctrina del Derecho» (Kant, 2012: 5), siendo su específico motor inmóvil, precisamente el principio de los principios, el principio supremo que equivale a la satisfacción del término técnico de garantías. El derecho exige de la política respuestas públicas que puedan ser políticas de paz efectivas contra la violencia desregulada y global. En nuestro actual contexto de bellum omnium o ausencia de garantías, esto significa políticas que ayuden a mitigar el miedo, sobre todo el miedo a la incertidumbre. De nuevo, cualquier vistazo fugaz a cualquier periódico nos hace temer en general, adoptar el temor como forma de vida. Esto se incrementa cuando se acercan momentos electorales: ya nos hemos acostumbrado a votar respirando el miedo a las represalias de los «mercados», e incluso hemos vivido momentos calificados por muchos como «tecnocráticos»y «postdemocráticos».

Dice Montesquieu que «en un Gobierno despótico es necesario el temor» (Montesquieu, 2012: 68). Asumiendo algo del estilo de Remo Bodei, podemos pensar el miedo como una interrupción en el proceso racional de cálculo de estrategias para la consecución de la paz o las garantías, es decir, la interrupción del cálculo del que hablábamos citando a Leibniz. Es aquello que por definición intranquiliza, inquieta, prepara para la guerra. Las consecuencias de que el miedo sea el principio-motor de una sociedad podemos leerlas, por ejemplo, en Los miserables de Victor Hugo. Sus síntomas nos rodean y penetran, en el 
estado colectivo de neurosis y compulsión que vivimos, ante el gran riesgo, la incertidumbre generalizada. Los tan cotidianamente llamados «mercados» no son legisladores sobre el papel pero necesitan el miedo a la incertidumbre para poder actuar como si lo fueran. Y prefieren La doctrina del shock al espíritu de moderación reclamado por Montesquieu y hoy tan anticuado. Es despotismo porque en esta situación no se respeta la «ley universal de la libertad» antes citada, y se interviene en los Gobiernos de no pocos países -el FMI es paradigmático a este respecto-.Y hay incertidumbre generalizada cuando no sabemos qué nos cabe esperar ni qué podemos hacer, por mucho que nos esforcemos - el tan cacareado lema de la «flexiseguridad» funciona aquí a modo de ejemplo-. Esto es «lo que hay», «es gibt», y lo vamos a desarrollar mínimamente, a la par de lo que podría haber y que aparece como un decir que hace del hacer actual una transgresión con respecto a sí mismo. Nuestro decir es así apofántico, pues muestra algo, un decir posible, la insurgencia del derecho en sentido estricto, de algo, el hacer fáctico, la globalización realmente existente.

\subsection{Globalización fáctica e insurgencia posible}

Aceptamos aquí la interpretación paradigmática de Immanuel Wallerstein, que la inscribe en El capitalismo histórico en el proceso de mercantilización de todas las cosas o «mercantilización generalizada» (Wallerstein, 2012: 11). Se trata del paso a un nuevo régimen de acumulación, y hablamos aquí en los mismos términos en los que hablaron no pocos teóricos a principios del XX cuando empleaban el término «imperialismo». Wallerstein es pesimista a este respecto, y piensa que vamos a estar en crisis al menos hasta el final del siglo XXI. Esto ahora nos importa poco, pues lo que nos interesa es palpar la violencia inherente a este proceso, más acá de sus crisis. Quizás para este propósito Giddens no nos valga, si bien dice algo cierto: se trata de «la intensificación mundial de las relaciones sociales que vincula localidades distantes, de tal manera que los acontecimientos locales son modelados por eventos que tienen lugar a muchas millas de distancia y viceversa» (Sousa Santos, 2009: 293). Sousa Santos pone más el énfasis en el movimiento violento de la parte hacia el todo, y por tanto aquí nos sirve mejor:

Ésta es mi definición de globalización: un proceso a través del cual una determinada condición o entidad local amplia su ámbito a todo el globo y, al hacerlo, adquiere la capacidad de designar como locales las condiciones o entidades rivales. Las consecuencias más importantes de esta definición son las que siguen. Primero, en las circunstancias del sistema mundo capitalista occidental 
no hay una globalización genuina. (...) La segunda de las consecuencias es que la globalización conlleva la localización (Ibídem: 309)

Es sintomático que acto seguido Sousa se ponga a hablar de Hollywood a modo de ejemplo de la «localización» implicada. Es justamente aquí EE. UU., y no otra «localización», el enemigo fáctico más poderoso del derecho en tanto que ideal regulativo de toda política de paz en tiempos de globalización. Lo vamos a ver con Sousa y con Ferrajoli, pues como ya nos enseñó Tucídides en sus Guerras del Peloponeso, el menos interesado en que reine la Idea de Derecho es el más poderoso, el más fuerte en estado de naturaleza, de bellum omnium. Es principalmente por la parte de EE. UU., como «localización», que nuestra «embrionaria constitución del mundo, la Carta de la ONU, la Declaración Universal de Derechos Humanos de 1948, los dos Pactos sobre los derechos de 1966» (Ferrajoli, 2011b: 475), es papel mojado.

Esto se ve muy bien en un ejemplo entre tantos de Sousa, que creo aquí importante comentar. Vamos a ver en este ejemplo como todo el derecho de gentes, todo el «derecho cósmico» de Pitágoras, toda la «comunidad internacional» de Vitoria, Suárez o Grocio, toda la «jurisprudencia universal» de Feuerbach, todo el cosmopolitismo de la «paz perpetua» de Kant o el «internacionalismo» de Marx en pos de un derecho que supere su obstáculo antijurídico burgués, no va de suyo, y que tiene razón Kant cuando dice que «no es un estado de naturaleza (...) debe, por tanto, ser instaurado» (Kant, 2013: 16). El ejemplo gira sobre el concepto de patrimonio común de la humanidad, y pertenece al ius humanitatis. El campo de batalla es, claro está, la ONU. Habla Sousa Santos:

(...) el ius humanitatis expresa la aspiración a una forma de gobierno de los recursos naturales o culturales que, dada la extrema importancia de éstos para la sostenibilidad y la calidad de la vida sobre la tierra, deben considerarse como propiedad global y utilizarse en beneficio de la humanidad como un todo, tanto presente como futura. (...) choca con dos principios dominantes del paradigma dominante: la propiedad (...) y la soberanía (...) No sorprende, entonces, que su aplicación haya sido tan reducida hasta ahora (...) está basada en principios que, si se desarrollasen plenamente, acarrearían la bancarrota del paradigma dominante (...) El concepto de patrimonio común de la humanidad fue formulado por primera vez en 1967 por el embajador de Malta ante la ONU, Arvid Pardo, en relación con las negociaciones de la ONU sobre la regulación internacional de los océanos y el lecho submarino (...) Desde entonces (...) ha sido aplicado (...) [a] la Luna, el espacio exterior y la Antártida. (...) Cinco elementos se asocian usualmente con el concepto de herencia común de la humanidad: no apropia- 
ción; administración por todos los pueblos; participación internacional en los beneficios obtenidos (...) uso pacífico (...) y conservación para las generaciones futuras (Sousa Santos, 2009: 436-437)

Lentamente esta propuesta del embajador maltés siguió adelante, y desembocó en la Convención sobre el Derecho del Mar, firmada en 1982. Como podemos imaginar, si pensamos en el año sobre todo, EE.UU., particularmente la Administración Reagan, en su parcial interés en la globalización realmente existente, no estaba por la labor de semejante emancipación universal. Merece en este sentido seguir leyendo a Sousa:

La posición de los Estados Unidos en este tema está bastante clara en la declaración de la Oficina de Información sobre Políticas de la Casa Blanca, fechada el 15 de abril de1983. La Convención sobre el Derecho del Mar «transfiere el control de los minerales oceánicos a una autoridad internacional dominada por Estados del Tercer Mundo, que son abiertamente hostiles a los enfoques del libre mercado y a los intereses de las naciones industrializadas del mundo libre...» (Ibídem: 439)

Atención, porque vamos a ver que la insurgencia presentada no es contra toda autoridad, esto es, no es una insurgencia anarquista. Aceptamos las palabras del enemigo del derecho en sentido estricto: el derecho como ideal regulativo de las políticas de paz, políticas que no den miedo sembrando incertidumbre, conlleva la transferencia de autoridad, de la parte al todo, es decir, el paso de la autoridad imperial a «la autoridad internacional». Esto, sin duda, no es un paraíso en la tierra, ni es un camino de rosas. Recordemos a Kant: es un campo de batalla en el que la paz debe ser instaurada, esto es, en el que la paz es una posibilidad, pero ciertamente la posibilidad intrínsecamente jurídica, y aquí hemos establecido que esto significa de pretendida utilidad universal. En este sentido concluye Sousa:

Aunque la Convención fue firmada originalmente por 159 Estados, se necesitaron doce años para que fuera ratificada por 60 Estados, que era el número requerido para que entrara en vigor. La Convención comenzó a regir en noviembre de 1994. Debido a la presión de los países industrializados (...) neutralizará o alterará algunas de las características más innovadoras del régimen del patrimonio común de la humanidad (Ibídem: 440)

Observamos aquí como el derecho es un ideal regulativo difícil, porque sin duda se marca un propósito difícil, en última instancia imposible, como 
decíamos: estar al servicio de las inclinaciones y padecimientos de la humanidad en tanto que conjunto total de los individuos sujetos de derechos. Es también, por tanto, una insurgencia racional posible ante una autoridad de hecho irracional, como observamos en la posición imperial de parte de EE. UU. El único imperio válido en términos jurídicos es el imperio de la ley (a este respecto, he pretendido desarrollar el concepto de ley en otro sitio ${ }^{1}$, en el que ley, libertad y garantías formaban un triángulo jurídico ideal que aquí no puedo desplegar). El derecho, sin duda, cuesta, pero aquí repetimos una pregunta típica en la obra de Ferrajoli, y clave tras lo que nietzscheanamente se popularizó como «muerte de Dios», esto es, tras el reconocimiento de la imposibilidad de fundamentar racionalmente ningún valor, más acá de la utilidad individual: ¿cuál es la alternativa?

Ferrajoli comparte con Sousa en que el intento de establecer la paz perpetua, el intento de que la ONU funcione efectivamente, atenta contra la distribución patrimonial de hecho (que soporta de hecho un movimiento mundial del capital y una mundial división del trabajo y del consumo) y contra lo que él considera una paradoja o aporía: la idea de soberanía, como afuera desregulado de la ley que hace la ley. Dejamos la profundización en este tema para una futura lectura de la obra del gran Carl Schmitt, ya que toca ir terminando. El asunto es que, ante el hobbesiano auctoritas, non veritas facit legem, ¿cuál es la auctoritas? Comparten aquí también Sousa y Ferrajoli que la posibilidad del Estado-nación pierde indefectiblemente fuerza, y que es necesario un cambio de paradigma, algo así como un Estadio mundial de derecho que haga frente a «las agresiones provenientes de la selva de los poderes desregulados, tanto políticos como económicos» (Ferrajoli, 2011b: 475b). Hace unos cuantos siglos, Beccaria empleó el derecho estricto como ideal regulativo intra muros del Estado, para intervenir contra sinsentidos tales como la pena de muerte o la tipificación como delito del suicidio. Sousa y Ferrajoli gestan el mismo movimiento intelectual, sólo que extra muros, para intervenir contra el sinsentido de la guerra. Tras desarrollar una primera conquista positiva del derecho en el siglo XX, a saber, la constitucionalización de los DDHH, Ferrajoli nos habla a este respecto de una segunda conquista:

Con la institución de la ONU, el derecho internacional pasó de ser un sistema de relaciones entre Estados soberanos basado únicamente en relaciones

1 Fernando PAZ TABALES, «¿Puede el derecho garantizar la diferencia como tal?», en La cuestión de la diferencia/ La diferencia en cuestión, Mira Editores, Zaragoza, 2016, pp. 447-458. 
de fuerza y por eso destinado a degenerar en la guerra mundial o de todos a ser un ordenamiento jurídico supraestatal que reúne a casi todos los Estados -191- y que se funda en la prohibición de la guerra y sobre los derechos fundamentales de todos los seres humanos (...) un pacto constitucional de convivencia (...) ordenamiento jurídico de tipo confederal (...) contrato social internacional, histórico y no metafórico (...) para sujetar a todos los Estados como pactum subiectionis y no sólo associaitionis, a un ordenamiento supranacional cuya razón social puede perfectamente identificarse con la garantía universal de paz y de los derechos humanos (Ibídem: 479)

Debe quedarnos claro que decir esto no es practicar la dudosa virtud de la ingenuidad. No: y este respecto «hay que añadir enseguida que estos cambios se han producido sólo sobre el papel» (Ibídem: 479). Pero la pregunta filosóficamente realista, que investiga los juicios secretos de la razón común más allá de la nostalgia y la melancolía, es: ¿por qué sólo se han producido sobre el papel? Imitamos aquí el gesto del pensamiento de Hobbes en el Leviatán: un conjunto de papeles, por mucho que puedan llegar a ser la «embrionaria constitución del mundo», no es prácticamente nada sin una fuerza suficiente que los haga cumplir, una fuerza con la que ninguna otra pueda medirse.

El derecho como ley del más débil aplicada al objeto-mundo es incompatible con los de hecho descomunales ejércitos privados, con el arsenal militar incuestionable de EE.UU, al servicio de sus parciales intereses y, sobre todo, los de sus empresas. Una ONU en la que algunos países tienen derecho a veto y que no es acompañada por una fuerza regulada al servicio de la ley, es poco efectiva. Algunos de los problemas que puedan surgir al respecto los conocemos, y han sido ensayadas soluciones estatales, como la división de poderes o el doble sometimiento de la ley a la ley. Pero estos problemas son un lujo con respecto al gran problema que supone la globalización fáctica y la autoridad imperial de EE.UU. En la globalización realmente existente «han crecido las desigualdades y las violaciones de los derechos humanos» (Ibídem: 480), y hay más incertidumbre que nunca. Un individuo nacido en, por ejemplo, Teruel hace cincuenta o sesenta años, sabía más o menos a qué atenerse en la dictadura franquista, que sin duda era «despótica» en el sentido de Montesquieu o en el de Kant. Muy otra es la situación actual, en la que vivimos sin saber cuál será el ánimo matutino de los «mercados», y si será diferente el vespertino. Fenómenos sociales como el TTIP o el CETA profundizan en esta globalización realmente existente, a la que le resulta muy incómodo el concepto de «seguridad jurídica», y que prefiere sin embargo que la seguridad ante la incertidumbre sea un privilegio de quien se la pueda pagar. 
A este panorama Ferrajoli lo llama «guerra infinita» (Ibídem: 503), y pone como ejemplos Yugoslavia, Afganistán o Irak. La «legítima defensa preventiva» invocada por la Administración Bush es, como el concepto de «guerra justa», una contradicción jurídica en los términos, y nos devuelve a la pre-modernidad. No obstante, quizás nos estamos embarcando fácticamente en un camino hacia La nueva Edad Media. Pero,

¿cuál es el criterio para que esta insurgencia posible, a saber, establecer el derecho o la paz perpetua como ideal regulativo de un nuevo orden mundial, no sea la mera excusa de una parte intentando copar, una vez más, el todo? Ferrajoli plantea dos, y con ellos terminamos nuestra intervención

La guerra (...) y la acción coercitiva [son diferentes]. (...) La diferencia entre las dos cosas se manifiesta en dos elementos: la tutela del inocente y la no instrumentalización de la coerción para fines o intereses de parte (...) es la misma diferencia que existe entre pena y venganza (...) Según los artículos 3942 de la Carta, el uso de la fuerza en la que [la acción coercitiva] consiste debe ser subordinado, como extrema ratio, a la puesta en práctica sin éxito, por parte del Consejo de Seguridad, de todos los remedios pacíficos idóneos para restablecer la paz. De las «medidas» y las «recomendaciones» previstas en los artículos 39-40 a las presiones diplomáticas y sanciones económicas previstas en el artículo 41. Sobre todo, no sólo la decisión sino también la «dirección estratégica» de la intervención están reservadas, por los artículos 47, 48 y 53, al Consejo de Seguridad, que por ello no puede delegar la gestión en uno o más Estados miembros (Ibídem: 491-492)

\subsection{Inconclusión: la Filosofía del Derecho y una embrionaria república democrática cosmopolita}

En La paz perpetua, Kant postula la razón común de la paz. Una vez postulada, se limita a desvelar sus juicios secretos, a modo de artículos para la paz perpetua, o implicaciones. Era éste el espíritu de esta modesta intervención, más acá de insurgencias muy imaginativas y extravagantes. Me he dedicado a definir brevemente el que considero que debe operar a modo de ideal regulativo, siempre y cuando la paz sea razón común. Con ánimo realista, he identificado a la ONU como campo de batalla y a EE. UU., en tanto que autoridad imperial, como obstáculo antijurídico clave, sin apostar en ningún caso a que fuera el único. El ejemplo del ius humanitatis nos ha servido para ilustrar la diferencia entre intimidación imperial y paz perpetua de una embrionaria república democrática cosmopolita, que encuentra no ingenuamente, sino rea- 
listamente su embrionaria constitución del mundo en la Carta de la ONU, la Declaración de 1948 y los Pactos sobre los derechos de 1966. Queda un largo camino que explorar y no es ésta, con toda la honestidad, conclusión alguna.

\subsection{Referencias}

DEBRAY, R., Crítica de la razón política, Cátedra, Madrid, 1983.

FERRAJOLI, L., Principia iuris. Teoría del derecho y de la democracia, Trotta, Madrid, 2011 (2011a: I. Teoría del derecho/ 2011b: II. Teoría de la democracia).

KANT, I., La Metafísica de las Costumbres, Tecnos, Madrid, 2012. KANT, I., La paz perpetua, Tecnos, Madrid, 2013.

LEIBNIZ, G. W., Los elementos del Derecho Natural, Tecnos, Madrid, 1991. MONTESQUIEU, Del Espíritu de las Leyes, Alianza, Madrid, 2012.

SCHMITT, C., El concepto de lo político, Alianza, 2014.

SOUSA SANTOS, B. de, Sociología jurídica crítica, Trotta, Madrid, 2009. WALLERSTEIN, I., El capitalismo histórico, Siglo XXI, 2012.

WATSON, P., La edad de la Nada. El mundo después de la muerte de Dios, Crítica, Madrid, 2017. 
18

\title{
GOBERNANZA AMBIENTAL EN EL MECANISMO DE DESARROLLO LIMPIO: LIMITACIONES INSTITUCIONALES PARA LA PARTICIPACIÓN CIUDADANA
}

\author{
María Lucía Viscuso \\ mviscuso@ucm.es
}

\subsection{Introducción}

La creciente preocupación por el cambio climático mundial debido a los efectos de las emisiones gases de efecto invernadero ha llevado al desarrollo de varias respuestas en los últimos años. A diferencia de otros tipos de problemas ambientales, la atmósfera es un bien común. Por lo tanto, las políticas enfocadas a reducir las emisiones representan un desafío para asegurar la coordinación y cooperación global, dado su carácter policéntrico y transnacional. La creación de mecanismos de créditos de carbono para limitar el efecto del calentamiento global ha abierto un debate técnico, económico y político sobre los efectos de la mercantilización de los recursos naturales.

Este trabajo tiene como objetivo explorar cuáles son las condiciones institucionales que impulsan la participación ciudadana en la gestión de proyectos del Mecanismos de Desarrollo Limpio, en lo sucesivo MDL, en dos etapas diferentes: antes y después del proceso de validación. Para responder a esta pregunta, se tienen en cuenta el marco institucional, las experiencias de participación y los conflictos desarrollados en cuatro proyectos de centrales hidroeléctricas en los siguientes países: Ecuador, Guatemala, Panamá y Perú. Se asume que la calidad satisfactoria de la participación depende de los mecanismos institucionales establecidos para asegurar la rendición de cuentas y lograr el cumplimiento de las regulaciones nacionales e internacionales. 


\subsection{Legitimidad y participación en el contexto de la Gobernanza Ambiental Global}

La inclusión de actores e instituciones supranacionales ha dado lugar a un escenario de gobernanza ambiental global, en el que dada la multiplicidad de actores en interacción se genera la necesidad de encontrar nuevas formas de dar legitimidad a las políticas y decisiones que tienen efectos a nivel local. El MDL es un caso paradigmático de este nuevo contexto ya que se enmarca en una constelación de múltiples actores que ponen en disputa tanto la soberanía estatal, como las relaciones de dominación entre países desarrollados y en desarrollo.

En este contexto, es necesario entender el rol de los actores involucrados en el entorno dinámico de las relaciones internacionales, en el que nuevos marcos institucionales promueven la colaboración entre diferentes tipos de actores. De este modo, se supera la dicotomía clásica entre actores públicos y privados (Kuchler, 2015), lo que complejiza el análisis de los procesos de toma de decisión. A modo de intentar resolver las limitaciones del multilateralismo ha tenido lugar la aparición del concepto de multi-stakeholdership, el cual sirve como criterio para mejorar la capacidad de respuesta, así como el cumplimiento y la inclusión de derechos, en particular para grupos tradicionalmente relegados (Elliot, 2004, Fisher y Green, 2004). De la misma manera, este cambio permite la aparición de enfoques bottom-up y sugiere la prominencia de formas híbridas y laxas que afectan la representación y deliberación (Bäckstrand, 2006a). Además, esta nueva forma de gobernanza en múltiples niveles, permite que la participación de actores no estatales se desarrolle en relaciones de poder horizontales (Bäckstrand, 2008, Lövbrand et al., 2009, Stripple, 2010), dando forma a una estructura de poder bifurcada, plurilateral, multi-nivel, y compleja (Bäckstrand, 2006a: 468).

Por su parte, Nanz y Steffek (2004) afirman que la sociedad civil tiene la capacidad de permear las fronteras de las estructuras formales de la gobernanza global. Los autores se refieren a la posibilidad de constituir una sociedad civil transnacional capaz de participar en una esfera pública, que podría potenciar la democratización a través de la exposición de la regulación global al escrutinio público, la incorporación de las preocupaciones de los ciudadanos en la agenda de las organizaciones internacionales, así como la capacitación 
de actores desfavorecidos para que cumplan un rol activo en la deliberación política.

Sin embargo, algunos estudios, desafían esta perspectiva optimista, ya que ven a la nueva tendencia participativa de la gobernanza ambiental como una máscara que reproduce las estructuras capitalistas y neoliberales en la que los actores poderosos son privilegiados (Paterson, 2001). Muchas de estas corrientes críticas cuestionan las relaciones de poder subyacentes detrás del MDL, acusándolas no sólo de mercantilizar el ambiente, sino de reforzar y perpetuar las relaciones de dominación de los países en desarrollo por el norte (Lohmann, 2001), continuando una antigua tradición colonial en la que los últimos bienes comunes globales son privatizados y liberalizados (Bachram, 2004). Los debates se centran en la idea de que el MDL representa una nueva forma de colonialismo de carbono, en el cual el poder de los estados se transfiere a las empresas, dañando la justicia ambiental y social (Wilson, 2011) y promoviendo un proceso que tiende a vender la naturaleza para ahorrar recursos (McAfee, 1999). Richman (2003) agrega que el mecanismo también implica una imposición de valores e instituciones occidentales, lo cual produce un daño a la soberanía local y nacional, además de contribuir al aumento de la desigualdad.

La cuestión interesante para este análisis es la necesidad de algún tipo de aporte ciudadano para asegurar un nivel de validación social, como es el caso de los estados democráticos que basan su soberanía en elecciones periódicas. Por lo tanto, es relevante incluir en el debate el concepto de legitimidad, como un requisito que debe acompañar a la participación. Respecto a la legitimidad, debería estar claro que los resultados de la acción pública se encuentren derivados de los intereses auténticos de los miembros de una comunidad (Scharpf, 1999). Asimismo, desde el lado de lo que se denomina input legitimacy, el significado de la legitimidad descansa en la interpretación de la ciudadanía sobre qué significa ser democrático y qué mecanismo permite prácticas son transparentes y responsables (Lövbrand, Nordqvist y Rindefjäll, 2007).

En el caso del MDL, la legitimidad puede interpretarse de varias maneras, a la luz del hecho de que las fuentes de legitimidad de una gobernanza global no son sólo la democracia, sino también la eficacia, la equidad, la paz y la estabilidad (Bäckstrand, 2006a). Por lo tanto, la legitimidad del input legitimacy puede entenderse como un requisito de inclusión de todas las sociedades 
involucradas y afectadas por los proyectos en las diferentes etapas del ciclo de políticas, resultando un proceso accountability (Bäckstrand, 2005) en el que la participación no se encuentra sólo limitada a algunas fases (Schunz y Bruyninckx, 2011).

\subsection{Complejidad institucional y limitaciones del Mecanismo de Desarrollo Limpio}

El MDL, establecido por el Protocolo de Kioto y bajo la órbita de la Convención Marco de las Naciones Unidas sobre el Cambio Climático, proporciona una herramienta para la acción conjunta entre países desarrollados y en desarrollo para reducir las emisiones y lograr beneficios de desarrollo sostenible. Es Los países desarrollados pueden conseguir unidades de certificadas de reducción de emisiones, denominadas CER, por medio de proyectos de reducción de emisiones en países en desarrollo. A través de la Autoridad Nacional Designada, el MDL permite a cada país participar en la selección de proyectos a ser implementados con el apoyo de auditores independientes acreditados por el MDL con competencia para realizar los procesos de validación, verificación y certificación de proyectos (Figura 1).

Los reglamentos oficiales del MDL establecen como requisito la participación de todas las partes interesadas en el proceso de toma de decisiones de los proyectos MDL. Existen instancias preestablecidas, antes del proceso de validación, en las cuales los desarrolladores del proyecto deben realizar una consulta local con los miembros de la comunidad para proporcionar información, recibir sus comentarios y minimizar cualquier efecto negativo antes de que comience el proyecto. Además, se establece que los ejecutores del proyecto deben desarrollar una apertura para los comentarios de la ciudadanía y organizaciones de 30 días antes de que se apruebe el proyecto, además de realizar visitas in situ y entrevistas.

Sin embargo, las etapas anteriores no tienen criterios comunes y específicos para el desarrollo y la evaluación de dichos requerimientos. Esta falla da lugar a procedimientos arbitrarios y diferenciados en los países en desarrollo que reciben los proyectos, lo que permite la interferencia de intereses privados en los proyectos financiados por el MDL y limita la participación de los ciudadanos en su definición. 


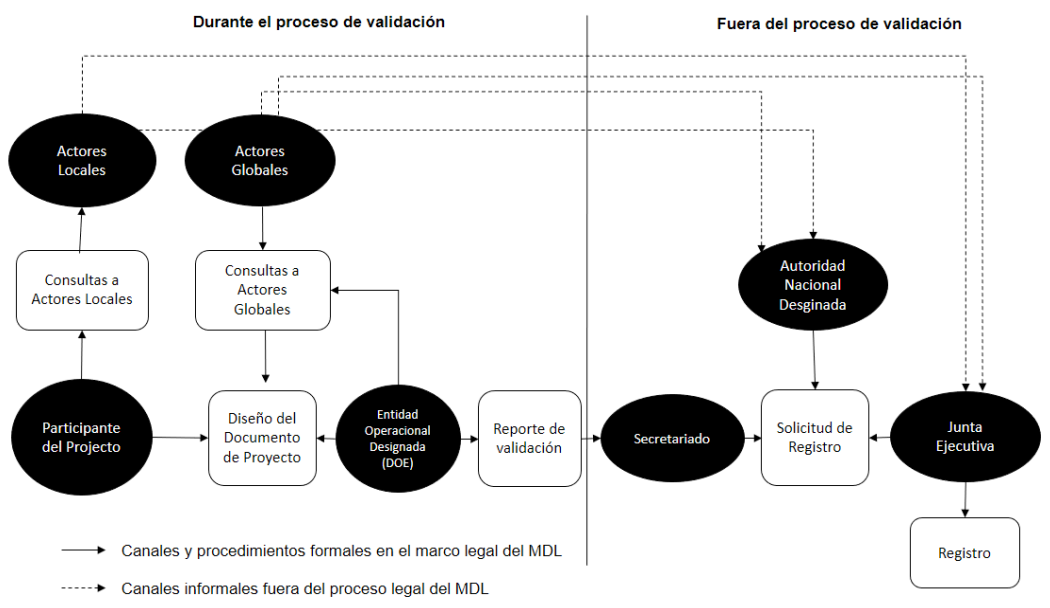

FIGURA 1: Oportunidades de participación antes y después de la validación de proyectos ${ }^{1}$.

Los reglamentos y procedimientos nacionales generan criterios desiguales para la aprobación y ejecución de proyectos, los cuales se agravan en planes hidroeléctricos, los cuales provocan serios impactos en la calidad de vida, así como transgreden derechos humanos e indígenas, obligando a comunidades a reubicarse, privándoles de sus medios de subsistencia, violando los derechos de autodeterminación y socavando los sitios sagrados de las comunidades nativas. Además, estos proyectos generan profundos cambios ambientales, sin lograr necesariamente reducciones significativas en las emisiones de carbono.

Asimismo, se han identificado varios problemas estructurales del MDL para que los interesados puedan participar en un proceso de formulación de políticas eficaz. Boström, Hallström (2013), Betsill y Corell (2008) identifican las asimetrías institucionales en el proceso de toma de decisiones, debido a los beneficios formales e informales del contexto institucional priorizan a algunos actores, intereses y grupos, obstruyendo a otros. En respuesta a esta falencia institucional, Bäckstrand (2006b) afirma la necesidad de llevar a cabo una redefinición del concepto de rendición de cuentas en la estructura de gobierno del MDL, así como enfatiza la importancia de incluir herramientas de legitimidad en las diferentes etapas del proceso de inclusión de los actores. Además, Nanz y Steffek (2004) se refieren a la necesidad de desarrollar una

1 Elaboración propia en base a Kuchler y Lövbrand (2014). 
esfera pública transnacional, que permita una participación más deliberativa y funcional en la gobernanza global.

Johl y Lador (2012) proponen diseñar un sistema de seguimiento para asegurar y registrar todos los procedimientos realizados a modo de garantizar la participación de las partes interesadas. Este sistema de presentación de informes se implementaría a través de diferentes niveles del ciclo de políticas del MDL, incluyendo cuatro aspectos principales: (1) mecanismos de rendición de cuentas tanto a nivel nacional como internacional; (2) directrices comunes para la presentación de informes; (3) procesos de monitoreo participativos e independientes; (4) mecanismos de quejas.

Asimismo, Johl y Lador (2012) sugieren la incorporación de enfoques basados en los derechos humanos al MDL, los cuales ayudarían a mejorar la legitimidad internacional y local del mecanismo, así como a reducir el riesgo de las poblaciones vulnerables, incorporando innovaciones tales como sistemas de vigilancia, instancias para elevar quejas, así como oportunidades para lograr una participación significativa y efectiva en todas las etapas de los procesos de toma de decisiones relevantes (Johl y Lador, 2012).

En cuanto al diseño institucional del MDL, se debe realizar una selección independiente de las entidades operacionales (Hickmann, 2013) o bien las decisiones deben ser tomadas por el Directorio Ejecutivo o la Secretaría (Haya, 2007; McCully, 2008; Schneider, 2007). Las entidades operacionales son las instituciones responsables de evaluar la calidad de las consultas realizadas el previas al proceso de ejecución del proyecto, aunque las directrices a seguir son muy amplias. Por ejemplo, deben comprobar si se realizan los pasos establecidos, qué partes son invitadas, registrar todos los comentarios, elaborar informes, así como supervisar la inclusión de los comentarios en el diseño del proyecto (Junta Ejecutiva del MDL, 2011).

Un elemento adicional central y poco discutido que limita la participación, es el aspecto tecnocrático. El cambio climático, y más aún las finanzas de carbono, implica varios aspectos técnicos, como el uso de conceptos complejos, todo lo cual se complica aún más debido a la falta de traducciones disponibles para todos los actores. ONGs, activistas y, por supuesto, las comunidades pueden ser persuadidas fácilmente debido a la intrincada retórica de las finanzas climáticas (Bachram, 2004).

Del mismo modo, la potenciación de las organizaciones y comunidades civiles es crucial para contribuir a la calidad de la esfera pública, así como 
para garantizar que la información de las organizaciones internacionales esté disponible y sea visible para el escrutinio transnacional (Nanz y Steffek, 2004). Esto también es relevante debido a las prácticas informales y las iniciativas ascendentes que también deben considerarse como elementos clave para mejorar la participación, la capacidad de respuesta y la transparencia. A pesar de que en todos los casos las partes involucradas no tienen prerrogativas formales, desarrollan otras estrategias para permear los procesos formales. Por ejemplo, diferentes evaluaciones revelan que antes y después de las cumbres ambientales, los principales grupos de interesados utilizan diferentes prácticas de lobby para influir en los textos y planes que detallan la implementación de los proyectos (Ferenz, 2002, Suomi, 2002).

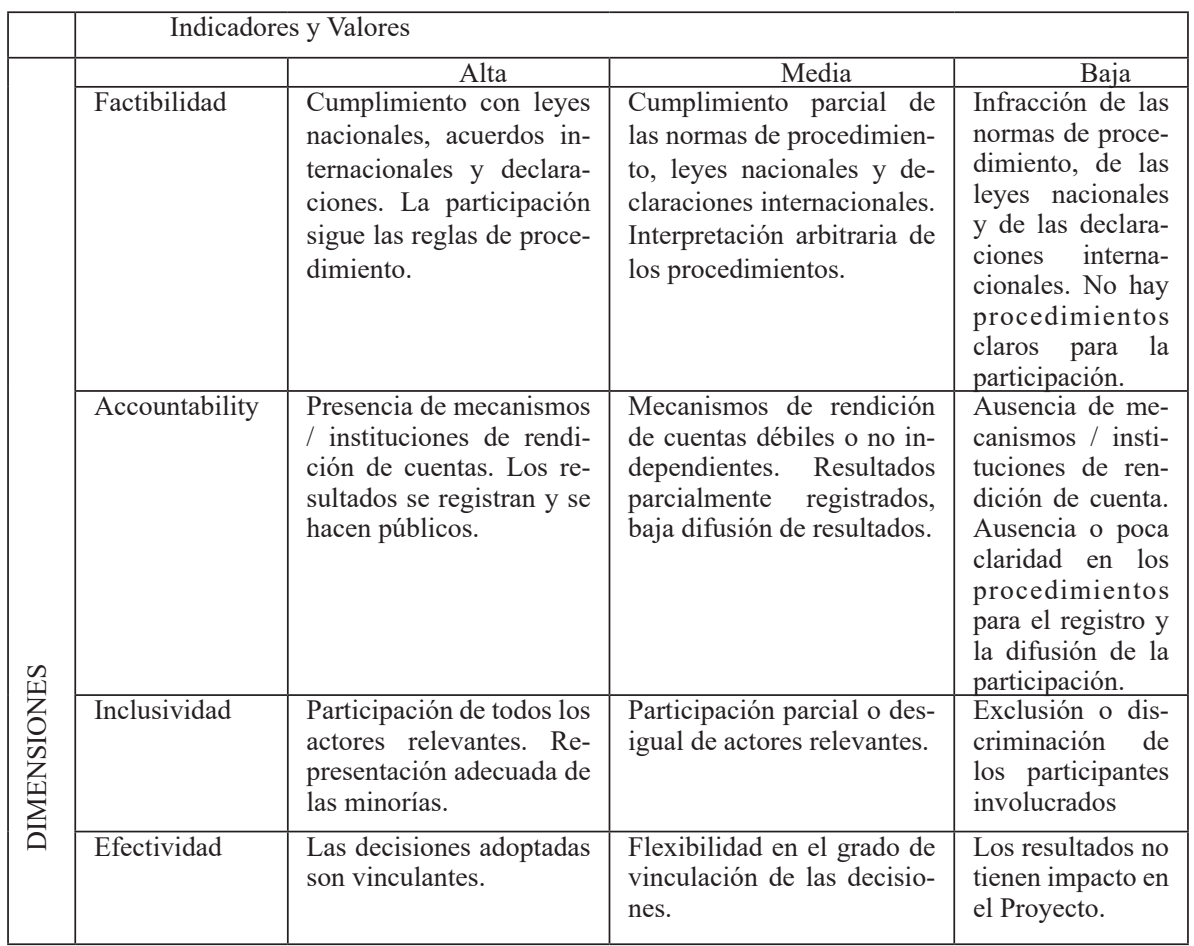

TABLA 1: Criterios para evaluar la calidad de la participación de las partes interesadas: dimensiones, indicadores y valores ${ }^{2}$

Para esta investigación los criterios seleccionados para evaluar la calidad de la participación de los actores son los detallados en la tabla 1.

2 Elaboración propia en base a Lieberherr (2013) y Pogrebinschi (2013). 


\subsection{Mecanismo de Desarrollo Limpio en América Latina: Criterios y análisis de casos estudiados}

En América Latina hasta 2016 han sido aprobados 1218 proyectos por el MDL, de los cuales 311 están relacionados con planes hidroeléctricos. Existen graves conflictos con un alto nivel de violencia, provocados por proyectos financiados por medio de este mecanismo, la mayoría de los cuales no han implementado adecuadamente los requerimientos de inclusión de los actores interesados, tanto en la selección como en la ejecución de los proyectos.

La selección de países y represas seleccionadas para esta comparación está relacionada con una serie de factores que incluyen particularidades políticas y sociodemográficas, como la presencia de grupos indígenas. Además, las características relacionadas con la implementación del MDL en los países han sido relevantes para la selección, tales como el tamaño de los proyectos, la capacidad instalada del proyecto, la cantidad esperada de reducción de emisiones y el papel de la hidroeléctrica en el total de proyectos MDL.

Por su parte, se ha elegido el caso de proyectos hidroeléctricos, dada la complejidad de desarrollar proyectos de este tipo, considerando que implican impactos sociales, económicos y ambientales profundos. Las represas requieren un nivel de inundación inicial para desarrollar un embalse y las estructuras necesarias pueden producir fluctuaciones de los recursos naturales, como la erosión, las sequías, las inundaciones, la extinción de especies y la migración. Estas condiciones obligan al reasentamiento de las poblaciones y a la pérdida de los medios de subsistencia, que tienen consecuencias socioculturales como la destrucción del patrimonio histórico y la desintegración de las comunidades.

\subsubsection{Barro Blanco, Panamá}

Desde 1981, un proyecto para crear una presa en el Río Tabasará en Chiriquí había sido propuesto y disputado por la comunidad local, la mayoría indígena. La propuesta de la presa estaba relacionada con otro proyecto polémico en el área: la mina de cobre de Cerro Colorado. Dicha presa nunca se materializó debido a la información errónea y la oposición de los residentes cercanos.

Sin embargo, en 2007 se otorgó un nuevo y mayor proyecto a la empresa GENISA. Este nuevo proyecto, Barro Blanco, requirió inundar un área de 258.67 hectáreas para su operación en el río, así como cinco hectáreas más 
para la construcción de la presa, la central eléctrica y las obras adicionales (Gibbons, Windfuhr y Putten, 2015). Se estima que se alcanzaría una capacidad instalada de 28,56 MW (UNFCCC, 2011), lo que sería suficiente para elevar la capacidad instalada de generación de energía panameña en un 2,35\% y reducir 1.400.292 toneladas de CO2e en veinte años (MDL Consejo Ejecutivo, 2010).

El informe de validación del proyecto creado en 2011 incluye una sección en la que se especifica lo realizado para garantizar una participación justa antes de la validación. Certifican que se realizaron entrevistas con las principales partes interesadas, sin embargo, la lista de participantes no incluye ningún representante de la comunidad. Además, el informe señala que las comunidades locales han sido consultadas y han demostrado su apoyo (AENOR, 2011), el cual fue concedido indirectamente a través de la Carta de Aceptación y la No Objeción firmada por las autoridades locales.

Fueron denunciadas violaciones consecutivas de los derechos indígenas por la comunidad Ngäbe Buglé y por varias organizaciones de derechos humanos, causando el inicio de protestas y tensiones en 2011. Como consecuencia, el gobierno firmó el acuerdo San Félix, en el cual se comprometieron a aprobar una ley para prohibir la explotación de los recursos naturales en la región (Anaya, 2014). Sin embargo, antes de aprobar dicha regulación, se eliminó uno de los principales artículos del acuerdo, el cual prohibiría la instalación de proyectos mineros e hidroeléctricos en la zona donde viven las comunidades Ngäbe Buglé (Anaya, 2014).

En 2016 la presa se completó, pero aún no ha iniciado actividades completas. Ha provocado varias protestas, también apoyada por otros grupos indígenas. Sigue existiendo un alto grado de tensión y conflicto social.

\subsubsection{Santa Rita, Guatemala}

En 2010, el gobierno guatemalteco otorgó el proyecto hidroeléctrico Santa Rita a la empresa Hidroeléctrica Santa Rita SA en el marco del MDL. El proyecto pretendía desarrollar la obra en el río Dolores, ubicado en el municipio de Alta Verapaz. La presa alcanzaría a producir una capacidad nominal de 24,2 MW2 al año, así como una reducción de 52.131 emisiones de GEI de CO2 (Junta Ejecutiva del MDL, 2006). 
El área del proyecto abarcaba 254 hectáreas, afectando potencialmente hasta 200,000 personas. Diferentes grupos indígenas vivían en las regiones circundantes, tales como Q'eqchi, Poqomchi Achi y Mestizo (Navas, 2014). La construcción de la presa podría tener como consecuencia impactos socioeconómicos y ambientales presentes y futuros, tales como desplazamientos, desposesiones de tierras, pérdida de medios de vida, biodiversidad y hábitat, contaminación de las aguas subterráneas, deforestación y riesgo de inundación (ECC, 2015: 2). Asimismo, luego de la validación del Proyecto, se presentaron numerosas denuncias de falta de participación de comunidades, organizaciones internacionales y de derechos humanos durante la apertura del plazo para comentarios.

Los grupos indígenas organizaron asambleas y, después de las sesiones de deliberación, enviaron informes al gobierno indicando su posición y las quejas sobre la presión ejercida por la compañía y otros grupos para obtener apoyo para los proyectos.

Los grupos indígenas organizaron asambleas y, después de las sesiones de deliberación, enviaron informes al gobierno indicando su posición y las quejas sobre la presión ejercida por la compañía y otros grupos para obtener apoyo para los proyectos. En 2013, después de varias denuncias, las comunidades lograron que la maquinaria para la construcción del proyecto fuera quitada. Según el Relator Especial de la ONU sobre los Derechos de los Pueblos Indígenas en 2014, se produjeron más episodios de violencia grave en las comunidades (Dasgupta, 2015), que podrían ser impulsadas por la empresa constructora (Peace Brigades International, 2014).

La Junta del MDL pidió a la institución de validación que revisara la evaluación del proyecto con respecto a la falta de participación de la comunidad. A pesar del alto nivel de conflicto y la solicitud de revisión, en 2014 se aprobó la planta de Santa Rita en el marco del MDL.

Se firmó un acuerdo entre las autoridades nacionales y locales, los sectores empresariales y las partes interesadas de la comunidad con la intención de iniciar la operación de la Hidro Santa Rita y resolver el conflicto. Sin embargo, no ha sido suficiente ya que los conflictos violentos permanecen en el territorio. 


\subsubsection{Baba, Ecuador}

El Proyecto Hidroeléctrico Multipropósito de Baba comenzó a desarrollarse en 2006 en las provincias de Guayas, Manabí y Los Ríos y fue dirigido por la empresa Hidroeléctrica Nacional Hidronación SA. Se esperaba que la nueva generación hidroeléctrica produjera $42 \mathrm{MW}$ por año y lograra una reducción de 318,991 tCO2e por año, lo que representa 2,232,937 tCO2e durante el período de acreditación de 7 años (UNFCCC, 2006).

Desde el inicio del proyecto se corría el riesgo de inundar 3.000 hectáreas de tierra, con el objetivo de dirigir el agua a la presa Daule Peripa (Greyl, 2014). El proyecto afectaría un total de dos áreas, Buena Fe y Valencia, que incluía una población de más de 80 mil habitantes y más de 40 comunidades, recintos o asentamientos.

Tanto las comunidades como las organizaciones internacionales denunciaron reubicaciones forzadas, prácticas violentas, intimidación, hostigamiento contra los líderes comunitarios, así como un supuesto asesinato de un miembro de la comunidad después de solicitar el apoyo legal de la Comisión Ecuménica de Derechos Humanos contra la represa.

El Estudio de Impacto Ambiental Final reconoció a sólo 191 personas afectadas directamente por el PMB, que son consideradas las únicas familias desplazadas por la creación del embalse. Sin embargo, los estudios de la organización Acción Ecológica concluyen que el número de desplazados sería mucho mayor, estimando un total de 1.773 personas que viven en la zona (Kopas y Astrid Puentes, 2011).

Como resultado de las fallas reconocidas en los informes ex ante, en diciembre de 2008 el Tribunal Constitucional del Ecuador concluyó que la autorización y ejecución del proyecto en la forma en que se llevaba a cabo violaba los derechos humanos y el derecho a la participación ciudadana. Por lo tanto, la Corte ordenó una revisión de la licencia ambiental por parte del Ministerio de Ambiente y solicitó a la Contraloría General la realización de una auditoría del proyecto (Kopas y Astrid Puentes, 2011). A pesar de la decisión de la Corte, el trabajo continuó.

La construcción de la presa de Baba se completó en 2013, posterior a la decisión del gobierno de llevar a cabo una serie de consultas comunitarias dada la fuerte oposición al proyecto. Estas ayudaron a desarrollar modifica- 
ciones al proyecto original y establecieron compensación a los afectados, así como incorporaron a varias agencias de evaluación.

\subsubsection{Marañón, Perú}

El Proyecto Hidroeléctrico Marañón abarca el desarrollo de una Central Hidroeléctrica ubicada en la cuenca alta del río Marañón, rodeada por las comunidades de Palanca, Cascanga, Quivilla y San Lorenzo de Pachas, atravesando los barrios de Llata, Jacas Grande, Quivilla y Pachas así como las provincias de Huamalíes y Dos de Mayo, ubicadas en la región de Huanuco. Podría alcanzar una capacidad instalada de $88,3 \mathrm{MW}$. Se calcula que la cantidad de reducciones que la hidroeléctrica puede lograr sería alrededor de 270.194 toneladas de dióxido de carbono por año (UNFCCC, 2012).

Están en marcha planes para construir alrededor de 20 proyectos hidroeléctricos en el Río Marañón, por lo que se estima que las inundaciones abarcarían varias áreas, las cuales corresponden en gran medida a dos comunidades indígenas: Awajún y Wampis (International Rivers, 2011).

Una de las principales críticas al proyecto se centra en la falta de veracidad y omisión de información en el Documento de Proyecto ( International Rivers, 2011). Por ejemplo, no se menciona la relación entre el Proyecto Marañón y los controvertidos proyectos mineros en el norte de Perú, que desde el 2006 son propiedad de la misma empresa: Hidroeléctrica Marañón S.R.L. Varias comunidades indígenas se han opuesto a este proyecto minero, Conga, debido al uso excesivo de agua está provocando la desaparición de muchas lagunas (International Rivers, 2011).

En el marco del debate sobre los efectos de la instalación de represas en el Río Marañón, se creó en el Congreso Nacional un Grupo de Trabajo sobre Plantas Hidroeléctricas en el Marañón. Hicieron un informe dirigido en particular a un conjunto de organizaciones que han formulado varias quejas sobre la viabilidad y los efectos nocivos del proyecto, como la Comisión de Pueblos Andinos, Pueblos Amazónicos y Afroperuanos, Medio Ambiente y Ecología, Derecho, Medio Ambiente y Recursos Naturales (DAR), Sociedad Peruana de Derecho Ambiental (SPDA), ProNaturaleza, Ashaninka Central del Río Ene (CARE), Foro Solidaridad Perú, Rainforest Foundation UK, Servicio de Educación Rural (SER), CIMA Cordillera Azul, Centro de Sostenibilidad Ambiental de la Universidad Peruana Cayetano Heredia (CSA-UPCH). El informe puso en duda varios de los argumentos oficiales que se utilizaron 
en defensa de la construcción de presas en el Marañón, poniendo de relieve que el principal beneficiario económico de la instalación de los proyectos es Brasil, considerando que el Acuerdo de Energía firmado en 2010 entre Perú y Brasil tiene implicaciones en términos de seguridad energética, por lo que causaría serias consecuencias ambientales para la Amazonía peruana y afectaría el derecho de la población local y nativa (Guevara Amasifuen e Inga Vásquez, 2012: 15).

Asimismo, el informe subraya los impactos potencialmente graves en los territorios indígenas, que implican un gran desplazamiento de comunidades, así como la pérdida de suministros de alimentos y la pesca. También enfatiza la falta de claridad y detalles de las condiciones y requerimientos para realizar el análisis de impacto de los proyectos (Guevara Amasifuen e Inga Vásquez, 2012). Mientras tanto, el grupo de trabajo con las organizaciones hicieron un llamamiento para derogar el Decreto, que fue rechazado en 2014 por la Comisión de Relaciones Exteriores del Congreso de la República.

En simultáneo, los habitantes de los pueblos afectados se han organizado entre sí y con ONGs para llevar a cabo acciones de protesta y denuncia, constituyendo un Comité de Lucha contra las Amenazas de los Proyectos Hidroeléctricos de Marañón en el Territorio Awajún. También se han unido a otras comunidades vecinas que apoyan la anulación del controvertido decreto. Mientras tanto, el gobierno actúa como mediador en el conflicto entre la empresa y la comunidad, que hasta ahora sólo ha desarrollado documentos en foros de diálogo. Sin embargo, la planta hidroeléctrica continúa en construcción.

\subsection{Resultados del análisis de los mecanismos y calidad de la participación}

La intención en esta sección es analizar cómo la participación tuvo lugar en los diferentes proyectos hidroeléctricos, en un esfuerzo por determinar cómo variaban las condiciones, tales como los procesos legales, institucionales, de rendición de cuentas, inclusión y efectividad y los mecanismos que influyeron en el proceso.

Cabe destacar que al analizar los casos se incorpora un alto nivel de reconocimiento formal de las declaraciones, tratados internacionales, protocolos y leyes nacionales en relación con los derechos referidos a las cuestiones ambientales y las comunidades indígenas, incluyendo amplios privilegios sobre 
sus territorios y recursos. Sin embargo, la mera presencia de estos derechos no ha desempeñado un papel importante en el cumplimiento de estos reglamentos, en la medida en que no se incorporan concretamente en todos los casos a través de reglamentos e instituciones locales encargados de vigilar y desarrollar políticas coherentes. Cabe mencionar el caso del Perú, que tiene una ley específica para asegurar la participación de los pueblos indígenas mediante la consulta previa obligatoria, que, aunque reconocida en el Convenio 169 de la Organización Internacional del Trabajo (OIT), no todos los países signatarios Institucionalizado.

En relación con el marco institucional de las oficinas responsables de los proyectos MDL, se evidencia que Ecuador y Perú tienen estructuras más sólidas para la gestión de los proyectos, lo que les ha permitido realizar un control más riguroso sobre la actividad de los participantes en el proyecto. Esto ha sido fundamental en las etapas de validación posteriores, aunque ninguno de los casos ha llevado a cabo apropiadamente un proceso de participación inclusiva y efectiva. Sin embargo, un grado alto de independencia de poderes ha permitido al Poder Judicial de Ecuador tomar medidas y solicitar informes de auditoría en el proceso de gestión de proyectos que el Ministerio de Medio Ambiente estaba realizando. También en Perú existe un marco institucional para realizar este tipo de proyectos debido a la existencia de una entidad coordinadora especial para proyectos MDL, el FONAM. Así mismo en Perú, hay varias instituciones en diferentes organismos que cumplen funciones de control para proyectos aprobados en el Poder Ejecutivo.

La primera etapa de participación analizada consistió en el proceso de participación de las partes antes de la validación final del proyecto. Lo sorprendente en esta etapa es que hay regulaciones establecidas por el Consejo Ejecutivo del MDL sobre los casos que deben ser emprendidos para asegurar la participación, tales como consultas locales y globales a los actores. Sin embargo, estas regulaciones tienen un formato de marco, no son vinculantes y no detallan requisitos específicos para realizar esta instancia. Por lo tanto, los requerimientos formales existentes son fáciles de lograr. Esto revela una grave deficiencia de las regulaciones propuestas por el Consejo Ejecutivo del MDL, ya que el alto grado de arbitrariedad permite un amplio margen para las acciones de las empresas.

Además, las instituciones responsables de la validación de las declaraciones realizadas por las empresas en los documentos del proyecto, consideraron que todo lo dicho por la empresa se cumplía el cien por ciento. Esto se dio 
incluso considerando que ninguno de los Documentos de Proyecto incluyó elementos de apoyo para verificar que la participación se había llevado a cabo, sólo algunas imágenes o resúmenes de comentarios per o no hay registro sistemático de las intervenciones de la comunidad, ni garantía de haber incluido lenguajes indígenas en estos mecanismos. Los detalles relativos a las personas invitadas, los criterios de selección y las condiciones de las reuniones están ausentes o son parciales.

Del mismo modo, es notable la falta de análisis para la selección de las muestras, así como el desconocimiento de las características sociodemográficas de cada área, la identidad de cada una de las comunidades involucradas y las regulaciones de los pueblos indígenas. Los casos de violencia, amenazas y persecución en el contexto de protestas requieren una reflexión sobre la necesidad de crear medidas legales, estructurales y de seguridad personal para garantizar condiciones que estimulen la participación.

En la segunda etapa examinada, tras la validación de los proyectos, se verifica la hipótesis propuesta con respecto a la competencia de las autoridades nacionales. Estamos de acuerdo con Michaelowa (2005) en que los organismos nacionales desempeñan un papel decisivo en el diseño y el cumplimiento de las condiciones para garantizar la participación de los interesados. En particular, la falta de normas no es una condición que limite la participación, sino más bien la falta de mecanismos e instituciones de control, seguimiento y auditoría. Los casos en que existen órganos autónomos, ya sea en la Legislatura o en el Poder Judicial, que llevan a cabo procesos de rendición de cuentas y crean oportunidades de interacción con los ciudadanos involucrados, se ha logrado aumentar la capacidad de respuesta y eficacia en relación con el interés de los ciudadanos.

En todos los casos debe destacarse el papel de las organizaciones internacionales y de la sociedad civil como motores de presión para difundir las transgresiones de derechos en el contexto de los proyectos analizados. Esto se puede ver en el sitio web del MDL, en el que las grandes ONG son el único grupo que envió comentarios al Consejo Ejecutivo.

Volviendo a los tipos inicialmente presentados para evaluar la calidad de la participación, los casos pueden ser evaluados como se muestra en la tabla 2. 


\begin{tabular}{|c|c|c|}
\hline & Durante el proceso de validación & Luego del Proceso de Validación \\
\hline Barro Blanco, Panamá & Baja & Baja \\
\hline Santa Rita, Guatemala & Media & Baja \\
\hline Baba, Ecuador & Media - Alta & Media - Alta \\
\hline Marañón, Perú & Media - Alta & Media - Alta \\
\hline
\end{tabular}

TABLA 2: Análisis de la calidad de la participación del MDL en las etapas de toma de decisiones

\subsection{Conclusión}

Se concluye que la calidad de la participación está condicionada por la falta de reglas claras por el MDL y la ausencia de mecanismos nacionales para asegurar la accountability y hacer cumplir las regulaciones en los distintos niveles de las instituciones involucradas. Así también, la participación ciudadana representa no sólo un argumento para dar validación social a las inversiones, sino también una poderosa herramienta para generar mayor efectividad en la implementación y resultados de los proyectos.

El estudio encontró que hay diferentes patrones con respecto a la calidad de la participación: antes y después de la validación del proyecto. En la primera etapa, se siguen las regulaciones propuestas por el MDL, que tienen un marco de acción amplio que permite a las empresas cumplir fácilmente con los requisitos de participación, sin involucrar una participación inclusiva y efectiva. Además, no hay mecanismos de rendición de cuentas, lo que profundiza esta amplia gama de acción de los desarrolladores del proyecto y las autoridades nacionales designadas.

Así también, la calidad de la participación después de la validación no tiene relación directa con las regulaciones, pero está en gran parte condicionada por las prácticas informales de las autoridades nacionales y la inclusión de otras agencias que controlan su actividad. La independencia de las agencias de rendición de cuentas y el papel que se da a las organizaciones de la sociedad civil permite mejorar la calidad de la participación y la capacidad de respuesta, no necesariamente directamente sino a través de sus representantes.

El dilema que subyace es que los países tienen una creciente necesidad de encontrar nuevas fuentes de energía limpia, lo que se ha reflejado no sólo en la política, sino como también en los reglamentos, leyes y decretos en los casos 
estudiados. La inclusión de la participación en la implementación de proyectos es costosa en términos de dinero, tiempo y dificultad de poder combinar visiones individuales con la necesidad de desarrollar obras a largo plazo. Sin embargo, observamos que la población en general no se enfrenta inicialmente a proyectos hidroeléctricos, sino que se opone a las condiciones en que se toman las decisiones, a la trasgresión a los derechos, a la escasez de información y a la comunicación poco clara.

Las futuras líneas de investigación deberían profundizar en la manera en que la participación influye en los objetivos del MDL, tanto en la reducción de las emisiones como en la consecución del desarrollo sostenible. Igualmente, sería importante centrarse en el diseño y la inclusión de mecanismos institucionales para mejorar la rendición de cuentas, la transparencia de los proyectos y analizar qué condiciones pueden mejorar la calidad de la legitimidad de los inputs. Sería interesante centrarse en otros incentivos que pueden incluirse para comprometer a los ciudadanos con grandes proyectos de generación de energía, estimular algún tipo de legitimación y tener en cuenta la creciente participación de los actores privados en el MDL y el rol de las autoridades políticas.

\subsection{Referencias}

AENOR (2011), CDM Validation Report. Generadora del Istmo, s.a (GENISA) Validation of the Project activity: Barro Blanco Hydroelectric Power Plan Project. Reference Number: 2008/0004/CDM/01. Madrid: Author. Disponible en https:/cdm. unfccc.int/filestorage/3/1/Y/31Y7Z2OSRN46KLECVBMTGDAPUWIH8F/ Validation\%20Report\%20BarroBlanco.pdf?t=ZTR8b2NndGJ0fDAb4KOk8eBWX9XLBUIJ5is

ANAYA, J. (2014), Report of the Special Rapporteur on the rights of indigenous peoples. The status of indigenous peoples' rights in Panama. Addendum (A/ HRC/27/52/Add.1). Panamá, Human Rights Council-UN.

BACHRAM, H. (2004), «Climate fraud and carbon colonialism. The new trade in greenhouse gases», Capitalism Nature Socialism, vol, 15 (4), pp. 5-20.

BÄCKSTRAND, K. (2005), «Accountability and Legitimacy of Networked Governance. Public-Private Partnerships for Sustainable Development», Paper presented at Conference International Organizations and Global Environmental Governance, Berlin, 2-3 December. Berlín, Freie Universität.

BÄCKSTRAND, K. (2006a), «Democratizing Global Environmental Governance? Stakeholder Democracy after the World Summit on Sustainable Development», European Journal of International Relations, vol. 12 (4), pp. 467-498.

BÄCKSTRAND, K. (2006b), «Multi-stakeholder partnerships for sustainable development. Rethinking legitimacy, accountability and effectiveness», Eur. Env., vol. 16 (5), pp. 290-306. 
BÄCKSTRAND, K. (2008), «Accountability of Networked Climate Governance. The Rise of Transnational Climate Partnerships», Global Environmental Politics, vol. 8 (3), pp. 74-102.

BETSILL, M. M.; CORELL, E. (2008), «Analytical framework: assessing the influence of NGO diplomats, NGO Diplomacy: The Influence of Nongovernmental Organizations in International Environmental Negotiations, ed. Michele M. Betsill and Elisabeth Corell, pp. 19-42.

BOSTRÖM, M.; HALLSTRÖM, K. (2013), «Global multi-stakeholder standard setters. How fragile are they?», Journal of Global Ethics, vol. 9 (1), pp. 93-110.

CDM EXECUTIVE BOARD (2006), Project Design Document Form for CDM Project Activities (F-CDM-PDD) Version 04.1. Santa Rita Hydroelectric Plant. Bonn: UNFCCC.

CDM EXECUTIVE BOARD (2010), CDM Project Design Document Form (CDMPDD), Barro Blanco Hydroelectric Power Plant Project - Version 03. Bonn: UNFCCC.

CDM EXECUTIVE BOARD (2011), Annex 15: Modalities and Procedures for Direct Communication with Stakeholders. Bonn: UNFCCC.

DASGUPTA, S. (2015), ‘Green’ hydropower dam fuels charges of gross human rights violations. Endangered Environmentalists. Mongabay. Disponible en https:// news.mongabay.com/2015/05/green-hydropower-dam-fuels-charges-of-grosshuman-rights-violations/

FERENZ, M. (2002), «Multistakeholder Dialogues: Learning from the UNCSD Experience», Background Paper No. 4 for the Third Preparatory Session, 24 March-15 April: Commission on Sustainable Development, Department of Economic and Social Affairs, United Nations.

GIBBONS, S.; WINDFUHR, M.; VAN PUTTEN, M. (2015), Barro Blanco Hydroelectric Project Panama, FMO-DEG Independent Complaints Mechanism, Panel report n. 1. Disponible en https://www.deginvest.de/DEG-Documents-in-English/About-DEG/Responsibility/Informe final barro blanco.pdf.

GREYL, L. (2014), Baba Dam Project - Los Ríos, Ecuador. Environmental Justice Atlas. Disponible en https://ejatlas.org/conflict/baba-dam-project-los-rios-ecuador

GUEVARA AMASIFUEN, M.; Inga Vásquez, L. (2012), Informe del Grupo de Trabajo sobre Centrales Hidroeléctricas en el Marañón. Grupo de Trabajo ad Hoc de Integración Energética. Lima, Ministerio de Energía.

HAYA, B. (2007), Failed mechanism: How the CDM is subsidizing hydro developers and harming the Kyoto Protocol, Berkeley: International Rivers.

HICKMANN, T. (2013), «Private authority in global climate governance, The case of the clean development mechanism». In Climate and Development, vol. 5 (1), pp. 46-54.

INTERNATIONAL RIVERS (2011), Comments on the CDM Project Design Document (PDD) for Marañón Hydroelectric Project (Perú).

JOHL, A.; LADOR, Y. (2012), A human rights-based approach to climate finance, Berlin, Friedrich-Ebert-Stiftung, Global Policy and Development. Disponible en https://cdm.unfecc.int/filestorage/T/P/B/TPBAAYMD90V6N5NDPXRT6V9FY95B8T/Comment $\% 20$ submitted $\% 20$ by $\% 20$ International $\% 20$ Rivers.pdf?t= eWt8b2I2a3dofDCIWRMifq2Hu7cyQWgiEaVV, updated on 12/23/2011 
KOPAS, J.; ASTRID PUENTES, R. (2011), The Baba River Hydroelectric Project in Ecuador. AIDA. Disponible en http://www.aida-americas.org/sites/default/files/ refDocuments/Estudio\%20de\%20Caso\%20Baba.pdf

KUCHLER, M. (2015), «Stakeholding as sorting of actors into categories. Implications for civil society participation in the CDM», International Environmental Agreements: Politics, Law and Economics, pp. 1-18.

KUCHLER, M., \& LÖVBRAND, E. (2014), «Simulative governance: on the collaborative language of civil society participation in the CDM's stakeholder framework», EASST 2014 Situating Solidarities: social challenges for science and technology studies, 17-19 September, Toruń, Poland, pp. 1-29.

LIEBERHERR, E. (2013), «The Role of Throughput in the Input-Output Legitimacy Debate: Insights from Public and Private Governance Modes in the Swiss and English Water Sectors», Presented at ICPP, Panel 39: The New Policies of Privatization, June 26-28, Grenoble, France. Zürich, Swiss Federal Institute of Aquatic Science and Technology.

LOHMANN, L. (2001), Democracy Or Carbocracy: Intellectual Corruption and the Future of the Climate Debate. Dorset: Corner House.

LÖVBRAND, E.; RINDEFJÄLL, T.; NORDQVIST, J. (2009), «Closing the Legitimacy Gap in Global Environmental Governance? Lessons from the Emerging CDM Market», Global Environmental Politics, vol. 9 (2), pp. 74-100.

MCAFEE, K. (1999), «Selling nature to save it? Biodiversity and green developmentalism», Environment and planning D: society and space, vol. 17(2), pp. 133-154.

MCCULlEY, P. (2008), «The Great Offset Swindle: How Carbon Credits are Gutting the Kyoto Protocol and Why They Must Be Scrapped. Bad Deal for the Planet: Why Carbon Offsets Aren't Working...And How to Create a Fair Global Climate Accord», Dams, Rivers and People Report 2008. L. Pottinger. Berkeley, CA, International Rivers, pp. 2- 14.

MICHAELOWA, A. (2005), «Creating the foundations for host country participation in the CDM: experiences and challenges in CDM capacity building», Climate Change and Carbon Markets: A Handbook of Emissions Reduction Mechanisms, pp. 305-320.

NANZ, P.; STEFFEK, J. (2004), «Global Governance, Participation and the Public Sphere», Government \& Opposition, vol. 39 (2), pp. 314-335.

NAVAS, G. (2014), Hidroeléctrica Santa Rita S.A. in Monte Olivo, Guatemala. Environmental Justice Atlas. Disponible en http://ejatlas.org/conflict/hidro-santa-ritamonte-olivo-guatemala

PATERSON, M. (2001), Understanding Global Environmental Politics: Domination, Accumulation and Resistance, London, Macmillan. 
PEACE BRIGADES INTERNATIONAL (2014), Deterioration in human rights situation in Monte Olivo. Urgent need to solve murders of two children and other attacks reported by the communities, as well as stop the ongoing violence. Disponible en http://www.pbi-guatemala.org/los-proyectos/pbi-guatemala/noticias/ spanish-news-holder/?no_cache $=1 \& \&$ tx_ttnews[tt_news] $=4091 \& \mathrm{cHash}=59 \mathrm{e} 81$ d20e7ed25131a9a627b3cc61c99?\&L=0,\%202014

POGREBINSCHI, T. (2013), «Democratic Innovations and Quality of Democracy. Do we need new and more creative recipes?», Proceedings of the European Consortium of Political Research 2013 General Conference, Bordeaux, 4-7 September.

RICHMAN, E. (2003), «Emissions trading and the development critique: exposing the threat to developing countries», NYUJ Int'l. L. \& Pol., vol. 36, pp.133-160.

SCHARPF, F. W. (1999), Governing in Europe: effective and democratic?, Oxford, University Press.

SCHNEIDER, L. (2007), "Is the CDM fulfilling its environmental and sustainable development objectives? An evaluation of the CDM and options for improvement», Öko-Institut for Applied Ecology, Berlin, vol. 248, pp. 1685-1703.

SCHUNZ, S.; BRUYNINCKX, H. (2011), "The democratic legitimacy of the contemporary global climate governance architecture». Leuven Centre for Global Governance Studies: Working Paper, vol. 75.

STRIPPLE, J. (2010), «Weberian climate policy: Administrative rationality organized as a market». In K. Bäckstrand, J. Khan, A. Kronsell \& E. Lövbrand (Eds.), Environmental politics and deliberative democracy: Examining the promise of new modes of governance, pp. 67-84, Cheltenham, Edward Elgar.

SUOMI, K. (2002), «Voices not Votes: Major Group Participation», World Summit on Sustainable Development in Johannesburg 2002' Master's thesis, Lund University International Master's Programme in Environmental Science. Lund: Lund University.

UNFCCC (2006), Clean Development Mechanism Project Design Document Form (CDM-PDD) Version 03. Multipurpose Baba Hydroelectric Project. Bonn: Author.

UNFCCC (2011), Project 3237: Barro Blanco Hydroelectric Power Plant Project. United Nations Framework Convention on Climate Change. Bonn: Author.

UNFCCC (2012), Clean Development Mechanism Project Design Document Form (CDM-PDD) Version 03. Marañón Hydroelectric Project. Bonn: Author.

WILSON, K. (2011), «Access to Justice for Victims of the International Carbon Offset Industry», Ecology Law Quarterly, vol. 38(4). 


\title{
LAS RONDAS CAMPESINAS GARANTES DE LA JUSTICIA AMBIENTAL FRENTE A LAS POLÍTICAS EXTRACTIVISTAS EN PERÚ
}

\author{
Raquel Neyra
}

El Perú es un país netamente agrario campesino. Desde las postrimerias de la época pre incaica el habitante labraba la tierra para su sustento. Una de las características geomorfológicas del país es estar atravesado de norte a sur o sur a norte por la Cordillera de los Andes creando una diversidad de pisos geográficos. Esta diversidad está compuesta por picos elevados hasta los $6000 \mathrm{msnm}$, llanuras de altura (pampas) y valles profundos y estrechos. El habitante de los Andes debía organizarse para proteger sus tierras y ganado en esta geografía particular. Es asi que en el Perú, en los años 70, en la región de Cajamarca, al norte del país, nace una organización sui generis llamada «rondas campesinas».

\subsection{Las rondas campesinas}

Las Rondas fueron creadas por los campesinos en Cuyumalca, centro poblado del distrito y provincia de Chota, región Cajamarca, exactamente el 29 de diciembre de 1976 con el objetivo de combatir el abigeato y la delincuencia. Es una organización netamente autónoma. La falta de presencia institucional del Estado los obliga a organizarse para defenderse de las intrusiones en su territorio de principalmente los ladrones de ganado y animales menores. Poco a poco, el ámbito de acción de las rondas se iría ampliando a todos los ámbitos y miembros de la comunidad: el maestro, el profesional, el comerciante, cualquier miembro de la comunidad puede ser rondero. Las rondas se convirtieron 
en verdaderas autoridades y asi como juzgaban a los abigeos, comenzaron a impartir justicia en la comunidad.

La palabra «rondas» deriva de la actividad principal que los campesinos designados voluntariamente realizan que es la de «rondar» en los campos y poblados. Los ronderos, miembros de las rondas, intervienen en caso de actos sospechosos o en presencia de personas extrañas dentro del territorio comunal. Ellos rondan mayoritariamente por las noches. Los ronderos y ronderas se apuestan en distintos puntos estratégicos del territorio comunal y por turnos vigilan la zona de todo movimiento sospechoso. Tienen todo el derecho de interpelar a las personas que transiten por ese lugar, interrogarlas y llevarlas a la «Casa rondera» en caso de no obtener respuesta satisfactoria. La casa rondera es el lugar donde los ronderos pernoctan y se reúnen.

Los miembros de la comunidad se reúnen en asambleas y eligen por quorum y a mano alzada a los miembros de las rondas. Los ronderos no perciben ningún sueldo. Las decisiones de las rondas se toman igualmente en quorum y asambleas donde participa toda la comunidad. Y lo que es altamente significativo es que ejercen justicia propia. La justicia que ejercen en su territorio es inmediata e inapelable y decidida en asambleas que actúan como tribunales. El castigo consiste la mayoría de veces en trabajo comunal, castigo que tiene como objetivo reparar el mal causado. A veces consiste en castigo físico, de ellos el más conocido es el látigo en la parte posterior del cuerpo. Es lo que se conoce como justicia rondera. Con el tiempo, el ámbito de acción de las rondas se amplió a todo acto o hecho delictivo o conflictivo dentro de la comunidad, como líos de tierras, de linderos de propiedades, problemas entre vecinos, comportamientos inadecuados de miembros de la comunidad, problemas familiares, violaciones, agresiones físicas, asesinatos, etc (Sánchez Ruiz, 2014).

Esta valiosa vigilancia de su territorio hizo que las rondas en Cajamarca impidieran así que los grupos terroristas de Sendero Luminoso o el MRTA ${ }^{1}$ que comenzaron su accionar en 1982 pudieran progresar en su afán de cooptar personas o sembrar el terror. Cajamarca fue prácticamente una de las pocas regiones del país que quedó libre de actos terroristas. Posteriormente, las rondas se difundieron en la región de Piura y después en todo el pais. La toma de decisiones y la aplicación de justicia propia se pueden considerar parte de lo que se conoce como «desborde popular» (Mattos Mar, 1984), cuando la población rebasa a la ineficiente o inexistente autoridad del estado y asume el rol

1 MRTA: Movimiento Revolucionario Túpac Amaru 
que el estado no es capaz de ejercer. Cansada de esperar y reclamar justicia, la ejerce ella misma.

La justicia rondera es de una ejemplaridad sin par; las decisiones, basadas en el sentido común, son colectivas y las acciones son tomadas en presencia de toda la comunidad. Se busca llegar a un consenso satisfactorio para todas las partes ya que el objetivo principal es devolver la calma y la armonía a la comunidad. El dirigente rondero es una persona reconocida y que goza de autoridad moral en la población. Los ronderos de diferentes comunidades aledañas se reúnen para discutir de los temas comunes a la vecindad. Cuando convocan a reunión en algún centro poblado o caserío de las alturas, los ronderos llegan a pie caminando por la jalca o a caballo vestidos de sus ponchos y chullos, todos chacchando coca para aguantar el frío y el hambre. Al llegar al acampado, se colocan por comunidad formándo un círculo; inmediatemente se elige a la mesa directiva, se lleva un acta de la asamblea que los ronderos y visitantes firmarán al finalizar la reunión. Disciplinadamente, un grupo se dedica a preparar la olla común, las raciones se distribuirán al finalizar la reunión. Toda persona que quiera tomar fotos y los visitantes deben presentarse ante la mesa directiva, identificarse y pedir la debida autorización. Si no lo hace, puede ser explulsado de la reunión.

Toda esta contribución positiva al bienestar común llevó al Estado a otorgarles reconocimiento oficial plasmado en el artículo 149 de la Constitución Peruana, artículo que proclama:

Artículo $149^{\circ}$.- Las autoridades de las Comunidades Campesinas y Nativas, con el apoyo de las Rondas Campesinas, pueden ejercer las funciones jurisdiccionales dentro de su ámbito territorial de conformidad con el derecho consuetudinario, siempre que no violen los derechos fundamentales de la persona. La ley establece las formas de coordinación de dicha jurisdicción especial con los Juzgados de Paz y con las demás instancias del Poder Judicial.

Y obtuvieron con la Ley $\mathrm{N}^{\mathrm{o}} 27908$ del 6 de enero de 2003 y su reglamento las modalidades de aplicación de la justicia rondera aunque de manera limitada porque restringe el ámbito de acción.

En síntesis, la Constitución y la ley les da potestad de ejercer justicia dentro de su territorio y sólo dentro de su territorio. En caso de delitos mayores, como violación o asesinato, los ronderos deben entregar al culpable a manos de la justicia ordinaria. 


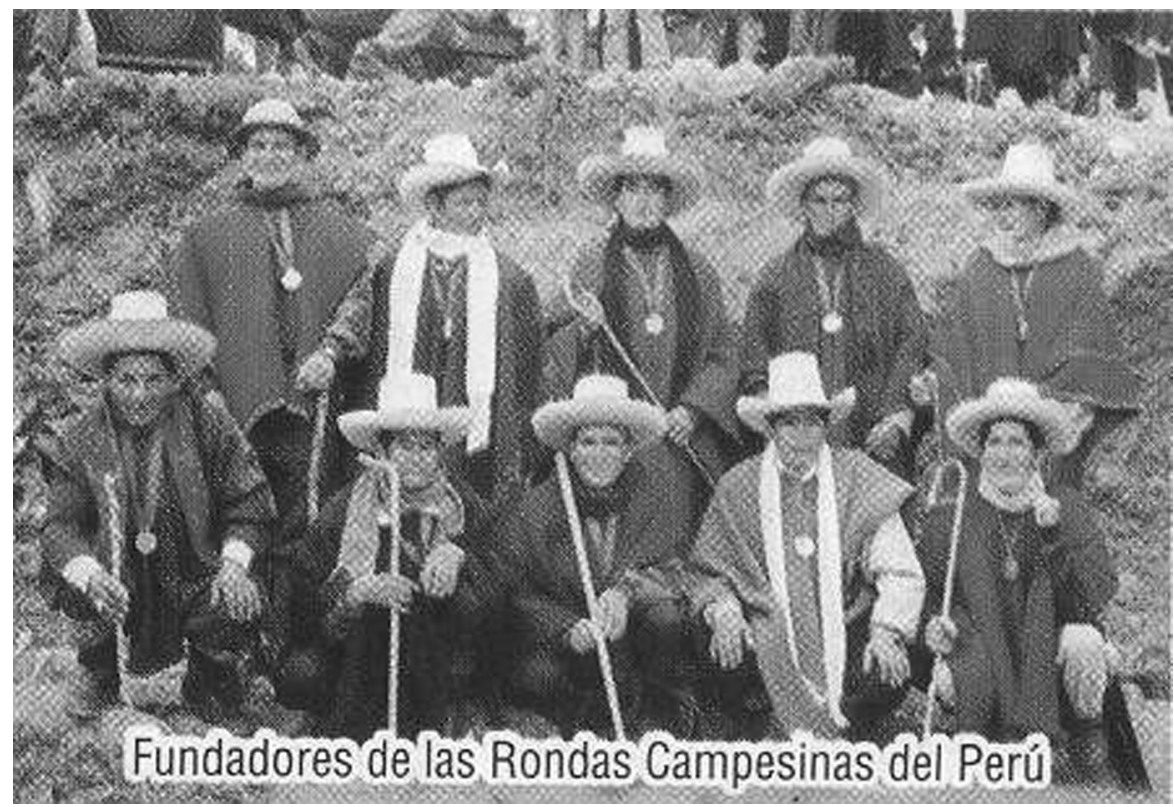

Foto: registro Central Unica de Rondas Campesinas, Cunarc

Las rondas campesinas están organizadas en Comités que integran las Federaciones distritales, provinciales y regionales. A nivel nacional se reagrupan bajo la CUNARC Central Única Nacional de Rondas Campesinas. Se estima que en la actualidad existirían cerca de 250000 ronderos, de los cuales sólo 100000 en Cajamarca, todos ellos reagrupados en unos 8000 comités. Lamentablemente, la politización de las rondas ha llevado a su división en Cajamarca, en Federación de Rondas Campesinas y en Comité Central de Rondas. Las rondas femeninas se crearon posteriormente en Cajamarca en 1988. Ellas deben de luchar aún mucho contra el machismo imperante pero su número va creciendo. Todavia hay miembros de la comunidad que critican su «ausencia del hogar» por ocuparse de los asuntos de la comunidad. A pesar de jugar un rol protagónico, a las mujeres ronderas aún no se les deja asumir un cargo dirigencial. Asi mismo, existen también «rondas escolares» como en Chulucanas (Piura) las cuales ejercen una acción de control y cuidado de una unidad escolar.

Desde hace algunos años existen también en Cajamarca las rondas urbanas. Su accionar se asemeja a las juntas vecinales y tienen potestad de detener 
a personas que estén cometiendo infracciones y luego entregarlas a la justicia ordinaria $^{2}$.

Muy naturalmente y siendo de su potestad detener a personas extrañas dentro del territorio de la comunidad, por consecuencia las rondas han tomado y siguen tomando parte muy activa en la defensa del medio ambiente: actúan en contra de la presencia de las mineras y de otros proyectos extractivos. Y como los proyectos mineros y extractivos son fuente de contaminación de las aguas que irrigan sus pastizales, que bebe el ganado y de consumo propio, de las tierras, del aire que respiran, y constituyen una de intromisión en el territorio comunal con los campamentos mineros, los tajos abiertos, y con las rutas construidas por las empresas, etc, los ronderos y ronderas actúan en defensa de su territorio. Muchas luchas de resistencia contra proyectos mineros extractivistas no hubieran sido posible sin la intervención activa de los ronderos, muchas veces a costa de su vida. Han estado presentes y liderando las luchas en Majaz, San Ignacio, Tabaconas, Conga, Chadín II, todos proyectos extractivos o de megarepresas. Ellas siguen jugando un rol preponderante como contra el proyecto minero Conga o últimamente en La Libertad contra la presencia de Barrick Gold (proyecto Lagunas Norte), de mineras canadienses (Candente Copper) o chinas (Zijin), entre otras. Con su resistencia cuestionan el modelo neoliberal predominante.

\subsection{Contexto histórico de la presencia de las rondas campesinas}

La guerra civil con Sendero Luminoso proseguía y se habia centrado en la ciudad de Lima después de haber arrasado con mucha violencia con la región de Ayacucho. En el año 90 sale elegido presidente Alberto Fujimori, apodado «el chino». Las clases populares se reconocieron en él por su aspecto físico por no ser él de origen «blanco», como lo fueron los presidentes anteriores (a excepción del General Juan Velasco Alvarado) que se habian caracterizado por ser «entreguistas», lo que quiere decir «a favor de las grandes empresas transnacionales, de las clases poderosas del pais, exportador de materias, bienes y ganancias hacia el exterior, etc». Sin embargo, aquél rector universitario de origen japonés que aparentemente llegaba al poder para enfrentarse al terror del grupo maoísta Sendero Luminoso y traer la paz, instauraría una de las peores dictaduras de nuestra historia.

2 Ordenanza Municipal n³90 CMPC, Municipalidad de Cajamarca, 27 de junio de 
El presidente Alberto Fujimori hereda el país sumido en una grave crisis de inseguridad, violencia, inflación galopante, inestabilidad laboral, etc. Aprovechando esta situación, reorienta directamente los timones del país hacia el neoliberalismo que en su caso, será implementado de manera violenta (Klein, 2007) con el famoso «Fujishock» de 1990.

El Fujishock aplica las medidas aprendidas del consenso de Washington, hay que barrer con todas las prácticas nacionalistas de los gobiernos anteriores. Fujimori privatiza a diestra y siniestra, aumenta los precios de los productos básicos, liberaliza el cambio del dólar, reduce los aranceles para los productos importados junto a un aumento de la carga impositiva de las exportaciones, aún muy por debajo de sus homólogos latinoamericanos. Para contener la elevada protesta social, Fujimori realiza un plan de asistencia social y construcción de infraestructuras (red de canalización de agua, electrificación rural, construcción de escuelas hasta la punta del cerro luego abandonadas por falta de presupuestos, etc) que contribuyen a su -lamentable- aceptación por parte de las masas populares pauperizadas a la par que se erige como el salvador del país al haber supuestamente derrotado a Sendero Luminoso y capturado a su líder Abimael Guzman.

Empieza un ciclo de privatizaciones de las empresas estatales mineras como Centromin, Hierro Perú, las refinerías de Ilo y Cajamarquilla que ya no eran rentables para su gobierno ${ }^{3}$. Al privatizarlas, se recurre a un despido masivo de sus trabajadores lo que por consecuencia va a debilitar a los sindicatos $^{4}$. Si bien el estado invierte en el saneamiento de estas empresas y asume la deuda frente al Banco Minero, es para hacerlas más atractivas a la venta y a su posterior liquidación. En el año 1992, Fujimori cierra el congreso con su denominado «autogolpe» e implanta de manera violenta y antidemocrática una serie de leyes que abrirán definitivamnte las puertas al capital nacional y extranjero. Una de ellas es la Ley de Minería.

La Ley General de Minería autoriza la prospección libre en todo el país (salvo zonas reservadas) y ya desde su primer título anuncia la orientación seguida: «El aprovechamiento de los recursos minerales se realiza a través de

3 Decreto Legislativo 674 de 1991 que declara de interés nacional la Promoción de la Inversión Privada

4 Es importante notar este punto ya que posteriormente, los actores mayores de la resistencias no van a ser los sindicatos sino como veremos, las fuerzas reagrupadas alrededor de la población con actividad agrícola 
la actividad empresarial del Estado y de los particulares, mediante el régimen de concesiones».

Actualmente, obtener la concesión de una parte del territorio Peruano es la cosa más sencilla del mundo. Te acercas a Ingemmet t, te enseñan un mapa, eliges la cuadrícula que más te apetezca, el funcionario lo contrasta con un ralo catastro no minero (que no choque con ninguna ruina o algún Parque Nacional, nada más), pagas un precio módico, y listo: ya tienes tu flamante pedazo de tierra para poder explorarla. ${ }^{6}$

Esta metodología es reforzada por la Ley de Tierras 26505 (artículo 7) que estipula que en la venta o transferencia de tierras eriazas comprendidas dentro de las concesiones mineras, deberá considerarse en primera oferta a los titulares de dichas concesiones que soliciten esa preferencia, precisando que esta venta directa no requerirá de subasta pública. Esto tiene como fundamento «dar mayor seguridad jurídica a las inversiónes mineras».

Y por último, en acorde con su autogolpe, establece una nueva constitución - lamentablemente todavía vigente - en la que el estado tomará posesión de las tierras «abandonadas» (artículo 88), siendo el estado el que decide qué son «tierras abandonadas». El carácter de inalienable, inembargable e imprescriptible de las tierras de las comunidades otorgado por la Constitución de 1979 fue suprimido en la Constitución de 1993 de Fujimori. Con el Artículo 131 autoriza la concesión sobre los recursos naturales. Finalmente, en 1996, la nueva Ley del Catastro Minero Nacional (Ley N N $^{\circ}$ 2615) modificó los derechos de tenencia de tierras facilitando aún más la posesión de concesiones. Estas medidas legales van a facilitar el implantamiento de empresas mineras que empujarán las fronteras de la extracción (Conde, Walter, 2015), es decir que la multiplicación de concesiones facilitará la expansión de las industrias extractivas ampliando la frontera extractiva.

Aprovechando de los precios altos de los minerales a nivel mundial y de las facilidades en la inversión, también tributarias, grandes grupos mineros se instalaron en el país, como Newmont, Barrick Gold, Xstrata Glencore, y un sin fin de empresas mineras canadienses, las petroleras Pluspetrol, Repsol, otras (Oxy y Shell dejan de operar). Se constituye Yanacocha SA con la participación del grupo Buenaventura. En 1995, el 47\% de las exportaciones procedían del sector minero. El gobierno peruano ,como otros en la región, adopta de

5 Instituto Geológico Minero y Metalúrgico

6 IDEELE Revista; 2015; En qué momento se concesionó el Perú? 
lleno la figura de país minero exportador haciéndolo dependiente del precio de estos minerales. Es el consenso de los commodities (Svampa, 2013) en el el cual los paises de América Latina aceptan hacer parte del mundo neoliberal con el rol que se le otorga, el de ser productor y exportador del commoditie que tiene en mayor abundancia. En el caso del Perú sera la minería.

Hemos escogido algunos aspectos jurídicos de esa época que derivaron en la constitución de concesiones en practicamente toda la franja costera y la zona andina. Igualmente lo está la Amazonía con los lotes petroleros e inclusive el fondo marítimo para la prospección petrolera. No queda ningún pedazo, ninguna hectárea que no pueda ser concesionada a alguna empresa. Es el país en venta.

Durante el gobierno de Fujimori prevaleció la Ley Forestal de los gobiernos anteriores. Los gobiernos posteriores siguen en la óptica de implementación del neoliberalismo. La Ley Forestal ${ }^{\circ} 27308$ promulgada en el año 2000 (gobierno de Alejandro Toledo 2000-2005) introduce la modalidad de concesión para el aprovechamiento de las tierras forestales (Artículo 10). El metabolismo social se recompone, el país pasa a ser exportador neto de minerales, las empresas mineras pasan a ser actores claves de ese metabolismo.

Bajo el gobierno del presidente Alan García prosiguen estas políticas y se aplica la misma violencia. Con su controvertido y ácido artículo llamado «El síndrome del perro del hortelano» que alude a las riquezas que posee el pais y que no pueden ser explotadas porque existe población que se opone a ello pero que tampoco aprovecha de las «bondades» de dichos territorios, se refería entre otros a la Amazonía ${ }^{7}$. Fue una manera burda y directa de imponer designios neoliberales. Alan García pretendía empujar las fronteras de la extracción hacia el territorio amazónico. Bajo el pretexto de tener que cumplir con las exigencias del proyectado Tratado de Libre Comercio con los EEUU, entre marzo y octubre del 2008, se dictaron cerca de 101 decretos lesivos para los intereses de la población indígena.

Por otro lado, el presidente Alan García impulsará junto al presidente Lula de Brasil el acuerdo enérgetico Perú Brasil en el cual se acuerda la construcción de megarepresas hidroenenergéticas en la cuenca amazónica. Las represas debían llevar electricidad a Brasil y el excedente sería utilizado por el

7 http://www.justiciaviva.org.pe/userfiles/26539211-Alan-García-Perez-y-el-perrodel-hortelano.pdf 
Perú para las actividades mineras. Este acuerdo levantó mucha oposición en la población, muchos proyectos fueron detenidos por la resistencia dirigida por los ronderos y rechazo que causaron, otros siguen en construcción. Posteriormente, en mayo del 2014, el congreso Peruano declarará este acuerdo energético como lesivo para los intereses nacionales y lo archivará definitivamente. Sin embargo, algunos de los proyectos se siguen llevando acabo fuera del acuerdo como Chadín 2 o Río Grande y no se desestima que algunos de los proyectos puedan volver a ser impulsados posteriormente como los de Pakitzapango o Inambari.

Con el gobierno del presidente Ollanta Humala se dicta el 31 de agosto del 2011 la Ley de la Consulta previa ${ }^{8}$ cuyo reglamento se promulga al año siguiente. Cabe recordar que el Convenio 169 de la OIT fue ratificado por el Perú en el año 1993 y forma parte de la legislación Peruana desde febrero del 1995. Sin embargo, durante el Gobierno de Ollanta Humala, a penas se han realizado algunas consultas previas tal como lo estipula el Convenio 169, las empresas se limitan a realizar talleres informativos con muchas irregularidades. El procedimiento ha sido adrede muy simplificado ${ }^{9}$. Con un reglamento muy limitante y excluyente ${ }^{10}$, la consulta previa del gobierno de Ollanta $\mathrm{Hu}-$ mala no es vinculante. El gobierno de Ollanta Humala se caracterizará por promover proyectos mineros a tajo abierto e impulsar la construcción de megarepresas a pesar de la muy fuerte oposición de la población. Esto conllevó a una serie de conflictos socio ambientales los cuales manejará con mano dura y causará la muerte de decenas de personas. Durante su gobierno, se dictaron los llamados «paquetazos ambientales» medidas legales promulgadas «en paquete» que afectarán en primer lugar al medioambiente, a los recursos naturales, a los territorios y poblaciones que allí habitan (Neyra, 2016).

Este es pues el contexto histórico acompañado de las medidas legales que van a encuadrar el extractivismo, nueva forma de extracción en grandes cantidades de los recursos naturales que se exportan sin casi procesamiento (Gudynas, 2014) y de manera violenta como lo veremos. La producción de minerales abarca en 2016 el 16,3\% del PBI y cerca del 35\% de las exportacio-

8 http://www.presidencia.gob.pe/ley-de-consulta-previa-promulgada-hoy-en-bagua

9 Ver capitulo sobre la consulta previa en este libro

10 Tienen derecho a consulta los pueblos indígenas reconocidos en la base de datos del Viceministerio de Interculturalidad 
nes; los principales minerales exportados son cobre, oro, plata, zinc, estaño, hierro ${ }^{11}$.

\subsection{El caso Conga: ronderos vs extractivismo}

En el 2004, la minera Yanacocha inicia sus actividades de exploración del Proyecto minero Conga en Cajamarca. Es proprietaria de concesiones en una zona de páramos y lagunas denominada Conga. Entre el 2008 y el 2009 se aprueban el Estudio de Impacto Ambiental Semidetallado (EIAsd) y sus dos modificaciones. El 27 de julio de 2011, un día antes del cambio de mando presidencial entre el presidente saliente Alan García y el presidente entrante Ollanta Humala, el proyecto recibe el aval del gobierno, el plan de financiación es aprobabado por las autoridades peruanas. No se realizó ninguna consulta previa, segun lo estipula el Convenio 169 de la OIT.

El proyecto minero Conga recibe su nombre de las más de 80 lagunas que constituyen la zona alto andina a más de 3500 metros de altitud en el departamento de Cajamarca; zona de bofedales y humedales que cumplen su función de absorción del agua alimentando las capas freáticas y formándo numerosos torrentes que darán nacimiento a rios (Jadibamba, Sendamal) o se vertirán en ellos. Las aguas de las lagunas de Conga viajan inclusive hasta los rios Jequetepeque y Marañón. Un proyecto de extracción de oro y cobre con reservas estimadas en 11 millones 800 mil onzas de oro que debe desarrollarse entre los distritos de Sorochuco y Huasmín en la provincia de Celendín, en el distrito de La Encañada en la provincia de Cajamarca y la provincia de Bambamarca a 3.700 y $4.262 \mathrm{msnm}$. El area de influencia directa se extiende sobre las 3000 ha y la indirecta afectará 16000 ha. Más de 100 ha de humedales y bofedales desaparecerían irremediablemente. En su etapa incial, se prevé que se vacíen cinco lagunas: dos de ellas - Azul y Chica- servirán de depósito de relaves mineros, una (Chailhuagón) será transformada en un reservorio (esta parte del proyecto ya fue realizada), de dos de ellas, El Perol y Mala se extraerán el oro y el cobre ${ }^{12}$. Tres reservorios más deben de ser construidos para reemplazar las aguas perdidas de las lagunas. Es un proyecto de mina a cielo abierto, con dos tajos, el más grande de $2 \mathrm{~km}$ de ancho por $1 \mathrm{~km}$ de profundidad. Durante los

11 Datos Instituto Nacional de Estadística e Informática y Banco Central deReserva del Perú.

12 El caso Conga ha sido denunciado 5 veces por France Libertés con mi colaboración y otras ONG's con estatus consultivo ante la CDDHH de la ONU en Ginebra entre los años 2013 y 2014, ver las Declaratorias OHCHR: A/HRC/24/NGO/10; A/HRC/23/NGO/4; A/HRC/22/ $\mathrm{NGO} / 31 ; \mathrm{A} / \mathrm{HRC} / 21 / \mathrm{NGO} / 77$ y $\mathrm{A} / \mathrm{HRC} / 20 / \mathrm{NGO} / 63$ y $\mathrm{A} / \mathrm{HRC} / 25 / \mathrm{NGO} / 31$ 
17 años de tiempo de vida del proyecto se removerán 92.000 toneladas de desechos de roca al día creándose 85.000 toneladas de relaves tóxicos promedio por día almacenados en un dique de relaves de 700 ha que se construirá sobre el valle del rio Jadibamba, desapareciendo el valle completamente. Unas 32 comunidades serán afectadas directamente. Cajamarca, primer productor lechero del pais, verá su agricultura y ganadería afectadas. Además, los relaves de mineral contaminarán las aguas volviendolas no aptas para el consumo humano y animal. Millones de metros cúbicos de agua desaparecerán con la destrucción de las lagunas, otros millones con la destrucción de los humedales, otros millones contaminados por la lixiviación y posterior contaminación de aguas por los relaves. (Neyra, 2013).

A pesar de la inversión calculada en USD 4800 millones, el precio del oro es tal, que estos proyectos de inversión minera siguen siendo atractivos para las empresas. La empresa Odebrecht tenía a cargo un contrato de construcción en este proyecto por un monto de USD 500 millones.

Al ver la magnitud del impacto de este proyecto minero sobre las tierras y aguas, los campesinos y ronderos se organizan y comienza la resistencia (Neyra, 2013). De la misma forma en la que venían organizándose y defendiéndose de los intrusos, abigeos y ladrones y ejerciendo justicia, van a organizarse y enfrentarse al gigante minero al invadir su territorio. Los ronderos hacen suya la defensa del territorio y se empoderan del reclamo ecologista que convierten en su baluarte. Conga será uno de los conflictos socioambientales más emblemáticos del país por la amplitud y la duración del conflicto. Las protestas de la población de Cajamarca contra el proyecto comenzaron en octubre de 2011 seguidas por una huelga indefinida a partir del 24 de noviembre de 2011. Los campesinos ocuparon la zona de las lagunas para protegerlas de la entrada de los camiones de Yanacocha. E1 29 de noviembre la policía intentó desalojarlos por la fuerza y 19 campesinos fueron heridos, 6 de ellos de gravedad por herida de bala. Los heridos conservarán secuelas para el resto de sus vidas; entre ellos está Elmer Campos, paralítico de los miembros inferiores.

El gobierno respondió con la declaración del Estado de Emergencia en la zona que duró 10 días y provocó una grave crisis gubernamental trayendo consigo un cambio de gobierno y el endurecimiento de su posición nombrando a un ex militar como Primer Ministro, Oscar Valdéz. Finalmente la huelga se levantó y el Estado de Emergencia igualmente. 
La empresa minera paraliza el proyecto CONGA en diciembre del 2011 a pedido del gobierno. El gobierno llama a tres expertos extranjeros para hacer viable el proyecto y revisar el estudio de impacto ambiental de CONGA. Paralelamente, el ingeniero Robert Moran ${ }^{13}$ emite un informe que desmiente las aseveraciones del EIA oficial el cual califica de insuficiente y no logra proporcionar la información técnica necesaria para que la población y los organismos reguladores puedan tomar decisiones (Moran, 2014).

Es decir que el Estado peruano, parcializado a favor de la empresa, reacciona una vez más implementado el proyecto tratando de paliar las reacciones de rechazo de la población con peritajes de terceros.

En el 2012 se constituye el Comando Unitario de Lucha (COMUL) liderado por los representantes ronderiles y frentes de defensa de Cajamarca, Bambamarca y Celendín. Las organizaciones representativas deciden hacer justicia por ellas mismas -participando del desborde popular- y enfrentarse al gobierno y al gigante minero. En febrero del 2012 tuvo lugar la Marcha del Agua, la primera en la historia del país, que partió de las lagunas de Conga hacia Lima, la capital del país, impulsada por los Frentes de Defensa y Rondas campesinas de Cajamarca. Participaron más de 40000 personas así como numerosos observadores extranjeros. Se unieron mas de 70 organizaciones de todo el país. El desborde popular es total.

El gobierno responde con la militarización de Cajamarca. Los dirigentes son perseguidos y denunciados. Las ciudades de Celendín y Bambamarca son ocupadas por los militares. Las manifestaciones en contra de su presencia y en contra del proyecto minero Conga son diarias, helicópteros sobrevuelan las ciudades. El 3 de julio en Celendín, los militares disparan y asesinan a cuatro personas, entre ellas un menor de edad. En Bambamarca, la población se organiza y se niega a vender alimentos a los militares, la población se posta sobre los techos de las casas y arroja proyectiles (piedras, maderos, etc) a los militares. Una persona muere asesinada por las balas de la policía. Finalmente y después de mucha resistencia que costó vidas, el proyecto es suspendido.

Desde octubre de ese año, los ronderos de las comunidades afectadas autodenominados «Guardianes de las Lagunas» realizan vigilias ante las lagunas advirtiendo al gobierno que no dejarán que el proyecto se lleve a cabo.

13 Ingeniero mundialmente conocido por su compromiso con la defensa del ambiente. 
Organizaciones que los representan junto a ONGs acudieron a la Comisión Interamericana de $\mathrm{DDHH}^{14}$.

El 30 de enero del 2013, la DINOES - fuerzas policiales especialesdestruyen con violencia el campamento rondero situado frente a la Laguna Namococha, distrito de Bambamarca, situado en una propiedad privada. El campamento fue retomado en abril del 2013, y una casa de guardianes fue construída con la colaboración de ronderos, campesinos y ambientalistas. Es decir que, a pesar de la suspensión del proyecto, el estado sigue favoreciendo a la empresa minera, se resiste a las acciones de vigilancia de los ronderos y mantiene abierta la posibilidad de efectuar el proyecto.

\subsection{Aportes}

Las rondas campesinas intervinieron en este conflicto, como en todos los conflictos mineros y extractivos actualmente existentes en el país, en defensa de su territorio, aplicando sus principios, de no dejar penetrar en su territorio a extraños y aplicando ellos mismos justicia. Cajamarca, es la región con más pasivos ambientales de todo el país producto de más de 200 años de minería. Los ronderos quieren mantener su ambiente limpio y sano y mientras puedan, si las fuerzas no les fallan, seguirán resistiendo. Adoptan la defensa del territorio y del ambiente, se resisten a los planes de acaparamiento de tierras por las empresas que buscan expandir las fronteras de la extracción. Los ronderos se resisten a la presencia de los nuevos abigeos: las empresas extractivas. Los ronderos hacen parte de los movimientos sociales latinoaméricanos que se han venido desarrollando en los últimos decenios que defienden otro lenguaje de valoración (Svampa, 2010) en el cual priman otros valores: lo que para las empresas son recursos para los ronderos es naturaleza parte integrante de su vida. los ronderos hacen parte integrante de la lucha por el medio ambiente, en defensa de la ecología y no buscan el «desarrollo» como lo entiende el neoliberalismo. Conga constituye un conflicto emblemático que reúne a todos los actores de la sociedad, ronderos, sociedad civil, empresas privadas, gobierno nacional, regional y local confrontados en defender cada uno dos visiones opuestas, desarrollo capitalista o vida (Martinez Alier et al, 2016).

14 Medida cautelar No.452-11 CIDH, mayo 2014, interpuesta por Asociación Interétnica de la Selva Peruana (AIDESEP), la Confederación Campesina del Perú (CCP), la Confederación Nacional Agraria (CNA), la Confederación Nacional de Comunidades del Perú Afectadas por la Minería (CONACAMI) y la Organización Nacional de Mujeres Indígenas, Andinas y Amazónicas del Perú (ONAMIAP). 
Todos estos actores son parte integrante del metabolismo social del país que se posicionan frente a la actividad extractiva y a los deshechos que causa esta actividad. La organización rondera demuestra así que es capaz de tomar las riendas en un conflicto socioambiental que les atañe profundamente y de determinar el rumbo del conflicto logrando detener proyectos extractivos. Al hacer suya la defensa del territorio y del ambiente, toma un camino opuesto al desarrollo impuesto por el modelo neoliberal. Estos logros convierten a la organización rondera en garante de la justicia ecológica por querer preservar su ambiente sano. Junto a las autoridades locales como municipales podrían constituir un ente rector y vigilante frente a la actividad contaminante de las industrias extractivas. Si los ronderos se cohesionaran a nivel nacional podrían tener un peso mucho mayor en la política ambiental del país y frenar más proyectos extractivos lesivos para la población y el ambiente.

\subsection{Bibliografia}

CONDE, Maria, WALTER, Mariane, 2015, Frontières de la marchandise, en «Décroissance, vocabulaire pour une nouvelle ère» compilado por G. Kallis, F. Demaria, G. D'Alisa, Ed. Le passager clandestin, 2015, Neuvy en Champagne, Francia.

GUDYNAS, Eduardo, 2014, El desarrollo revisitado desde los debates sobre los extractivismos y sus alternativas, Universidad de Huelva, II Congreso Internacional de Estudios de Desarrollo, 16-18 de junio de 2014.

KLEIN, Naomi, 2007, La doctrina del shock, el auge del capitalismo del desastre, Editorial Paiso Ibérica, 2014, Madrid

MATOS MAR, José, 1984, Desborde Popular y crisis del Estado, ediciones IEP, 1986, Lima.

MARTINEZ ALIER, DEL BENE, SCHEIDEL, 2016, Is there a Global Environmental Justice Movement? Colloquium Paper $n^{\circ} 16$, Global Governance/politics, climate justice \& agrarian/social justice: Linkages and challenges, International Colloquium, 46 February, 2016, International Institut of Social Studies, La Haya

MORAN, Robert, 2014, Once Comentarios sobre el Informe de los Peritos de Conga, Servindi, abril 2014, Lima.

NEYRA, RAQUEL, 2013, L'accaparement des terres au Pérou. Les cas d'Olmos, de San Martin (Shawi) et de Conga, en L'expropriation des terres et la formation du latifundium en Amérique latine, Revue Histoire de l'Amérique Latine, Vol 8 (2013) Paris.

NEYRA, Raquel, 2013, Agricultura versus extractivismo La lucha por la supervivencia en el departamento de Cajamarca Perú, SEHA, Sociedad Española de Historia Agraria, Artículo presentado para el XIV Congreso de la SEHA: http://seha. info/congresos/artículos/CD.3.\%20Neyra.pdf

QUIJANO, Aníbal, 2008, «El Movimiento Indígena y las Cuestiones Pendientes en América Latina» el Cotidiano N· 151, 2008, pp. $107-120$. 
SÁNCHEZ RUIZ, Oscar, 2014, Justicia Rondera, Edición especial para el XI Congreso de Rondas Campesinas y Urbanas de Cajamarca, 2014, Cajamarca, Perú.

SVAMPA, Maristella, 2013, «Consenso de los Commodities» y lenguajes de valoración en América Latina, artículo en Revista Nueva Sociedad n 244 , marzoabril 2013, disponible en www.nuso.org, Buenos Aires.

SVAMPA, Maristella, 2010, Movimientos Sociales, matrices socio-políticos y nuevos escenarios en América Latina, trabajo realizado para la Revista OneWorld Perspectives, Working Papers 01/2010, Universität Kassel, Alemania. 


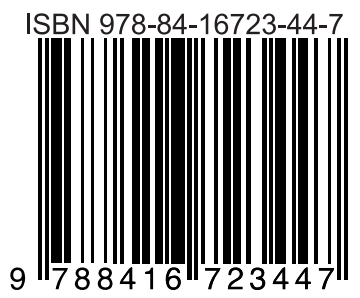

